\title{
CORPORATE GOVERNANCE AND \\ HEDGE FUND ACTIVISM
}

\author{
By \\ SHANE GOODWIN \\ Bachelor of Science in Business Administration \\ Collins College of Business \\ The University of Tulsa \\ Tulsa, Oklahoma \\ 1993 \\ Master of Business Administration \\ J.L. Kellogg Graduate School of Management \\ Northwestern University \\ Evanston, Illinois \\ 1999
}

Submitted to the Faculty of the

Graduate College of the

Oklahoma State University

in partial fulfillment of

the requirements for

the Degree of

DOCTOR OF PHILOSOPHY

December 2015 


\section{CORPORATE GOVERNANCE AND HEDGE FUND ACTIVISM}

Dissertation Approved:

Dr. Ramesh Rao

Dissertation Adviser

Dr. Gary Trennepohl

Dr. Indraneel Chakraborty

Dr. Aaron Hill 


\section{ACKNOWLEDGEMENTS}

It would not have been possible to pursue my Ph.D. without the help and support of the kind people around me, to only some of whom it is possible to provide particular mention here.

Above all, I would like to thank my wife Greta for her personal support and great patience at all times. My wonderful children Jack, Katy, Ellie, Hunter and Connor were very understanding and gave me tremendous support throughout. To my Parents, who instilled a continued thirst for knowledge and always promoted a pursuit of academic excellence for my brothers and me.

I would like to express the deepest appreciation to my committee chair Dr. Ramesh Rao, who continually and convincingly conveyed a spirit of adventure with respect to research and scholarship, and an excitement in regard to teaching.

Without his guidance and persistent help this dissertation would not have been possible.

I would like to thank my committee members, Dr. Gary Trennepohl, Dr. Indraneel Chakraborty and Dr. Aaron Hill, for their invaluable counsel, support and friendship on both an academic and a personal level.

iii

Acknowledgements reflect the views of the author and are not endorsed by committee members or Oklahoma State University. 
Name: SHANE GOODWIN

Date of Degree: DECEMBER 2015

Title of Study: CORPORATE GOVERNANCE AND HEDGE FUND ACTIVISM Major Field: BUSINESS ADMINISTRATION

\begin{abstract}
Over the past two decades, hedge fund activism has emerged as a new mechanism of corporate governance that brings about operational, financial and governance reforms to a corporation. Many prominent business executives and legal scholars are convinced that the American economy will suffer unless hedge fund activism with its perceived short-termism agenda is significantly restricted. Shareholder activists and their proponents claim they function as a disciplinary mechanism to monitor management and are instrumental in mitigating the agency conflict between managers and shareholders. I find statistically meaningful empirical evidence to reject the anecdotal conventional wisdom that hedge fund activism is detrimental to the long term interests of companies and their long term shareholders. Moreover, my findings suggest that hedge funds generate substantial long term value for target firms and its long term shareholders when they function as a shareholder advocate to monitor management through active board engagement.
\end{abstract}




\section{TABLE OF CONTENTS}

Chapter $\quad$ Page

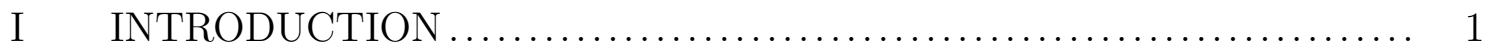

II REVIEW OF LITERATURE $\ldots \ldots \ldots \ldots \ldots \ldots \ldots \ldots \ldots \ldots \ldots \ldots \ldots \ldots \ldots \ldots \ldots \ldots$

II.A Theoretical Foundations of Shareholder Activism ............... 7

II.B History of Shareholder Activism ......................... 9

II.C Determinants of Shareholder Activism .................... 13

II.C.1 Prior Firm Performance ....................... 14

II.C.2 Firm Size.................................. 18

II.C.3 Free Cash Flow $\ldots \ldots \ldots \ldots \ldots \ldots \ldots \ldots \ldots \ldots \ldots \ldots \ldots \ldots$

II.C.4 Board of Director Characteristics .................. 19

II.C.5 Ownership Structure ......................... 21

II.D Active Monitoring by Shareholders ........................ 22

II.E Efficacy of Shareholder Activism $\ldots \ldots \ldots \ldots \ldots \ldots \ldots \ldots \ldots \ldots \ldots$

II.E.1 Impact on Firm Performance..................... 27

II.E.2 Short-term Market-based Firm Performance ............ 28

II.E.3 Long-term Market-based Firm Performance.............. 29

II.E.4 Accounting-based Firm Performance ................ 31

II.F Research Opportunities $\ldots \ldots \ldots \ldots \ldots \ldots \ldots \ldots \ldots \ldots \ldots \ldots \ldots \ldots \ldots \ldots \ldots$

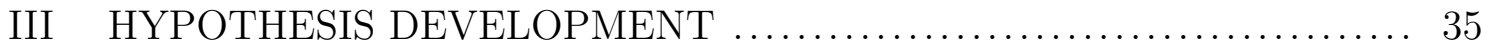

III.A Determinants of Hedge Fund Activism - Ex Ante Intervention ... . 37

III.A.1 Prior Firm Performance $(H 1) \ldots \ldots \ldots \ldots \ldots \ldots \ldots \ldots \ldots$ 
III.A.2 Ownership Structure (H2) $\ldots \ldots \ldots \ldots \ldots \ldots \ldots \ldots \ldots \ldots \ldots$

III.B Activist Hedge Fund Intervention - Board Representation (H3) . . 41

III.C Active Monitoring by Shareholders - Ex Post Intervention ....... 42

III.C.1 Short-term Effects of Active Hedge Fund Monitoring (H4) 44

III.C.2 Long-term Effects of Active Hedge Fund Monitoring

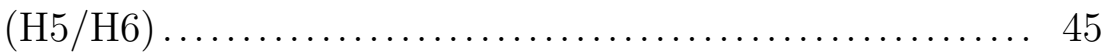

III.D Research Contribution.................................... 46

IV ECONOMETRIC METHODOLOGY $\ldots \ldots \ldots \ldots \ldots \ldots \ldots \ldots \ldots \ldots \ldots \ldots$

IV.A Endogeneity and Selection Bias............................ 49

IV.A.1 Research Design .................................. 50

IV.A.2 Matching Methods ............................. 51

IV.A.3 Treatment Effects ............................... 51

IV.A.4 Propensity Score Matching .......................... 53

IV.A.4.iv Assessing Unconfoundedness and Overlap ....... 56

IV.B Panel Data Methods.................................... 59

IV.B.1 Fixed and Random Effects ........................ 59

IV.C Event Study Methodology $\ldots \ldots \ldots \ldots \ldots \ldots \ldots \ldots \ldots \ldots \ldots \ldots \ldots \ldots \ldots \ldots \ldots \ldots$

IV.C.1 Empirical models for estimation period............... 62

IV.C.1.i Market Model ............................. 62

IV.C.1.i Fama-French Three-Factor Model .............. 64

IV.C.1.i Fama-French-Momentum Four-Factor Model .... 65

IV.C.1.i Market Adjusted Returns Model .............. 66

IV.C.1.i Fama-French Calendar Time Portfolio Regressions 66

IV.C.2 Event Study Test Statistics......................... 67

IV.C.2.ii Event Studies Centered on a Single Date ....... 67

IV.C.2.ii Correction for Correlation of Abnormal Returns . 69

IV.C.3 Standardized Cross-Sectional Test $\ldots \ldots \ldots \ldots \ldots \ldots \ldots \ldots \ldots$

IV.C.4 Time-series Standard Deviation Test ................ 71 
IV.C.5 Cross-sectional standard deviation test ............. 72

IV.C.6 Skewness-adjusted Transformed Normal Test ........... 73

IV.C.7 Long-Horizon Event Study Methodology ................ 73

V DATA AND EMPIRICAL TESTING ......................... 76

V.A Characteristics of Target Firms and Activist Campaigns

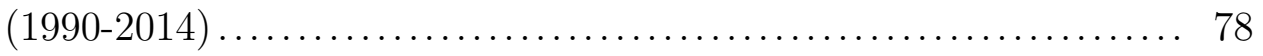

V.A.1 Objectives of Activist Campaigns .................. 78

V.A.2 Target Firm Characteristics: Vulnerability of Target Firms to Shareholder Activism .................. 80

V.B Short Selling: A Signal of Agency Cost $(\mathrm{H} 1) \ldots \ldots \ldots \ldots \ldots \ldots \ldots$

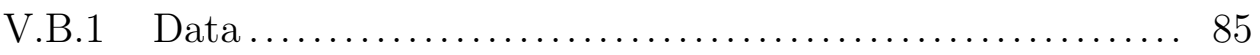

V.B.2 Empirical Results............................ 85

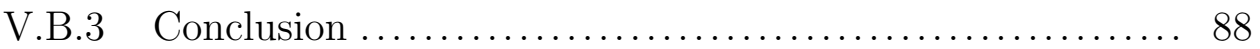

V.C Inside Ownership: The Cost of Agency (H2) ................ 89

V.C.1 Data..................................... 89

V.C.2 Empirical Results............................ 89

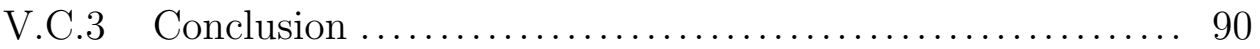

V.D Activist Hedge Fund Intervention: Board Representation (H3) ... 91

V.D.1 Data....................................... 91

V.D.2 Empirical Results............................... 92

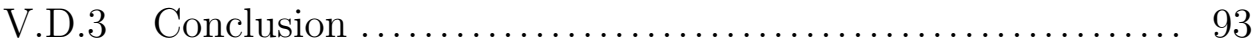

V.E Short-term Active Hedge Fund Monitoring $(\mathrm{H} 4) \ldots \ldots \ldots \ldots \ldots \ldots . . . . .63$

V.E.1 Initial Market Reaction: The Model .................... 94

V.E.2 Empirical Results............................. 95

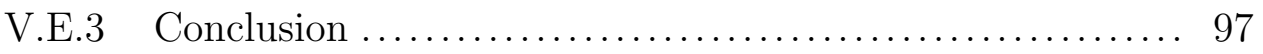

V.F Long-term Performance of Hedge Fund Monitoring (H5/H6) ..... 98

V.F.1 Buy-and-hold abnormal returns $(B H A R)$ Approach ..... 98

V.F.2 Empirical Results.............................. 100 
V.F.3 Calendar-time portfolio approach (Jensen's alpha) ....... 102

V.F.4 Empirical Results............................. 104

V.F.5 Conclusion .......................................... 107

V.F.6 Long-term Stock Returns: Individual Firm Regressions... 107

V.F.7 Empirical Results................................ 109

V.F.8 Measuring Cross-Sectional Firm Operating Performance.. 110

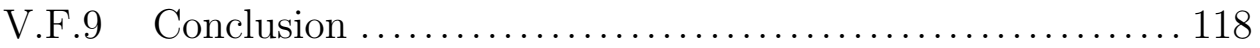

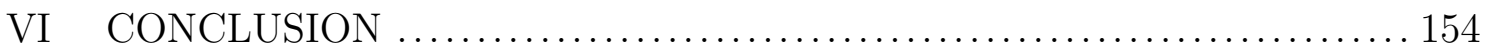

VII REFERENCES ................................................ 156

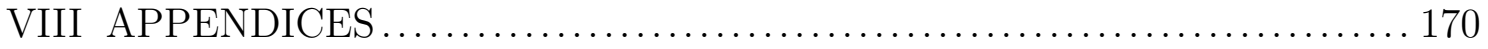

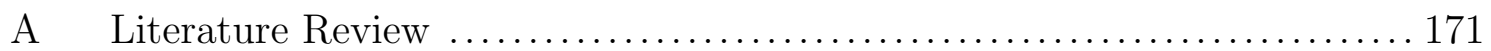

B Hypothesis 1: Short Selling ................................... 175

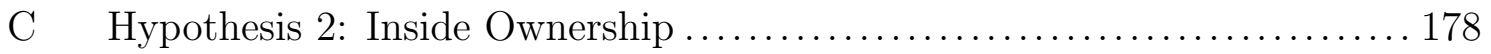

D Hypothesis 3: Hedge Fund Board Representation ...................... 181

E Hypothesis 4: Short Term Efficacy of Shareholder Activism .............. 191

F Hypothesis 5: Long Term Returns of Target Firms (Total Shareholder

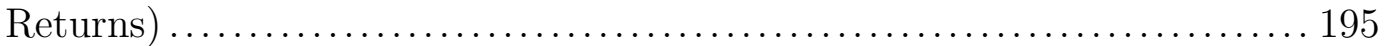

G Hypothesis 6: Long Term Operating Performance and Governance Structure of Target Firms ..................................... 204 


\section{LIST OF FIGURES}

Figure

V.2 H1: Short Interest Position: Target Firms vs. Matched Firms and Industry Composite Ex Ante and Ex Post Activism.................. 86

V.3 Buy and Hold Portfolio Returns: Treatment Group vs. Control Groups .... 101

V.4 Long-term Operating Performance: Log Linear Revenue Growth........... 112

V.5 Long-term Operating Performance: Tobin's Q ...................... 113

V.6 Long-term Operating Performance: ROA........................... 115

V.7 Long-term Operating Performance: Median Operating Margin ............ 117

V.1 Data Collection Methodology ....................................... 120

V.8 Buy and Hold Portfolio Returns: All Activist Interventions ............. 151

V.9 Buy and Hold Portfolio Returns: Hedge Fund Activism................. 151

V.10 Buy and Hold Portfolio Returns: Non-Hedge Fund Activism ............... 152

V.11 Buy and Hold Portfolio Returns: Hedge Fund Board Representation) ...... 152

V.12 Buy and Hold Portfolio Returns: Non-Hedge Fund Board Representation . 153

V.13 Buy and Hold Portfolio Returns: Target Firm "Wins" Proxy Fight: No

Hedge Fund Board Representation ............................... 153

F.1 Total Shareholder Return: All Activist Interventions ................... 197

F.2 Total Shareholder Return: Hedge Fund Activism ........................ 198

F.3 Total Shareholder Return: Non-Hedge Fund Activism ................... 201

F.4 Total Shareholder Return: Hedge Fund Board Representation ............ 201 
F.5 Total Shareholder Return: Target Firm "Wins" Proxy Fight: No Hedge

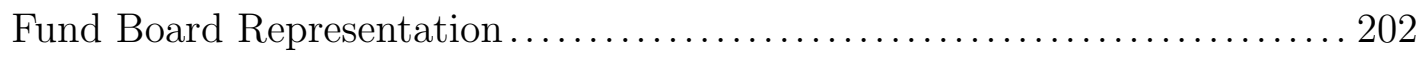

F.6 Total Shareholder Return: Non-Hedge Fund Board Representation ......... 202 


\section{LIST OF TABLES}

Table

V.1 Objectives and Characteristics of Activist Campaigns (1990-2014) ........ 121

V.2 Governance and Corporate Defense Profile of Target Firms (1990-2014) ... 122

V.3 Timing to Sale/Merger: Target Firms vs. Matched Firms ................ 123

V.4 Timing to CEO Change: Target Firms vs. Matched Firms ............... 124

V.5 Target Firm Characteristics: Comparison of Target Firms to Matched Firms from 1990-2014 (All Activist Interventions) ................... 126

V.6 Target Firm Characteristics: Comparison of Target Firms to Matched Firms from 1990-2014 (Hedge Fund Activism) ....................... 127

V.7 Target Firm Characteristics: Comparison of Target Firms to Matched Firms from 1990-2014 (Non-Hedge Fund Activism) ................... 128

V.8 Treatment Group: Comparison of Target Firms to Matched Firms from 1990-2014 (Hedge Fund Board Representation) ........................ 129

V.9 Control Group II: Comparison of Target Firms to Matched Firms from 1990-2014 (Non-Hedge Fund Board Representation).................... 130

V.10 Control Group I: Comparison of Target Firms to Matched Firms from 1990-2014 (Target Firm "Wins" Proxy Fight: No Hedge Fund Board

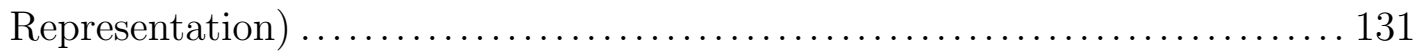

V.11 Vulnerability of Target Firms to Shareholder Activism: Probit Regression . 132 V.12 H1: Change in Short Interest Position of Target Firms Ex Ante Activist Intervention (Hedge Fund Activism versus Non-Hedge Fund Activism) .... 133 
V.13 H1: Change in Short Interest Ratio Relative to Other Vulnerability Variables: Probit Regression

V.14 H1: Hedge Fund Activism: Short Interest Position of Target Firms Ex Ante Activist Intervention (Logistic Regression Model) 135

V.15 H1: Non-Hedge Fund Activism: Short Interest Position of Target Firms Ex Ante Activist Intervention (Logistic Regression Model)

V.16 H2: Hedge Fund Activism: Corporate "Inside" Ownership (Logistic

Regression Model)

V.17 H2: Quarterly Corporate Ownership of Hedge Fund Activist Interventions:

Robustness Check ............................................ 138

V.18 H3: Hedge Fund Board Representation: Corporate "Inside" Ownership of

Target Firms (Logistic Regression Model) ........................... 139

V.19 H3: Hedge Fund Board Representation: Corporate "Inside" Ownership of

Target Firms: Robustness Analysis ................................. 140

V.20 H4: Short-term Efficacy of Hedge Fund Board Representation (Event Study)141

V.21 H4: Short-term Efficacy of Non-Hedge Fund Board Representation (Event

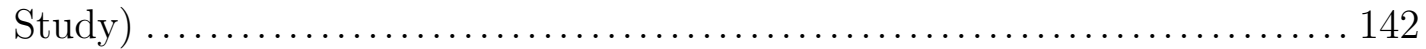

V.22 H4: Short-term Efficacy of Target Firms that "Won" Proxy Fight: Failed Attempt at Hedge Board Representation (Event Study) ................. 143

V.23 H5: Calendar-time Portfolio Abnormal Returns: Jensen's Alpha (Hedge

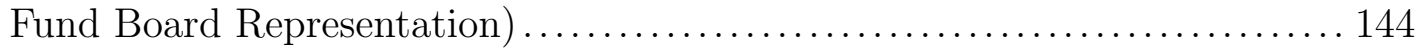

V.24 H5: Calendar-time Portfolio Abnormal Returns: Jensen's Alpha

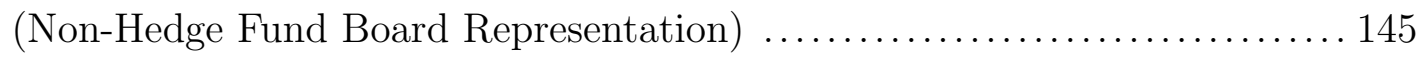

V.25 H5: Calendar-time Portfolio Abnormal Returns: Jensen's Alpha (Target Firm that "Won" a Proxy Fight: No Hedge Fund Board Representation) . 146

V.26 H5: Long-term Abnormal Returns of Treatment and Control Groups

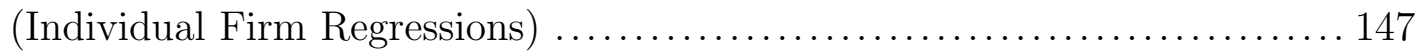


V.27 H6: Long-term Operating Performance of Treatment Group (Hedge Fund

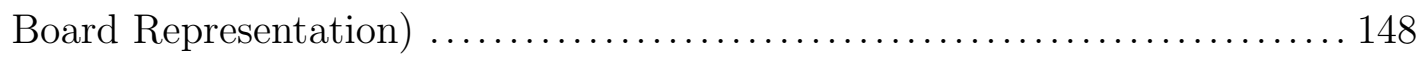

V.28 H6: Long-term Operating Performance of Control Group I (Failed

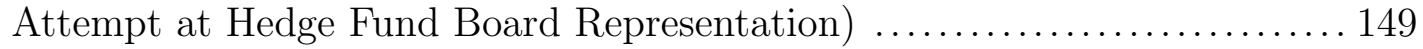

V.29 H6: Long-term Operating Performance of Control Group II: Non-Hedge Fund Board Representation..................................... 150

A.1 Literature Overview: Determinants of Shareholder Activism (Ex-ante

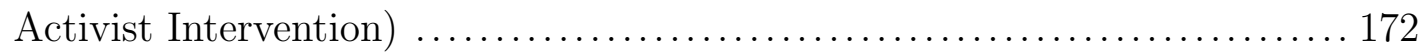

A.2 Literature Overview: Outcomes of Shareholder Activism (Ex-post

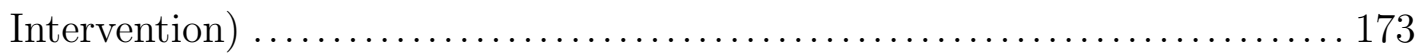

A.3 Literature Overview: Outcomes of Shareholder Activism (Ex-post

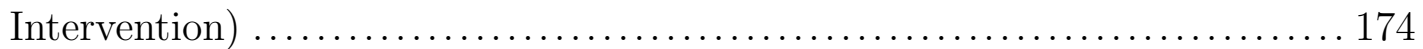

B.1 H1: Hedge Fund Activism: Short Interest Position of Target Firms Ex Ante Activist Intervention (Probit Regression Model) .................. 176

B.2 H1: Non-Hedge Fund Activism: Short Interest Position of Target Firms Ex Ante Activist Intervention (Probit Regression Model) ............... 177

C.1 H2: Hedge Fund Activism: Corporate "Inside" Ownership (Probit

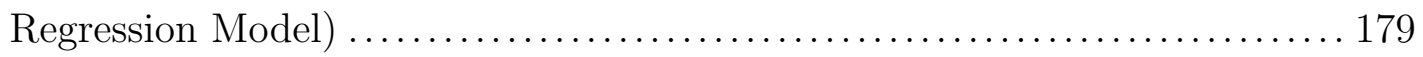

C.2 H2: Non-Hedge Fund Activism: Corporate "Inside" Ownership (Probit

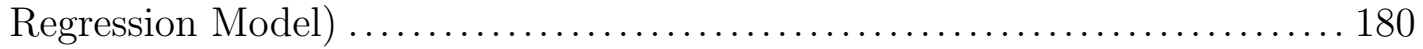

D.1 H3: Hedge Fund Board Representation: Corporate "Inside" Ownership of

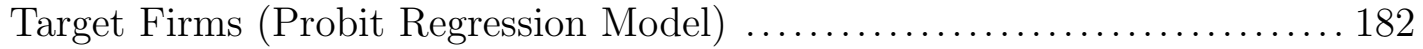

D.2 H3: Non-Hedge Fund Board Representation: Corporate "Inside" Ownership of Target Firms (Probit Regression Model) .................. 183

D.3 H3: Corporate "Inside" Ownership of Target Firms that "Won" Proxy Fight: No Hedge Fund Board Representation (Probit Regression Model) ... 184 
D.4 H3: Hedge Fund Board Representation: Corporate "Inside" Ownership of Target Firms (Logistic Regression Model) ............................. 185

D.5 H3: Non-Hedge Fund Board Representation: Corporate "Inside" Ownership of Target Firms (Logistic Regression Model) ................. 186

D.6 H3: Corporate "Inside" Ownership of Target Firms that "Won" Proxy Fight: No Hedge Fund Board Representation (Logistic Regression Model) . 187

D.7 H3: Corporate "Inside" Ownership of Target Firms by Hedge Fund Activists Seeking Board Representation ........................... 188

D.8 H3: Corporate "Inside" Ownership of Target Firms by Non-Hedge Fund Activists Seeking Board Representation ............................. 189

D.9 H3: Corporate Inside Ownership of Target Firms that "Won" Proxy Fight: Failed Attempt at Hedge Board Representation ........................ 190

E.1 H4: Short-term Efficacy of All Activist Interventions (Event Study) ....... 192

E.2 H4: Short-term Efficacy of Hedge Fund Activist Interventions (Event Study) 193

E.3 H4: Short-term Efficacy of Non-Hedge Fund Activist Interventions (Event

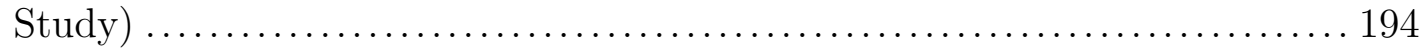

F.1 H5: Calendar-time Portfolio Abnormal Returns: Jensen's Alpha (All

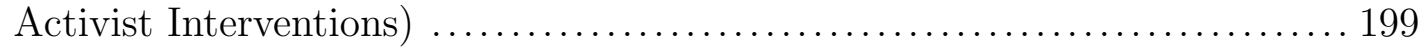

F.2 H5: Calendar-time Portfolio Abnormal Returns: Jensen's Alpha (Hedge

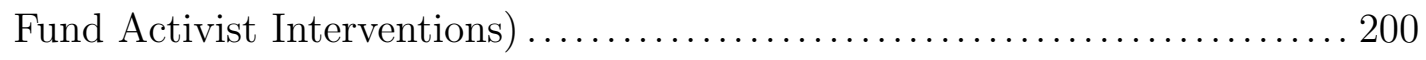

F.3 H5: Calendar-time Portfolio Abnormal Returns: Jensen's Alpha (Non-Hedge Fund Activist Interventions) ........................... 203

G.1 Long-term Operating Performance: Revenue Growth and Operating Margin Ex Ante and Ex Post All Activist Intervention .................. 205

G.2 Long-term Operating Performance: ROA and Tobin's Q Ex Ante and Ex Post All Activist Intervention ................................... 206 
G.3 Long-term Operating Performance: ROE and ROIC Ex Ante and Ex Post

All Activist Intervention ...................................... 207

G.4 Long-term Operating Performance: Enterprise Value / LTM EBITDA Ex

Ante and Ex Post All Activist Intervention ............................ 208

G.5 Long-term Operating Performance: Cash-to-Market Capitalization and

Cash-to-Assets Ex Ante and Ex Post All Activist Intervention ............. 209

G.6 Long-term Operating Performance: Debt-to-EBITDA and Net Leverage

Ex Ante and Ex Post All Activist Intervention ....................... 210

G.7 Long-term Operating Performance: Capital Expenditure Ex Ante and Ex

Post All Activist Intervention ..................................... 211

G.8 Long-term Operating Performance: Dividend Yield and Share Repurchase

Ex Ante and Ex Post All Activist Intervention ....................... 212

G.9 Long-term Operating Performance: EPS Estimates and Research Analyst

Recommendations Ex Ante and Ex Post All Activist Intervention ......... 213

G.10 Long-term Operating Performance: Multiple Business Segments and

Herfindahl-Hirschman Index Ex Ante and Ex Post All Activist Intervention214

G.11 Corporate Governance: 13D Filings Ex Ante and Ex Post All Activist

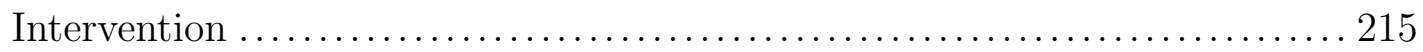

G.12 Corporate Governance: Classified Board and Poison Pill Ex Ante and Ex

Post All Activist Intervention ................................... 216

G.13 Long-term Operating Performance: Revenue Growth and Operating

Margin Ex Ante and Ex Post Hedge Fund Activist Intervention .......... 217

G.14 Long-term Operating Performance: ROA and Tobin's Q Ex Ante and Ex

Post Activist Intervention....................................... 218

G.15 Long-term Operating Performance: ROE and ROIC Ex Ante and Ex Post

Hedge Fund Activist Intervention ................................ 219

G.16 Long-term Operating Performance: Enterprise Value / LTM EBITDA Ex

Ante and Ex Post Hedge Fund Activist Intervention ................... 220 
G.17 Long-term Operating Performance: Cash-to-Market Capitalization and

Cash-to-Assets Ex Ante and Ex Post Hedge Fund Activist Intervention .... 221

G.18 Long-term Operating Performance: Debt-to-EBITDA and Net Leverage

Ex Ante and Ex Post Hedge Fund Activist Intervention .................. 222

G.19 Long-term Operating Performance: Capital Expenditure Ex Ante and Ex

Post Hedge Fund Activist Intervention ............................. 223

G.20 Long-term Operating Performance: Dividend Yield and Share Repurchase

Ex Ante and Ex Post Hedge Fund Activist Intervention .................. 224

G.21 Long-term Operating Performance: EPS Estimates and Research Analyst

Recommendations Ex Ante and Ex Post Hedge Fund Activist Intervention 225

G.22 Long-term Operating Performance: Multiple Business Segments and Herfindahl-Hirschman Index Ex Ante and Ex Post Hedge Fund Activist

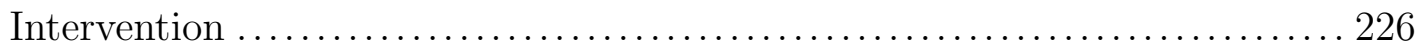

G.23 Corporate Governance: 13D Filings Ex Ante and Ex Post Hedge Fund

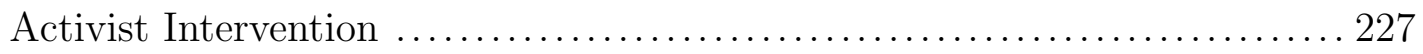

G.24 Corporate Governance: Classified Board and Poison Pill Ex Ante and Ex

Post Hedge Fund Activist Intervention .............................. 228

G.25 Long-term Operating Performance: Revenue Growth and Operating

Margin Ex Ante and Ex Post Non-Hedge Fund Activist Intervention ....... 229

G.26 Long-term Operating Performance: ROA and Tobin's Q Ex Ante and Ex

Post Activist Intervention....................................... 230

G.27 Long-term Operating Performance: ROE and ROIC Ex Ante and Ex Post

Non-Hedge Fund Activist Intervention............................. 231

G.28 Long-term Operating Performance: Enterprise Value / LTM EBITDA Ex

Ante and Ex Post Non-Hedge Fund Activist Intervention................. 232

G.29 Long-term Operating Performance: Cash-to-Market Capitalization and

Cash-to-Assets Ex Ante and Ex Post Non-Hedge Fund Activist Intervention233 
G.30 Long-term Operating Performance: Debt-to-EBITDA and Net Leverage

Ex Ante and Ex Post Non-Hedge Fund Activist Intervention.............. 234

G.31 Long-term Operating Performance: Capital Expenditure Ex Ante and Ex

Post Non-Hedge Fund Activist Intervention ........................... 235

G.32 Long-term Operating Performance: Dividend Yield and Share Repurchase

Ex Ante and Ex Post Non-Hedge Fund Activist Intervention............. 236

G.33 Long-term Operating Performance: EPS Estimates and Research Analyst

Recommendations Ex Ante and Ex Post Non-Hedge Fund Activist

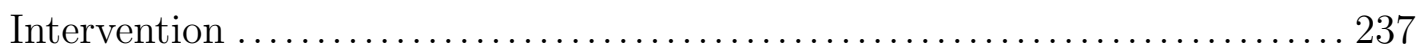

G.34 Long-term Operating Performance: Multiple Business Segments and

Herfindahl-Hirschman Index Ex Ante and Ex Post Non-Hedge Fund

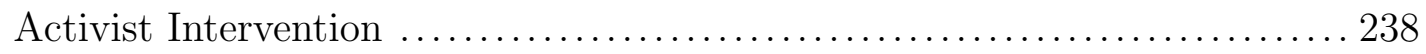

G.35 Corporate Governance: 13D Filings Ex Ante and Ex Post Non-Hedge

Fund Activist Intervention ....................................... 239

G.36 Corporate Governance: Classified Board and Poison Pill Ex Ante and Ex

Post Non-Hedge Fund Activist Intervention ......................... 240

G.37 Long-term Operating Performance: Revenue Growth and Operating

Margin Ex Ante and Ex Post Hedge Fund Board Representation .......... 241

G.38 Long-term Operating Performance: ROA and Tobin's Q Ex Ante and Ex

Post Activist Intervention....................................... 242

G.39 Long-term Operating Performance: ROE and ROIC Ex Ante and Ex Post

Hedge Fund Board Representation ................................ 243

G.40 Long-term Operating Performance: Enterprise Value / LTM EBITDA Ex

Ante and Ex Post Hedge Fund Board Representation .................... 244

G.41 Long-term Operating Performance: Cash-to-Market Capitalization and

Cash-to-Assets Ex Ante and Ex Post Hedge Fund Board Representation... 245

G.42 Long-term Operating Performance: Debt-to-EBITDA and Net Leverage

Ex Ante and Ex Post Hedge Fund Board Representation ................. 246 
G.43 Long-term Operating Performance: Dividend Yield and Share Repurchase

Ex Ante and Ex Post Hedge Fund Board Representation

G.44 Long-term Operating Performance: EPS Estimates and Research Analyst

Recommendations Ex Ante and Ex Post Hedge Fund Board Representation249

G.45 Long-term Operating Performance: Multiple Business Segments and

Herfindahl-Hirschman Index Ex Ante and Ex Post Hedge Fund Board

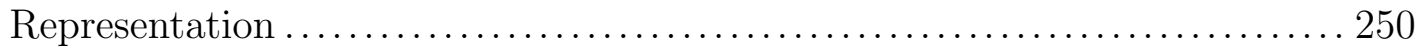

G.46 Corporate Governance: 13D Filings Ex Ante and Ex Post Hedge Fund

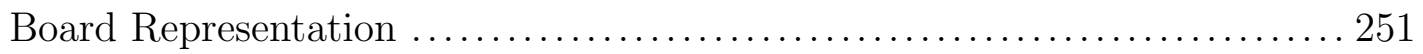

G.47 Corporate Governance: Classified Board and Poison Pill Ex Ante and Ex

Post Hedge Fund Board Representation .............................. 252

G.48 Long-term Operating Performance: Revenue Growth and Operating

Margin Ex Ante and Ex Post Non-Hedge Fund Board Representation...... 253

G.49 Long-term Operating Performance: ROA and Tobin's Q Ex Ante and Ex

Post Activist Intervention...................................... 254

G.50 Long-term Operating Performance: ROE and ROIC Ex Ante and Ex Post

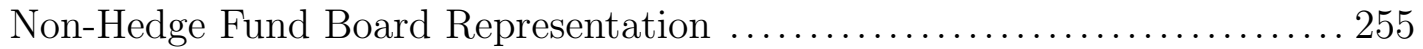

G.51 Long-term Operating Performance: Enterprise Value / LTM EBITDA Ex

Ante and Ex Post Non-Hedge Fund Board Representation................ 256

G.52 Long-term Operating Performance: Cash-to-Market Capitalization and

Cash-to-Assets Ex Ante and Ex Post Non-Hedge Fund Board Representation257

G.53 Long-term Operating Performance: Debt-to-EBITDA and Net Leverage

Ex Ante and Ex Post Non-Hedge Fund Board Representation............. 258

G.54 Long-term Operating Performance: Capital Expenditure Ex Ante and Ex

Post Non-Hedge Fund Board Representation.......................... 259

G.55 Long-term Operating Performance: Dividend Yield and Share Repurchase

Ex Ante and Ex Post Non-Hedge Fund Board Representation............. 260 
G.56 Long-term Operating Performance: EPS Estimates and Research Analyst Recommendations Ex Ante and Ex Post Non-Hedge Fund Board

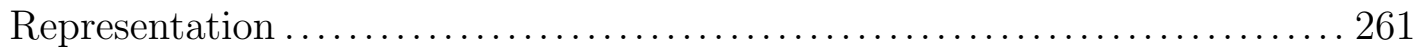

G.57 Long-term Operating Performance: Multiple Business Segments and Herfindahl-Hirschman Index Ex Ante and Ex Post Non-Hedge Fund Board Representation ............................................... 262

G.58 Corporate Governance: 13D Filings Ex Ante and Ex Post Non-Hedge

Fund Board Representation ..................................... 263

G.59 Corporate Governance: Classified Board and Poison Pill Ex Ante and Ex Post Non-Hedge Fund Board Representation........................... 264

G.60 Long-term Operating Performance: Revenue Growth and Operating Margin Ex Ante and Ex Post Failed Attempt at Hedge Fund Board Representation .................................................. 265

G.61 Long-term Operating Performance: ROA and Tobin's Q Ex Ante and Ex

Post Activist Intervention....................................... 266

G.62 Long-term Operating Performance: ROE and ROIC Ex Ante and Ex Post

Failed Attempt at Hedge Fund Board Representation ................... 267

G.63 Long-term Operating Performance: Enterprise Value / LTM EBITDA Ex

Ante and Ex Post Failed Attempt at Hedge Fund Board Representation ... 268

G.64 Long-term Operating Performance: Cash-to-Market Capitalization and Cash-to-Assets Ex Ante and Ex Post Failed Attempt at Hedge Fund Board Representation ................................................ 269

G.65 Long-term Operating Performance: Debt-to-EBITDA and Net Leverage

Ex Ante and Ex Post Failed Attempt to Hedge Fund Board Representation270 G.66 Long-term Operating Performance: Capital Expenditure Ex Ante and Ex

Post Failed Attempt at Hedge Fund Board Representation ............... 271

G.67 Long-term Operating Performance: Dividend Yield and Share Repurchase

Ex Ante and Ex Post Faile Attempt at Hedge Fund Board Representation 272 
G.68 Long-term Operating Performance: EPS Estimates and Research Analyst Recommendations Ex Ante and Ex Post Failed Attempt at Hedge Fund

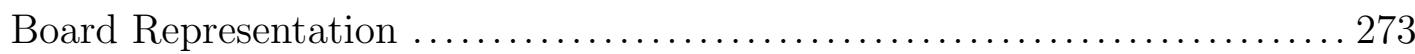

G.69 Long-term Operating Performance: Multiple Business Segments and Herfindahl-Hirschman Index Ex Ante and Ex Post Failed Attempts at Hedge Fund Board Representation ............................... 274

G.70 Corporate Governance: 13D Filings Ex Ante and Ex Post Failed Attempt at Hedge Fund Board Representation ............................. 275

G.71 Corporate Governance: Classified Board and Poison Pill Ex Ante and Ex Post Failed Attempt at Hedge Fund Board Representation ............... 276 


\section{CHAPTER I}

\section{INTRODUCTION}

Agency conflict in publicly traded corporations with dispersed ownership is at the heart of corporate governance literature, which focuses on mechanisms to discipline incumbent management. One possible solution to mitigate agency cost is for shareholders to actively monitor the firm's management. However, while monitoring may reduce agency and improve firm value, this effort is not without cost, and the benefits from monitoring are enjoyed by all shareholders (Grossman \& Hart, 1980).

Shareholders who serve as active monitors of firm management to provide a disciplinary mechanism is not a new concept. Earlier studies have shown that when institutional investors, particularly mutual funds and pension funds, follow an activist agenda, they do not achieve significant benefits for shareholders (Black, 1998; Gillan \& Starks, 2007; Karpoff, 2001; Romano 2001). Nevertheless, hedge funds have increasingly engaged in shareholder activism, and monitoring that differs fundamentally from previous activist efforts by other institutional investors. Unlike mutual funds and pension funds, hedge funds are able to influence corporate boards and managements due to key differences arising from their organizational form and incentive structures.

Hedge funds employ highly incentivized managers who control large, unregulated pools of capital. Because they are not subject to regulation that governs mutual funds and pension funds, hedge funds can hold highly concentrated positions in a small number of companies and use leverage and derivatives to extend 
their reach. In addition, hedge fund managers do not experience conflicts of interest because they are not beholden to the management of the firms whose shares they hold. Consequently, hedge funds are better positioned to act as informed monitors than other institutional investors.

My dissertation addresses two fundamental questions with respect to hedge fund activism: (a) What are the determinants of hedge fund activist interventions and the characteristics of the Target Firms? and (b) Does hedge fund activism create long-term value for Target Firms and their long-term shareholders? My research fills the important void in the literature with respect to the shareholder activism initiated by hedge funds. My novel approach to "corporate inside" ownership and short-interest positions as instrumented variables that predict a Target Firm's vulnerability to hedge fund activism contributes to the literature on the determinants of shareholder activism.

Because shareholder activism has evolved significantly over the past 25 years, it is imperative to ensure that the extant literature properly reflects the changing financial markets. First, all meaningful academic research with respect to shareholder activism is predicated on data that use very small sample sizes, usually fewer than 200 Target Firms or activist interventions. Additionally, most datasets have limited time series and nearly all of the research is based on data prior to 2005 . The most comprehensive dataset was used by Brav, Jiang, and Kim (2015) who used approximately 2,000 activist interventions from 1994-2007. Since 2007, shareholder activism has increased significantly, particularly by hedge funds. To be sure, approximately $60 \%$ of activist interventions have occurred since 2007 , and approximately $75 \%$ of those events were instigated by hedge funds.

Second, Judge, Gaur, and Muller-Kahle (2010) noted that there are two types of shareholder activism: governance-focused activists and economically-motivated activists. Previous studies have not clearly delineated between these investment styles. In this study, I define governance-focused activism 
as dissident shareholders who submit shareholder resolutions to effectuate a change to the governance structure of a company (i.e., change from a plurality voting system to a majority voting standard with respect to director elections) or to make recommendations with respect to executive compensation.

A large portion of proxy resolutions are focused on corporate social responsibility initiatives. Furthermore, some pension funds put pressure on Target Firms to improve their corporate social responsibility practices. Thus, researchers attempting to measure financially related effects of shareholder activism may not find any impact on the financial performance or corporate governance measures due to the presence of socially driven shareholder activism.

Economically-motivated activism differs from governance-focused activism with respect to strategic objectives and the tactics used during a campaign. Economically motivated activists are focused on changing the strategic direction of the corporation and/or the capital structure via returning excess cash to the shareholders. Governance-focused activism facilitated the proliferation for the economically-motivated activist to launch successful campaigns. During the mid-1990s, labor union pension funds and hedge funds became more active in economically-motivated activism (Gillan \& Starks, 2007). Accordingly, my dissertation research is focused exclusively on economically-motivated activists (i.e., hedge funds) and has not conflated governance-focused activist agendas.

Third, the vast majority of activist interventions studies is primarily constructed from Schedule 13D filings, the mandatory federal securities law filings under Section 13(d) of the 1934 Exchange Act. That law states that investors must file with the SEC within 10 days of acquiring more than $5 \%$ of any class of securities of a publicly traded company if they have an interest in influencing the management of the company. The presumption is a shareholder who files a $13 \mathrm{D}$ is unequivocally motivated to change the strategic direction of the company. However, I claim that this motivation is not always the case. As previously noted, some activist campaigns 
are centered on corporate governance reforms (i.e., board declassification, removal of shareholder rights plan, etc.) and not on meaningful long-term strategic changes to the Target Firm. I contend that any shareholder with sincere conviction to challenge the current strategic direction of a firm would, ultimately, seek board representation if that shareholder's demands were not supported by the firm's incumbent management. I view board representation as a signal of an activist's long-term commitment to the firm.

In this study, I start with a much more expansive sample of activist interventions. Figure V.1 illustrates my comprehensive dataset of shareholder activist events, which includes 5,728 interventions from 1984-2014. Of those, 4,295 $75 \%$ filed a 13D. However, approximately $27 \%$ of all activist interventions were focused on board engagement, either through a proxy contest $(1,293)$ or through a nonproxy contest dissident campaign that resulted in board representation via private negotiations with the target management team and its board of directors (239). To be sure, nearly three-quarters of activist interventions did not seek board representation to actively monitor management. Moreover, GAMCO Asset Management, a hedge fund founded by Mario Gabeli, has filed 493 13Ds since 1996. However, it has launched only 18 proxy fights $4 \%$ and won board representation only 10 times $2 \%$ to date. In contrast, Carl Icahn has launched proxy fights and won board representation at eBay, Genzyme, Time Warner, and Yahoo! without filing a $13 \mathrm{D}$.

Accordingly, I claim that there are numerous 13D filings of activist interventions that otherwise include good performing companies with strong management in which a dissident was not compelled to seek board representation to actively monitor management and function as a disciplinary mechanism.

Additionally, there are over 90 activist interventions that led to board representation without filing a 13D. Therefore, I assert that the optimal dataset to test empirically the long-term efficacy of hedge fund activism should be based on board 
representation of Target Firms by a shareholder activist and not merely the fact that a shareholder crossed 5\% ownership and might seek (not will seek) to influence strategic change at the Target Firm. To be sure, an activist willing to incur significant financial cost not borne by all shareholders, which Gantchev (2013) estimated is approximately $\$ 10$ million per proxy contest, has genuine conviction that the Target Firm requires strategic change that management is unwilling to execute without shareholder interference.

Fourth, the results of examining the effects of shareholder activism are also largely equivocal. The bulk of researchers have concentrated on measuring short-term, market-based performance effects upon the announcement of an activism effort. There are few studies on the longer term impact of shareholder activism using accounting and market-based measures, and their results are mixed. More studies are needed to measure the longer term impact of shareholder activism on firm performance measures.

Fifth, there may be methodological problems that are clouding results of shareholder activism studies. For example, many of the empirical studies on this topic are descriptive in nature. More sophisticated statistical models would add much to the validity and reliability of the results. Therefore, a more comprehensive approach to the study of shareholder activism is warranted. Additionally, some studies suffer from methodological problems. For example, many studies that calculated cumulative abnormal returns $(C A R s)$ used vastly different empirical methods to calculate return. Nelson (2006) argued that four prior studies examining shareholder returns around the release of the CalPERS focus list had methodology problems that severely impacted their results. Accordingly, this suggests the need for more refined measurement models of shareholder and hedge fund activism.

My expansive, hand-collected dataset and unique empirical research design methodology with respect to board representation fills the important gap in the literature regarding the long-term efficacy of hedge fund activists serving as a 
disciplinary mechanism on Target Firms by actively seeking board representation to monitor management and reduce agency cost. Moreover, my findings have important policy implications related to the ongoing debate on corporate governance and the rights and roles of shareholders. My findings suggest that hedge fund activism generates substantial long-term value for Target Firms and its long-term shareholders when they function as a shareholder advocate to monitor management through active board engagement. Furthermore, contrary to conventional wisdom and extant literature, hedge fund activists that seek board representation are focused on long-term corporate initiatives to increase shareholder value rather than a "sale of the company" agenda. It is very common for hedge fund activists to seek replacement of the management team to accomplish the activist's agenda ex post the board seat grant date as opposed to forcing a sale of the company.

Accordingly, my manuscript is organized into several chapters. First, in Chapter II, I discuss the theoretical foundation and history of shareholder activism and provide a thorough review of the extant literature relating to the causes and effects of shareholder activism. In Chapter III, I present my hypotheses to argue that hedge fund activism generates substantial long-term value for Target Firms and their long-term shareholders when those activist hedge funds function as a shareholder advocate to monitor management through active board engagement. Chapter IV addresses the most important and pervasive econometric issues confronting studies in empirical corporate finance, primarily endogeneity and selection bias. In Chapter V, I present a comprehensive, empirical overview of shareholder activism with my expansive, manually constructed dataset of 5,728 activist interventions from 1984-2014. Lastly, in Chapter VI, I provide concluding remarks to address the critical question with respect to the long-term efficacy of hedge fund activists serving as a disciplinary mechanism on the Target Firm by actively seeking board representation to monitor management and reduce agency cost. 


\section{CHAPTER II}

\section{REVIEW OF LITERATURE}

In this chapter, the theoretical foundation and history of shareholder

activism is briefly outlined, and a thorough review of the literature relating to the causes and effects of shareholder activism is conducted. The following literature review is divided into several sections. First, I discuss the underlying theoretical basis of shareholder activism. Second, I provide an extensive review of how shareholder activism has evolved over time. Third, the extant literature with respect to the determinants of shareholder activism ex ante an intervention is reviewed. Fourth, a review of the prior literature with respect to active monitoring by shareholders to mitigate agency cost is studied. Lastly, the short and long-term efficacy of shareholder activism (ex post intervention) on both Target Firms and shareholders is investigated. Research gaps are identified that can be used to contribute to shareholder activism and hedge fund literature.

\section{II.A Theoretical Foundations of Shareholder Activism}

The underlying theoretical foundation in the study of shareholder activism is agency theory. The central tenet of agency theory is an overarching concern with the divergence of interests between principals and agents (Berle \& Means, 1932; Jensen \& Meckling, 1976). Berle and Means (1932) laid the foundations for future work in agency theory when they identified the problems that could occur when ownership of the firm is separated from the control of the firm. Berle and Means traced the growth of the American corporation from a single proprietorship to a public 
corporation and suggested that this new structure was likely to give rise to problems of ownership and control. In that transition, control of the corporation is placed in the hands of professional managers who have little or no ownership interest. As a result, there is the fear that managers may be acting in their own self-interest instead of in the interests of the corporation. Thus, opportunistic managerial decision-making could adversely impact company performance.

The presumption of opportunistic behavior by managers gave rise to agency theory, which was further enhanced by Jensen and Meckling (1976) and Fama and Jensen (1983) who posited that managers may misuse corporate assets for their own personal benefit at the expense of shareholders, causing principal-agent issues. Thus, agency costs can diminish corporate performance. As a result, agency theory logic would suggest that shareholder activism is one external control option for owners who are dissatisfied with the management of their assets.

The first line of defense against managerial opportunism is a board of directors who closely monitor the activities of the executive management team. The rise of shareholder activism may be in part due to the failure of the board of directors to monitor and discipline the management team. The board of directors also has the responsibility of hiring and firing the management team and overseeing the strategic direction of the firm. Moreover, boards are the legal representatives of the corporation's owners, although the legal responsibility of directors to shareholders can vary by state and by country (Huse \& Rindova, 2001). Some have argued that the board of directors has not done a good job in their role as monitor and failed to remove underperforming executives (Lorsch \& Maciver, 1989; Mace, 1986; Weisbach, 1988). In addition, Jensen and Smith (1985) argued that managers are more likely to minimize risk and engage in short-term investments and employee growth strategies to increase their compensation as well as their job security. Thus, the lack of internal control mechanisms may lead to the rise of nontraditional external control mechanisms like shareholder activism. As 
such, shareholder activism can serve as a "substitute" governance mechanism for internal controls.

If the board of directors cannot monitor the management team effectively, shareholders will be dissatisfied with both management and, perhaps, the board as well. Shareholders have three options: (a) Sell their shares, (b) passively continue to hold their shares in the hope that performance will improve over time, or (c) continue to hold their shares and attempt to influence the firm. Clearly, the third option is the path chosen by shareholder activists in economies where capital markets are relatively liquid. However, activism is not costless, and only shareholders with the knowledge and resources can attempt to "voice" their displeasure with underperforming corporations (Admati, Pfleiderer, \& Zechner 1994; Shleifer \& Vishny, 1986).

While agency theory is the theoretical basis for almost all of the previous research on shareholder activism, its explanatory power is increasingly being challenged by self-interested legal practitioners and judicial scholars. However, their assertions are primary based on anecdotes and not supported rigorous econometric examination. Firms may be faced with not only principal-agent problems but also principal-principal problems. Critics claim economically-motivated shareholder activists may have different objectives for their Target Firms than other shareholders. However, active board engagement is supported and endorsed by other shareholders because an activist would need the voting support of the majority of shareholders.

\section{II.B History of Shareholder Activism}

Shareholder activism has evolved over time. Gillan and Starks (2007) and Marens (2002) traced the history of shareholder activism in the United States. Gillan and Starks (2007) noted that U.S. financial institutions were the primary outside monitors of U.S. firms in the early 1900s. With the crash of 1929, the government 
began to limit the role of financial institutions in corporate governance. Gillan and Starks stated that laws and regulations passed by the U.S. government at that time led to a widening gap between shareholders and control. In 1942, the Securities and Exchange Commission first allowed proxy resolutions ${ }^{1}$. Typically, shareholder proposals fall roughly into two main groups:

1. Corporate social responsibility proposals, which include proposals relating to product safety, employment discrimination, affirmative action, environmental pollution, nuclear power, et cetera. Other social responsibility proposals have been suggested to tobacco companies to promote anti-smoking agendas, non-participation in the Arab boycott of Israel, cessation of operation in South Africa during the apartheid era, and divestment from Northern Ireland; and

2. Corporate governance proposals are related to traditional issues such as cumulative voting, antitakeover features, selection of auditors, location of shareholder meetings, and executive compensation.

Pursuant to SEC 14a-8 rules, the proponent of a proposal to be printed and circulated in a corporate management's proxy statement must have been a record or a beneficial owner of shares for at least one year. The market value of shares owned by the proponent must exceed $\$ 2,000$ or, if less, must equal at least $1 \%$ of the shares entitled to vote on the proposal. Given the de minimis requirements to submit a proposal, most shareholder activism at this time was conducted by individual investors. This situation led to the emergence of the so-called gadflies who attended annual shareholder meetings to voice their disapproval on issues of governance, labor, and corporate social responsibility. Marens (2002) wrote that these gadflies included individual investors and union leadership. Some of the more well-known gadflies included Lewis and John Gilbert, who are regarded as two of the early proxy resolution pioneers, and Wilma Soss, who founded the Federation of

\footnotetext{
${ }^{1}$ Since 1942, the Securities and Exchange Commission, under rule 14a-8, has required corporate management to include shareholder proposals in its solicitation materials.
} 
Women Shareholders. Lewis Gilbert began six decades of activism with his attendance of the 1932 shareholder meeting of Consolidated Gas Company (Talner, 1983). Marens (2002) noted that these early shareholder activists were able to garner attention for future discussions on expanding ownership rights. Table I provides an overview of the shareholder activism literature.

In the 1980s, shareholder activism occurred mostly in response to the emergence of corporate raiders and management teams who were paying greenmail to fend off takeovers (Gillan \& Starks, 2007; Marens, 2002). Among the most notable corporate raiders of the 1980s were Carl Icahn, Nelson Peltz, Robert M. Bass, T. Boone Pickens, and Sir James Goldsmith. The term "corporate raider" was used to describe an investor who buys a large percentage of shares in a perceived undervalued corporation. The large ownership position provided the corporate raider significant voting rights, which could then be used to push for change within the company's management and board of directors. These investors used a number of the same tactics and targeted the same type of companies as more traditional leveraged buyouts and in many ways could be considered as forerunners of the later private equity firms. The 1980s were also the first time institutional investors began their involvement in shareholder activism. At this time, CalPERS became more active in shareholder activism. Empirical work on shareholder activism was also in its infancy.

In the 1990s, U.S. regulatory changes brought increased levels of activism 2. There was a movement away from full takeovers to a more politically based type of shareholder activism (Black, 1992; Pound, 1992). In 1992, the SEC changed its regulations on proxy resolutions, making it easier to put a proxy resolution on the ballot to be voted on during an annual shareholder meeting.

\footnotetext{
${ }^{2}$ The new proxy-reform regulations have facilitated shareholder monitoring of management by reducing the costs and the regulatory barriers to collective shareholder action. Specifically, restrictions on shareholder communication were loosened, access to proxy information and nominating candidates for board of director elections was liberalized, and public announcements about proxy voting issues were permitted.
} 
Before the proxy reforms, any oral or written communication intended to affect the proxy voting decision of more than 10 shareholders was considered a proxy solicitation, which was defined broadly as any communication that was "reasonably calculated to result in the procurement, withholding, or revocation of a proxy, or were part of a continuous plan that (would) end in solicitation and (was) calculated to pave the way for a proposal's success" (Sharara \& Hoke-Witherspoon, 1992). Prior to making a solicitation, a formal proxy statement approved by the SEC was required, which was then mailed to all shareholders. Choi (1997) related public filings with the SEC delayed shareholder communications, imposed filing and direct mailing costs on proxy solicitors, and discouraged potential solicitors desiring anonymity from communicating their views.

In their study of U.S. proxy resolutions from 1988 to 1998, Graves, Rehbein, and Waddock (2001) reported that governance-related resolutions did not appear on proxy resolutions until 1993 but have grown steadily since then. They also reported that compensation-related activism via proxy resolutions did not start until 1995. This governance-focused activism facilitated the proliferation of economically-motivated activists, who in turn launched successful campaigns. Economically motivated activism differs from governance-focused activism with respect to strategic objectives and the tactics used during a campaign.

Economically motivated activists are focused on changing the strategic direction of the corporation and / or the financial position via returning capital to the shareholders. During this time, labor union pension funds and hedge funds became more active in economically-motivated activism, while takeover activity by corporate raiders slowed down (Gillan \& Starks, 2007).

During the last 15 years, three major changes have impacted shareholder activism. The first change is the continued growth of institutional investor ownership. Gillan and Starks (2007) noted that institutional investor ownership in the United States was approximately 10\% in 1953 and reached to over $60 \%$ by 2005 . 
Institutional ownership in 2014 was estimated at 70\%, which is consistent with my findings. The second change is the increased use of proxy resolutions by all types of investors. The number of proxy resolutions can change from year to year depending upon the nature of the campaign. In some years organizations will experience an increase in takeover defense repeals (i.e., board declassification, shareholder rights plans, etc.), while other years will be much more focused on executive compensation. The third change is the tremendous growth of the hedge fund industry in the last decade. As of 2014, there were over 10,000 hedge funds with approximately $\$ 2.5$ trillion of assets under management (HedgeFund Monitor, 2014). Kahan and Rock (2006) reported that hedge funds are different from other types of shareholder activists because of their structure, operations, and objectives. They do not operate under the same regulatory and political constraints that affect the other types of activists. Hedge funds have few conflicts of interest, and their managers are extremely well compensated. However, they have been criticized for being too short-term focused at the expense of the long-term value creation of their Target Firms.

\section{II.C Determinants of Shareholder Activism}

In this section, previous literature focusing on the determinants of shareholder activism is reviewed. Regarding the factors and causes of shareholder activism, researchers have found characteristics of shareholder activism in four areas of a firm: the firm, the CEO, the board of directors, and the ownership. Table A.1 provides an overview of the extant literature with respect to determinants of shareholder activism. First, firm characteristics such as prior firm performance, firm size, amount of diversification, growth prospects, and levels of free cash flow are the most commonly studied characteristics of shareholder activism. Researchers of only a few studies have looked at how shareholder activism could be driven by ownership structure. 


\section{II.C.1 Prior Firm Performance}

Numerous U.S.-based studies have found that the prior performance of firms has led shareholder activists to Target Firms. Studies have measured firm performance with market-based measures and financial measures ${ }^{3}$.

Predominantly, most of the activist interventions targeted firms with poor operating performance or for being undervalued relative to their peers. However, Klein and Zur (2009) found evidence that U.S. hedge funds in their sample targeted profitable firms, although they only used 151 sample firms from 2003-2005.

A few studies used proxy resolutions as the mechanism of shareholder activism and found evidence that multiple types of investor groups target companies due to performance issues. Bizjak and Marquette (1998) studied multiple types of activists who were using shareholder resolutions in an effort to remove poison pills in Target Firms.

With a sample of 193 resolutions in the US involving poison pills from 1986 to 1993, they found that poor performance by target companies and making management resistance to restructuring or removing their poison pills was a predictor of shareholder activism. Johnson and Shackell-Dowell (1997) conducted a study of 169 executive compensation proposals made by 74 shareholder activists against 106 U.S. firms from 1992 to 1995. They found that poor performance led to firms being targeted by gadflies and institutional investors.

Choi's (2000) study of 361 proxy resolutions targeting 277 U.S. companies from 1991 to 1995 found that poor stock performance was driving the issuance of proxy resolutions. Mulherin and Poulsen (1998) studied proxy contests for board seats between 1979 and 1994. In their sample of 270 U.S. proxy contests, they found

\footnotetext{
${ }^{3}$ Many of these studies used measures of Tobin's Q as an indicator of a firm's market performance. Tobin's $\mathrm{Q}$ is defined as the market value of a firm's assets divided by the replacement costs of a firm's assets (Brainard \& Tobin, 1968). If a firm has a $Q$ value of greater than 1, it presumes the existence of intangible assets that bring the value of the firm above and beyond the value of its physical assets. Doukas (1995) suggested that well-managed firms have a Tobin's Q value of over 1, and poorly-managed firms have Tobin's Q values less than 1.
} 
that firms with poor performance were more likely to be targeted for a proxy contest.

Thomas et al. (2005) examined 1,454 proxy resolutions in the U.S. from 2000 to 2004 and found that poor performance was also driving shareholder activism efforts. Renneboog and Szilagyi (2006) used a sample of 2,800 shareholder proposals in the United States from 1996 to 2005 and also found that shareholder activists targeted underperforming companies.

More recently, Buchanan and Yang (2009) studied U.S. and U.K. shareholder proposals from 2000 to 2006 with 3,812 proposals at 764 U.S. firms and 508 proposals at 85 U.K. firms and found that shareholder activists Target Firms with low book to market ratios.

Other studies looked at shareholder activism efforts of investor groups like the U.S. Shareholders Association and the Council of Institutional Investors. Strickland, Wiles, and Zenner (1996) examined shareholder activism efforts of the U.S. Shareholders Association. Their sample consisted of 216 proposals at 85 U.S. firms between 1990 and 1993. They found that poor stock performance was a key characteristic of shareholder activism. Opler and Sokobin (1998) and Caton, Goh, and Donaldson (2001) both used samples derived from shareholder activism targets of the Council of Institutional Investors.

Opler and Sokobin's (1998) sample was 96 U.S. firms from 1991 to 1993 and Caton et al.'s (2001) was 138 U.S. companies from 1991 to 1995. Both studies found that the Council of Institutional Investors targeted firms with poor stock performance. Bethel, Liebeskind, and Opler (1998) examined block share purchases in the 1980s and focused on investors like Carl Icahn, Bass Brothers, Mario Gabelli, and George Soros. Bethel et al. followed McConnell and Servaes (1990) in defining two primary groups of shareholders: blockholders and insider owners. McConnell and Servaes' classification of shareholder groups follows the SEC filing procedures, which define a "blockholder" as a direct owner of a beneficial interest of $5 \%$ or more 
of a firm's outstanding shares and an "insider" as an officer or director of a firm or a member of an officer's or director's family. Like many other studies, they found that these U.S. activists almost always Target Firms that are not meeting financial performance targets. In their study, McConnell and Servaes measured performance by low profitability as measured by ROA and low market-to-book values. Their sample consisted of 151 activist block purchases of $5 \%$ or greater equity stake made during the 1980s.

A number of researchers have found a negative relationship between prior firm performance and shareholder activism among pension funds. There were four studies that have focused on shareholder activism of multiple U.S.-based pension funds. First, Wahal (1996) looked at shareholder activism efforts of nine large U.S. pension funds via proxy resolutions, letters, and meetings using a sample of 356 targets within 146 firms from 1987 to 1993 and found they often targeted poor performing firms. Second, Karpoff, Malatesta, and Walking (1996) examined 269 U.S. companies facing 522 shareholder resolutions from 1986 to 1990 and found that many shareholder resolutions by a mix of public and private investor groups and individual investors were targeted at companies with poor performance. Third, Del Guercio and Hawkins (1999) studied 266 proxy resolutions at 125 firms by the five largest U.S. pension funds from 1987 to 1993 and found that some, but not all, of the pension funds targeted firms with poor performance. Last, Del Guercio, Seery, and Woidtke (2008) focused on "just vote no" proxy resolutions issued by public pension funds. Their sample included 112 "just vote no" campaigns in the United States from 1990 to 2003 and found that public pension funds targeted firms with poor firm performance.

Shareholder activism by the U.S.-based CalPERS pension fund has also been widely studied. Nesbitt (1994) looked at 42 investments made by the CalPERS pension fund from 1987 to 1992 and found that CalPERS targeted underperforming companies using market-based performance measures. All of the following studies 
found that CalPERS targeted firms with poor stock price performance. Smith (1996) studied shareholder activism efforts by CalPERS using a sample of 51 firms targeted by CalPERS from 1987 to 1993. Crutchley, Hudson, and Jensen (1998) studied public announcements made by CalPERS announcing the firms who were on their focus list. Their sample included 47 firms targeted by CalPERS from 1992 to 1997. English, Smythe, and McNeil (2004) also studied 63 targets in 43 firms from 1992 to 1997 that were placed on the CalPERS focus list. Moreover, Wu (2004) looked at 37 firms from 1988 to 1995 that were on the CalPERS focus list.

Finally, Becht et al. (2009) looked at shareholder activism in the U.K. by one pension fund, the Hermes U.K. Focus Fund (HUKFF), from 1998 to 2004. In 2005, HUKFF had 61 billion pounds under management. Their sample consisted of 41 companies of which the fund had discussions with 30. U.K. laws require companies to make a public disclosure when they have acquired just $3 \%$ of a firm's shares. Becht et al.'s main innovation is the study of one fund with full insider access to records of the fund's activities. According to internal documents, one of the three criteria for targeting firms was that the firm is underperforming.

Boyson and Mooradian (2007) [20] looked at U.S. hedge funds from 1994 to 2005 with a sample of 111 hedge funds and 89 hedge fund management companies and 397 Target Firms. They found that the hedge funds in their sample targeted firms with low measures of Tobin's $\mathrm{Q}$ and low stock performance. Greenwood and Schor (2007) found that U.S. hedge funds targeted firms with low market-to-book ratios and those who were underperforming in their industry. Using a sample of 784 hedge funds from 1993 to 2006, they also showed that hedge funds Target Firms with lower long-term industry abnormal returns funds. Brav, Jiang, Partnoy, and Thomas (2008) analyzed shareholder activism by U.S. hedge funds and used a sample of 888 events by 131 activist hedge funds from 2001 through 2005 . They found that hedge funds target companies with low market value relative to book value. 
Surprisingly, Klein and Zur's (2006) study was the only one that found that hedge funds were more likely to target cash-rich, profitable firms. They tracked 151 firms targeted by U.S. hedge funds from 2003 to 2005 . They noted that hedge funds target profitable firms with the goal of short-term gains via increased dividend payouts and short-term increases in stock price. The shareholder activism literature clearly points to firms being targeted by numerous types of shareholder activists for poor firm performance.

\section{II.C.2 Firm Size}

Previous activism research also suggested that there may be a relationship between firm size and the likelihood of shareholder activism. However, empirical results found support for both positive and negative effects. The following four U.S.-based studies found support for shareholder activists targeting larger firms. Three of the four studies examined pension fund activism. Smith (1996) studied CalPERS activism, while Del Guercio et al. (2008) studied "just vote no" campaigns on proxy resolutions, and Carleton et al. (1998) looked at 65 targets in 45 firms targeted by the pension fund TIAA-CREFF from 1992 to 1996. Renneboog and Szilagyi (2006) studied over 2,800 shareholder proposals by various types of activists from 1996 to 2005 and found that large firms were targeted by shareholder activists.

While many of the studies found support for various types of activists to target smaller firms, studies on shareholder activism by blockholder activists and hedge funds found that these activists tend to target smaller firms in order to be able to purchase a $5 \%$ or larger share of equity in the target company. Bethel et al. (1998) found that the activist blockholders of the 1980s targeted smaller firms.

Woidtke (2002) found that pension fund activists were more likely to target smaller firms than larger firms in the United States. Faccio and Lasfer (2000) noted that U.K. pension funds tended to target smaller firms when engaging in activist efforts through block share purchases. Boyson and Mooradian (2007), Bratton (2007), and 
Greenwood and Schor (2007) concluded that hedge fund activists prefer smaller firms as Target Firms in the United States. Two potential reasons for this relationship are that economically-motivated activists may prefer to limit the cost of activism and that smaller firms are expected to be less costly to catalyze an intervention. In addition, larger firms have the resources and political connections to resist shareholder activism.

\section{II.C.3 Free Cash Flow}

Free cash flow is excess cash beyond what a firm requires for normal ongoing operations and capital investment. It is a classic agency argument that high levels of free cash flow create agency problems in that managers can invest in low net present value projects (Cuthbertson \& Gasparro, 1995; Griffin \& Wiggins, 1992) Jensen (1986) argued that high levels of free cash flow create agency problems between shareholders and managers over whether excess cash should be used within the firm or redistributed to shareholders in the form of dividends or share buybacks.

Bratton (2007) examined a sample of 130 domestic firms between 2002 and 2006 that were targeted by hedge funds and found that many target companies have high levels of free cash flow. Bratton defined high levels of cash flow as cash to total assets ratio of 0.15 or greater plus a cash-to-debt ratio of 0.50 or greater. Bratton (2007) found that $38 \%$ of the Target Firms in the sample are cash rich. Brav et al. (2008) also found that hedge funds Target Firms with high levels of excess cash.

\section{II.C.4 Board of Director Characteristics}

I have focused my study on the characteristics of directors for several reasons. First, boards of directors have the purview and influence over dividend policy and help mitigate agency conflicts between management and shareholders (Easterbrook, 1984). Dividend policy is an area in which conflicts between management and shareholders may occur (Easterbrook, 1984; Jensen, 1986), and the board is the 
ultimate internal governance mechanism charged with protecting shareholders' interests. Second, prior research has yet to unequivocally demonstrate the empirical association between greater board independence and shareholder protection generally (Clark, 2005; Finkelstein \& Hambrick, 1995; Zahra \& Pearce, 1989). To be sure, the board of directors serves as a disciplinary mechanism to mitigate agency conflicts between management and shareholders.

Researchers of only a handful of studies have found empirical evidence of links between board of director characteristics and shareholder activism. These studies examined board composition (i.e., the make-up of insiders versus outsiders serving on the board), CEO duality, and board of director size. Only three studies examined how board structure may be a cause of shareholder activism, and the empirical results find support that shareholder activists Target Firms with a higher percentage of insiders. First, Wahal (1996) found that the nine largest U.S. pension funds Target Firms with high percentages of insiders on the board of directors. Second, Akyol and Carroll (2006) determined that U.S. firms targeted for poison-pill removal were more likely to act when the board of directors had a higher percentage of outsiders. Third, in their study of US and U.K. shareholder proposals, Buchanan and Yang (2009) U.K. presented contradictory findings and found that activists Target Firms with high percentages of outsiders on the board.

Wu (2004) found evidence that board of director size is a characteristic of shareholder activism by the CalPERS pension fund. He found that CalPERS was more likely to include a firm on its focus list if the total number of board members was under 5 or over 15. Buchanan and Yang (2009) showed a positive relationship between board size and activism in their sample of U.K. and U.S. shareholder proposals.

Finally, Wahal (1996) and Buchanan and Yang (2009) also looked at the issue of CEO duality, which occurs when the CEO also holds the Chairperson of the Board position. Wahal (1996) found that U.S. pension funds were more likely to 
Target Firms that had CEO duality, and Buchanan and Yang (2009) identified similar results in their sample of U.S. and U.K. shareholder proposals. In conclusion, only a limited number of studies examined whether board structure or other board of director characteristics may be causing firms to be targeted by shareholder activists. However, there is a void in the literature with respect to hedge fund activism and board structure. In the next section, evidence of ownership characteristics and shareholder activism are examined.

\section{II.C.5 Ownership Structure}

Over the last several decades, there has been a dramatic change with respect to the ownership of U.S. publicly-traded corporations, primarily in the significant growth of institutional shareholdings. The SEC (1973) reported that institutional ownership increased from a mere $5 \%$ in 1945 to $24 \%$ in 1965 . Today, institutional ownership exceeds $70 \%$. The dramatic increase in the ownership of these large investors has raised interest in their role in monitoring managers, which will be addressed in Section II.D.

Prior studies have looked at whether shareholder activists have targeted firms because of their ownership structures. Specifically, some work has looked at levels of institutional ownership and/or insider ownership as a predictor of shareholder activism. Stickland et al. (1996) found that firms targeted by the U.S. Shareholders Association were more likely to be targeted if they had high levels of institutional ownership. Bizjak and Marquette (1998) found that poison-pill resolutions were more likely to be put forward when block ownership was low. Carleton et al. (1998) noted evidence of some bandwagon effects as the pension fund TIAA-CREFF was more likely to Target Firms that had a concentrated ownership of activist institutions.

Three studies looked at insider ownership as a determinant of shareholder

activism. Bethel et al. (1998) found that firms with low insider ownership are more 
likely to be targeted among blockholders. However, their study did not address hedge funds or activists specifically: It was predicated on any group that acquired a $5 \%$ position. Both Bizjak and Marquette (1998) and Akyol and Carroll (2006) studied proxy resolutions directed at poison pill removal and both found that insider shareholding was negatively associated with activists' efforts to remove poison pills via proxy resolutions and negotiations.

\section{II.D Active Monitoring by Shareholders}

In this section, I review the extant literature with respect to active monitoring by shareholders. As noted in Section II.C.5, the dramatic increase in the ownership of these large investors has raised interest in their role in monitoring management. Demsetz (1983) and Shleifer and Vishny (1986) argued that owners of large blocks of shares have greater incentives to monitor managers. Jarrell and Poulsen (1987), in a similar vein, argued that sophisticated, well-informed shareholders such as institutions are likely to vote more consistently in accordance with their economic interests than are less informed shareholders. Agrawal and Mandelker (1990) referred to this tendency as the "active monitoring hypothesis." On the other hand, it is often claimed that many large investors are passive voters (Pound, 1988). They either always vote with management, follow the "Wall Street Rule" of abstaining from voting, or sell their shares to avoid voting. This tendency is referred to as the "passive voting hypothesis."

Shareholders' serving as active monitors of firm management to provide a disciplinary mechanism is not a new concept. Gillan and Starks (2007) defined shareholder activists as "investors who, dissatisfied with some aspect of a company's management or operations, try to bring about change within the company without a change in control". Tirole (2006) provided the following definition: "Active monitoring consists in interfering with management in order to increase the value of the investors' claims". Examples of active monitoring include, among others, 
proposing corporate governance changes, requesting to meet with management to discuss the strategic direction of the corporation, demanding (both privately and publicly) operational changes and capital distribution policy modifications, and seeking board representation.

However, hedge funds have increasingly engaged in shareholder activism and monitoring that differs fundamentally from previous activist efforts by other institutional investors. Earlier studies have shown that when institutional investors, particularly mutual funds and pension funds, follow an activist agenda, they do not achieve significant benefits for shareholders (Black, 1998; Gillan \& Starks, 2007; Karpoff, 2001; Romano, 2001). Unlike mutual funds and pension funds, hedge funds are able to influence corporate boards and managements due to key differences arising from their organizational form and incentive structures.

An implicit assumption of using institutional ownership as a proxy for institutional monitoring is that large shareholders have more incentives to monitor. However, as pointed out by Shleifer and Vishny (1986) and Admati et al. (1994), free-riding by small shareholders may deter the costly monitoring of large institutional investors. Maug (1998) and Kahn and Winton (1998) argued that liquidity concerns and the information environment may also affect institutional investors' choice between trading and monitoring. Parrino, Sias, and Starks (2003) provided evidence that certain institutional investors "vote with their feet" rather than monitor.

Even if large shareholders do monitor, Burkart, Gromb and Panunzi (1997) demonstrated that firm value may be compromised if tight control results in a loss of managerial discretion that causes the holdup problem. As such, another strand of literature investigates the effect of institutional monitoring through shareholder activism. As noted in Gillan and Starks (2007), there was a rise of institutional activism during the 1990s as the market for corporate control declined. Karpoff et al. (1996) found that shareholder proposals have negligible effects on share values or 
operating returns. Smith (1996) focused on firms targeted by CalPERS and found institutional activism is ineffective in improving the Target Firms' operating performance.

Carleton, Nelson, and Weisbach (1998) concluded that institutional activism does not result in large operational changes. The advantage of shareholder activism approach is that in such events institutional investors directly signal their effort to monitor. Nevertheless, as noted in Carleton et al. and Becht, Franks, Mayer, and Rossi (2010), public activism does not occur frequently, and it is often the last resort for institutional investors. It is a common practice that institutional investors try to influence their Target Firms through private negotiations. As a result, this absence of publicly available information may potentially explain the general insignificant results in the literature.

As advisors, the directors provide expertise and counsel to the $\mathrm{CEO}$ and the management. As monitors, they prevent the CEO and the management from engaging in activities that harm shareholders. (See, for example, Boone, Field, Karpoff, \& Raheja, 2007; Coles, Daniel, Naveen, 2008; Linck, Netter, \& Yang, 2008). Based on detailed data on allocation of board meeting minutes, Schwartz-Ziv and Weisbach (2013) suggested that boards can be characterized as active monitors. In his framework of corporate governance, Gillan (2006) placed the board of directors at the apex of internal governance.

Jiang and Liu (2014) found that large firms and firms with poor prior performance are more likely to have institutional directors. Further, firms with large boards and high board independence are more likely have institutional directors on their boards. These findings are largely consistent with what other researchers in the literature have discussed about the targets of institutional monitoring. Additionally, Jiang and Liu found that monitoring by institutional directors has a generally negative but rather weak effect on corporate governance and informational efficiency. Moreover, institutional directors are negatively related to future firm performance 
and this negative relation is statistically significant over 1-year to 5-year horizons.

Although Jiang and Liu's (2014) findings cast doubt on the effectiveness of institutional monitoring, I suggest there are several potential explanations. For example, heterogeneity of institutional directors may give rise to differences in monitoring incentives by different types of institutional investors. As such, the negative impact of institutional directors may be driven by particular types of institutional investors with motives unaligned with other shareholders. It is also possible that institutional board seats epitomize the empowerment of institutional investors compared to other minority shareholders, which creates conflict of interest within shareholder groups.

Hedge funds employ highly incentivized managers who control large, unregulated pools of capital. Because they are not subject to regulation that governs mutual funds and pension funds, hedge funds can hold highly concentrated positions in a small number of companies and use leverage and derivatives to extend their reach. In addition, hedge fund managers do not experience conflicts of interest because they are not beholden to the management of the firms whose shares they hold. In summary, hedge funds are better positioned to act as informed monitors than other institutional investors.

Theory predicts that large shareholders should be effective monitors of the managers of publicly listed firms, reducing the free-rider problem (Grossman \& Hart, 1980; Shleifer \& Vishny, 1986). Yet the evidence that large shareholders increase shareholder value is mixed. In two recent surveys, Karpoff (2001) and Romano (2001) conclude that activism conducted by large institutional shareholders (i.e., pension funds and mutual funds) has had little impact on firm performance. Additionally, Karpoff et al. (1996), Wahal (1996), and Gillan and Starks (2000) report no persuasive evidence that shareholder proposals increase firm values, improve operating performance or even influence firm policies. Therefore, hedge funds are the best positioned funds to function as a shareholder advocates to 
monitor management through active board engagement.

When shareholders are dissatisfied with the performance of a corporation and its board of directors, they can intervene via a proxy contest. The proxy contest process is a meticulously regulated election mechanism that can be invoked when 'one group, referred to as 'dissidents' or 'insurgents' attempt to obtain seats on the firm's board of directors currently in the hands of another group, referred to as 'incumbents' or "management"' (Dodd \& Warner, 1983). The objective is to displace incumbents with the dissidents' preferred candidates to bring about an overall improvement in enterprise financial performance and shareholder value. Although dissident shareholders do not always obtain a majority of board seats, they manage in many cases to capture some seats. Notwithstanding proxy contest outcome, there is evidence that share price performance is positively and significantly associated with the proxy contest process (Dodd \& Warner, 1983).

Within three years of a proxy contest event, many publicly held firms experience major changes, including resignations of top management within one year of the contest followed by sale or liquidation of the firm. Proxy contest shareholder gains derive largely from the dissident linked sale of the corporation (DeAngelo \& DeAngelo, 1989). Mulherin and Poulsen (1998) determined that "on average, proxy contests create value". Research has confirmed that the bulk of shareholder wealth gains arise from firms acquired in the period surrounding the contest. In contrast, management turnover in firms that are not acquired results in a significant and positive effect on stock owners' value proposition because organizations engaged in management changes are more inclined to restructure following a proxy contest event.

The rate of management turnover for proxy contest challenged firms is much higher compared to organizations not involved in proxy contest activity and is directly proportional to the share of seats at the board won by proxy contenders. When the majority of seats are won by proxy contesters, the highest management 
turnover is observed, reflecting the importance of intangible issues such as job security (Yen \& Chen, 2005).

\section{II.E Efficacy of Shareholder Activism}

In this section, I review the literature concerning the effects of shareholder activism. The bulk of the studies on shareholder activism have examined the impact of shareholder activism on firm performance announcement effects. Prior literature has also examined effects such as turnover in the executive management team and board of director ranks, acquisition of board seats, changes to board composition or size, executive compensation, and strategic changes such as acquisitions or divestments and changes to the company's handling of excess cash via dividend payouts and/or stock repurchases.

\section{II.E.1 Impact on Firm Performance}

Tables A.2 and A.3 provide an overview of the extant literature with efficacy of shareholder activism. The activism literature shows equivocal results of shareholder activism's impact on short-term or long-term financial results using either market-based or accounting-based measures. Short-term, market-based returns focus on cumulative abnormal returns $(C A R s)$ around the announcement window after an activist "goes public" with his or her dissatisfaction or after an activist files a schedule $13 \mathrm{D}$ with the SEC indicating that the activist has purchased at least a $5 \%$ equity stake. Typically, short-term, market-based performance measures changes in market-based performance up to 90 days after the announcement. Measures of long-term performance typically report returns one year or more after the activist announcement of proxy resolution or an equity purchase using accounting-based and/or market-based measures.

Many of the earlier researchers found no impact on firm performance. Three literature reviews conducted by Black (1998), Romano (2001), and Karpoff 
(2001) reported insignificant effects on firm performance. Black (1998) examined shareholder activism by institutional investors, Romano (2001) reviewed nine studies of pension funds and investment groups, and Karpoff (2001) reviewed 25 studies from 1994 to 2001.

\section{II.E.2 Short-term Market-based Firm Performance}

Many researchers have used event studies and attempt to capture $C A R s$ around the announcement of a proxy resolution, the filing of a 13D, or a particular firm's placement on a pension fund's focus list. Regarding shareholder activism by activist blockholders, short-term returns are largely positive. Faulkener et al. (1990) found short-term $C A R s$ of $2.8 \%$ after the announcement and 81 day returns of $11.74 \%$. Bethel et al. (1998) reported short-term stock gains upon the announcement of the purchase of $5 \%$ or greater equity stake. Finally, Croci's (2007) study of blockholder activists in Europe identified positive $C A R s$ upon announcement of acquisition by a blockholder activist. Short-term return results are mixed for two studies that concerned investor groups. While Strickland et al. (1996) acknowledged positive $C A R s$ for firms targeted by the US Shareholders Association, Caton et al. (2001) reported negative $C A R s$ upon the announcement of being placed on a Council of Institutional Investor target list.

Examining the research on pension funds, the impact on short-term returns is equivocal. Wahal (1996), Carleton et al. (1998), and Nelson (2005) found no evidence of $C A R s$. Other researchers measuring $C A R s$ upon the announcement of being placed on a CalPERS focus list find positive returns (Anson et al., 2003; , Barber, 2006; English et al., 2004). Nelson (2005) argued that the Anson et al. (2003) study contained many methodological flaws and that Anson et al. were also CalPERS employees and could have conflict of interest.

Generally, hedge funds achieve positive $C A R s$ upon the announcement of the 13D filing signifying an equity purchase of $5 \%$ or more. Klein and Zur (2006) 
reported a CAR of $10.3 \%$ after a 13D filing. Bratton (2007) noted positive CARs in the first 3 days around the announcement of a block purchase. Brav et al. (2008) showed large positive average abnormal returns between $5 \%$ and $7 \%$ during the announcement window. Finally, Clifford (2008) found excess returns of $3.39 \%$ after announcement of the 13D filing.

Mixed results also emerge when examining other studies of proxy resolutions filed by multiple types of activists. Renneboog and Szilagyi's (2006) study of 2,800 proxy resolutions and Del Guercio et al.'s (2008) "just vote no" proxy resolution study both found small positive $C A R s$ upon announcement that a proxy resolution had been filed. However, Prevost, Rao, and Williams (2009) identified no short-term returns upon announcement of a proxy filing by labor unions.

\section{II.E.3 Long-term Market-based Firm Performance}

Regarding the studies that concern market-based performance of a year or longer, again the findings are largely equivocal. Three studies of the impact of shareholder resolutions by all types of investors generally found no impact on stock price. Karpoff et al. (1996) and Thomas et al. (2005) both noted no change in shareholder returns as a result of proxy resolutions issued. While Gillan and Starks (2000) found no short-term impact on stock price, they reported positive 1-year share returns as result of proxy resolutions issued. Their sample consisted of 2,042 proxy resolutions submitted at 451 U.S. companies from 1987 to 1994. Buchanan and Yang (2009) reported positive 1-year stock returns for their U.S. sample of proxy resolutions.

Few academic studies have examined market-based performance over longer periods. Opler and Sobokin (1998) examined shareholder activism efforts of the Council of Institutional Investors and found that they were able to generate positive 1-year average share returns of $11.6 \%$. The results of pension fund studies are again equivocal. Four studies reported no evidence of changes in shareholder value in either the short- or the long-term (Del Guercio \& Hawkins, 1999; Faccio \& 
Lasfer, 2000; Smith, 1996; Wahal, 1996).

An examination of the studies on the CalPERS pension fund shows the findings are mixed. Smith (1996) found no impact on shareholder value in the shortor the long-term based on his sample of 51 firms targeted by CalPERS from 1987 to 1993. Yet, other researchers focusing on the CalPERS pension fund reported positive gains in shareholder value. Nesbitt (1994) examined 42 investments made by CalPERS from 1987 to 1992 and found market based performance increases of 41\%. In addition, Anson et al. (2003) showed significant returns of $59 \%$ in the year following the release of the CalPERS list of targeted firms. Their sample included firms placed on the focus list from 1992 to 2001. More recently, Barber (2006) examined a sample of 115 firms from 1990 to 2005 that were placed on the CalPERS target list, and his results demonstrated both short-term and long-term market-based gains. While short-term gains were small but significant, 5-year gains outperformed the market by $32 \%$.

More recently, Bebchuk, Brav, and Jiang (2013) found that contrary to the claim that hedge fund activists adversely impact the long-term interests of organizations and their shareholders, there is evidence that activist interventions lead to improved operating performance in the five years that follow the interventions. Venkiteshwaran, Iyer, and Rao (2010) conducted a detailed study of hedge fund activist Carl Icahn's 13D filings and subsequent firm performance and found significant share price increases for the target companies (of about 10\%) around the time Icahn disclosed his intentions publicly. Additionally, they found a significant number (33\%) of Icahn's targets ended up being acquired or taken private within 18 months of his initial investment. The shareholders of those companies earned abnormal returns of almost $25 \%$ from the time of Icahn's initial investment through the sale of the company. 


\section{II.E.4 Accounting-based Firm Performance}

While most researchers in this area have focused on market-based measures of performance, a few have studied accounting-based measures of performance as indicators of the effects of shareholder activism. Typically, accounting-based performance is based on annual figures. Overall, the results are mixed.

In their study of activist blockholders, Bethel et al. (1998) found long-term gains in ROA three years after blockholder activists in the 1980 s purchased a $5 \%$ or larger equity stake. Two studies concerning pension fund performance reported no evidence of changes in accounting-based performance measures (Del Guercio \& Hawkins, 1999; Wahal 1996). The findings on performance effects of hedge fund activism are also mixed. Klein and Zur (2006) reported declines in both ROA and ROE one year after the $5 \%$ equity stake purchase. However, two studies found positive results. First, Brav et al. (2008) found that firms targeted by hedge funds see increases in ROE and ROA. Second, Clifford (2008) reported a large positive increase of $1.22 \%$ in ROA in the year following the acquisition.

\section{II.F Research Opportunities}

Based on the review of the literature in this chapter, five important points can be raised. First, most of the prior literature on hedge fund activism has been driven by the finance and legal disciplines. It is important to note that all meaningful academic research with respect to hedge fund activism is predicated on data that use very small sample sizes, usually fewer than 200 Target Firms or activist interventions. Additionally, most datasets have limited time series, and nearly all of the research is based on data prior to 2005. The most comprehensive dataset was used by Brav, Jiang, and Kim (2015) who used approximately 2,000 activist interventions from 1994-2007. Since 2007, shareholder activism, particularly by hedge funds, has increased significantly. To be sure, approximately $60 \%$ of activist 
interventions have occurred since 2007, and approximately $75 \%$ of those events were instigated by hedge funds.

Second, Judge et al. (2010) noted that there appear to be two types of shareholder activism: governance-focused activists and economically-motivated activists. Previous studies have not clearly delineated between these investment styles. A large portion of proxy resolutions are focused on CSR initiatives primarily initiated by pension funds. Thus, studies attempting to measure financially related effects of shareholder activism may not find any impact on the financial performance or corporate governance measures due to the presence of socially driven shareholder activism. For example, Woidke (2002) determined that privately-owned pension funds are more focused on performance, while publicly owned pension funds are more focused on social issues. It is necessary to delineate clearly between hedge fund activism (economically-motivated) and other shareholder sponsored activism (governance-focused activist activity by pension funds).

Third, the vast majority of shareholder activism literature is predicated on Schedule 13D filings. However, I assert that the optimal dataset to test empirically the efficacy of shareholder activism should be based on board representation of Target Firms by a shareholder activist. Therefore, I started with a much more expansive sample of activist interventions. My comprehensive dataset of shareholder activist events for analysis in this study includes 5,728 interventions from 1984-2014. Of those, 4,295 (75\%) filed a 13D. However, approximately $27 \%$ of all activist interventions were focused on board engagement, either through a proxy contest $(1,293)$ or a nonproxy contest dissident campaign $(239)$ that resulted in board representation via private negotiations with the target management team and its board of directors. To be sure, nearly three-quarters of activist interventions did not seek board representation to actively monitor management. Moreover, GAMCO Asset Management, a hedge fund founded by Mario Gabeli, has filed 493 13Ds since 1996; however, it has launched only 18 proxy fights (4\%) and won board 
representation only 10 times $(2 \%)$ to date. In contrast, Carl Icahn has launched proxy fights and won board representation at eBay, Genzyme, Time Warner, and Yahoo! without filing a 13D.

Accordingly, I claim that there are numerous 13D filings of activist interventions that otherwise include good performing companies with strong management that a dissident was not compelled to seek board representation to actively monitor management and function as a disciplinary mechanism.

Additionally, there are over 90 activist interventions that led to board representation without filing a 13D. Therefore, I assert that the optimal dataset to analyze empirically the long-term efficacy of hedge fund activism should be based on board representation of Target Firms by a shareholder activist and not merely the fact that a shareholder crossed 5\% ownership and might (not will) seek to influence strategic change at the Target Firm. To be sure, an activist who is willing to incur significant financial cost not borne by all shareholders, which Gantchev (2012) estimateed is approximately $\$ 10$ million per proxy contest, has genuine conviction that the Target Firm requires strategic change that management is unwilling to execute without shareholder interference.

Fourth, the results of examining the effects of shareholder activism are also largely equivocal. The bulk of studies concentrate on measuring short-term, market-based performance effects upon the announcement of an activism effort. Few studies of the longer-term impact of shareholder activism use accounting and market-based measures, and their results are mixed. More studies are needed to measure the longer-term impact of shareholder activism on firm performance measures.

Fifth, there may be methodological problems clouding results of shareholder activism studies. For example, many of the empirical studies are descriptive in nature. More sophisticated statistical models would add much to the validity and reliability of the results. A more comprehensive approach to the study 
of shareholder activism is warranted. Moreover, many other studies that calculate $C A R s$ use vastly different empirical methods to calculate return. Nelson (2006) argued that four prior studies examining shareholder returns around the release of the CalPERS focus list had methodology problems that severely impacted their results. This finding suggests the need for more refined measurement models of hedge fund activism. 


\section{CHAPTER III}

\section{HYPOTHESIS DEVELOPMENT}

In this chapter, I present my hypotheses to argue that hedge fund activism generates substantial long-term value for Target Firms and their long-term shareholders when those activist funds function as a shareholder advocate to monitor management through active board engagement. Earlier studies have shown that when institutional investors, particularly mutual funds and pension funds, follow an activist agenda, they do not achieve significant benefits for shareholders (Black, 1998; Gillan \& Starks, 2007; Karpoff, 2001; Romano, 2001). Unlike mutual funds and pension funds, hedge funds are able to influence corporate boards and managements due to key differences arising from their organizational form and the incentive structures.

An implicit assumption of using institutional ownership as a proxy for institutional monitoring is that large shareholders have more incentives to monitor. However, as pointed out by Shleifer and Vishny (1986) and Admati et al. (1994), free-riding by small shareholders may deter the costly monitoring of large institutional investors. Maug (1998) and Kahn and Winton (1998) argued that liquidity concerns and the information environment may also affect institutional investors' choice between trading and monitoring. Parrino, Sias and Starks (2003) provided evidence that certain institutional investors "vote with their feet" rather than monitor.

Hedge funds employ highly incentivized managers who manage large, unregulated pools of capital. Because they are not subject to regulation that 
governs mutual funds and pension funds, they can hold highly concentrated positions in a small number of companies and use leverage and derivatives to extend their reach. In addition, hedge fund managers do not experience conflicts of interest because they are not beholden to the management of the firms whose shares they hold. As a result, hedge funds are better positioned to act as informed monitors than other institutional investors.

It is important to note the typical chronology with respect to a hedge fund activist campaign: (a) Target Firm identification (ex ante the intervention), (b) the campaign or intervention, and (c) active monitoring (ex post the intervention). First, an activist hedge fund manager will identify and target corporations that he or she believes will benefit from active shareholder engagement. Second, once a Target Firm is identified, the hedge fund will start to build a position (i.e., accumulate stock). Third, the hedge fund manager will initiate a private conversation with either the management team or the board of directors to suggest, and frequently demand, certain strategic changes to the firm. Once the hedge fund exceeds a $5 \%$ beneficial ownership position, the manger needs to determine whether to file a 13D (active) or a $13 \mathrm{G}$ (passive) to satisfy the SEC requirement. At this point, the hedge fund will determine if it will make its campaign public to solicit support of other shareholders. If the firm refuses to comply with hedge fund's demands, the hedge fund manager will determine if he or she wants to seek board representation to make the necessary changes to the firm.

My hypotheses are organized in accordance to the typical sequence of events with respect to a hedge fund activist campaign. First, I focus on two characteristics of Target Firms that are identified by activist hedge funds: prior firm performance and ownership structure. I have a novel approach to examine a Target Firm's vulnerability with respect to hedge fund activism based on its prior firm performance. My original methodology examines a Target Firm's performance ex ante an intervention using short interest as an instrumented variable, which has not 
been used in prior literature. Furthermore, my use of a unique dataset and empirical design to test "corporate inside" ownership of Target Firms is not in the extant literature. I define corporate inside ownership as equity securities that are beneficially owned by the company's officers and directors ${ }^{4}$. I exclude any institutions or noncompany officers and directors who are required to file with the SEC because they are beneficial owners of more than $10 \%$ of a class of the company's equity securities.

Second, I address the intervention (i.e., proxy contest) initiated by activist hedge funds. Dissatisfied shareholders can nominate an alternative slate of directors by initiating a proxy contest and, therefore, provide all shareholders with a clear alternative to incumbent nominees. Finally, I address active monitoring by hedge fund activists to provide a disciplinary mechanism on the incumbent management.

\section{III.A Determinants of Hedge Fund Activism - Ex Ante Intervention}

\section{III.A.1 Prior Firm Performance (H1)}

Numerous studies have used various market and accounting-based financial measures to investigate firm performance (i.e., underperforming and/or undervalued relative to peers) to determine the vulnerability of a Target Firm by an activist hedge fund. However, short interest ratio (i.e., shares sold short) as a measure of a Target Firm's performance has not been used to determine a company's vulnerability regarding hedge fund activism. If an investor believes that a firm is overvalued and expects the company's share price will decline, then the investor can sell short the company's security and buy it back (i.e., generate a long position) at a lower price to make a profit.

\footnotetext{
${ }^{4}$ Corporate insiders - meaning a company's officers and directors and any beneficial owners of more than $10 \%$ of a class of the company's equity securities registered under Section 12 of the Securities Exchange Act of 1934 - must file with the SEC a statement of ownership regarding those securities. On August 27, 2002, the SEC adopted rules and amendments to Section 16 of the Exchange Act, implementing the provisions of the Sarbanes-Oxley Act of 2002 that accelerated the deadline for filing most insider ownership reports.
} 
According to Asquith, Pathak, and Ritter (2005), shares sold short, as a percentage of shares outstanding, have more than doubled in the last 20 years. In dollar terms, the increase is more than twentyfold. During this time, there has been a renewed interest among [whom?] in the role of the financial markets to discipline managers. Shareholders, particularly large blockholders, may induce good managerial behavior by exiting and pushing down stock prices when bad managerial actions are taken (e.g., Admati \& Pfleiderer, 2009; Edmans, 2009; Edmans \& Manso, 2011) $)^{5}$. In this regard, informed trading ("exit") provides an alternative governance mechanism that shareholders can adopt in addition to the traditional "intervention" type of internal governance (e.g., Chen, Harford, \& Li, 2007; McCahery, Starks, \& Sautner, 2010; Parrino et al., 2003). Indeed, to some extent, exit and intervention offer substituting governance mechanisms that shareholders can select based on their trade-off between benefits and costs (e.g., Edmans \& Manso, 2011; Edmans et al., 2013).

A more general question is whether informed trading, such as short selling, can be used as a proxy for managerial misbehavior. Short sellers are known to be informed (Asquith et al., 2005; Boehmer, Jones, \& Zhang, 2008; Cohen, Diether, \& Malloy, 2007; Senchack \& Starks, 1993) and highly motivated to attack bad firms (e.g., Hirshleifer, Teoh, \& Yu, 2011; Karpoff \& Lou, 2010) ${ }^{6}$. Short selling appears to discipline managers and reduce their incentives to manipulate (Massa, Zhang, \& Zhang, 2013). Further, Massa et al. (2013) claimed that shareholders can rely on the external disciplining mechanism of short selling instead of engaging in direct monitoring of managers. I posit that short selling is a signal of increased agency cost and is a proxy for expected future firm performance that can be used by activist hedge funds to identify potential targets to serve as a disciplinary

\footnotetext{
${ }^{5}$ For instance, Edmans and Manso (2011) concluded that "informed trading causes prices to more accurately reflect fundamental value, in turn inducing the manager to undertake actions that enhance value."

${ }^{6}$ Other market participants may also influence the shareholders of firms in this way; however, the short-selling channel is particularly powerful because short sellers are known to be good at processing negative information (e.g., Hirshleifer et al.,, 2011; Karpoff \& Lou, 2010).
} 
mechanism to monitor management via board representation.

It is now widely accepted that if short selling is costly and there are heterogeneous investor beliefs, a stock can be overvalued and generate low subsequent returns. This hypothesis originates with Miller (1977), and its cross-sectional predictions have motivated many recent empirical studies.

There are now three distinct empirical literatures on short selling. The oldest contends that high short interest ratios (shares sold short/shares outstanding) forecast low future returns. The second literature investigates the actual cost of short selling by looking at the rebate rate on borrowed stock. The third and most recent empirical short-sale literature assumes that short sales depend on stock ownership by mutual funds and institutions. This literature assumes either that the number of institutions owning a stock is a proxy for heterogeneous expectations or that most lendable shares are from institutional owners.

Each of these literatures examines an instrument relevant to short-sale constraints. Constraints exist when investors wish to sell short but either are unable to borrow shares or can only do so by receiving a low rebate rate on the proceeds from their short sales. In this study, I combine the first and third literatures to identify short-sale constraints. As previously stated, I assert that short selling is a signal of increased agency cost and is a proxy for expected future firm performance that can be used by activist hedge funds to identify potential targets to serve as a disciplinary mechanism to monitor management via board representation.

To be sure, there is a void in the hedge fund activism literature regarding the use of short interest position as a proxy of firm performance ex ante to an intervention. Therefore, I hypothesize the following:

Hypothesis 1: There is a significant positive correlation between hedge fund activism and an increase in the short-interest position experienced by Target Firms ex ante an activist intervention. 


\section{III.A.2 Ownership Structure (H2)}

Three studies concerned insider ownership as a determinant of shareholder activism. Bethel et al. (1998) found that firms with low insider ownership are more likely to be targeted among blockholders. Both Bizjak and Marquette (1998) and Akyol and Carroll (2006) studied proxy resolutions directed at poison pill removal and found that insider shareholding was negatively associated with activists' efforts to remove poison pills via proxy resolutions and negotiations.

Relatively little is known about how ownership characteristics of firms lead them to be targeted by shareholder activists. Bethel et al. (1998) defined "blockholder" as any group owning $5 \%$ or more. This included pension funds, banks, and other investors. They did not delineate between activist and nonactivist investors. Because hedge fund activists ultimately rely on the support of other shareholders, I assert that many activist hedge funds Target Firms with nominal "corporate inside" ownership. I define "corporate inside" ownership as equity securities that are beneficially owned by the company's officers and directors, and I exclude any institutions or noncompany officers and directors who are considered insiders by SEC because they are beneficial owners of more than $10 \%$ of a class of the company's equity securities.

Hedge fund activists target companies with nominal "corporate ownership"

for two primary reasons. First, this targeting will ensure an increased likelihood of success if a management team cannot "block" a proxy voting contest, and second, it supports the narrative that a management team with nominal ownership is entrenched and not acting in the best interest of the owners. Given this significant gap in the literature, I hypothesize the following:

Hypothesis 2: There is a significant positive correlation between hedge fund activism and nominal "corporate inside" ownership. 
III.B Activist Hedge Fund Intervention - Board Representation (H3)

Shleifer and Vishny (1997) explained that "corporate governance deals with the ways in which the suppliers of finance to corporations assure themselves of getting a return on their investment". The fundamental feature of corporate governance is shareholders' right to elect directors to represent their interests. For corporate governance to be effective, shareholders who are dissatisfied with a board's performance must have a mechanism for replacing directors. If shareholders' impact on electing and replacing directors is weak, so is the connection between owners and managers.

Shareholders have two main tools for removing poorly performing directors. First, shareholders can use an uncontested election. Prior literature has shown that attempts to remove directors through uncontested elections have not been effective. In regular elections, shareholders cannot technically vote out a director but instead can only withhold their authority to vote in favor of a nominee. Most U.S. firms have plurality voting rules in uncontested elections, and as a result, removing directors in uncontested elections is almost impossible. Specifically, a director can be reelected even if just a few shareholders vote for him or her. Thus, the prospect of shareholders having an effective voice in removing directors in uncontested elections seems limited, and directors do not appear to suffer reputational effects from low votes (Cai, Garner, \& Walkling, 2009).

Second, shareholders can discipline directors through proxy contests. Dissatisfied shareholders can nominate an alternative slate of directors by initiating a proxy contest and, therefore, provide all shareholders with a clear alternative to incumbent nominees.

Proxy contests have become more frequent. The number of contests for board seats increased from 270 contests during 1979-1994 (Mulherin \& Poulsen, 1998) to 1,294 during my sample covering 1995-2014, indicating a 380\% increase in 
the frequency of proxy contests. Second, the relative importance of the proxy-contest mechanism increased as well. During the 1980s, dissident shareholders more often relied on hostile tender offers to effectuate change at a Target Firm. However, during the last decade, activist shareholders have relied more often on proxy contests. More importantly, hedge fund activists are the primary initiators of proxy contests, launching 812 (63\%) of all proxy fights since 1995. Activist hedge funds face limited regulatory constraints and can be effective in exploiting the proxy-contest mechanism (Brav, Jiang, Partnoy, \& Thomas, 2008).

It is important to note that settlement agreements have increased in frequency over the past five years. A settlement agreement between a Target Firm and an activist hedge fund usually entails board representation by a representative of the hedge fund but also includes standstill provision and a nondisparagement agreement by the activist for a period of time, usually 18 to 36 months. Target firms will agree to settle with an activist hedge fund to forego a proxy contest that can be both very costly and time-consuming.

There have been many studies with respect to proxy contests, but there is a void in the literature regarding activist hedge fund seeking board representation to act as a disciplinary mechanism to monitor management. Therefore, I hypothesize the following:

Hypothesis 3: There is a significant positive correlation between board representation of an activist hedge fund and nominal "corporate inside" ownership ex post the Board Seat Grant Date.

\section{III.C Active Monitoring by Shareholders - Ex Post Intervention}

The main premise of my study is that institutional directors represent the interest of institutional investors, and their major role is to monitor the management. As pointed out in Berle and Means (1932) among others, the main purpose of board of directors is to mitigate the agency problem arising from the separation of ownership 
and control in corporations. The literature on board of directors has further suggested that directors play the dual role of advising and monitoring.

While the topic of shareholder activism is not new, the topic of hedge funds as activists is rather new. Activist hedge funds have been the most prominent and successful proponents of institutional shareholder activism in recent decades (Gillan \& Starks, 2007). Boyson and Mooradian (2011) noted that the idea of hedge funds as activists is in direct contrast with their image as short-term, opportunistic investors. For example, in the early 2000s, prime brokerage operations of investment banks were very frequently the banks' only profitable divisions, due to heavy trading volume among their hedge fund clients. Hence, the thought of hedge funds as long-term investors is somewhat counterintuitive.

It is important to define clearly the activist hedge fund asset class vis-à-vis the hedge fund alternative investment asset complex. Since 1997, hedge funds have experienced hyperbolic growth. According to Hedge Fund Monitor (year), as of 1997 there were fewer than 1,000 hedge funds that had approximately $\$ 120$ billion of assets under management (AUM). As of 2014, there were over 10,000 hedge funds that had AUM of approximately $\$ 2.5$ trillion. While hedge funds and AUM have grown over ten-fold and twenty-fold, respectively, the dedicated activist hedge fund has only experienced growth as an asset class recently. As of 2014, there were approximately 100 activist hedge funds that had about $\$ 120$ billion AUM.

Therefore, only a fraction of the hedge fund alternative investment asset complex. Although classified as a hedge fund, the activist hedge fund manager employs a differentiated investment strategy that by design is a longer-term approach as opposed to other opportunistic hedge funds like dedicated short bias, convertible, and merger arbitrage funds. 


\section{III.C.1 Short-term Effects of Active Hedge Fund Monitoring (H4)}

Theory predicts that large shareholders should be effective monitors of the managers of publicly listed firms, reducing the free-rider problem (Grossman \& Hart, 1980; Shleifer \& Vishny, 1986). Yet the evidence that large shareholders increase shareholder value is mixed. In two recent surveys, Karpoff (2001) and Romano (2001) concluded that activism conducted by large institutional shareholders (i.e., pension funds and mutual funds) has had little impact on firm performance. Additionally, Karpoff et al. (1996), Wahal (1996), and Gillan and Starks (2000) reported no persuasive evidence that shareholder proposals increase firm values, improve operating performance, or even influence firm policies.

Brav et al. (2008) produced the only credible study conducted to test empirically the short-term effects of activist hedge funds on Target Firms. Using a data set from 2001 to 2006, the authors concluded that activist hedge funds in the United States proposed strategic, operational, and financial remedies and attained success or partial success in two-thirds of the cases. The abnormal stock return upon announcement of activism is approximately $7 \%$, with no reversal during the subsequent year. Target firms experience increases in payout, operating performance, and higher CEO turnover after activism.

Their dataset, which is consistent with the vast majority activist intervention studies, is primarily constructed from Schedule 13D filings. The presumption is a shareholder that files a 13D is unequivocally motivated to change the strategic direction of the company. However, I claim that is not always the case. As previously noted, some activist campaigns are centered on corporate governance reforms (i.e., board declassification, removal of shareholder rights plan, etc.) and not meaningful long-term strategic changes to the Target Firm. I contend that any shareholder with sincere conviction to challenge the current strategic direction of a firm would, ultimately, seek board representation if their demands were not 
supported by the firm's incumbent management. I view board representation as a signal of an activist's long-term commitment to the firm.

Typically, a hedge fund activist will request board representation privately to the Target Firm's management. If denied, the hedge fund manager can actively pursue board representation via a proxy contest. There is a significant absence in the literature with respect to hedge funds creating value for the Target Firms by functioning as a disciplinary mechanism to monitor management via board representation. Therefore, I hypothesize the following:

Hypothesis 4: There is a significant positive "initial" market reaction on the announcement date that a hedge fund dissident shareholder has been granted board representation to function as a disciplinary mechanism to monitor management.

III.C.2 Long-term Effects of Active Hedge Fund Monitoring (H5/H6) Activist hedge funds have been the most prominent and successful proponents of institutional shareholder activism in recent decades (Gillan \& Starks 2007). As noted in Section III.C.1, few studies have concerned the impact of hedge fund activism and short-term performance of Target Firms. Importantly, there are no credible studies in the finance literature with respect to hedge fund activism and its long-term implications (i.e., greater than one year) for the Target Firms' long-term shareholders and the long-term operating performance of those firms.

Most recently, Bebchuk et al. (2013) found that contrary to the claim that hedge fund activists adversely impact the long-term interests of organizations and their shareholders, there is evidence that activist interventions lead to improved operating performance in the five years that follow the interventions. These findings were published in the Columbia Law Review, not in a highly regarded finance journal.

Consistent with their previous research, Bebchuk et al. (2013) used a 
dataset primarily constructed from Schedule 13D filings. As previously stated, I contend that any shareholder with sincere conviction to challenge the current strategic direction of a firm would, ultimately, seek board representation if their demands were not supported by the firm's incumbent management. I view board representation as a signal of an activist's long-term commitment to the firm.

Additionally, board representation is a costly endeavor not borne by all shareholders, which further validates the activist's credibility as a long-term shareholder of the firm. Therefore, I hypothesize the following:

Hypothesis 5: Hedge fund activism generates statistically significant long-term value for the Target Firms and its long-term share when they function as a disciplinary mechanism to monitor management via board representation.

Hypothesis 6: Hedge fund activism generates statistically significant improvement in long-term operating performance for the Target Firms and its long-term share when they function as a disciplinary mechanism to monitor management via board representation.

\section{III.D Research Contribution}

My research fills the important void with respect to the shareholder activism initiated by hedge funds. My novel approach to inside ownership and short-interest positions as instrumented variables that predict a Target Firm's vulnerability to hedge fund activism contributes to the literature on the determinants of shareholder activism.

My expansive, hand-collected dataset and unique empirical research design methodology with respect to board representation fills the important gap in the literature regarding the long-term efficacy of hedge fund activists serving as a disciplinary mechanism on the firm by actively seeking board representation to monitor management. Additionally, I contribute to the literature regarding shareholder activists as self-interested, myopic investors at the expense of the 
long-term interest of the company and its long-term shareholders. Moreover, my findings have important policy implications related to the ongoing debate on corporate governance and the rights and roles of shareholders. My findings suggest that hedge fund activism generates substantial long-term value for Target Firms and their long-term shareholders when they function as a shareholder advocate to monitor management through active board engagement. 


\section{CHAPTER IV}

\section{ECONOMETRIC METHODOLOGY}

In this chapter, I address the econometric methodology to test empirically the alternative hypotheses that were discussed in Section III. To examine the ex post disciplinary effects by dissident shareholders, I examine and measure firm performance and long-term abnormal stock returns up to five years from the board seat grant date. Additionally, I conduct similar tests during the five-year period prior to the intervention. I contrast those results to two Control Groups (refer to Chapter 6 for details regarding Control Groups) and to similar Matched Firms (the same 4-digit SIC industry code) in the Compustat database.

There are two important econometric issues that need to be addressed: self-selection bias and endogeneity. In Section IV.A, I provide the econometric principle and a detailed analysis of how to address each potential bias.

The structure of my hypothesis testing and empirical analysis is consistent with the typical sequence of events with respect to a hedge fund activist campaign, as discussed in Section III. The combination of complex decision processes facing firms and limited information available to researchers ensures that endogeneity concerns are present in every study. In this section, I begin by reviewing the sources of endogeneity — omitted variables, simultaneity, and measurement error — and their implications for inference. I then discuss in detail a number of econometric techniques aimed at addressing endogeneity problems. 


\section{IV.A Endogeneity and Selection Bias}

According to Roberts and Whited (2012), one of the most important and ubiquitous issues confronting studies in empirical corporate finance is endogeneity, which is essentially a correlation between the explanatory variables and the error term in a regression. Endogeneity leads to biased and inconsistent parameter estimates that make reliable inference virtually impossible. In many cases, endogeneity can be severe enough to reverse even qualitative inference.

There are several potential sources of endogeneity in the study of hedge fund activism. I have addressed many of these through the design of the study. One source of endogeneity is the timing with respect to the announcement of board representation by an activist hedge fund. If not handled correctly, this endogeneity can invalidate results concerning the market's short-run reaction. I conducted a search of news events around the announcement date and eliminated confounding news.

A second potential source of endogeneity is in a hedge fund's decision to target a firm. This endogeneity may present a problem for researchers comparing activism targets to firms not targeted by activism because these firms likely differ from each other in observable and unobservable ways. However, my research design reduced this problem in that to appear in my sample, a firm must already have been a target of hedge fund activism. To be sure, my analysis was conditional upon being a hedge fund activist target with respect to the Control Group I. Further, I carefully selected a control sample to deal with unobserved heterogeneity in hedge fund manager skill or technique. Similar to propensity score matching methodology, I construct a control group of all hedge fund activist campaigns that did not result in board representation during the same period. Therefore, I examine not only firms that granted at least one board seat to a dissident shareholder and its ex post

effects treatment group but also companies that were challenged by dissatisfied 
shareholders and did not suffer the ex post disciplinary effects by the dissident control group.

An important problem of causal inference is how to estimate treatment effects in observational studies: situations in which a group of units is exposed to a well-defined treatment (i.e., shareholder activism, board representation), but no systematic methods of experimental design are used to maintain a control group. It is well recognized that the estimate of a causal effect obtained by comparing a treatment group with a nonexperimental comparison group could be biased because of problems such as self-selection or some systematic judgment by the researcher in selecting units to be assigned to the treatment. Therefore, I used propensity score matching methods to correct for sample selection bias due to observable differences between the treatment and comparison groups.

\section{IV.A.1 Research Design}

One potential solution to self-selection bias is through the construction of the research design. To address self-selection bias, I construct two Control Groups (the "Control Groups"). Control Group I is Target Firms of all proxy fights campaigns that did not result in board representation during the same period. Therefore, I examine not only Target Firms that granted at least one board seat to a dissident shareholder and its ex post effects (the "Treatment Group") but also companies that were challenged by dissatisfied shareholders and did not suffer the ex post disciplinary effects by the dissident (the "Control Group I"). Control Group II is comprised of Target Firms that granted at least one board seat to a Non-hedge Fund dissident shareholder during the same time period. Accordingly, I examine the ex post disciplinary effects on Target Firms by an activist shareholder that is not affiliated with a Hedge Fund. 


\section{IV.A.2 Matching Methods}

Matching methods estimate the counterfactual outcomes of subjects by using the outcomes from a subsample of "similar" subjects from the other group (treatment or control). Perhaps more important is the recognition that matching methods do not rely on a clear source of exogenous variation for identification. This fact is important and distinguishes matching from Instrumental Variables and Regression Discontinuity Design. Matching alleviates some of the concerns associated with linear regression and can mitigate asymptotic biases arising from endogeneity or self-selection. Accordingly, matching can provide a useful robustness test for regression based analysis.

Matching involves pairing treatment and comparison units that are similar in terms of their observable characteristics. When the relevant differences between any two units are captured in the observable (pretreatment) covariates, which occurs when outcomes are independent of assignment to treatment conditional on pretreatment covariates, matching methods can yield an unbiased estimate of the treatment impact. The first generation of matching methods paired observations based on either a single variable or weighting several variables (see, inter alia, Bassi 1984; Cave \& Bos, 1995; Czajka, Hirabayashi, Little, \& Rubin, 1992; Cochran \& Rubin, 1973; Raynor, 1983; Rosenbaum, 1995; Rubin, 1973, 1979; Westat, 1981; studies cited in Barnow, 1987).

\section{IV.A.3 Treatment Effects}

The first important assumption for the identification of treatment effects (i.e., ATE, ATET, ATU) is referred to as unconfoundedness:

$$
(y(0), y(1)) \perp d \mid X
$$

This assumption says that the potential outcomes $(y(0)$ and $y(1))$ are 
statistically inde- pendent $(\perp)$ of treatment assignment $(d)$ conditional on the observable covariates, $X=\left(x_{1}, \ldots, x_{k}\right)^{7}$. In other words, assignment to treatment and control groups is as though it were random, conditional on the observable characteristics of the subjects.

This assumption is akin to a stronger version of the orthogonality assumption for regression. Consider the linear regression model assuming a constant treatment effect $\beta_{1}$,

$$
y=\beta_{0}+\beta_{1} d+\beta_{2} x_{1}+\ldots+\beta_{k+1} x_{k}+u
$$

Unconfoundedness is equivalent to statistical independence of $d$ and $u$ conditional on $\left(x_{1}, \ldots, x_{k}\right)$, a stronger assumption than orthogonality or mean independence.

The second identifying assumption is referred to as overlap:

$$
0<\operatorname{Pr}(d=1 \mid X)<1
$$

This assumption says that for each value of the covariates, there is a positive probability of being in the treatment group and in the control group. To see the importance of this assumption, imagine if it did not hold for some value of $X$, say $X^{\prime}$. Specifically, if $\operatorname{Pr}\left(d=1 \mid X=X^{\prime}\right)=1$, then there are no control subjects with a covariate vector equal to $X^{\prime}$.

Practically speaking, this means that there are no subjects available in the control group that are similar in terms of covariate values to the treatment subjects with covariates equal to $X^{\prime}$. This makes estimation of the counterfactual problematic since there are no comparable control subjects. A similar argument

\footnotetext{
${ }^{7}$ This assumption is also referred to as "ignorable treatment assignment" (Rosenbaum and Rubin, 1983), "conditional independence" (Lechner, 1999), and "selection on observables" (Barnow, Cain, and Goldberger, 1980). An equivalent expression of this assumption is that $\operatorname{Pr}(d=1 \mid y(0), y(1), X)=$ $\operatorname{Pr}(d=1 \mid X)$.
} 
holds when $\operatorname{Pr}\left(d=1 \mid X=X^{\prime}\right)=0$ so that there are no comparable treatment subjects to match with controls at $X=X^{\prime}$.

Under unconfoundedness and overlap, I use the matched control (treatment) subjects to estimate the unobserved counterfactual and recover the treatment effects of interest. Consider the ATE for a subpopulation with a certain $X=X^{\prime}$.

$$
\begin{array}{r}
A T E\left(X^{\prime}\right) \equiv E\left[y(1)-y(0) \mid X=X^{\prime}\right] \\
=E\left[y(1)-y(0) \mid d=d^{\prime}, X=X^{\prime}\right] \\
=E\left[y \mid d=1, X=X^{\prime}\right]-E\left[y \mid d=0, X=X^{\prime}\right]
\end{array}
$$

The first equality follows from unconfoundedness, and the second from $y=d y(1)+(1-d) y(0)$. To estimate the expectations in the last expression requires data for both treatment and control subjects at $X=X^{\prime}$. This requirement illustrates the importance of the overlap assumption. To recover the unconditional ATE, one merely need integrate over the covariate distribution $X$.

\section{IV.A.4 Propensity Score Matching}

An important result due to Rosenbaum and Rubin (1983) is that if one is willing to assume unconfoundedness, then conditioning on the entire $k$-dimensional vector $X$ is unnecessary. Instead, one can condition on the one-dimensional propensity score, $p s(x)$, defined as the probability of receiving treatment conditional on the covariates,

$$
p s(x) \equiv \operatorname{Pr}(d=1 \mid X)=E(d \mid X)
$$

The motivation for focusing on propensity score matching methods is that in many applications of interest, the dimensionality of the observable characteristics is high. With a small number of characteristics (e.g., two binary variables), matching is straightforward. However, when there are many variables, it is difficult 
to determine along which dimensions to match units or which weighting scheme to adopt. Propensity score matching methods are especially useful under such circumstances because they provide a natural weighting scheme that yields unbiased estimates of the treatment impact.

First, I start with a sample of observations on outcomes, covariates, and assignment indicators $\left(y_{i}, X_{i}, d_{i}\right) . y$ and $d$ are univariate random variables representing the outcome and assignment indicator, respectively; $X$ is a $k$-dimensional vector of random variables assumed to be unaffected by the treatment. I use similar industry (same four digit SIC code), same year, log assets, market value / book value and institutional ownership as variables for matching.

Let $l_{m}(i)$ be the index such that

$$
\sum_{j \mid d_{j} \neq d_{i}} l\left(\left\|X_{j}-X_{l}\right\| \leq d_{i},\right. \text { and }
$$

In words, if $i$ is the observation of interest, then $l_{m}(i)$ is the index of the observation in the group - treatment or control - that $i$ is not in (hence, $d_{l} \neq d_{i}$ ), and that is the $m^{\text {th }}$ closest in terms of the distance measure based on the norm $\|$ I. To clarify this idea, consider the $4^{t h}$ observation $(i=4)$ and assume that it is in the treatment group. The index $l_{1}(4)$ points to the observation in the control group that is closest $(m=1)$ to the $4^{\text {th }}$ observation in terms of the distance between their covariates. The index $l_{2}(4)$ points to the observation in the control group that is next closest $(m=2)$ to the $4^{\text {th }}$ observation.

I define $L_{M}(i)=\left\{l_{1}(i), \ldots, l_{M}(i)\right\}$ to be the set of indices for the first $M$ matches to unit $i$. The estimated or imputed potential outcomes for observation $i$ are:

$$
\hat{y}_{i}(0)=\left\{\frac{1}{M} \sum j \epsilon L_{\left.M(i)_{j}^{y}\right)}^{y_{i}}\right\}_{i f d_{i=1}}^{i f d_{i=0}}
$$




$$
\hat{y}_{i}(1)=\left\{\frac{1}{M} \sum j \epsilon L_{\left.M(i)_{j}^{y}\right)}^{y_{i}}\right\}_{i f d_{i=1}}^{i f d_{i=0}}
$$

When observation $i$ is in the treatment group $d_{i}=1$, there is no need to impute the potential outcome $y_{i}(1)$ because I observe this value in $y_{i}$. However, I do not observe $y_{i}(0)$, which I estimate as the average outcome of the $M$ closest matches to observation $i$ in the control group. The intuition is similar when observation $i$ is in the control group.

With estimates of the potential outcomes, the matching estimator of the average treat- ment effect (ATE) is:

$$
\frac{1}{N} \sum_{i=1}^{N}\left[\hat{y}_{i}(1)-\hat{y}_{i}(0)\right]
$$

The matching estimator of the average treatment effect for the treated (ATET) is:

$$
\frac{1}{N_{1}} \sum_{i: d_{i}=1}^{N}\left[y_{i}-\hat{y}_{i}(0)\right]
$$

where $N_{1}$ is the number of treated observations. Finally, the matching estimator of the average treatment effect for the untreated (ATU) is:

$$
\frac{1}{N_{0}} \sum_{i: d_{i}=0}^{N}\left[\hat{y}_{i}(1)-y_{i}\right]
$$

where $N_{0}$ is the number of untreated (i.e., control) observations. Thus, the ATET and ATU are simply average differences over the subsample of observations that are treated or untreated, respectively.

Alternatively, instead of matching directly on all of the covariates $X$, one can just match on the propensity score. In other words, redefine $l_{m}(i)$ to be the index such that

$$
d_{l} \neq d_{i}, \text { and }
$$




$$
\sum_{j \mid d_{j} \neq d_{i}} l\left(\left|\widehat{p s}\left(X_{j}\right)-\widehat{p s}\left(X_{i}\right)\right| \leq \widehat{p s}\left(X_{l}\right)-\widehat{p s}\left(X_{i}\right) \mid\right)=m
$$

\section{IV.A.4.iv Assessing Unconfoundedness and Overlap}

The key identifying assumption behind matching, unconfoundedness, is untestable because the counterfactual outcome is not observable. The analogy with regression estimators is immediate; the orthogonality between covariates and errors is untestable because the errors are unobservable. While matching avoids the functional form restrictions imposed by regression, it does require knowledge and measurement of the relevant covariates $X$, much like regression. As such, if selection occurs on unobservables, then matching falls prey to the same endogeneity problems in regression that arise from omitted variables. From a practical standpoint, matching will not solve a fundamental endogeneity problem. However, it can offer a nice robustness test.

That said, one can conduct a number of falsification tests to help alleviate concerns over violation of the unconfoundedness assumption. Rosenbaum (1987) suggests estimating a treatment effect in a situation where there should not be an effect, a task accomplished in the presence of multiple control groups. These tests and their intuition are exactly analogous to those found in our discussion of natural experiments.

One example can be found in Lemmon and Roberts (2010) who use propensity score matching in conjunction with difference-in-differences estimation to identify the effect of credit supply contractions on corporate behavior. One result they find is that the contraction in borrowing among speculative-grade firms associated with the collapse of the junk bond market and regulatory reform in the early 1990s was greater among those firms located in the northeast portion of the country.

The identification concern is that aggregate demand fell more sharply in 
the northeast relative to the rest of the country so that the relatively larger contraction in borrowing among speculative grade borrowers was due to declining demand, and not a contraction in supply. To exclude this alternative, the authors re-estimate their treatment effect on investment-grade firms and unrated firms. If the contraction was due to more rapidly declining investment opportunities in the Northeast, one might expect to see a similar treatment effect among these other firms. The authors find no such effect among these other control groups.

The other identifying assumption is overlap. One way to inspect this assumption is to plot the distributions of covariates by treatment group. In one or two dimensions, this is straightforward. In higher dimensions, one can look at pairs of marginal distributions. However, this comparison may be uninformative about overlap because the assumption is about the joint, not marginal, distribution of the covariates.

For propensity score matching, one can inspect the distribution of propensity scores in treatment and control groups. If estimating the propensity score nonparametrically, then one may wish to undersmooth by choosing a bandwidth smaller than optimal or by including higher-order terms in a series expansion. Doing so may introduce noise but at the benefit of reduced bias.

There are several options for addressing a lack of overlap. One is to simply discard bad matches, or accept only matches with a propensity score difference below a certain threshold.

Likewise, one can drop all matches where individual covariates are severely mismatched. One can also discard all treatment or control observations with estimated propensity scores above or below a certain value. What determines a "bad match" or how to choose the propensity score threshold is ultimately subjective, but requires some justification.

When matching on covariates, there are several options for the distance metric. Abadie and Imbens (2006) suggest using the inverse of the covariates' 
variances (the Mahalanobis metric):

$$
|| X_{i}-X_{j}||=\sqrt{\left(X_{i}-X_{j}\right)^{\prime} \sum_{X}^{-1}\left(X_{i}-X_{j}\right)}
$$

where $\Sigma_{X}$ is the covariance matrix of the covariates, and $\left(\Sigma_{X}{ }^{-1}\right)$ is a diagonal matrix equal to the diagonal elements of $\left(\Sigma_{X}{ }^{-1}\right)$ and zero everywhere else, which will reduce differences in covariates within matched pairs in all directions.

I am interested in estimating the propensity score as precisely as possible to eliminate, or at least mitigate, any selection bias in my estimate of the treatment effect. There are a number of strategies for estimating the propensity score including: ordinary least squares, maximum likelihood (e.g., logit, probit), or a nonparametric approach, such as a kernel estimator, series estimator, sieve estimator, etc.). I use a logit model of maximum likelihood.

Following Dehejia and Wahba (2002) and Smith and Todd (2005), I use the "nearest neighbor" matching methodology. I use the single (i.e., best) match to the Target Firm. This methodology leads to the least biased and most credible estimates. However, it can lead to the least precise estimates. This tension reflects the usual bias-variance tradeoff in estimation. I match firms using the replacement methodology which allows for better matches and less bias. I chose this methodology since the primary objective in empirical corporate finance studies is proper identification.

The choice of covariates is important. I follow the guidelines suggested by Heckman et al.(1998) that in order for matching estimators to have low bias, a rich set of variables related to treatment assignment and outcomes is needed. Identification of the treatment effects turns crucially on the ability to absorb all outcome relevant heterogeneity with observable measures. Accordingly, I use the following covariates for matching affect the likelihood of being assigned into the treated group: Log Market Capitalization, Log Assets, Market Value / Book Value 
(Tobin's Q), Institutional Ownership and fixed effects for both Industry and Year. The treatment effect of interest will typically determine for which observations matches are needed. If interest lies in the ATE, then estimates of the counterfactuals for both treatment and control observations are needed. Thus, I need to find matches for both observations in both groups. If I were interested only in the ATET, then I would have only found matches for the treatment observations, and vice versa for the ATU. My primary focus is on the ATET, particularly the ex post effects of the Target Firms that received the disciplinary effect by hedge fund monitoring.

\section{IV.B Panel Data Methods}

As previously explained, one of the most common causes of endogeneity in empirical corporate finance is omitted variables, and omitted variables are a problem because of the considerable heterogeneity present in many empirical corporate finance settings. Panel data can sometimes offer a partial, but by no means complete and costless, solution to this problem.

\section{IV.B.1 Fixed and Random Effects}

I start with a simplified and sample version of Equation ?? that contains only one regressor but in which I explicitly indicate the time and individual subscripts on the variables,

$$
y_{i t}=\beta_{0}+\beta_{1} x_{i t}+u_{i t},(i=1, \ldots, N ; t=1, \ldots, T)
$$

where the error term, $u_{i t}$, can be decomposed as

$$
u_{i t}=c_{i}+e_{i t}
$$

The term $c_{i}$ can be interpreted as capturing the aggregate effect of all of the unobservable, time-invariant explanatory variables for $y_{i t}$. To focus attention on 
the issues specific to panel data, I assume that $e_{i t}$ has a zero mean conditional on $x_{i t}$ and $c_{i}$ for all $t$.

The relevant issue from an estimation perspective is whether $c_{i}$ and $x_{i t}$ are correlated. If they are, then $c_{i}$ is referred to as a "fixed effect." If they are not, then $c_{i}$ is referred to as a "random effect." In the former case, endogeneity is obviously a concern since the explanatory variable is correlated with a component of the error term. In the latter, endogeneity is not a concern; however, the computation of standard errors is affected. ${ }^{8}$

Two possible remedies to the endogeneity problem in the case of fixed effects is to run what is called a least squares dummy variable regression, which is simply the inclusion of firm-specific intercepts in Equation (IV.13). However, in many moderately large data sets, this approach is infeasible, so the usual and equivalent remedy is to apply OLS to the following deviations-from-individual-means regression:

$$
\left(y_{i t}-\frac{1}{T} \sum_{t=1}^{T} y_{i t}\right)=\beta_{1}\left(x_{i t}-\frac{1}{T} \sum_{t=1}^{T} x_{i t}\right)+\left(e_{i t}-\frac{1}{T} \sum_{t=1}^{T} e_{i t}\right)
$$

The regression equation (4.7) does not contain the fixed effect, $c_{i}$, because

$$
\left(c_{i}-T^{-1} \sum_{T}^{t=1} c_{i}\right)=0
$$

so this transformation solves this particular endogeneity problem. Alternatively, one can remove the fixed effects through differencing and estimating the resulting equation by OLS

$$
\Delta y_{i t}=\beta_{1} \Delta x_{i t}+\Delta e_{i t}
$$

Fixed effects can ameliorate endogeneity concerns, but, as is the case with

\footnotetext{
${ }^{8}$ Feasible Generalized Least Squares is often employed to estimate parameters in random effects situations.
} 
all econometric techniques, they should be used only after thinking carefully about the economic forces that might cause fixed effects to be an issue in the first place. Relatedly, fixed effects cannot remedy any arbitrary endogeneity problem and are by no means an endogeneity panacea. Indeed, they do nothing to address endogeneity associated with correlation between $x_{i t}$ and $e_{i t}$. Accordingly, I used Industry and Year fixed effects in certain empirical tests.

\section{IV.C Event Study Methodology}

Long-horizon event studies have an extensive history, including the original stock split event study by Fama, Fisher, Jensen, and Roll (1969). As evidence inconsistent with the efficient markets hypothesis started to accumulate in the late 1970s and early 1980s, interest in long-horizon studies continued. Evidence on the postearnings announcement effect (Ball \& Brown, 1968; Jones \& Litzenberger, 1970), size effect (Banz, 1981), and earnings yield effect (Basu, 1977, 1983) contributed to skepticism about the CAPM as well as market efficiency. This evidence prompted researchers to develop hypotheses about market inefficiency stemming from investors' information processing biases (DeBondt \& Thaler, 1985, 1987) and limits to arbitrage (DeLong, Schleifer, Summers, \& Waldmann, 1990a, 1990b; Shleifer \& Vishny, 1997).

The "anomalies" literature and the attempts to model the anomalies as market inefficiencies has led to a burgeoning field known as behavioral finance. Research in this field formalizes (and tests) the security pricing implications of investors' information processing biases. Because the behavioral biases might be persistent and arbitrage forces might take a long time to correct the mispricing, a vast body of literature hypothesizes and studies abnormal performance over long horizons of one-to-five years following a wide range of corporate events. The events might be one-time (unpredictable) phenomena like an initial public offering or a seasoned equity offering, or they may be recurring events such as earnings announcements. 
Both cumulative abnormal returns $(C A R s)$ and buy-and-hold abnormal return $(B H A R)$ methods tested the null hypothesis that abnormal performance is equal to zero. The abnormal returns for an event were calculated as follows:

After calculating event $C A R s$, I calculated and reported the cumulative average abnormal return $(C A A R)$. Where, the $C A A R$ is the arithmetic average of all sample event CARs and is calculated as follows:

Under each method, the abnormal return measured is the same as the returns to a trading rule, which buys sample securities at the beginning of the first period and holds through the end of the last period. CARs and BHARs correspond to security holder wealth changes around an event. Further, when applied to postevent periods, tests using these measures provide information about market efficiency because systematically nonzero abnormal returns following an event are inconsistent with efficiency and imply a profitable trading rule (ignoring trading costs).

While post event, risk-performance measurement is crucial in long-horizon tests, actual measurement is not straightforward. Two main methods for assessing and calibrating postevent, risk-adjusted performance were used in this study: characteristic-based matching approach (also known as BHAR) and the Jensen's alpha approach, which is also known as the calendar-time portfolio approach (Fama, 1998; Mitchell \& Stafford, 2000). Analysis and comparison of the methods is detailed below.

\section{IV.C.1 Empirical models for estimation period}

\section{IV.C.1.i Market Model}

I assume that security returns follow a single factor market model,

$$
R_{j t}=\alpha_{j}+\beta_{j} R_{m t}+\epsilon_{j t},
$$


where $R_{j t}$ is the rate of return of the common stock of the $j^{\text {th }}$ firm on day $t ; R_{m t}$ is the rate of return of a market index on day $t ; \epsilon_{j t}$ is a random variable that, by construction, must have an expected value of zero, and is assumed to be uncorrelated with $R_{m t}$, uncorrelated with $R_{k t}$ for $k \neq j$, not autocorrelated, and homoskedastic. $\beta_{j}$ is a parameter that measures the sensitivity of $R_{j t}$ to the market index. I define the abnormal return (or prediction error) for the common stock of the $j^{\text {th }}$ firm on day $t$ as:

$$
A_{j t}=R_{j t}-\left(\hat{\alpha}_{j}+\hat{\beta}_{j} R_{m t}\right)
$$

where the coefficients $\hat{\alpha}_{j}$ and $\hat{\beta}_{j}$ are ordinary least squares estimates of $\alpha_{j}$ and $\beta_{j}$.

The average abnormal return (or average prediction error) $A A R_{t}$ is the sample mean:

$$
A A R_{t}=\frac{\sum_{j=1}^{N} A_{j t}}{N}
$$

where $t$ is defined in trading days relative to the Event Date (e.g. $t=-60$ means 60 trading days before the event).

Over an interval of two or more trading days beginning with day $T_{1}$, and ending with $T_{2}$, the cumulative average abnormal return is

$$
C A A R_{T_{1}, T_{2}}=\frac{1}{N} \sum_{j=1}^{N} \sum_{t=T_{1}}^{T_{2}} A_{j t}
$$

Over an interval of two or more trading days beginning with day $T_{1}$, and ending with $T_{2}$, the buy-and-hold abnormal return is

$$
\begin{aligned}
& B H A R_{j, T_{1}, T_{2}}= \\
& {\left[\prod_{t=T_{1}}^{T_{2}}\left(1+R_{j t}\right)-1\right]-\left[\left(1+\hat{\alpha}_{j}\right)^{\left(T_{2}-T_{1}+1\right)}-1\right]} \\
& -\hat{\beta}_{j}\left[\prod_{t=T_{1}}^{T_{2}}\left(1+R_{m t}\right)-1\right]
\end{aligned}
$$


The average compounded abnormal return is is

$$
A C A R_{T_{1}, T_{2}}=\frac{1}{N} \sum_{j=1}^{N} B H A R_{j, T_{1}, T_{2}}
$$

\section{IV.C.1.i Fama-French Three-Factor Model}

The Fama-French (1993) three-factor model for generating returns during the estimation period is:

$$
R_{j t}=\alpha+\beta_{j} R_{m t}+s_{j} S M B_{t}+h_{j} H M L_{t}+\epsilon_{j t} .
$$

where $R_{j t}$ is the rate of return of the common stock of the $j^{t h}$ firm on day $t ; R_{m t}$ is the rate of return of a market index on day $t ; S M B_{t}$ is the average return on small market-capitalization portfolios minus the average return on three large market-capitalization portfolios; $H M L_{t}$ is the average return on two high book-to-market equity portfolios minus the average return on two low book-to-market equity portfolios; $\epsilon_{j t}$ is a random variable that, by construction, must have an expected value of zero, and is assumed to be uncorrelated with $R_{m t}$, uncorrelated with $R_{k t}$ for $k \neq j$, not autocorrelated, and homoskedastic. See Fama and French (1993) for a detailed description of $S M B_{t}$ and $H M L_{t} . \beta_{j}$ is a parameter that measures the sensitivity of $R_{j t}$ to the excess return on the market index; $s_{j}$ measures the sensitivity of $R_{j t}$ to the difference between small and large capitalization stock returns; and $h_{j}$ measures the sensitivity of $R_{j t}$ to the difference between value and growth stock returns.

Define the abnormal return (or prediction error) for the common stock of the $j^{\text {th }}$ firm on day $t$ as:

$$
A_{j t}=R_{j t}-\left(\hat{\alpha}_{j}+\hat{\beta}_{j} R_{m t}+\hat{s}_{j} S M B_{t}+\hat{h}_{j} H M L_{t}\right),
$$


where the coefficients $\hat{\alpha}_{j}, \hat{\beta}_{j}, \hat{s}_{j}$ and $\hat{h}_{j}$ are ordinary least squares estimates of $\alpha_{j}$, $\beta_{j}, s_{j}$ and $h_{j}$.

The average abnormal return, cumulative abnormal return, buy-and-hold abnormal return and related concepts are analogous to those defined in the market model section above.

\section{IV.C.1.i Fama-French-Momentum Four-Factor Model}

The Fama-French (1993) three-factor model can be augmented by the momentum factor as suggested by Carhart (1997), as the return-generating model during the estimation period. The model is:

$$
R_{j t}=\alpha+\beta_{j} R_{m t}+s_{j} S M B_{t}+h_{j} H M L_{t}+u_{j} U M D_{t}+\epsilon_{j t}
$$

where $R_{j t}$ is the rate of return of the common stock of the $j^{\text {th }}$ firm on day $t ; R_{m t}$ is the rate of return of a market index on day $t ; S M B_{t}$ is the average return on small market-capitalization portfolios minus the average return on three large market-capitalization portfolios; $H M L_{t}$ is the average return on two high book-to-market equity portfolios minus the average return on two low book-to-market equity portfolios; $U M D_{t}$ is the average return on two high prior return portfolios minus the average return on two low prior return portfolios. $\epsilon_{j t}$ is a random variable that, by construction, must have an expected value of zero, and is assumed to be uncorrelated with $R_{m t}$, uncorrelated with $R_{k t}$ for $k \neq j$, not autocorrelated, and homoskedastic. $\beta_{j}$ is a parameter that measures the sensitivity of $R_{j t}$ to the excess return on the market index; $s_{j}$ measures the sensitivity of $R_{j t}$ to the difference between small and large capitalization stock returns; $h_{j}$ measures the sensitivity of $R_{j t}$ to the difference between value and growth stock returns; and $u_{j}$ measures the sensitivity of $R_{j t}$ to the difference between high prior return stock returns and low prior return stock returns. 
Define the abnormal return (or prediction error) for the common stock of the $j^{\text {th }}$ firm on day $t$ as:

$$
A_{j t}=R_{j t}-\left(\hat{\alpha}_{j}+\hat{\beta}_{j} R_{m t}+\hat{s}_{j} S M B_{t}+\hat{h}_{j} H M L_{t}+\hat{u}_{j} U M D_{t}\right)
$$

where the coefficients $\hat{\alpha}_{j}, \hat{\beta}_{j}, \hat{s}_{j}, \hat{h}_{j}$ and $\hat{u}_{j}$ are ordinary least squares estimates of $\alpha_{j}, \beta_{j}, s_{j} h_{j}$ and $u_{j}$

The average abnormal return, cumulative abnormal return, buy-and-hold abnormal return and related concepts are analogous to those defined in the market model section above.

\section{IV.C.1.i Market Adjusted Returns Model}

Market adjusted returns are computed by subtracting the observed return on the market index for day $t, R_{m t}$, from the rate of return of the common stock of the $j^{\text {th }}$ firm on day $t$ :

$$
A_{j t}=R_{j t}-R_{m t}
$$

The definitions of the average abnormal return, cumulative average abnormal return and average compounded abnormal return are analogous to those for market model abnormal returns above.

\section{IV.C.1.i Fama-French Calendar Time Portfolio Regressions}

The calendar-time portfolio model using Fama-French (1993) factors is:

$$
R_{p t}-R_{f t}=\alpha+\beta\left(R_{m t}-R_{f t}\right)+s S M B_{t}+h H M L_{t}+\epsilon_{p t},
$$

where $R_{f t}$ is the one-month Treasury bill rate and other symbols are as defined above. A portfolio is formed for each date that includes each sample firm having the date in its event period. In an event study using monthly data, portfolios 
are formed monthly in calendar time. Portfolios can either be equally-weighted or value-weighted. The regression is estimated on portfolio returns. The estimate of the average abnormal return is alpha $(\alpha)$. I used ordinary least squares (OLS) to estimate the model and test the null hypothesis $\alpha=0$. Additionally, I used the Fama-French-Momentum four factor model to test the null hypothesis $\alpha=0$.

\section{IV.C.2 Event Study Test Statistics}

The literature refers to the Patell (1976) test as a standardized abnormal return test or a test assuming cross-sectional independence. Many published studies use the Patell test (see, for example, Linn and McConnell, 1983; Schipper and Smith, 1986; and Haw, Pastena and Lilien, 1990).

\section{IV.C.2.ii Event Studies Centered on a Single Date}

Under the null hypothesis, each $A_{j t}$ has mean zero and variance $\sigma_{A_{j t}}^{2}$. The maximum likelihood estimate of the variance is,

$$
s_{A_{j t}}^{2}=s_{A_{j}}^{2}\left[1+\frac{1}{M_{j}}+\frac{\left(R_{m t}-\overline{R_{m E s t}}\right)^{2}}{\sum_{k=E_{1}}^{E_{2}}\left(R_{m k}-\overline{R_{m E s t}}\right)^{2}}\right]
$$

where

$$
s_{A_{j}}^{2}=\frac{\sum_{k=E_{1}}^{E_{2}} A_{j k}^{2}}{M_{j}-2},
$$

$R_{m t}$ is the observed return on the market index on day $t, \overline{R_{m E s t}}$ is the mean market return over the estimation period and $M_{j}$ is the number of non-missing trading day returns in the interval $E_{1}$ through $E_{2}$ used to estimate the parameters for firm $j$.

$$
\text { I define the standardized abnormal return (or standardized prediction error) }
$$

as

$$
S A R_{j t}=\frac{A_{j t}}{s_{A_{j t}}} .
$$

Under the null hypothesis, each $S A R_{j t}$ follows a Student's $t$ distribution with 
$M_{j}-2$ degrees of freedom. Summing the $S A R_{j t}$ across the sample, I obtain

$$
T S A R_{t}=\sum_{j=1}^{N} S A R_{j t}
$$

The expected value of $T S A R_{t}$ is zero. The variance of $T S A R_{t}$ is

$$
Q_{t}=\sum_{j=1}^{N} \frac{M_{j}-2}{M_{j}-4}
$$

The test statistic for the null hypothesis that $C A A R_{T_{1}, T_{2}}=0$ is

$$
Z_{T_{1}, T_{2}}=\frac{1}{\sqrt{N}} \sum_{j=1}^{N} Z_{T_{1}, T_{2}}^{j},
$$

where

$$
Z_{T_{1}, T_{2}}^{j}=\frac{1}{\sqrt{Q_{T_{1}, T_{2}}^{j}}} \sum_{t=T_{1}}^{T_{2}} S A R_{j t}
$$

and

$$
Q_{T_{1}, T_{2}}^{j}=\left(T_{2}-T_{1}+1\right) \frac{M_{j}-2}{M_{j}-4}
$$

Under cross-sectional independence of the $Z_{T_{1}, T_{2}}^{j}$ and other conditions (see Patell, 1976), $Z_{T_{1}, T_{2}}$ follows the standard normal distribution under the null hypothesis.

If abnormal returns are serially uncorrelated, the variance of $C A R_{j}$ is the sum of the variances of the daily abnormal returns:

$$
s_{C A R_{T_{1 j}, T_{2 j}}}^{2}=s_{A R_{j}}^{2}\left[L_{j}+\frac{L_{j}}{M_{j}}+\frac{\sum_{t=T_{1 j}}^{T_{2 j}}\left(R_{m t}-\overline{R_{m E s t}}\right)^{2}}{\sum_{k=1}^{M_{j}}\left(R_{m k}-\overline{R_{m E s t}}\right)^{2}}\right]
$$

The precision-weighted average is constructed using the relative weights implied by the definition of $Z_{T_{1}, T_{2}}$. Thus, the precision-weighted average will always have the same sign as the corresponding $Z_{T_{1}, T_{2}}$. The formula for the 
precision-weighted average is

$$
P W C A A R_{T_{1}, T_{2}}=\sum_{j=1}^{N} \sum_{t=T_{1}}^{T_{2}} w_{j} A_{j t}
$$

where

$$
w_{j}=\frac{\left(\sum_{t=T_{1}}^{T_{2}} s_{A_{j t}}^{2}\right)^{-\frac{1}{2}}}{\sum_{i=1}^{N}\left(\sum_{t=T_{1}}^{T_{2}} s_{A_{i t}}^{2}\right)^{-\frac{1}{2}}}
$$

The precision-weighted $C A A R$ fulfills the reporting needs for which researchers sometimes report an average standardized cumulative abnormal return (average $S C A R$ ). The precision-weighted $C A A R$, as a weighted average of the original $C A R \mathrm{~s}$, preserves the portfolio interpretation that $C A A R$ offers but average $S C A R$ does not.

\section{IV.C.2.ii Correction for Correlation of Abnormal Returns}

Following Mikkelson and Partch (1988), the corrected test statistic for the null hypothesis that $C A A R=0$ is

$$
z_{C A A R}=N^{-\frac{1}{2}} \sum_{j=1}^{N} \frac{C A R_{T_{1 j}, T_{2 j}}}{s_{C A R_{T_{1 j}, T_{2 j}}}}
$$

where

$$
s_{C A R_{T_{1 j}, T_{2 j}}}^{2}=s_{A R_{j}}^{2}\left\{L_{j}\left[1+\frac{L_{j}}{M_{j}}+\frac{\left(\sum_{t=T_{1 j}}^{T_{2 j}} R_{m t}-L_{j} \overline{R_{m E s t}}\right)^{2}}{\sum_{k=1}^{M_{j}}\left(R_{m k}-\overline{R_{m E s t}}\right)^{2}}\right]\right\}
$$

For an event study centered on a single Event Date, $T_{1 j}, T_{2 j}$ (and $L_{j}$ if there is no missing return) are equal across firms and the subscript $j$ can be dropped from them. The corrected test accounts for the fact that within the 
window, the abnormal returns for each stock are serially correlated. The serial correlation occurs because all the abnormal returns are functions of the same market model intercept and slope estimators. Applications of the corrected test in addition to Mikkelson and Partch (1988) include Mais, Moore and Rogers (1989), Cowan, Nayar and Singh (1990), Mann and Sicherman (1991) and Lee (1992). Simulation evidence of the properties of the corrected and uncorrected Patell tests appears in Karafiath and Spencer (1991, using Monte Carlo experiments) and Cowan (1993, using sampling experiments with CRSP data). Both papers report that the bias in the uncorrected test is small in event windows shorter than 60 days but serious in event windows longer than 100 days. Mikkelson and Partch (1988) acknowledge Craig Ansley for the original derivation of the corrected test statistic in an event study context. For other derivations and discussion, see Cantrell, Maloney and Mitchell (1989) and Sweeney (1991).

\section{IV.C.3 Standardized Cross-Sectional Test}

Boehmer, Musumeci and Poulsen (1991) introduce the standardized cross-sectional test for market model abnormal returns and report its empirical properties. The test is the same as the Patell test described above except that there is a final empirical cross-sectional variance adjustment in place of the analytical variance of the total standardized prediction error. For additional discussion of event-date variance increases and related tests, see Sanders and Robins (1991).

For day $t$ in the event period, the test statistic is

$$
z_{t}=\frac{T S A R_{t}}{N^{\frac{1}{2}}\left(s_{S A R_{\bullet}}\right)}
$$

where

$$
s_{S A R_{\bullet}}^{2}=\frac{1}{N-1} \sum_{i=1}^{N}\left(S A R_{i t}-\frac{1}{N} \sum_{j=1}^{N} S A R_{j t}\right)^{2}
$$

extends the cross-sectional standardized test to multiperiod windows using 
the correction for serial correlation described above. I define the standardized cumulative abnormal return for stock $j$ as

$$
S C A R_{T_{1 j}, T_{2 j}}=\left(C A R_{T_{1 j}, T_{2 j}} / s_{C A R_{T_{1 j}, T_{2 j}}}\right)
$$

where $s_{C A R_{T_{1 j}, T_{2 j}}}$ is as defined in equation IV.34. Then the standardized cross-sectional test statistic for the null hypothesis that $C A A R=0$ is

$$
z_{t}=\frac{\sum_{i=1}^{N} S C A R_{T_{1 j}, T_{2 j}}}{N^{\frac{1}{2}} s_{S C A R \bullet t}}
$$

where

$$
s_{S C A R_{\bullet} t}^{2}=\frac{1}{N-1} \sum_{i=1}^{N}\left(S C A R_{T_{1 i}, T_{2 i}}-\frac{1}{N} \sum_{j=1}^{N} S C A R_{T_{1 j}, T_{2 j}}\right)^{2}
$$

\section{IV.C.4 Time-series Standard Deviation Test}

The time-series standard deviation test, also known as the "crude dependence adjustment" test (Brown and Warner, 1980), uses a single variance estimate for the entire portfolio. Therefore, the time series standard deviation test does not take account of unequal return variances across securities. On the other hand, it avoids the potential problem of cross-sectional correlation of security returns. The estimated variance of $A A R_{t}$ is

$$
\hat{\sigma}_{A A R}^{2}=\frac{\sum_{t=E_{1}}^{E_{2}}\left(A A R_{t}-\overline{A A R}\right)^{2}}{M-2},
$$

where the market model parameters are estimated over the estimation period of $M=E_{2}-E_{1}+1$ days and

$$
\overline{A A R}=\frac{\sum_{t=E_{1}}^{E_{2}} A A R_{t}}{M}
$$


The portfolio test statistic for day $t$ in event time is

$$
\mathrm{t}=\frac{A A R_{t}}{\hat{\sigma}_{A A R}}
$$

Assuming time-series independence, the test statistic for $C A A R_{T_{1}, T_{2}}$ is

$$
\mathrm{t}=\frac{C A A R_{t}}{\left(T_{2}-T_{1}+1\right)^{\frac{1}{2}} \hat{\sigma}_{A A R}}
$$

Many studies use the time series standard deviation test (for example, see Dopuch, Holthausen and Leftwich, 1986 and Brickley, Dark and Weisbach, 1991).

\section{IV.C.5 Cross-sectional standard deviation test}

I substituted a daily cross-sectional standard deviation for the portfolio time-series standard deviation in the non-standardized tests. The portfolio test statistic for day $t$ in event time is

$$
\mathrm{t}=\frac{A A R_{t}}{\hat{\sigma}_{A A R_{t}} / \sqrt{N}}
$$

where

$$
\hat{\sigma}_{A A R_{t}}^{2}=\frac{1}{N-1} \sum_{i=1}^{N}\left(A_{i t}-\frac{1}{N} \sum_{j=1}^{N} A_{j t}\right)^{2}
$$

The estimated variance of $C A A R_{T_{1}, T_{2}}$ is

$$
\hat{\sigma}_{C A A R_{T_{1}, T_{2}}}^{2}=\frac{1}{N-1} \sum_{i=1}^{N}\left(C A R_{i, T_{1}, T_{2}}-\frac{1}{N} \sum_{j=1}^{N} C A R_{j, T_{1}, T_{2}}\right)^{2}
$$

The test statistic for $C A A R_{T_{1}, T_{2}}$ is

$$
\mathrm{t}_{C A A R}=\frac{C A A R_{T_{1}, T_{2}}}{\hat{\sigma}_{C A A R_{T_{1}, T_{2}}} / \sqrt{N}}
$$

Brown and Warner (1985) report that the cross-sectional test is well-specified for Event Date variance increases but not very powerful. Boehmer, 
Musumeci and Poulsen (1991) report that the standardized cross-sectional test (see above) is more powerful and equally well specified. Cowan (1992) reports that the generalized sign test (see below) also is well specified for Event Date variance increases and more powerful than the cross-sectional test.

\section{IV.C.6 Skewness-adjusted Transformed Normal Test}

The transformed normal test (Hall, 1992) can be applied to mean abnormal return and to window mean cumulative or compounded abnormal return. I assume that it is applied to average compounded abnormal return. Estimate the cross-sectional standard deviation by

$$
\hat{\sigma}_{B H A R}=\left[\frac{1}{N-1} \sum_{i=1}^{N}\left(B H A R_{i, T_{1}, T_{2}}-A C A R_{T_{1}, T_{2}}\right)^{2}\right]^{\frac{1}{2}}
$$

and the skewness by

$$
\hat{\gamma}=\frac{N}{(N-1)(N-2)} \sum_{i=1}^{N}\left(B H A R_{i, T_{1}, T_{2}}-A C A R_{T_{1}, T_{2}}\right)^{3} \hat{\sigma}_{B H A R}^{-3}
$$

Define

$$
S=\frac{A C A R_{T_{1}, T_{2}}}{\hat{\sigma}_{B H A R} / \sqrt{N}}
$$

The skewness-adjusted transformed normal test statistic is

$$
t_{1}=S+\frac{1}{3} \hat{\gamma} S^{2}+\frac{1}{27} \hat{\gamma}^{2} S^{3}+\frac{1}{6 N} \hat{\gamma}
$$

\section{IV.C.7 Long-Horizon Event Study Methodology}

As discussed in Section IV.C, long-horizon event studies have an extensive history. The "anomalies" literature and the attempts to model the anomalies as market

inefficiencies has led to a burgeoning field known as behavioral finance. Research in this field formalizes (and tests) the security pricing implications of investors' 
information processing biases. Because the behavioral biases might be persistent and arbitrage forces might take a long time to correct the mispricing, a vast body of literature hypothesizes and studies abnormal performance over long horizons of one-to-five years following a wide range of corporate event $\mathrm{s}$. The events might be one-time (unpredictable) phenomena like an initial public offering or a seasoned equity offering, or they may be recurring events such as earnings announcements.

Both cumulative abnormal returns (CAR) and buy-and-hold abnormal return $(B H A R)$ methods test the null hypothesis that abnormal performance is equal to zero. The abnormal returns for an event were calculated as follows:

$$
C A R_{i}\left(t_{1}, t_{2}\right)=\sum_{t=t_{1}}^{t_{2}} A R_{i t}
$$

After calculating event $C A R s$, I calculate and report the cumulative average abnormal return (CAAR). Where, the CAAR is the arithmetic average of all sample event $C A R s$, and is calculated as follows:

$$
C A R_{i}\left(t_{1}, t_{2}\right)=\frac{1}{N} \sum_{j=1_{1}}^{N} \sum_{t=t_{1}}^{t_{2}} A R_{i t}
$$

Under each method, the abnormal return measured is the same as the returns to a trading rule which buys sample securities at the beginning of the first period, and holds through the end of the last period. CARs and BHARs correspond to security holder wealth changes around an event. Further, when applied to post-event periods, tests using these measures provide information about market efficiency, because systematically nonzero abnormal returns following an event are inconsistent with efficiency and imply a profitable trading rule (ignoring trading costs).

While post-event risk-adjusted performance measurement is crucial in long-horizon tests, actual measurement is not straightforward. Two main methods for assessing and calibrating post-event risk-adjusted performance are used: 
characteristic-based matching approach (also known as BHAR) and the Jensen's alpha approach, which is also known as the calendar-time portfolio approach (Fama, 1998; Mitchell \& Stafford, 2000).

Alternative explanations for the high abnormal event-day return examined in the previous section that refute value creation include a temporary price impact caused by buying pressure from the hedge fund or their followers, and market over-reaction. Brav et al. (2008) found the run up in price around the announcement window is accompanied by abnormally high trading volume. If the price impact is purely temporary and reflects a trading friction rather than information about prospective value change, then Target Firms should experience negative abnormal returns shortly after the event. This is not supported by extending the event windows to $[-60,+60]$ days. 


\section{CHAPTER V}

\section{DATA AND EMPIRICAL TESTING}

There is no central database of activist hedge funds. Therefore, I construct an independent dataset of all activist interventions from 1984-2014 from various sources, including Compustat, Capital IQ, FactSet, ISS Proxy Data, SharkRepellent, and the SEC's EDGAR database. Additionally, my dataset includes Schedule 13D filings, the mandatory federal securities law filings under Section 13(d) of the 1934 Exchange Act that investors must file with the SEC within 10 days of acquiring more than $5 \%$ of any class of securities of a publicly traded company if they have an interest in influencing the management of the company. My manually constructed database of shareholder activist events (see Figure V.1) includes 5,958 interventions from 1984-2014. Similar to Gillan and Starks (2007), I define shareholder activist event as a purposeful intervention by "investors who, dissatisfied with some aspect of a company's management or operations, try to bring about change within the company without a change in control".

My dataset sample collection methodology includes a multi-step procedure. The vast majority of shareholder activism literature is predicated on Schedule 13D filings. However, I start with a much more expansive sample of activist interventions: 5,958 interventions from 1984-2014.

In my second step, I narrow the time series to 1990-2014, since the quantity and quality of financial information prior to 1990 is limited and unreliable. Next, I exclude certain events in which (a) the primary purpose of the filer is to be involved in the bankruptcy reorganization or the financing of a distressed firm; and 
(b) the target is a closed-end fund or other non-regular corporation. I exclude duplicate campaigns by multiple activists (i.e., the wolf-pack), so the dataset includes information about the Target Firm only once with respect to a specific campaign. If a Target Firm were to file for bankruptcy protection or liquidation during my multistep compilation, I include the financial information of the Target Firm up to the Chapter 11 or Chapter 7 filing date. More specifically, the bankrupt firm would account for $100 \%$ loss as it relates to stock return and portfolio analyses. I winsorize all unbounded variables and financial data at the $1.0 \%$ and $99.0 \%$ in each tail to adjust for outliers. As discussed in Chapter IV, there are two important econometric issues that need to be addressed: self-selection bias and endogeneity. To address and mitigate those concerns, I create the following six distinct groups:

1. All Activist Interventions (4,186 Target Firms): includes hedge funds, corporations, public pension funds, mutual funds, labor unions, religious groups and individuals that initiated an activist campaign against a Target Firm;

2. Hedge Fund Activists (3,202 Target Firms): only includes hedge funds that initiated an activist campaign against a Target Firm;

3. Non-Hedge Fund Activists (984 Target Firms): includes corporations, public pension funds, mutual funds, labor unions, religious groups and individuals (excludes hedge funds) that initiated an activist campaign against a Target Firm;

4. Treatment Group: Board representation by Hedge Fund Activists (582 Target Firms): only includes hedge funds that sought and won board representation to actively monitor management of a Target Firm;

5. Control Group I: Target Firms that "won" the proxy fight against Hedge Fund Activists (115 Target Firms): this group is the primary Control Group 
since it's comprised of Target Firms that faced the "threat" of hedge fund board representation but the majority of the shareholders supported the incumbent management team and board. Therefore, this group did not receive active monitoring by a hedge fund activist nor it's collateral effects as a disciplinary mechanism; and

6. Control Group II: Board representation by Non-Hedge Fund Activists (121 Target Firms): includes corporations, public pension funds, mutual funds, labor unions, religious groups and individuals (excludes hedge funds) that sought and won board representation to actively monitor management of a Target Firm.

\section{V.A Characteristics of Target Firms and Activist Campaigns (1990-2014)}

In this section, I provide a detailed overview of the objectives and characteristics of shareholder activist campaigns against Target Firms. Table V.1 reports the characteristics of shareholder activist campaigns against Target Firms. The table provides a comparison of the six groups that are defined in Section V, which reports the results of my Treatment Group and Control Groups.

\section{V.A.1 Objectives of Activist Campaigns}

Hedge fund activism involves various objectives and tactics against Target

Firms. Table V.1 summarizes the stated objectives of the various activist interventions from 1990 to 2014 when dissident shareholders announce their intent to intervene. The panel is organized by the underlying motives with respect to a campaign. The objectives are not mutually exclusive as one activist campaign can be attributable to multiple issues. It is important to note the differences between objectives and tactics among the various types of activists (i.e., hedge fund versus non-hedge fund activist interventions). Hedge Fund Activists are more likely (85\%) 
to file a $13 \mathrm{D}$ to initiate a campaign against a Target Firm versus a Non-Hedge Fund Activist, which files a 13D $43 \%$ of the time. Hedge Fund Activists do not focus on corporate governance reforms exclusively but rather interventions that emphasize maximizing shareholder value though operational improvements, a change in strategic direction, a sale of the company, capital distribution policy (29\%) and $\backslash$ or a replacement of the management team. These findings are consistent with Greenwood and Schor (2009). However, Hedge Fund Activists may employ various governance-focused tactics at the onset of a campaign, such as removal of a anti-takeover provisions to facilitate a successful intervention. Non-Hedge Fund Activists are more likely to initiate a campaign centered of corporate governance enhancements (17\%) and submit precatory shareholder proposals (21\%) as their primary campaign objective. The Treatment Group (board representation by Hedge Fund Activists) is very focused on either board representation or control (72\%) and almost $90 \%$ of the Treatment Group are 13D filers, which substantiates their credibility as motivated shareholders seeking to optimize value.

Table V.2 reports the governance and corporate defense profile of shareholder activist campaigns against Target Firms. Hedge Fund Activists are more likely to win board representation (53\%) versus Non-Hedge Fund Activists $(27 \%)$ with respect to the total number of board seats sought. Interestingly, Hedge Fund Activists that win board representation initiate a proxy contest $48 \%$ of the time, but only $14 \%$ of all proxy fights "go the distance" (i.e., to a shareholder vote). In sharp contrast, Target Firms of both Control Groups face a high likelihood of a proxy contest. Not surprisingly, Control Group I (Target Firms that "won" the proxy fight against Hedge Fund Activists) experience proxy fights 100\% of time, whereas, Control Group II (board representation by Non-Hedge Fund Activists) face proxy contests $77 \%$ of all interventions and the proxy fights will "go to a shareholder vote" $34 \%$ of the time. These results suggest that Target Firms are more likely to compromise and reach a settlement with a credible Hedge Fund 
Activist rather than expend a lot of time and resources fighting a campaign.

However, Target Firms are more reluctant to settle with a Non-hedge Fund Activist. This may be due to the lack of credibility of the activist and scarcity of potential resources to support an expensive campaign to completion.

Panel B of Table V.3 reports that 29\% of the Target Firms are sold within two years ex post an activist intervention. This is consistent with the findings of Greenwood and Schor (2009). However, it is important to note that only $18 \%$ of the Target Firms of the Treatment Group are sold or merged during the same time series. This substantiates my assertion that when a hedge fund activist seeks board representation they are more likely focused on other corporate initiatives to increase shareholder value rather than a "sale of the company" agenda. Not surprising, it is very common for Hedge Fund Activists to seek a replacement of the management team (primarily the CEO) to accomplish the Hedge Fund Activist agenda. Panel D of Table 5.4 reports that $44 \%$ of Target Firm CEOs are replaced within two years of the Hedge Fund activist joining the board compared to only $8 \%$ of Matched Firms during the same time period.

\section{V.A.2 Target Firm Characteristics: Vulnerability of Target Firms to Shareholder}

\section{Activism}

What type of companies do activist target? This is an important question to address. Tables V.5 through V.10 report the characteristics of Target Firms by all activists (both governance-focused and economically-motivated) and Hedge Fund and Non-hedge Fund activists either seeking board representation or other governance objectives. I compare and contrast the Target Firms to a set of Matched Firms, the target firms' same four-digit SIC industry and the CRSP/Compustat universe for the fiscal quarter ex ante the activist intervention. I use numerous financial metrics, governance measures and market-based data as variables.

Table V.11 reports the maximum likelihood probit regression with respect 
to the probability of a company being targeted by activist shareholders. The regressions cover all CRSP/Compustat firms from 1990 to 2014, which include both event and non-event observations. The dependent variable is a dummy variable equal to one if the Target Firm experiences an activist intervention during that specific month and zero for all non-activist firms. All Target Firm characteristics and variables are from various financial databases (including CRSP/Compustat, Thomson Reuters, NYSE, IBES, Risk Metrics, FactSet and Institutional Shareholder Services). I controlled for both industry and year fixed effects. See Section IV.B.1 for a detailed discussion with respect to fixed and random effects.

Tables V.6 and V.7 report the characteristics of Target Firms and of both Hedge Fund and Non-hedge Fund activism. I examine multiple firm specific attributes relative to Matched Firms, the Target Firm's same four-digit SIC industry and the CRSP/Compustat universe for the fiscal quarter ex ante the activist intervention. Matched Firms are in the same four-digit SIC industry and matched by market value and asset size using nearest neighbor propensity scoring methodology. Industry Adjusted are all companies in the same four-digit SIC industry. The results are consistent with the extant literature.

Following my classification methodology outlined in Section V on page 78, Table V.11 reports the results of the six activist intervention groups. The Event Date $\left(t_{0}\right)$ is either the the filing date of the $13 \mathrm{D}$ or the announcement of a campaign for All Activist, Hedge Fund Activist and Non-Hedge Fund Activist interventions. The Event Date $\left(t_{0}\right)$ with respect to the Treatment Group (Hedge Fund board representation) and the Control Group II (Non-hedge Fund board representation) is the board seat grant date and Event Date $\left(t_{0}\right)$ of Control Group I (Target Firms that "Won" Proxy Fight) is announcement date of the proxy fight results.

There are several important trends and factors to note. The negative coefficients with respect to Log Market Capitalization across all groups (except Non-hedge fund Board Representation) indicate that the Target Firms are generally 
smaller than the non-Target Firms with respect to market capitalization. This result is robust and consistent with many other studies including Klein and Zur (2009), Greenwood and Schor (2009), Clifford (2008), Boyson and Mooradian (2007), and Mietzner and Schweizer (2008). However, the coefficients relating to Log Assets are positive and significant. Suggesting that Target Firms are under-valued relative to comparable firms.

Next, I examine the coefficients with respect to valuation. The coefficients of $\mathrm{EV} / \operatorname{EBITDA}_{(t-3)}$, which is defined as ((book value of debt + book value of equity - cash) / LTM EBITDA) three-months prior to the Event Date, are negative and significant regarding Hedge Fund Activism and with respect to my Treatment Group. These results suggests that activist hedge funds attempt to identify undervalued companies where there is a potential to improve its operations. Furthermore, this substantiates that Hedge Fund Activists resemble "value investors." As a robustness check, I investigated several other valuation metrics, including Tobin's Q (Equation V.7).

Target Firms tend to be low-growth companies in terms of Revenue Growth, which is defined as the last-twelve-months (LTM) rolling sales trend. With respect to return measures, return on invested capital (ROIC) coefficients are negative and significant. Indicating that Hedge Fund Activists target companies for board representation that significantly under-perform their peers. These results differ from many other studies, including Brav et al (2008) that report positive ROA of Target Firms prior to an activist intervention.

The next set of variables concern capital structure. I examine the leverage profile (Debt / EBITDA) and Cash-to-Market Capitalization of the Target Firms of my Treatment Group and of both Control Groups. All of the coefficients relating to capital structure are statistically insignificant. Although Target Firms have lower share repurchase ratio relative to peers, they have a higher dividend yield (but insignificant). 
Next, I investigate both Institutional Ownership and Management/Board Ownership. Refer to Hypothesis 2 and 3 for a more detailed examination with respect to the correlation between Hedge Fund activism and nominal "corporate inside" ownership. Conventional wisdom suggests that Target Firms of hedge fund activism have higher institutional ownership and lower "inside" or management ownership. This ownership profile allows an activist to garner the support of the other institutional shareholders since the incumbent management team and board do not have sufficient ownership to "block" an activist attempt. The ownership coefficients in this model are statistically insignificant, however, there is qualitative evidence to support the conventional wisdom based on the signs of each ownership coefficient.

The next set of variables have not been reviewed by other scholars with respect to hedge fund activism. First, the coefficient with respect the Multiple Segments is a dummy variable if the target firm has more than one business unit that accounted for over $10 \%$ of sales prior to the event. The coefficients are positive and significant regarding Hedge Fund Activist interventions. This supports the general claim that Target Firms may have various business segments that are not core to the primary business.

Next, I examine Analyst Sell Recommendations, which is a dummy variable if greater than $50 \%$ if the research analysts had either a HOLD or SELL on the Target Firm prior to the event. Target Firms of Hedge Fund Activists had positive and statistically significant coefficients, indicating that the majority of the research analysts had a negative perception of the Target Firms prior an activist intervention. This substantiates that most Target Firms are either under-performing relative to peers or a have fundamental misalignment of value expectations.

Finally, I investigate a company's ability to manage investors expectations with respect to earnings. This is important, since it is a measure of the management team's ability and credibility vis-à-vis investors and the broader financial 
community. I use the following variable, Miss Earnings Estimate $(t-1)$, which is a dummy variable if the firm missed its most recently updated estimates reported by I/B/E/S by greater than 5\%. Target Firms of Hedge Fund Activists tend to miss its most recent earnings ex ante an activist intervention. This is economically significant since it reflects very poorly on a Target Firm to manage investor expectations. It supports the general narrative that a management team does not have a command or understanding of its business.

In summary, the characteristics of Target Firms of shareholder activism suggest that the type of activist (i.e., Hedge Fund versus Non-Hedge Fund) target different firms depending upon the activist's primary agenda. Hedge Fund Activists that are seeking board representation to monitor the firm more closely target slow growth companies experiencing significant under-performance relative to peers that need longer term operational solutions to improve shareholder returns rather than changing financial and capital distribution policies. 
This section tests empirically Hypothesis 1 discussed in Chapter III. The hypothesis is as follows: There is a significant positive correlation between hedge fund activism and an increase in the short-interest position experienced by Target Firms ex ante an activist intervention.

\section{V.B.1 Data}

Short Interest Ratio is defined as:

$$
\text { Short Interest Ratio }=\frac{\text { Shares Sold Short }}{\text { Total Shares Outstanding }}
$$

Short interest reflects the Target Firms short position on the last business day of the each month. The short interest data was collected via FT Interactive and Compustat which includes all positions from the New York Stock Exchange, American Stock Exchange, and NASDAQ. The data was aggregated and merged into my shareholder activist dataset using GVKEY and CUSIP firm identifiers. All potentially unbounded variables are winsorized at the $1 \%$ and $99 \%$ extremes.

\section{V.B.2 Empirical Results}

Figure V.2 illustrates an increasing trend with respect to a Target Firms short interest position ex ante a Hedge Fund Activist intervention. I compare all Target Firms to Matched Firms as well as to its industry peers. Next, I determine the statistical significance with respect to the change of the Target Firms' short interest ratio as a predictor of hedge fund activism. 
Figure V.2: Short Interest Position:

Target Firms vs. Matched Firms and Industry Composite Ex Ante and Ex Post Activism Event

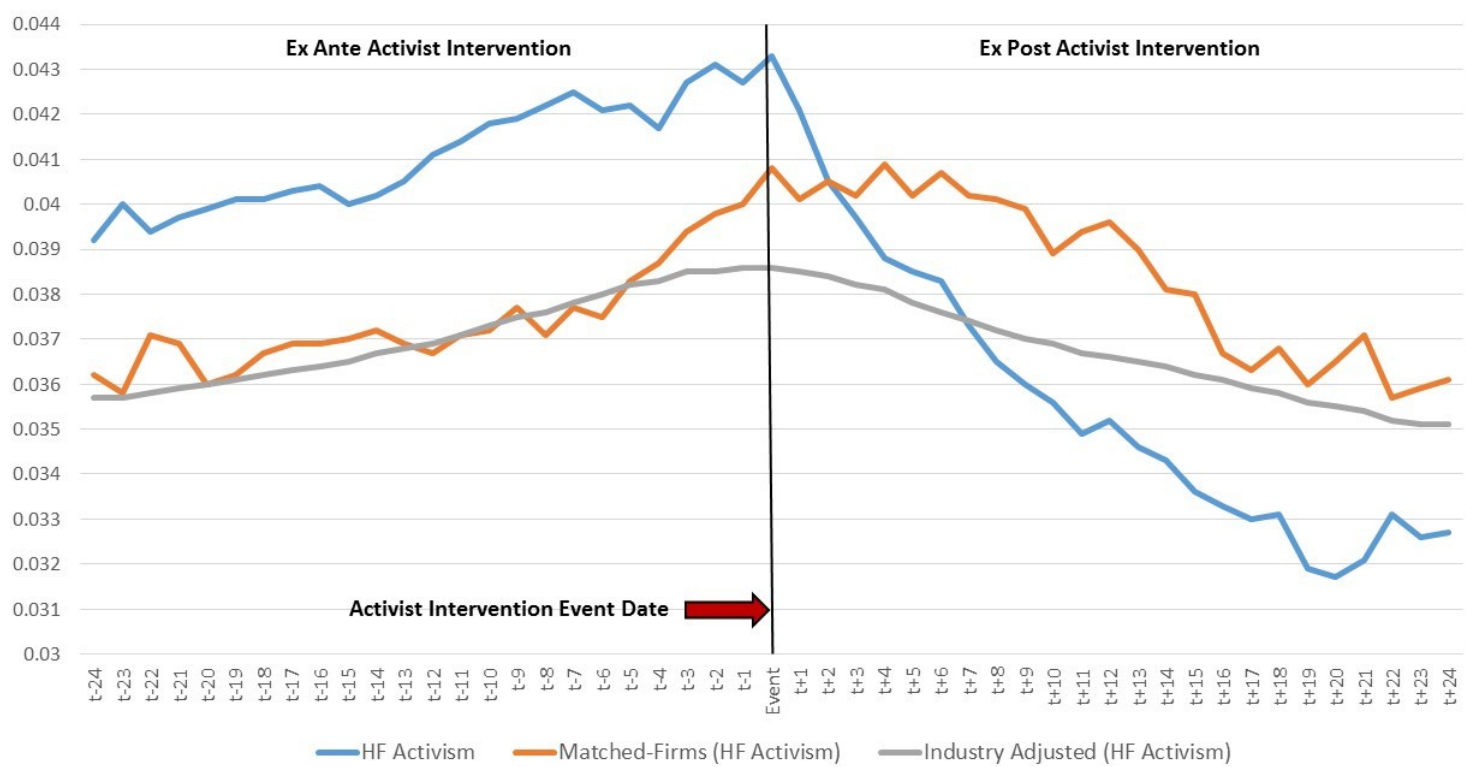

I conduct several empirical tests to determine statistical significance. First, I perform logistic and maximum likelihood probit regressions with respect to the change in the monthly short interest position of Target Firms of hedge fund and non-hedge fund activist interventions between t- 6 and $\mathrm{t}-1$ the event. I apply both industry and year fixed effects to each model. The logistic regression coefficients provide the change in the $\log$ (odds) of the outcome for a one unit increase in the predictor variable.

Table V.12 reports the $\log ($ odds) of the change in monthly short interest ratio position of Target Firms of both Hedge Fund (Model I and II) and Non-hedge Fund (Model III and IV) activist interventions. Model I reports a statistically significant likelihood of being targeted by a Hedge Fund activist when a Target Firm experiences a growth in its short interest ratio six months prior to an activist 
intervention. After controlling for both industry and year fixed effects (refer to Model II), the coefficient with respect to the short interest ratio is still positive, however, the is not statistically significant.

Both Model's III and IV report the change of a Target Firm's short interest ratio position six months ex ante an activist intervention by Non-hedge Fund activists. Although both coefficients of each model are negative, they are not statistically significant with or without fixed effects included in the models.

As a robustness check, I test empirically the change of the monthly short interest ratio using a multivariate probit regression that includes other variables that explain Hedge Fund activism (refer to V.11) to determine if statistical significance is maintained. Table V.13 reports the results of Hedge Fund Activist interventions and Non-Hedge Fund Activists with respect to the change in short interest ratio between t-6 through t-1. The Event Date $\left(t_{0}\right)$ is either the the filing date of the $13 \mathrm{D}$ or the announcement of a campaign for activist interventions. Model I (no fixed effects) and Model II (with fixed effects) report a positive coefficient with respect to an increasing change in the short interest ratio prior to the Hedge Fund announcing its campaign. However, the coefficients are not statistically significant. Both Model's III and IV, report the change in monthly short interest ratio position of Target Firms of Non-hedge Fund activist interventions. Both coefficients of each model are negative and statistically insignificant.

Although my hypothesis was predicated on a change (an increase) in the short interest position of Target Firms, I investigated the absolute magnitude of Target Firms short interest position. Table V.15 reports the $\log$ (odds) of the monthly short interest ratio position (not the marginal change) of Target Firms six months ex ante and ex post a Non-Hedge Fund Activist intervention. This implies an increase in the probability of hedge fund activism as the Target Firms short interest position meaningfully increases relative to its peers. At the time of the announcement of the event (Model VII), the $\log ($ odds) short interest ratio increases 
to 1.131 which suggests a $76 \%$ probability of hedge fund activism will occur or 3.1 times more likely. There is a sharp decline in a Target Firms short interest position following the announcement of a Hedge Fund Activist campaign. As a robustness check, I perform a probit regression (Table: B.1), which reports similar results as the logistic regression.

Table V.15 reports the $\log ($ odds) of the monthly short interest ratio position (not the marginal change) of Target Firms six months ex ante and ex post a Non-Hedge Fund Activist intervention. Although Models I through VII generate positive coefficients; they are not statistically significant. This suggests that the short position of Non-Hedge Fund activism is not statistically meaningful vis-à-vis Hedge Fund activism. Similar to the results of Hedge Fund activism, Non-hedge Fund related activism yields comparable negative results ex post the announcement. The probit regression model (Table: B.2) generated similar results as the logistic regression.

\section{V.B.3 Conclusion}

In summary, notwithstanding the statistically significant evidence to support an increase in the absolute magnitude of the Target Firms short interest position, there is no statistically significant support with respect to the marginal "change" of the Target Firm's short interest position ex ante a Hedge Fund intervention. Therefore, based on the empirical testing, I "fail" to reject the null hypothesis and I cannot conclude There is a significant positive correlation between Hedge Fund activism and an increase in the short-interest position experienced by Target Firms ex ante an activist intervention. 


\section{V.C Inside Ownership: The Cost of Agency (H2)}

This section empirically tests Hypothesis 2 discussed in Chapter III. The hypothesis is as follows: There is a significant positive correlation between Hedge Fund activism and nominal "corporate inside" ownership.

\section{V.C.1 Data}

The data on investor ownership are from the FactSet/LionShares database, which provides portfolio holdings of both institutional and individual investors. FactSet compiles ownership information from public filings by investors (such as 13-F filings, Form 3 and Form 4), company annual reports, stock exchanges, and regulatory agencies around the world. It is important to note that I define "corporate inside" ownership as equity securities beneficially owned by the company's officers and directors ${ }^{7}$. I exclude any institutions or noncompany officers and directors that are required to file with the SEC because they are beneficial owners of more than $10 \%$ of a class of the company's equity securities. Institutions are defined as professional money managers, including mutual fund companies, investment advisors, pension funds, bank trusts, and insurance companies. I combine FactSet/LionShares database with my hand-collected hedge fund activist database using GVKEY and CUSIP firm identifiers to merge the datasets.

\section{V.C.2 Empirical Results}

I conduct several empirical tests to determine statistical significance with respect to Hedge Fund activism and "corporate inside" ownership. First, I perform a logistic and probit regressions with respect to the quarterly inside ownership

\footnotetext{
${ }^{7}$ Corporate insiders - meaning a company's officers and directors, and any beneficial owners of more than $10 \%$ of a class of the company's equity securities registered under Section 12 of the Securities Exchange Act of 1934 - must file with the SEC a statement of ownership regarding those securities. On August 27, 2002, the SEC adopted rules and amendments to Section 16 of the Exchange Act, implementing the provisions of the Sarbanes-Oxley Act of 2002 that accelerated the deadline for filing most insider ownership reports.
} 
position of Target Firms three months (one fiscal quarter) ex ante a Hedge Fund activist intervention. I apply both industry and year fixed effects to each model. The logistic regression coefficients provide the change in the $\log$ (odds) of the outcome for a one unit increase in the predictor variable. Table V.16 reports the $\log$ (odds) of the quarterly "corporate inside" ownership of Target Firms one fiscal quarter ex ante an activist intervention. Models I and II demonstrate a negative (lower "corporate inside" ownership position) and statistically significant with respect to Hedge Fund activist interventions.

Next, I examine the "corporate inside" ownership of Non-hedge Fund activist interventions. Models III and IV report a statistically significant and negative or a lower inside ownership position with respect to Non-hedge Fund activist interventions. As a robustness check, I further test the "corporate inside" ownership using a multivariate probit regression model that includes other variables that explain Hedge Fund activism (refer to V.11) to determine if statistical significance is maintained.

Table V.17 reports the results of Hedge Fund Activist interventions and Non-Hedge Fund Activists with respect to "corporate inside" ownership $(t-3$ months $)$. The Event Date $\left(t_{0}\right)$ is either the the filing date of the $13 \mathrm{D}$ or the announcement of a campaign for activist interventions. Model I (no fixed effects) and Model II (with fixed effects) report a negative and statistically significant coefficient with respect to the "corporate inside" ownership $(t-3$ months $)$ prior to a Hedge Fund announcing its campaign. However, the coefficients are not statistically significant in both Model III and IV, which report the "corporate inside" ownership $(t-3$ months $)$ of Target Firms of Non-hedge Fund activist interventions.

\section{V.C.3 Conclusion}

The results of the empirical testing show a statistically meaningful correlation between Hedge Fund activism and nominal "corporate inside" ownership. 
After further stressing my hypothesis by using a multivariate probit regression model to include meaningful activist characteristics and contrast those results to Non-hedge Fund activist interventions, I report a statistically significant difference. Therefore, I reject the null hypothesis to conclude There is a significant positive correlation between hedge fund activism and nominal "corporate inside" ownership.

\section{V.D Activist Hedge Fund Intervention: Board Representation (H3)}

This section empirically tests Hypothesis 3 discussed in Chapter III. The hypothesis is as follows: There is a significant positive correlation between board representation of an activist hedge fund and nominal "corporate inside" ownership ex post the Board Seat Grant Date.

\section{V.D.1 Data}

Similar to the previous section, the data on investor ownership are from the FactSet/LionShares database, which provides portfolio holdings of both institutional and individual investors. FactSet compiles ownership information from public filings by investors (such as 13-F filings, Form 3 and Form 4), company annual reports, stock exchanges, and regulatory agencies around the world. It is important to note that I define "corporate inside" ownership as equity securities beneficially owned by the company's officers and directors ${ }^{7}$. I exclude any institutions or noncompany officers and directors that are required to file with the SEC because they are beneficial owners of more than $10 \%$ of a class of the company's equity securities. Institutions are defined as professional money managers, including mutual fund companies, investment advisors, pension funds,

\footnotetext{
${ }^{7}$ Corporate insiders - meaning a company's officers and directors, and any beneficial owners of more than $10 \%$ of a class of the company's equity securities registered under Section 12 of the Securities Exchange Act of 1934 - must file with the SEC a statement of ownership regarding those securities. On August 27, 2002, the SEC adopted rules and amendments to Section 16 of the Exchange Act, implementing the provisions of the Sarbanes-Oxley Act of 2002 that accelerated the deadline for filing most insider ownership reports.
} 
bank trusts, and insurance companies. I combine FactSet/LionShares database with my hand-collected hedge fund activist database using GVKEY and CUSIP firm identifiers to merge the datasets.

\section{V.D.2 Empirical Results}

Similar to Hypotheses 1 and 2, I conduct several empirical tests to determine statistical significance board representation of an Hedge Fund Activist ex post an intervention and nominal "corporate inside" ownership $(t-3$ months $)$. To address and mitigate the concern with respect to endogeneity, I compare the results of the Treatment Group ("Hedge Fund Board Representation") to both Control Groups. See Section V for a detailed discussion regarding the development of the Treatment and Control Groups. First, I perform a logistic and probit regressions with respect to the quarterly inside ownership position of Target Firms three months (one fiscal quarter) ex ante for the Treatment Group and both Control Groups (see Table V.18). The Treatment Group is all Target Firms that granted at least one board seat to a dissident Hedge Fund, Control Group I is defined as Target Firms of all proxy fights campaigns that did not result in board representation during the same period and Control Group II is comprised of Target Firms that granted at least one board seat to a Non-hedge Fund dissident shareholder during the same time period. I apply both industry and year fixed effects to each model. The logistic regression coefficients provide the change in the $\log$ (odds) of the outcome for a one unit increase in the predictor variable. Only Models I and II (the Treatment Group) demonstrate a statistically significant and negative or a lower "corporate inside" ownership $(t-3$ months $)$ position with respect to an activist interventions. The results for both Control Groups are not statistically significant.

Next, I stress further my model to test nominal "corporate inside" ownership $_{(t-3 \text { months })}$ by using a multivariate probit regression model that includes other variables that explain Hedge Fund activism (refer to V.11) to determine if 
statistical significance is maintained. Table V.19 reports the results of Hedge Fund board representation, Non-Hedge Fund board representation and Target Firms that did not receive the treatment effects of active monitoring by a dissident shareholder. Models I and II demonstrate a statistically significant negative or a lower "corporate inside" ownership $(t-3$ months $)$ position with respect to Hedge Fund board representation. Both Control Groups report statistically insignificant results with respect to inside ownership. Interestingly, Target Firms that "won" the proxy fight against Hedge Fund Activists report a positive a coefficient (statistically insignificant) with respect to "corporate inside" ownership using a robust model.

\section{V.D.3 Conclusion}

The results of the empirical testing show a statistically meaningful correlation between board representation of a Hedge Fund Activist and nominal "corporate inside" ownership $(t-3$ months $)$ ex post the Board Seat Grant Date. In contrast, Control Group I and Control Group II are not statistically significant and Target Firms that "won" the proxy fight against Hedge Fund Activists report positive coefficients with respect to "corporate inside" ownership. Therefore, I find statistically significant support to reject the null hypothesis to conclude There is a significant positive correlation between board representation of an activist hedge fund and nominal "corporate inside" ownership $(t-3$ months $)$ ex post the Board Seat Grant Date.

\section{V.E Short-term Active Hedge Fund Monitoring (H4)}

This section concerns Hypothesis 4, which reads as follows: There is a significant positive "initial" market reaction on the announcement date that a hedge fund dissident shareholder has been granted board representation to function as a disciplinary mechanism to monitor management. 


\section{V.E.1 Initial Market Reaction: The Model}

I examine the market reaction in the 3-day, 5-day, 7-day, 11-day and 21-day windows around the board seat grant date or announcement date via a press release of the results of the proxy contest. As noted in Section IV.C, I employ a standard event study methodology using the market model and a four-factor model to measure normal performance. I report the cumulative abnormal return $(C A R)$ for the 3-day, 5-day, 7-day, 11-day and 21-day windows around the board seat grant date or announcement date via a press release of the results of the proxy contest. The resulting time series of daily excess returns is regressed using the Market Model (Refer to IV.C.1.i) and the Fama-French (1993) three-factor Model and augmented by the momentum factor as suggested by Carhart (1997).

With respect to the Market Model, I assume that Target Firm returns are given by:

$$
R_{j t}=\alpha_{j}+\beta_{j} R_{m t}+\epsilon_{j t}
$$

The regression coefficients $\alpha_{i}$ and $\beta_{i}$ are estimated in an ordinary least squares (OLS) regression during the estimation period one year (255 trading days) prior to the event period (event days -305 through -50). As proxy for the return for the market portfolio $R_{m t}$, both the Center for Research on Security Prices (CRSP) value weighted index and the CRSP equal weighted index were used.

The Four Factor Model for abnormal return or (prediction error) for a Target Firm and its match $\left(j^{\text {th }}\right)$ on day $t$ is as follows:

$$
A_{j t}=R_{j t}-\left(\hat{\alpha}_{j}+\hat{\beta}_{j} R_{m t}+\hat{s}_{j} S M B_{t}+\hat{h}_{j} H M L_{t}+\hat{u}_{j} U M D_{t}\right)
$$

where the coefficients $\hat{\alpha}_{j}, \hat{\beta}_{j}, \hat{s}_{j}, \hat{h}_{j}$ and $\hat{u}_{j}$ are ordinary least squares estimates of $\alpha_{j}, \beta_{j}, s_{j} h_{j}$ and $u_{j}$. where $R_{j t}$ is the rate of return of the common 
stock of the $j^{\text {th }}$ firm on day $t ; R_{m t}$ is the rate of return of a market index on day $t$; $S M B_{t}$ is the average return on small market-capitalization portfolios minus the average return on three large market-capitalization portfolios; $H M L_{t}$ is the average return on two high book-to-market equity portfolios minus the average return on two low book-to-market equity portfolios; $U M D_{t}$ is the average return on two high prior return portfolios minus the average return on two low prior return portfolios. $\epsilon_{j t}$ is a random variable that, by construction, must have an expected value of zero, and is assumed to be uncorrelated with $R_{m t}$, uncorrelated with $R_{k t}$ for $k \neq j$, not autocorrelated, and homoskedastic. $\beta_{j}$ is a parameter that measures the sensitivity of $R_{j t}$ to the excess return on the market index; $s_{j}$ measures the sensitivity of $R_{j t}$ to the difference between small and large capitalization stock returns; $h_{j}$ measures the sensitivity of $R_{j t}$ to the difference between value and growth stock returns; and $u_{j}$ measures the sensitivity of $R_{j t}$ to the difference between high prior return stock returns and low prior return stock returns.

\section{V.E.2 Empirical Results}

In this section, I investigate the short-term market performance of Target and Matched Firms, with an event study using various performance windows. To conduct a comprehensive investigation, I replicate prior findings with respect to All Activist interventions, which include Hedge Fund and Non-Hedge Fund activism. The Event Date $\left(t_{0}\right)$ is either the the filing date of the $13 \mathrm{D}$ or the announcement of a campaign for All Activist, Hedge Fund and Non-Hedge Fund Interventions.

Tables E.1, E.2 and E.3, summarize the cumulative abnormal returns $(C A R s)$ for Target Firms and the Matched Firms for All Activism, Hedge Fund and Non-Hedge Fund Intervention classifications. CARs are calculated in excess of the equal and value weighted NYSE/AMEX/NASDAQ index from CRSP. Using a variety of event windows and multiple factor models, the difference in performance between Target Firms and Matched Firms is always positive and statistically 
significant. Using value weighted, Fama-French-Momentum Model during $(-10,+10)$ event window, the return in excess of the matched sample is approximately $5 \%$ for all Hedge Fund Interventions. The results are consistent with previous findings from Brav et al. (2008) and Boyson and Mooradian (2007).

Next, I investigate short-term market performance of Target and Matched Firms for the Treatment Group (Hedge Fund board representation) and both Control Groups (Target Firms that "Won" Proxy Fight and Non-hedge Fund board representation). The table below summarizes the $C A R s$ of Target Firms for the Treatment Group and Control Groups. More detailed results are presented in Tables V.20, V.21 and V.22, where I consider alternate announcement windows, market indices and Fama-French abnormal return model. The Event Date $\left(t_{0}\right)$ with respect to the Treatment Group (Hedge Fund board representation) and the Control Group II (Non-hedge Fund board representation) is the board seat grant date and Event Date $\left(t_{0}\right)$ of Control Group I (Target Firms that "Won" Proxy Fight) is announcement date of the proxy fight results. Using the Market Model (see Equation IV.C.1.i), Model I reports a statistically significant $C A R$ (at the $1 \%$ level) of $1.25 \%$ for the 5-day window for the Treatment Group. In contrast, Model II reports a statistically significant $C A R$ of $-1.26 \%$ for Control Group I, Target Firms that "Won" a Proxy Fight and were not receive the treatment effects of active board representation by a Hedge Fund. Control Group II report a CAR of $0.32 \%$ during $(-2,+2)$ event window. However, these results were not statistically significant.

\begin{tabular}{lccc}
\hline & $\begin{array}{c}\text { Model I } \\
\text { Treatment Group }\end{array}$ & $\begin{array}{c}\text { Model II } \\
\text { Control Group I }\end{array}$ & $\begin{array}{c}\text { Model III } \\
\text { Control Group II }\end{array}$ \\
\hline CAR $_{(-2,+2)}$ & $1.25 \%^{* * *}$ & $-1.26 \%^{* * *}$ & $0.32 \%$ \\
Observations & 538 & 114 & 107 \\
\hline
\end{tabular}

As noted earlier, Tables V.20, V.21 and V.22 provide additional analysis 
using a variety of event windows and multiple factor models, the difference in performance between Target Firms and Matched Firms with respect to the Treatment Group is always positive and statistically significant. Using value weighted, Fama-French-Momentum Model during $(-2,+2)$ event window, the CAR is $1.36 \%$ and statistically significant at the 1\% level. I sharp contrast, Control Group I (Target Firms that "Won" Proxy Fight) report a -1.24\% statistically significant CAR. Control Group II report a CAR of $0.32 \%$ during $(-2,+2)$ event window. However, these results were not statistically significant.

\section{V.E.3 Conclusion}

The results of this section indicate that activism is perceived favorably by the stock market, with strong evidence of short-term increases in a Target Firms' stock price. Within my dataset of sample Target Firms, certain types of activism are strongly positively related to short-term stock performance. Target Firms of Hedge Fund activists that seek board representation generate positive and statistically significant stock performance relative to Target Firms that did not receive the disciplinary effects of hedge fund monitoring. Therefore, I find statistically significant support to reject the null hypothesis to conclude that there is significant positive "initial" market reaction on the announcement date that a hedge fund dissident shareholder has been granted board representation to function as a disciplinary mechanism to monitor management.

Next, I examine longer-term performance of hedge fund activism. Since my sample covers a long time frame, I have a large number of completed activism events, allowing the assessment of the long-term impact of hedge fund activism. I will also address the question of whether hedge fund activism creates lasting value for Target Firms, which benefits all stockholders in the target rather than only investors in the hedge fund. 


\section{V.F Long-term Performance of Hedge Fund Monitoring (H5/H6)}

This section empirically tests Hypotheses 5 and 6 discussed in Chapter III. For reference, the hypotheses with respect to long-term performance of Hedge Fund monitoring is as follows:

Hypothesis 5: Hedge fund activism generates statistically significant long-term value for the Target Firms and its long-term shareholders when they function as a disciplinary mechanism to monitor management via board representation.

Hypothesis 6: Hedge fund activism generates statistically significant improvement in long-term operating performance for the Target Firms and its long-term share when they function as a disciplinary mechanism to monitor management via board representation.

\section{V.F.1 Buy-and-hold abnormal returns (BHAR) Approach}

In recent years, following the works of Ikenberry, Lakonishok, and Vermaelen (1995), Barber and Lyon (1997), and Lyon et al. (1999), the characteristic-based matching approach (also known as the buy-and-hold abnormal returns, $B H A R$ ) has been widely used. Mitchell and Stafford (2000) described $B H A R$ returns as "the average multiyear return from a strategy of investing in all firms that complete an event and selling at the end of a pre-specified holding period versus a comparable strategy using otherwise similar nonevent firms". An appealing feature of using $B H A R$ is that buy-and-hold returns better resemble investors' actual investment experience than periodic (monthly) rebalancing entailed in other approaches to measuring risk-adjusted performance. The joint-test problem remains in that any inference on the basis of $B H A R$ hinges on the validity of the assumption that event firms differ from the "otherwise similar nonevent firms" only in that they experience the event. I implicitly assume an expected return model in 
which the matched characteristics (e.g., size and book-to- market) perfectly proxy for the expected return on a security. Because corporate events themselves are unlikely to be random occurrences (i.e., they are unlikely to be exogenous with respect to past performance and expected returns), there is a danger that the event and nonevent samples differ systematically in their expected returns, notwithstanding the matching on certain firm characteristics. This makes matching on (unobservable) expected returns more difficult, especially in the case of event firms experiencing extreme prior performance.

Once a matching firm or portfolio is identified, BHAR calculation is straightforward. A T-month $B H A R$ for event firm $i$ is defined as:

$$
\operatorname{BHAR}_{i}(t, T)=\prod_{t=1 \text { toT }}\left(1+R_{i, t}\right)-\prod_{t=1 t o T}\left(1+R_{B, t}\right)
$$

Where $R_{B}$ is the return on either a nonevent firm that is matched to the event firm $i$ or a matched (benchmark) portfolio. If the researcher believes that the Carhart's (1997) four- factor model is an adequate description of expected returns, then firm-specific matching might entail identifying a nonevent firm that is closest to an event firm on the basis of firm size (i.e., market capitalization of equity), book-to-market ratio, and past 1- year return.

Alternatively, characteristic portfolio matching would identify the portfolio of all nonevent stocks that share the same quintile ranking on size, book-to-market, and momentum as the event firm (see Daniel, Grinblatt, Titman, \& Wermers, 1997, or Lyon, Barber, \& Tsai, 1997, for details of benchmark portfolio construction). The return on the matched portfolio is the benchmark portfolio return, $R_{B}$. For the sample of event firms, the mean $B H A R$ is calculated as the (equal or value-weighted) average of the individual firm BHARs. Additionally, I tested the significance of each coefficient using the following equation: 


$$
t_{B H A R}=\frac{\overline{B H A R_{i t}}}{\left(\sigma\left(B H A R_{i t}\right) / \sqrt{n}\right)}
$$

Total Shareholder Return $(T S R)$, which is a variation of $B H A R$, is a financial return measure commonly used in practice. I investigate $T S R$ as a robustness check with respect to $B H A R$ and find comparable results. Refer to Appendix F for more details regarding TSR.

\section{V.F.2 Empirical Results}

Following my classification methodology outlined in Section V on page 78, I construct six BHAR portfolios of stocks from 1994-2014. Figure V.8 presents buy-and-hold portfolio returns of Target Firms with respect to all All Activist interventions relative to Matched Firms. Over a 20 year period, the long-term returns of all shareholder activist interventions generated approximately $340 \%$ return, which out-performed a portfolio of similar firms during the same time period, which only achieved 270\%. Figure V.9 presents buy-and-hold portfolio returns of Target Firms with respect to all Hedge Fund Activist interventions relative to Matched Firms. As of December 31, 2014, the Hedge Fund Activist BHAR portfolio generated over 330\% return while the Matched Firm portfolio was a consistent laggard and yielded a $267 \%$ return over the same period. In contrast, Figure V.10 the Non-Hedge Fund Activist BHAR portfolio only generated over $192 \%$ return while its Matched Firm portfolio yielded an approximate $285 \%$ return over the same period.

Next, I examine the Treatment Group and compare the results to both Control Groups as well as a portfolio of Matched Firms for each grouping. Figure V.11 presents buy-and-hold portfolio returns of Target Firms of the Treatment Group relative to a portfolio of Matched Firms during the same time series. As of December 31, 2014, the long-term buy-and-hold portfolio returns to shareholders of the Treatment Group was over 260\%. Conversely, a portfolio of Matched Firms only 
generated $185 \%$ during the same time series.

Reviewing the buy-and-hold portfolio returns of the Control Groups, Figure V.12 and Figure V.13 present portfolio returns of Target Firms with respect to all Non-Hedge Fund board representation and Target Firms that defeated the hedge fund in a proxy fight. As of December 31, 2014, the Control Group I under-performed a portfolio of Matched Firms during the same period and Control Group II significantly under-performed its comparable Matched Firms. This substantiates that Hedge fund activism generates long-term value for the Target Firms and its long-term shareholders when they function as a disciplinary mechanism to monitor management via board representation.

Figure V.3 below provides a return comparison of an 18-year "Buy and Hold Portfolio" with respect to the Treatment Group and both Control Groups. During the time series, the Treatment Group generated over 280\%, whereas both Control Groups yielded approximately 225\%. These results are consistent with Hypothesis 5.

Figure V.3: Buy and Hold Portfolio Returns: Treatment Group vs. Control Groups

Buy and Hold Portfolio Hedge Fund Board Representation: Treatment Group vs Control Groups

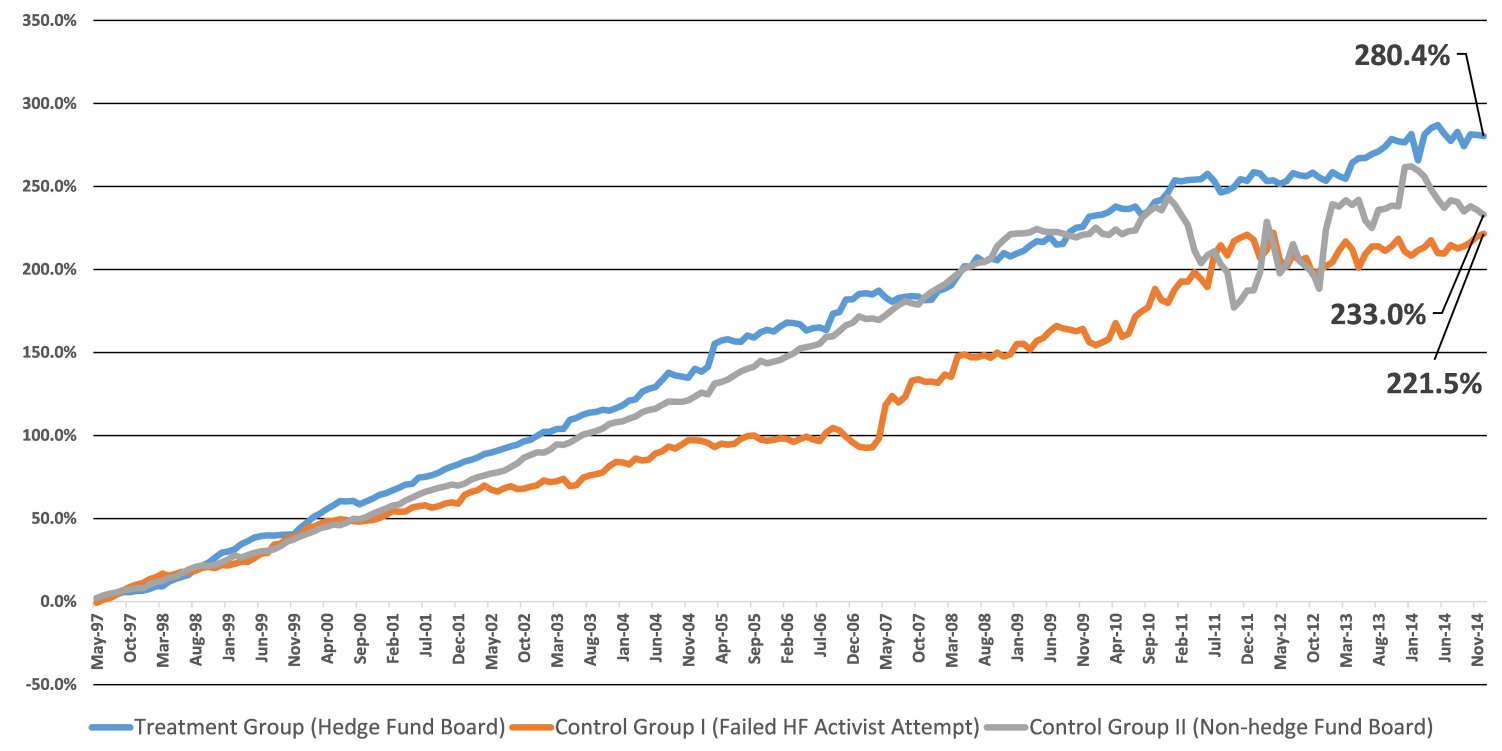


Next, I test the statistical significance of the 18-year "Buy and Hold Portfolio" with respect to the Treatment Group and both Control Groups. I test the equality of matched pairs with respect to the observations of the Treatment Group and both Control Groups using the Wilcoxon matched-pairs signed-ranks test (Wilcoxon 1945). The Wilcoxon signed rank sum test is the non-parametric version of a paired samples t-test. The null hypothesis is that both distributions are the same. Each Buy and Hold Portfolio consists of 212 monthly observations. The results of the Wilcoxon matched-pairs signed-ranks test, which are presented in Table ?? below, report a statistically significant difference at a p-value of 0.06 between Treatment Group and Control Group I (Target Firms that did not benefit from the disciplinary mechanism of active monitoring by a Hedge Fund via (board representation). There is no statistically significant difference between the Treatment Group and Control Group II.

\begin{tabular}{lccc}
\hline & Observations & z-test & p-value \\
\hline Treatment Group vs. Control Group I & 212 & 1.88 & 0.06 \\
Treatment Group vs. Control Group II & 212 & 1.04 & 0.30 \\
\hline
\end{tabular}

V.F.3 Calendar-time portfolio approach (Jensen's alpha)

The calendar-time portfolio or Jensen's alpha approach to estimating risk-adjusted abnormal performance is an alternative to the $B H A R$ calculation using a matched-firm approach to risk adjustment. Jaffe (1974) and Mandelker (1974) introduced a calendar time methodology to the financial-economics literature, and it has since been advocated by many, including Fama (1998), Mitchell and Stafford (2000), and Brav and Gompers (1997).

The distinguishing feature of the most recent variants of the approach is to calculate calendar-time portfolio returns for firms experiencing an event, and 
calibrate whether they are abnormal in a multifactor regression. The estimated intercept from the regression of portfolio returns against factor returns is the postevent abnormal performance of the sample of event firms.

I implement Calendar-time Portfolio Abnormal Returns (Jensen's Alpha) for a 5-year period during Ex Post an activist intervention. In each calendar month over the entire sample period, a portfolio was constructed comprising all firms experiencing the event within the previous month. Because the number of event firms is not uniformly distributed over the sample period, the number of firms included in a portfolio is not constant through time. As a result, some new firms are added each month, and some firms exit each month. Accordingly, the portfolios are rebalanced each month, and an equal or value-weighted portfolio excess return is calculated. The resulting time series of monthly excess returns is regressed on the Fama-French (1993) three-factor Model as follows:

- $R_{j t}$ is the equal or value-weighted return for calendar month $t$ for the portfolio of event firms that experienced the event within previous $\mathrm{T}$ years,

- $R_{f t}$ is the risk-free rate,

- $R_{M t}$ is the return on the CRSP value-weight market portfolio,

- $S M B_{t}$, is the difference between the return on the portfolio of "small" stocks and "big" stocks;

- $H M L_{t}$ is the difference between the return a portfolio of "high" and "low" book-to-market stocks;

- $\alpha$ is the average monthly abnormal return on a portfolio of firms over the t-month post-event period,

- $\beta$ is the beta (the sensitivities) of the event portfolio to the three factors.

I report the long-term abnormal returns associated of Target Firms of all activist interventions as well as report regression estimates and level of significance from both equal-weighted and value-weighted calendar-time portfolio regressions. The 
portfolio holding period was determined based on actual trading days and indicates the holding period in years relative to the date that the board seat(s) was granted. For example, the portfolio with holding period [Event +1$]$, will continually add Target Firms that have added an activist/dissident shareholder to their respective board during the year from the date the seat was granted. The portfolio will hold these firms until the earlier of December 31, 2014, a delisting date as a result of a Chapter 11 filing or a sale/merger. Coefficients marked with *** are significant at the $1 \%$ level, ${ }^{* *}$ at the $5 \%$ level and $*$ at the $10 \%$ level. The regression takes the form:

$$
R_{j t}-R_{f t}=\alpha+\beta p, R_{M}-R_{f t}+\beta p, S M B_{t},+\beta p, H M L_{t}+\epsilon_{j t}
$$

Inferences about the abnormal performance are made on the basis of the estimated alpha and its statistical significance. Because alpha is the average monthly abnormal performance over the T-month post-event period, it can be used to calculate annualized post-event abnormal performance. I reported the long-term abnormal returns associated with firms that granted at least one board seat to an activist/dissident shareholder as well as report regression estimates and t-statistics from value-weighted calendar-time portfolio regressions. The portfolio holding period was determined based on actual trading days and indicates the holding period in years relative to the date that the board seat(s) was granted. For example, the portfolio with holding period [Event +1$]$, will continually add Target Firms that have added an activist/dissident shareholder to their respective board during the year from the date the seat was granted. The portfolio will hold these firms until the earlier of December 31, 2014, a delisting date as a result of a Chapter 11 filing or a sale/merger.

\section{V.F.4 Empirical Results}

Following my classification methodology outlined in Section V, I construct six calendar-time portfolios (Jensen-alpha approach) to estimate risk-adjusted 
abnormal performance. In this section, I investigate the long-run market performance of Target and Matched Firms using calendar-time portfolios for all groups. I discuss in detail my findings of the Treatment Group (Hedge Fund Board Representation) relative to both Control Groups and provide the results for All Activist, Hedge Fund and Non-Hedge Fund Interventions in the Appendix F.

Tables F.1, F.2 and F.3, summarize the cumulative abnormal returns $(C A R s)$, the precision-weighted cumulative average abnormal returns (PWCAAR) (Equation IV.33) and the calendar-time portfolio cumulative abnormal returns (CTCARs) for Target Firms and the Matched Firms for All Activism, Hedge Fund and Non-Hedge Fund Intervention classifications. CARs, PWCAARs and $C T C A R s$ are calculated in excess of the equal and value weighted NYSE/AMEX/NASDAQ index from CRSP. Using the three-factor model (Equation V.6), the difference in performance between Target Firms and Matched Firms is always positive and statistically significant. Examining Table F.2, which reports the results from Hedge Fund Activist Interventions, I find that the Target Firms of Hedge Fund activism generate $17.8 \%$ CAR, 31.8\% PWCAAR and $27.5 \%$ CTCAR five years ex post the activist intervention. In contrast, the Matched Firms report a statistically significant negative returns during the same time period. This substantiates that Hedge Fund Activists generate long-term value for Target Firms and its long-term shareholders.

Next, I investigate long-run market performance of Target and Matched Firms for the Treatment Group (Hedge Fund Board Representation) and both Control Groups (Target Firms that "Won" Proxy Fight and Non-hedge Fund Board Representation). Tables V.23, V.24 and V.25, report the CARs, PWCAARs and CTCARs for Target Firms and the Matched Firms for the Treatment Group and Control Groups using equal and value weighted market indices.

The table below summarizes the calendar-time portfolio abnormal returns using CTCARs and an equally weighted index. Similar to the other models, 
CTCARs are calculated in excess of the equal weighted NYSE/AMEX/NASDAQ index from CRSP. Using a variety of event windows and a three-factor model, the Target Firms of the Treatment Group generate positive and statistically significant abnormal returns ex post the board seat grant date. In contrast, Control Group I reports negative abnormal returns that are not statistically significant. Consistent with my other findings, Control Group II results are positive and significant in certain event windows. This is additional support to substantiate that dissident shareholders generate long-term value for the Target Firms and its long-term shareholders when they function as a disciplinary mechanism to monitor management via board representation.

Next, I test statistically for the difference between the calendar-time portfolio abnormal returns means of the Treatment Group relative to both Control Groups. The test procedure I used is a two-sample t-test. The null hypothesis states that there is no difference between the two means. The table below reports a positive and statistically significant difference between Treatment Group and Control Group I (Target Firms that did not benefit from the disciplinary mechanism of active monitoring by a Hedge Fund via board representation). With the exception of Event +2 , there is negative and statistically significant difference between the Treatment Group and Control Group II. Essentially, Target Firms benefited from board representation of both Hedge Fund and Non-Hedge Fund activists. 


\begin{tabular}{lccccc}
\hline & {$[$ Event +1$]$} & {$[$ Event +2$]$} & {$[$ Event +3$]$} & {$[$ Event +4$]$} & {$[$ Event +5$]$} \\
\hline Abnormal Return (Jensen's $\alpha$ ) & & & & & \\
Treatment Group & $8.84^{* * *}$ & $14.76^{* * *}$ & $19.85^{* * *}$ & $16.36^{* * *}$ & $11.63^{* * *}$ \\
Control Group I & -1.11 & -6.40 & -5.61 & 14.76 & -13.22 \\
Control Group II & 11.47 & 14.78 & $22.96^{*}$ & $26.91^{*}$ & $40.23^{* *}$ \\
\hline Differences (t-test) & & & & & \\
Treatment Group vs. Control Group I & $9.95^{* * *}$ & $21.16^{* * *}$ & $25.46^{* * *}$ & $1.6^{* *}$ & $24.85^{* * *}$ \\
Treatment Group vs. Control Group II & $-2.63^{* * *}$ & -0.02 & $-3.11^{* * *}$ & $-10.55^{* * *}$ & $-28.60^{* * *}$ \\
\hline
\end{tabular}

\section{V.F.5 Conclusion}

In summary, the foregoing results suggest that Hedge Fund Activist seeking board representation generate positive "alpha" $(\alpha)$ around event time for Target Firms and the positive abnormal returns do not revert up to a five years ex post the board seat grant date. Therefore, the evidence clearly refutes the market over-reaction hypothesis and supports the hypothesis (H5) that Hedge Fund Activism creates long-term value for Target Firms and its long-term shareholders when they function as a disciplinary mechanism to monitor management via board representation.

\section{V.F.6 Long-term Stock Returns: Individual Firm Regressions}

I conduct a more formal long-term return analysis using individual firm-level regressions around the Event Date. For this study, I examine long-term stock returns for each individual Target Firm that granted at least one board seat to a Hedge Fund Activist (the Treatment Group) and contrast those results with both Control Groups. To identify whether stock returns are abnormally low or high, I use a benchmark for comparative purposes. Such benchmarks of comparison are provided by the capital asset pricing model (CAPM), the Fama-French three factor 
model, and the Fama-French-Carhart four factor asset-pricing models. These models provide a prediction of the return that normally would be expected for a given security during a given period and, therefore, enable researchers to identifying abnormal returns.

I use the Fama-French three factor model to estimate an "alpha," $(\alpha)$ the average excess return that is not explained by the three market-wide factors identified by Fama and French (1993). I estimate the excess return on the market as the value-weight return of all CRSP firms incorporated in the US and listed on the NYSE, AMEX, or NASDAQ that have a CRSP share code of 10 or 11 at the beginning of month $t$, good shares and price data at the beginning of $t$, and good return data for $\mathrm{t}$ minus the 1-month Treasury bill rate from Ibbotson Associates. Specifically, I estimate for each firm $i$ an alpha $(\alpha)$ using the following regression:

$$
r_{i t}-r_{f}=\alpha_{i}+\beta_{i 1} R M R F_{t}+\beta_{i 2} S M B_{t}+\beta_{i 3} H M L_{t}+E_{i t}
$$

The Fama-French factors are constructed using the six value-weight portfolios formed on size and book-to-market. SMB (Small Minus Big) is the average return on the three small portfolios minus the average return on the three big portfolios. HML (High Minus Low) is the average return on the two value portfolios minus the average return on the two growth portfolios, and I estimate the excess return on the market similar to the methodology used in the capital asset pricing model.

For each of the Target Firms in the Treatment Group, I estimate a monthly alpha, or abnormal return, for a 5-year period prior to date the board seat was granted. In addition, I estimate monthly alphas for a 5-year period (annually) following one day post the board seat grant date. To the extent that Target Firms delist from the sample, I incorporate the financial returns up to the delisting date. Additionally, to the extent Target Firms file for Chapter 11 bankruptcy protection, I incorporate the returns from the firm up to the date of filing for bankruptcy. 
For each of the periods, I provide the average alpha for all the firms in this sample. I also indicate the statistical significance of this study's results; however, as is now well known in the financial economics literature, the standard error of the average of the estimated alphas understates the unobserved variability in performance, and the reported t-stats should thus be treated as merely suggestive (Fama, 1998).

\section{V.F.7 Empirical Results}

I construct three equally-weighted regressions to examine the long-term market performance of individual Target Firms. The results are reported in Table V.26. Panel A in Table V.26 reports the alpha $(\alpha)$ for the Treatment Group. The Target Firms report statistically significant, negative alphas ex ante board representation by an activist Hedge Fund. Ex post the board seat grant date, there is a noticeable improvement in stock returns in the event windows after the first year. Notwithstanding the slightly negative alpha in Year One, the Target Firms improved significantly relative to the prior year. These findings are consistent and robust when using other multi-factor models.

In contrast, Control Group I (Target Firms that "Won" Proxy Fight), which are reported in Panel $\mathrm{B}$, generate insignificant negative returns $(\alpha)$ throughout the time series. Consistent with my earlier findings in $B H A R$ and calendar-time portfolio testing, Control Group II (Non-hedge Fund Board Representation) report insignificant positive returns $(\alpha)$ ex post the board seat grant date by a Non-Hedge Fund activist. Notwithstanding that Control Group II generates greater returns, the Target Firms of the Treatment Group experience positive abnormal returns consistent with results of Brav et al. (2008) which substantiates that hedge funds generate long-term value for the Target Firms and its long-term shareholders when they function as a disciplinary mechanism to monitor management via board representation. 
In summary, the foregoing results of statistically significant findings in $B H A R$ and calendar-time portfolio testing, economically significant (statistically insignificant ex post) individual firm regressions and the evidence in the extant literature suggest that the long term returns are positive for Target Firms of Hedge Fund activists that seek board representation, and the positive abnormal returns do not revert up to a five years ex post the board seat grant date. Therefore, the evidence clearly refutes the market over-reaction hypothesis and supports the hypothesis (H5) that Hedge Fund activism creates long-term value for the Target Firms and its long-term shareholders when they function as a disciplinary mechanism to monitor management via board representation.

\section{V.F.8 Measuring Cross-Sectional Firm Operating Performance}

If Hedge Fund activists create shareholder value by intervening in the Target Firms, one would expect improvements in terms of operating performance, capital structure and corporate governance after the intervention. This section reviews the evidence with respect to the change in Target Firms post-targeting along various financial measures of corporate policy and performance.

I examine numerous financial metrics and corporate governance attributes for robustness (see Appendix G), including the following measures of firm performance: Revenue growth, Tobin's Q, return on assets (ROA) and return on invested capital (ROIC), which are the most widely used and accepted firm performance proxies. Additionally, because the conventional wisdom and the common narrative is that shareholder activists negatively affect long-term operating performance and decrease capital investment, I measure operating margin (EBIT/Sales) and capital investment policy (CAPEX/Assets). Additionally, I report the industry adjusted differences for all financial metrics of the Treatment Group and the Control Groups as well as compare the results to similar Matched Firms (firms in the same 4-digit SIC industry). 
Following my classification methodology outlined in Section V, I examine the operating metrics five years ex ante and ex post the activist intervention. The Event Date $\left(t_{0}\right)$ is either the the filing date of the 13D or the announcement of a campaign for All Activist, Hedge Fund and Non-Hedge Fund interventions. The Event Date $\left(t_{0}\right)$ with respect to the Treatment Group (Hedge Fund Board Representation) and the Control Group II (Non-hedge Fund Board Representation) is the board seat grant date and Event Date $\left(t_{0}\right)$ of Control Group I (Target Firms that "Won" Proxy Fight) is announcement date of the proxy fight results.

The tables in Appendix G detail the cross-sectional financial performance and governance metrics with respect to all six groups. Since my study is primarily concerned with Hedge Fund Board Representation, in this section I will discuss the long-run operational performance of Target and Matched Firms for the Treatment Group and both Control Groups. To keep the discussion manageable, I focus on a few key variables. The results are presented in Tables V.27, V.28 and V.29.

Figure V.4 illustrates the log linear revenue growth of the Treatment Group and both Control Groups. Tables V.27, V.28 and V.29 report that all groups experience a significant decrease in revenue ex ante an activist intervention, which is consistent with the under-performance hypothesis of Target Firms. The Target Firms of the Treatment Group experience a 4.2\% CAGR [Event +1, Event +5] ex post the board seat grant date compared to $3.4 \%$ CAGR ex ante the Hedge Fund activist intervention. This improvement compares very favorably relative to both Control Groups that report an approximate 2.4\% CAGR during the same time series and less than the Target Firms experienced prior to the intervention. The log linear revenue growth trend for the Treatment Group yields an $R^{2}$ of $89 \%$.

Table G.37 reports the results of revenue growth for the Treatment Group Target Firms relative to Match Firms and industry peers. The Target Firms report a negative and statistically significant difference between the means of Match Firms and an industry composite with respect to a sales growth ex ante an intervention. 
Figure V.4: Long-term Operating Performance: Log Linear Revenue Growth

\section{Long-term Operating Performance} Log Linear Revenue Growth: Treatment Group vs Control Groups

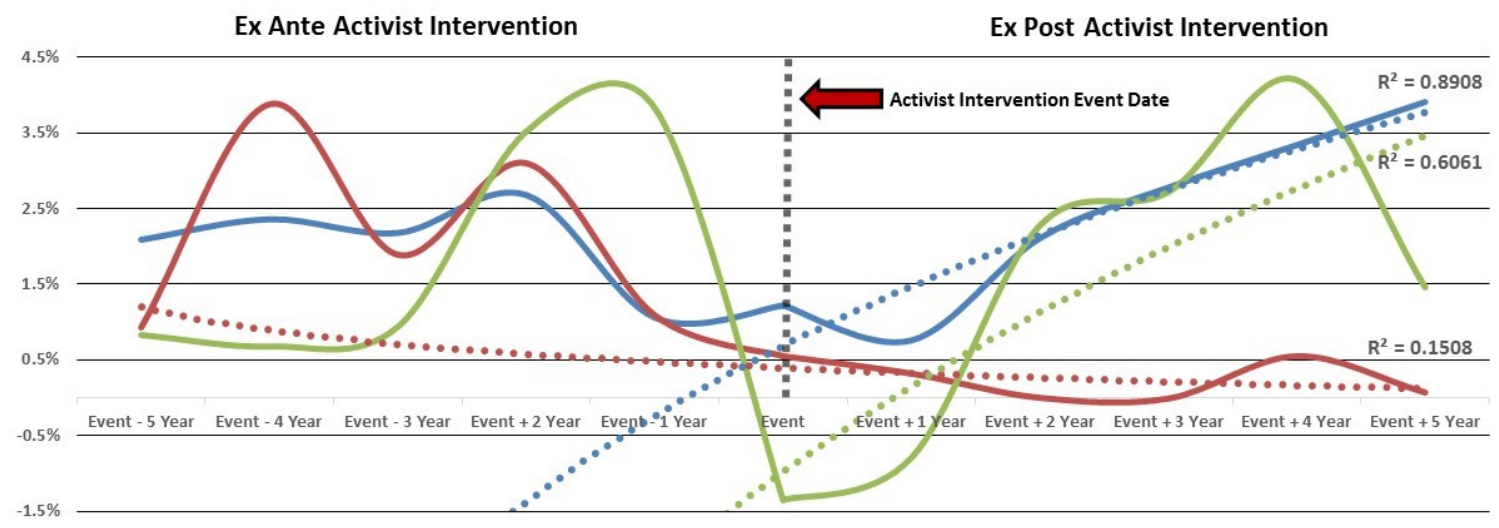

... . Log. (Treatment Group Ex Post Event) … . Log. (Control Group I Ex Post Event) … L Log. (Control Group II Ex Post Event)

Tobin's Q is named after the Nobel Prize winner James Tobin and is calculated as the ratio of market value to asset replacement value (Yermack, 1996). The formula for Tobin's $\mathrm{Q}$ is as follows:

$$
\text { Tobin's } Q=\frac{\text { Market value of assets }}{\text { Replacement cost of assets }}
$$

As an approximation, the market value of assets is computed as market value of equity plus book value of assets minus book value of equity, following Brown and Caylor (2006). The asset replacement value is taken as the book value of assets. A Tobin's Q ratio greater than 1 indicates the good quality of a firm's investment decisions: It has invested in positive NPV investment projects rather than in negative NPV investment projects, and the returns meet or exceed expectations. In contrast, Tobin's Q lower than 1 suggests that the firm did not even earn its returns expected by investors from the investment projects to cover the cost of capital.

Figure V.5 reports the Q Ratio of the Treatment Group and both Control Groups. Consistent with the extant literature (Brav et al, 2008), I find that Target Firms' performance for all groups deteriorates prior to an activist intervention. The 
mean Q Ratio for the Treatment Group declines significantly from 2.1 five years prior to the Event date to 1.7 on the date the board seat is granted to a dissident Hedge Fund. The foregoing results were statistically significant at the $1 \%$ level. The mean Q Ratio for the Treatment Group increased from 1.7 to 2.2 five years ex post the board seat grant date, reflecting a $32.5 \%$ increase. During the same period, the Control Group experienced a similar improvement in its Q Ratio.

\section{Figure V.5: Long-term Operating Performance: Tobin's Q}

Tobin's Q: Treatment Group vs Control Groups

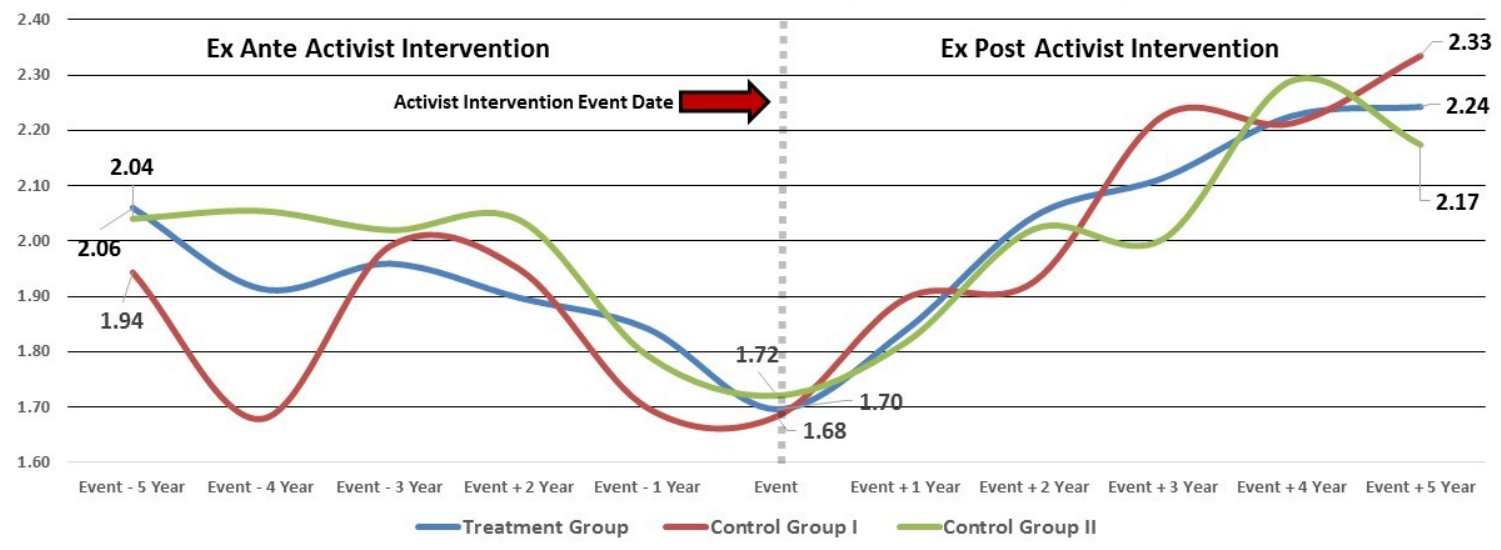

Table G.38 reports the results of the Treatment Group Target Firms' Q Ratio vis-à-vis to Match Firms and an industry composite. The Target Firms report a negative and statistically significant difference between means of Match Firms and industry peers prior to an activist intervention. The Treatment Group reports a positive and statistically insignificant difference between Target Firms and Match Firms during Year 3 ex post the board seat grant date.

Return on assets is calculated as earnings before interest and taxes (EBIT) multiplied by the reciprocal of the effective rate divided by the average of total assets for the year. Return on assets (ROA) indicates how management's efficiency in using its assets to generate earnings. Calculated by dividing a company's annual earnings by its total assets, ROA is generally displayed as a percentage. Sometimes 
this figure is referred to as return on investment, an indicator of how a company's profitability:

$$
\text { Return on Assets }=\frac{(E B I T *(1-\text { tax rate }))}{((\text { Total Assets }(t)+\operatorname{Total} A \operatorname{ssets}(t-1) / 2)}
$$

Figure V.6 reports the ROA of the Treatment Group and both Control Groups. I find that Target Firms' performance for the Treatment Group declines significantly from $7.1 \%$ five years prior to the Event date to $3.3 \%$ on the date the board seat is granted to a Hedge Fund dissident. The foregoing results were statistically significant at the $1 \%$ level. This is consistent with the findings of Brav et al, (2008). All Target Firms experience a dramatic decline in ROA one year prior to the Event date. Which substantiates a intervention from dissident shareholders. The Target Firms of the Treatment Group report a $88 \%$ increase in ROA five years ex post the board seat grant date. In contrast, the Target Firms that did not grant a board seat to a dissident shareholder (Control Group I), experienced a $10 \%$ decline in ROA during the same time series. 
Figure V.6: Long-term Operating Performance: ROA

\section{Long-term Operating Performance ROA: Treatment Group vs Control Groups}

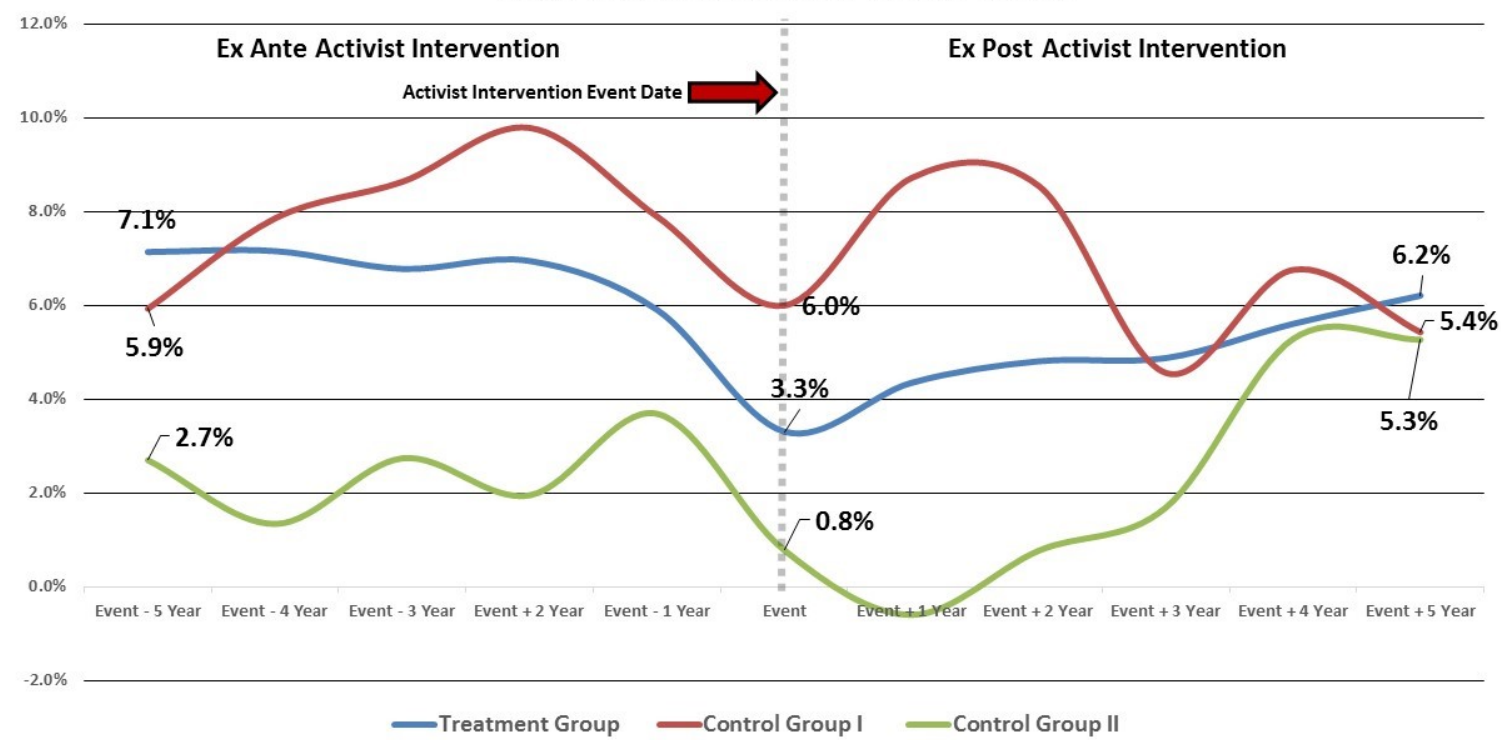

Table G.38 reports the results of ROA for the Treatment Group Target Firms vis-à-vis to Match Firms and an industry composite. The Target Firms report a negative and statistically significant difference between means of Match Firms and industry peers prior to an activist intervention. Year 5 ex post the board seat grant date, the Target Firms of Treatment Group report a positive and statistically significant difference between Target Firms and industry peers as well as a positive and statistically insignificant median difference between Target Firms and Match Firms.

Return on invested capital (ROIC) is calculated as earnings before interest and taxes (EBIT) multiplied by the reciprocal of the effective rate divided by the average of total debt and total common equity for the Target Firms. ROIC calculation is used to assess a firm's efficiency at allocating the capital under its control to profitable investments. The return on invested capital measure gives a sense of how well a company is using its available cash to generate returns. The calculation is as follows: 


$$
R O I C=\frac{(E B I T *(1-\text { tax rate }))}{((\text { Debt }+ \text { Pref. }+ \text { Common })(t))+((\text { Debt }+ \text { Pref. }+ \text { Common })(t-1)) / 2)}
$$

Tables V.27, V.28 and V.29 report that all groups experience a decline in ROIC one year ex ante the Event date. However, both the Treatment Group and Control Group II experience a significant deterioration in ROIC from [Event -5] to the Event date. Five years ex post the board seat grant date, the Treatment Group report a $100 \%$ increase in $\mathrm{ROIC}$ during the review period.

Table G.39 reports the results of ROIC for the Treatment Group Target Firms relative to Match Firms and industry peers. The Target Firms report a negative and statistically significant difference between means of Match Firms and industry peers prior to an activist intervention. Year 5 ex post the board seat grant date, the Target Firms of Treatment Group report a positive and statistically insignificant difference between Target Firms and Matched Firms. However, Target Firms report a negative and statistically significant difference in means relative to its industry peers.

Operating margin is calculated as earnings before interest, taxes, depreciation and amortization divided by total revenue generated by the Target Firms. A ratio is used to measure a company's pricing strategy and operating efficiency. Operating margin is a measurement of what proportion of a company's revenue remains after paying for variable costs of production such as wages, raw materials, and so forth and provides an understanding of how much a company makes (before interest and taxes) on each dollar of sales. The calculation is as follows:

$$
\text { Operating Margin }=\frac{E B I T D A}{\text { Sales }}
$$

A frequently invoked claim by opponents of hedge fund activism is that 
activist interventions lead to deteriorating operating performance of the Target Firms ex post the activist event. I test empirically the operating performance of Target Firms of the groups. Figure V.7 illustrates the median operating margin of the Treatment Group and both Control Groups. Tables V.27, V.28 and V.29 report the mean operating margin for all Target Firms. I find that all groups experience a dramatic decrease in performance during from [Event -2] to the Event date. which is consistent with the under-performance hypothesis of Target Firms and the extant literature. Additionally, I find that Target Firms' operating performance steadily improves for all groups ex post the Event date.

Figure V.7: Long-term Operating Performance: Median Operating Margin Operating Margin: Treatment Group vs Control Groups

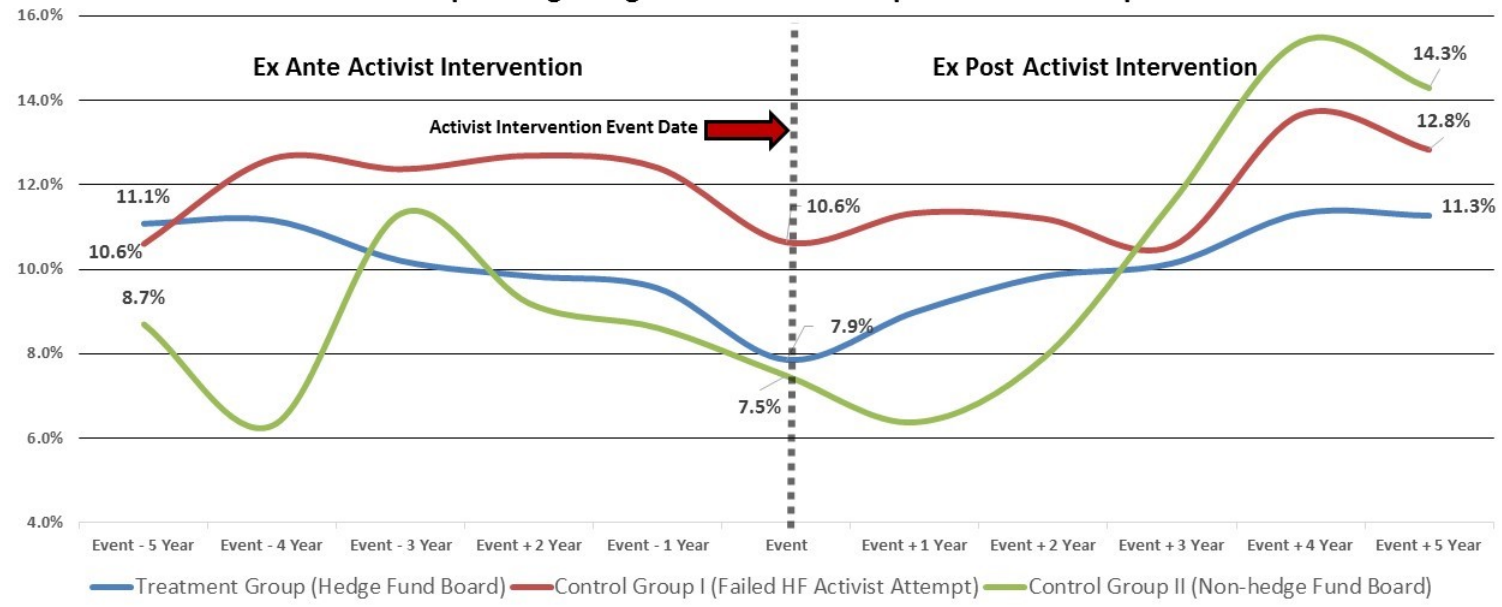

Table G.37 reports the results of operating margin for the Treatment Group Target Firms relative to Match Firms and industry peers. The Target Firms report a positve and statistically significant difference between the means of its industry peers five years ex post the board seat grant date, which support Hypothesis 6 .

Capital expenditures relative to sales (CAPEX / Assets) is calculated as total capital expenditures divided by the firm's total assets. This metric provides measure of how much the firm is investing for future growth opportunities as well as maintaining existing fixed assets. The calculation is as follows: 


$$
\text { CAPEX-to-Assets }=\frac{\text { Total Capital Expenditures }}{\text { Total Assets }}
$$

Tables V.27, V.28 and V.29 report the capital investment policy (CAPEX/Assets) of the Target Firms for the Treatment Group and for both the Control Groups. All groups experience a decline of fixed asset investment leading into the Event. During the treatment period, Target Firms that granted at least one board seat to Hedge Fund activists, increased capital spending to levels consistent with the capital policy of the firms prior to the intervention. A commonly invoked claim by opponents of hedge fund activism is that activist interventions lead to significant decrease in capital spending. I find no evidence to support that claim. Table G.41 reports the results of fixed asset investment for the Treatment Group Target Firms relative to Match Firms and industry peers. The Target Firms report a negative and statistically significant difference between the means of its industry peers five and Matched Firms ex ante the board seat grant date. Although, the Target Firms resume a capital spending policy consistent with prior levels ex post the Hedge Fund board seat grant date, although those differences are statistically insignificant.

\section{V.F.9 Conclusion}

In summary, I find that Target Firms significantly under-perform Matched Firms and a composite of industry peers ex ante a Hedge Fund Activist obtaining at least one board seat. These findings are consistent with previous literature. However, these Target Firms demonstrate a dramatic improvement post intervention, up to five years ex post the board seat grant date. Many of these results are statistically significant. I contrast these findings to both Control Groups. The results indicate that Hedge Fund activists that seek board representation have been successful in improving operating performance, increasing payouts, enhancing

corporate governance and reducing agency costs of Target Firms. More importantly, 
I find no evidence that there is a reversal in operating performance. Overall, the Treatment Group experiences better operating performance five years ex post board representation then Control Group I. 
Figure V.1: Data Collection Methodology

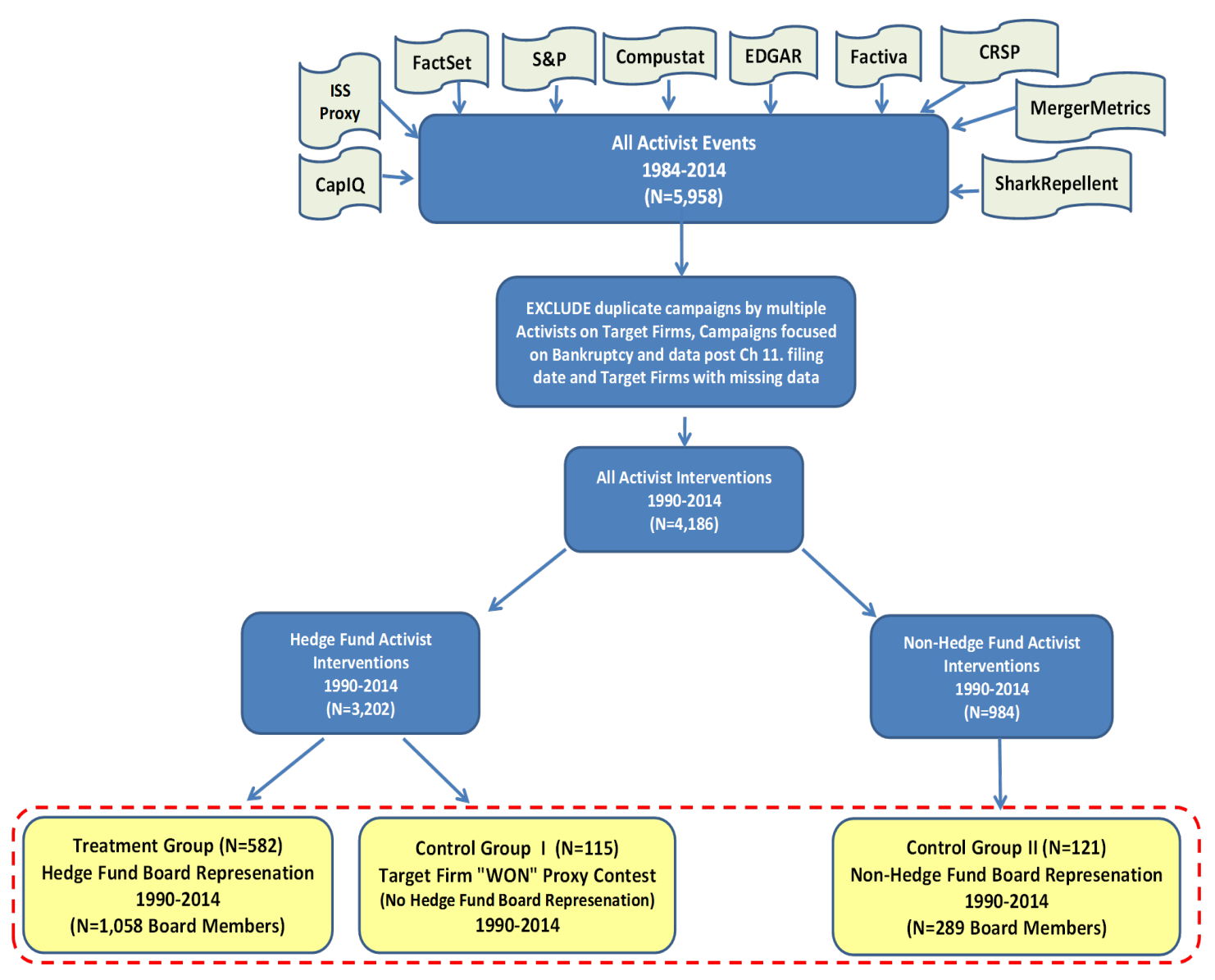

There is no central database of activist hedge funds. Therefore, I constructed an independent dataset of all activist interventions from 1984-2014 from various sources, including Compustat, Capital IQ, FactSet, ISS Proxy Data, SharkRepellent, and the SEC's EDGAR database. Additionally, my dataset includes Schedule 13D filings, the mandatory federal securities law filings under Section 13(d) of the 1934 Exchange Act that investors must file with the SEC within 10 days of acquiring more than $5 \%$ of any class of securities of a publicly traded company if they have an interest in influencing the management of the company. My manually constructed database of shareholder activist events includes 5,958 interventions from 1984-2014. Similar to Gillan and Starks (2007), I define shareholder activist event as a purposeful intervention by "investors who, dissatisfied with some aspect of a company's management or operations, try to bring about change within the company without a change in control". My data collection comprised a multistep procedure. The vast majority of shareholder activism literature is predicated on Schedule 13D filings. However, I started with a much more expansive sample of activist interventions: 5,958 interventions from 1984-2014. In my second step, I narrowed the time frame to 1990-2014. Next, I excluded certain events in which (a) the primary purpose of the filer is to be involved in the bankruptcy reorganization or the financing of a distressed firm; and (b) the target is a closed-end fund or other non-regular corporation. I excluded duplicate campaigns by multiple activists (i.e., the wolf-pack), so the dataset includes information about the Target Firm only once with respect to a specific campaign. If a Target Firm were to file for bankruptcy protection or liquidation during this multistep compilation, I would have included financial information from the Target Firm up to the Chapter 11 or Chapter 7 filing date. More specifically, the bankrupt firm would account for $100 \%$ loss as it relates to stock return and portfolio analyses. I winsorized all unbounded variables and financial data at the $1.0 \%$ and $99.0 \%$ in each tail to adjust for outliers. As discussed in Chapter IV, there are two important econometric issues that need to be addressed: self-selection bias and endogeneity. To address and mitigate those concerns, I created the following six distinct groups:

1. All Activist Interventions (4,186 Target Firms): includes hedge funds, corporations, public pension funds, mutual funds, labor unions, religious groups and individuals that initiated an activist campaign against a Target Firm;

2. Hedge Fund Activists (3,202 Target Firms): only includes hedge funds that initiated an activist campaign against a Target Firm;

3. Non-Hedge Fund Activists (984 Target Firms): includes corporations, public pension funds, mutual funds, labor unions, religious groups and individuals (excludes hedge funds) that initiated an activist campaign against a Target Firm;

4. Treatment Group: Board representation by Hedge Fund Activists (582 Target Firms): only includes hedge funds that sought and won board representation to actively monitor management of a Target Firm;

5. Control Group I: Target Firms that "won" the proxy fight against Hedge Fund Activists (115 Target Firms): this group is the primary Control Group since it's comprised of Target Firms that faced the threat of hedge fund board representation but the majority of the shareholders supported the incumbent management team and board. Therefore, this group did not receive active monitoring by a hedge fund activist nor it's collateral effects as a disciplinary mechanism; and

6. Control Group II: Board representation by Non-Hedge Fund Activists (121 Target Firms): includes corporations, public pension funds, mutual funds, labor unions, religious groups and individuals (excludes hedge funds) that sought and won board representation to actively monitor management of a Target Firm. 
Table V.1: Objectives and Characteristics of Activist Campaigns (1990-2014)

This table reports the objectives and characteristics of shareholder activist campaigns against Target Firms. The table provides a comparison of six groups: 1) All Activist Interventions (which includes hedge funds, corporations, public pension funds, mutual funds, labor unions, religious groups and individuals); 2) Hedge Fund Activists; 3) Non-Hedge Fund Activists; 4) Board representation by Hedge Fund Activists ("Treatment Group"); 5) Board representation by Non-Hedge Fund Activists; and 6) Target Firms that "won" the proxy fight against Hedge Fund Activists: No Board representation by Hedge Fund Activists ("Control Group").

\begin{tabular}{|c|c|c|c|c|c|c|c|c|c|c|c|c|}
\hline & \multicolumn{2}{|c|}{$(1)$} & \multicolumn{2}{|c|}{$(2)$} & \multicolumn{2}{|c|}{$(3)$} & \multicolumn{2}{|c|}{ (4) } & \multicolumn{2}{|c|}{$(5)$} & \multicolumn{2}{|c|}{$(6)$} \\
\hline & \multicolumn{2}{|c|}{$\begin{array}{l}\text { All Activist } \\
\text { Interventions }\end{array}$} & \multicolumn{2}{|c|}{$\begin{array}{l}\text { Hedge Fund } \\
\text { Activist } \\
\text { Interventions }\end{array}$} & \multicolumn{2}{|c|}{$\begin{array}{l}\text { Non-Hedge } \\
\text { Fund Activist } \\
\text { Interventions }\end{array}$} & \multicolumn{2}{|c|}{\begin{tabular}{|l} 
Hedge \\
Fund Board \\
Representation
\end{tabular}} & \multicolumn{2}{|c|}{$\begin{array}{l}\text { Non-Hedge } \\
\text { Fund Board } \\
\text { Representation }\end{array}$} & \multicolumn{2}{|c|}{$\begin{array}{l}\text { Target Firm } \\
\text { 'Wins" Proxy } \\
\text { Fight }\end{array}$} \\
\hline Number of Target Firms & & 86 & 3,2 & 02 & & 84 & & 82 & & 121 & & 15 \\
\hline 13D Filer & 3,140 & $75 \%$ & 2,721 & $85 \%$ & 421 & $43 \%$ & 517 & $89 \%$ & 93 & $77 \%$ & 112 & $97 \%$ \\
\hline Board Control & 272 & $6 \%$ & 156 & $5 \%$ & 116 & $12 \%$ & 87 & $15 \%$ & 75 & $5 \%$ & 72 & $63 \%$ \\
\hline Board Representation & 857 & $20 \%$ & 660 & $21 \%$ & 197 & $20 \%$ & 332 & $57 \%$ & 3 & $3 \%$ & 1 & $1 \%$ \\
\hline Enhance Corporate Governance & 134 & $3 \%$ & 84 & $3 \%$ & 50 & $5 \%$ & 10 & $2 \%$ & 9 & $7 \%$ & 10 & $9 \%$ \\
\hline Hostile/Unsolicited Acquisition & 123 & $3 \%$ & 36 & $1 \%$ & 87 & $9 \%$ & 6 & $1 \%$ & 0 & $0 \%$ & 5 & $4 \%$ \\
\hline Maximize Shareholder Value & 1,098 & $26 \%$ & 925 & $29 \%$ & 172 & $17 \%$ & 99 & $17 \%$ & 0 & $0 \%$ & 6 & $5 \%$ \\
\hline Public Short Position/Bear Raid & 25 & $1 \%$ & 21 & $1 \%$ & 4 & $0 \%$ & 3 & $1 \%$ & 0 & $0 \%$ & 0 & $0 \%$ \\
\hline Remove Officer(s) & 34 & $1 \%$ & 21 & $1 \%$ & 13 & $1 \%$ & 5 & $1 \%$ & 1 & $0 \%$ & 0 & $0 \%$ \\
\hline Support Dissident Group in Proxy Fight & 49 & $1 \%$ & 40 & $1 \%$ & 10 & $1 \%$ & 2 & $0 \%$ & 0 & $0 \%$ & 0 & $0 \%$ \\
\hline Vote Against a Management Proposal & 148 & $4 \%$ & 91 & $3 \%$ & 57 & $6 \%$ & 2 & $0 \%$ & 0 & $0 \%$ & 0 & $0 \%$ \\
\hline Vote For a Management Proposal & 43 & $1 \%$ & 29 & $1 \%$ & 14 & $1 \%$ & 2 & $0 \%$ & 0 & $0 \%$ & 0 & $0 \%$ \\
\hline Vote For a Stockholder Proposal & 373 & $9 \%$ & 165 & $5 \%$ & 208 & $21 \%$ & 4 & $1 \%$ & 0 & $0 \%$ & 0 & $0 \%$ \\
\hline Vote/Activism Against a Merger & 224 & $5 \%$ & 168 & $5 \%$ & 56 & $6 \%$ & 3 & $1 \%$ & 0 & $0 \%$ & 0 & $0 \%$ \\
\hline
\end{tabular}




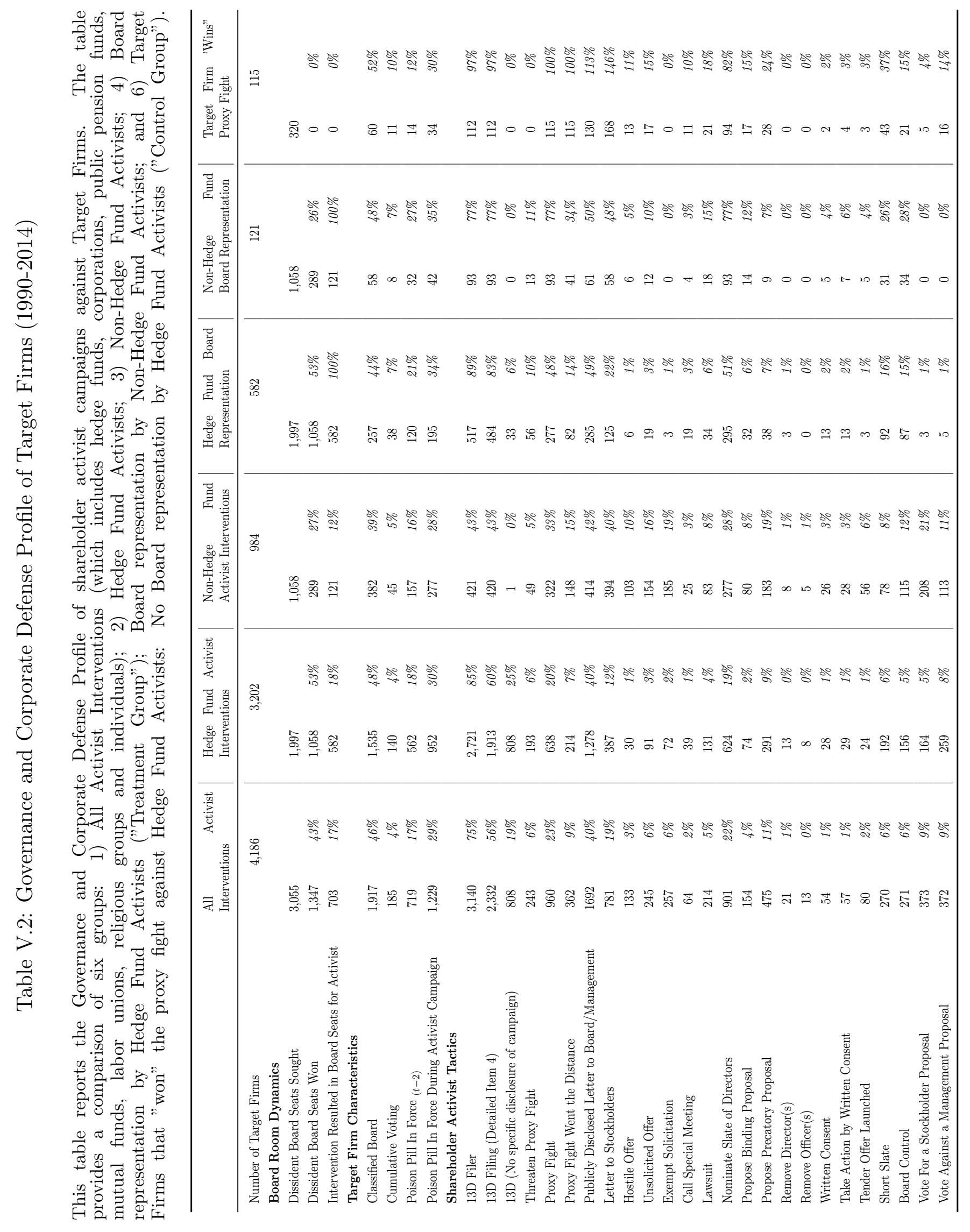


Table V.3: Timing to Sale/Merger: Target Firms vs. Matched Firms

\begin{tabular}{|c|c|c|c|c|c|c|c|c|c|c|c|}
\hline \multicolumn{12}{|c|}{ Panel A: All Activist Interventions } \\
\hline \multicolumn{4}{|c|}{ Target Firms $(\mathrm{N}=4,186)$} & \multicolumn{4}{|c|}{ Matched Firms $(N=4,186)$} & \multicolumn{4}{|c|}{ CRSP/Compustat Universe $(\mathrm{N}=1,816,396)$} \\
\hline \multicolumn{4}{|c|}{ Sale/Merger Ex Post Announcement Date } & \multicolumn{4}{|c|}{ Sale/Merger Ex Post Announcement Date } & \multicolumn{4}{|c|}{ Sale/Merger Ex Post Announcement Date } \\
\hline Timeframe & Observations & Percent & Cumulative & Timeframe & Observations & Percent & Cumulative & Timeframe & Observations & Percent & Cumulative \\
\hline$<\operatorname{Six}(6)$ Months & 559 & $13 \%$ & $13 \%$ & $<\operatorname{Six}(6)$ Months & 199 & $5 \%$ & $5 \%$ & $<\operatorname{Six}(6)$ Months & 64,870 & $4 \%$ & $4 \%$ \\
\hline 6-12 months & 248 & $6 \%$ & $19 \%$ & $6-12$ months & 140 & $3 \%$ & $8 \%$ & 6-12 months & 56,859 & $3 \%$ & $7 \%$ \\
\hline 1-2 Years & 319 & $8 \%$ & $27 \%$ & 1-2 Years & 237 & $6 \%$ & $14 \%$ & 1-2 Years & 108,325 & $6 \%$ & $13 \%$ \\
\hline 2-3 Years & 176 & $4 \%$ & $31 \%$ & 2-3 Years & 193 & $5 \%$ & $18 \%$ & 2-3 Years & 96,680 & $5 \%$ & $18 \%$ \\
\hline 3-5 Years & 243 & $6 \%$ & $37 \%$ & 3-5 Years & 259 & $6 \%$ & $25 \%$ & 3-5 Years & 156,731 & $9 \%$ & $27 \%$ \\
\hline$>5$ Years & 2,641 & $63 \%$ & $100 \%$ & $>5$ Years & 3,158 & $75 \%$ & $100 \%$ & $>5$ Years & $1,332,931$ & $73 \%$ & $100 \%$ \\
\hline Total & 4,186 & & & Total & 4,186 & & & Total & $1,816,396$ & & \\
\hline
\end{tabular}

Panel B: Hedge Fund Activist Interventions

Target Firms $(\mathrm{N}=3,202)$

Matched Firms $(\mathrm{N}=3,202)$

CRSP/Compustat Universe $(\mathrm{N}=1,817,378)$

\begin{tabular}{|c|c|c|c|c|c|c|c|c|c|c|c|}
\hline \multicolumn{4}{|c|}{ Sale/Merger Ex Post Announcement Date } & \multicolumn{4}{|c|}{ Sale/Merger Ex Post Announcement Date } & \multicolumn{4}{|c|}{ Sale/Merger Ex Post Announcement Date } \\
\hline Timeframe & Observations & Percent & Cumulative & Timeframe & Observations & Percent & Cumulative & Timeframe & Observations & Percent & Cumulative \\
\hline$<\operatorname{Six}(6)$ Months & 483 & $15 \%$ & $15 \%$ & $<\operatorname{Six}(6)$ Months & 167 & $5 \%$ & $5 \%$ & $<\operatorname{Six}(6)$ Months & 65,352 & $4 \%$ & $4 \%$ \\
\hline 6-12 months & 191 & $6 \%$ & $21 \%$ & 6-12 months & 112 & $4 \%$ & $9 \%$ & 6-12 months & 57,050 & $3 \%$ & $7 \%$ \\
\hline 1-2 Years & 243 & $8 \%$ & $29 \%$ & 1-2 Years & 182 & $6 \%$ & $14 \%$ & 1-2 Years & 108,567 & $6 \%$ & $13 \%$ \\
\hline 2-3 Years & 143 & $4 \%$ & $33 \%$ & 2-3 Years & 155 & $5 \%$ & $19 \%$ & 2-3 Years & 96,823 & $5 \%$ & $18 \%$ \\
\hline 3-5 Years & 189 & $6 \%$ & $39 \%$ & 3-5 Years & 202 & $6 \%$ & $26 \%$ & 3-5 Years & 156,920 & $9 \%$ & $27 \%$ \\
\hline$>5$ Years & 1,953 & $61 \%$ & $100 \%$ & $>5$ Years & 2,384 & $74 \%$ & $100 \%$ & $>5$ Years & $1,334,886$ & $73 \%$ & $100 \%$ \\
\hline Total & 3,202 & & & Total & 3,202 & & & Total & $1,817,378$ & & \\
\hline
\end{tabular}

Panel C: Non-Hedge Fund Activist Interventions

Target Firms $(\mathrm{N}=984)$

Matched Firms $(\mathrm{N}=984)$

CRSP/Compustat Universe $(\mathrm{N}=1,819,598)$

\begin{tabular}{|c|c|c|c|c|c|c|c|c|c|c|c|}
\hline \multicolumn{4}{|c|}{ Sale/Merger Ex Post Announcement Date } & \multicolumn{4}{|c|}{ Sale/Merger Ex Post Announcement Date } & \multicolumn{4}{|c|}{ Sale/Merger Ex Post Announcement Date } \\
\hline Timeframe & Observations & Percent & Cumulative & Timeframe & Observations & Percent & Cumulative & Timeframe & Observations & Percent & Cumulative \\
\hline$<\operatorname{Six}(6)$ Months & 77 & $8 \%$ & $8 \%$ & $<\operatorname{Six}(6)$ Months & 31 & $3 \%$ & $3 \%$ & $<\operatorname{Six}(6)$ Months & 65,352 & $4 \%$ & $4 \%$ \\
\hline 6-12 months & 57 & $6 \%$ & $14 \%$ & 6-12 months & 28 & $3 \%$ & $6 \%$ & 6-12 months & 57,050 & $3 \%$ & $7 \%$ \\
\hline 1-2 Years & 77 & $8 \%$ & $21 \%$ & 1-2 Years & 55 & $6 \%$ & $12 \%$ & 1-2 Years & 108,567 & $6 \%$ & $13 \%$ \\
\hline 2-3 Years & 33 & $3 \%$ & $25 \%$ & 2-3 Years & 38 & $4 \%$ & $15 \%$ & 2-3 Years & 96,823 & $5 \%$ & $18 \%$ \\
\hline 3-5 Years & 54 & $5 \%$ & $30 \%$ & 3-5 Years & 57 & $6 \%$ & $21 \%$ & 3-5 Years & 156,920 & $9 \%$ & $27 \%$ \\
\hline$>5$ Years & 686 & $70 \%$ & $100 \%$ & $>5$ Years & 775 & $79 \%$ & $100 \%$ & $>5$ Years & $1,334,886$ & $73 \%$ & $100 \%$ \\
\hline Total & 984 & & & Total & 984 & & & Total & $1,819,598$ & & \\
\hline
\end{tabular}

Panel D: Hedge Fund Board Representation

Target Firms $(\mathrm{N}=582)$

Matched Firms $(\mathrm{N}=582)$

CRSP/Compustat Universe $(\mathrm{N}=1,820,000)$

\begin{tabular}{|c|c|c|c|c|c|c|c|c|c|c|c|}
\hline \multicolumn{4}{|c|}{ Sale/Merger Ex Post Dissident Seat Date } & \multicolumn{4}{|c|}{ Sale/Merger Ex Post Dissident Seat Date } & \multicolumn{4}{|c|}{ Sale/Merger Ex Post Dissident Seat Date } \\
\hline Timeframe & Observations & Percent & Cumulative & Timeframe & Observations & Percent & Cumulative & Timeframe & Observations & Percent & Cumulative \\
\hline$<\operatorname{Six}(6)$ Months & 6 & $1 \%$ & $1 \%$ & $<\operatorname{Six}(6)$ Months & 17 & $3 \%$ & $3 \%$ & $<\operatorname{Six}(6)$ Months & 65,423 & $4 \%$ & $4 \%$ \\
\hline 6-12 months & 31 & $5 \%$ & $6 \%$ & 6-12 months & 13 & $2 \%$ & $5 \%$ & 6-12 months & 57,076 & $3 \%$ & $7 \%$ \\
\hline 1-2 Years & 65 & $11 \%$ & $18 \%$ & 1-2 Years & 26 & $4 \%$ & $10 \%$ & 1-2 Years & 108,579 & $6 \%$ & $13 \%$ \\
\hline 2-3 Years & 32 & $6 \%$ & $23 \%$ & 2-3 Years & 20 & $3 \%$ & $13 \%$ & 2-3 Years & 96,824 & $5 \%$ & $18 \%$ \\
\hline 3-5 Years & 43 & $7 \%$ & $30 \%$ & 3-5 Years & 51 & $9 \%$ & $22 \%$ & 3-5 Years & 156,931 & $9 \%$ & $27 \%$ \\
\hline$>5$ Years & 405 & $70 \%$ & $100 \%$ & $>5$ Years & 455 & $78 \%$ & $100 \%$ & $>5$ Years & $1,335,167$ & $73 \%$ & $100 \%$ \\
\hline Total & 582 & & & Total & 582 & & & Total & $1,820,000$ & & \\
\hline
\end{tabular}


Table 5.3: Timing to Sale/Merger: Target Firms vs. Matched Firms

Panel E: Non-Hedge Fund Board Representation

Target Firms $(\mathrm{N}=121) \quad$ Matched Firms $(\mathrm{N}=121) \quad$ CRSP/Compustat Universe $(\mathrm{N}=1,820,460)$

\begin{tabular}{|c|c|c|c|c|c|c|c|c|c|c|c|}
\hline \multicolumn{4}{|c|}{ Sale/Merger Ex Post Dissident Seat Date } & \multicolumn{4}{|c|}{ Sale/Merger Ex Post Dissident Seat Date } & \multicolumn{4}{|c|}{ Sale/Merger Ex Post Dissident Seat Date } \\
\hline Timeframe & Observations & Percent & Cumulative & Timeframe & Observations & Percent & Cumulative & Timeframe & Observations & Percent & Cumulative \\
\hline$<\operatorname{Six}(6)$ Months & 6 & $5 \%$ & $5 \%$ & $<\operatorname{Six}(6)$ Months & 3 & $2 \%$ & $2 \%$ & $<\operatorname{Six}(6)$ Months & 65,423 & $4 \%$ & $4 \%$ \\
\hline $6-12$ months & 5 & $4 \%$ & $9 \%$ & $6-12$ months & 6 & $5 \%$ & $7 \%$ & $6-12$ months & 57,102 & $3 \%$ & $7 \%$ \\
\hline 1-2 Years & 14 & $12 \%$ & $21 \%$ & 1-2 Years & 8 & $7 \%$ & $14 \%$ & 1-2 Years & 108,630 & $6 \%$ & $13 \%$ \\
\hline 2-3 Years & 7 & $6 \%$ & $26 \%$ & 2-3 Years & 4 & $3 \%$ & $17 \%$ & 2-3 Years & 96,849 & $5 \%$ & $18 \%$ \\
\hline 3-5 Years & 10 & $8 \%$ & $35 \%$ & 3-5 Years & 8 & $7 \%$ & $24 \%$ & 3-5 Years & 156,964 & $9 \%$ & $27 \%$ \\
\hline$>5$ Years & 79 & $65 \%$ & $100 \%$ & $>5$ Years & 92 & $76 \%$ & $100 \%$ & $>5$ Years & $1,335,492$ & $73 \%$ & $100 \%$ \\
\hline Total & 121 & & & Total & 121 & & & Total & $1,820,460$ & & \\
\hline
\end{tabular}

Panel F: Target Firm "Wins" Proxy Fight: No Hedge Fund Board Representation

Target Firms $(\mathrm{N}=115)$

Matched Firms $(\mathrm{N}=115)$

CRSP/Compustat Universe $(\mathrm{N}=1,820,486)$

\begin{tabular}{|c|c|c|c|c|c|c|c|c|c|c|c|}
\hline \multicolumn{4}{|c|}{ Sale/Merger Ex Post Target Firm Proxy Fight Win } & \multicolumn{4}{|c|}{ Sale/Merger Ex Post Target Firm Proxy Fight Win } & \multicolumn{4}{|c|}{ Sale/Merger Ex Post Target Firm Proxy Fight Win } \\
\hline Timeframe & Observations & Percent & Cumulative & Timeframe & Observations & Percent & Cumulative & Timeframe & Observations & Percent & Cumulative \\
\hline$<\operatorname{Six}(6)$ Months & 3 & $3 \%$ & $3 \%$ & $<\operatorname{Six}(6)$ Months & 3 & $3 \%$ & $3 \%$ & $<\operatorname{Six}(6)$ Months & 65,430 & $4 \%$ & $4 \%$ \\
\hline 6-12 months & 4 & $3 \%$ & $6 \%$ & 6-12 months & 6 & $5 \%$ & $8 \%$ & $6-12$ months & 57,104 & $3 \%$ & $7 \%$ \\
\hline 1-2 Years & 9 & $8 \%$ & $14 \%$ & 1-2 Years & 7 & $6 \%$ & $14 \%$ & 1-2 Years & 108,637 & $6 \%$ & $13 \%$ \\
\hline 2-3 Years & 6 & $5 \%$ & $19 \%$ & 2-3 Years & 7 & $6 \%$ & $20 \%$ & 2-3 Years & 96,850 & $5 \%$ & $18 \%$ \\
\hline 3-5 Years & 10 & $9 \%$ & $28 \%$ & 3-5 Years & 7 & $6 \%$ & $26 \%$ & $3-5$ Years & 156,966 & $9 \%$ & $27 \%$ \\
\hline$>5$ Years & 83 & $72 \%$ & $100 \%$ & $>5$ Years & 85 & $74 \%$ & $100 \%$ & $>5$ Years & $1,335,499$ & $73 \%$ & $100 \%$ \\
\hline Total & 115 & & & Total & 115 & & & Total & $1,820,486$ & & \\
\hline
\end{tabular}

Table V.4: Timing to CEO Change: Target Firms vs. Matched Firms

\begin{tabular}{|c|c|c|c|c|c|c|c|c|c|c|c|}
\hline \multicolumn{12}{|c|}{ Panel A: All Activist Interventions } \\
\hline \multicolumn{4}{|c|}{ Target Firms $(\mathrm{N}=4,186)$} & \multicolumn{4}{|c|}{ Matched Firms $(\mathrm{N}=4,186)$} & \multicolumn{4}{|c|}{ CRSP/Compustat Universe $(\mathrm{N}=1,816,411)$} \\
\hline \multicolumn{4}{|c|}{ CEO Change Ex Post Announcement Date } & \multicolumn{4}{|c|}{ CEO Change Ex Post Announcement Date } & \multicolumn{4}{|c|}{ CEO Change Ex Post Announcement Date } \\
\hline Timeframe & Observations & Percent & Cumulative & Timeframe & Observations & Percent & Cumulative & Timeframe & Observations & Percent & Cumulative \\
\hline$<\operatorname{Six}(6)$ Months & 630 & $15 \%$ & $15 \%$ & $<\operatorname{Six}(6)$ Months & 152 & $4 \%$ & $4 \%$ & $<\operatorname{Six}(6)$ Months & 26,503 & $1 \%$ & $1 \%$ \\
\hline 6-12 months & 285 & $7 \%$ & $22 \%$ & $6-12$ months & 65 & $2 \%$ & $5 \%$ & $6-12$ months & 15,909 & $1 \%$ & $2 \%$ \\
\hline 1-2 Years & 319 & $8 \%$ & $29 \%$ & 1-2 Years & 111 & $3 \%$ & $8 \%$ & 1-2 Years & 27,811 & $2 \%$ & $4 \%$ \\
\hline 2-3 Years & 186 & $4 \%$ & $34 \%$ & 2-3 Years & 83 & $2 \%$ & $10 \%$ & 2-3 Years & 23,730 & $1 \%$ & $5 \%$ \\
\hline 3-5 Years & 188 & $4 \%$ & $38 \%$ & 3-5 Years & 113 & $3 \%$ & $13 \%$ & 3-5 Years & 38,852 & $2 \%$ & $7 \%$ \\
\hline$>5$ Years & 2,548 & $62 \%$ & $100 \%$ & $>5$ Years & 3,662 & $87 \%$ & $100 \%$ & $>5$ Years & $1,683,606$ & $93 \%$ & $100 \%$ \\
\hline Total & 4,186 & & & Total & 4,186 & & & Total & $1,816,411$ & & \\
\hline
\end{tabular}

Panel B: Hedge Fund Activist Interventions

Target Firms $(\mathrm{N}=3,202)$

Matched Firms $(\mathrm{N}=3,202)$

CRSP/Compustat Universe $(\mathrm{N}=1,817,395)$

\begin{tabular}{|c|c|c|c|c|c|c|c|c|c|c|c|}
\hline \multicolumn{4}{|c|}{ CEO Change Ex Post Announcement Date } & \multicolumn{4}{|c|}{ CEO Change Ex Post Announcement Date } & \multicolumn{4}{|c|}{ CEO Change Ex Post Announcement Date } \\
\hline Timeframe & Observations & Percent & Cumulative & Timeframe & Observations & Percent & Cumulative & Timeframe & Observations & Percent & Cumulative \\
\hline$<\operatorname{Six}(6)$ Months & 468 & $15 \%$ & $15 \%$ & $<\operatorname{Six}(6)$ Months & 105 & $3 \%$ & $3 \%$ & $<\operatorname{Six}(6)$ Months & 26,665 & $1 \%$ & $1 \%$ \\
\hline 6-12 months & 199 & $6 \%$ & $21 \%$ & $6-12$ months & 51 & $2 \%$ & $5 \%$ & 6-12 months & 15,995 & $1 \%$ & $2 \%$ \\
\hline 1-2 Years & 233 & $7 \%$ & $28 \%$ & 1-2 Years & 82 & $3 \%$ & $7 \%$ & 1-2 Years & 27,897 & $2 \%$ & $4 \%$ \\
\hline 2-3 Years & 140 & $4 \%$ & $32 \%$ & 2-3 Years & 59 & $2 \%$ & $9 \%$ & 2-3 Years & 23,776 & $1 \%$ & $5 \%$ \\
\hline 3-5 Years & 124 & $4 \%$ & $36 \%$ & 3-5 Years & 89 & $3 \%$ & $12 \%$ & 3-5 Years & 38,916 & $2 \%$ & $7 \%$ \\
\hline$>5$ Years & 2,038 & $64 \%$ & $100 \%$ & $>5$ Years & 2,816 & $88 \%$ & $100 \%$ & $>5$ Years & $1,684,146$ & $93 \%$ & $100 \%$ \\
\hline Total & 3,202 & & & Total & 3,202 & & & Total & $1,817,395$ & & \\
\hline
\end{tabular}


Table 5.4: Timing to CEO Change: Target Firms vs. Matched Firms Panel C: Non-Hedge Fund Activist Interventions

Target Firms $(\mathrm{N}=984)$

Matched Firms $(\mathrm{N}=984)$

CRSP/Compustat Universe $(\mathrm{N}=1,819,617)$

\begin{tabular}{|c|c|c|c|c|c|c|c|c|c|c|c|}
\hline \multicolumn{4}{|c|}{ CEO Change Ex Post Announcement Date } & \multicolumn{4}{|c|}{ CEO Change Ex Post Announcement Date } & \multicolumn{4}{|c|}{ CEO Change Ex Post Announcement Date } \\
\hline Timeframe & Observations & Percent & Cumulative & Timeframe & Observations & Percent & Cumulative & Timeframe & Observations & Percent & Cumulative \\
\hline$<\operatorname{Six}(6)$ Months & 162 & $16 \%$ & $16 \%$ & $<\operatorname{Six}(6)$ Months & 47 & $5 \%$ & $5 \%$ & $<\operatorname{Six}(6)$ Months & 26,971 & $1 \%$ & $1 \%$ \\
\hline 6-12 months & 86 & $9 \%$ & $25 \%$ & 6-12 months & 14 & $1 \%$ & $6 \%$ & 6-12 months & 16,108 & $1 \%$ & $2 \%$ \\
\hline 1-2 Years & 86 & $9 \%$ & $34 \%$ & 1-2 Years & 29 & $3 \%$ & $9 \%$ & 1-2 Years & 28,044 & $2 \%$ & $4 \%$ \\
\hline 2-3 Years & 46 & $5 \%$ & $39 \%$ & 2-3 Years & 24 & $2 \%$ & $12 \%$ & 2-3 Years & 23,870 & $1 \%$ & $5 \%$ \\
\hline 3-5 Years & 64 & $7 \%$ & $45 \%$ & 3-5 Years & 24 & $2 \%$ & $14 \%$ & 3-5 Years & 38,976 & $2 \%$ & $7 \%$ \\
\hline$>5$ Years & 540 & $55 \%$ & $100 \%$ & $>5$ Years & 846 & $86 \%$ & $100 \%$ & $>5$ Years & $1,685,648$ & $93 \%$ & $100 \%$ \\
\hline Total & 984 & & & Total & 984 & & & Total & $1,819,617$ & & \\
\hline
\end{tabular}

Panel D: Hedge Fund Board Representation

Target Firms $(\mathrm{N}=582)$

Matched Firms $(\mathrm{N}=582)$

CRSP/Compustat Universe $(\mathrm{N}=1,820,019)$

\begin{tabular}{|c|c|c|c|c|c|c|c|c|c|c|c|}
\hline \multicolumn{4}{|c|}{ CEO Change Ex Post Dissident Seat Date } & \multicolumn{4}{|c|}{ CEO Change Ex Post Dissident Seat Date } & \multicolumn{4}{|c|}{ CEO Change Ex Post Dissident Seat Date } \\
\hline Timeframe & Observations & Percent & Cumulative & Timeframe & Observations & Percent & Cumulative & Timeframe & Observations & Percent & Cumulative \\
\hline$<\operatorname{Six}(6)$ Months & 128 & $22 \%$ & $22 \%$ & $<\operatorname{Six}(6)$ Months & 24 & $4 \%$ & $4 \%$ & $<\operatorname{Six}(6)$ Months & 27,005 & $1 \%$ & $1 \%$ \\
\hline 6-12 months & 62 & $11 \%$ & $33 \%$ & $6-12$ months & 10 & $2 \%$ & $6 \%$ & $6-12$ months & 16,132 & $1 \%$ & $2 \%$ \\
\hline 1-2 Years & 66 & $11 \%$ & $44 \%$ & 1-2 Years & 15 & $3 \%$ & $8 \%$ & 1-2 Years & 28,064 & $2 \%$ & $4 \%$ \\
\hline 2-3 Years & 24 & $4 \%$ & $48 \%$ & 2-3 Years & 14 & $2 \%$ & $11 \%$ & 2-3 Years & 23,892 & $1 \%$ & $5 \%$ \\
\hline 3-5 Years & 16 & $3 \%$ & $51 \%$ & 3-5 Years & 18 & $3 \%$ & $14 \%$ & 3-5 Years & 39,024 & $2 \%$ & $7 \%$ \\
\hline$>5$ Years & 286 & $49 \%$ & $100 \%$ & $>5$ Years & 501 & $86 \%$ & $100 \%$ & $>5$ Years & $1,685,902$ & $93 \%$ & $100 \%$ \\
\hline Total & 582 & & & Total & 582 & & & Total & $1,820,019$ & & \\
\hline
\end{tabular}

Panel E: Non-Hedge Fund Board Representation

Target Firms $(\mathrm{N}=121)$

Matched Firms $(\mathrm{N}=121)$

CRSP/Compustat Universe $(\mathrm{N}=1,820,480)$

\begin{tabular}{|c|c|c|c|c|c|c|c|c|c|c|c|}
\hline \multicolumn{4}{|c|}{ CEO Change Ex Post Dissident Seat Date } & \multicolumn{4}{|c|}{ CEO Change Ex Post Dissident Seat Date } & \multicolumn{4}{|c|}{ CEO Change Ex Post Dissident Seat Date } \\
\hline Timeframe & Observations & Percent & Cumulative & Timeframe & Observations & Percent & Cumulative & Timeframe & Observations & Percent & Cumulative \\
\hline$<\operatorname{Six}(6)$ Months & 32 & $26 \%$ & $26 \%$ & $<\operatorname{Six}(6)$ Months & 5 & $4 \%$ & $4 \%$ & $<\operatorname{Six}(6)$ Months & 27,101 & $1 \%$ & $1 \%$ \\
\hline 6-12 months & 20 & $17 \%$ & $43 \%$ & 6-12 months & 2 & $2 \%$ & $6 \%$ & $6-12$ months & 16,174 & $1 \%$ & $2 \%$ \\
\hline 1-2 Years & 20 & $17 \%$ & $60 \%$ & 1-2 Years & 2 & $2 \%$ & $7 \%$ & 1-2 Years & 28,110 & $2 \%$ & $4 \%$ \\
\hline 2-3 Years & 4 & $3 \%$ & $63 \%$ & 2-3 Years & 4 & $3 \%$ & $11 \%$ & 2-3 Years & 23,912 & $1 \%$ & $5 \%$ \\
\hline 3-5 Years & 5 & $4 \%$ & $67 \%$ & 3-5 Years & 1 & $1 \%$ & $12 \%$ & $3-5$ Years & 39,035 & $2 \%$ & $7 \%$ \\
\hline$>5$ Years & 40 & $33 \%$ & $100 \%$ & $>5$ Years & 107 & $88 \%$ & $100 \%$ & $>5$ Years & $1,686,148$ & $93 \%$ & $100 \%$ \\
\hline Total & 121 & & & Total & 121 & & & Total & $1,820,480$ & & \\
\hline
\end{tabular}

Panel F: Target Firm "Wins" Proxy Fight: No Hedge Fund Board Representation

Target Firms $(\mathrm{N}=115)$

Matched Firms $(\mathrm{N}=115)$

CRSP/Compustat Universe $(\mathrm{N}=1,820,486)$

\begin{tabular}{|c|c|c|c|c|c|c|c|c|c|c|c|}
\hline \multirow{2}{*}{$\begin{array}{l}\text { CEO Change Ex } \\
\text { Timeframe }\end{array}$} & \multicolumn{2}{|c|}{ Post Target Firm Proxy } & \multirow{2}{*}{$\begin{array}{l}\text { Fight Win } \\
\text { Cumulative }\end{array}$} & \multicolumn{4}{|c|}{ CEO Change Ex Post Target Firm Proxy Fight Win } & \multicolumn{4}{|c|}{ CEO Change Ex Post Target Firm Proxy Fight Win } \\
\hline & Observations & Percent & & Timeframe & Observations & Percent & Cumulative & Timeframe & Observations & Percent & Cumulative \\
\hline$<\operatorname{Six}(6)$ Months & 12 & $10 \%$ & $10 \%$ & $<\operatorname{Six}(6)$ Months & 3 & $3 \%$ & $3 \%$ & $<\operatorname{Six}(6)$ Months & 27,104 & $1 \%$ & $1 \%$ \\
\hline 6-12 months & 9 & $8 \%$ & $18 \%$ & 6-12 months & 1 & $1 \%$ & $3 \%$ & 6-12 months & 16,181 & $1 \%$ & $2 \%$ \\
\hline 1-2 Years & 11 & $10 \%$ & $28 \%$ & 1-2 Years & 2 & $2 \%$ & $5 \%$ & 1-2 Years & 28,114 & $2 \%$ & $4 \%$ \\
\hline 2-3 Years & 9 & $8 \%$ & $36 \%$ & 2-3 Years & 5 & $4 \%$ & $10 \%$ & 2-3 Years & 23,906 & $1 \%$ & $5 \%$ \\
\hline 3-5 Years & 6 & $5 \%$ & $41 \%$ & 3-5 Years & 4 & $3 \%$ & $13 \%$ & $3-5$ Years & 39,024 & $2 \%$ & $7 \%$ \\
\hline$>5$ Years & 68 & $59 \%$ & $100 \%$ & $>5$ Years & 100 & $87 \%$ & $100 \%$ & $>5$ Years & $1,686,157$ & $93 \%$ & $100 \%$ \\
\hline Total & 115 & & & Total & 115 & & & Total & $1,820,486$ & & \\
\hline
\end{tabular}




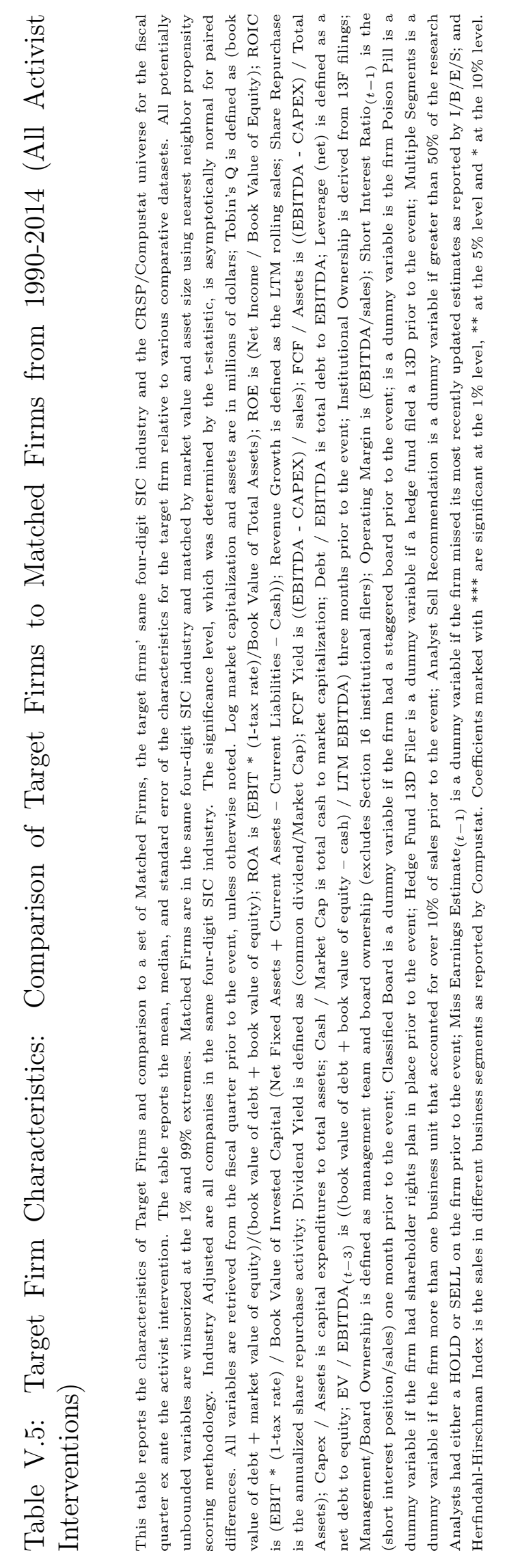

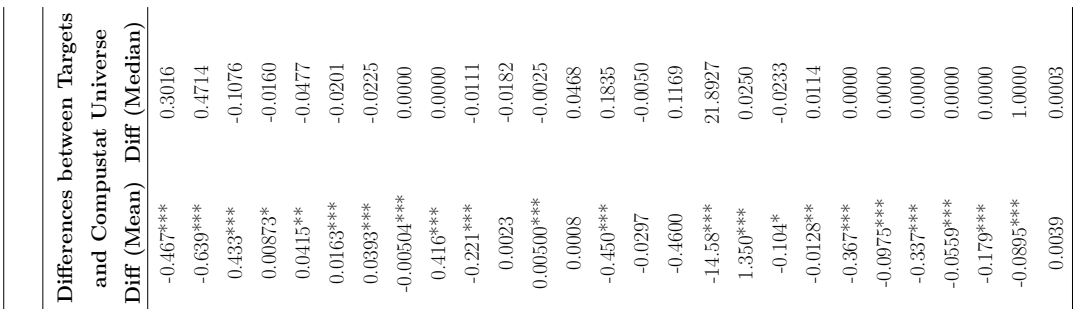

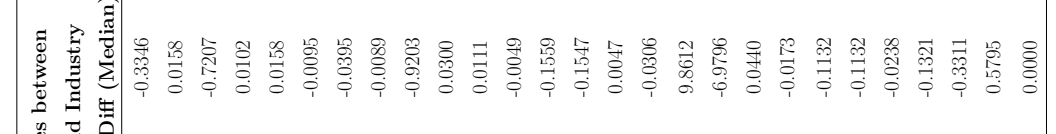

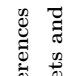

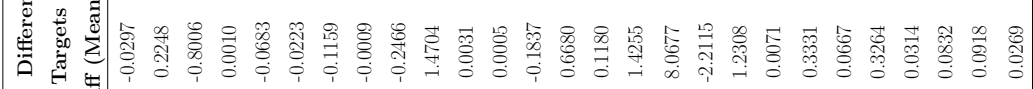
旅

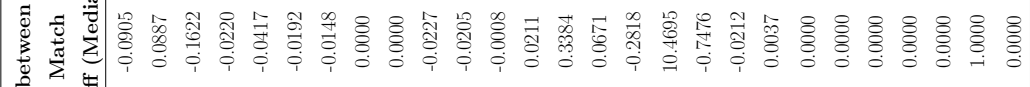

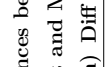

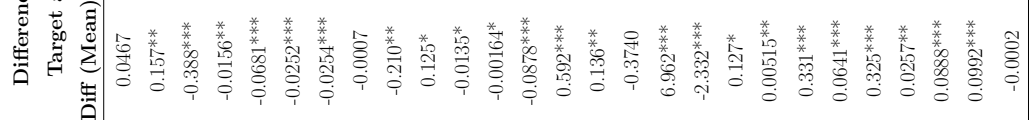

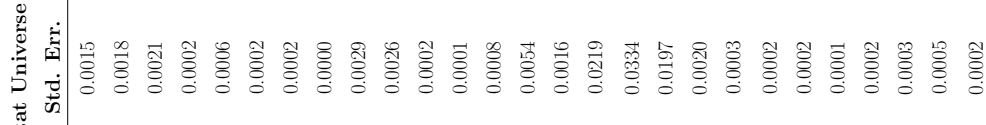

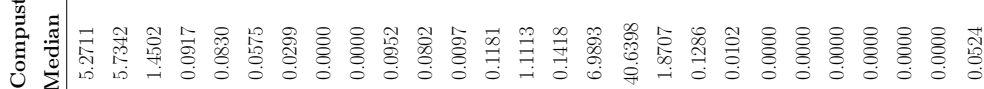

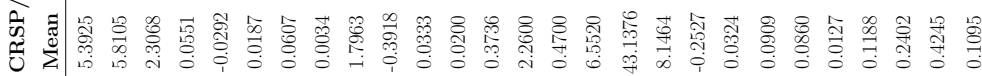

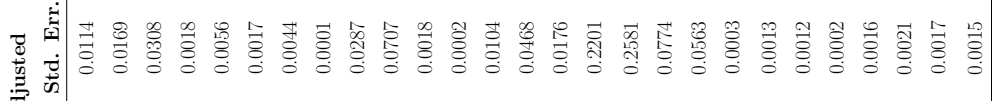

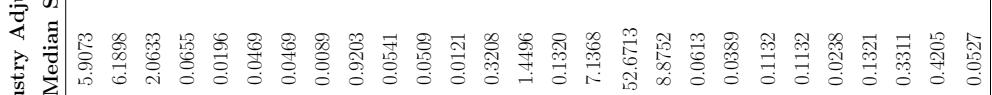

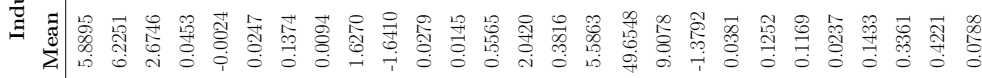

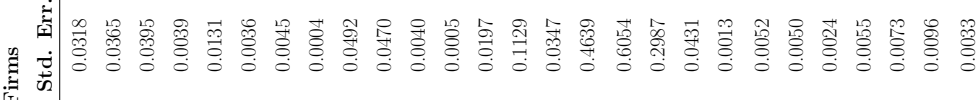

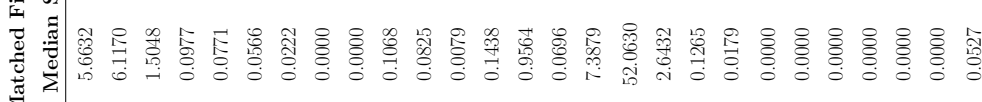

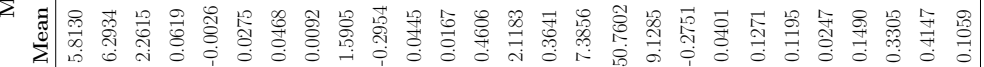

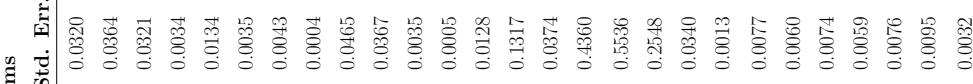
然

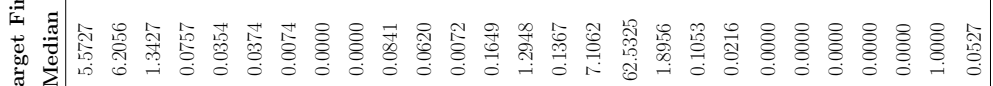

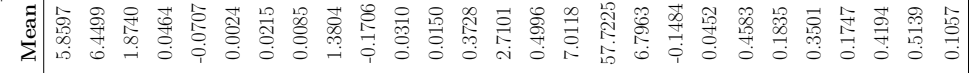

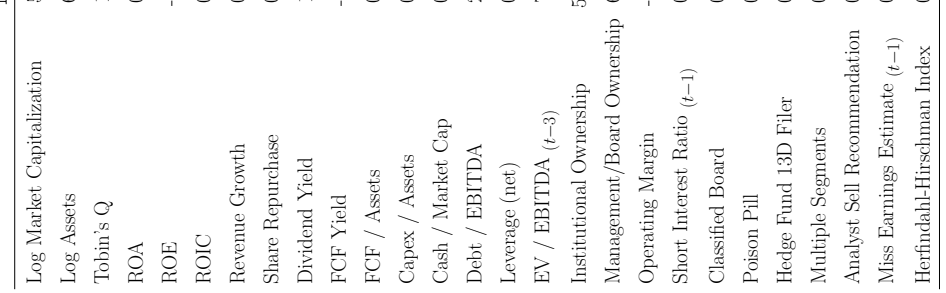




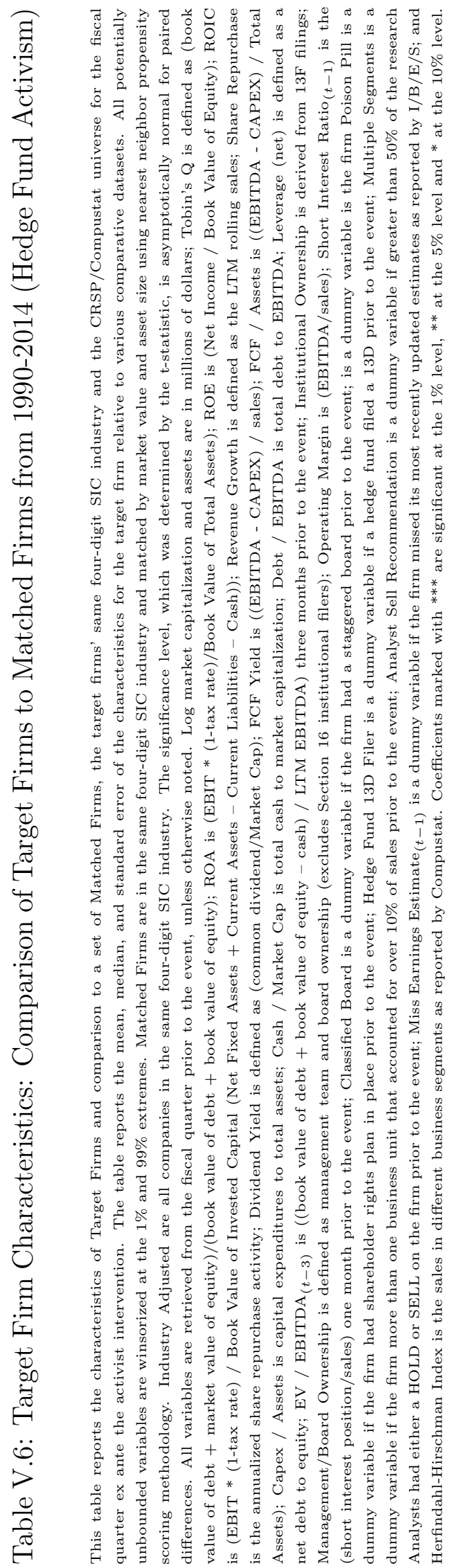

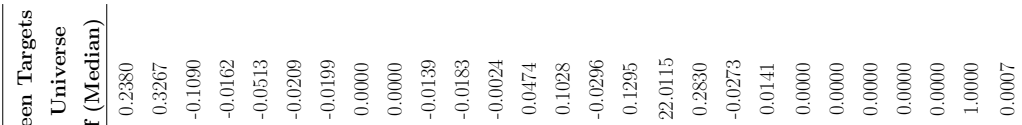

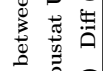

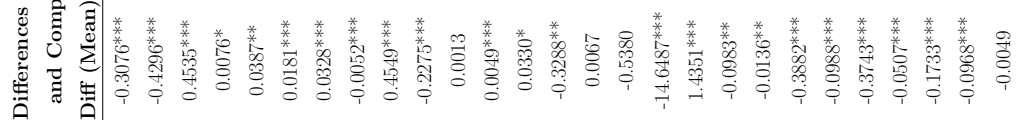

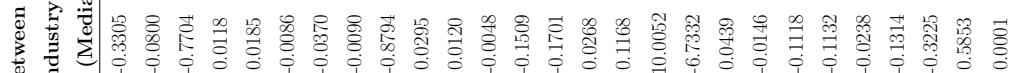

要

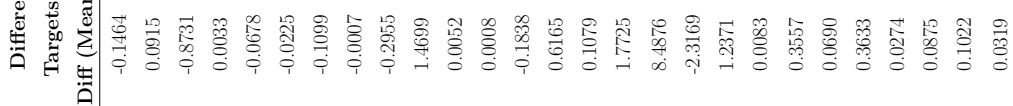

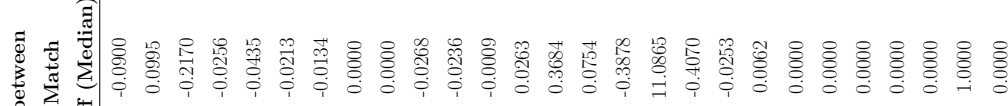
का

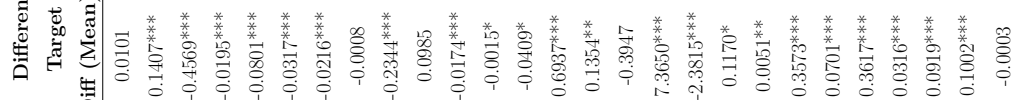
:

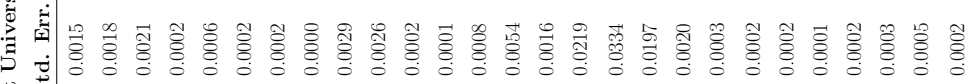

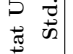

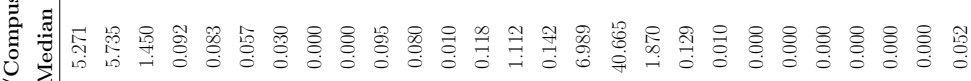

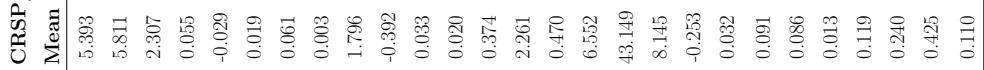

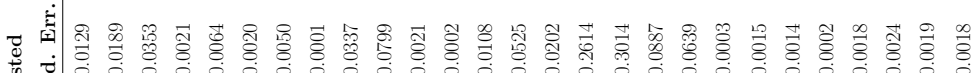

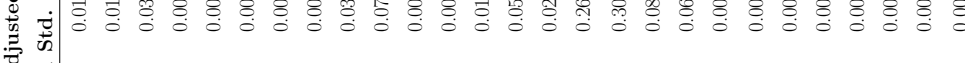

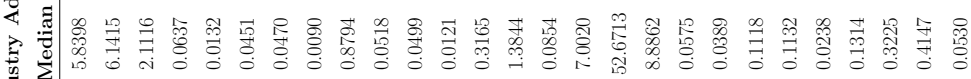

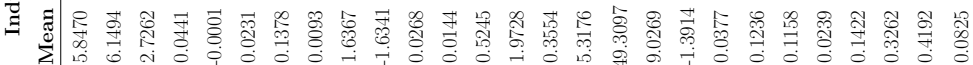

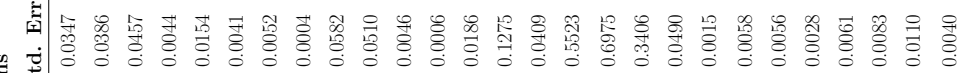

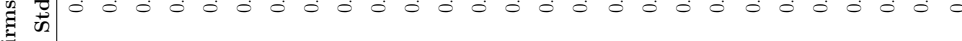

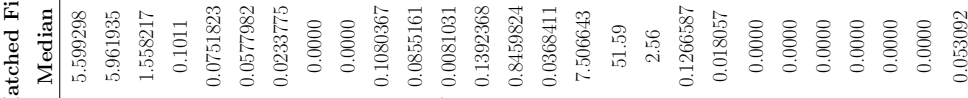

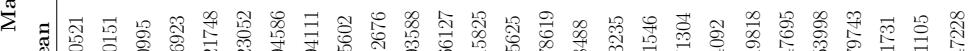

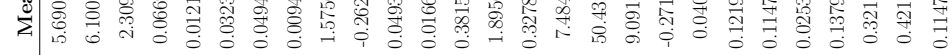

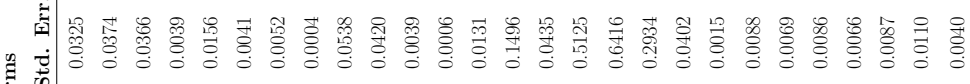

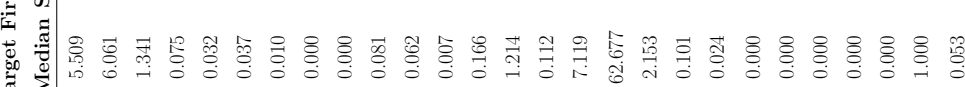

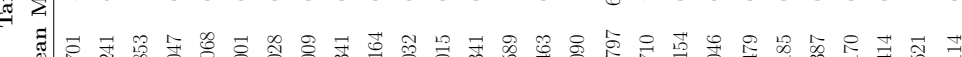

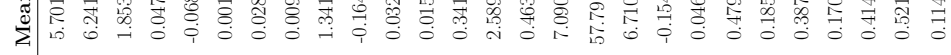

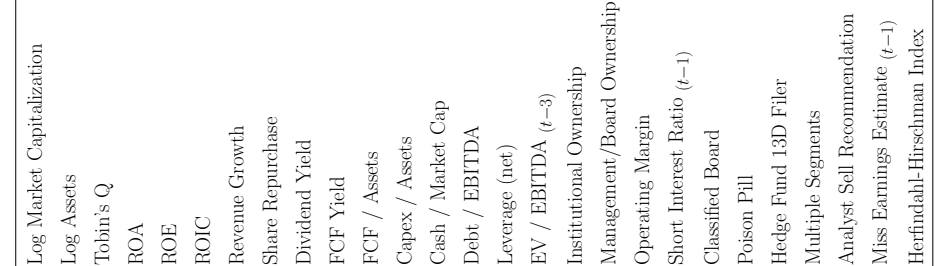




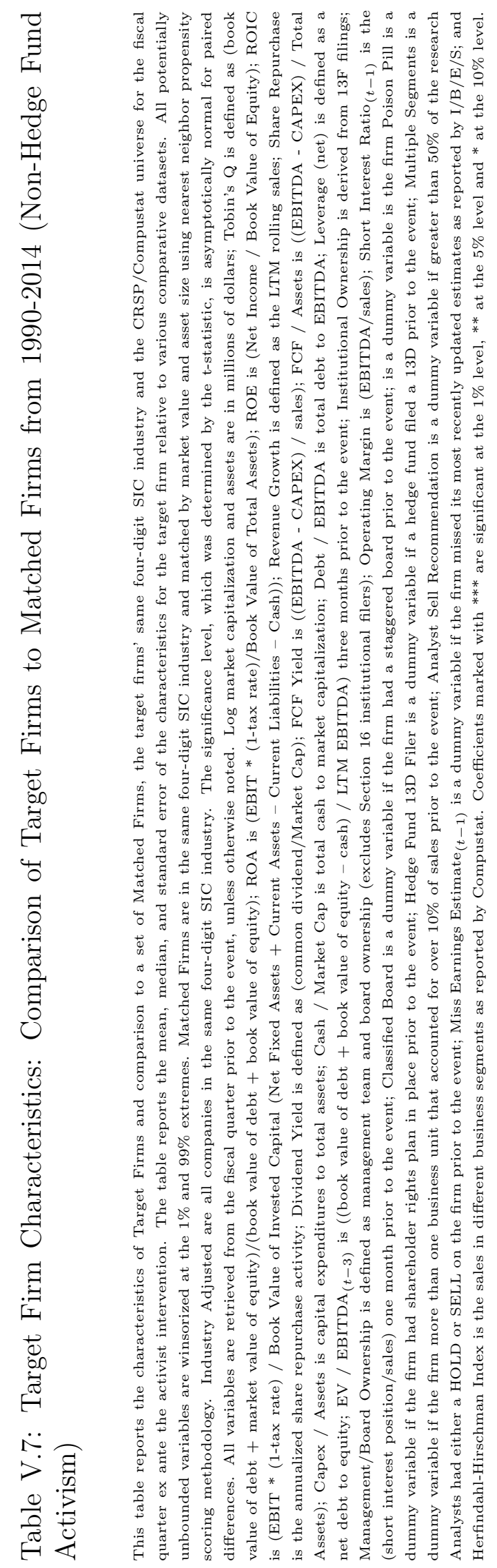

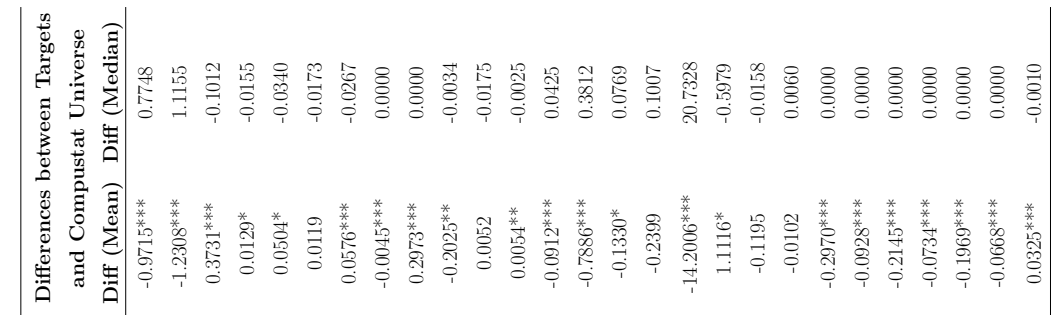

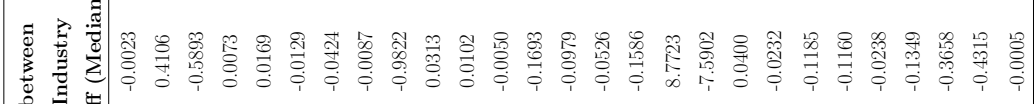

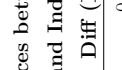

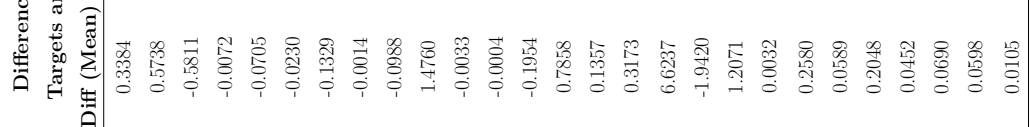

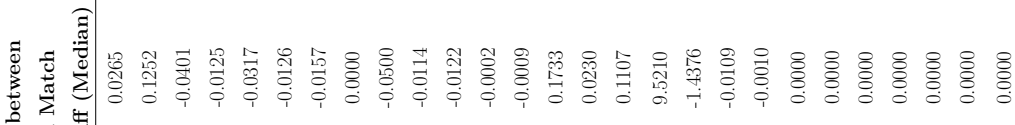

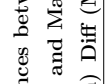

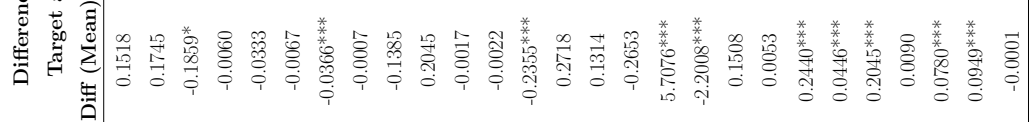

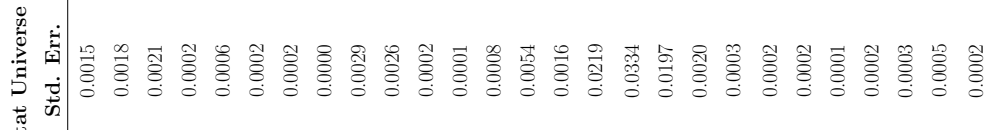

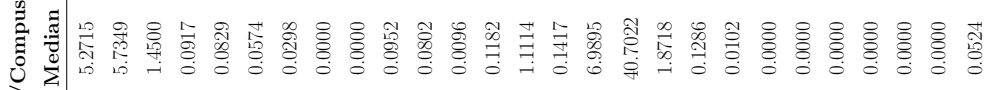

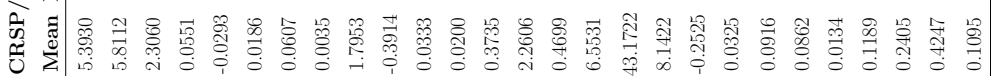

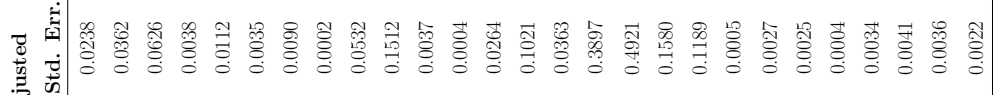

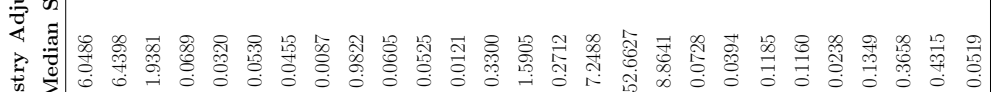

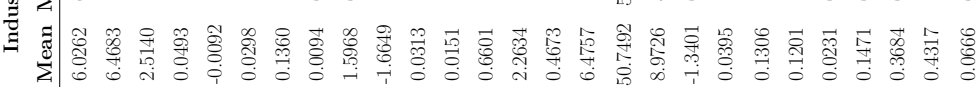

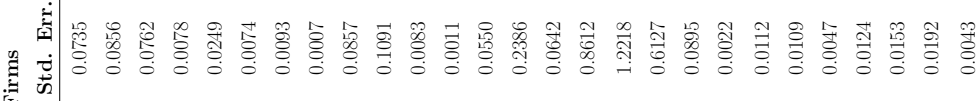

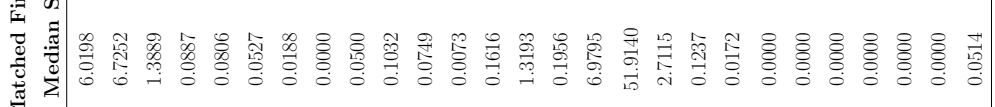

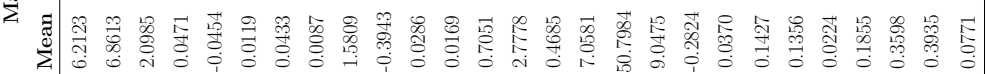

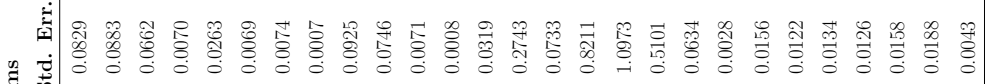
量部

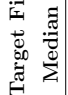

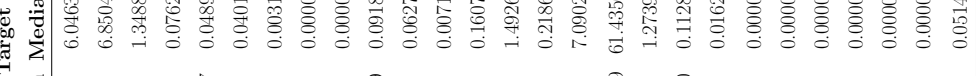

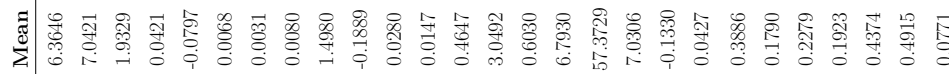

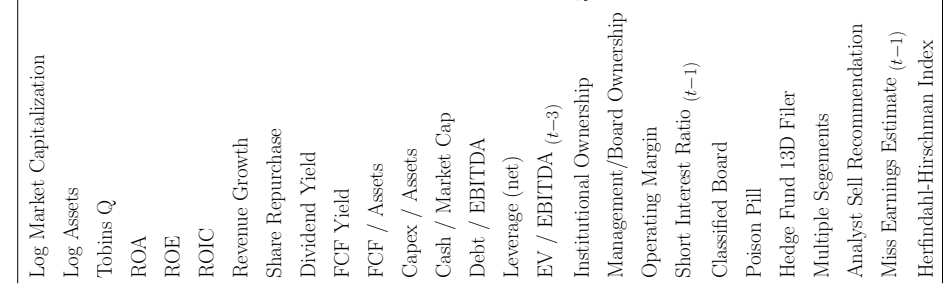




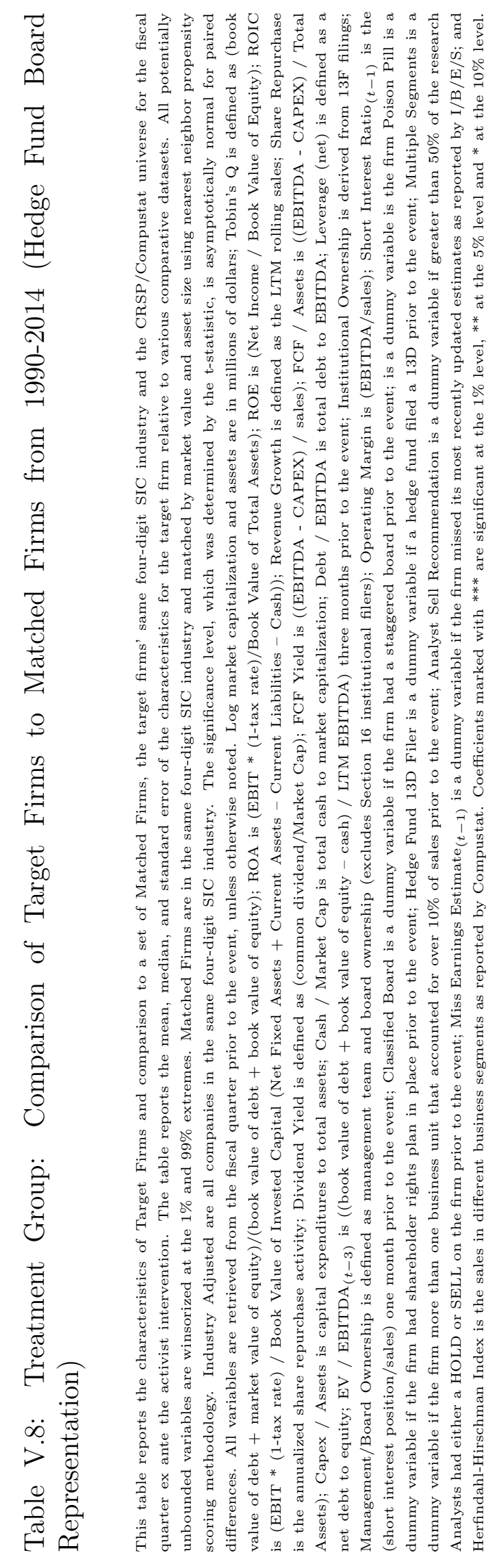

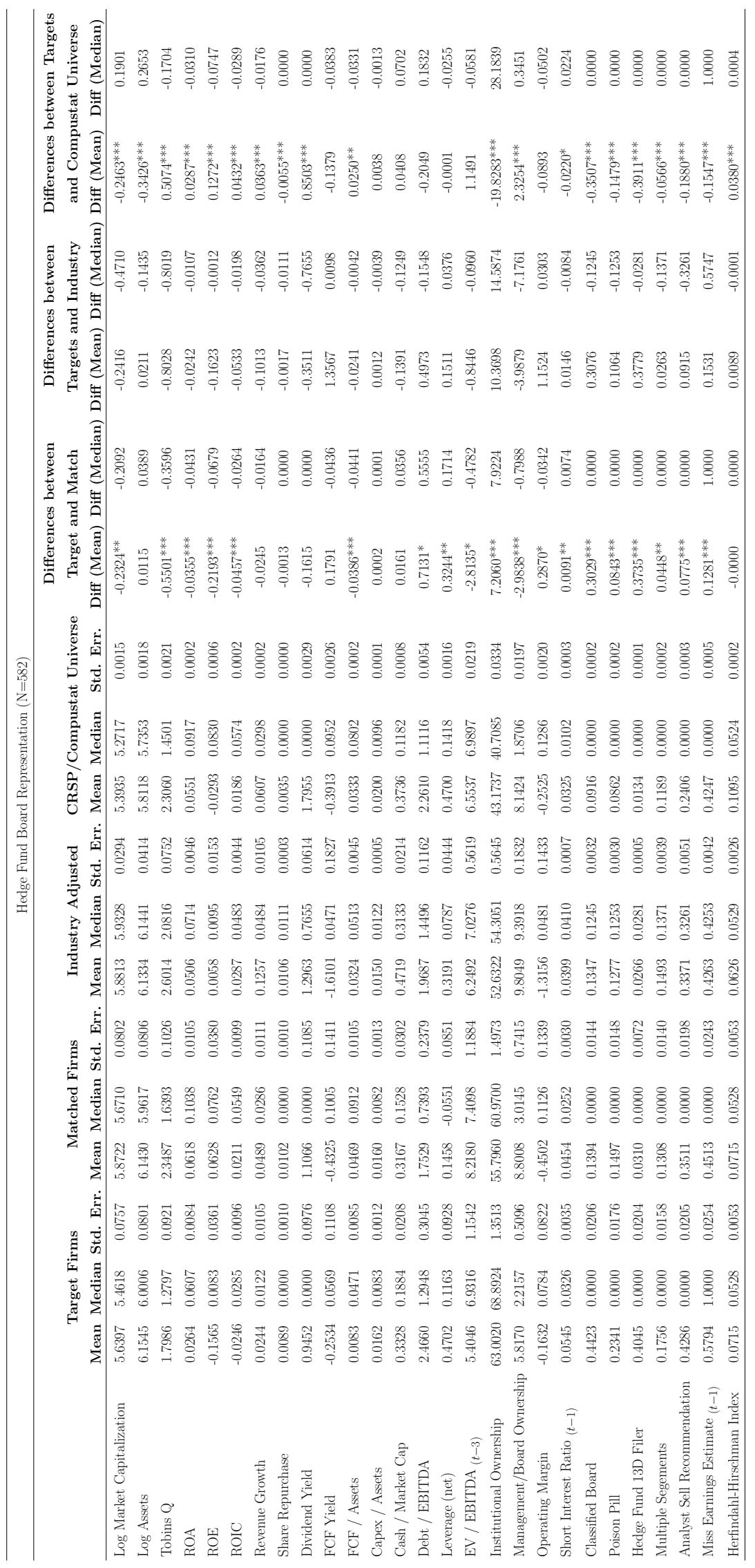




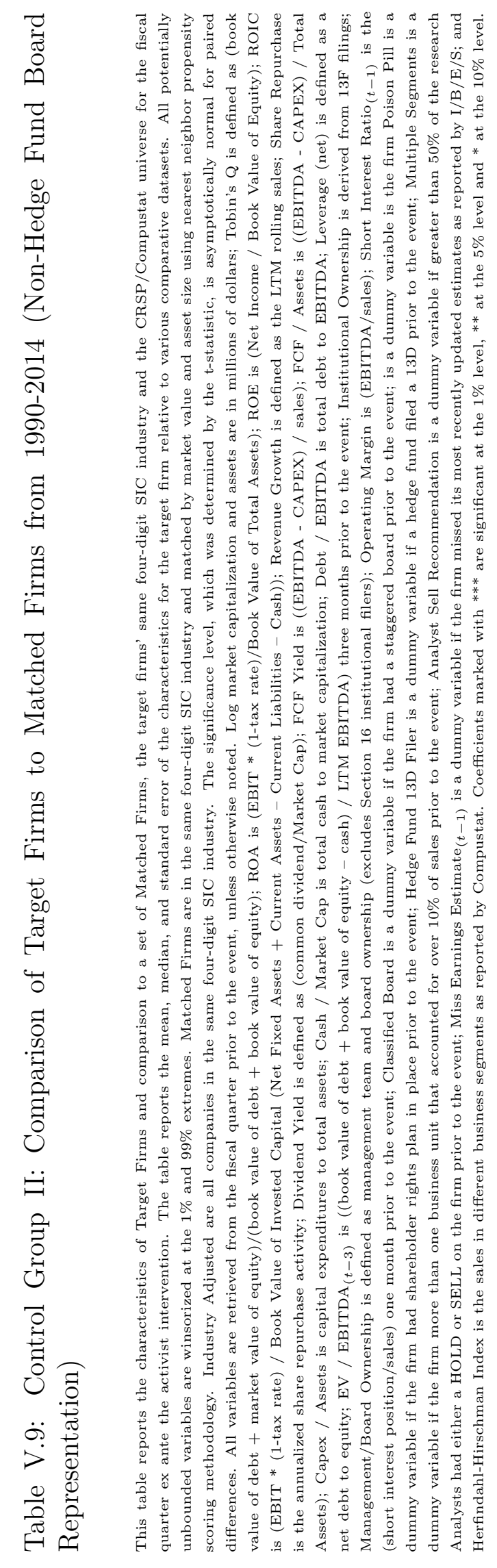

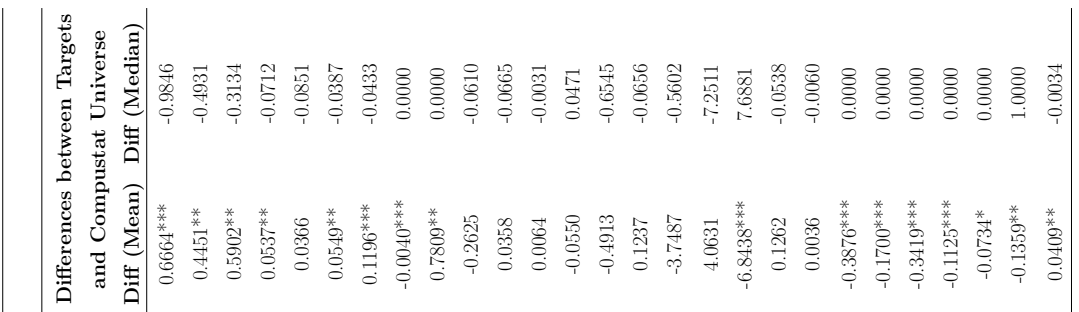

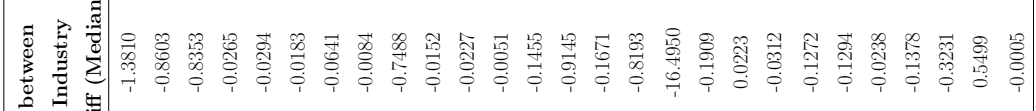

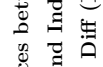

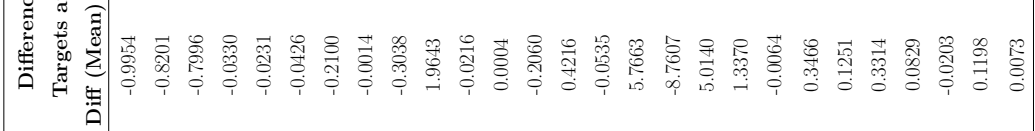

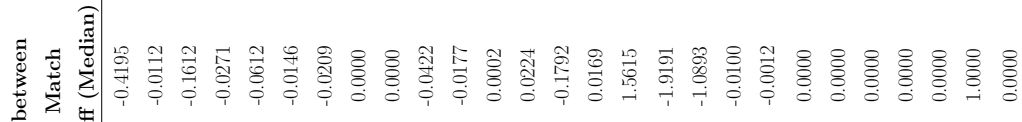

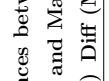

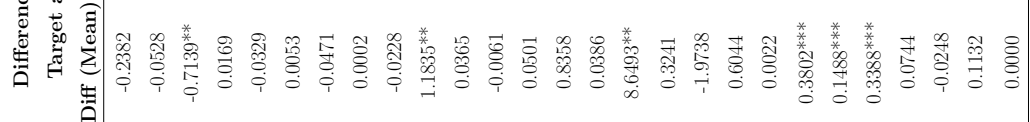
Emmmmimmmmm

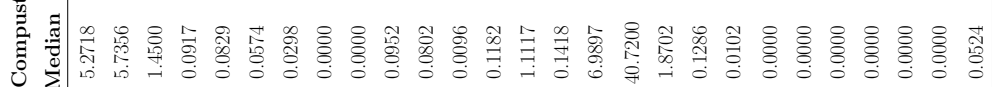

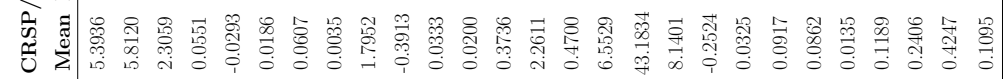

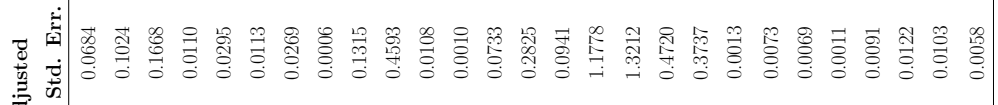

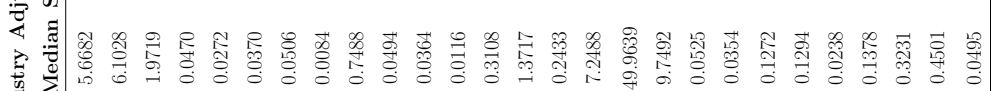

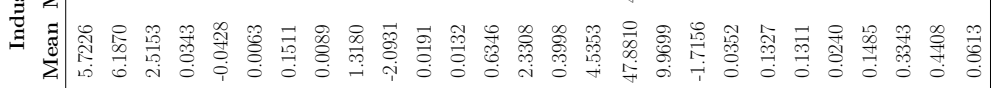

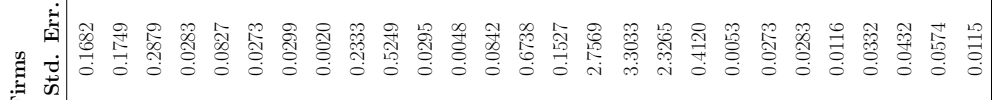
HUH

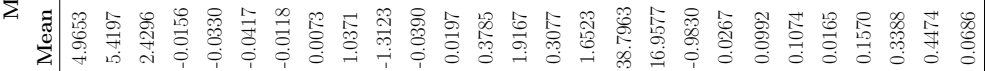

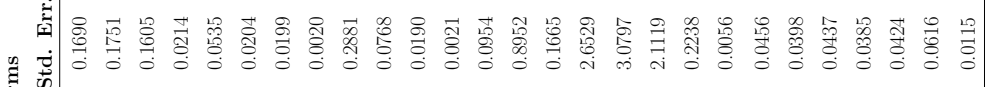
Hagnim

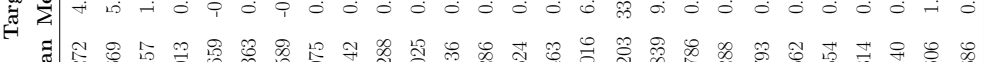

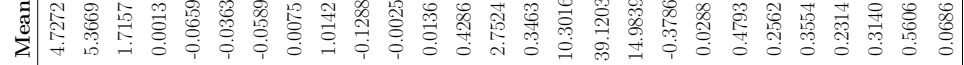

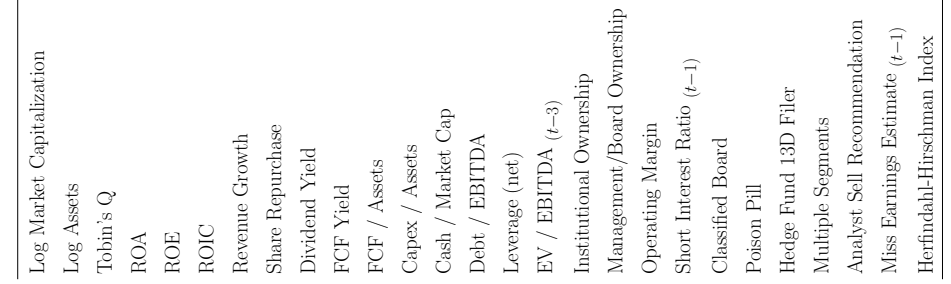




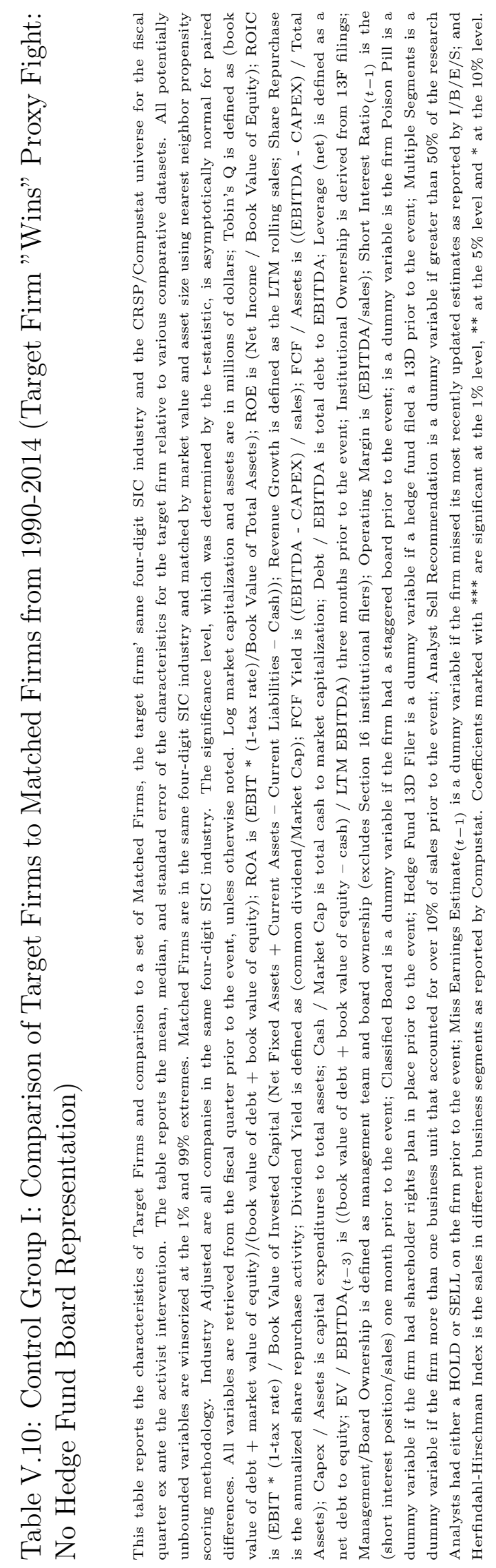

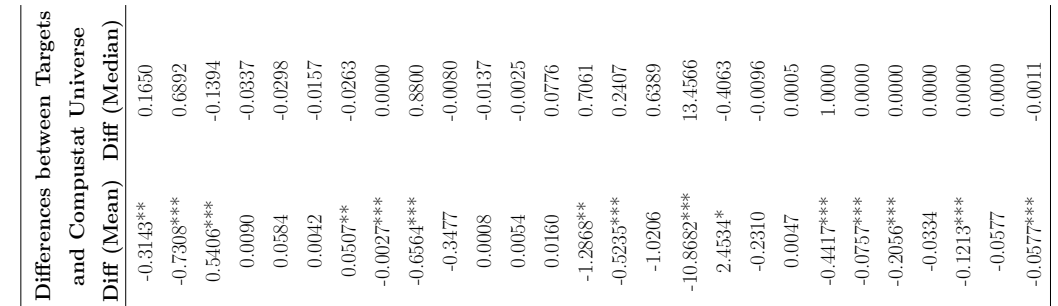

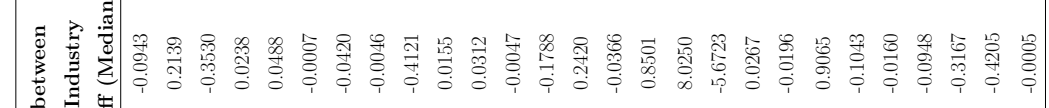

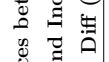

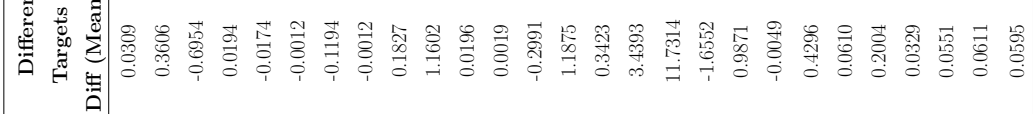

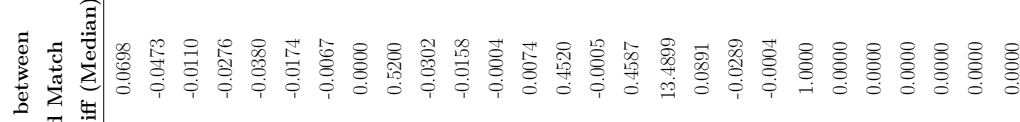
旅譬

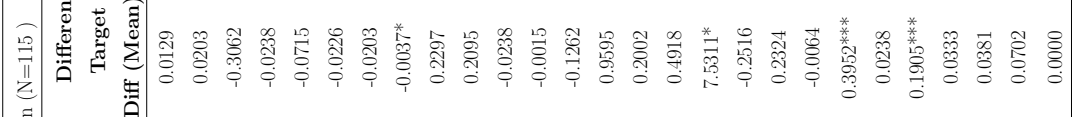

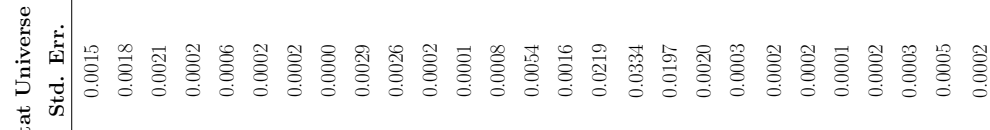

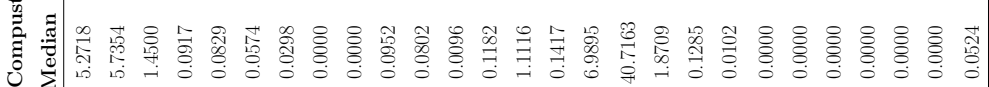

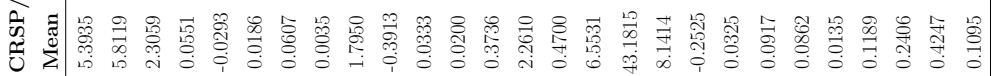

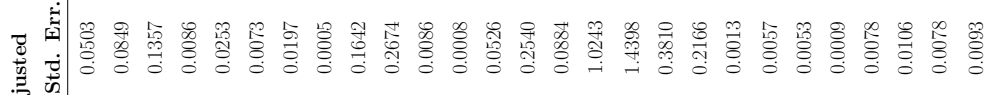

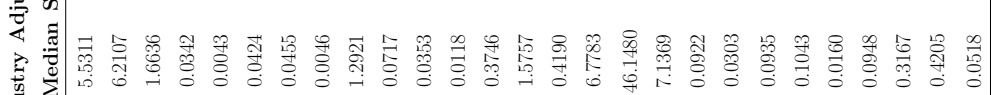

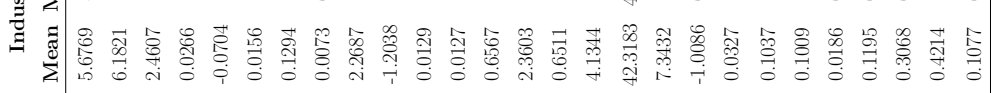

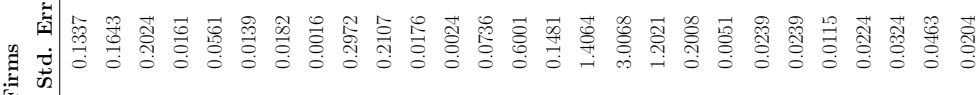

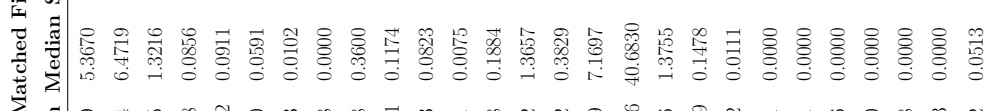

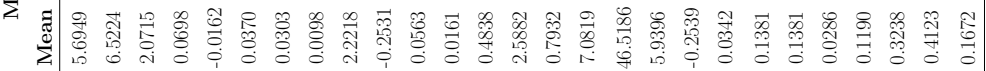

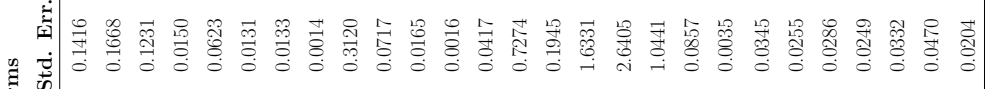

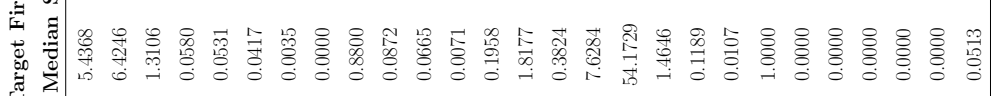

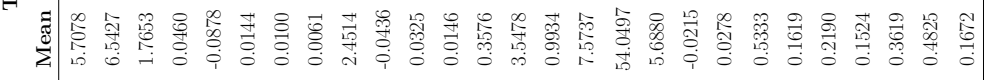
| 


\section{Table V.11: Vulnerability of Target Firms to Shareholder Activism: Probit Regression}

The table provides a comparison of Six Activist Groups: 1) All Activist Interventions (which includes hedge funds, corporations, public pension funds, mutual funds, labor unions, religious groups and individuals); 2) Hedge Fund Activists; 3) Non-Hedge Fund Activists; 4) Board representation by Hedge Fund Activists ("Treatment Group"); Board representation by Non-Hedge Fund Activists; and 6) Target Firms that "won" the proxy fight against Hedge Fund Activists: No Board representation by Hedge Fund Activists ("Control Group"). All potentially unbounded variables are winsorized at the $1 \%$ and $99 \%$ extremes. The significance level, which was determined by the t-statistic, is asymptotically normal for paired differences. All variables are retrieved from the fiscal quarter prior to the event, unless otherwise noted. Log market capitalization and assets are in millions of dollars; Tobin's Q is defined as (book value of debt + market value of equity)/(book value of debt + book value of equity); ROA is (EBIT * (1-tax rate)/Book Value of Total Assets); ROE is (Net Income / Book Value of Equity); ROIC is (EBIT * (1-tax rate) / Book Value of Invested Capital (Net Fixed Assets + Current Assets - Current Liabilities - Cash)); Revenue Growth is defined as the LTM rolling sales; Share Repurchase is the annualized share repurchase activity; Dividend Yield is defined as (common dividend/Market Cap); FCF Yield is ((EBITDA - CAPEX) / sales); FCF / Assets is ((EBITDA - CAPEX) / Total Assets); Capex / Assets is capital expenditures to total assets; Cash / Market Cap is total cash to market capitalization; Debt / EBITDA is total debt to EBITDA; Leverage (net) is defined as a net debt to equity; EV / $\operatorname{EBITDA}_{(t-3)}$ is ((book value of debt + book value of equity - cash) / LTM EBITDA) three months prior to the event; Institutional Ownership is derived from $13 \mathrm{~F}$ filings; Management/Board Ownership is defined as management team and board ownership (excludes Section 16 institutional filers); Operating Margin is (EBITDA/sales); Short Interest Ratio $_{(t-1)}$ is the (short interest position/sales) one month prior to the event; Classified Board is a dummy variable if the firm had a staggered board prior to the event; is a dummy variable is the firm Poison Pill is a dummy variable if the firm had shareholder rights plan in place prior to the event; Hedge Fund 13D Filer is a dummy variable if a hedge fund filed a $13 \mathrm{D}$ prior to the event; Multiple Segments is a dummy variable if the firm more than one business unit that accounted for over $10 \%$ of sales prior to the event; Analyst Sell Recommendation is a dummy variable if greater than 50\% of the research Analysts had either a HOLD or SELL on the firm prior to the event; Miss Earnings Estimate $_{(t-1)}$ is a dummy variable if the firm missed its most recently updated estimates as reported by $\mathrm{I} / \mathrm{B} / \mathrm{E} / \mathrm{S}$; and Herfindahl-Hirschman Index is the sales in different business segments as reported by Compustat. $t$ statistics in parentheses. Coefficients marked with *** are significant at the $1 \%$ level, $* *$ at the $5 \%$ level and $*$ at the $10 \%$ level.

\begin{tabular}{|c|c|c|c|c|c|c|}
\hline & (1) & (2) & $(3)$ & (4) & (5) & (6) \\
\hline & All & Hedge Fund & Non-HF & HF Board & Non-HF Board & Target "Wins" \\
\hline & Activism & Activism & Activism & Representation & Representation & Proxy Fight \\
\hline Revenue Growth & -0.0407 & 0.162 & $-0.525^{* *}$ & $-0.890^{*}$ & -95.95 & -9.384 \\
\hline Share Repurchase & $-11.32^{*}$ & -7.028 & $-25.68^{*}$ & -10.43 & -1048.3 & 2178.8 \\
\hline Dividend Yield & 0.00379 & -0.0131 & 0.00170 & 0.0133 & 2.433 & 55.85 \\
\hline FCF Yield & 0.0247 & 0.0335 & 0.0534 & 0.105 & 10.64 & -35.92 \\
\hline Cash / Market Cap & $-0.414^{* * *}$ & -0.402 & $-0.712^{* * *}$ & -0.388 & -55.74 & 445.9 \\
\hline Debt / EBITDA & 0.00298 & -0.00456 & -0.0231 & 0.0334 & 8.713 & -18.25 \\
\hline $\mathrm{EV} / \operatorname{EBITDA}_{(t-3)}$ & $-0.00412^{* *}$ & $-0.00610^{* * *}$ & -0.00401 & $-0.00923^{*}$ & -1.042 & 17.82 \\
\hline Institutional Ownership & -0.000174 & 0.00192 & -0.00550 & 0.00915 & 0.648 & 0.175 \\
\hline Management/Board Ownership & -0.00262 & -0.00234 & -0.00401 & -0.0202 & -0.0181 & 16.94 \\
\hline Classified Board & $0.394^{* * *}$ & $0.450^{* * *}$ & $0.381^{* *}$ & $0.487^{*}$ & 34.21 & 108.6 \\
\hline Poison Pill & 0.0709 & $0.211^{*}$ & -0.209 & -0.301 & 20.46 & 36.72 \\
\hline Hedge Fund 13D Filer & $2.058^{* * *}$ & $2.304^{* * *}$ & $1.504^{* * *}$ & $3.235^{* * *}$ & NM & NM \\
\hline Total Shareholder Return $(t-12)$ & 0.0296 & 0.0354 & -0.0452 & -0.248 & -37.94 & 50.56 \\
\hline $\mathrm{ROIC}$ & $-2.717^{* * *}$ & $-3.650^{* * *}$ & -1.652 & $-4.948^{*}$ & -153.1 & 4891.0 \\
\hline $\mathrm{ROA}$ & 0.156 & 0.0379 & 0.295 & -1.299 & -28.19 & -2545.7 \\
\hline Log Market Capitalization & $-0.245^{* * *}$ & $-0.217^{* *}$ & $-0.487^{* * *}$ & -0.117 & 45.64 & -166.9 \\
\hline Log Assets & $0.356^{* * *}$ & $0.299^{* * *}$ & $0.597^{* * *}$ & 0.147 & -46.99 & 97.22 \\
\hline Tobin's Q & 0.0238 & -0.00568 & $0.137^{* *}$ & -0.0500 & -1.874 & -35.62 \\
\hline Herfindahl-Hirschman Index & $7.774^{*}$ & $10.01^{*}$ & 5.731 & 13.25 & 1631.2 & 14378.4 \\
\hline Short Interest Ratio & -0.968 & $-2.453^{* *}$ & 1.457 & 0.193 & 430.4 & -1260.2 \\
\hline Multiple Segments & 0.126 & $0.194^{*}$ & -0.0858 & 0.306 & NM & NM \\
\hline Analyst Sell Recommendation & $0.216^{* * *}$ & $0.298^{* * *}$ & 0.0384 & 0.279 & NM & NM \\
\hline Miss Earnings Estimate $_{(t-1)}$ & 0.0603 & 0.0886 & 0.0903 & -0.332 & NM & NM \\
\hline Constant & $-1.641^{* * *}$ & $-1.788^{* * *}$ & $-1.147^{*}$ & -1.641 & -141.1 & -1165.5 \\
\hline Industry Fixed Effects & Yes & Yes & Yes & Yes & Yes & Yes \\
\hline Year Fixed Effects & Yes & Yes & Yes & Yes & Yes & Yes \\
\hline Observations & 1,569 & 1,146 & 420 & 263 & 37 & 32 \\
\hline Pseudo $R^{2}$ & $25.3 \%$ & $32.8 \%$ & $18.6 \%$ & $50.2 \%$ & NM & NM \\
\hline
\end{tabular}


Table V.12: H1: Change in Short Interest Position of Target Firms Ex Ante Activist Intervention (Hedge Fund Activism versus Non-Hedge Fund Activism)

This table reports the change in Short Interest Position of Target Firms of hedge fund and non-hedge fund activist interventions between t- 6 and $\mathrm{t}-1$ the event. The Short Interest Ratio is defined as (Shares Sold Short / Total Shares Outstanding). All potentially unbounded variables are winsorized at the $1 \%$ and $99 \%$ extremes. $t$ statistics in parentheses. The significance level, which was determined by the $t$ statistic, is asymptotically normal for paired differences. Coefficients marked with *** are significant at the $1 \%$ level, ${ }^{* *}$ at the $5 \%$ level and $*$ at the $10 \%$ level.

\begin{tabular}{lcccc}
\hline & $\begin{array}{c}\text { Model I } \\
\text { Hedge Fund }\end{array}$ & $\begin{array}{c}\text { Model II } \\
\text { Hedge Fund }\end{array}$ & $\begin{array}{c}\text { Model III } \\
\text { Non-Hedge Fund }\end{array}$ & $\begin{array}{c}\text { Model IV } \\
\text { Non-Hedge Fund }\end{array}$ \\
\hline \multirow{4}{*}{$\begin{array}{l}\text { Short Interest Ratio (t-6 through t-1) } \\
\text { Constant }\end{array}$} & $1.168^{* * *}$ & 0.4074 & -0.4719 & -0.5704 \\
& $5.981^{* * *}$ & $5.820^{* * *}$ & $7.125^{* * *}$ & $5.797^{* * *}$ \\
Industry Fixed Effects & No & Yes & No & Yes \\
Year Fixed Effects & No & Yes & No & Yes \\
\hline Observations & $1,129,351$ & $1,043,596$ & $1,129,351$ & 832,217 \\
Pseudo $R^{2}$ & $0.0 \%$ & $5.7 \%$ & $0.0 \%$ & $5.1 \%$ \\
\hline
\end{tabular}


Table V.13: H1: Change in Short Interest Ratio Relative to Other Vulnerability Variables: Probit Regression

This table reports the change in Short Interest Position of Target Firms of hedge fund and non-hedge fund activist interventions between t-6 and t-1 the event. The Short Interest Ratio is defined as (Shares Sold Short / Total Shares Outstanding). All potentially unbounded variables are winsorized at the $1 \%$ and $99 \%$ extremes. The significance level, which was determined by the t-statistic, is asymptotically normal for paired differences. All variables are retrieved from the fiscal quarter prior to the event, unless otherwise noted. Revenue Growth is defined as the LTM rolling sales; Log market capitalization and assets are in millions of dollars; Tobin's Q is defined as (book value of debt + market value of equity)/(book value of debt + book value of equity); ROA is (EBIT * (1-tax rate)/Book Value of Total Assets); ROIC is (EBIT * (1-tax rate) / Book Value of Invested Capital (Net Fixed Assets + Current Assets - Current Liabilities - Cash)); Cash / Market Cap is total cash to market capitalization; Debt / EBITDA is total debt to EBITDA; Leverage (net) is defined as a net debt to equity; EV / $\operatorname{EBITDA}_{(t-3)}$ is ((book value of debt + book value of equity - cash) / LTM EBITDA) three months prior to the event; Institutional Ownership is derived from 13F filings; Operating Margin is (EBITDA/sales); Classified Board is a dummy variable if the firm had a staggered board prior to the event; is a dummy variable is the firm Poison Pill is a dummy variable if the firm had shareholder rights plan in place prior to the event; Hedge Fund 13D Filer is a dummy variable if a hedge fund filed a 13D prior to the event; Multiple Segments is a dummy variable if the firm more than one business unit that accounted for over $10 \%$ of sales prior to the event; and Herfindahl-Hirschman Index is the sales in different business segments as reported by Compustat. $t$ statistics in parentheses. Coefficients marked with ${ }^{* * *}$ are significant at the $1 \%$ level, $* *$ at the $5 \%$ level and ${ }^{*}$ at the $10 \%$ level.

\begin{tabular}{lcccc}
\hline & $\begin{array}{c}\text { Model I } \\
\text { Hedge Fund }\end{array}$ & $\begin{array}{c}\text { Model II } \\
\text { Hedge Fund }\end{array}$ & $\begin{array}{c}\text { Model III } \\
\text { Non-Hedge Fund }\end{array}$ & $\begin{array}{c}\text { Model IV } \\
\text { Non-Hedge Fund }\end{array}$ \\
\hline$\triangle$ Short Interest Ratio(t-6 through t-1) & 0.876 & 0.659 & -0.980 & -1.613 \\
Revenue Growth & 0.016 & 0.001 & $-0.236^{*}$ & $-0.238^{*}$ \\
Log Market Capitalization & $-0.221^{* * *}$ & $-0.270^{* * *}$ & $-0.249^{* * *}$ & $-0.298^{* * *}$ \\
Log Assets & $0.181^{* * *}$ & $0.224^{* * *}$ & $0.305^{* * *}$ & $0.354^{* * *}$ \\
Tobin's Q & $-0.035^{* *}$ & $-0.035^{* *}$ & 0.023 & 0.025 \\
ROA & 0.600 & 0.924 & -0.284 & -0.023 \\
ROIC & $-2.643^{* * *}$ & $-2.926^{* * *}$ & -1.249 & -1.232 \\
Total Shareholder Return(t-12) & 0.021 & 0.0128 & -0.141 & $-0.195^{* *}$ \\
Cash / Market Cap & $-0.261^{* * *}$ & $-0.337^{* * *}$ & $-0.448^{* * *}$ & $-0.550^{* * *}$ \\
Debt / EBITDA & $0.009^{*}$ & $0.010^{*}$ & -0.005 & -0.006 \\
Institutional Ownership & $0.006^{* * *}$ & $0.006^{* * *}$ & -0.0004 & -0.0005 \\
Herfindahl-Hirschman Index & $1.370^{*}$ & 2.717 & 0.341 & $10.240^{* *}$ \\
Multiple Segments & $0.149^{* *}$ & $0.175^{* * *}$ & $-0.173^{*}$ & $-0.183^{*}$ \\
Classified Board & $0.604^{* * *}$ & $0.639^{* * *}$ & $0.440^{* * *}$ & $0.504^{* * *}$ \\
Poison Pill & $0.148^{* *}$ & $0.213^{* * *}$ & 0.0485 & 0.0735 \\
Constant & $-0.361^{* * *}$ & $-0.412^{*}$ & $-0.460^{* * *}$ & $-1.039^{* * *}$ \\
Industry Fixed Effects & No & Yes & No & Yes \\
Year Fixed Effects & No & Yes & No & Yes \\
\hline Observations & 2,690 & 2,684 & 961 & 959 \\
Pseudo $R^{2}$ & $8.5 \%$ & $10.1 \%$ & $6.0 \%$ & $8.3 \%$ \\
\hline \hline & & & & \\
\hline
\end{tabular}




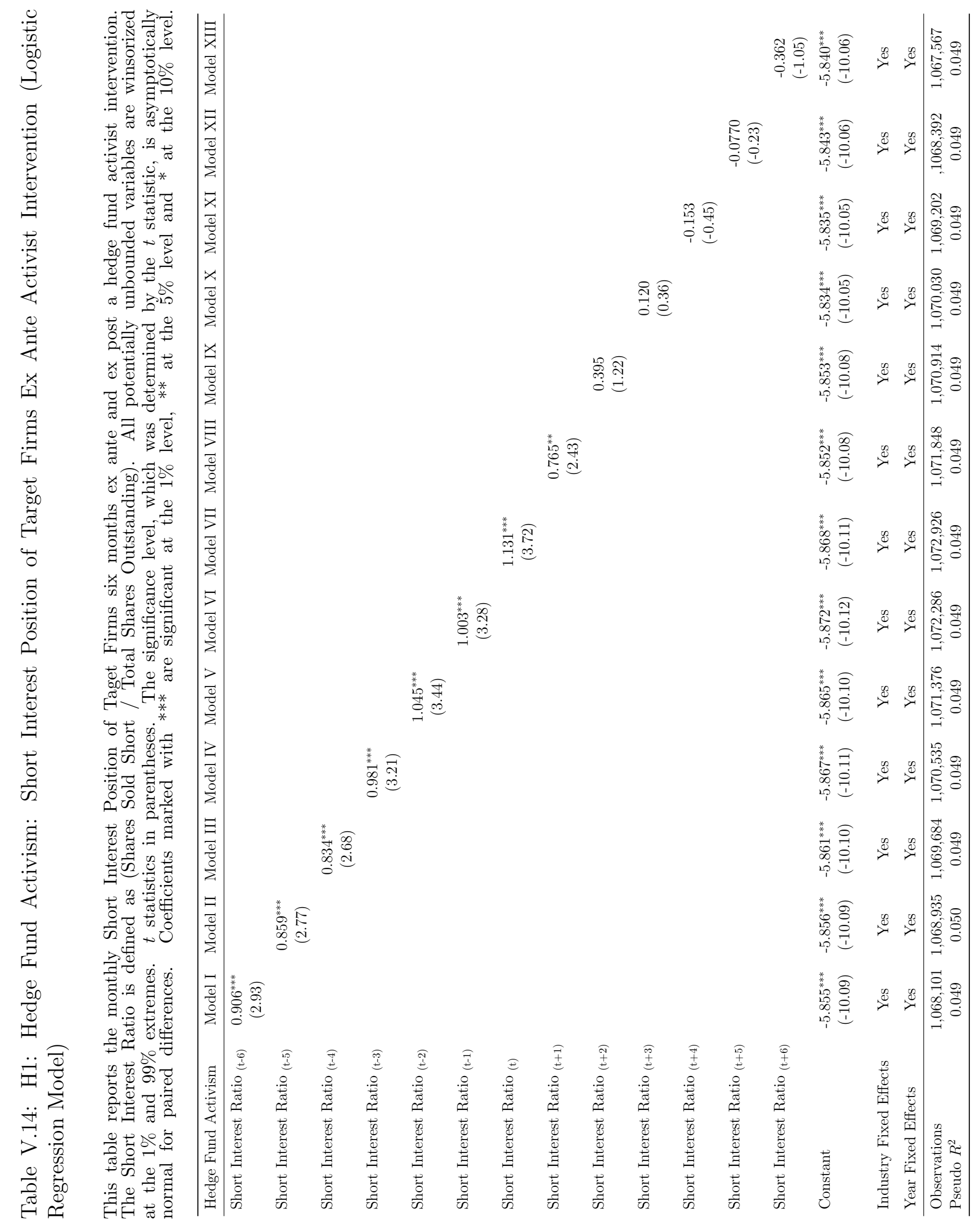




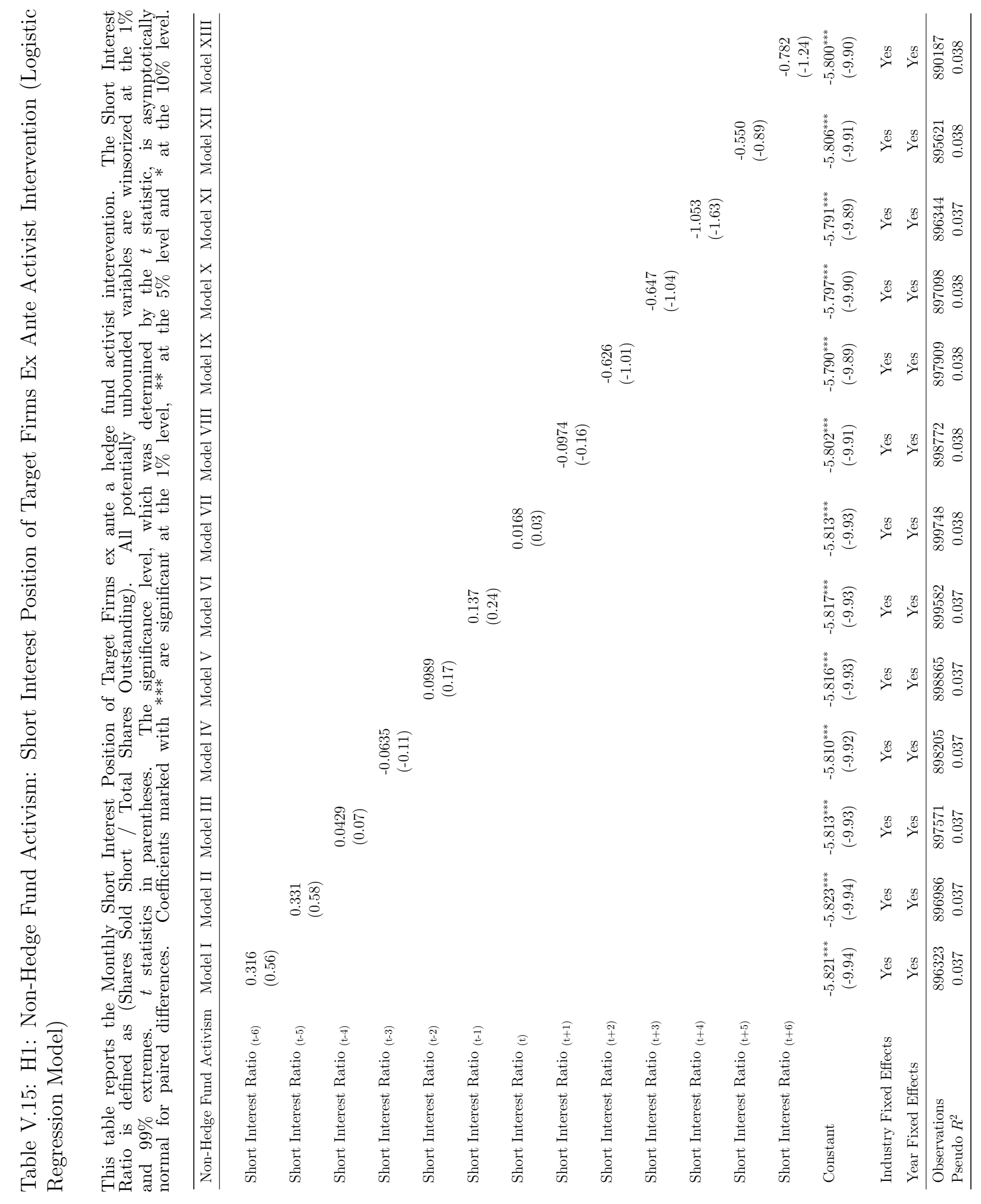




\section{Table V.16: H2: Hedge Fund Activism: Corporate "Inside" Ownership (Logistic Regression Model)}

This table reports the Quarterly Corporate Ownership of Target Firms one month ex ante for both Hedge Fund and Non-hedge Fund activist intereventions. The ownership data is from the FactSet/LionShares database, which provides portfolio holdings of both institutional and individual investors. FactSet compiles ownership information from public filings by investors (such as 13-F filings, Form 3 and Form 4), company annual reports, stock exchanges, and regulatory agencies around the world. The SEC "Corporate insiders" as a company's officers and directors, and any beneficial owners of more than $10 \%$ of a class of the company's equity securities registered under Section 12 of the Securities Exchange Act of 1934 - must file with the SEC a statement of ownership regarding those securities. The data in the table excludes any institutions or noncompany officers and directors that are required to file with the SEC because they are beneficial owners of more than $10 \%$ of a class of the company's equity securities. Institutions are defined as professional money managers, including mutual fund companies, investment advisors, pension funds, bank trusts, and insurance companies. All potentially unbounded variables are winsorized at the $1 \%$ and $99 \%$ extremes. $t$ statistics in parentheses. The significance level, which was determined by the $t$ statistic, is asymptotically normal for paired differences. Coefficients marked with ${ }^{* * *}$ are significant at the $1 \%$ level, $* *$ at the $5 \%$ level and $*$ at the $10 \%$ level.

\begin{tabular}{lcccc}
\hline & $\begin{array}{c}\text { Model I } \\
\text { Hedge Fund }\end{array}$ & $\begin{array}{c}\text { Model II } \\
\text { Hedge Fund }\end{array}$ & $\begin{array}{c}\text { Model III } \\
\text { Non-Hedge Fund }\end{array}$ & $\begin{array}{c}\text { Model IV } \\
\text { Non-Hedge Fund }\end{array}$ \\
\hline & & & & \\
Corporate "Insider" Ownership (t-1) & $-0.0095^{* * *}$ & $-0.0103^{* * *}$ & $-0.0078^{* * *}$ & $-0.0075^{* *}$ \\
Constant & $-0.0601^{* * *}$ & 0.0476 & 0.0541 & 0.1768 \\
& & & & \\
Industry Fixed Effects & No & Yes & No & Yes \\
Year Fixed Effects & No & Yes & No & Yes \\
\hline Observations & 3,043 & 2,763 & 1,059 & 1,041 \\
Pseudo $R^{2}$ & $1.0 \%$ & $1.4 \%$ & $1.0 \%$ & $2.6 \%$ \\
\hline
\end{tabular}




\section{Table V.17: H2: Quarterly Corporate Ownership of Hedge Fund Activist}

Interventions: Robustness Check

This table reports the Quarterly Corporate Ownership of Target Firms one month ex ante for both Hedge Fund and Non-hedge Fund activist intereventions. The ownership data is from the FactSet/LionShares database, which provides portfolio holdings of both institutional and individual investors. All potentially unbounded variables are winsorized at the $1 \%$ and $99 \%$ extremes. The significance level, which was determined by the t-statistic, is asymptotically normal for paired differences. All variables are retrieved from the fiscal quarter prior to the event, unless otherwise noted. Management/Board Ownership is defined as management team and board ownership (excludes Section 16 institutional filers); Log market capitalization and assets are in millions of dollars; Tobin's Q is defined as (book value of debt + market value of equity)/(book value of debt + book value of equity); ROA is (EBIT * (1-tax rate)/Book Value of Total Assets); ROIC is $($ EBIT * (1-tax rate) / Book Value of Invested Capital (Net Fixed Assets + Current Assets - Current Liabilities - Cash)); Revenue Growth is defined as the LTM rolling sales; Cash / Market Cap is total cash to market capitalization; Debt / EBITDA is total debt to EBITDA; Leverage (net) is defined as a net debt to equity; EV / $\operatorname{EBITDA}_{(t-3)}$ is ((book value of debt + book value of equity - cash) / LTM EBITDA) three months prior to the event; Institutional Ownership is derived from $13 \mathrm{~F}$ filings; Operating Margin is (EBITDA/sales); Classified Board is a dummy variable if the firm had a staggered board prior to the event; is a dummy variable is the firm Poison Pill is a dummy variable if the firm had shareholder rights plan in place prior to the event; Hedge Fund 13D Filer is a dummy variable if a hedge fund filed a 13D prior to the event; Multiple Segments is a dummy variable if the firm more than one business unit that accounted for over $10 \%$ of sales prior to the event; and Herfindahl-Hirschman Index is the sales in different business segments as reported by Compustat. $t$ statistics in parentheses. Coefficients marked with *** are significant at the $1 \%$ level, $* *$ at the $5 \%$ level and $*$ at the $10 \%$ level.

\begin{tabular}{lcccc}
\hline & $\begin{array}{c}\text { Model I } \\
\text { Hedge Fund }\end{array}$ & $\begin{array}{c}\text { Model II } \\
\text { Hedge Fund }\end{array}$ & $\begin{array}{c}\text { Model III } \\
\text { Non-Hedge Fund }\end{array}$ & $\begin{array}{c}\text { Model IV } \\
\text { Non-Hedge Fund }\end{array}$ \\
\hline Corporate "Insider" Ownership (t-1) & $-0.006^{* *}$ & $-0.006^{* *}$ & -0.005 & -0.006 \\
Revenue Growth & -0.0152 & -0.0221 & $-0.456^{* * *}$ & $-0.472^{* * *}$ \\
Log Market Capitalization & $-0.256^{* * *}$ & $-0.287^{* * *}$ & $-0.321^{* * *}$ & $-0.333^{* * *}$ \\
Log Assets & $0.239^{* * *}$ & $0.271^{* * *}$ & $0.406^{* * *}$ & $0.424^{* * *}$ \\
Tobin's Q & -0.0182 & -0.0209 & 0.0507 & 0.0367 \\
ROA & $0-0.207$ & -0.002 & -0.865 & -0.408 \\
ROIC & $-2.092^{* *}$ & $-2.292^{* *}$ & -0.113 & -0.056 \\
Total Shareholder Return $(t-12)$ & -0.024 & -0.031 & -0.100 & -0.095 \\
Cash / Market Cap & -0.133 & $-0.184^{*}$ & -0.170 & -0.217 \\
Debt / EBITDA & $0.012^{*}$ & $0.011^{*}$ & -0.008 & -0.008 \\
Institutional Ownership & $0.005^{* * *}$ & $0.004^{* * *}$ & $-0.005^{* *}$ & $-0.006^{* *}$ \\
Herfindahl-Hirschman Index & $1.812^{* *}$ & $6.182^{*}$ & 0.145 & $9.151^{*}$ \\
Multiple Segments & $0.154^{* *}$ & $0.162^{* *}$ & $-0.209^{*}$ & -0.141 \\
Classified Board & $0.595^{* * *}$ & $0.654^{* * *}$ & $0.452^{* * *}$ & $0.541^{* * *}$ \\
Poison Pill & $0.178^{* *}$ & $0.254^{* * *}$ & -0.135 & -0.156 \\
Constant & $-0.538^{* * *}$ & $-0.661^{* *}$ & -0.348 & $-0.878^{* *}$ \\
Industry Fixed Effects & No & Yes & No & Yes \\
Year Fixed Effects & No & Yes & No & Yes \\
\hline Observations & 1,927 & 1,927 & 733 & 733 \\
Pseudo $R^{2}$ & $9.3 \%$ & $11.0 \%$ & $7.7 \%$ & $10.7 \%$ \\
\hline \hline
\end{tabular}




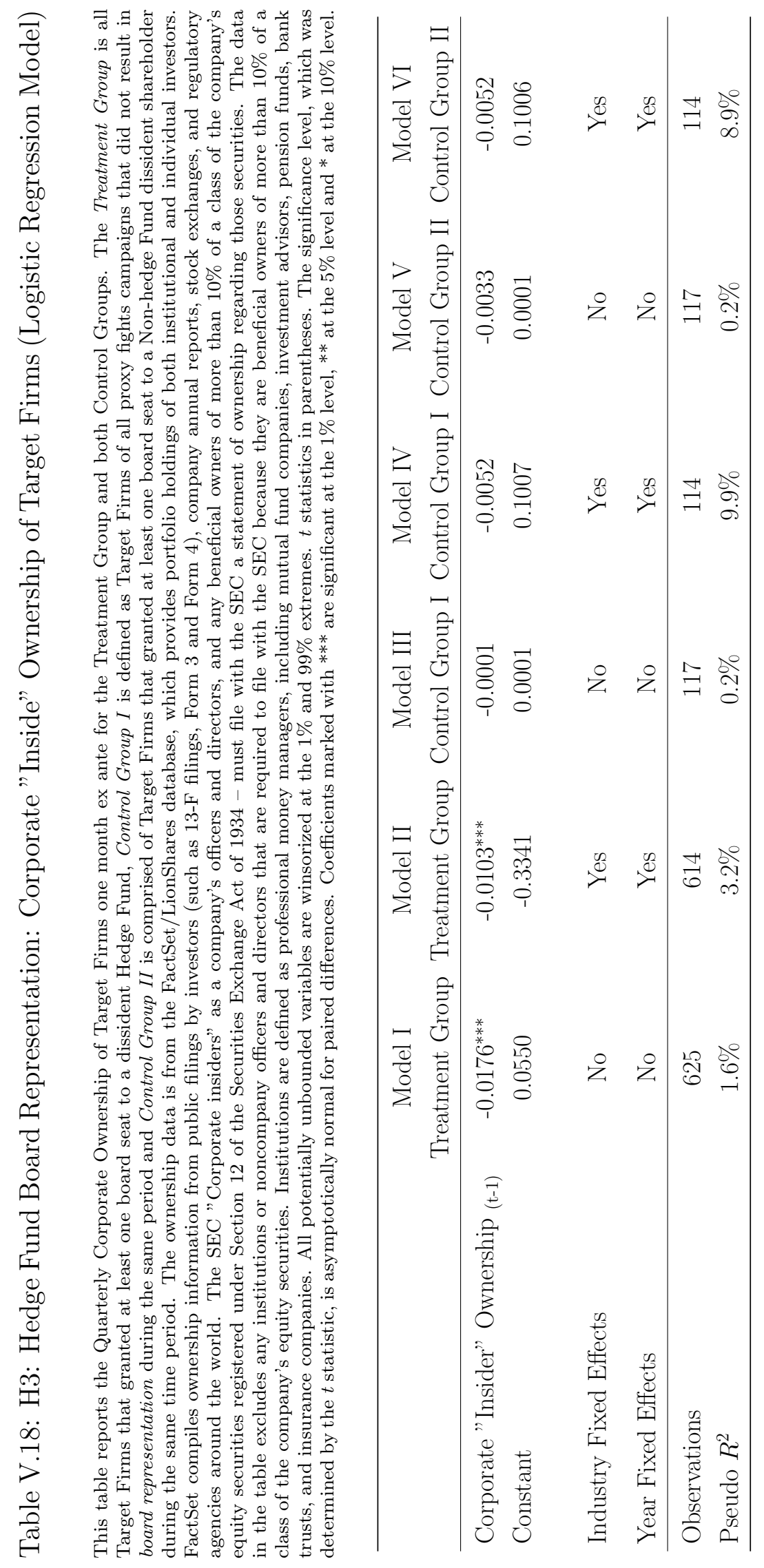




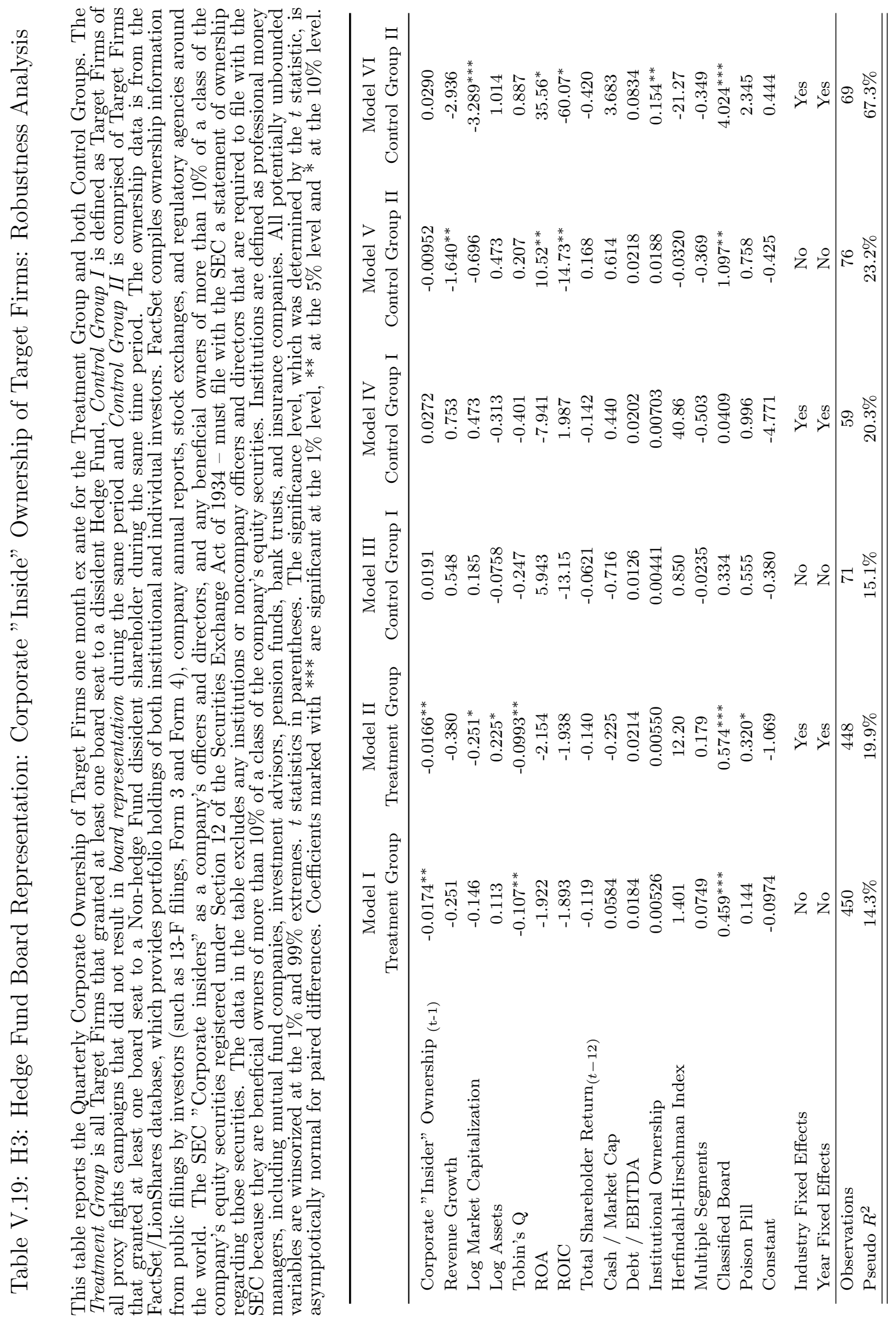




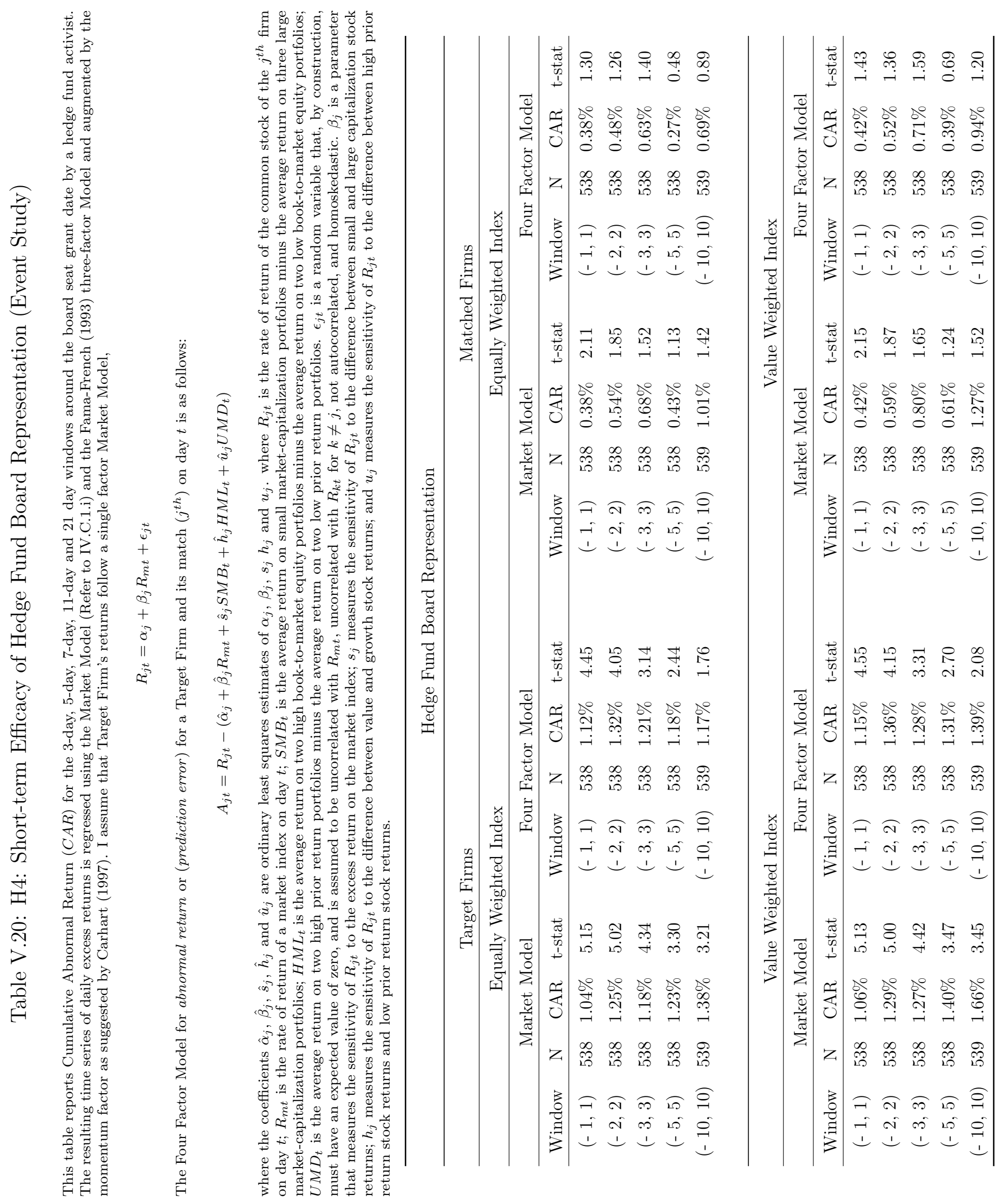




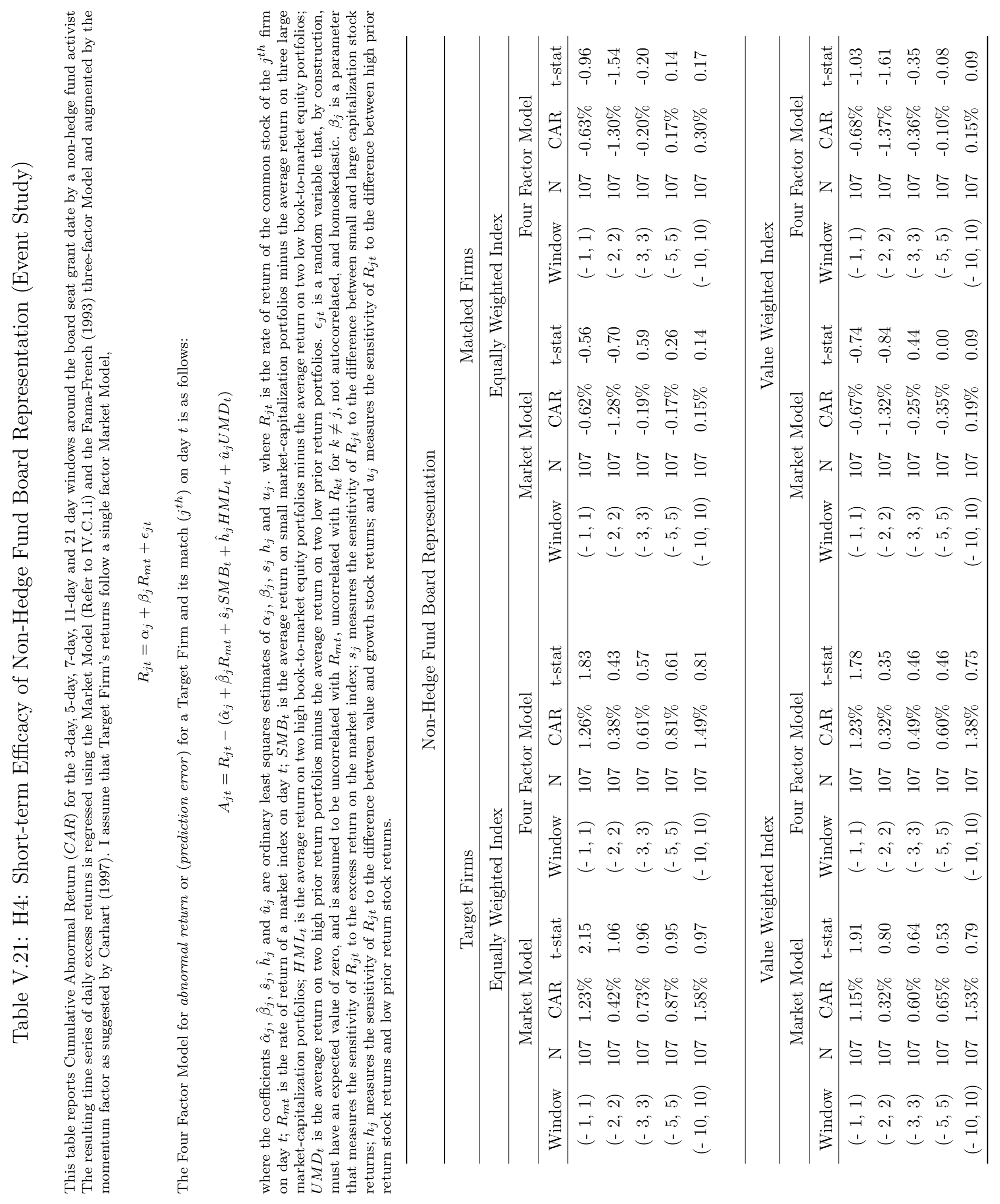




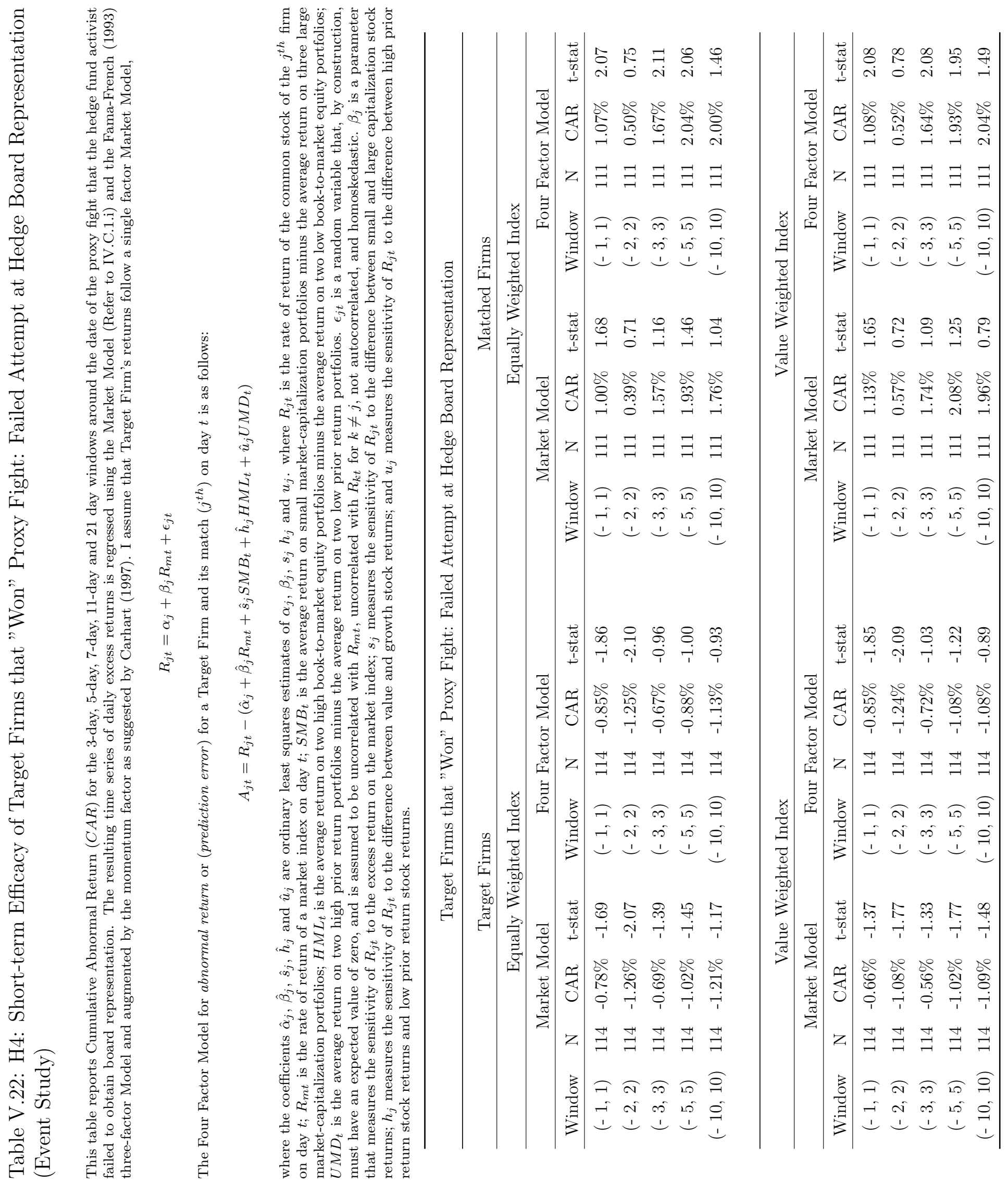


Table V.23: H5: Calendar-time Portfolio Abnormal Returns: Jensen's Alpha (Hedge Fund Board Representation)

This table report Calendar-time Portfolio Abnormal Returns (Jensen's Alpha) for a 5-year period during Ex Post an activist intervention. In each calendar month over the entire sample period, a portfolio was constructed comprising all firms experiencing the event within the previous month. Because the number of event firms is not uniformly distributed over the sample period, the number of firms included in a portfolio is not constant through time. As a result, some new firms are added each month, and some firms exit each month. Accordingly, the portfolios are rebalanced each month, and an equal or value-weighted portfolio excess return is calculated. The resulting time series of monthly excess returns is regressed on the Fama-French (1993) three-factor Model as follows:

- $R_{j t}$ is the equal or value-weighted return for calendar month $t$ for the portfolio of event firms that experienced the event within previous $\mathrm{T}$ years,

- $R_{f t}$ is the risk-free rate,

- $R_{M t}$ is the return on the CRSP value-weight market portfolio,

- $S M B_{t}$, is the difference between the return on the portfolio of "small" stocks and "big" stocks;

- $H M L_{t}$ is the difference between the return a portfolio of "high" and "low" book-to-market stocks;

- $\alpha$ is the average monthly abnormal return on a portfolio of firms over the t-month post-event period,

- $\beta$ is the beta (the sensitivities) of the event portfolio to the three factors.

I report the long-term abnormal returns associated of Target Firms of Hedge Fund Board Representation (target Firms that granted at least one board seat to hedge fund an activist/dissident shareholder) as well as report regression estimates and level of significance from both equal-weighted and value-weighted calendar-time portfolio regressions. The portfolio holding period was determined based on actual trading days and indicates the holding period in years relative to the date that the board seat(s) was granted. For example, the portfolio with holding period [Event +1 ], will continually add target firms that have added an activist/dissident shareholder to their respective board during the year from the date the seat was granted. The portfolio will hold these firms until the earlier of December 31, 2014, a delisting date as a result of a Chapter 11 filing or a sale/merger. Coefficients marked with *** are significant at the $1 \%$ level, ${ }^{* *}$ at the $5 \%$ level and $*$ at the $10 \%$ level. The regression takes the form:

$$
R_{j t}-R_{f t}=\alpha+\beta p, R_{M}-R_{f t}+\beta p, S M B_{t},+\beta p, H M L_{t}+\epsilon_{j t}
$$

\begin{tabular}{|c|c|c|c|c|c|c|c|}
\hline \multicolumn{8}{|c|}{ Panel A: Target Firms (Hedge Fund Board Representation) } \\
\hline & $\mathrm{N}$ & CAR & $\begin{array}{l}\text { qually-We } \\
\text { PWCAAR }\end{array}$ & $\begin{array}{l}\text { ghted } \\
\text { Calendar-Time } \\
\text { Portfolio CAR }\end{array}$ & CAR & Value-Weig & $\begin{array}{l}\text { hted } \\
\text { Calendar-Time } \\
\text { Portfolio CAR }\end{array}$ \\
\hline Event Year +1 & 495 & $0.0940^{* * *}$ & $0.0608^{* * *}$ & $0.0884^{* * *}$ & $0.0977^{* * *}$ & $0.0778^{* * *}$ & $0.0857^{* * *}$ \\
\hline Event Year +2 & 495 & $0.1348^{* * *}$ & $0.2834^{* * *}$ & $0.1476^{* * *}$ & $0.1244^{* * *}$ & $0.3077^{* * *}$ & $0.2213^{* * *}$ \\
\hline Event Year +3 & 495 & $0.1889^{* * *}$ & $0.4852^{* * *}$ & $0.1985^{* * *}$ & $0.1456^{* * *}$ & $0.4910^{* * *}$ & $0.2904^{* * *}$ \\
\hline Event Year +4 & 495 & $0.1718^{* * *}$ & $0.5970^{* * *}$ & $0.1636^{* * *}$ & $0.0949 * * *$ & $0.6178^{* * *}$ & $0.3315^{* *}$ \\
\hline Event Year +5 & 495 & $0.1550^{* * *}$ & $0.6407^{* * *}$ & $0.1163^{* * *}$ & $\mathrm{NM}$ & $0.6710^{* * *}$ & $\mathrm{NM}$ \\
\hline \multicolumn{8}{|c|}{ Panel B: Matched Firms (Hedge Fund Board Representation) } \\
\hline & $\mathrm{N}$ & CAR & $\begin{array}{l}\text { qually-We } \\
\text { PWCAAR }\end{array}$ & $\begin{array}{l}\text { ghted } \\
\text { Calendar-Time } \\
\text { Portfolio CAR }\end{array}$ & CAR & Value-Weig & $\begin{array}{l}\text { hted } \\
\text { Calendar-Time } \\
\text { Portfolio CAR }\end{array}$ \\
\hline Event Year +1 & 495 & $0.0402^{* * *}$ & $0.0667^{* *}$ & 0.0154 & $0.0418^{* * *}$ & $0.0785^{* *}$ & $0.0131^{* *}$ \\
\hline Event Year +2 & 495 & $0.0286^{* * *}$ & $0.0797^{* *}$ & 0.0049 & $0.0384^{* * *}$ & $0.1061^{* *}$ & 0.0118 \\
\hline Event Year +3 & 495 & $0.021^{* * *}$ & $0.1176^{* *}$ & -0.0162 & $0.0291^{* * *}$ & $0.1435^{* *}$ & -0.0168 \\
\hline Event Year +4 & 495 & $0.0177^{* * *}$ & $0.1344^{*}$ & -0.0453 & $0.0117^{* * *}$ & $0.1418^{*}$ & -0.0527 \\
\hline Event Year +5 & 495 & $0.0352^{* * *}$ & $0.2066^{*}$ & -0.0372 & $0.0176^{* * *}$ & $0.1921^{*}$ & -0.0610 \\
\hline \multicolumn{8}{|c|}{ Panel C: Differences (Hedge Fund Board Representation) } \\
\hline & $\mathrm{N}$ & CAR & $\begin{array}{l}\text { qually-We } \\
\text { PWCAAR }\end{array}$ & $\begin{array}{l}\text { ghted } \\
\text { Calendar-Time } \\
\text { Portfolio CAR }\end{array}$ & CAR & Value-Weig & $\begin{array}{l}\text { hted } \\
\text { Calendar-Time } \\
\text { Portfolio CAR }\end{array}$ \\
\hline Event Year +1 & 495 & 0.0538 & -0.0059 & 0.0730 & 0.0559 & -0.0007 & 0.0726 \\
\hline Event Year +2 & 495 & 0.1062 & 0.2037 & 0.1427 & 0.0860 & 0.2016 & 0.2095 \\
\hline Event Year +3 & 495 & 0.1679 & 0.3676 & 0.2147 & 0.1165 & 0.3475 & 0.3072 \\
\hline Event Year +4 & 495 & 0.1541 & 0.4626 & 0.2089 & 0.0832 & 0.4760 & 0.3842 \\
\hline Event Year +5 & 495 & 0.1198 & 0.4341 & 0.1535 & NM & 0.4789 & $\mathrm{NM}$ \\
\hline
\end{tabular}


Table V.24: H5: Calendar-time Portfolio Abnormal Returns: Jensen's Alpha (Non-Hedge Fund Board Representation)

This table report Calendar-time Portfolio Abnormal Returns (Jensen's Alpha) for a 5-year period during Ex Post an activist intervention. In each calendar month over the entire sample period, a portfolio was constructed comprising all firms experiencing the event within the previous month. Because the number of event firms is not uniformly distributed over the sample period, the number of firms included in a portfolio is not constant through time. As a result, some new firms are added each month, and some firms exit each month. Accordingly, the portfolios are rebalanced each month, and an equal or value-weighted portfolio excess return is calculated. The resulting time series of monthly excess returns is regressed on the Fama-French (1993) three-factor Model as follows:

- $R_{j t}$ is the equal or value-weighted return for calendar month $t$ for the portfolio of event firms that experienced the event within previous $\mathrm{T}$ years,

- $R_{f t}$ is the risk-free rate,

- $R_{M t}$ is the return on the CRSP value-weight market portfolio,

- $S M B_{t}$, is the difference between the return on the portfolio of "small" stocks and "big" stocks;

- $H M L_{t}$ is the difference between the return a portfolio of "high" and "low" book-to-market stocks;

- $\alpha$ is the average monthly abnormal return on a portfolio of firms over the t-month post-event period,

- $\beta$ is the beta (the sensitivities) of the event portfolio to the three factors.

I report the long-term abnormal returns associated of Target Firms of Non-Hedge Fund Board Representation (target Firms that granted at least one board seat to a non-hedge fund activist/dissident shareholder) as well as report regression estimates and level of significance from both equal-weighted and value-weighted calendar-time portfolio regressions. The portfolio holding period was determined based on actual trading days and indicates the holding period in years relative to the date that the board seat(s) was granted. For example, the portfolio with holding period [Event +1 , will continually add target firms that have added an activist/dissident shareholder to their respective board during the year from the date the seat was granted. The portfolio will hold these firms until the earlier of December 31, 2014, a delisting date as a result of a Chapter 11 filing or a sale/merger. Coefficients marked with *** are significant at the $1 \%$ level, ${ }^{* *}$ at the $5 \%$ level and ${ }^{*}$ at the $10 \%$ level. The regression takes the form:

$$
R_{j t}-R_{f t}=\alpha+\beta p, R_{M}-R_{f t}+\beta p, S M B_{t},+\beta p, H M L_{t}+\epsilon_{j t}
$$

\begin{tabular}{|c|c|c|c|c|c|c|c|}
\hline \multicolumn{8}{|c|}{ Panel A: Target Firms (Non-Hedge Fund Board Representation) } \\
\hline & $\mathrm{N}$ & CAR & $\begin{array}{l}\text { qually-Weig } \\
\text { PWCAAR }\end{array}$ & $\begin{array}{l}\text { Calendar-Time } \\
\text { Portfolio CAR }\end{array}$ & CAR & $\begin{array}{l}\text { Value-Weig } \\
\text { PWCAAR }\end{array}$ & $\begin{array}{l}\text { hted } \\
\text { Calendar-Time } \\
\text { Portfolio CAR }\end{array}$ \\
\hline Event Year +1 & 106 & $0.0775^{*}$ & 0.0534 & 0.1147 & 0.0973* & 0.0557 & $0.1251^{*}$ \\
\hline Event Year +2 & 106 & $0.0928^{* *}$ & 0.1155 & 0.1478 & $0.1106^{* *}$ & 0.1109 & 0.1506 \\
\hline Event Year +3 & 108 & $0.1422^{* * *}$ & $0.2403^{* *}$ & $0.2296^{*}$ & $0.1223^{* * *}$ & 0.1961 & 0.1944 \\
\hline Event Year +4 & 108 & $0.1802^{* * *}$ & $0.2966^{* *}$ & $0.2691^{*}$ & $0.1374^{* * *}$ & 0.2173 & 0.1987 \\
\hline Event Year +5 & 110 & $0.2514^{* * *}$ & $0.4192 * *$ & $0.4023^{* *}$ & $0.1974^{* * *}$ & $0.3100^{*}$ & $0.3183^{*}$ \\
\hline \multicolumn{8}{|c|}{ Panel B: Matched Firms (Non-Hedge Fund Board Representations) } \\
\hline & $\mathrm{N}$ & CAR & qually-Weiq & $\begin{array}{l}\text { Shted } \\
\text { Calendar-Time } \\
\text { Portfolio CAR }\end{array}$ & CAR & Value-Weig & $\begin{array}{l}\text { hted } \\
\text { Calendar-Time } \\
\text { Portfolio CAR }\end{array}$ \\
\hline Event Year +1 & 106 & $-0.08^{* * *}$ & $-0.0939^{*}$ & -0.0825 & $-0.0653^{* * *}$ & $-0.0843^{* *}$ & -0.0776 \\
\hline Event Year +2 & 106 & $-0.1419 * * *$ & $-0.1527^{*}$ & $-0.1325^{*}$ & $-0.1397^{* * *}$ & $-0.1307^{*}$ & $-0.1527^{*}$ \\
\hline Event Year +3 & 108 & $-0.1665^{* * *}$ & $-0.1577^{*}$ & $-0.1754^{*}$ & $-0.1743^{* *}$ & $-0.1255^{*}$ & $-0.212^{*}$ \\
\hline Event Year +4 & 108 & $-0.1452^{* * *}$ & -0.1666 & -0.1683 & $-0.1784^{* * *}$ & $-0.1484^{*}$ & $-0.2336^{*}$ \\
\hline Event Year +5 & 110 & $-0.107^{* * *}$ & -0.1507 & -0.1406 & $-0.1737^{* * *}$ & -0.1700 & -0.2424 \\
\hline \multicolumn{8}{|c|}{ Panel C: Differences (Non-Hedge Fund Board Representation) } \\
\hline & & \multicolumn{3}{|c|}{$\begin{array}{l}\text { Equally-Weighted } \\
\text { Calendar-Time }\end{array}$} & \multicolumn{3}{|c|}{ Value-Weighted } \\
\hline & $\mathrm{N}$ & CAR & PWCAAR & Portfolio CAR & CAR & PWCAAR & Portfolio CAR \\
\hline Event Year +1 & 106 & 0.1575 & 0.1473 & 0.1972 & 0.1626 & 0.1400 & 0.2027 \\
\hline Event Year +2 & 106 & 0.2347 & 0.2682 & 0.2803 & 0.2503 & 0.2416 & 0.3033 \\
\hline Event Year +3 & 108 & 0.3087 & 0.3980 & 0.4050 & 0.2966 & 0.3216 & 0.4064 \\
\hline Event Year +4 & 108 & 0.3254 & 0.4632 & 0.4374 & 0.3158 & 0.3657 & 0.4323 \\
\hline Event Year +5 & 110 & 0.3584 & 0.5699 & 0.5429 & 0.3711 & 0.4800 & 0.5607 \\
\hline
\end{tabular}


Table V.25: H5: Calendar-time Portfolio Abnormal Returns: Jensen's Alpha (Target Firm that "Won" a Proxy Fight: No Hedge Fund Board Representation)

This table report Calendar-time Portfolio Abnormal Returns (Jensen's Alpha) for a 5-year period during Ex Post an activist intervention. In each calendar month over the entire sample period, a portfolio was constructed comprising all firms experiencing the event within the previous month. Because the number of event firms is not uniformly distributed over the sample period, the number of firms included in a portfolio is not constant through time. As a result, some new firms are added each month, and some firms exit each month. Accordingly, the portfolios are rebalanced each month, and an equal or value-weighted portfolio excess return is calculated. The resulting time series of monthly excess returns is regressed on the Fama-French (1993) three-factor Model as follows:

- $R_{j t}$ is the equal or value-weighted return for calendar month $t$ for the portfolio of event firms that experienced the event within previous $\mathrm{T}$ years,

- $R_{f t}$ is the risk-free rate,

- $R_{M t}$ is the return on the CRSP value-weight market portfolio,

- $S M B_{t}$, is the difference between the return on the portfolio of "small" stocks and "big" stocks;

- $H M L_{t}$ is the difference between the return a portfolio of "high" and "low" book-to-market stocks;

- $\alpha$ is the average monthly abnormal return on a portfolio of firms over the t-month post-event period,

- $\beta$ is the beta (the sensitivities) of the event portfolio to the three factors.

I report the long-term abnormal returns associated of Target Firms that "Won" a Proxy Fight (i.e., no Hedge Fund Board Representation) as well as report regression estimates and level of significance from both equal-weighted and value-weighted calendar-time portfolio regressions. The portfolio holding period was determined based on actual trading days and indicates the holding period in years relative to the date that the board seat(s) was granted. For example, the portfolio with holding period [Event +1 ], will continually add target firms that have added an activist/dissident shareholder to their respective board during the year from the date the seat was granted. The portfolio will hold these firms until the earlier of December 31, 2014, a delisting date as a result of a Chapter 11 filing or a sale/merger. Coefficients marked with ${ }^{* * *}$ are significant at the $1 \%$ level, ${ }^{* *}$ at the $5 \%$ level and $*$ at the $10 \%$ level. The regression takes the form:

$$
R_{j t}-R_{f t}=\alpha+\beta p, R_{M}-R_{f t}+\beta p, S M B_{t},+\beta p, H M L_{t}+\epsilon_{j t}
$$

Panel A: Target Firms (Failed Attempt by Hedge Fund Board Representation)

\begin{tabular}{lc|ccc|ccc}
\hline & & \multicolumn{3}{|c|}{ Equally-Weighted } & \multicolumn{3}{c}{ Value-Weighted } \\
& $\mathrm{N}$ & CAR & PWCAAR & Portfolio CAR & CAR & PWCAAR & Portfolio CAR \\
\hline Event Year +1 & 112 & -0.0065 & 0.0113 & -0.0111 & 0.0435 & 0.0272 & 0.0512 \\
Event Year +2 & 112 & -0.0263 & 0.0013 & -0.0640 & 0.0474 & 0.0172 & 0.0394 \\
Event Year +3 & 112 & $0.0134^{* *}$ & 0.1111 & -0.0561 & $0.1169^{* *}$ & 0.1263 & 0.0922 \\
Event Year +4 & 112 & $-0.0423^{*}$ & 0.1004 & -0.1476 & $0.0893^{* *}$ & 0.1308 & 0.0450 \\
Event Year +5 & 112 & $-0.0293^{*}$ & 0.0975 & -0.1322 & $0.085^{* *}$ & 0.1107 & 0.0437 \\
\hline
\end{tabular}

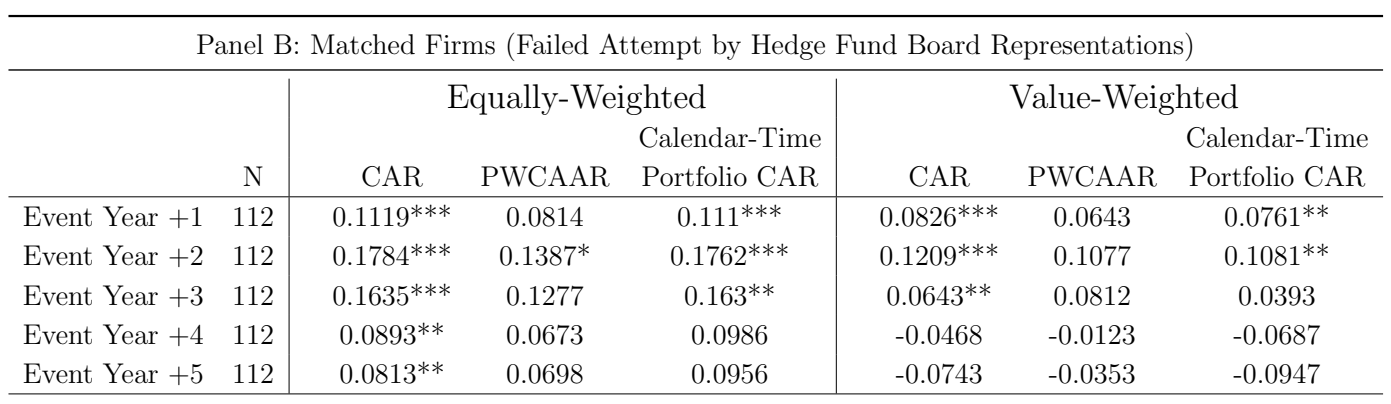

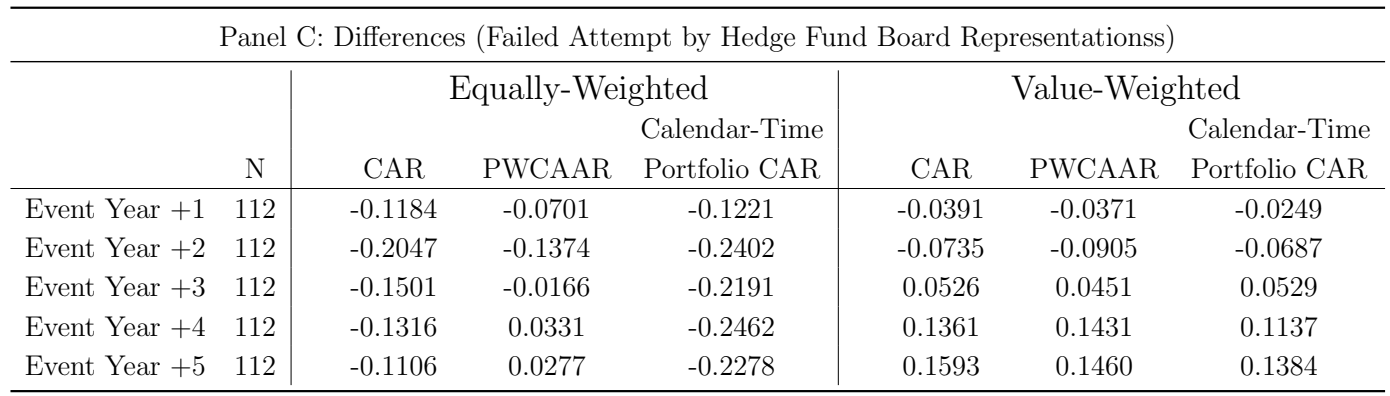




\section{Table V.26: H5: Long-term Abnormal Returns of Treatment and Control Groups (Individual Firm Regressions)}

The table reports statistics on long-term abnormal returns associated with Target firms of all shareholder activist interventions. I report regression estimates and level of significance from value-weighted calendar-time portfolio regressions. The 'portfolio holding period,' indicates the holding period in months relative to the month of the hedge fund intervention. For example, the portfolio with holding period $[+1,+12]$, continually adds target firms that have had an activist event in the preceding month and holds these firms through a year after their respective activism event. I report regression results separately for all Target Firms in Panel A, Matched Firms in Panel B and the differences between Target Firms and Matched Firm $\alpha$ in Panel C. $\alpha$ is the estimate of the regression intercept from the factor model. $\beta p, R_{M}-R_{f}$ is the loading on the market excess return. $\beta p, S M B$ and $\beta p, H M L$ are the estimates of portfolio factor loadings on the Fama-French size and book-to-market factors. Adjusted $R^{2}$ is derived from the monthly observations. Coefficients marked with $* * *$ are significant at the $1 \%$ level, $* *$ at the $5 \%$ level and ${ }^{*}$ at the $10 \%$ level. The regression takes the form:

$$
R_{j t}-R_{f t}=\alpha+\beta p, R_{M}-R_{f t}+\beta p, S M B_{t},+\beta p, H M L_{t}+\epsilon_{j t}
$$

Panel A: Target Firm Long-term Abnormal Returns of Treatment Group (Fama-French Model)

\begin{tabular}{|c|c|c|c|c|c|c|c|c|c|c|}
\hline \multicolumn{11}{|c|}{ Holding Period (in Years) } \\
\hline & {$[$ Event -5$]$} & [Event -4] & [Event -3] & [Event -2] & [Event -1] & {$[$ Event +1$]$} & {$[$ Event +2$]$} & {$[$ Event +3$]$} & {$[$ Event +4$]$} & [Event +5] \\
\hline$\alpha$ & $-0.270^{* * *}$ & $-0.1440^{*}$ & $-0.1908^{* * *}$ & $-0.1296^{* * *}$ & $-0.0564^{*}$ & -0.006 & 0.0552 & 0.0828 & 0.0768 & 0.084 \\
\hline$\beta p, R_{M^{-}} R_{f}$ & $1.0233^{* * *}$ & $0.9866^{* * *}$ & $0.9889^{* * *}$ & $0.9506^{* * *}$ & $0.9039^{* * *}$ & $0.9863^{* * *}$ & $0.9665^{* * *}$ & $0.9665^{* * *}$ & $0.9986^{* * *}$ & $1.0023^{* * *}$ \\
\hline$\beta p, \mathrm{SMB}$ & $0.6494^{* * *}$ & $0.6668^{* * *}$ & $0.5981^{* * *}$ & $0.6142^{* * *}$ & $0.7282^{* * *}$ & $0.5354^{* * *}$ & $0.5465^{* * *}$ & $0.5465^{* * *}$ & $0.4928^{* * *}$ & $0.4875^{* * *}$ \\
\hline$\beta p, \mathrm{HML}$ & $0.4441^{* * *}$ & $0.4868^{* * *}$ & $0.4753^{* * *}$ & $0.4055^{* * *}$ & $0.3876^{* * *}$ & $0.4773^{* * *}$ & $0.5455^{* * *}$ & $0.5455^{* * *}$ & $0.529^{* * *}$ & $0.5136^{* * *}$ \\
\hline Adjusted $R^{2}$ & $74.34 \%$ & $73.12 \%$ & $72.93 \%$ & $71.34 \%$ & $59.49 \%$ & $57.59 \%$ & $63.14 \%$ & $63.14 \%$ & $68.40 \%$ & $69.45 \%$ \\
\hline F-Test & $262.65^{* * *}$ & $235.90^{* * *}$ & $222.79^{* * *}$ & $195.98^{* * *}$ & $110.14^{* * *}$ & $96.51^{* * *}$ & $121.48^{* * *}$ & $121.48^{* * *}$ & $153.24^{* * *}$ & $160.91^{* * *}$ \\
\hline
\end{tabular}

Panel B: Target Firm Long-term Abnormal Returns of Control Group I (Fama-French Model)

\begin{tabular}{|c|c|c|c|c|c|c|c|c|c|c|}
\hline \multicolumn{11}{|c|}{ Holding Period (in Years) } \\
\hline & [Event -5] & [Event -4] & [Event -3] & [Event -2] & [Event -1] & {$[$ Event +1$]$} & {$[$ Event +2$]$} & {$[$ Event +3$]$} & {$[$ Event +4$]$} & [Event +5$]$ \\
\hline$\alpha$ & $-0.2520^{*}$ & -0.1392 & $-0.2556^{* * *}$ & $-0.2280^{* * *}$ & -0.0048 & -0.0300 & -0.0768 & -0.0252 & -0.0240 & -0.0360 \\
\hline$\beta p, R_{M^{-}} R_{f}$ & $0.9773^{* * *}$ & $0.923^{* * *}$ & $1.0092^{* * *}$ & $0.9638^{* * *}$ & $0.7258^{* * *}$ & $1.2693^{* * *}$ & $1.2671^{* * *}$ & $1.1957^{* * *}$ & $1.2172^{* * *}$ & $1.1947^{* * *}$ \\
\hline$\beta p, \mathrm{SMB}$ & $0.6837^{* * *}$ & $0.6648^{* * *}$ & $0.4459^{* * *}$ & $0.264^{* * *}$ & $0.382^{* * *}$ & $0.4754^{* * *}$ & $0.4465^{* * *}$ & $0.3843^{* * *}$ & $0.4019^{* * *}$ & $0.3893^{* * *}$ \\
\hline$\beta p, \mathrm{HML}$ & $0.2899^{* * *}$ & $0.195^{* * *}$ & $0.248^{* * *}$ & $0.274^{* * *}$ & $0.4052^{* * *}$ & $0.8408^{* * *}$ & $0.7289^{* * *}$ & $0.6317^{* * *}$ & $0.6544^{* * *}$ & $0.6122^{* * *}$ \\
\hline Adjusted $R^{2}$ & $66.67 \%$ & $63.16 \%$ & $55.69 \%$ & $44.25 \%$ & $21.49 \%$ & $40.36 \%$ & $50.00 \%$ & $51.70 \%$ & $55.87 \%$ & $56.94 \%$ \\
\hline F-Test & $150.39^{* * *}$ & $122.15^{* * *}$ & $84.78^{* * *}$ & $51.01^{* * *}$ & $17.60^{* * *}$ & $40.70^{* * *}$ & $59.67^{* * *}$ & $63.79^{* * *}$ & $75.29^{* * *}$ & $78.59^{* * *}$ \\
\hline
\end{tabular}

Panel C: Target Firm Long-term Abnormal Returns of Control Group II (Fama-French Model)

\begin{tabular}{lccccccccccc}
\hline \multicolumn{10}{c}{ Holding Period (in Years) } \\
\hline & {$[$ Event -5] } & {$[$ Event -4] } & {$[$ Event -3] } & {$[$ Event -2] } & {$[$ Event -1] } & {$[$ Event +1] } & {$[$ Event +2] } & {$[$ Event +3] } & {$[$ Event +4] } & {$[$ Event +5] } \\
\hline$\alpha$ & -0.042 & 0.0048 & -0.0756 & -0.1032 & 0.1428 & $0.0852^{*}$ & 0.1224 & $0.2232^{*}$ & 0.24 & 0.306 \\
$\beta p, R_{M^{-} R_{f}}$ & $0.9255^{* * *}$ & $0.9174^{* * *}$ & $0.9139^{* * *}$ & $0.9053^{* * *}$ & $1.1254^{* * *}$ & $0.6955^{* * *}$ & $0.6484^{* * *}$ & $0.7163^{* * *}$ & $0.7397^{* * *}$ & $0.7436^{* * *}$ \\
$\beta p, \mathrm{SMB}$ & $0.4955^{* * *}$ & $0.5664^{* * *}$ & $0.5169^{* * *}$ & $0.4659^{* * *}$ & 0.0999 & $0.3198^{*}$ & $0.434^{* * *}$ & $0.4003^{* * *}$ & $0.3959^{* * *}$ & $0.403^{* * *}$ \\
$\beta p, \mathrm{HML}$ & $0.324^{* * *}$ & $0.3624^{* * *}$ & $0.4247^{* * *}$ & $0.4537^{* * *}$ & 0.0683 & $0.5826^{* * *}$ & $0.5913^{* * *}$ & $0.5934^{* * *}$ & $0.5719^{* * *}$ & $0.5909^{* * *}$ \\
& & & & & & & & & & & \\
Adjusted $R^{2}$ & $57.18 \%$ & $54.85 \%$ & $58.54 \%$ & $45.49 \%$ & $11.08 \%$ & $19.45 \%$ & $22.76 \%$ & $35.26 \%$ & $37.09 \%$ & $38.79 \%$ \\
F-Test & $57.18 \%$ & $54.85 \%$ & $58.54 \%$ & $45.49 \%$ & $11.08 \%$ & $19.45 \%$ & $22.76 \%$ & $35.26 \%$ & $37.09 \%$ & $38.79 \%$ \\
\hline \hline
\end{tabular}




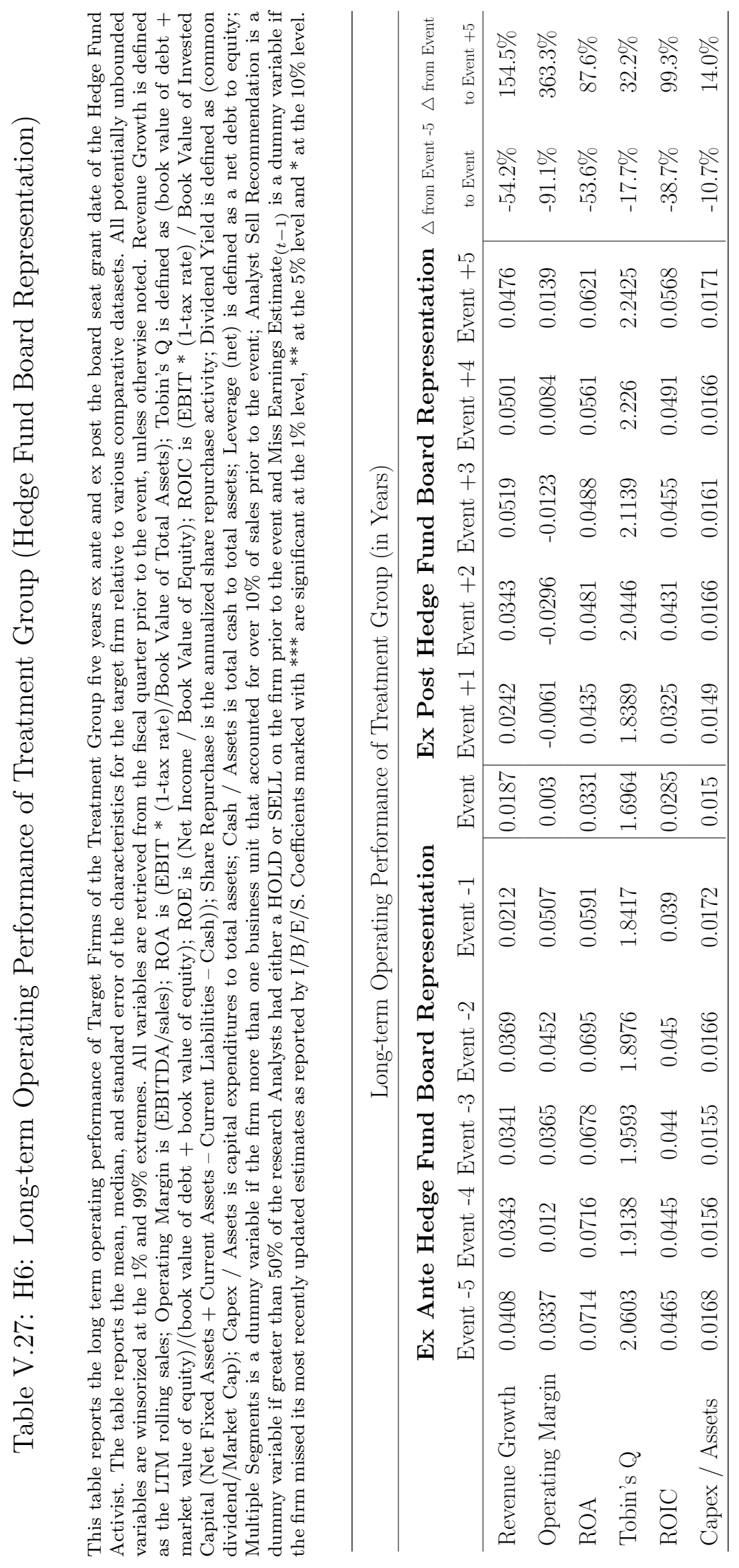



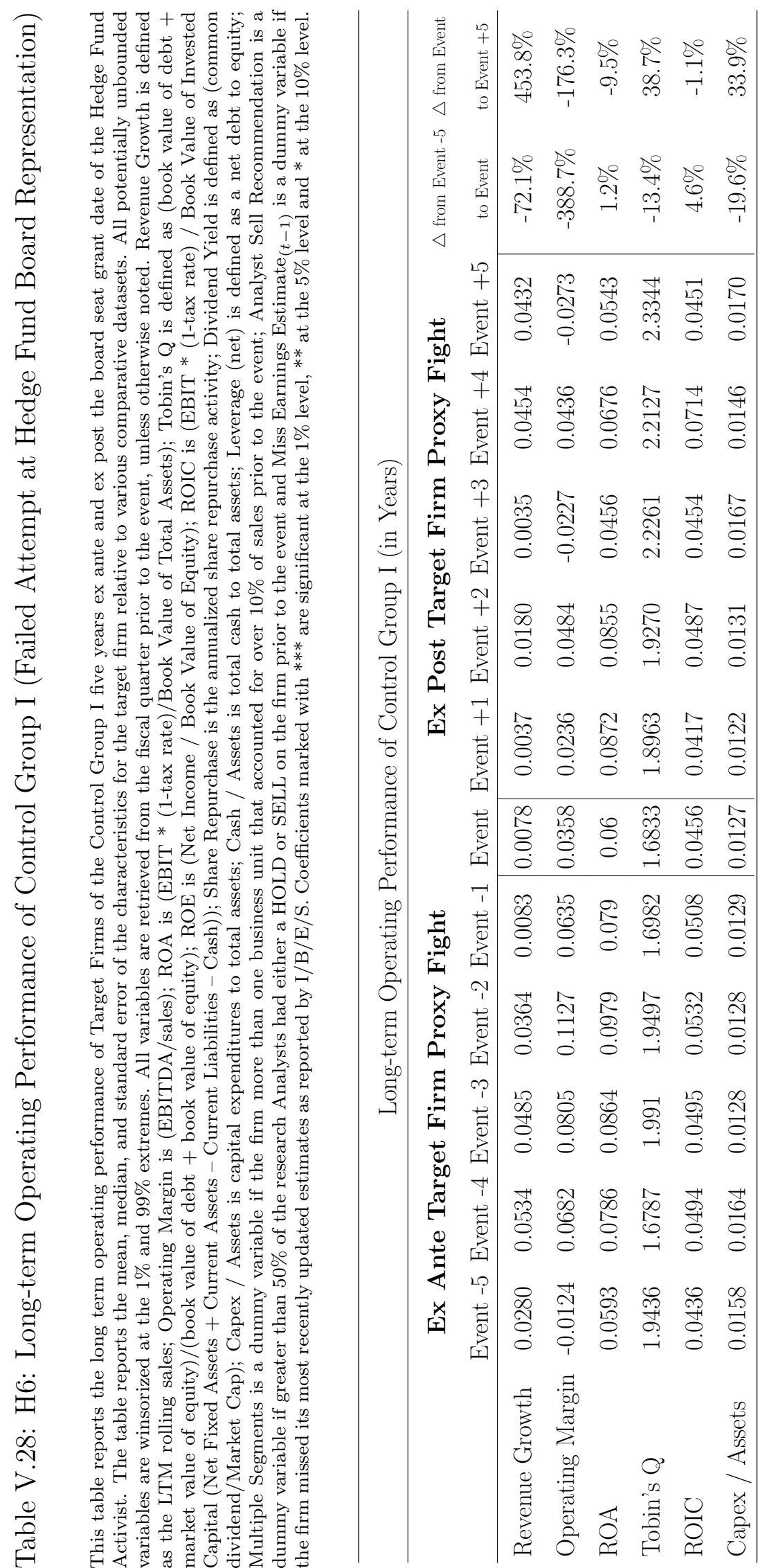


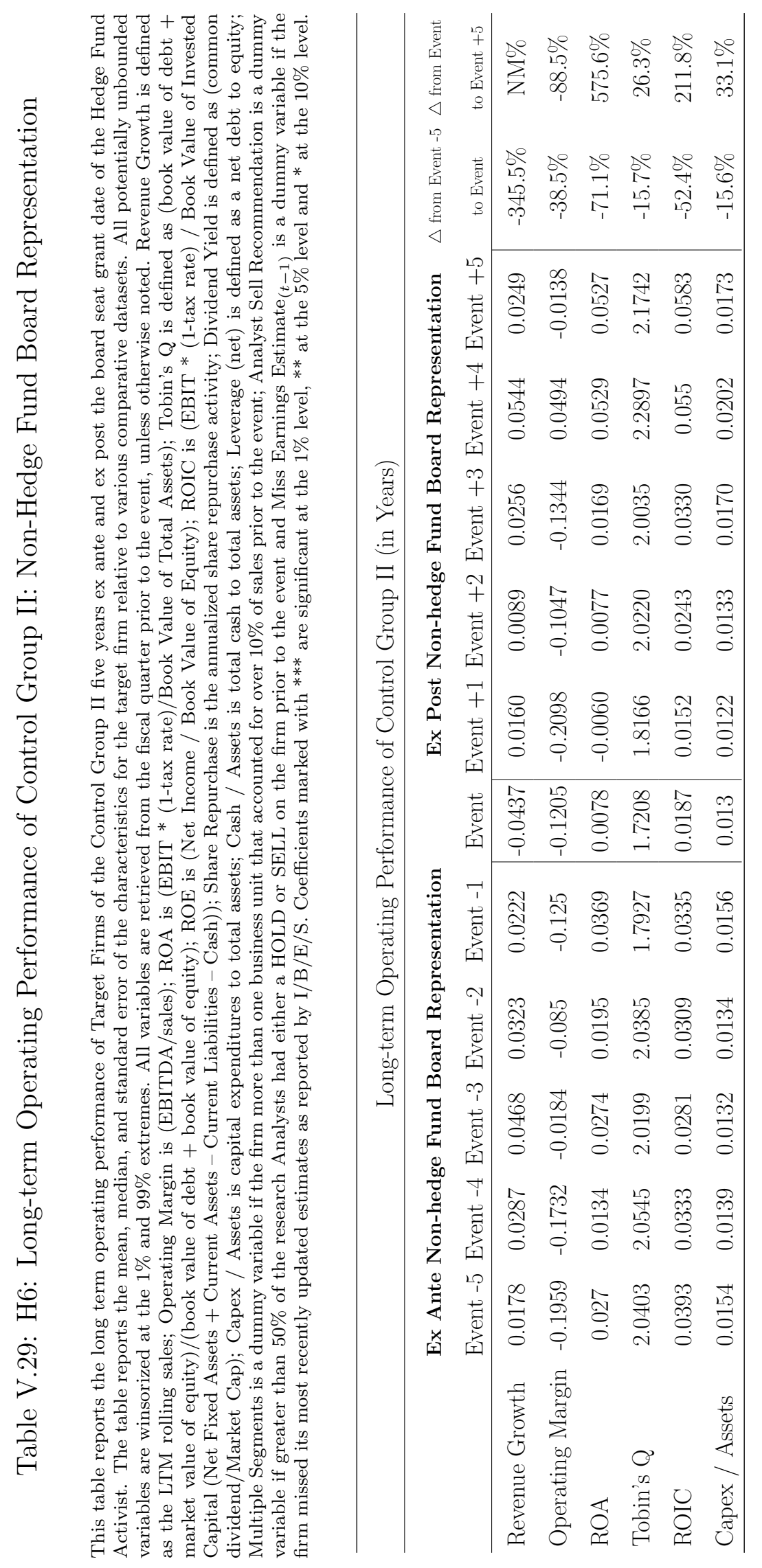


Figure V.8: Buy and Hold Portfolio Returns: All Activist Intervention

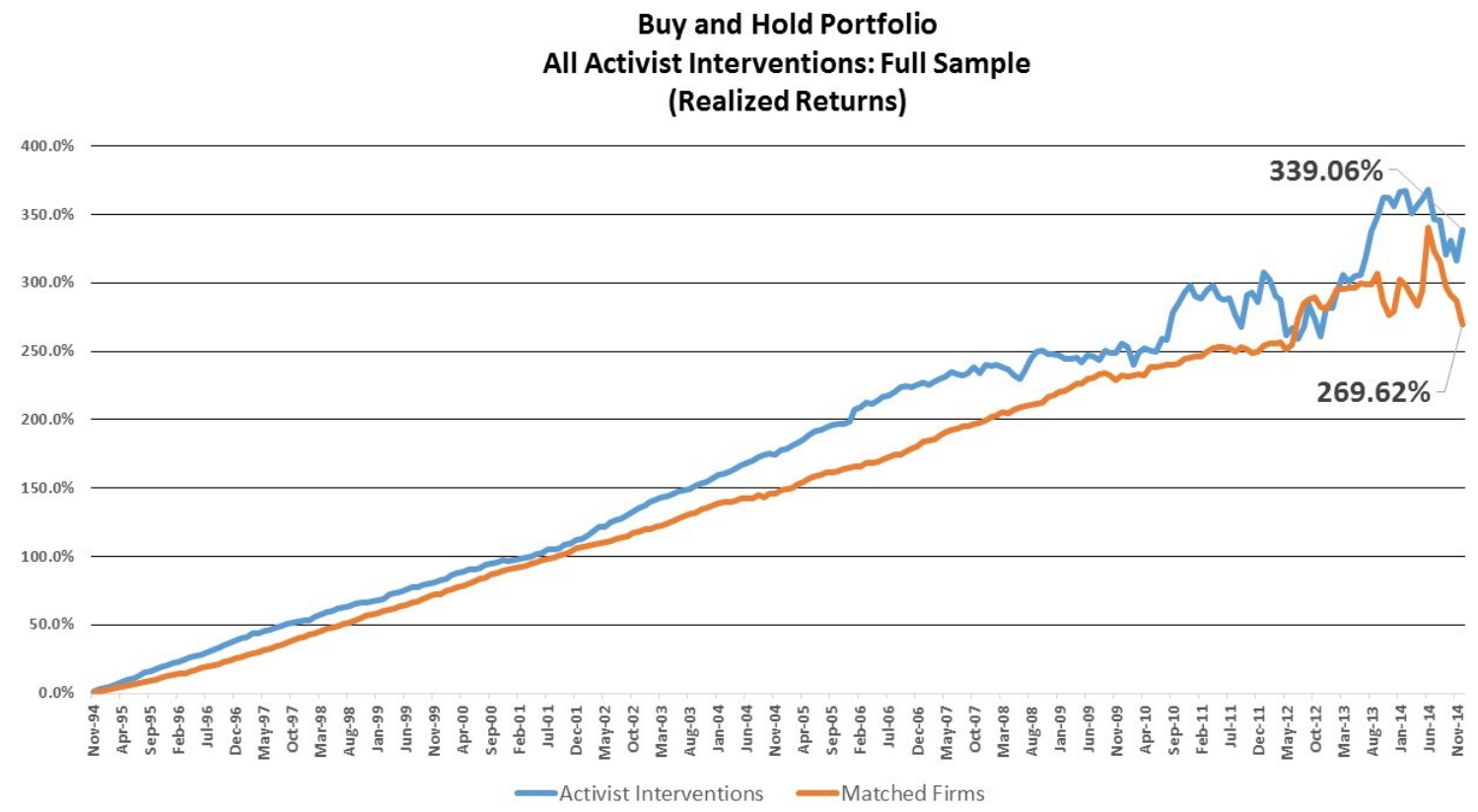

Figure V.9: Buy and Hold Portfolio Returns: Hedge Fund Activism

Buy and Hold Portfolio

Hedge Fund Activist Interventions

(Realized Returns)

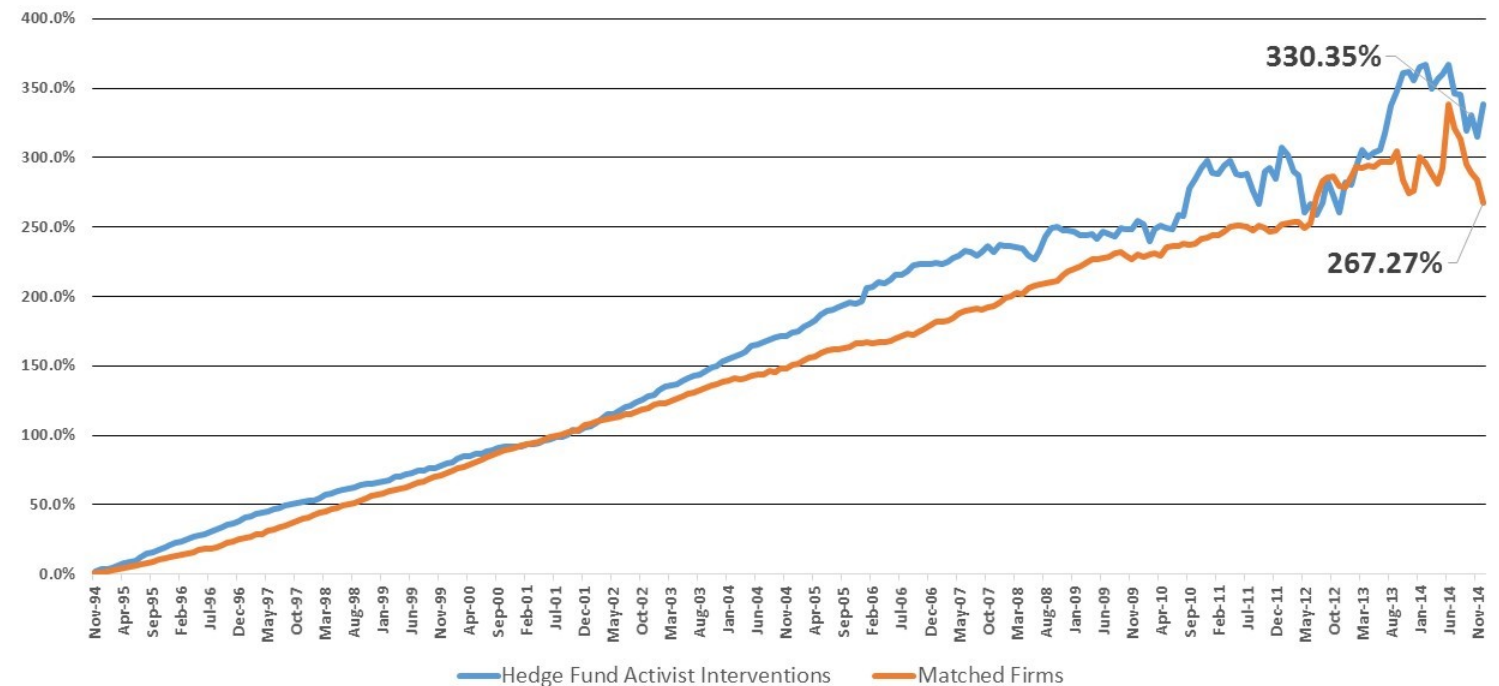


Figure V.10: Buy and Hold Portfolio Returns: Non-Hedge Fund Activism

Buy and Hold Portfolio

Non-Hedge Fund Activist Interventions

(Realized Returns)

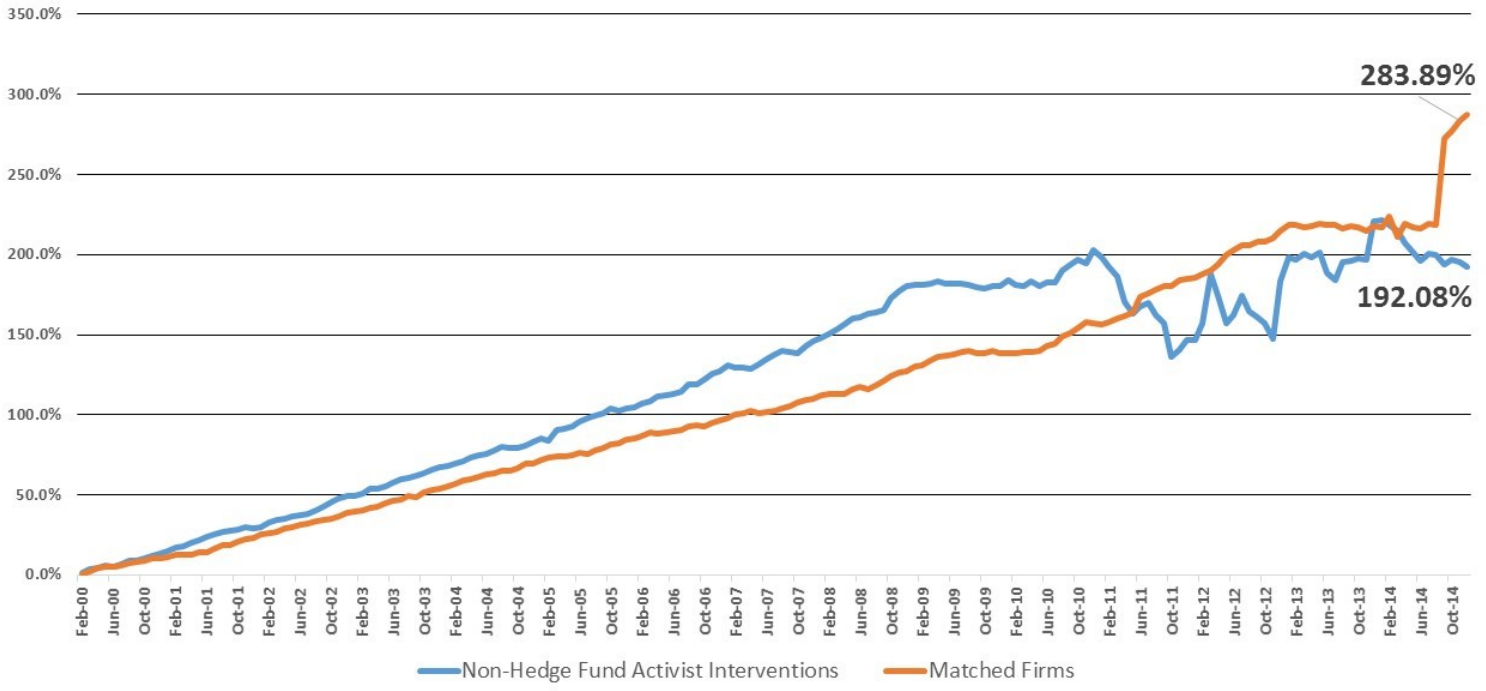

Figure V.11: Buy and Hold Portfolio Returns: Hedge Fund Board Representation (Treatment Group)

\section{Buy and Hold Portfolio Hedge Fund Board Representation (Realized Returns)}

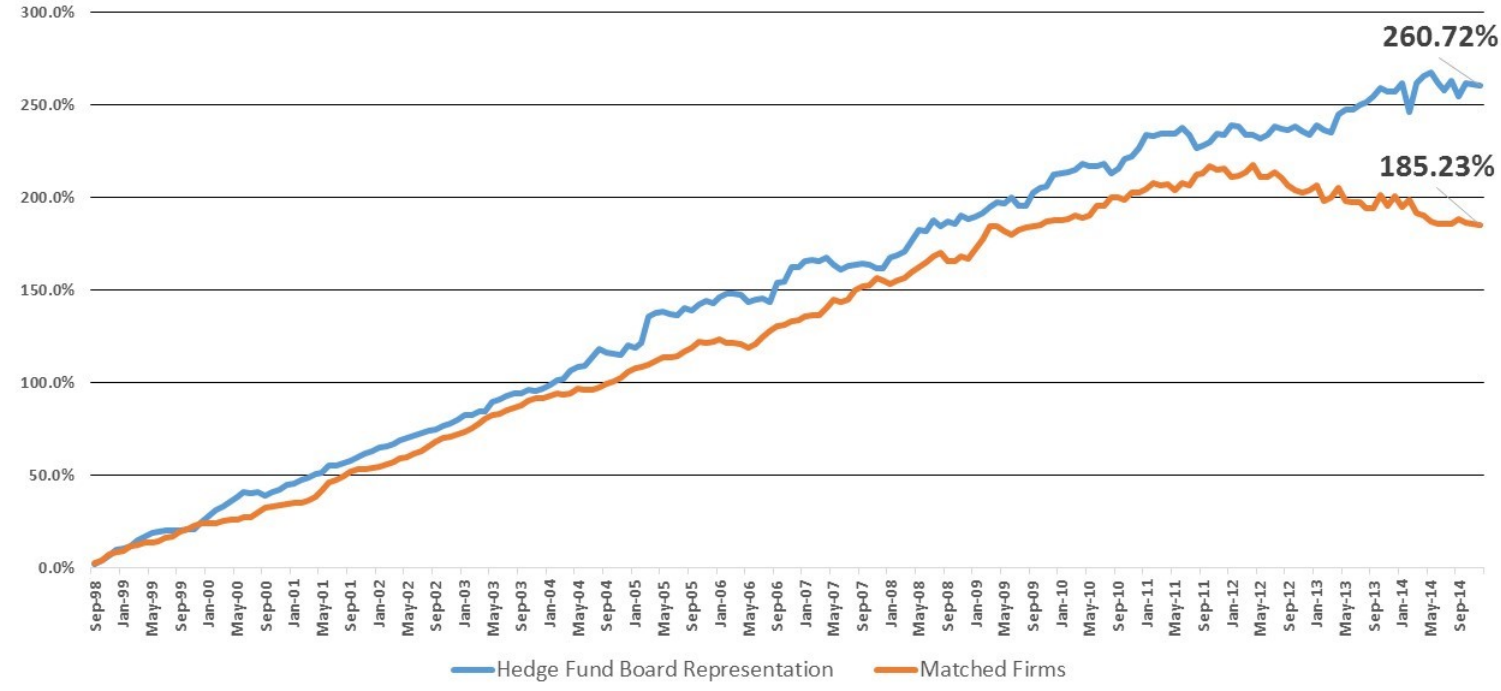


Figure V.12: Buy and Hold Portfolio Returns: Non-Hedge Fund Board Representation (Control Group II)

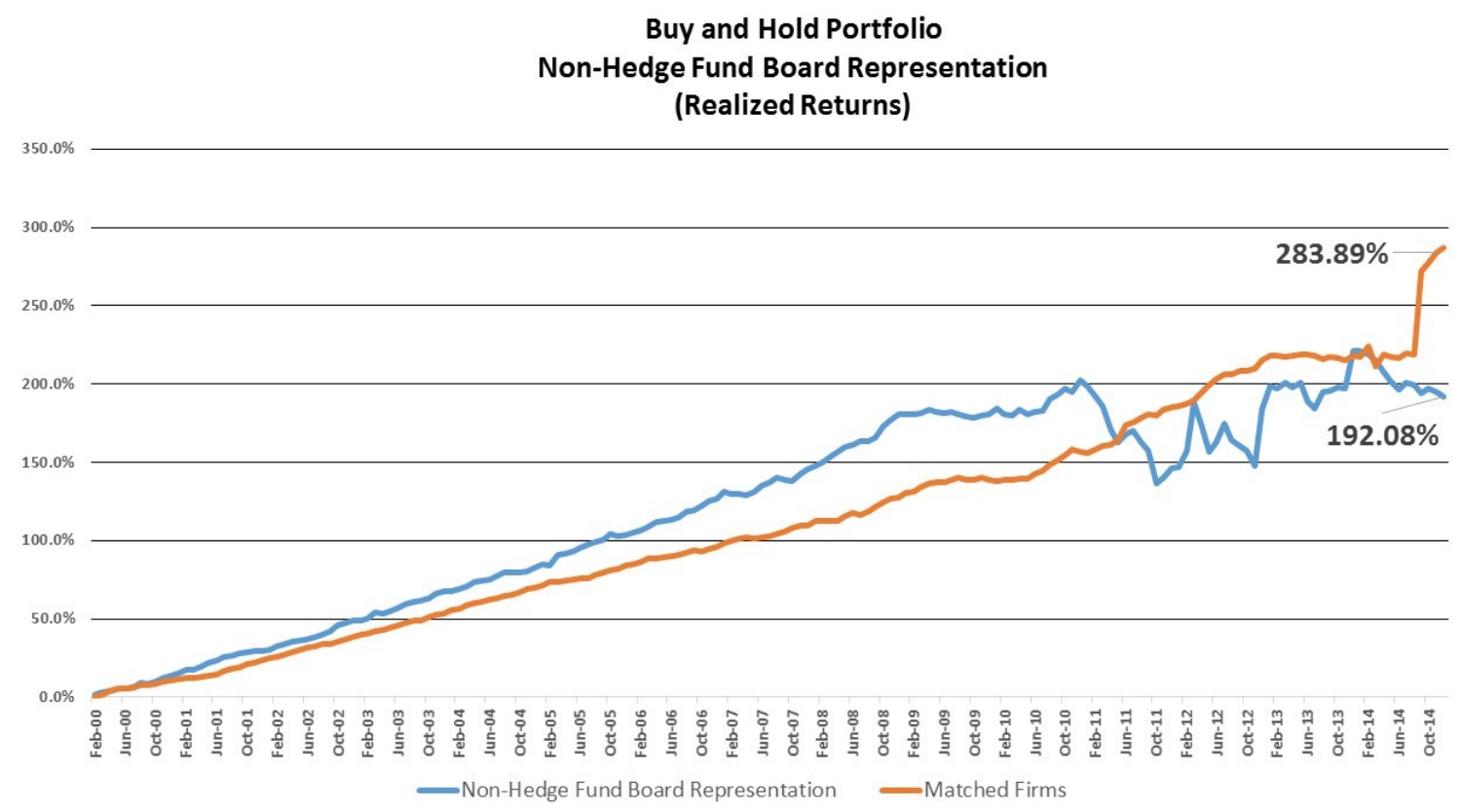

Figure V.13: Buy and Hold Portfolio Returns: Target Firm "Wins" Proxy Fight: No Hedge Fund Board Representation (Control Group I)

\section{Buy and Hold Portfolio}

Failed Attempt at Hedge Fund Board Representation

(Realized Returns)

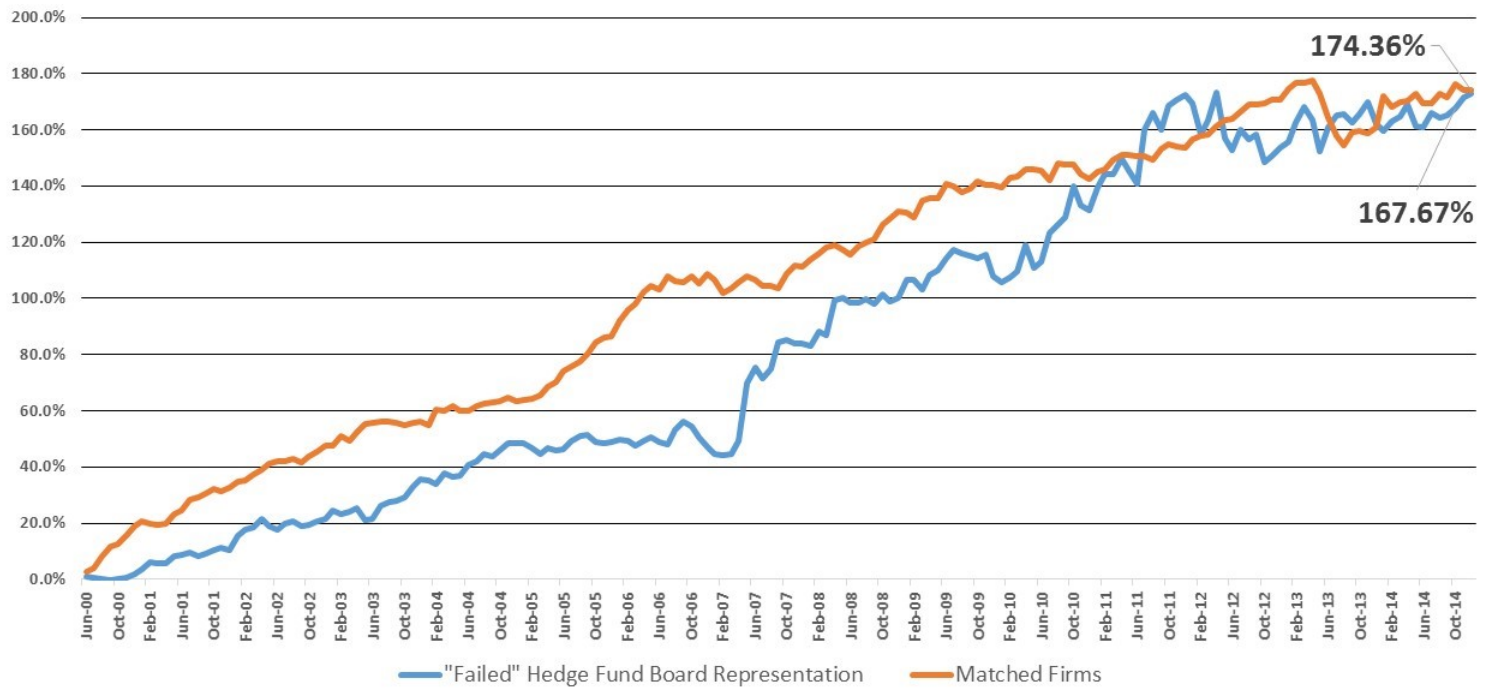




\section{CHAPTER VI}

\section{CONCLUSION}

Over the past two decades, Hedge Fund activism has emerged as new form of corporate governance mechanism that brings about operational, financial, and governance reforms to a corporation. Many prominent business executives and legal scholars are convinced that the entire American economy will suffer unless Hedge Fund activism with its perceived short-termism agenda is significantly restricted. Shareholder activists and their proponents claim they function as a disciplinary mechanism to monitor management and are instrumental in mitigating the agency conflict between managers and shareholders.

The vast majority of shareholder activism literature is predicated on Schedule 13D filings. However, I assert that the optimal dataset to test empirically the long-term effects of shareholder activism should be based on board representation of Target Firms by a Hedge Fund Activist. My research fills the important void with respect to the shareholder activism initiated by Hedge Funds. My novel approach to inside ownership and short-interest positions as instrumented variables that predict a Target Firm's vulnerability to hedge fund activism contributes to the literature on the determinants of shareholder activism.

My expansive, hand-collected dataset and unique empirical research design methodology with respect to board representation fills an important gap in the literature regarding the long-term efficacy of Hedge Fund Activists serving as a disciplinary mechanism on Target Firms by actively seeking board representation to monitor management. Additionally, I am contributing to the literature regarding 
shareholder activists as self-interested, myopic investors at the expense of the long-term interest of the company and its long-term shareholders. Moreover, my findings have important policy implications related to the ongoing debate on corporate governance and the rights and roles of shareholders. My findings suggest that Hedge Fund Activists generate substantial long-term value for Target Firms and their long-term shareholders when those hedge funds function as a shareholder advocate to monitor management through active board engagement. 
CHAPTER VII

REFERENCES 


\section{Bibliography}

[1] A. R. Admati and P. Pfleiderer. The wall street walk and shareholder activism: Exit as a form of voice. Review of Financial Studies, 22:2645-2685, 2009 .

[2] A. R. Admati, P. Pfleiderer, and J. Zechner. Large shareholder activism, risk sharing, and financial market equilibrium. Journal of Political Economy, 102:1097-1130, 1994.

[3] A. Agrawal and G. Mandelker. Large shareholders and the monitoring of managers: The case of antitakeover charter amendments. Journal of Financial and Quantitative Analysis, 25(2):143-161, 1990.

[4] A. C. Akyol and C. A. Carroll. Removing poison pills: A case of shareholder activism. Working paper, University of Alabama at Tuscaloosa, 2006.

[5] P. Asquith, P. Pathak, and J. Ritter. Short interest, institutional ownership, and stock returns. Journal of Financial Economics, 78(2):243-276, 2005.

[6] R. Ball and P. Brown. An empirical evaluation of accounting income numbers. Journal of Accounting Research., 6:1968, 1968.

[7] R. W. Banz. The relationship between return and market value of common stocks. Journal of Financial Economics, 9(1):3-18, 1981.

[8] B. Barber and J. Lyon. Detecting long-run abnormal stock returns: The empirical power and specification of test statistics. Journal of Financial Economics, 43:341-372, 1997. 
[9] B. M. Barber. Monitoring the monitor: Evaluating calpers' activism. Journal of Investing, 16:66-88, 2006.

[10] L. Bassi. Estimating the effects of training programs with nonrandom selection. Review of Economics and Statistics, 66:36-43, 1984.

[11] S. Basu. Investment performance of common stocks in relation to their price-earnings ratio: A test of the efficient market hypothesis. Journal of Finance, 32:663-682, 1977.

[12] S. Basu. The relationship between earnings yield, market value and return for nyse common stocks: Further evidence. Journal of Financial Economics, 12:129-156, 1983.

[13] L. A. Bebchuk, A. Brav, and W. Jiang. The long-term effects of hedge fund activism. Retrieved from wj, 2006, 2013.

[14] M. Becht, J. Franks, C. Mayer, and S. Rossi. Returns to shareholder activism: Evidence from a clinical study of the hermes u. Focus Fund. Review of Financial Studies, 22(8):3093-3129, 2009.

[15] A. Berle and G. Means. The modern corporation and private property. Edison, NJ: Transaction (Original work published, 1932, 1991.

[16] J. E. Bethel, J. P. Liebeskind, and T. Opler. Block share purchases and corporate performance. Journal of Finance, 53(2):605-634, 1998.

[17] J. M. Bizjak and C. J. Marquette. Are shareholder proposals all bark and no bite? Evidence from shareholder resolutions to rescind poison pills. Journal of Financial and Quantitative Analysis, 33:499-521, 1998.

[18] B. S. Black. Institutional investors and corporate governance: The case for institutional voice. Journal of Applied Corporate Finance, 5(3):19-32, 1992. 
[19] E. Boehmer, C. Jones, and X. Zhang. Which shorts are informed? Journal of Finance, 63:491-527, 2008.

[20] N. M. Boyson and R. M. Mooradian. Hedge funds as shareholder activists from 1994-2005. Retrieved from, 2007.

[21] N. M. Boyson and R. M. Mooradian. Corporate governance and hedge fund activism. Review of Derivatives Research, 14(2):169-204, 2011.

[22] W. W. Bratton. Hedge funds and governance targets (working paper no. 80/2007). Brussels: European Corporate Governance Institute, 2007.

[23] A. Brav, W. Jiang, and H. Kim. The real effects of hedge fund activism: productivity, asset allocation, and labor outcomes (nber. Working paper, No. 17517). Cambridge, MA: National Bureau of Economic Research. Retrieved from, 2015.

[24] A. Brav, W. Jiang, F. Partnoy, and R. Thomas. Hedge fund activism, corporate governance, and firm performance. Journal of Finance, 63(4):1729-1775, 2008.

[25] L. D. Brown and M. L. Caylor. A temporal analysis of quarterly earnings thresholds: Propensities and valuation consequences. Accounting Review, $80: 423-440,2005$.

[26] L. D. Brown and M. L. Caylor. Corporate governance and firm operating performance. Review of Quantitative Finance and Accounting, 32:129-144, 2009.

[27] S. Brown and J. Warner. Measuring security price performance. Journal of Financial Economics, 8:205-258, 1980.

[28] S. Brown and J. Warner. Using daily stock returns: The case of event studies. Journal of Financial Economics, 14:3-31, 1985. 
[29] B. Buchanan and April) Yang, T. (2009. A comparative analysis of shareholder activism in the US and UK: Evidence from shareholder proposals. Paper presented at the European Financial Management Assocation symposium, Cambridge, UK. Retrieved from.

[30] J. Cai, J. Garner, and R. Walkling. Electing directors. Journal of Finance, 64(5):2389-242, 2009.

[31] M. M. Carhart. On persistence in mutual fund performance. Journal of Finance, 52:57-82, 1997.

[32] W. T. Carleton, J. M. Nelson, and M. S. Weisbach. The influence of institutions on corporate governance through private negotiations: Evidence from tiaa-cref. Journal of Finance, 53:1335-1362, 1998.

[33] G. L. Caton, J. Goh, and J. Donaldson. The effectiveness of institutional activism. Financial Analysts Journal, 57:21-26, 2001.

[34] G. Cave and H. Bos. The value of a GED in a choice-based experimental sample. Manpower Demonstration Research Corporation, New York, NY, 1995.

[35] X. Chen, J. Harford, and K. Li. Monitoring: Which institutions matter? Journal of Financial Economics, 86:279-305, 2007.

[36] R. Clark. Corporate governance changes in the wake of the sarbanes-oxley act: A morality tale for policymakers too. (discussion paper no. 525). Cambridge, MA: Harvard University, 2005.

[37] C. P. Clifford. Value creation or destruction? Hedge funds as shareholder activists. Journal of Corporate Finance, 14:323-336, 2008.

[38] W. G. Cochran and D. B. Rubin. Controlling bias in observational studies: A review. Sankhya: The Indian Journal of Statistics, Series A, 35:417-446, 1973. 
[39] L. Cohen, K. Diether, and C. Malloy. Supply and demand shifts in the shorting market. Journal of Finance, 62:2061-2096, 2007.

[40] C. E. Crutchley, C. D. Hudson, and M. R. H. Jensen. Shareholders wealth effects of calpers' activism. Financial Services Review, 7:1-10, 1998.

[41] J. Czajka, S. M. Hirabayashi, R. J. A. Little, and D. B. Rubin. Projecting from advance data using propensity modeling: An application to income and tax statistics. Journal of Business and Economic Statistics, 10(2):117-131, 1992.

[42] K. Daniel, M. Grinblatt, S. Titman, and R. Wermers. Measuring mutual fund performance with characteristic-based benchmarks. Journal of Finance., 52(3):1035-1058, 1997.

[43] H. DeAngelo and L. DeAngelo. Proxy contests and the governance of publicly held corporations. Journal of Financial Economics, 23:29-59, 1989.

[44] W. F. M. DeBondt and R. H. Thaler. Does the stock market overreact? Journal of Finance, 40:557-581, 1985.

[45] W. F. M. DeBondt and R. H. Thaler. Further evidence on investor overreaction and stock market seasonality. Journal of Finance, 42(3):557-581, 1987.

[46] J. B. DeLong, A. Shleifer, L. H. Summers, and R. J. Waldmann. Noise trader risk in ?nancial markets. Journal of Political Economy, 98:703-738, 1990.

[47] H. Demsetz. The structure of ownership and the theory of the firm. Journal of Law and Economics, 26:375-390, 1983.

[48] P. Dodd and J. B. Warner. On corporate governance: A study of proxy contests. Journal of Financial Economics, 11:401-438, 1983. 
[49] J. Doukas. Overinvestment, tobin's q and gains from foreign acquisitions. Journal of Banking \& Finance, 19:1285-1303, 1995.

[50] F. Easterbrook. Two agency-cost explanations of dividends. American Economic Review, 74:650-659, 1984.

[51] A. Edmans. Blockholder trading, market efficiency, and managerial myopia. Journal of Finance, 64:2481-2513, 2009.

[52] A. Edmans and G. Manso. Governance through trading and intervention: A theory of multiple blockholders. Review of Financial Studies, 24:2395-2428, 2011.

[53] P. C. English, T. I. Smythe, and C. R. McNeil. The calpers effect revisited. Journal of Corporate Finance, 10:157-174, 2004.

[54] E. F. Fama. Market ef?ciency, long-term returns, and behavioral ?nance. Journal of Financial Economics., 49:283-306, 1998.

[55] E. F. Fama, L. Fisher, M. C. Jensen, and R. Roll. The adjustment of stock prices to new information. International Economic Review, 10:1-21, 1969.

[56] E. F. Fama and K. R. French. Common risk factors in the returns on stocks and bonds. Journal of Financial Economics., 33:3-56, 1993.

[57] S. Finkelstein and D. Hambrick. Chief executive compensation: A study of the interaction of markets and political processes. Strategic Management Journal, 10:121-134, 1989.

[58] N. Gantchev. The costs of shareholder activism: Evidence from a sequential decision model. Journal of Financial Economics, 107(3):610-631, 2013.

[59] S. L. Gillan and L. T. Starks. Corporate governance proposals and shareholder activism: The role of institutional investors. Journal of Financial Economics, 57:275-305, 2000. 
[60] S. L. Gillan and L. T. Starks. The evolution of shareholder activism in the united states. Journal of Applied Corporate Finance, 19:55-73, 2007.

[61] S. B. Graves, K. Rehbein, and S. Waddock. Fad and fashion in shareholder activism: The landscape of shareholder resolutions, 1988-1998. Business and Society Review, 106:293-314, 2001.

[62] J. M. Griffin and S. N. Wiggins. Takeovers: Managerial incompetence or managerial shirking? Economic Inquiry, 30(2):355-370, 1992.

[63] S. J. Grossman and O. D. Hart. Takeover bids, the free-rider problem, and the theory of the corporation. Bell Journal of Economics, 11:42-64, 1980.

[64] Del Guercio. D., \& hawkins, j. (1999). The motivation and impact of pension fund activism. Journal of Financial Economics, 52:293-340.

[65] Del Guercio and Seery D. L., \& woidtke, t. (2008). Do boards pay attention when institutional investor activists "just vote no"? Journal of Financial Economics, 90(1):84-103.

[66] D. Hirshleifer, S. H. Teoh, and J. Yu. Short arbitrage, return asymmetry and the accrual anomaly. Review of Financial Studies, 24:2429-2461, 2011.

[67] M. Huse and V. P. Rindova. Stakeholders' expectations of board roles: The case of subsidiary boards. Journal of Management and Governance, $5(2): 153-178,2001$.

[68] D. Ikenberry, J. Lakonishok, and C. T. Vermaelen. Market underreaction to open market share repurchases. Journal of Financial Economics, pages 181-208, 1995.

[69] J. F. Jaffe. Special information and insider trading. Journal of Business, 47(3):410-28, 1974. 
[70] G. Jarrell and A. Poulsen. Shark repellents and stock prices: The effects of antitakeover amendments since 1980. Journal of Financial Economics, 19:127-168, 1987.

[71] M. Jensen and C. W. Smith. Stockholder, manager, and creditor interests: Applications of agency theory. In E. Altman and M. Subrahmanyam, editors, Recent advances in corporate finance, pages 94-131. Irwin. Retrieved from, Homewood, IL, 1985.

[72] M. C. Jensen and W. H. Meckling. Theory of the firm: Managerial behavior, agency costs, and ownership structure. Journal of Financial Economics., 3(4):305-360, 1976.

[73] George J. Jiang and Chang Liu. Getting on board: The monitoring effect of institutional directors. Working Paper, 2014.

[74] M. F. Johnson and M. B. Shackell-Dowell. Shareholder proposals on executive compensation. Retrieved from, 1997.

[75] C. P. Jones and R. H. Litzenberger. Quarterly earnings reports and intermediate stock price trends. Journal of Finance., 25:143-148, 1970.

[76] W. Q. Judge, A. S. Gaur, and M. I. Muller-Kahle. Antecedents of shareholder activism in target firms: Evidence from a multi-country study. Corporate Governance: An International Review, 18(4):258-273, 2010.

[77] M. Kahan and E. B. Rock. Funds in corporate governance and corporate control (Working Paper No. 99). University of Pennsylvania Law School, Philadelphia, PA, 2006.

[78] C. Kahn and A. Winton. Ownership structure, speculation, and shareholder intervention. Journal of Finance, 53:99-129, 1998. 
[79] J. Karpoff. Does shareholder activism work? A survey of empirical ?ndings. Unpublished manuscript, University of Washington, Seattle, WA, 2001.

[80] J. Karpoff and Z. Lou. Short sellers and financial misconduct. Journal of Finance, 65:1879-1913, 2010.

[81] J. M. Karpoff, P. H. Malatesta, and R. A. Walkling. Corporate governance and shareholder initiatives: Empirical evidence. Journal of Financial Economics, 42:365-395, 1996.

[82] A. Klein and E. Zur. Entrepreneurial shareholder activism: Hedge funds and other private investors. Journal of Finance., 64:187-229, 2009.

[83] J. W. Lorsch and E. Maciver. Pawns or potentates: The reality of America's corporate boards. Harvard Business School Press, Boston, MA, 1989.

[84] J. D. Lyon, B. M. Barber, and C.-l. Tsai. Improved methods for tests of long-run abnormal stock returns. Journal of Finance., 54:165-201, 1999.

[85] M. L. Mace. Directors: Myth and reality. Boston, MA: Harvard Business School Press. (Original work published, 1971, 1986.

[86] G. Mandelker. Risk and return: The case of merging firms. Journal of Financial Economics, 1(4):303-335, 1974.

[87] R. Marens. Inventing corporate governance: The mid-century emergence of shareholder activism. Journal of Business and Management, 8:365-389, 2002.

[88] M. Massa, B. Zhang, and H. Zhang. The invisible hand of short selling: Does short selling disciplines earnings manipulation? Retrieved from, 2013.

[89] E. Maug. Large shareholders as monitors: Is there a trade-off between liquidity and control? Journal of Finance, 53:65-98, 1998. 
[90] J. McCahery, L. Starks, and Z. Sautner. Behind the scenes: The corporate governance preferences of institutional investors. Retrieved from, 2010.

[91] J. J. McConnell and H. Servaes. Additional evidence on equity ownership and corporate value. Journal of Financial Economics, 27:595-612, 1990.

[92] E. Miller. Risk, uncertainty, and divergence of opinion. Journal of Finance, 32:1151-1168, 1977.

[93] M. Mitchell and E. Stafford. Managerial decisions and long-term stock price performance. Journal of Business., 73:287-329, 2000.

[94] J. H. Mulherin and A. B. Poulsen. Proxy contests and corporate change: Implications for shareholder wealth. Journal of Financial Economics, 47:15, 1998.

[95] J. M. Nelson. Does good corporate governance really work? More evidence from CalPERS. Journal of Asset Management, 6:274-287, 2005.

[96] J. M. Nelson. The calpers effect revisited again. Journal of Corporate Finance, 12:187-213, 2006.

[97] S. L. Nesbitt. Long-term rewards from shareholder activism: A study of the calpers effect. Journal of Applied Corporate Finance, 6:75-80, 1994.

[98] T. C. Opler and J. Sokobin. Does coordinated institutional activism work? An analysis of the activities of the Council of Institutional Investors, 1998.

[99] R. Parrino, R. Sias, and L. Starks. Voting with their feet: Institutional ownership changes around forced ceo turnover. Journal of Financial Economics, 68:3-46, 2003.

[100] J. Pound. Proxy contests and the efficiency of shareholder oversight. Journal of Financial Economics, 20:237-265, 1988. 
[101] J. Pound. Raiders, targets, and politics: The history and future of American corporate control. Journal of Applied Corporate Finance, 5(3):6-18, 1992.

[102] A. K. Prevost, R. P. Rao, and M. A. Williams. Labor unions as shareholder proposals: Lessons from the 1997 proxy season. Financial Management, 28:89-98, 2009.

[103] W. J. Raynor. Caliper pair-matching on a continuous variable in case control studies. Communications in Statistics: Theory and Methods, 12:1499-1509, 1983.

[104] L. Renneboog and P. G. Szilagyi. The success and relevance of shareholder activism through proxy proposals. Retrieved from, 2006.

[105] M. R. Roberts and T. M. Whited. Endogeneity in empirical corporate ?nance. In M. Constantinides and R. Stulz, editors, Handbook of the economics of finance (Vol, pages 493-572. Elsevier, 2, . Oxford, UK, 2013.

[106] R. Romano. Making institutional investor activism a valuable mechanism of corporate governance (Faculty Scholarship Series Paper 1916). Yale Law School, New Haven, CT, 2001.

[107] P. Rosenbaum. Observational studies. Springer Verlag, New York, NY, 1995.

[108] A. J. Senchack and L. Starks. Short-sale restrictions and market reaction to short-interest announcements. Journal of Financial and Quantitative Analysis, 28:177-194, 1993.

[109] N. Sharara and A. Hoke-Witherspoon. The evolution of the 1992 shareholder communication proxy rules and their impact on corporate governance. Business Lawyer, 49:327-358, 1993.

[110] A. Shleifer and R. W. Vishny. Large shareholders and corporate control. Journal of Political Economy, 94(3):461-488, 1986. 
[111] A. Shleifer and R. W. Vishny. Limits of arbitrage. Journal of Finance, 52(1):35-55, 1997.

[112] M. P. Smith. Shareholder activism by institutional investors: Evidence from calpers. Journal of Finance, 51:227-252, 1996.

[113] D. Strickland, K. W. Wiles, and M. Zenner. A requiem for the usa: Is small shareholder monitoring effective? Journal of Financial Economics, 40(2):319-338, 1996.

[114] R. Thomas and J. Cotter. Shareholder proposals post-Enron: What's changed, what's the same. Retrieved from, 2005.

[115] J. Tirole. The theory of corporate finance. Princeton University Press, Princeton, NJ, 2006.

[116] V. Venkiteshwaran, S. R. Iyer, and R. P. Rao. Is carl icahn good for long-term shareholders? A case study in shareholder activism. Journal of Applied Corporate Finance, 22(4):45-57, 2010.

[117] S. Wahal. Pension fund activism and ?rm performance. Journal of Financial and Quantitative Analysis, 31(1):1-23, 1996.

[118] M. S. Weisbach. Outside directors and ceo turnover. Journal of Financial Economics, 20:431-460, 1988.

[119] Inc Westat. Continuous Longitudinal Manpower Survey Net Impact Report No. 1: Impact on 1977 Earnings of New FY 1976 CETA Enrollees in Selected Program Activities. Retrieved from, 1981.

[120] T. Woidtke. Agents watching agents? Evidence from pension fund ownership and firm value. Journal of Financial Economics, 63:99-131, 2002. 
[121] Y. Wu. The impact of public opinion on board structure changes, director career progression, and ceo turnover: Evidence from calpers' corporate governance program. Journal of Corporate Finance, 10(1):199-227, 2004.

[122] G. Yen and Y-l. Chen. Proxy contest, board reelection, and managerial turnover: Yes, the proxy contest outcome matters. Managerial and Decision Economics, 26(1):15-23, 2005.

[123] D. Yermack. Higher market valuation of companies with a small board of directors. Journal of Financial Economics, 40:185-211, 1996.

[124] S. Zahra and J. Pearce. Boards of directors and corporate financial performance: A review and integrative model. Journal of Management, 2:291-334, 1989. 
CHAPTER VIII

APPENDICES 
Appendix A

LITERATURE REVIEW 


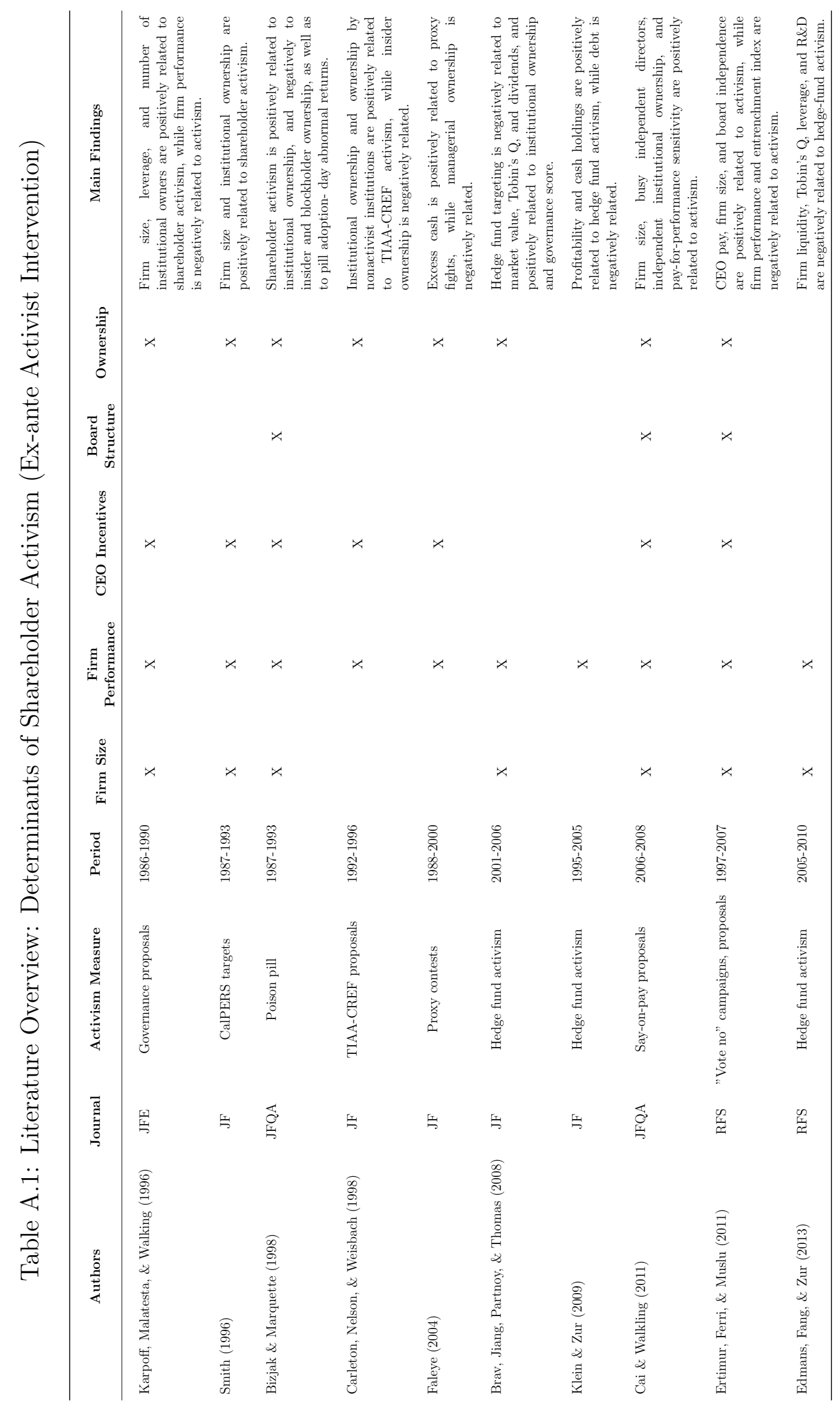




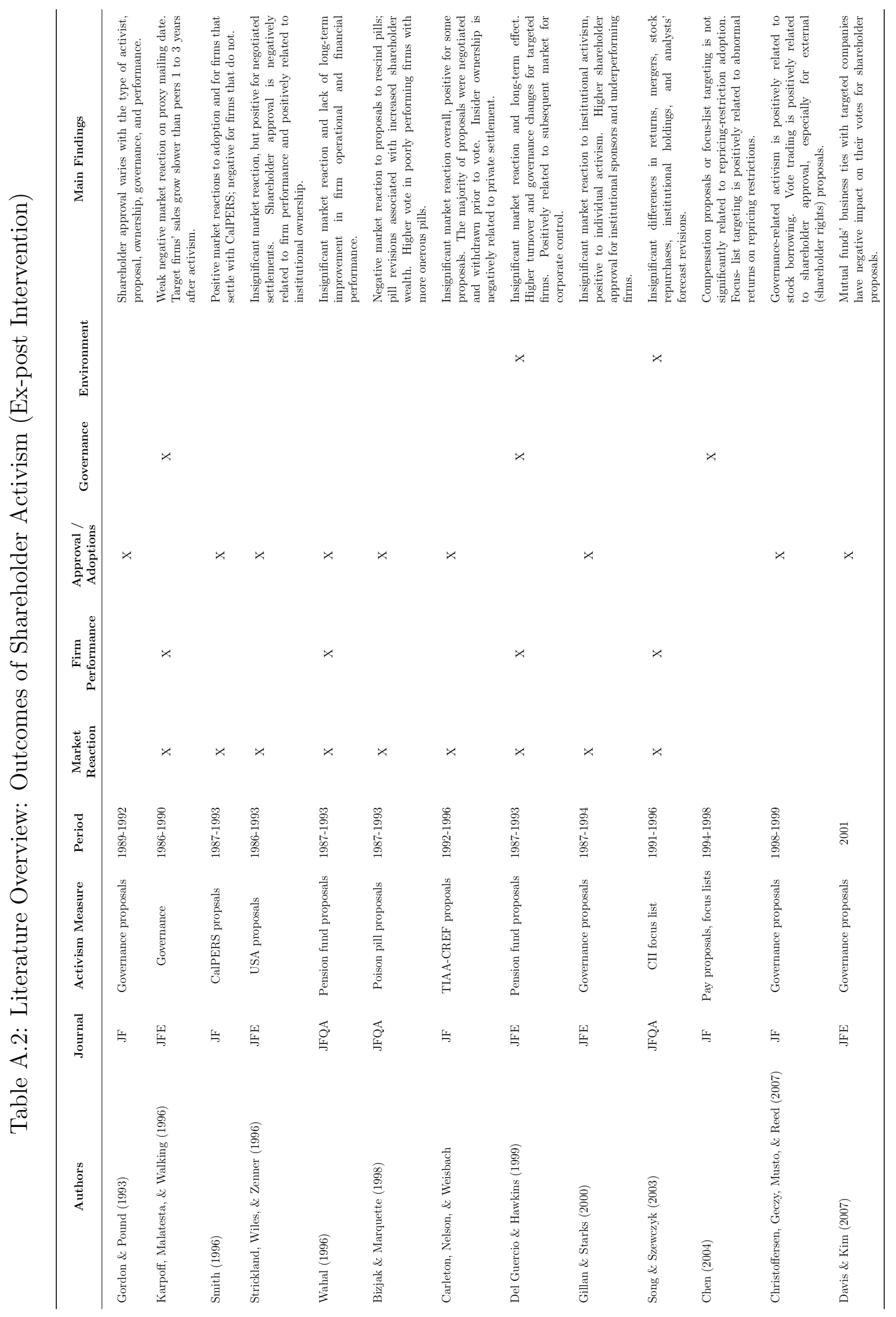




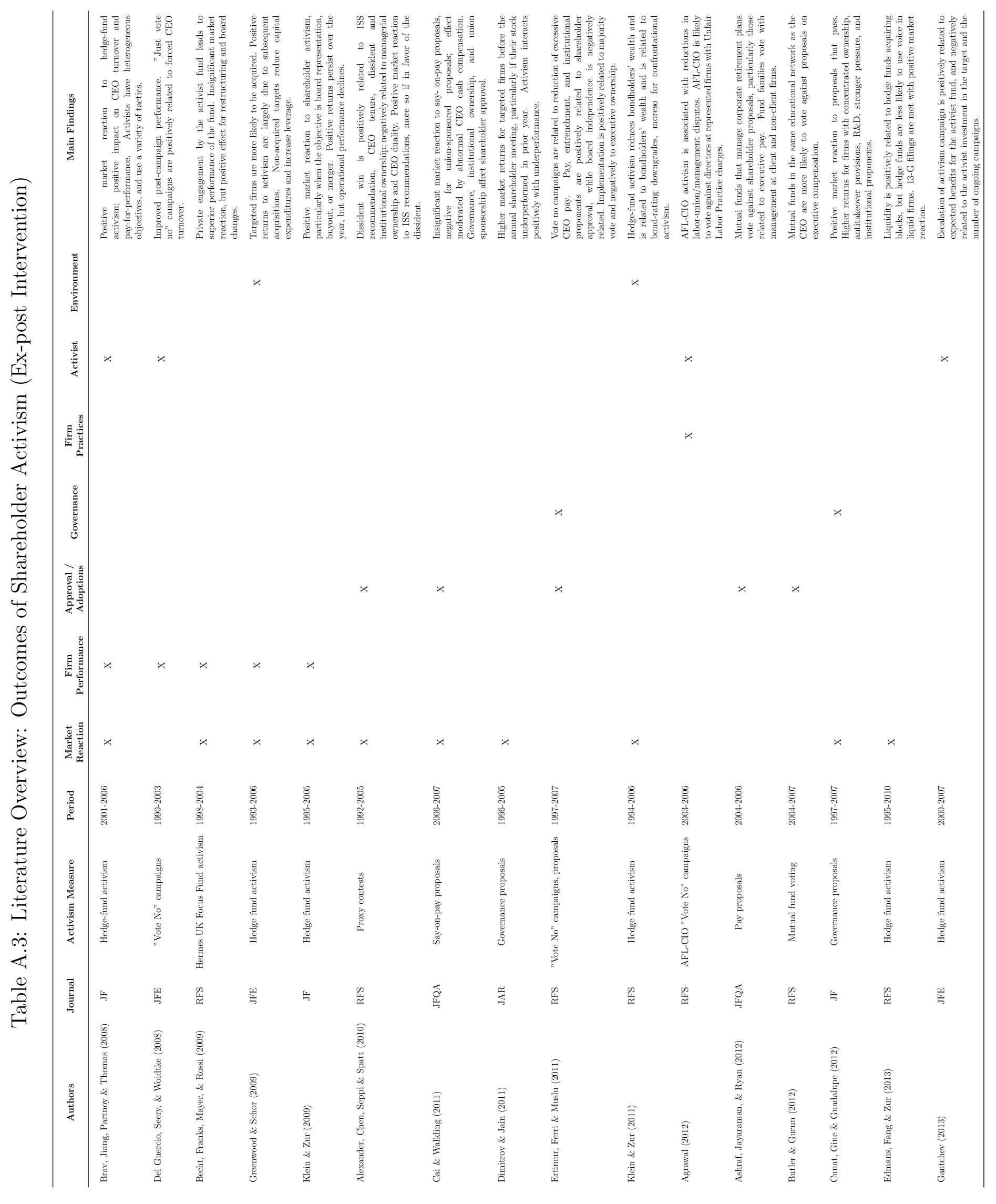


Appendix B

HYPOTHESIS 1: SHORT SELLING 


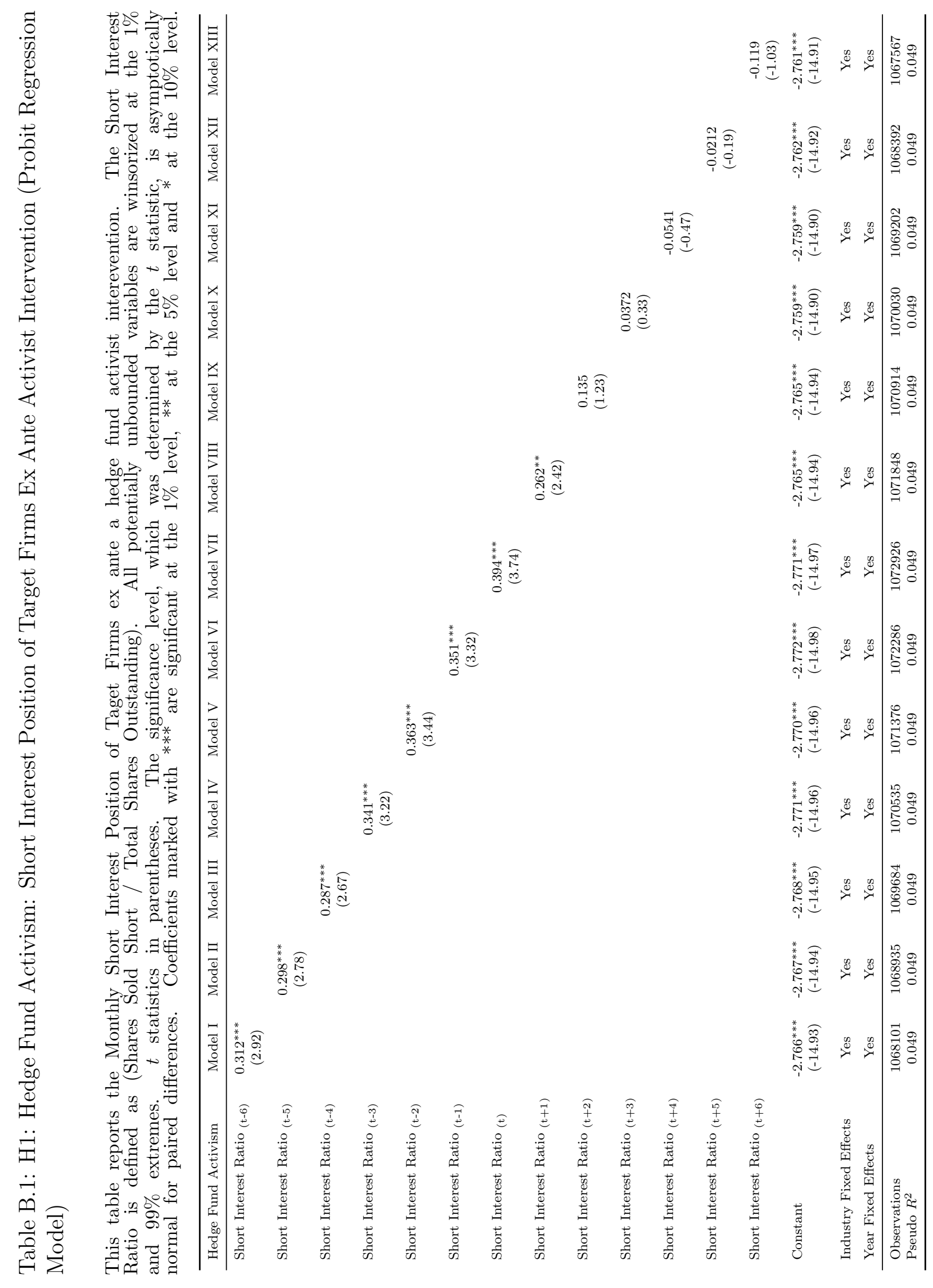




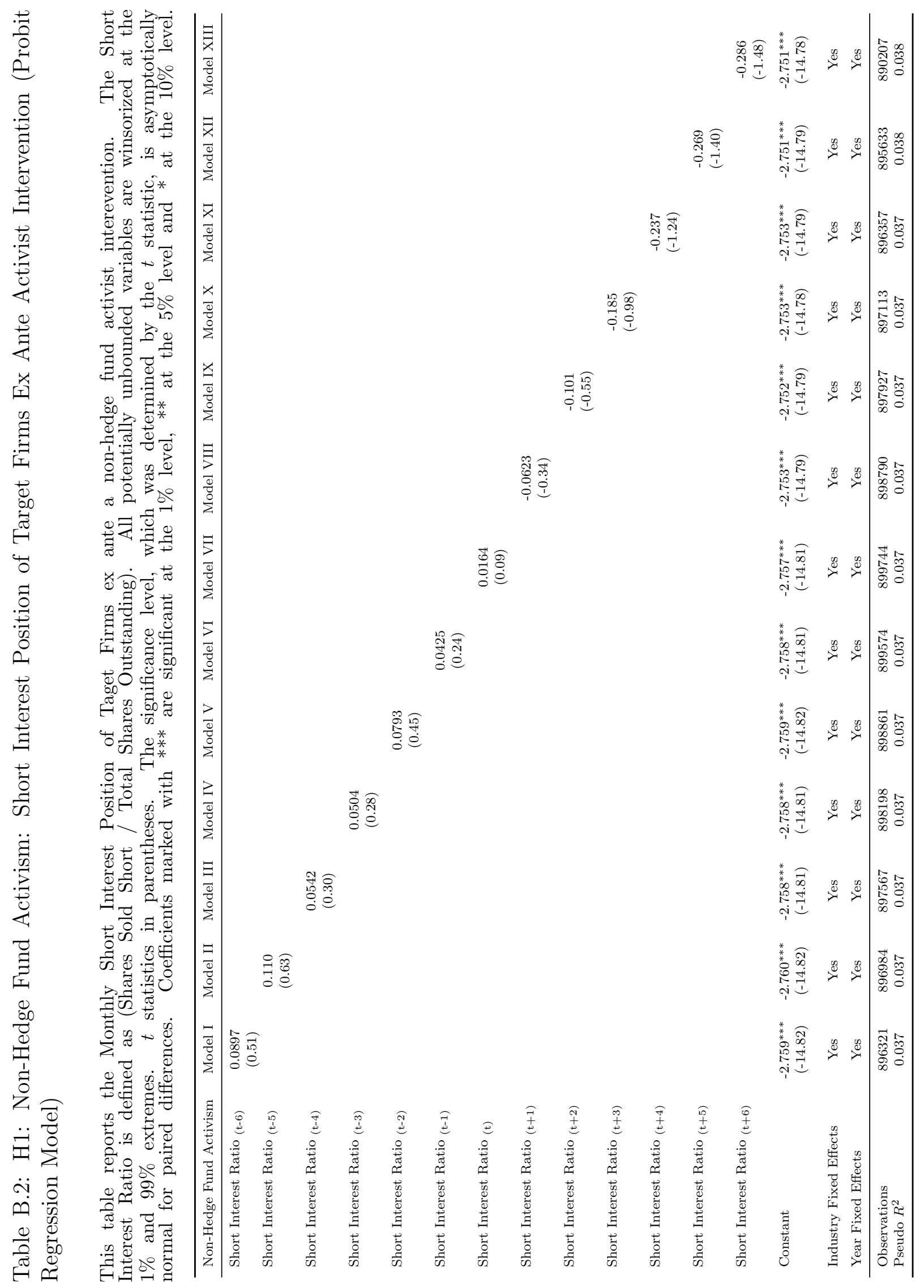


Appendix C

HYPOTHESIS 2: INSIDE OWNERSHIP 
Table C.1: H2: Hedge Fund Activism: Corporate "Inside" Ownership (Probit Regression Model)

This table reports the Quarterly Corporate Ownership of Taget Firms 18 months ex ante a hedge fund activist interevention. The ownership data is from the FactSet/LionShares database, which provides portfolio holdings of both institutional and individual investors. FactSet compiles ownership information from public filings by investors (such as 13-F filings, Form 3 and Form 4), company annual reports, stock exchanges, and regulatory agencies around the world. The SEC "Corporate insiders" as a company's officers and directors, and any beneficial owners of more than $10 \%$ of a class of the company's equity securities registered under Section 12 of the Securities Exchange Act of 1934 - must file with the SEC a statement of ownership regarding those securities. The data in the table excludes any institutions or noncompany officers and directors that are required to file with the SEC because they are beneficial owners of more than $10 \%$ of a class of the company's equity securities. Institutions are defined as professional money managers, including mutual fund companies, investment advisors, pension funds, bank trusts, and insurance companies. All potentially unbounded variables are winsorized at the $1 \%$ and $99 \%$ extremes. $t$ statistics in parentheses. The significance level, which was determined by the $t$ statistic, is asymptotically normal for paired differences. Coefficients marked with ${ }^{* * *}$ are significant at the $1 \%$ level, ${ }^{* *}$ at the $5 \%$ level and ${ }^{*}$ at the $10 \%$ level.

\begin{tabular}{|c|c|c|c|c|c|c|}
\hline Hedge Fund Activism & Model I & Model II & Model III & Model IV & Model V & Model VI \\
\hline Corporate "Insider" Ownership (t-6) & $\begin{array}{c}-0.0110^{* * *} \\
(-4.70)\end{array}$ & & & & & \\
\hline Corporate "Insider" Ownership (t-5) & & $\begin{array}{c}-0.0117^{* * *} \\
(-5.02)\end{array}$ & & & & \\
\hline Corporate "Insider" Ownership $(\mathrm{t}-4)$ & & & $\begin{array}{c}-0.0119^{* * *} \\
(-5.10)\end{array}$ & & & \\
\hline Corporate "Insider" Ownership (t-3) & & & & $\begin{array}{c}-0.0120^{* * *} \\
(-5.16)\end{array}$ & & \\
\hline Corporate "Insider" Ownership $(\mathrm{t}-2)$ & & & & & $\begin{array}{c}-0.0117^{* * *} \\
(-5.05)\end{array}$ & \\
\hline Corporate "Insider" Ownership (t-1) & & & & & & $\begin{array}{c}-0.0119^{* * *} \\
(-5.14)\end{array}$ \\
\hline Constant & $\begin{array}{c}0.0138 \\
(0.06)\end{array}$ & $\begin{array}{c}0.00771 \\
(0.03)\end{array}$ & $\begin{array}{c}0.0443 \\
(0.20)\end{array}$ & $\begin{array}{r}0.0437 \\
(0.19)\end{array}$ & $\begin{array}{c}0.0399 \\
(0.18)\end{array}$ & $\begin{array}{c}0.0515 \\
(0.24)\end{array}$ \\
\hline Industry Fixed Effects & Yes & Yes & Yes & Yes & Yes & Yes \\
\hline Year Fixed Effects & Yes & Yes & Yes & Yes & Yes & Yes \\
\hline Observations & 2,737 & 2,739 & 2,743 & 2,747 & 2,754 & 2,763 \\
\hline Pseudo $R^{2}$ & 0.011 & 0.012 & 0.012 & 0.012 & 0.012 & 0.012 \\
\hline
\end{tabular}




\section{Table C.2: H2: Non-Hedge Fund Activism: Corporate "Inside" Ownership (Probit}

Regression Model)

This table reports the Quarterly Corporate Ownership of Taget Firms 18 months ex ante a non-hedge fund activist interevention. The ownership data is from the FactSet/LionShares database, which provides portfolio holdings of both institutional and individual investors. FactSet compiles ownership information from public filings by investors (such as 13-F filings, Form 3 and Form 4), company annual reports, stock exchanges, and regulatory agencies around the world. The SEC "Corporate insiders" as a company's officers and directors, and any beneficial owners of more than $10 \%$ of a class of the company's equity securities registered under Section 12 of the Securities Exchange Act of 1934 - must file with the SEC a statement of ownership regarding those securities. The data in the table excludes any institutions or noncompany officers and directors that are required to file with the SEC because they are beneficial owners of more than $10 \%$ of a class of the company's equity securities. Institutions are defined as professional money managers, including mutual fund companies, investment advisors, pension funds, bank trusts, and insurance companies. All potentially unbounded variables are winsorized at the $1 \%$ and $99 \%$ extremes. $t$ statistics in parentheses. The significance level, which was determined by the $t$ statistic, is asymptotically normal for paired differences. Coefficients marked with $* * *$ are significant at the $1 \%$ level, $* *$ at the $5 \%$ level and $*$ at the $10 \%$ level.

\begin{tabular}{|c|c|c|c|c|c|c|}
\hline Non-Hedge Fund Activism & Model I & Model II & Model III & Model IV & Model V & Model VI \\
\hline Corporate "Insider" Ownership (t-6) & $\begin{array}{c}-0.00932^{* *} \\
(-2.50)\end{array}$ & & & & & \\
\hline Corporate "Insider" Ownership (t-5) & & $\begin{array}{c}-0.00855^{* *} \\
(-2.31)\end{array}$ & & & & \\
\hline Corporate "Insider" Ownership (t-4) & & & $\begin{array}{c}-0.00879^{* *} \\
(-2.35)\end{array}$ & & & \\
\hline Corporate "Insider" Ownership (t-3) & & & & $\begin{array}{c}-0.00813^{* *} \\
(-2.19)\end{array}$ & & \\
\hline Corporate "Insider" Ownership (t-2) & & & & & $\begin{array}{c}-0.00789^{* *} \\
(-2.12)\end{array}$ & \\
\hline Corporate "Insider" Ownership (t-1) & & & & & & $\begin{array}{c}-0.00813^{* *} \\
(-2.20)\end{array}$ \\
\hline Constant & $\begin{array}{l}0.159 \\
(0.61)\end{array}$ & $\begin{array}{l}0.157 \\
(0.60)\end{array}$ & $\begin{array}{l}0.158 \\
(0.61)\end{array}$ & $\begin{array}{l}0.155 \\
(0.60)\end{array}$ & $\begin{array}{l}0.159 \\
(0.61)\end{array}$ & $\begin{array}{l}0.156 \\
(0.60)\end{array}$ \\
\hline Industry Fixed Effects & Yes & Yes & Yes & Yes & Yes & Yes \\
\hline Year Fixed Effects & Yes & Yes & Yes & Yes & Yes & Yes \\
\hline Observations & 1,033 & 1,035 & 1,034 & 1,038 & 1,040 & 1,043 \\
\hline Pseudo $R^{2}$ & 0.023 & 0.022 & 0.022 & 0.022 & 0.022 & 0.022 \\
\hline
\end{tabular}


Appendix D

HYPOTHESIS 3: HEDGE FUND BOARD REPRESENTATION 
Table D.1: H3: Hedge Fund Board Representation: Corporate "Inside" Ownership of Target Firms (Probit Regression Model)

This table reports the Quarterly Corporate Ownership of Taget Firms 18 months ex ante board representation by an activist hedge fund. The ownership data is from the FactSet/LionShares database, which provides portfolio holdings of both institutional and individual investors. FactSet compiles ownership information from public filings by investors (such as 13-F filings, Form 3 and Form 4), company annual reports, stock exchanges, and regulatory agencies around the world. The SEC "Corporate insiders" as a company's officers and directors, and any beneficial owners of more than $10 \%$ of a class of the company's equity securities registered under Section 12 of the Securities Exchange Act of 1934 - must file with the SEC a statement of ownership regarding those securities. The data in the table excludes any institutions or noncompany officers and directors that are required to file with the SEC because they are beneficial owners of more than $10 \%$ of a class of the company's equity securities. Institutions are defined as professional money managers, including mutual fund companies, investment advisors, pension funds, bank trusts, and insurance companies. All potentially unbounded variables are winsorized at the $1 \%$ and $99 \%$ extremes. $t$ statistics in parentheses. The significance level, which was determined by the $t$ statistic, is asymptotically normal for paired differences. Coefficients marked with *** are significant at the $1 \%$ level, ** at the $5 \%$ level and * at the $10 \%$ level.

\begin{tabular}{|c|c|c|c|c|c|c|c|}
\hline Hedge Fund Board Representation & Model I & Model II & Model III & Model IV & Model V & Model VI & Model VII \\
\hline Corporate "Insider" Ownership ${ }_{(\mathrm{t}-6)}$ & $\begin{array}{c}-0.0166^{* * *} \\
(-3.05)\end{array}$ & & & & & & \\
\hline Corporate "Insider" Ownership (t-5) & & $\begin{array}{c}-0.0148^{* * *} \\
(-2.76)\end{array}$ & & & & & \\
\hline Corporate "Insider" Ownership (t-4) & & & $\begin{array}{c}-0.0155^{* * *} \\
(-2.87)\end{array}$ & & & & \\
\hline Corporate "Insider" Ownership (t-3) & & & & $\begin{array}{c}-0.0168^{* * *} \\
(-3.04)\end{array}$ & & & \\
\hline Corporate "Insider" Ownership $(\mathrm{t}-2)$ & & & & & $\begin{array}{c}-0.0167^{* * *} \\
(-3.02)\end{array}$ & & \\
\hline Corporate "Insider" Ownership (t-1) & & & & & & $\begin{array}{c}-0.0180^{* * *} \\
(-3.20)\end{array}$ & \\
\hline Corporate "Insider" Ownership (t) & & & & & & & $\begin{array}{c}-0.0165^{* * *} \\
(-3.00)\end{array}$ \\
\hline Constant & $\begin{array}{l}-0.368 \\
(-0.48)\end{array}$ & $\begin{array}{l}-0.373 \\
(-0.49)\end{array}$ & $\begin{array}{l}-0.369 \\
(-0.48)\end{array}$ & $\begin{array}{l}-0.363 \\
(-0.47)\end{array}$ & $\begin{array}{l}-0.366 \\
(-0.48)\end{array}$ & $\begin{array}{l}-0.354 \\
(-0.46)\end{array}$ & $\begin{array}{l}-0.363 \\
(-0.48)\end{array}$ \\
\hline Industry Fixed Effects & Yes & Yes & Yes & Yes & Yes & Yes & Yes \\
\hline Year Fixed Effects & Yes & Yes & Yes & Yes & Yes & Yes & Yes \\
\hline Observations & 605 & 611 & 611 & 612 & 612 & 616 & 616 \\
\hline Pseudo $R^{2}$ & 0.025 & 0.025 & 0.027 & 0.027 & 0.027 & 0.029 & 0.027 \\
\hline
\end{tabular}




\section{Table D.2: H3: Non-Hedge Fund Board Representation: Corporate "Inside" Ownership of Target Firms (Probit Regression Model)}

This table reports the Quarterly Corporate Ownership of Taget Firms 18 months ex ante board representation by a non-hedge fund activist. The ownership data is from the FactSet/LionShares database, which provides portfolio holdings of both institutional and individual investors. FactSet compiles ownership information from public filings by investors (such as 13-F filings, Form 3 and Form 4), company annual reports, stock exchanges, and regulatory agencies around the world. The SEC "Corporate insiders" as a company's officers and directors, and any beneficial owners of more than $10 \%$ of a class of the company's equity securities registered under Section 12 of the Securities Exchange Act of 1934 - must file with the SEC a statement of ownership regarding those securities. The data in the table excludes any institutions or noncompany officers and directors that are required to file with the SEC because they are beneficial owners of more than $10 \%$ of a class of the company's equity securities. Institutions are defined as professional money managers, including mutual fund companies, investment advisors, pension funds, bank trusts, and insurance companies. All potentially unbounded variables are winsorized at the $1 \%$ and $99 \%$ extremes. $t$ statistics in parentheses. The significance level, which was determined by the $t$ statistic, is asymptotically normal for paired differences. Coefficients marked with $* * *$ are significant at the $1 \%$ level, $* *$ at the $5 \%$ level and $*$ at the $10 \%$ level.

\begin{tabular}{|c|c|c|c|c|c|c|c|}
\hline Non-Hedge Fund Board Representation & Model I & Model II & Model III & Model IV & Model V & Model VI & Model VII \\
\hline Corporate "Insider" Ownership (t-6) & $\begin{array}{c}-0.00851 \\
(-0.86)\end{array}$ & & & & & & \\
\hline Corporate "Insider" Ownership (t-5) & & $\begin{array}{c}-0.00721 \\
(-0.72)\end{array}$ & & & & & \\
\hline Corporate "Insider" Ownership (t-4) & & & $\begin{array}{c}-0.00788 \\
(-0.79)\end{array}$ & & & & \\
\hline Corporate "Insider" Ownership (t-3) & & & & $\begin{array}{c}-0.0108 \\
(-1.09)\end{array}$ & & & \\
\hline Corporate "Insider" Ownership (t-2) & & & & & $\begin{array}{c}-0.0112 \\
(-1.12)\end{array}$ & & \\
\hline Corporate "Insider" Ownership (t-1) & & & & & & $\begin{array}{c}-0.0126 \\
(-1.25)\end{array}$ & \\
\hline Corporate "Insider" Ownership (t) & & & & & & & $\begin{array}{c}-0.00969 \\
(-0.96)\end{array}$ \\
\hline Constant & $\begin{array}{l}0.271 \\
(0.58)\end{array}$ & $\begin{array}{l}0.267 \\
(0.57)\end{array}$ & $\begin{array}{l}0.274 \\
(0.59)\end{array}$ & $\begin{array}{l}0.286 \\
(0.61)\end{array}$ & $\begin{array}{l}0.317 \\
(0.68)\end{array}$ & $\begin{array}{l}0.313 \\
(0.67)\end{array}$ & $\begin{array}{l}0.298 \\
(0.64)\end{array}$ \\
\hline Industry Fixed Effects & Yes & Yes & Yes & Yes & Yes & Yes & Yes \\
\hline Year Fixed Effects & Yes & Yes & Yes & Yes & Yes & Yes & Yes \\
\hline Observations & 108 & 108 & 108 & 110 & 111 & 111 & 111 \\
\hline Pseudo $R^{2}$ & 0.094 & 0.092 & 0.093 & 0.089 & 0.091 & 0.093 & 0.089 \\
\hline
\end{tabular}




\section{Table D.3: H3: Corporate "Inside" Ownership of Target Firms that "Won" Proxy Fight: No Hedge Fund Board Representation (Probit Regression Model)}

This table reports the Quarterly Corporate Ownership of Taget Firms 18 months ex ante a Target Firm that won the proxy fight against a hedge fund activist. The ownership data is from the FactSet/LionShares database, which provides portfolio holdings of both institutional and individual investors. FactSet compiles ownership information from public filings by investors (such as 13-F filings, Form 3 and Form 4), company annual reports, stock exchanges, and regulatory agencies around the world. The SEC "Corporate insiders" as a company's officers and directors, and any beneficial owners of more than $10 \%$ of a class of the company's equity securities registered under Section 12 of the Securities Exchange Act of 1934 - must file with the SEC a statement of ownership regarding those securities. The data in the table excludes any institutions or noncompany officers and directors that are required to file with the SEC because they are beneficial owners of more than $10 \%$ of a class of the company's equity securities. Institutions are defined as professional money managers, including mutual fund companies, investment advisors, pension funds, bank trusts, and insurance companies. All potentially unbounded variables are winsorized at the $1 \%$ and $99 \%$ extremes. $t$ statistics in parentheses. The significance level, which was determined by the $t$ statistic, is asymptotically normal for paired differences. Coefficients marked with $* * *$ are significant at the $1 \%$ level, ** at the $5 \%$ level and $*$ at the $10 \%$ level.

\begin{tabular}{|c|c|c|c|c|c|c|c|}
\hline Target "Wins" Proxy Fight & Model I & Model II & Model III & Model IV & Model V & Model VI & Model VII \\
\hline Corporate "Insider" Ownership (t-6) & $\begin{array}{c}0.00324 \\
(0.24)\end{array}$ & & & & & & \\
\hline Corporate "Insider" Ownership (t-5) & & $\begin{array}{c}0.00624 \\
(0.46)\end{array}$ & & & & & \\
\hline Corporate "Insider" Ownership (t-4) & & & $\begin{array}{c}0.00664 \\
(0.49)\end{array}$ & & & & \\
\hline Corporate "Insider" Ownership (t-3) & & & & $\begin{array}{c}0.00824 \\
(0.62)\end{array}$ & & & \\
\hline Corporate "Insider" Ownership (t-2) & & & & & $\begin{array}{c}0.00585 \\
(0.44)\end{array}$ & & \\
\hline Corporate "Insider" Ownership (t-1) & & & & & & $\begin{array}{c}0.00609 \\
(0.46)\end{array}$ & \\
\hline Corporate "Insider" Ownership (t) & & & & & & & $\begin{array}{c}0.00672 \\
(0.51)\end{array}$ \\
\hline Constant & $\begin{array}{l}-1.099 \\
(-1.13)\end{array}$ & $\begin{array}{l}-1.062 \\
(-1.09)\end{array}$ & $\begin{array}{l}-1.036 \\
(-1.06)\end{array}$ & $\begin{array}{l}-1.000 \\
(-1.03)\end{array}$ & $\begin{array}{l}-1.028 \\
(-1.05)\end{array}$ & $\begin{array}{l}-1.014 \\
(-1.04)\end{array}$ & $\begin{array}{l}-1.007 \\
(-1.03)\end{array}$ \\
\hline Industry Fixed Effects & Yes & Yes & Yes & Yes & Yes & Yes & Yes \\
\hline Year Fixed Effects & Yes & Yes & Yes & Yes & Yes & Yes & Yes \\
\hline Observations & 151 & 151 & 151 & 154 & 154 & 155 & 155 \\
\hline Pseudo $R^{2}$ & 0.035 & 0.036 & 0.034 & 0.036 & 0.035 & 0.031 & 0.031 \\
\hline
\end{tabular}


Table D.4: H3: Hedge Fund Board Representation: Corporate "Inside" Ownership of Target Firms (Logistic Regression Model)

This table reports the Quarterly Corporate Ownership of Taget Firms 18 months ex ante board representation by an activist hedge fund. The ownership data is from the FactSet/LionShares database, which provides portfolio holdings of both institutional and individual investors. FactSet compiles ownership information from public filings by investors (such as 13-F filings, Form 3 and Form 4), company annual reports, stock exchanges, and regulatory agencies around the world. The SEC "Corporate insiders" as a company's officers and directors, and any beneficial owners of more than $10 \%$ of a class of the company's equity securities registered under Section 12 of the Securities Exchange Act of 1934 - must file with the SEC a statement of ownership regarding those securities. The data in the table excludes any institutions or noncompany officers and directors that are required to file with the SEC because they are beneficial owners of more than $10 \%$ of a class of the company's equity securities. Institutions are defined as professional money managers, including mutual fund companies, investment advisors, pension funds, bank trusts, and insurance companies. All potentially unbounded variables are winsorized at the $1 \%$ and $99 \%$ extremes. $t$ statistics in parentheses. The significance level, which was determined by the $t$ statistic, is asymptotically normal for paired differences. Coefficients marked with *** are significant at the $1 \%$ level, ${ }^{* *}$ at the $5 \%$ level and ${ }^{*}$ at the $10 \%$ level.

\begin{tabular}{|c|c|c|c|c|c|c|c|}
\hline Hedge Fund Activism & Model I & Model II & Model III & Model IV & Model V & Model VI & Model VII \\
\hline Corporate "Insider" Ownership (t-6) & $\begin{array}{c}-0.0270^{* * *} \\
(-3.02)\end{array}$ & & & & & & \\
\hline Corporate "Insider" Ownership (t-5) & & $\begin{array}{c}-0.0241^{* * *} \\
(-2.75)\end{array}$ & & & & & \\
\hline Corporate "Insider" Ownership (t-4) & & & $\begin{array}{c}-0.0253^{* * *} \\
(-2.86)\end{array}$ & & & & \\
\hline Corporate "Insider" Ownership (t-3) & & & & $\begin{array}{c}-0.0273^{* * *} \\
(-3.02)\end{array}$ & & & \\
\hline Corporate "Insider" Ownership (t-2) & & & & & $\begin{array}{c}-0.0272^{* * *} \\
(-3.00)\end{array}$ & & \\
\hline Corporate "Insider" Ownership (t-1) & & & & & & $\begin{array}{c}-0.0293^{* * *} \\
(-3.17)\end{array}$ & \\
\hline Corporate "Insider" Ownership $(\mathrm{t})$ & & & & & & & $\begin{array}{c}-0.0270^{* * *} \\
(-2.98)\end{array}$ \\
\hline Constant & $\begin{array}{l}-0.584 \\
(-0.47)\end{array}$ & $\begin{array}{l}-0.592 \\
(-0.48)\end{array}$ & $\begin{array}{l}-0.584 \\
(-0.47)\end{array}$ & $\begin{array}{l}-0.576 \\
(-0.46)\end{array}$ & $\begin{array}{l}-0.580 \\
(-0.47)\end{array}$ & $\begin{array}{l}-0.564 \\
(-0.46)\end{array}$ & $\begin{array}{l}-0.577 \\
(-0.47)\end{array}$ \\
\hline Industry Fixed Effects & Yes & Yes & Yes & Yes & Yes & Yes & Yes \\
\hline Year Fixed Effects & Yes & Yes & Yes & Yes & Yes & Yes & Yes \\
\hline Observations & 605 & 611 & 611 & 612 & 612 & 616 & 616 \\
\hline Pseudo $R^{2}$ & 0.025 & 0.025 & 0.027 & 0.027 & 0.027 & 0.029 & 0.027 \\
\hline
\end{tabular}




\section{Table D.5: H3: Non-Hedge Fund Board Representation: Corporate "Inside" Ownership of Target Firms (Logistic Regression Model)}

This table reports the Quarterly Corporate Ownership of Target Firms 18 months ex ante board representation by a non-hedge fund activist. The ownership data is from the FactSet/LionShares database, which provides portfolio holdings of both institutional and individual investors. FactSet compiles ownership information from public filings by investors (such as 13-F filings, Form 3 and Form 4), company annual reports, stock exchanges, and regulatory agencies around the world. The SEC "Corporate insiders" as a company's officers and directors, and any beneficial owners of more than $10 \%$ of a class of the company's equity securities registered under Section 12 of the Securities Exchange Act of 1934 - must file with the SEC a statement of ownership regarding those securities. The data in the table excludes any institutions or noncompany officers and directors that are required to file with the SEC because they are beneficial owners of more than $10 \%$ of a class of the company's equity securities. Institutions are defined as professional money managers, including mutual fund companies, investment advisors, pension funds, bank trusts, and insurance companies. All potentially unbounded variables are winsorized at the $1 \%$ and $99 \%$ extremes. $t$ statistics in parentheses. The significance level, which was determined by the $t$ statistic, is asymptotically normal for paired differences. Coefficients marked with $* * *$ are significant at the $1 \%$ level, ** at the $5 \%$ level and $*$ at the $10 \%$ level.

\begin{tabular}{|c|c|c|c|c|c|c|c|}
\hline Hedge Fund Activism & Model I & Model II & Model III & Model IV & Model V & Model VI & Model VII \\
\hline Corporate "Insider" Ownership (t-6) & $\begin{array}{r}-0.0137 \\
(-0.85)\end{array}$ & & & & & & \\
\hline Corporate "Insider" Ownership (t-5) & & $\begin{array}{c}-0.0117 \\
(-0.71)\end{array}$ & & & & & \\
\hline Corporate "Insider" Ownership (t-4) & & & $\begin{array}{r}-0.0127 \\
(-0.78)\end{array}$ & & & & \\
\hline Corporate "Insider" Ownership (t-3) & & & & $\begin{array}{c}-0.0176 \\
(-1.08)\end{array}$ & & & \\
\hline Corporate "Insider" Ownership (t-2) & & & & & $\begin{array}{c}-0.0185 \\
(-1.13)\end{array}$ & & \\
\hline Corporate "Insider" Ownership (t-1) & & & & & & $\begin{array}{c}-0.0207 \\
(-1.26)\end{array}$ & \\
\hline Corporate "Insider" Ownership (t) & & & & & & & $\begin{array}{c}-0.0158 \\
(-0.96)\end{array}$ \\
\hline Constant & $\begin{array}{l}0.434 \\
(0.58)\end{array}$ & $\begin{array}{l}0.427 \\
(0.57)\end{array}$ & $\begin{array}{l}0.437 \\
(0.59)\end{array}$ & $\begin{array}{l}0.459 \\
(0.62)\end{array}$ & $\begin{array}{l}0.512 \\
(0.68)\end{array}$ & $\begin{array}{l}0.505 \\
(0.68)\end{array}$ & $\begin{array}{l}0.478 \\
(0.64)\end{array}$ \\
\hline Industry Fixed Effects & Yes & Yes & Yes & Yes & Yes & Yes & Yes \\
\hline Year Fixed Effects & Yes & Yes & Yes & Yes & Yes & Yes & Yes \\
\hline Observations & 108 & 108 & 108 & 110 & 111 & 111 & 111 \\
\hline Pseudo $R^{2}$ & 0.095 & 0.093 & 0.094 & 0.090 & 0.092 & 0.094 & 0.089 \\
\hline
\end{tabular}


Table D.6: H3: Corporate "Inside" Ownership of Target Firms that "Won" Proxy Fight: No Hedge Fund Board Representation (Logistic Regression Model)

This table reports the Quarterly Corporate Ownership of Target Firms 18 months ex ante a Target Firm that won the proxy fight against a hedge fund activist. The ownership data is from the FactSet/LionShares database, which provides portfolio holdings of both institutional and individual investors. FactSet compiles ownership information from public filings by investors (such as 13-F filings, Form 3 and Form 4), company annual reports, stock exchanges, and regulatory agencies around the world. The SEC "Corporate insiders" as a company's officers and directors, and any beneficial owners of more than $10 \%$ of a class of the company's equity securities registered under Section 12 of the Securities Exchange Act of 1934 - must file with the SEC a statement of ownership regarding those securities. The data in the table excludes any institutions or noncompany officers and directors that are required to file with the SEC because they are beneficial owners of more than $10 \%$ of a class of the company's equity securities. Institutions are defined as professional money managers, including mutual fund companies, investment advisors, pension funds, bank trusts, and insurance companies. All potentially unbounded variables are winsorized at the $1 \%$ and $99 \%$ extremes. $t$ statistics in parentheses. The significance level, which was determined by the $t$ statistic, is asymptotically normal for paired differences. Coefficients marked with $* * *$ are significant at the $1 \%$ level, $* *$ at the $5 \%$ level and $*$ at the $10 \%$ level.

\begin{tabular}{|c|c|c|c|c|c|c|c|}
\hline Hedge Fund Activism & Model I & Model II & Model III & Model IV & Model V & Model VI & Model VII \\
\hline Corporate "Insider" Ownership (t-6) & $\begin{array}{c}0.00510 \\
(0.23)\end{array}$ & & & & & & \\
\hline Corporate "Insider" Ownership (t-5) & & $\begin{array}{c}0.00998 \\
(0.46)\end{array}$ & & & & & \\
\hline Corporate "Insider" Ownership (t-4) & & & $\begin{array}{c}0.0107 \\
(0.49)\end{array}$ & & & & \\
\hline Corporate "Insider" Ownership (t-3) & & & & $\begin{array}{c}0.0133 \\
(0.62)\end{array}$ & & & \\
\hline Corporate "Insider" Ownership (t-2) & & & & & $\begin{array}{c}0.00941 \\
(0.44)\end{array}$ & & \\
\hline Corporate "Insider" Ownership (t-1) & & & & & & $\begin{array}{c}0.00987 \\
(0.46)\end{array}$ & \\
\hline Corporate "Insider" Ownership (t) & & & & & & & $\begin{array}{c}0.0109 \\
(0.51)\end{array}$ \\
\hline Constant & $\begin{array}{l}-1.764 \\
(-1.10)\end{array}$ & $\begin{array}{l}-1.705 \\
(-1.07)\end{array}$ & $\begin{array}{l}-1.668 \\
(-1.04)\end{array}$ & $\begin{array}{l}-1.611 \\
(-1.01)\end{array}$ & $\begin{array}{l}-1.653 \\
(-1.03)\end{array}$ & $\begin{array}{l}-1.630 \\
(-1.02)\end{array}$ & $\begin{array}{l}-1.619 \\
(-1.01)\end{array}$ \\
\hline Industry Fixed Effects & Yes & Yes & Yes & Yes & Yes & Yes & Yes \\
\hline Year Fixed Effects & Yes & Yes & Yes & Yes & Yes & Yes & Yes \\
\hline Observations & 151 & 151 & 151 & 154 & 154 & 155 & 155 \\
\hline Pseudo $R^{2}$ & 0.035 & 0.035 & 0.033 & 0.035 & 0.034 & 0.031 & 0.031 \\
\hline
\end{tabular}


Table D.7: H3: Corporate "Inside" Ownership of Target Firms by Hedge Fund Activists Seeking Board Representation

This table reports the Quarterly Corporate Ownership of Target Firms five years ex ante board representation by an activist hedge fund. The ownership data is from the FactSet/LionShares database, which provides portfolio holdings of both institutional and individual investors. FactSet compiles ownership information from public filings by investors (such as 13-F filings, Form 3 and Form 4), company annual reports, stock exchanges, and regulatory agencies around the world. The SEC "Corporate insiders" as a company's officers and directors, and any beneficial owners of more than 10\% of a class of the company's equity securities registered under Section 12 of the Securities Exchange Act of 1934 - must file with the SEC a statement of ownership regarding those securities. The data in the table excludes any institutions or noncompany officers and directors that are required to file with the SEC because they are beneficial owners of more than $10 \%$ of a class of the company's equity securities. Institutions are defined as professional money managers, including mutual fund companies, investment advisors, pension funds, bank trusts, and insurance companies. All potentially unbounded variables are winsorized at the $1 \%$ and $99 \%$ extremes. The table reports the mean, median, and standard error of the Quarterly Corporate Ownership of Taget Firms relative to comparative datasets. The significance level, which was determined by the $t$ statistic, is asymptotically normal for paired differences. Coefficients marked with $* * *$ are significant at the $1 \%$ level, $* *$ at the $5 \%$ level and ${ }^{*}$ at the $10 \%$ level.

\begin{tabular}{|c|c|c|c|c|c|c|c|c|c|c|c|c|c|}
\hline \multirow[b]{4}{*}{ Quarter } & \multicolumn{13}{|c|}{ Panel A: Corporate Inside Ownership of Target Firms by Hedge Fund Activists Seeking Board Representation } \\
\hline & \multirow{2}{*}{\multicolumn{3}{|c|}{ Target Firms }} & \multicolumn{8}{|c|}{ Differences between } & \multirow{2}{*}{\multicolumn{2}{|c|}{$\begin{array}{l}\text { Differences between } \\
\text { Target and Industry }\end{array}$}} \\
\hline & & & & & atched $\mathrm{Fi}$ & rms & Target a & nd Match & Ind & ustry Adj & usted & & \\
\hline & Mean & Median & Std. Err. & Mean & Median & Std. Err. & Diff (Mean) & Diff (Median) & Mean & Median & Std. Err. & Diff (Mean) & Diff (Median) \\
\hline Event -20 & 6.1492 & 2.0765 & 0.5172 & 8.6607 & 3.2796 & 0.6426 & $-2.5115^{* * *}$ & -1.2031 & 8.1737 & 8.0826 & 0.2271 & $-2.0245^{* * *}$ & -6.0061 \\
\hline Event -19 & 6.223 & 2.0876 & 0.5194 & 8.7324 & 3.5403 & 0.6387 & $-2.5094^{* * *}$ & -1.4527 & 8.2201 & 8.0897 & 0.2267 & $-1.9971^{* * *}$ & -6.0021 \\
\hline Event -18 & 6.1523 & 2.3363 & 0.5121 & 8.7096 & 3.5293 & 0.6339 & $-2.5573^{* * *}$ & -1.1930 & 8.2963 & 8.0016 & 0.2269 & $-2.144^{* * *}$ & -5.6653 \\
\hline Event -17 & 6.1117 & 2.44 & 0.5021 & 8.5745 & 3.4852 & 0.6274 & $-2.4628^{* * *}$ & -1.0452 & 8.35 & 8.0082 & 0.2263 & $-2.2383^{* * *}$ & -5.5682 \\
\hline Event -16 & 6.0164 & 2.3753 & 0.4978 & 8.7412 & 3.5327 & 0.6374 & $-2.7248^{* * * *}$ & -1.1574 & 8.4098 & 8.1656 & 0.2267 & $-2.3934^{* * *}$ & -5.7903 \\
\hline Event -15 & 5.8737 & 2.425 & 0.4855 & 8.5789 & 3.5098 & 0.6327 & $-2.7052^{* * *}$ & -1.0848 & 8.469 & 8.2997 & 0.228 & $-2.5953^{* * *}$ & -5.8747 \\
\hline Event -14 & 5.9359 & 2.5535 & 0.4943 & 8.6395 & 3.5098 & 0.6374 & $-2.7036^{* * *}$ & -0.9563 & 8.5292 & 8.2974 & 0.2281 & $-2.5933^{* * *}$ & -5.7439 \\
\hline Event -13 & 5.9961 & 2.5581 & 0.4952 & 8.6345 & 3.5146 & 0.6404 & $-2.6384^{* * *}$ & -0.9565 & 8.5904 & 8.3815 & 0.2293 & $-2.5943^{* * *}$ & -5.8234 \\
\hline Event - 12 & 5.9105 & 2.375 & 0.4851 & 8.6781 & 3.5214 & 0.6354 & $-2.7676^{* * *}$ & -1.1464 & 8.6713 & 8.4459 & 0.2307 & $-2.7608^{* * *}$ & -6.0709 \\
\hline Event -11 & 5.9439 & 2.3796 & 0.4805 & 8.7096 & 3.6218 & 0.6359 & $-2.7657^{* * *}$ & -1.2422 & 8.6194 & 8.515 & 0.2317 & $-2.6755^{* * *}$ & -6.1354 \\
\hline Event -10 & 5.9338 & 2.4892 & 0.4818 & 8.6187 & 3.5679 & 0.6311 & $-2.6849^{* * *}$ & -1.0787 & 8.6771 & 8.5487 & 0.2327 & -2.7433 *** & -6.0595 \\
\hline Event -9 & 5.8211 & 2.41 & 0.4741 & 8.5441 & 3.5212 & 0.6273 & $-2.723^{* * *}$ & -1.1112 & 8.7406 & 8.6103 & 0.2342 & $-2.9195^{* * *}$ & -6.2003 \\
\hline Event -8 & 5.8159 & 2.44 & 0.472 & 8.5369 & 3.3602 & 0.6307 & $-2.721^{* * * *}$ & -0.9202 & 8.7837 & 8.6302 & 0.2355 & $-2.9678 * * *$ & -6.1902 \\
\hline Event -7 & 5.9297 & 2.4237 & 0.4876 & 8.3147 & 3.2584 & 0.6199 & $-2.385^{* * *}$ & -0.8347 & 8.825 & 8.6251 & 0.2359 & $-2.8953^{* * *}$ & -6.2014 \\
\hline Event -6 & 6.0025 & 2.4505 & 0.5001 & 8.3758 & 3.0492 & 0.6243 & $-2.3733^{* * *}$ & -0.5987 & 8.8743 & 8.6415 & 0.2377 & $-2.8718^{* * *}$ & -6.1910 \\
\hline Event -5 & 6.1294 & 2.5542 & 0.5067 & 8.385 & 3.1563 & 0.6261 & $-2.2556^{* * *}$ & -0.6021 & 8.9212 & 8.6334 & 0.2387 & $-2.7918^{* * *}$ & -6.0792 \\
\hline Event -4 & 6.0404 & 2.5405 & 0.4934 & 8.3522 & 3.2963 & 0.623 & $-2.3118 * * *$ & -0.7558 & 8.9573 & 8.6467 & 0.2393 & $-2.9169^{* * *}$ & -6.1062 \\
\hline Event -3 & 5.898 & 2.5962 & 0.471 & 8.3116 & 3.2908 & 0.6223 & $-2.4136^{* * *}$ & -0.6946 & 8.9461 & 8.6182 & 0.2329 & $-3.0481^{* * *}$ & -6.0220 \\
\hline Event -2 & 5.8541 & 2.5101 & 0.4678 & 8.2353 & 3.1745 & 0.621 & $-2.3812^{* * *}$ & -0.6644 & 8.9985 & 8.679 & 0.2354 & $-3.1444^{* * *}$ & -6.1689 \\
\hline Event -1 & 5.6279 & 2.3182 & 0.4567 & 8.1575 & 2.979 & 0.6167 & $-2.5296^{* * *}$ & -0.6608 & 9.0208 & 8.6965 & 0.2354 & $-3.3929^{* * *}$ & -6.3783 \\
\hline Event & 5.6988 & 2.18 & 0.4769 & 8.0991 & 2.979 & 0.6175 & $-2.4003^{* * *}$ & -0.7990 & 8.9985 & 8.679 & 0.2354 & $-3.2997 * * *$ & -6.4990 \\
\hline
\end{tabular}


Table D.8: H3: Corporate "Inside" Ownership of Target Firms by Non-Hedge Fund Activists Seeking Board Representation

This table reports the Quarterly Corporate Ownership of Target Firms five years ex ante board representation by an activist non-hedge fund. The ownership data is from the FactSet/LionShares database, which provides portfolio holdings of both institutional and individual investors. FactSet compiles ownership information from public filings by investors (such as 13-F filings, Form 3 and Form 4), company annual reports, stock exchanges, and regulatory agencies around the world. The SEC "Corporate insiders" as a company's officers and directors, and any beneficial owners of more than 10\% of a class of the company's equity securities registered under Section 12 of the Securities Exchange Act of 1934 - must file with the SEC a statement of ownership regarding those securities. The data in the table excludes any institutions or noncompany officers and directors that are required to file with the SEC because they are beneficial owners of more than $10 \%$ of a class of the company's equity securities. Institutions are defined as professional money managers, including mutual fund companies, investment advisors, pension funds, bank trusts, and insurance companies. All potentially unbounded variables are winsorized at the $1 \%$ and $99 \%$ extremes. The table reports the mean, median, and standard error of the Quarterly Corporate Ownership of Taget Firms relative to comparative datasets. The significance level, which was determined by the $t$ statistic, is asymptotically normal for paired differences. Coefficients marked with *** are significant at the $1 \%$ level, $* *$ at the $5 \%$ level and ${ }^{*}$ at the $10 \%$ level.

\begin{tabular}{|c|c|c|c|c|c|c|c|c|c|c|c|c|c|}
\hline \multirow[b]{3}{*}{ Quarter } & \multirow{2}{*}{\multicolumn{3}{|c|}{ Target Firms }} & \multirow{2}{*}{\multicolumn{3}{|c|}{ Matched Firms }} & \multicolumn{2}{|c|}{ Differences between } & \multirow{2}{*}{\multicolumn{3}{|c|}{ Industry Adjusted }} & \multirow{2}{*}{\multicolumn{2}{|c|}{$\begin{array}{l}\text { Differences between } \\
\text { Target and Industry }\end{array}$}} \\
\hline & & & & & & & Target a & nd Match & & & & & \\
\hline & Mean & Median & Std. Err. & Mean & Median & Std. Err. & Diff (Mean) & Diff (Median) & Mean & Median & Std. Err. & Diff (Mean) & Diff (Median) \\
\hline Event -20 & 12.2769 & 7.1543 & 1.7322 & 12.7141 & 7.1141 & 1.7995 & -0.4372 & 0.0402 & 9.3537 & 8.8565 & 0.6172 & 2.9232 & -1.7022 \\
\hline Event -19 & 12.1953 & 7.1543 & 1.7453 & 12.7092 & 6.9715 & 1.8112 & -0.5139 & 0.1828 & 9.5273 & 8.8319 & 0.6337 & 2.668 & -1.6776 \\
\hline Event -18 & 12.2151 & 6.7625 & 1.7971 & 13.4115 & 7.8061 & 1.8738 & -1.1964 & -1.0436 & 9.6294 & 8.8662 & 0.6381 & 2.5857 & -2.1037 \\
\hline Event -17 & 13.1149 & 8.5983 & 1.8362 & 13.5722 & 7.8061 & 1.884 & -0.4573 & 0.7922 & 9.7221 & 9.0124 & 0.6375 & $3.3928^{*}$ & -0.4141 \\
\hline Event -16 & 12.7159 & 7.8961 & 1.7833 & 13.3441 & 7.0124 & 1.8652 & -0.6282 & 0.8837 & 9.8083 & 9.1015 & 0.634 & 2.9076 & -1.2054 \\
\hline Event -15 & 12.721 & 8.525 & 1.7602 & 13.8368 & 8.8934 & 1.8832 & -1.1158 & -0.3684 & 9.8909 & 9.0895 & 0.6313 & 2.8301 & -0.5645 \\
\hline Event -14 & 12.8126 & 8.7792 & 1.7594 & 14.0403 & 8.9673 & 1.9087 & -1.2277 & -0.1881 & 9.9703 & 9.1049 & 0.6294 & 2.8423 & -0.3257 \\
\hline Event -13 & 13.3697 & 9.4262 & 1.8131 & 14.2952 & 8.9673 & 1.902 & -0.9255 & 0.4589 & 10.0627 & 9.0536 & 0.6286 & $3.307^{*}$ & 0.3726 \\
\hline Event -12 & 13.7817 & 8.6404 & 1.8595 & 13.5372 & 8.9673 & 1.8321 & 0.2445 & -0.3269 & 10.165 & 9.093 & 0.6301 & $3.6167^{*}$ & -0.4526 \\
\hline Event -11 & 14.0314 & 8.6404 & 1.8535 & 14.1216 & 9.6492 & 1.8889 & -0.0902 & -1.0088 & 10.1695 & 9.015 & 0.6332 & $3.8619^{* *}$ & -0.3746 \\
\hline Event -10 & 14.0055 & 8.4372 & 1.8511 & 14.6295 & 10.5138 & 1.9032 & -0.624 & -2.0766 & 10.2069 & 8.9278 & 0.6362 & $3.7986^{*}$ & -0.4906 \\
\hline Event -9 & 14.2371 & 9.0002 & 1.8582 & 14.8421 & 10.1069 & 1.9028 & -0.605 & -1.1067 & 10.0324 & 8.9104 & 0.5861 & $4.2047^{* *}$ & 0.0898 \\
\hline Event -8 & 14.2132 & 9.0002 & 1.8588 & 14.9577 & 10.2633 & 1.9094 & -0.7445 & -1.2631 & 10.0479 & 8.9415 & 0.5821 & $4.1653^{* *}$ & 0.0587 \\
\hline Event -7 & 13.9631 & 9.0002 & 1.8153 & 15.1081 & 11.0323 & 1.9292 & -1.145 & -2.0321 & 10.143 & 9.0068 & 0.5809 & $3.8201^{* *}$ & -0.0066 \\
\hline Event -6 & 14.0088 & 9.0725 & 1.8511 & 15.1206 & 10.3311 & 1.9172 & -1.1118 & -1.2586 & 10.219 & 9.4697 & 0.5847 & $3.7898^{*}$ & -0.3972 \\
\hline Event -5 & 14.0738 & 9.0725 & 1.8577 & 14.7684 & 11.0304 & 1.8637 & -0.6946 & -1.9579 & 10.2596 & 9.7688 & 0.5867 & $3.8142^{*}$ & -0.6963 \\
\hline Event -4 & 13.7876 & 9.0725 & 1.8276 & 15.0064 & 10.3311 & 1.9053 & -1.2188 & -1.2586 & 10.319 & 9.8422 & 0.5934 & $3.4686^{*}$ & -0.7697 \\
\hline Event -3 & 13.5355 & 9.2229 & 1.7714 & 15.5859 & 10.2258 & 1.9559 & -2.0504 & -1.0029 & 10.3056 & 9.897 & 0.5925 & $3.2299^{*}$ & -0.6741 \\
\hline Event -2 & 13.7879 & 9.3316 & 1.7457 & 15.4021 & 9.6492 & 1.9545 & -1.6142 & -0.3176 & 10.2566 & 9.7964 & 0.5932 & $3.5313^{*}$ & -0.4648 \\
\hline Event -1 & 13.873 & 9.342 & 1.7716 & 15.8072 & 9.996 & 1.9895 & -1.9342 & -0.6540 & 10.2635 & 9.8858 & 0.5912 & $3.6095^{*}$ & -0.5438 \\
\hline Event & 13.9782 & 9.5583 & 1.7741 & 15.486 & 10.6476 & 1.9389 & -1.5078 & -1.0893 & 10.2635 & 9.8858 & 0.5912 & $3.7147^{* *}$ & -0.3275 \\
\hline
\end{tabular}




\section{Table D.9: H3: Corporate Inside Ownership of Target Firms that "Won" Proxy Fight: Failed Attempt at Hedge Board Representation}

This table reports the Quarterly Corporate Ownership of Target Firms that won the proxy fight against an activist hedge fund seeking board representation. The ownership data is from the FactSet/LionShares database, which provides portfolio holdings of both institutional and individual investors. FactSet compiles ownership information from public filings by investors (such as 13-F filings, Form 3 and Form 4), company annual reports, stock exchanges, and regulatory agencies around the world. The SEC "Corporate insiders" as a company's officers and directors, and any beneficial owners of more than $10 \%$ of a class of the company's equity securities registered under Section 12 of the Securities Exchange Act of 1934 - must file with the SEC a statement of ownership regarding those securities. The data in the table excludes any institutions or noncompany officers and directors that are required to file with the SEC because they are beneficial owners of more than $10 \%$ of a class of the company's equity securities. Institutions are defined as professional money managers, including mutual fund companies, investment advisors, pension funds, bank trusts, and insurance companies. All potentially unbounded variables are winsorized at the $1 \%$ and $99 \%$ extremes. The table reports the mean, median, and standard error of the Quarterly Corporate Ownership of Taget Firms relative to comparative datasets. The significance level, which was determined by the $t$ statistic, is asymptotically normal for paired differences. Coefficients marked with $* * *$ are significant at the $1 \%$ level, ${ }^{* *}$ at the $5 \%$ level and $*$ at the $10 \%$ level.

\begin{tabular}{|c|c|c|c|c|c|c|c|c|c|c|c|c|c|}
\hline \multirow[b]{3}{*}{ Quarter } & \multirow{2}{*}{\multicolumn{3}{|c|}{ Target Firms }} & \multirow{2}{*}{\multicolumn{3}{|c|}{ Matched Firms }} & \multicolumn{2}{|c|}{ Differences between } & \multirow{2}{*}{\multicolumn{3}{|c|}{ Industry Adjusted }} & \multirow{2}{*}{\multicolumn{2}{|c|}{$\begin{array}{l}\text { Differences between } \\
\text { Target and Industry }\end{array}$}} \\
\hline & & & & & & & Target & and Match & & & & & \\
\hline & Mean & Median & Std. Err. & Mean & Median & Std. Err. & Diff (Mean) & Diff (Median) & Mean & Median & Std. Err. & Diff (Mean) & Diff (Median) \\
\hline Event -20 & 5.0002 & 1.4662 & 0.9772 & 5.0283 & 1.1418 & 0.9190 & -0.0281 & 0.3244 & 7.4863 & 1.8709 & 0.0165 & $2.4861^{*}$ & -0.4047 \\
\hline Event -19 & 5.2755 & 1.4664 & 1.0311 & 5.1395 & 1.1418 & 0.9238 & 0.1360 & 0.3246 & 7.4862 & 1.8709 & 0.0165 & $2.2108^{*}$ & -0.4045 \\
\hline Event -18 & 4.9003 & 1.4666 & 0.9555 & 5.0245 & 1.0858 & 0.9161 & -0.1242 & 0.3808 & 7.4863 & 1.8709 & 0.0165 & $2.5860^{* *}$ & -0.4043 \\
\hline Event -17 & 4.9426 & 1.4900 & 0.9535 & 5.1707 & 1.2558 & 0.9253 & -0.2281 & 0.2342 & 7.4863 & 1.8709 & 0.0165 & $2.5437^{* *}$ & -0.3809 \\
\hline Event -16 & 4.8543 & 1.4800 & 0.9431 & 5.1139 & 1.2957 & 0.9671 & -0.2596 & 0.1843 & 7.4863 & 1.8709 & 0.0165 & $2.6320^{* *}$ & -0.3909 \\
\hline Event -15 & 4.9331 & 1.4800 & 0.9521 & 5.0942 & 1.2957 & 0.9666 & -0.1611 & 0.1843 & 7.4863 & 1.8709 & 0.0165 & $2.5532^{* *}$ & -0.3909 \\
\hline Event -14 & 4.9710 & 1.5200 & 0.9718 & 5.1094 & 1.3662 & 0.9454 & -0.1384 & 0.1538 & 7.4863 & 1.8709 & 0.0165 & $2.5153^{*}$ & -0.3509 \\
\hline Event -13 & 5.0344 & 1.5100 & 0.9750 & 5.1772 & 1.3414 & 0.9585 & -0.1428 & 0.1686 & 7.4863 & 1.8709 & 0.0165 & $2.4519^{*}$ & -0.3609 \\
\hline Event -12 & 4.8855 & 1.4783 & 0.9632 & 5.4689 & 1.3283 & 1.0216 & -0.5834 & 0.1500 & 7.4863 & 1.8709 & 0.0165 & $2.6008^{* *}$ & -0.3926 \\
\hline Event -11 & 5.0988 & 1.3844 & 0.9816 & 5.2269 & 1.2800 & 0.9863 & -0.1281 & 0.1044 & 7.4863 & 1.8709 & 0.0165 & $2.3875^{*}$ & -0.4865 \\
\hline Event -10 & 5.0966 & 1.4900 & 0.9785 & 4.4743 & 1.1714 & 0.8584 & 0.6223 & 0.3186 & 7.4863 & 1.8709 & 0.0165 & $2.3897^{*}$ & -0.3809 \\
\hline Event -9 & 5.2162 & 1.4978 & 0.9620 & 4.5393 & 1.3401 & 0.8556 & 0.6769 & 0.1577 & 7.4863 & 1.8709 & 0.0165 & $2.2700^{*}$ & -0.3731 \\
\hline Event -8 & 5.4099 & 1.5100 & 0.9642 & 5.0818 & 1.3689 & 0.9476 & 0.3281 & 0.1411 & 7.4862 & 1.8709 & 0.0165 & $2.0763^{*}$ & -0.3609 \\
\hline Event -7 & 5.1861 & 1.3789 & 0.9546 & 5.1014 & 1.3145 & 0.9395 & 0.0847 & 0.0644 & 7.4863 & 1.8709 & 0.0165 & $2.3002^{*}$ & -0.4920 \\
\hline Event -6 & 5.2602 & 1.3665 & 0.9648 & 5.0418 & 1.2416 & 0.9419 & 0.2184 & 0.1249 & 7.4863 & 1.8709 & 0.0165 & $2.2261^{*}$ & -0.5044 \\
\hline Event -5 & 5.2565 & 1.3747 & 0.9936 & 4.9582 & 1.2557 & 0.9621 & 0.2983 & 0.1190 & 7.4863 & 1.8709 & 0.0165 & $2.2298^{*}$ & -0.4962 \\
\hline Event -4 & 5.3513 & 1.4683 & 0.9939 & 4.9852 & 1.1568 & 0.9756 & 0.3661 & 0.3115 & 7.4863 & 1.8709 & 0.0165 & $2.1350^{*}$ & -0.4026 \\
\hline Event -3 & 5.4105 & 1.4683 & 0.9964 & 4.8084 & 1.1232 & 0.9490 & 0.6021 & 0.3451 & 7.4863 & 1.8709 & 0.0165 & $2.0758^{*}$ & -0.4026 \\
\hline Event -2 & 5.4210 & 1.4066 & 1.0041 & 5.0868 & 1.1232 & 0.9568 & 0.3342 & 0.2834 & 7.4863 & 1.8709 & 0.0165 & $2.0653^{*}$ & -0.4643 \\
\hline Event -1 & 5.4929 & 1.4181 & 0.9950 & 5.4983 & 1.3755 & 1.0230 & -0.0054 & 0.0426 & 7.4862 & 1.8709 & 0.0165 & 1.9934 & -0.4528 \\
\hline Event & 5.5736 & 1.4646 & 0.9945 & 5.5105 & 1.3755 & 1.0224 & 0.0631 & 0.0891 & 7.4862 & 1.8709 & 0.0165 & 1.9126 & -0.4063 \\
\hline
\end{tabular}


Appendix E

HYPOTHESIS 4: SHORT TERM EFFICACY OF SHAREHOLDER ACTIVISM 


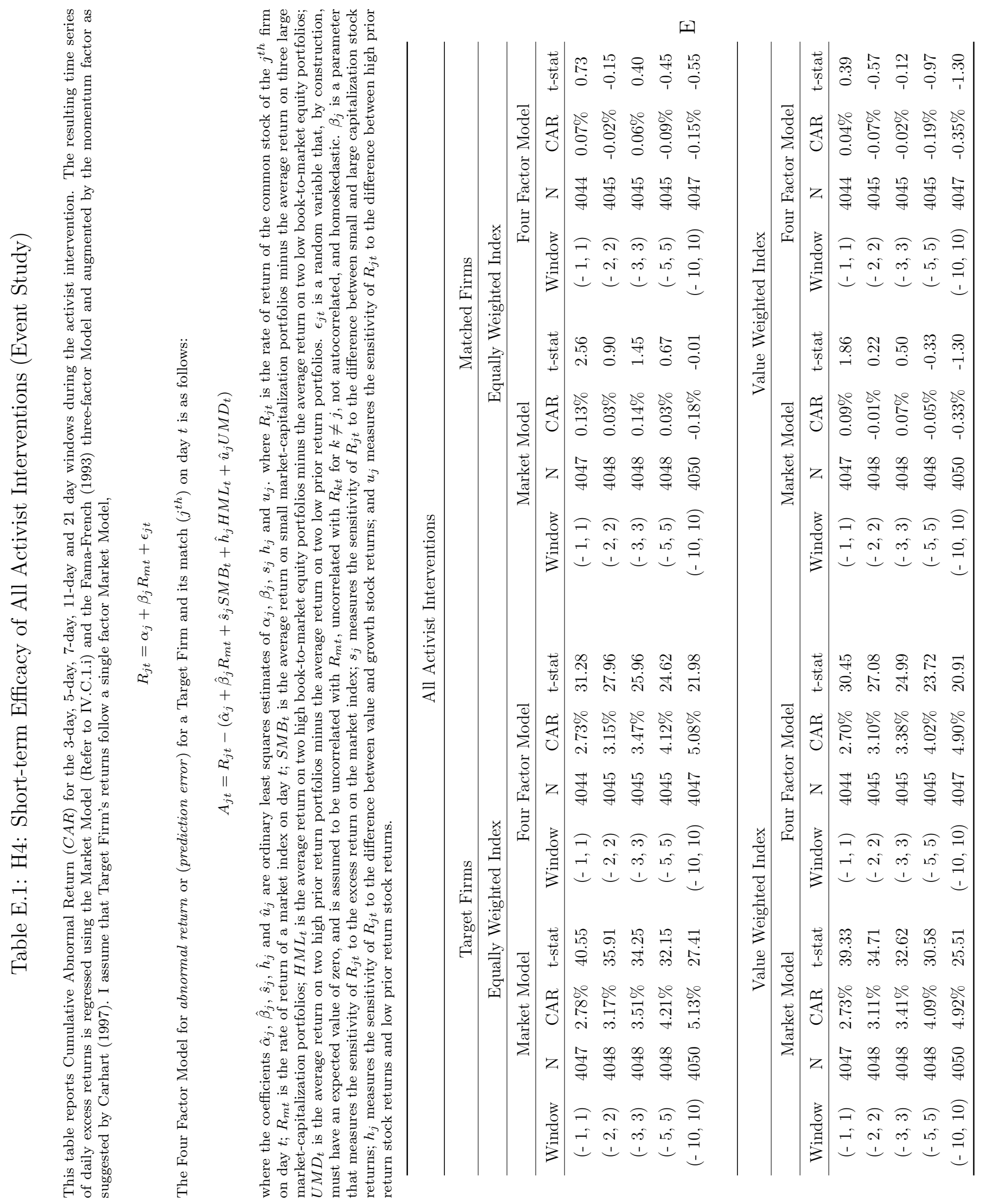




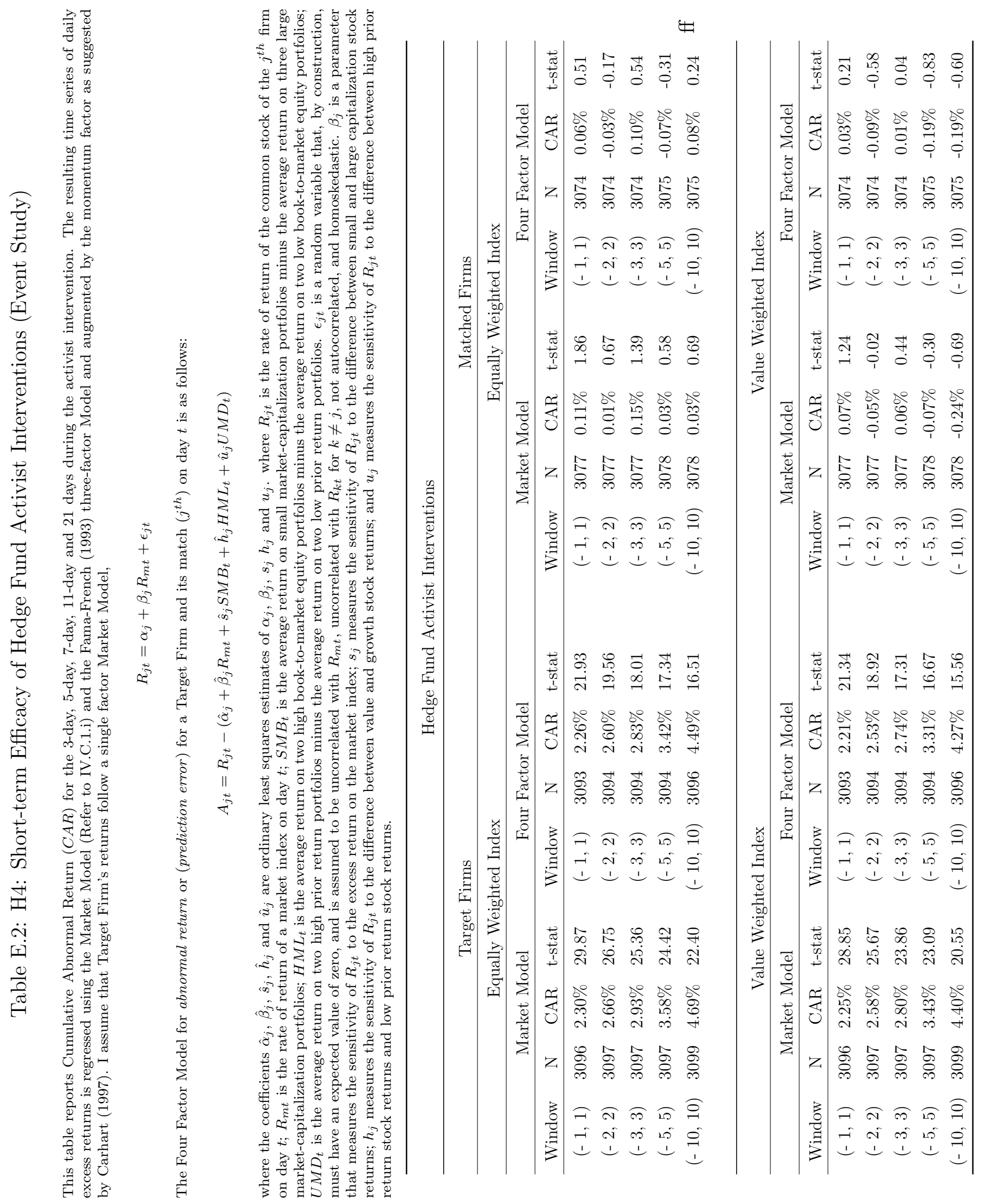




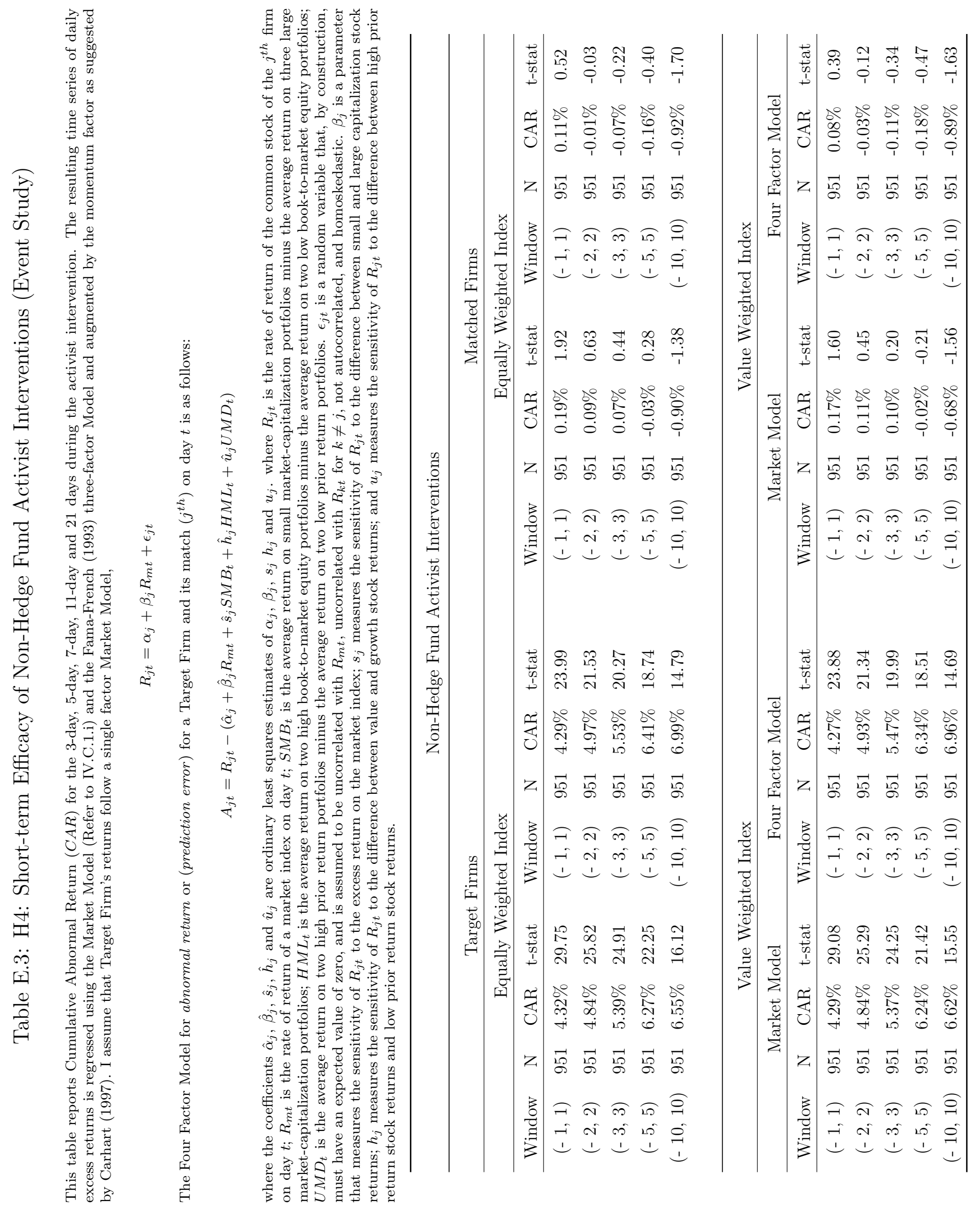


Appendix F

HYPOTHESIS 5: LONG TERM RETURNS OF TARGET FIRMS (TOTAL SHAREHOLDER RETURNS) 
I investigate Total Shareholder Return (TSR), a commonly used financial return measure, for Target Firms and Matched Firms. TSR is calculated as follows:

$$
\text { Total Shareholder Return }=\frac{\left(P_{t+x}-P_{0}\right)+\text { Dividends }}{P_{0}}
$$

The formula for the TSR (Equation F.1) is the appreciation in the stock price plus any dividends paid, divided by the original price of the stock. In equation (F.1), $P_{0}$ is the initial price of the stock and $P_{t+x}$ is the ending stock price. The return measures both capital appreciation and income from dividends. The first portion of the numerator of the $T S R$ formula measures how much the value of the stock has increased $\left(P_{t+x}-P_{0}\right)$. The denominator of the formula to calculate a stock's total return is the original price of the stock which is used due to being the original amount invested.

First, I compare TSR from Hedge Fund Activist interventions to Non-Hedge Fund Activist interventions. The Event Date $\left(t_{0}\right)$ with respect to the activist intervention is the either the announcement or filing date of the 13D. Figure F.2 illustrates an under-performance of Target Firms of Hedge Fund activism ex ante the intervention compared to Matched Firms. However, there is a discernible change with respect to the return profile ex post the Hedge Fund intervention. Five years ex post Event $\left(t_{0}\right)$, the portfolio of Hedge Fund activism generat 177.5\% TSR, whereas, Matched Firms yield 161.3\% TSR. This refutes the claim that activist campaigns generate positive abnormal returns in the short run but, ultimately, reverse to yield negative returns.

Figure F.3 depicts the TSR profile of Target Firms and Matched Firms Non-hedge Fund activism. The return profile ex ante the activist intervention was similar to the Hedge Fund Activist targets, however, the Target Firms did not perform as well as the Matched Firms during the same long-term event window ex post the Event.

Next, I examine the Treatment Group (Hedge Fund Board Representation) 


\section{All Activist Interventions (TSR)}

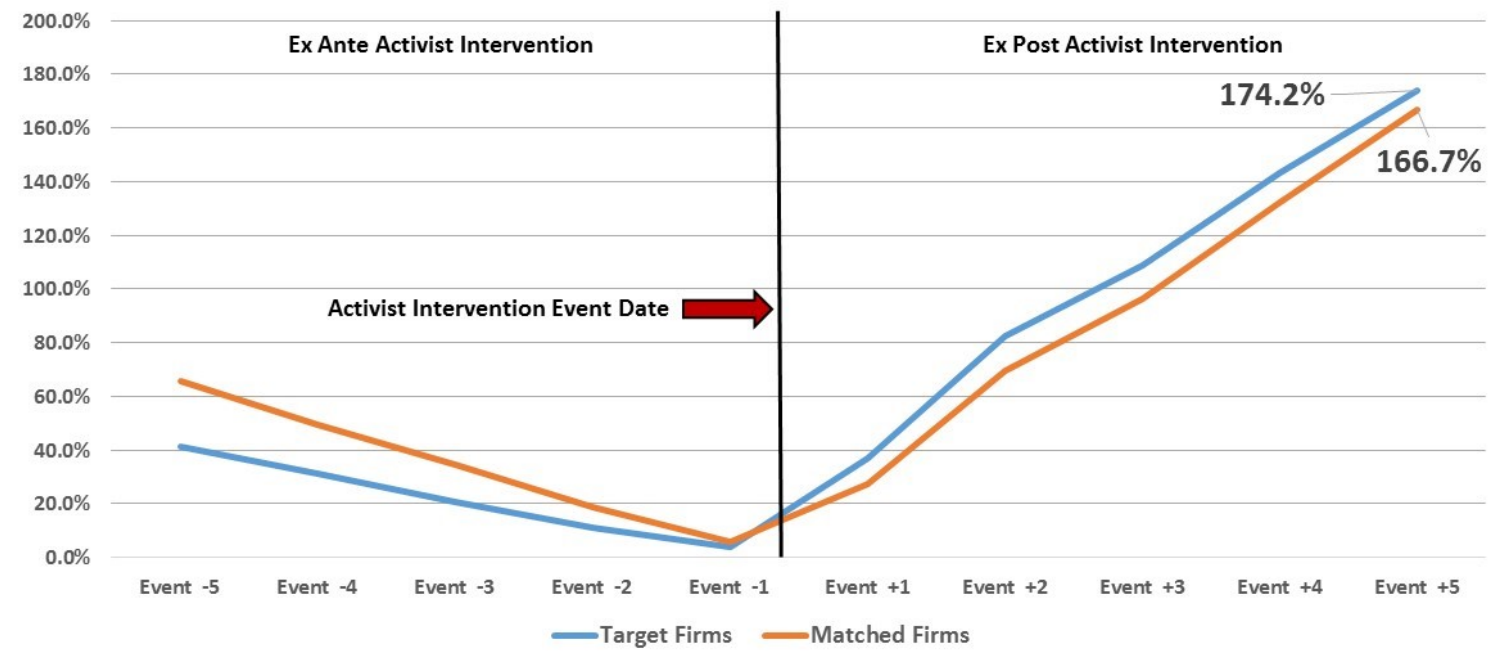

Figure F.1: Total Shareholder Return: All Activist Interventions

and both control groups (Control Group I: Target Firms that "Won" Proxy Fight) and (Control Group II: Non-hedge Fund Board Representation). The Event Date $\left(t_{0}\right)$ with respect to the Treatment Group and Control Group II is the board seat grant date and for Control Group I Event Date $\left(t_{0}\right)$ is the announcement date of the proxy fight results. Figure F.4 illustrates a significant under-performance of Target Firms of the Treatment Group ex ante the intervention compared to Matched Firms. However, there is a immediate improvement with respect to the return profile ex post the board seat grant date relative to Matched Firms. Five years ex post Event $\left(t_{0}\right)$, the portfolio of Treatment Target Firms $185.5 \%$ TSR, whereas, Matched Firms yield $170.8 \%$ TSR. This substantiates that hedge funds generate long-term value for the Target Firms and its long-term shareholders when they function as a disciplinary mechanism to monitor management via board representation.

I then examine the TSR profile of both control groups relative to a sample of Matched Firms. Figure F.5 illustrates a under-performance of Target Firms of Control Group I ex ante the intervention compared to Matched Firms. However, it takes over three years for the Target Firms' TSR to exceed Matched Firms.

Figure F.6 illustrates a similar under-performance of Target Firms of 


\section{Hedge Fund Activist Interventions (TSR)}

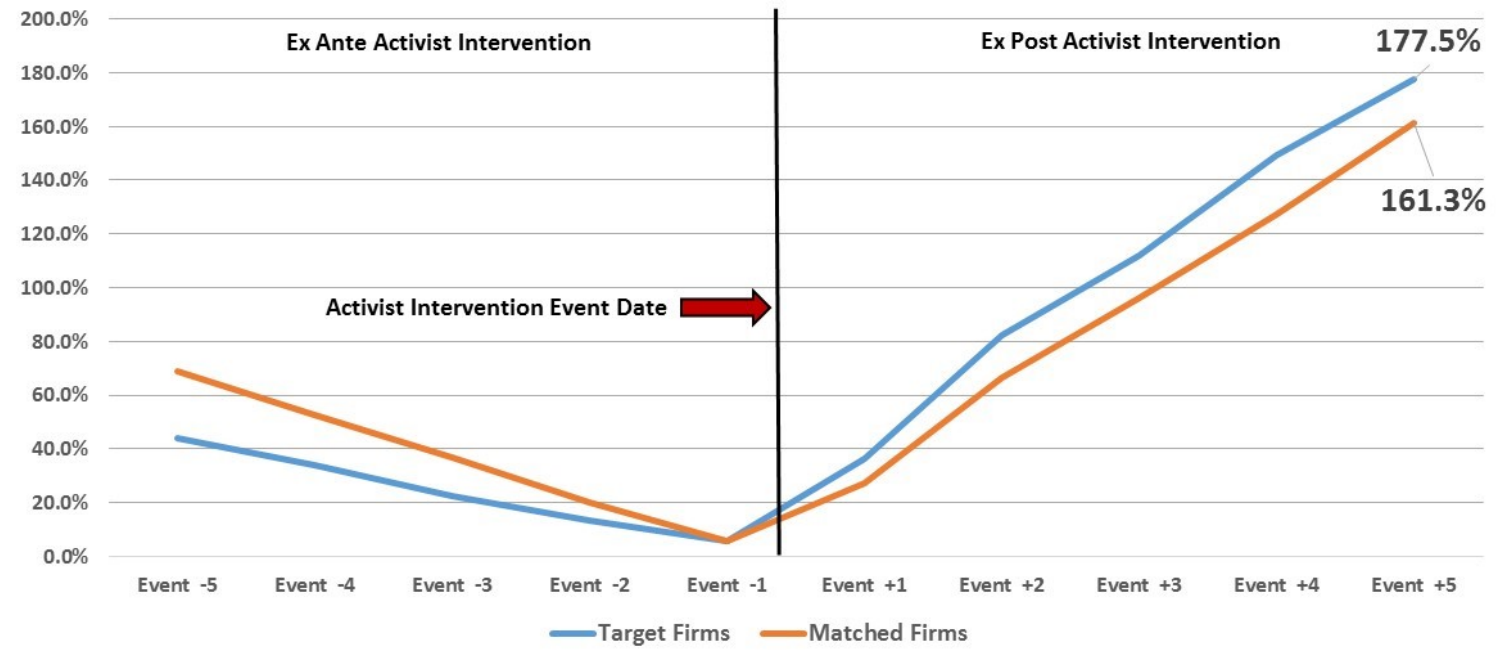

Figure F.2: Total Shareholder Return: Hedge Fund Activism

Control Group II ex ante the intervention compared to Matched Firms. However, the Target Firms did not perform as well as the Matched Firms during the same long-term event window ex post the Event. Five years ex post Event $\left(t_{0}\right)$, the portfolio of Control Group II Target Firms report 129.1\% TSR, whereas, Matched Firms yield $182.1 \%$ TSR. This provides support that hedge fund board representation generates long-term value (refer to Figure F.4), whereas, non-hedge funds yielded lower TSR as a disciplinary mechanism to monitor management via board representation. 
Table F.1: H5: Calendar-time Portfolio Abnormal Returns: Jensen's Alpha (All Activist Interventions)

This table report Calendar-time Portfolio Abnormal Returns (Jensen's Alpha) for a 5-year period during Ex Post an activist intervention. In each calendar month over the entire sample period, a portfolio was constructed comprising all firms experiencing the event within the previous month. Because the number of event firms is not uniformly distributed over the sample period, the number of firms included in a portfolio is not constant through time. As a result, some new firms are added each month, and some firms exit each month. Accordingly, the portfolios are rebalanced each month, and an equal or value-weighted portfolio excess return is calculated. The resulting time series of monthly excess returns is regressed on the Fama-French (1993) three-factor Model as follows:

- $R_{j t}$ is the equal or value-weighted return for calendar month $t$ for the portfolio of event firms that experienced the event within previous $\mathrm{T}$ years,

- $R_{f t}$ is the risk-free rate,

- $R_{M t}$ is the return on the CRSP value-weight market portfolio,

- $S M B_{t}$, is the difference between the return on the portfolio of "small" stocks and "big" stocks;

- $H M L_{t}$ is the difference between the return a portfolio of "high" and "low" book-to-market stocks;

- $\alpha$ is the average monthly abnormal return on a portfolio of firms over the t-month post-event period,

- $\beta$ is the beta (the sensitivities) of the event portfolio to the three factors.

I report the long-term abnormal returns associated of Target Firms of all activist interventions as well as report regression estimates and level of significance from both equal-weighted and value-weighted calendar-time portfolio regressions. The portfolio holding period was determined based on actual trading days and indicates the holding period in years relative to the date that the board seat(s) was granted. For example, the portfolio with holding period [Event +1 , will continually add target firms that have added an activist/dissident shareholder to their respective board during the year from the date the seat was granted. The portfolio will hold these firms until the earlier of December 31, 2014, a delisting date as a result of a Chapter 11 filing or a sale/merger. Coefficients marked with *** are significant at the $1 \%$ level, ${ }^{* *}$ at the $5 \%$ level and ${ }^{*}$ at the $10 \%$ level. The regression takes the form:

$$
R_{j t}-R_{f t}=\alpha+\beta p, R_{M}-R_{f t}+\beta p, S M B_{t},+\beta p, H M L_{t}+\epsilon_{j t}
$$

\begin{tabular}{|c|c|c|c|c|c|c|c|}
\hline \multicolumn{8}{|c|}{ Panel A: Target Firms (All of Activist Interventions) } \\
\hline & & \multicolumn{3}{|c|}{ Equally-Weighted } & \multicolumn{3}{|c|}{ Value-Weighted } \\
\hline & & & & Calendar-Time & & & Calendar-Time \\
\hline & $\mathrm{N}$ & CAR & PWCAAR & Portfolio CAR & CAR & PWCAAR & Portfolio CAR \\
\hline Event Year +1 & 3974 & $0.0855^{* * *}$ & $0.0818^{* * *}$ & $0.0994^{* * *}$ & $0.0787^{* * *}$ & $0.0769^{* * *}$ & $0.0984^{* * *}$ \\
\hline Event Year +2 & 3978 & $0.1275^{* * *}$ & $0.1621^{* * *}$ & $0.1544^{* * *}$ & $0.1245^{* * *}$ & $0.1567^{* * *}$ & $0.1583^{* * *}$ \\
\hline Event Year +3 & 3978 & $0.151^{* * *}$ & $0.2136^{* * *}$ & $0.1983^{* * *}$ & $0.1378^{* * *}$ & $0.1894^{* * *}$ & $0.2072^{* * *}$ \\
\hline Event Year +4 & 3978 & $0.1761^{* * *}$ & $0.2842^{* * *}$ & $0.2003^{* * *}$ & $0.151^{* * *}$ & $0.2381 * * *$ & $0.2159^{* * *}$ \\
\hline Event Year +5 & 3991 & $0.1946^{* * *}$ & $0.3513^{* * *}$ & $0.219^{* * *}$ & $0.1608^{* * *}$ & $0.2899^{* * *}$ & $0.2387^{* * *}$ \\
\hline
\end{tabular}

Panel B: Matched Firms (All Activist Interventions)

\begin{tabular}{lc|ccc|ccc}
\hline & \multicolumn{3}{|c|}{} & \multicolumn{3}{|c|}{ Equally-Weighted } & \multicolumn{3}{c}{ Value-Weighted } \\
& $\mathrm{N}$ & CAR & PWCAAR & Portfolio CAR & CAR & PWCAAR & Calendar-Time \\
& & Portfolio CAR \\
\hline Event Year +1 & 3974 & $-0.0281^{* * *}$ & $0.0151^{* * *}$ & $-0.0419^{* * *}$ & $-0.031^{* *}$ & 0.0092 & -0.0350 \\
Event Year +2 & 3978 & $-0.0724^{* * *}$ & $0.0223^{* * *}$ & $-0.0983^{* * *}$ & $-0.0605^{* * *}$ & 0.0222 & -0.0798 \\
Event Year +3 & 3978 & $-0.0985^{* * *}$ & $0.0235^{* * *}$ & $-0.1444^{* * *}$ & $-0.1022^{* *}$ & $0.0177^{* *}$ & $-0.1327^{*}$ \\
Event Year +4 & 3978 & $-0.103^{* * *}$ & $0.0578^{* * *}$ & $-0.1674^{* * *}$ & $-0.1236^{* * *}$ & $0.0242^{* *}$ & -0.1585 \\
Event Year +5 & 3991 & $-0.1131^{* * *}$ & $0.1068^{* * *}$ & $-0.1923^{* * *}$ & $-0.1473^{* * *}$ & $0.0314^{* *}$ & -0.1772 \\
\hline
\end{tabular}

Panel C: Differences (All Activist Interventions)

\begin{tabular}{lc|ccc|ccc}
\hline & & \multicolumn{3}{|c|}{$\begin{array}{c}\text { Equally-Weighted } \\
\text { Calendar-Time }\end{array}$} & \multicolumn{2}{c}{ Value-Weighted } \\
& CAR & PWCAAR & Portfolio CAR & CAR & PWCAAR & $\begin{array}{c}\text { Palendar-Time } \\
\text { Portfolio CAR }\end{array}$ \\
\hline Event Year +1 & 3974 & 0.1136 & 0.0667 & 0.1413 & 0.1097 & 0.0677 & 0.1334 \\
Event Year +2 & 3978 & 0.1999 & 0.1398 & 0.2527 & 0.1850 & 0.1345 & 0.2381 \\
Event Year +3 & 3978 & 0.2495 & 0.1901 & 0.3427 & 0.2400 & 0.1717 & 0.3399 \\
Event Year +4 & 3978 & 0.2791 & 0.2264 & 0.3677 & 0.2746 & 0.2139 & 0.3744 \\
Event Year +5 & 3991 & 0.3077 & 0.2445 & 0.4113 & 0.3081 & 0.2585 & 0.4159 \\
\hline
\end{tabular}


Table F.2: H5: Calendar-time Portfolio Abnormal Returns: Jensen's Alpha (Hedge Fund Activist Interventions)

This table report Calendar-time Portfolio Abnormal Returns (Jensen's Alpha) for a 5-year period during Ex Post an activist intervention. In each calendar month over the entire sample period, a portfolio was constructed comprising all firms experiencing the event within the previous month. Because the number of event firms is not uniformly distributed over the sample period, the number of firms included in a portfolio is not constant through time. As a result, some new firms are added each month, and some firms exit each month. Accordingly, the portfolios are rebalanced each month, and an equal or value-weighted portfolio excess return is calculated. The resulting time series of monthly excess returns is regressed on the Fama-French (1993) three-factor Model as follows:

- $R_{j t}$ is the equal or value-weighted return for calendar month $t$ for the portfolio of event firms that experienced the event within previous $\mathrm{T}$ years,

- $R_{f t}$ is the risk-free rate,

- $R_{M t}$ is the return on the CRSP value-weight market portfolio,

- $S M B_{t}$, is the difference between the return on the portfolio of "small" stocks and "big" stocks;

- $H M L_{t}$ is the difference between the return a portfolio of "high" and "low" book-to-market stocks;

- $\alpha$ is the average monthly abnormal return on a portfolio of firms over the t-month post-event period,

- $\beta$ is the beta (the sensitivities) of the event portfolio to the three factors.

I report the long-term abnormal returns associated of Target Firms of Hedge Fund activist interventions as well as report regression estimates and level of significance from both equal-weighted and value-weighted calendar-time portfolio regressions. The portfolio holding period was determined based on actual trading days and indicates the holding period in years relative to the date that the board seat(s) was granted. For example, the portfolio with holding period [Event +1 ], will continually add target firms that have added an activist/dissident shareholder to their respective board during the year from the date the seat was granted. The portfolio will hold these firms until the earlier of December 31, 2014, a delisting date as a result of a Chapter 11 filing or a sale/merger. Coefficients marked with ${ }^{* * *}$ are significant at the $1 \%$ level, ${ }^{* *}$ at the $5 \%$ level and ${ }^{*}$ at the $10 \%$ level. The regression takes the form:

$$
R_{j t}-R_{f t}=\alpha+\beta p, R_{M}-R_{f t}+\beta p, S M B_{t},+\beta p, H M L_{t}+\epsilon_{j t}
$$

\begin{tabular}{|c|c|c|c|c|c|c|c|}
\hline \multicolumn{8}{|c|}{ Panel A: Target Firms (Hedge Fund Activist Interventions) } \\
\hline & $\mathrm{N}$ & CAR & $\begin{array}{l}\text { qually-Wei } \\
\text { PWCAAR }\end{array}$ & $\begin{array}{l}\text { Shted } \\
\text { Calendar-Time } \\
\text { Portfolio CAR }\end{array}$ & CAR & Value-Weig & $\begin{array}{l}\text { hted } \\
\text { Calendar-Time } \\
\text { Portfolio CAR }\end{array}$ \\
\hline Event Year +1 & 3020 & $0.0833^{* * *}$ & $0.0856^{* * *}$ & $0.0856^{* * *}$ & $0.0746^{* * *}$ & $0.0774^{* * *}$ & $0.1083^{* * *}$ \\
\hline Event Year +2 & 3978 & $0.1297^{* * *}$ & $0.1719^{* * *}$ & $0.1719^{* * *}$ & $0.1265^{* * *}$ & $0.1628^{* * *}$ & $0.173^{* * *}$ \\
\hline Event Year +3 & 3978 & $0.1585^{* * *}$ & $0.2302^{* * *}$ & $0.2302^{* * *}$ & $0.1484^{* * *}$ & $0.2051^{* * *}$ & $0.2277^{* * *}$ \\
\hline Event Year +4 & 3978 & $0.1861^{* * *}$ & $0.3057^{* * *}$ & $0.3057^{* * *}$ & $0.1659^{* * *}$ & $0.2605^{* * *}$ & $0.2473^{* * *}$ \\
\hline Event Year +5 & 3030 & $0.2052^{* * *}$ & $0.3743^{* * *}$ & $0.3743^{* * *}$ & $0.178^{* * *}$ & $0.3176^{* * *}$ & $0.2754^{* * *}$ \\
\hline \multicolumn{8}{|c|}{ Panel B: Matched Firms (Hedge Fund Activist Interventions) } \\
\hline & $\mathrm{N}$ & CAR & qually-Wei & $\begin{array}{l}\text { Shted } \\
\text { Calendar-Time } \\
\text { Portfolio CAR }\end{array}$ & CAR & Value-Weig & $\begin{array}{l}\text { hted } \\
\text { Calendar-Time } \\
\text { Portfolio CAR }\end{array}$ \\
\hline Event Year +1 & 3020 & $-0.03^{* * *}$ & 0.0224 & $-0.0377^{* * *}$ & $-0.0357^{*}$ & 0.0109 & $-0.0267 * * *$ \\
\hline Event Year +2 & 3978 & $-0.0794^{* * *}$ & 0.0331 & $-0.1001^{* * *}$ & $-0.0656^{* * *}$ & 0.0263 & $-0.0751^{* * *}$ \\
\hline Event Year +3 & 3978 & $-0.1044^{* * *}$ & $0.032^{*}$ & $-0.153^{* * *}$ & $-0.103^{* *}$ & $0.023^{*}$ & $-0.133^{* * *}$ \\
\hline Event Year +4 & 3978 & $-0.1064^{* * *}$ & $0.0768^{*}$ & $-0.1756^{* * *}$ & $-0.1204^{* * *}$ & $0.0366^{*}$ & $-0.1557 * * *$ \\
\hline Event Year +5 & 3030 & $-0.1175^{* * *}$ & $0.1358^{* *}$ & $-0.2091^{* * *}$ & $-0.1444^{* * *}$ & $0.0465 *$ & $-0.1802^{* * *}$ \\
\hline \multicolumn{8}{|c|}{ Panel C: Differences (Hedge Fund Activist Interventions) } \\
\hline & $\mathrm{N}$ & CAR & $\begin{array}{l}\text { qually-Wei } \\
\text { PWCAAR }\end{array}$ & $\begin{array}{l}\text { Shted } \\
\text { Calendar-Time } \\
\text { Portfolio CAR }\end{array}$ & CAR & $\begin{array}{l}\text { Value-Weig } \\
\text { PWCAAR }\end{array}$ & $\begin{array}{l}\text { hted } \\
\text { Calendar-Time } \\
\text { Portfolio CAR }\end{array}$ \\
\hline Event Year +1 & 3020 & 0.1133 & 0.0632 & 0.1233 & 0.1103 & 0.0665 & 0.1350 \\
\hline Event Year +2 & 3978 & 0.2091 & 0.1388 & 0.2720 & 0.1921 & 0.1365 & 0.2481 \\
\hline Event Year +3 & 3978 & 0.2629 & 0.1982 & 0.3832 & 0.2514 & 0.1821 & 0.3607 \\
\hline Event Year +4 & 3978 & 0.2925 & 0.2289 & 0.4813 & 0.2863 & 0.2239 & 0.4030 \\
\hline Event Year +5 & 3030 & 0.3227 & 0.2385 & 0.5834 & 0.3224 & 0.2711 & 0.4556 \\
\hline
\end{tabular}


Non-Hedge Fund Activist Interventions (TSR)

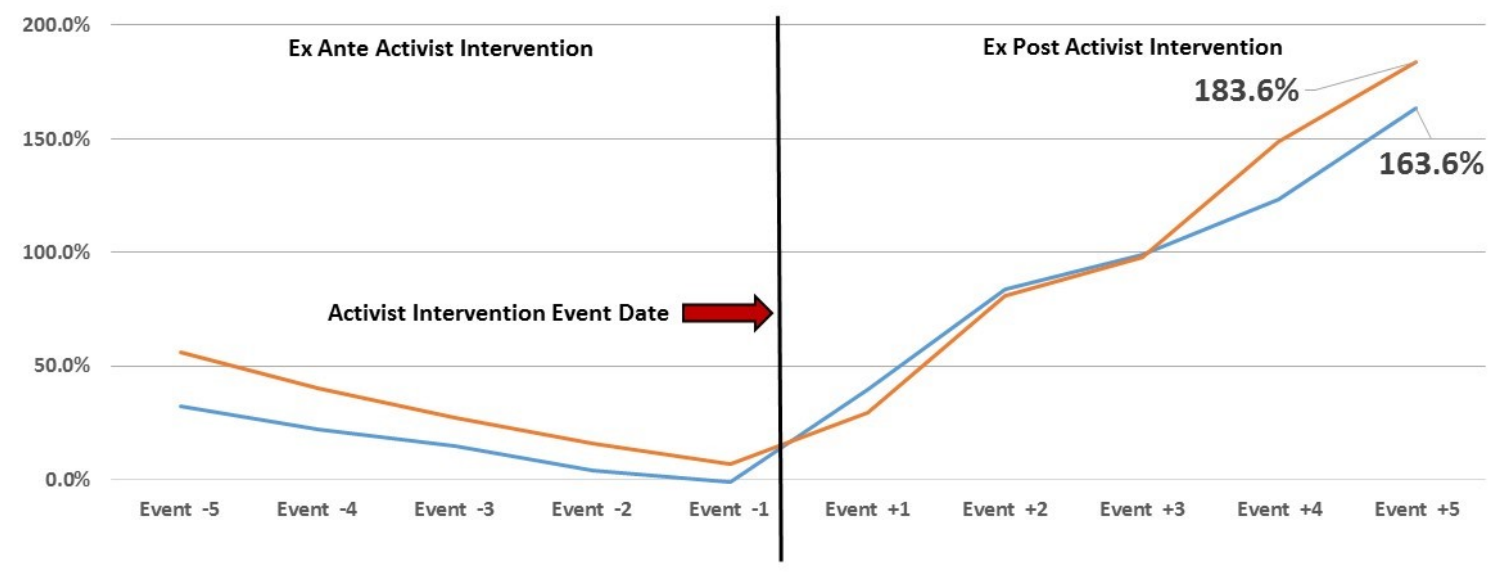

$-50.0 \%$

$$
\text { — Target Firms —Matched Firms }
$$

Figure F.3: Total Shareholder Return: Non-Hedge Fund Activism

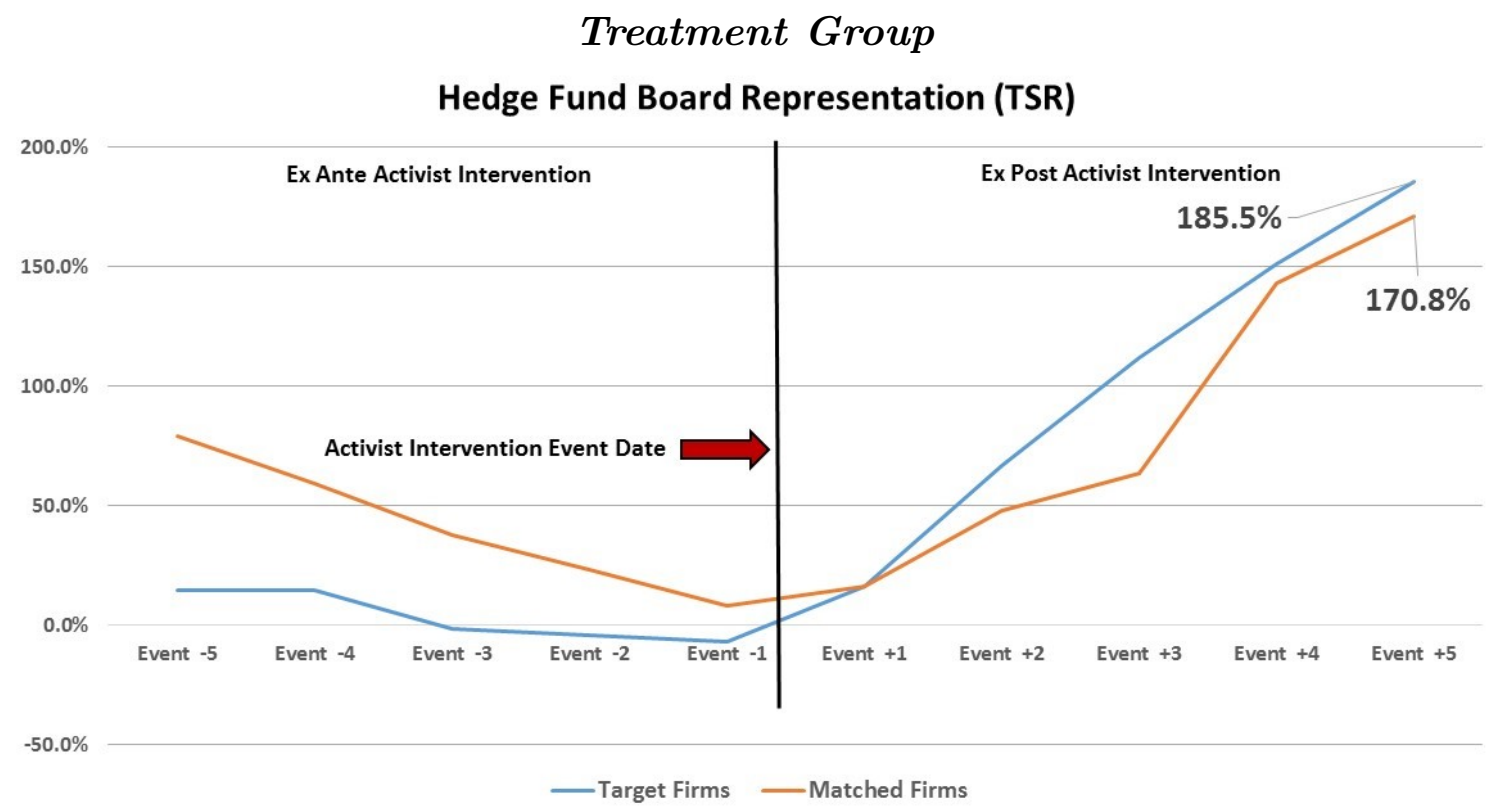

Figure F.4: Total Shareholder Return: Hedge Fund Board Representation (Treatment Group) 


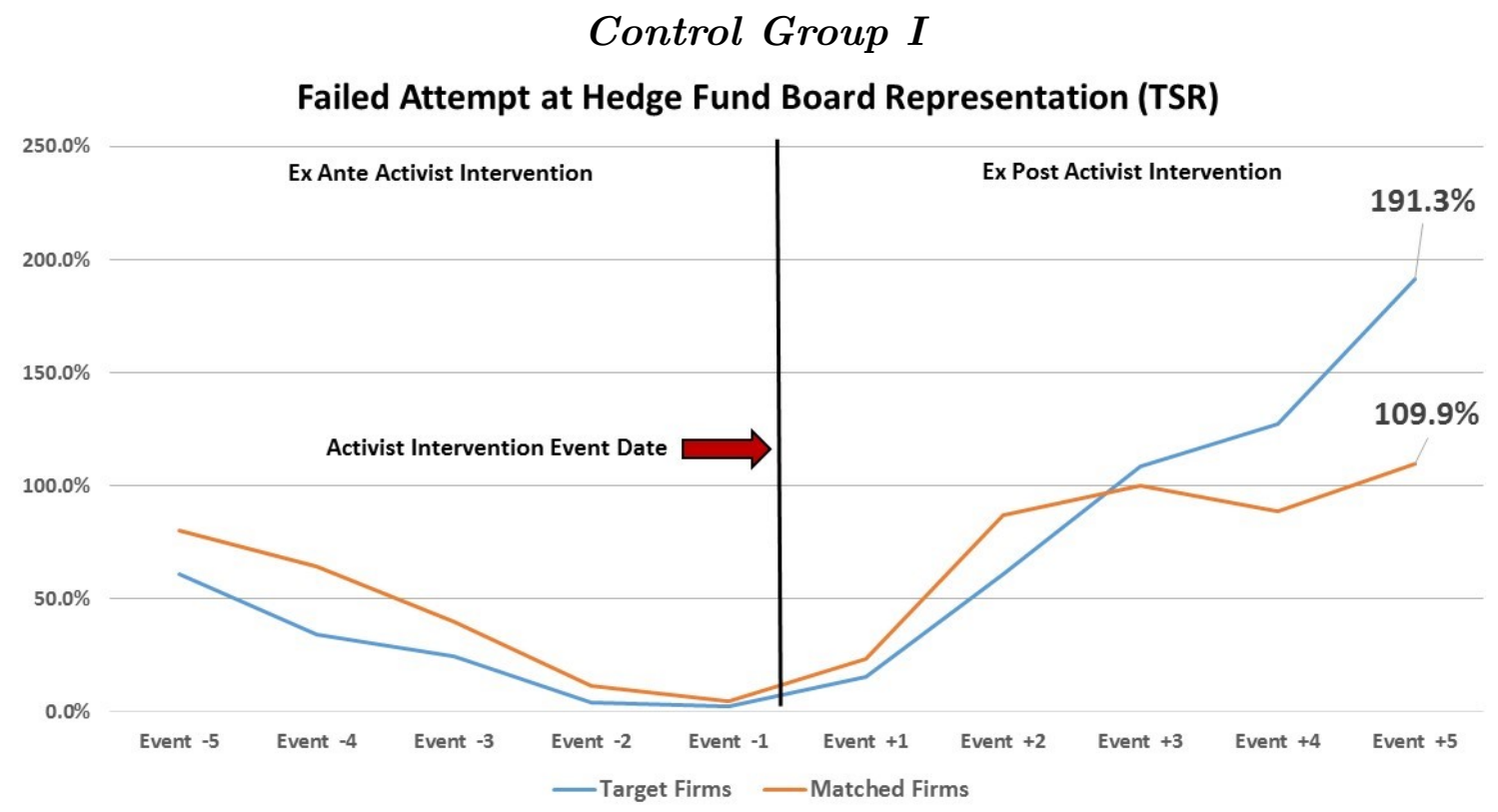

Figure F.5: Total Shareholder Return: Target Firm "Wins" Proxy Fight: No Hedge Fund Board Representation (Control Group I)

\section{Control Group II}

Non-Hedge Fund Board Representation (TSR)

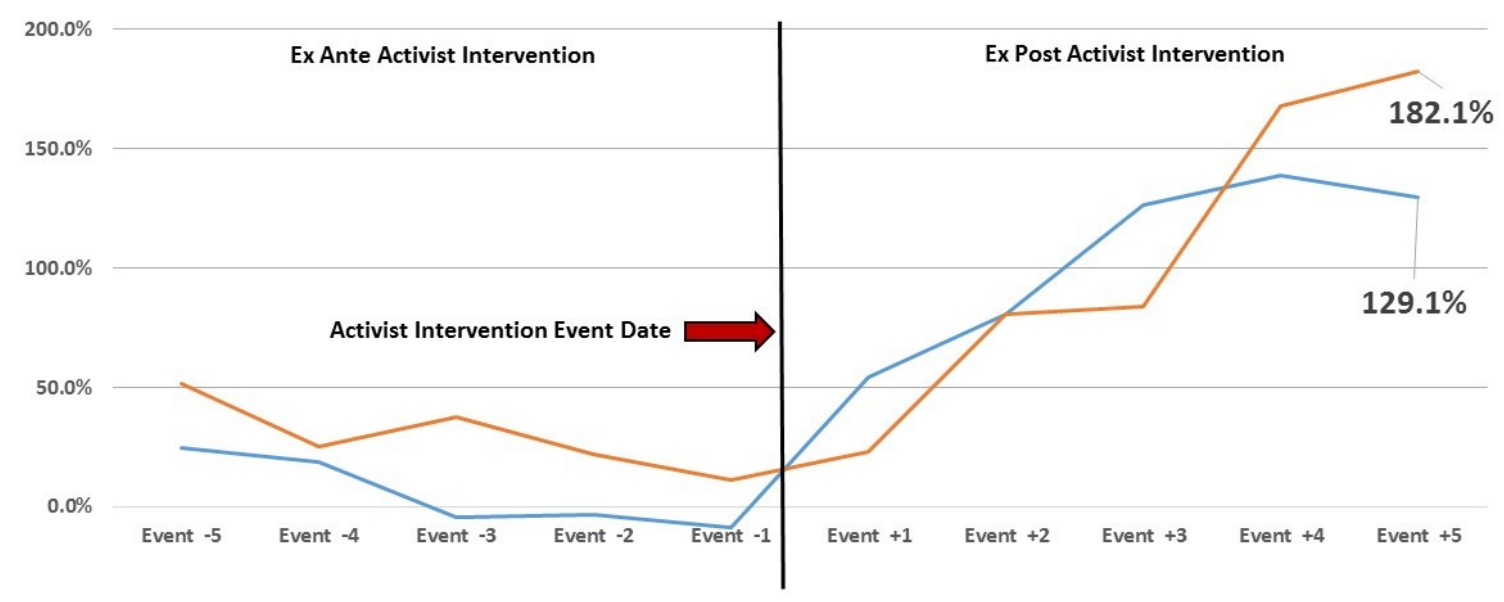

s.00x

$$
\text { — Target Firms — Matched Firms }
$$

Figure F.6: Total Shareholder Return: Non-Hedge Fund Board Representation (Control Group I) 


\section{Table F.3: H5: Calendar-time Portfolio Abnormal Returns: Jensen's Alpha (Non-Hedge Fund Activist Interventions)}

This table report Calendar-time Portfolio Abnormal Returns (Jensen's Alpha) for a 5-year period during Ex Post an activist intervention. In each calendar month over the entire sample period, a portfolio was constructed comprising all firms experiencing the event within the previous month. Because the number of event firms is not uniformly distributed over the sample period, the number of firms included in a portfolio is not constant through time. As a result, some new firms are added each month, and some firms exit each month. Accordingly, the portfolios are rebalanced each month, and an equal or value-weighted portfolio excess return is calculated. The resulting time series of monthly excess returns is regressed on the Fama-French (1993) three-factor Model as follows:

- $R_{j t}$ is the equal or value-weighted return for calendar month $t$ for the portfolio of event firms that experienced the event within previous $\mathrm{T}$ years,

- $R_{f t}$ is the risk-free rate,

- $R_{M t}$ is the return on the CRSP value-weight market portfolio,

- $S M B_{t}$, is the difference between the return on the portfolio of "small" stocks and "big" stocks;

- $H M L_{t}$ is the difference between the return a portfolio of "high" and "low" book-to-market stocks;

- $\alpha$ is the average monthly abnormal return on a portfolio of firms over the t-month post-event period,

- $\beta$ is the beta (the sensitivities) of the event portfolio to the three factors.

I report the long-term abnormal returns associated of Target Firms of Non-Hedge Fund activist interventions as well as report regression estimates and level of significance from both equal-weighted and value-weighted calendar-time portfolio regressions. The portfolio holding period was determined based on actual trading days and indicates the holding period in years relative to the date that the board seat(s) was granted. For example, the portfolio with holding period [Event +1 ], will continually add target firms that have added an activist/dissident shareholder to their respective board during the year from the date the seat was granted. The portfolio will hold these firms until the earlier of December 31, 2014, a delisting date as a result of a Chapter 11 filing or a sale/merger. Coefficients marked with ${ }^{* * *}$ are significant at the $1 \%$ level, ${ }^{* *}$ at the $5 \%$ level and ${ }^{*}$ at the $10 \%$ level. The regression takes the form:

$$
R_{j t}-R_{f t}=\alpha+\beta p, R_{M}-R_{f t}+\beta p, S M B_{t},+\beta p, H M L_{t}+\epsilon_{j t}
$$

\begin{tabular}{|c|c|c|c|c|c|c|c|}
\hline \multicolumn{8}{|c|}{ Panel A: Target Firms (Non-Hedge Fund Activist Interventions) } \\
\hline & & \multicolumn{3}{|c|}{ Equally-Weighted } & \multicolumn{3}{|c|}{ Value-Weighted } \\
\hline & & & & Calendar-Time & & & Calendar-Time \\
\hline & $\mathrm{N}$ & CAR & PWCAAR & Portfolio CAR & CAR & PWCAAR & Portfolio CAR \\
\hline Event Year +1 & 954 & $0.0925^{* * *}$ & $0.0709^{* * *}$ & $0.0986^{* * *}$ & $0.0918^{* * *}$ & $0.076^{* * *}$ & $0.0916^{* * *}$ \\
\hline Event Year +2 & 955 & $0.1207^{* * *}$ & $0.1331^{* * *}$ & $0.143^{* * *}$ & $0.118^{* * *}$ & $0.1396^{* * *}$ & $0.13^{* * *}$ \\
\hline Event Year +3 & 957 & $0.1274^{* * *}$ & $0.1657^{* * *}$ & $0.155^{* * *}$ & $0.1042^{* * *}$ & $0.1452^{* * *}$ & $0.124^{* * *}$ \\
\hline Event Year +4 & 957 & $0.1444^{* * *}$ & $0.2225^{* * *}$ & $0.1696^{* * *}$ & $0.1039^{* * *}$ & $0.1749^{* * *}$ & $0.1151^{* * *}$ \\
\hline Event Year +5 & 961 & $0.1609^{* * *}$ & $0.2852^{* * *}$ & $0.1745^{* * *}$ & $0.1066^{* * *}$ & $0.2115^{* * *}$ & $0.1034^{* * *}$ \\
\hline
\end{tabular}

Panel B: Matched Firms (Non-Hedge Fund Activist Interventions)

\begin{tabular}{|c|c|c|c|c|c|c|c|}
\hline & $\mathrm{N}$ & CAR & $\begin{array}{l}\text { qually-We } \\
\text { PWCAAR }\end{array}$ & $\begin{array}{l}\text { ghted } \\
\text { Calendar-Time } \\
\text { Portfolio CAR }\end{array}$ & CAR & Value-Wei & $\begin{array}{l}\text { hted } \\
\text { Calendar-Time } \\
\text { Portfolio CAR }\end{array}$ \\
\hline Event Year +1 & 954 & -0.0232 & -0.0079 & -0.0446 & -0.0176 & 0.0039 & -0.0525 \\
\hline Event Year +2 & 955 & -0.0508 & -0.0122 & $-0.0738 * * *$ & -0.0460 & 0.0089 & $-0.0936^{* *}$ \\
\hline Event Year +3 & 957 & -0.0800 & $-0.0043^{*}$ & $-0.1178^{* * *}$ & -0.1014 & 0.0004 & $-0.1679^{* * *}$ \\
\hline Event Year +4 & 957 & -0.0928 & $-0.0028^{*}$ & $-0.158^{* * *}$ & -0.1359 & $-0.0147^{* *}$ & $-0.2403^{* * *}$ \\
\hline Event Year +5 & 961 & -0.1003 & $0.0144^{*}$ & $-0.1569^{* *}$ & -0.1587 & $-0.0164^{* *}$ & $-0.2594^{* * *}$ \\
\hline
\end{tabular}

Panel C: Differences (Non-Hedge Fund Activist Interventions)

\begin{tabular}{lc|ccc|ccc}
\hline & & \multicolumn{2}{|c|}{$\begin{array}{c}\text { Equally-Weighted } \\
\text { Calendar-Time }\end{array}$} & \multicolumn{3}{c}{ Value-Weighted } \\
& $\mathrm{N}$ & CAR & PWCAAR & Portfolio CAR & PWCAR & CAAR & $\begin{array}{c}\text { Calendar-Time } \\
\text { Portfolio CAR }\end{array}$ \\
\hline Event Year +1 & 954 & 0.1157 & 0.0788 & 0.1432 & 0.1094 & 0.0721 & 0.1441 \\
Event Year +2 & 955 & 0.1715 & 0.1453 & 0.2168 & 0.1640 & 0.1307 & 0.2236 \\
Event Year +3 & 957 & 0.2074 & 0.1700 & 0.2728 & 0.2056 & 0.1448 & 0.2919 \\
Event Year +4 & 957 & 0.2372 & 0.2253 & 0.3276 & 0.2398 & 0.1896 & 0.3554 \\
Event Year +5 & 961 & 0.2612 & 0.2708 & 0.3314 & 0.2653 & 0.2279 & 0.3628 \\
\hline
\end{tabular}


Appendix G

HYPOTHESIS 6: LONG TERM OPERATING PERFORMANCE AND GOVERNANCE STRUCTURE OF TARGET FIRMS 


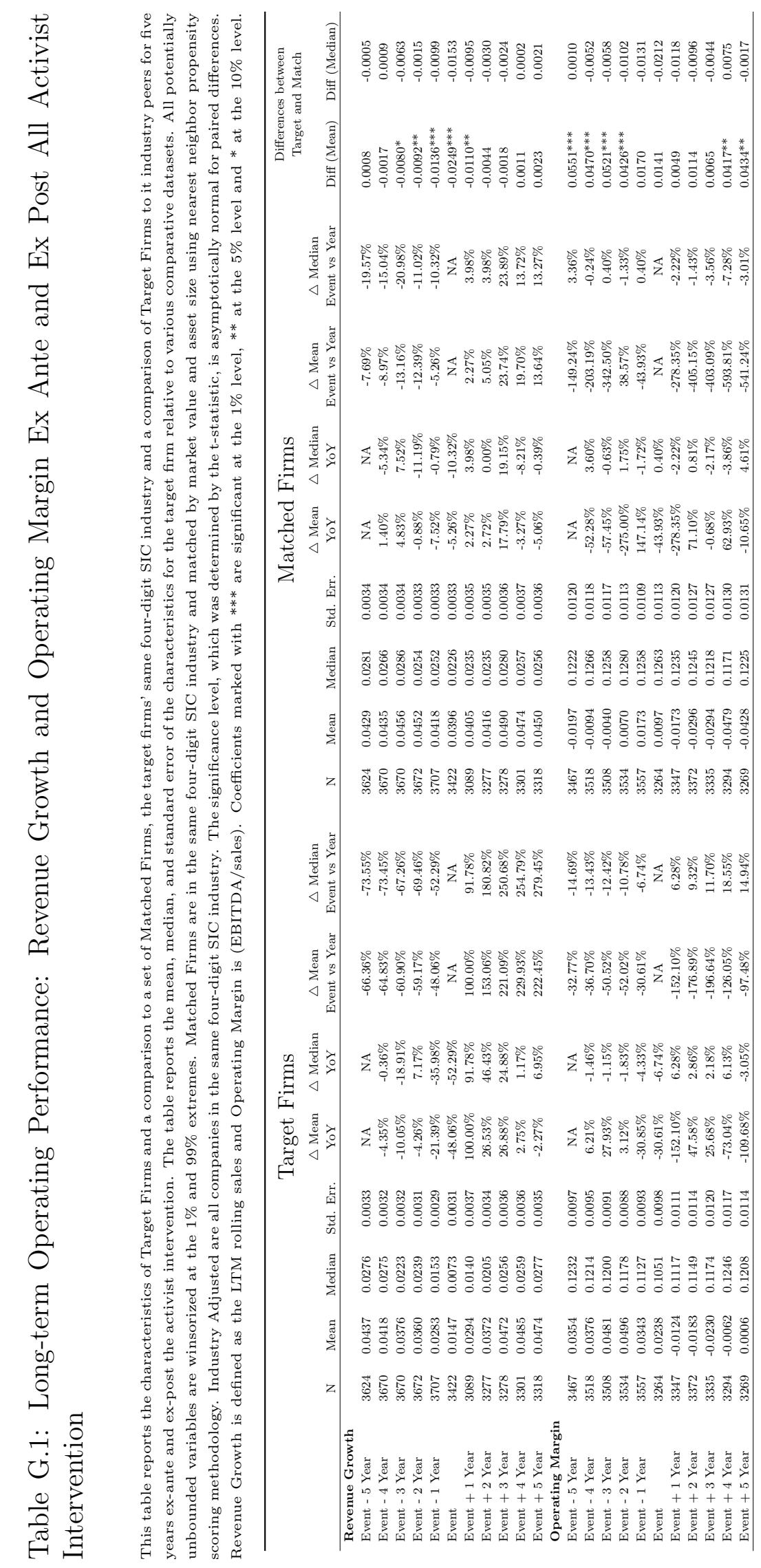

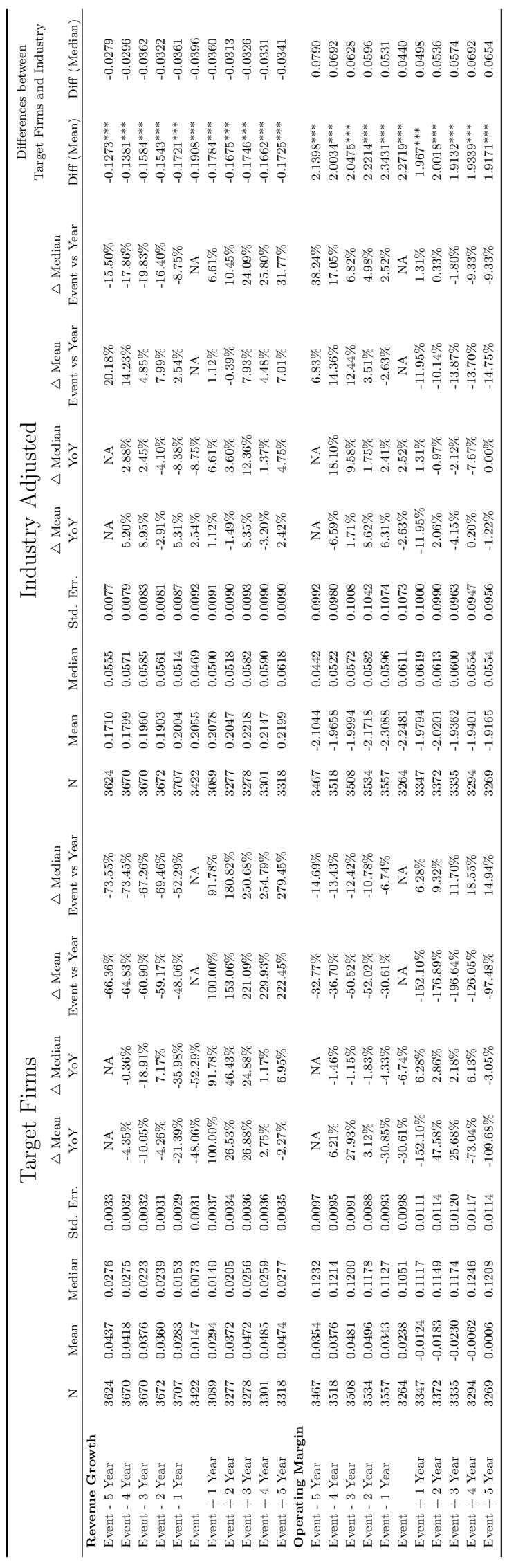



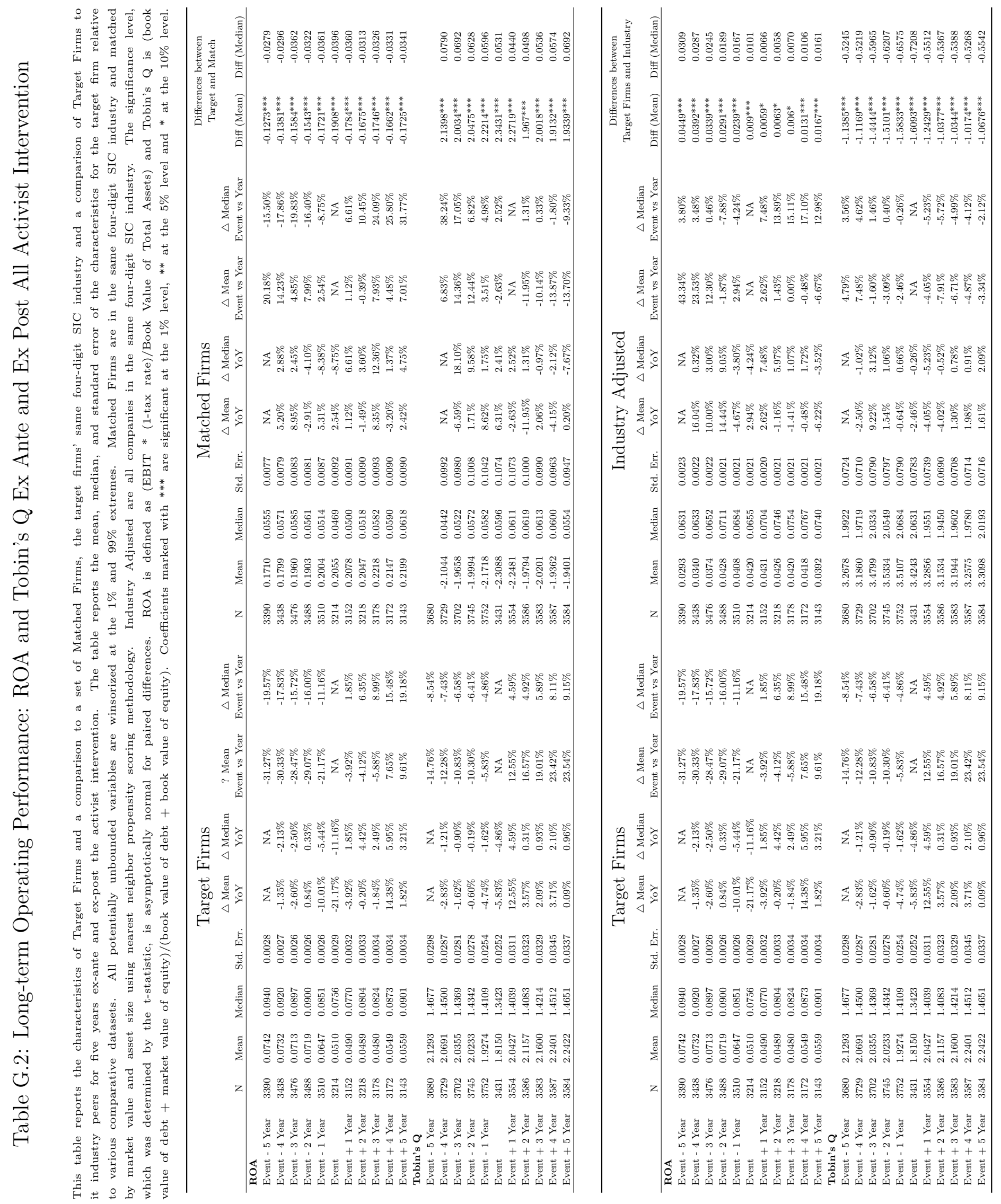


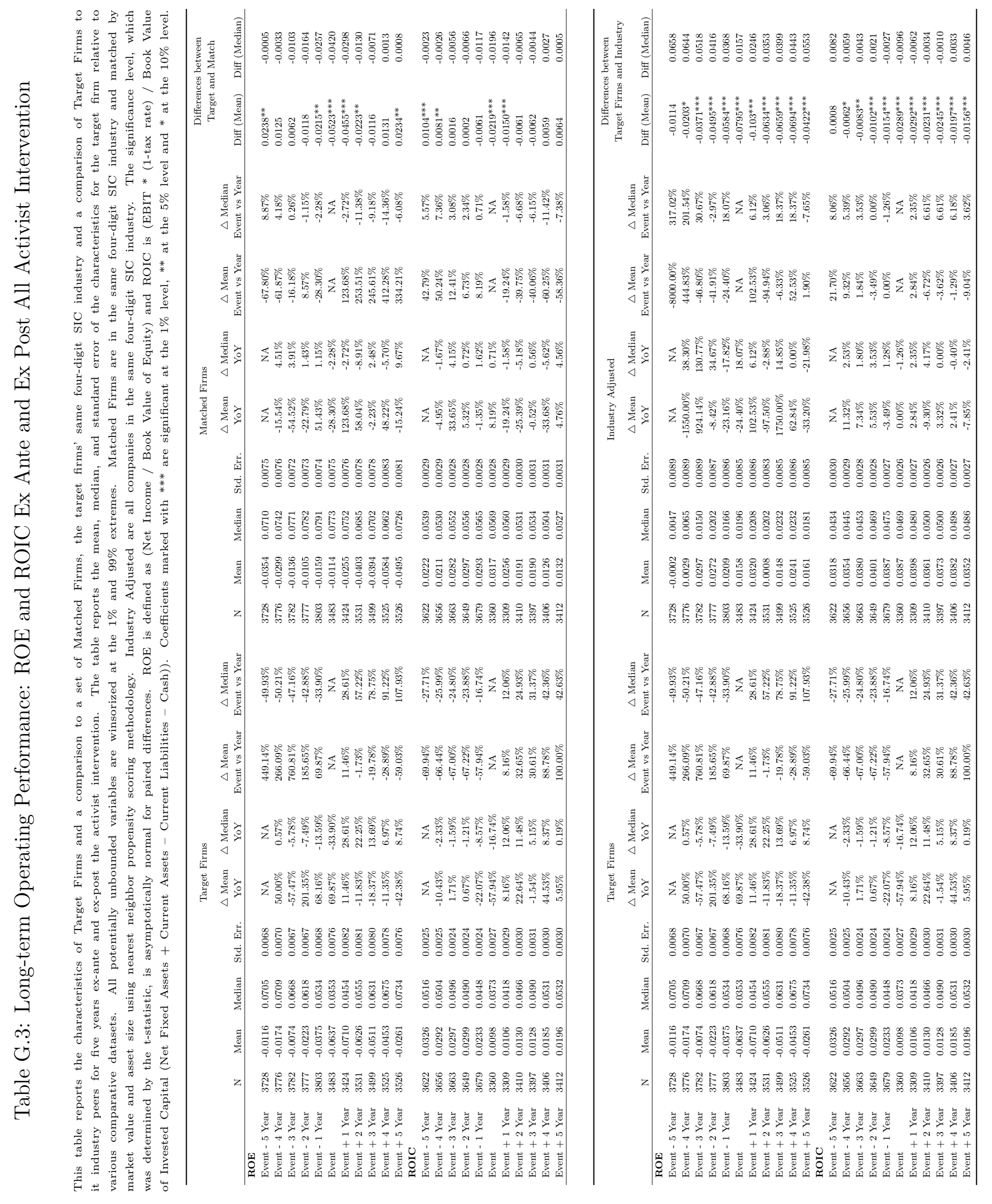



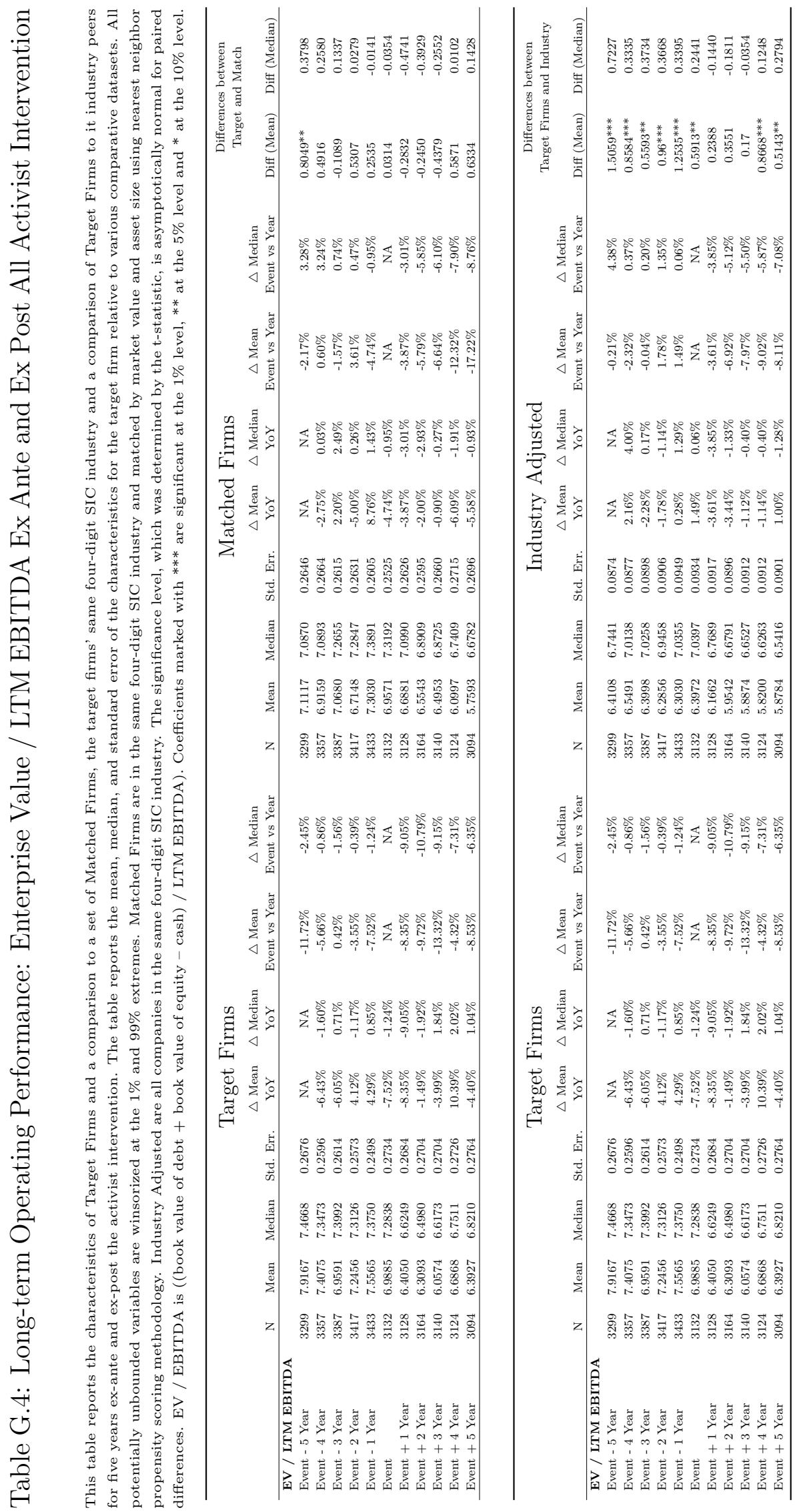

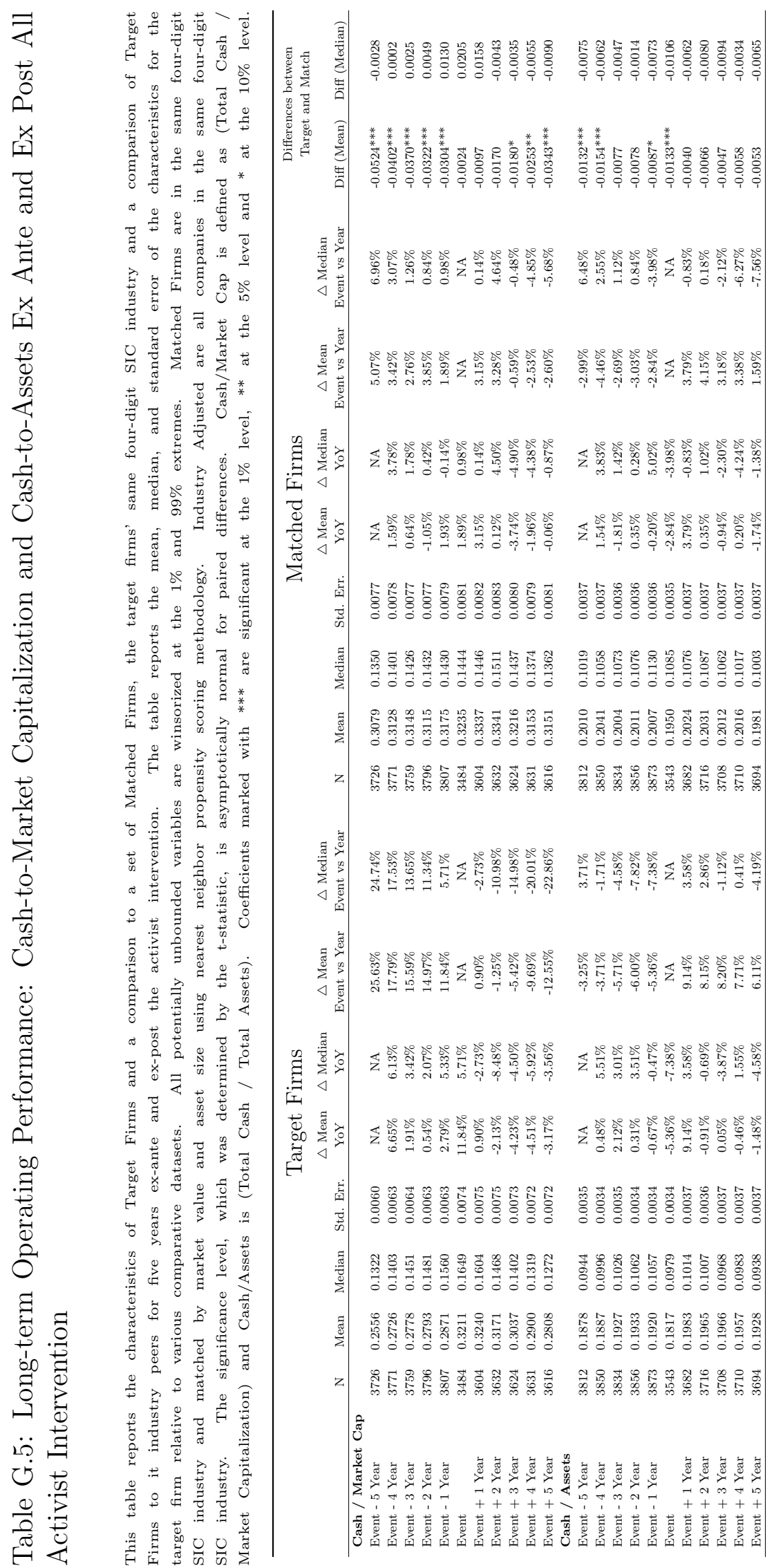

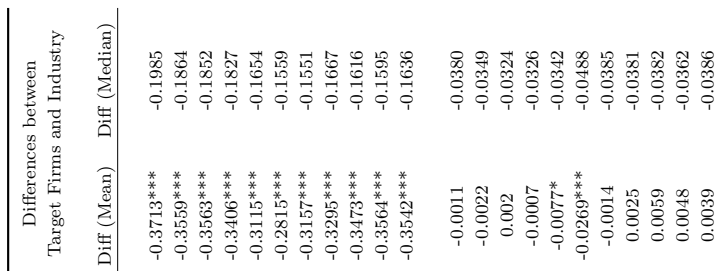

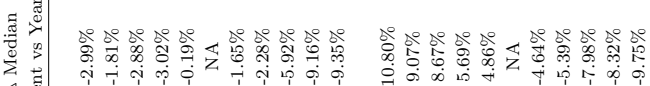

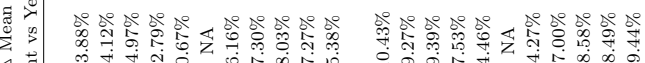

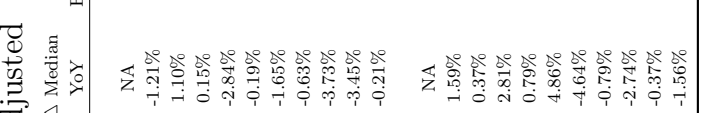
要

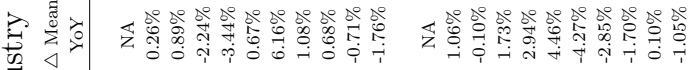
寻苗 究

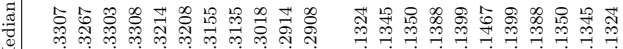

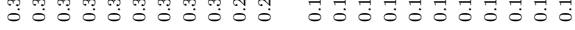

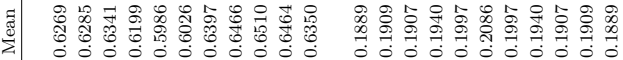

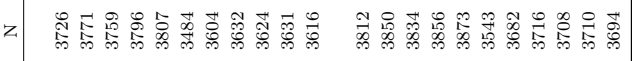

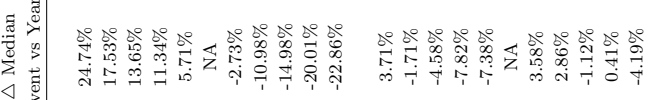

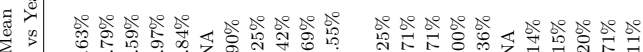

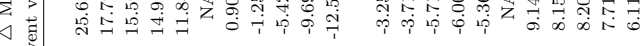

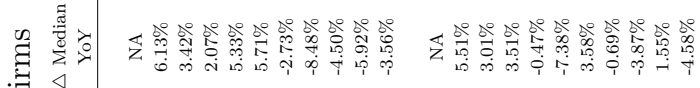

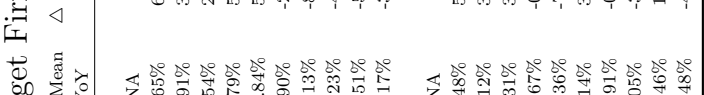

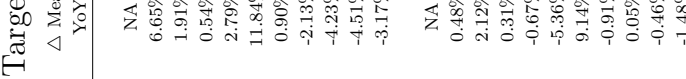

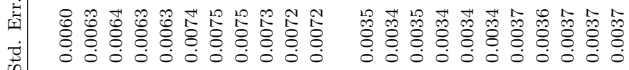

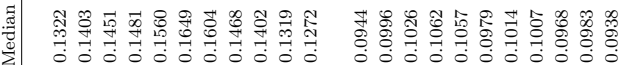

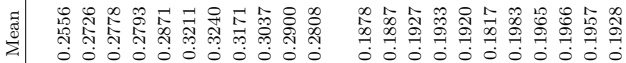

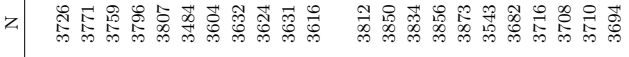
ฮิ

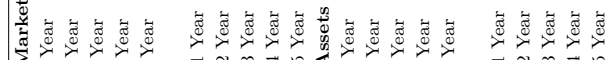

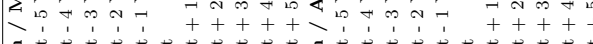

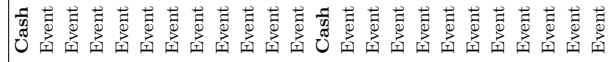




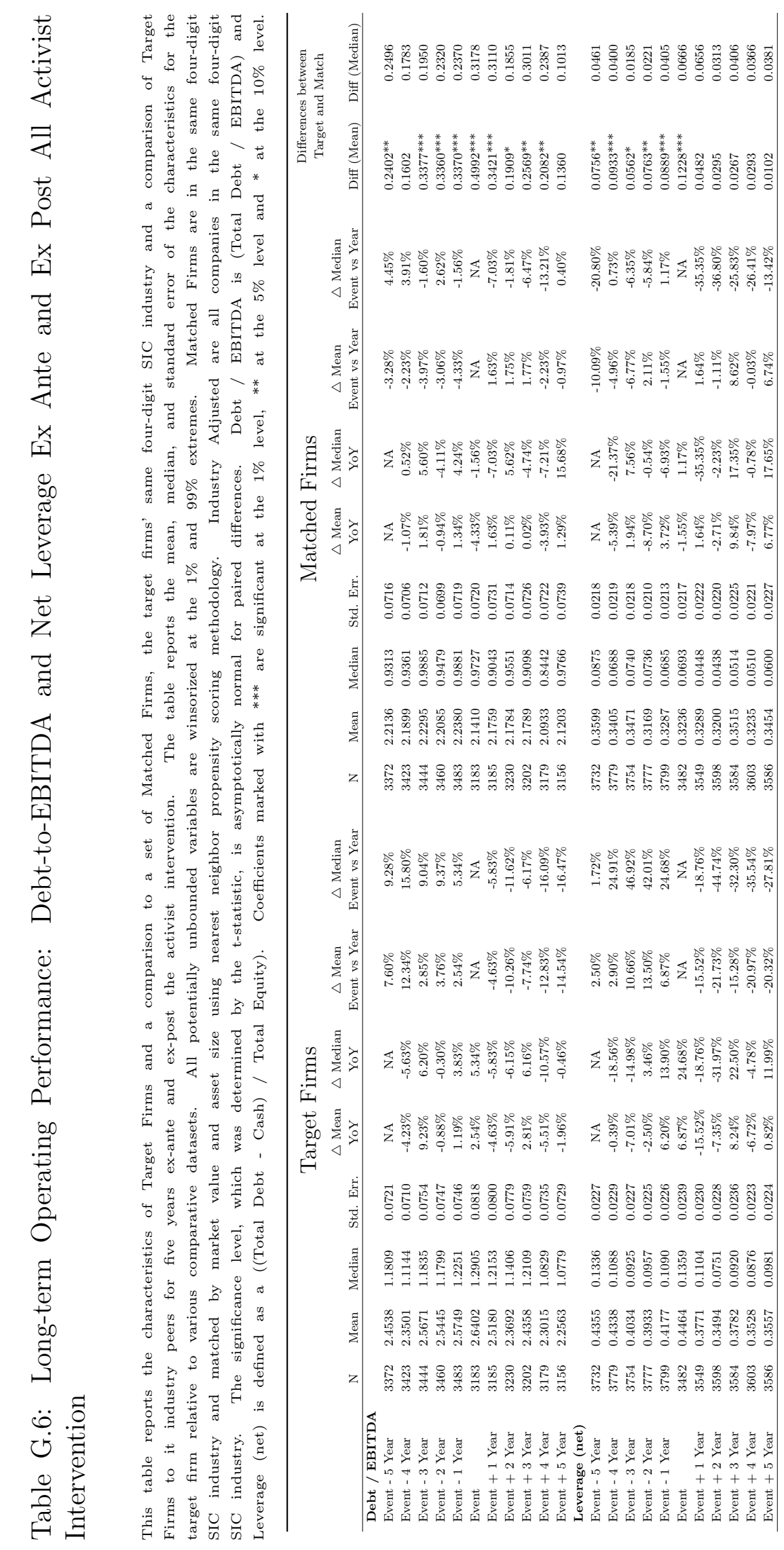

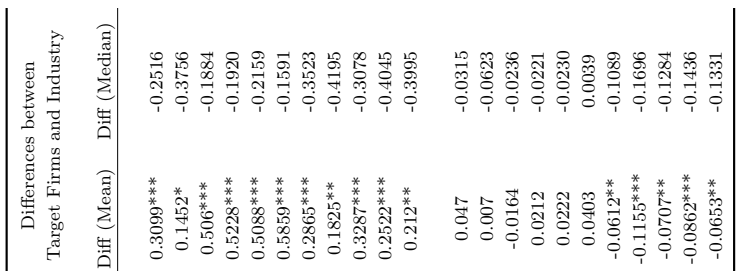

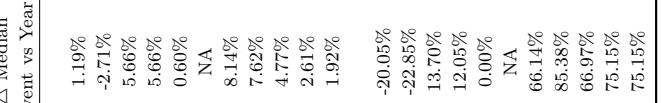

$\checkmark$ 离

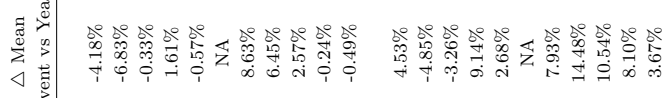

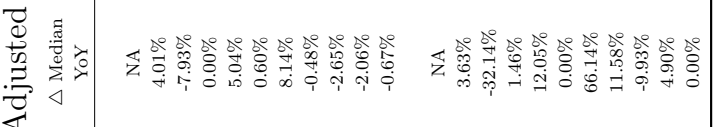

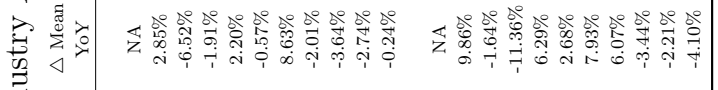

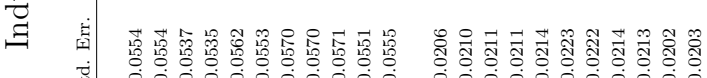

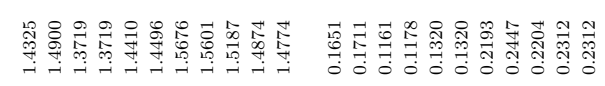

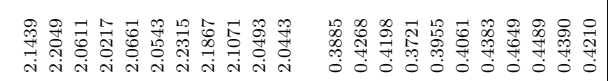

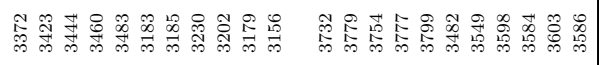

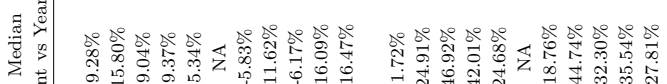

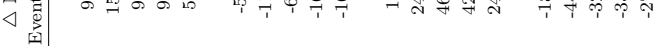

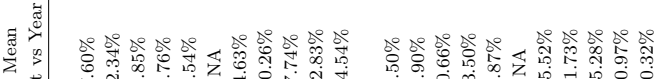

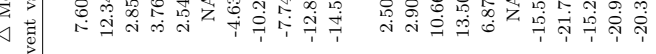

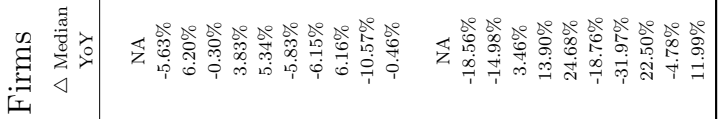

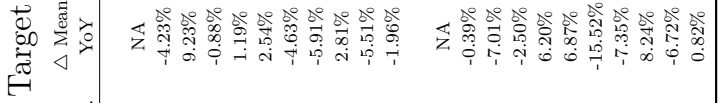

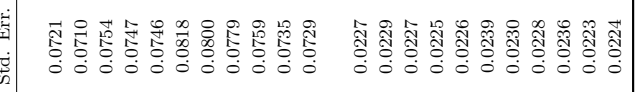

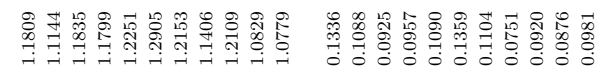

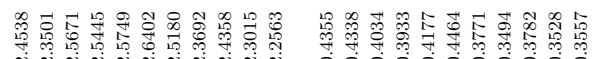

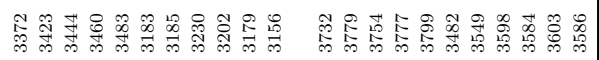

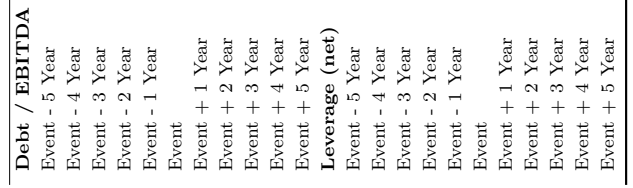




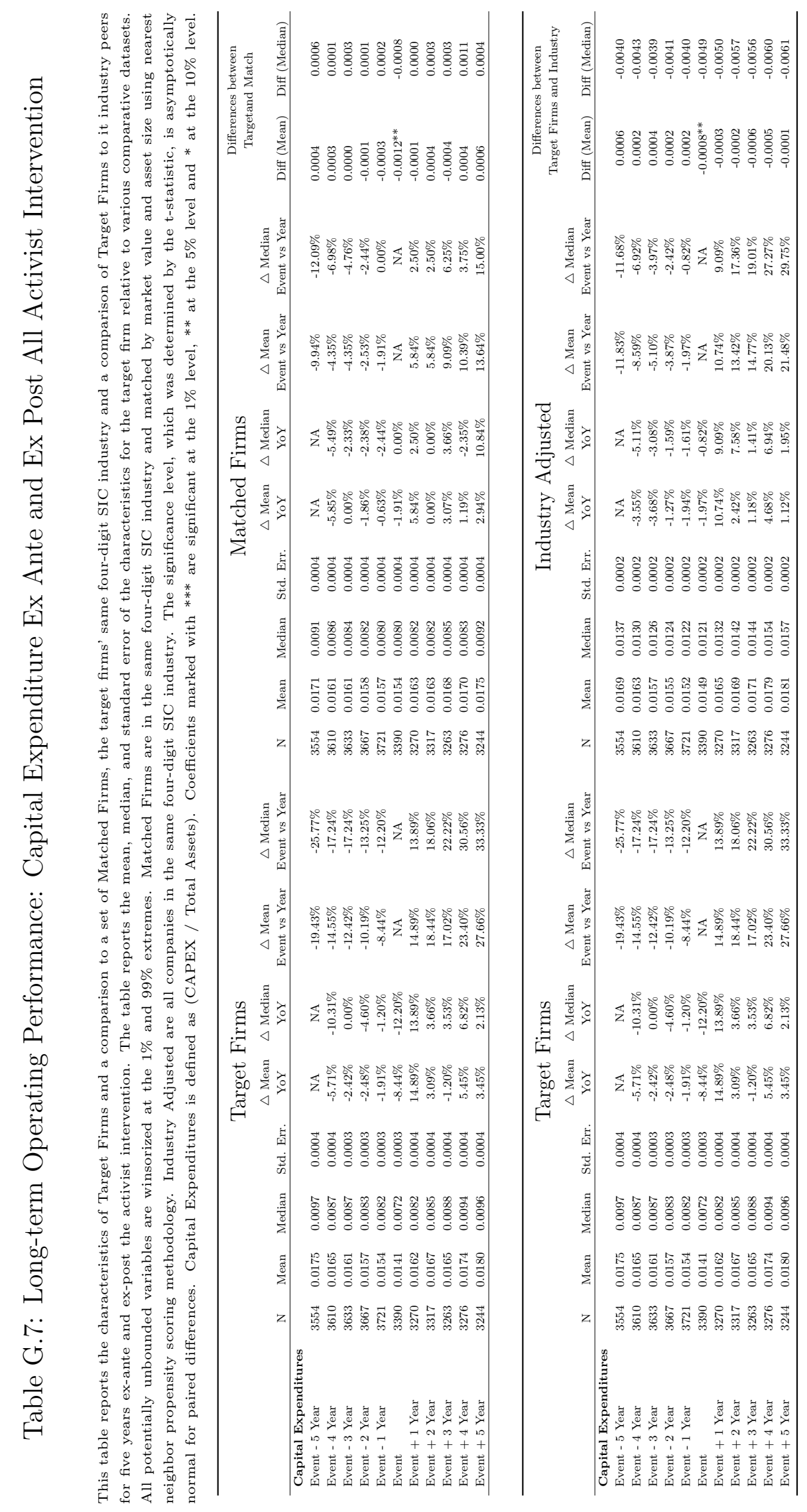




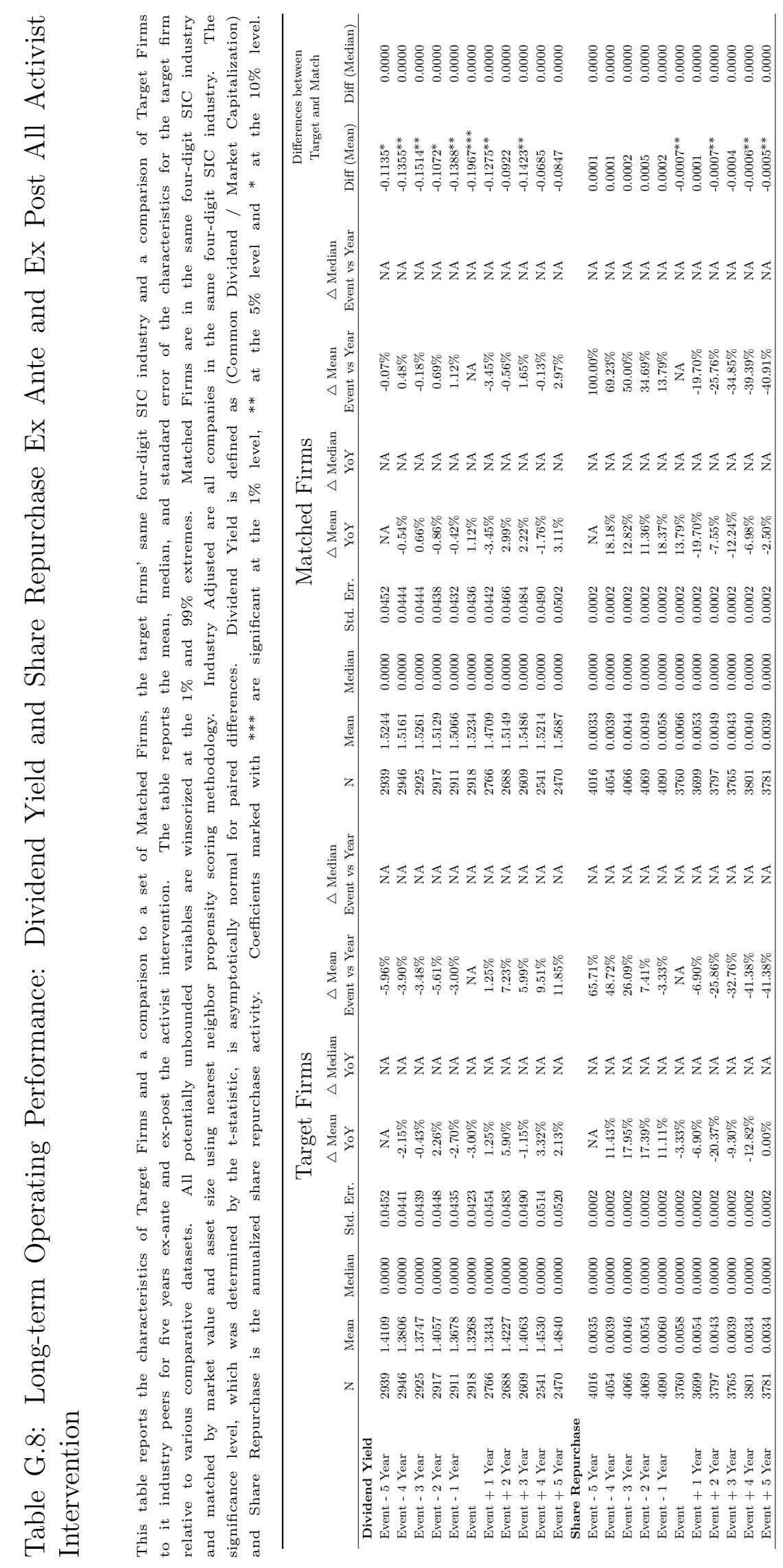

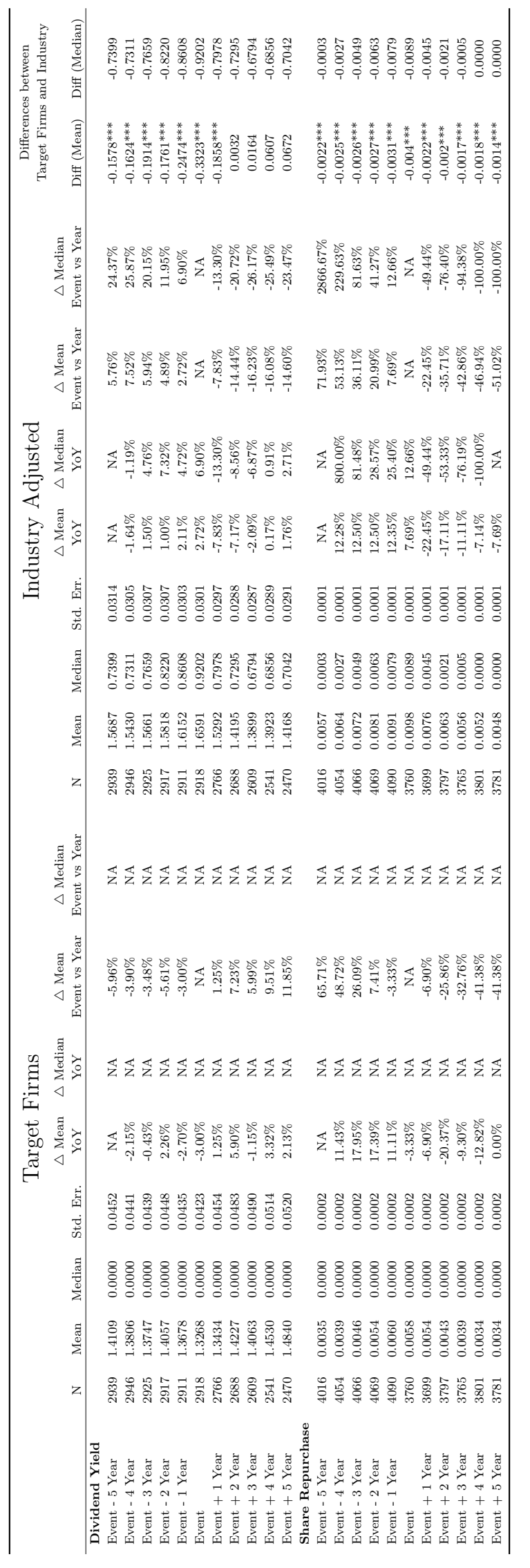




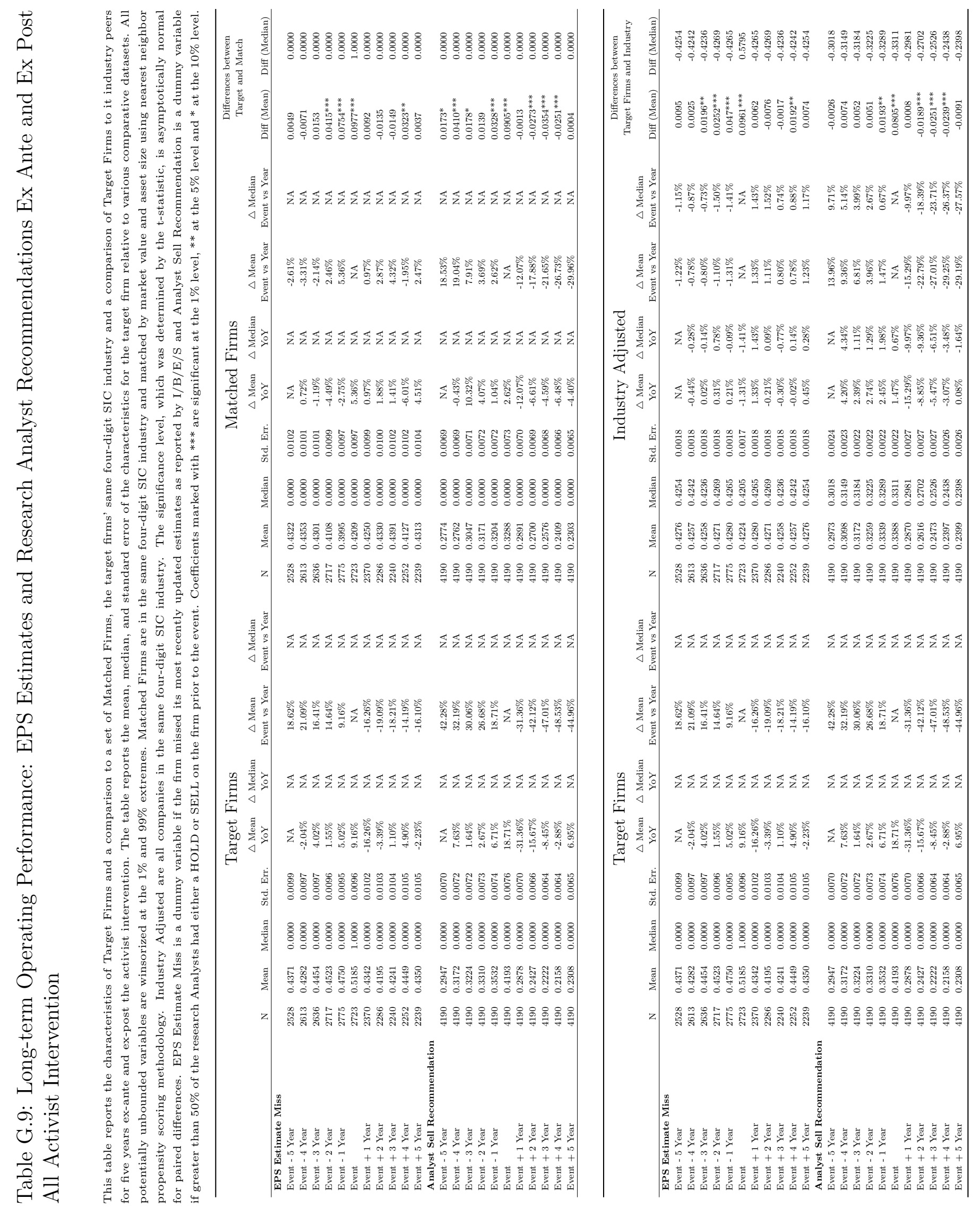




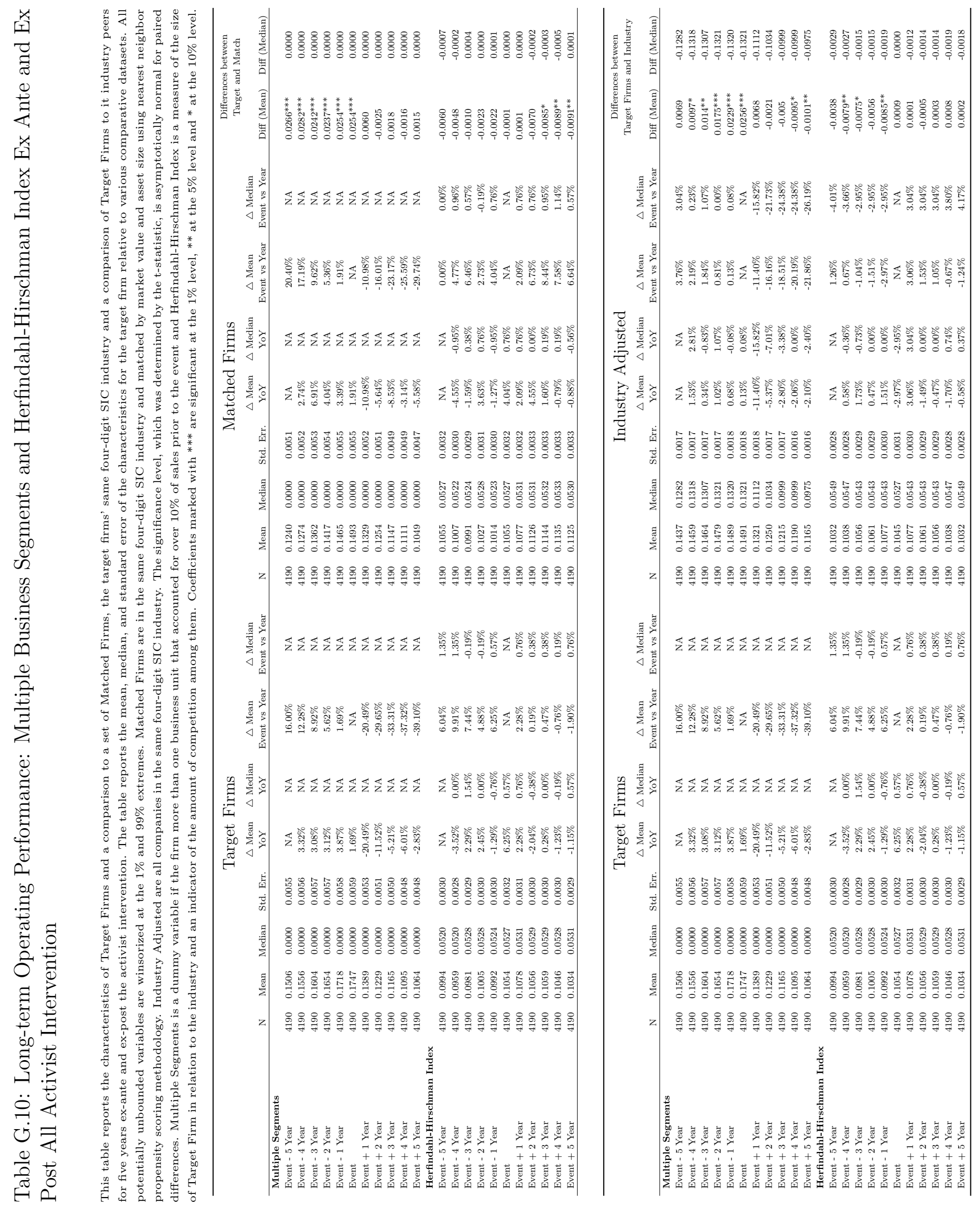



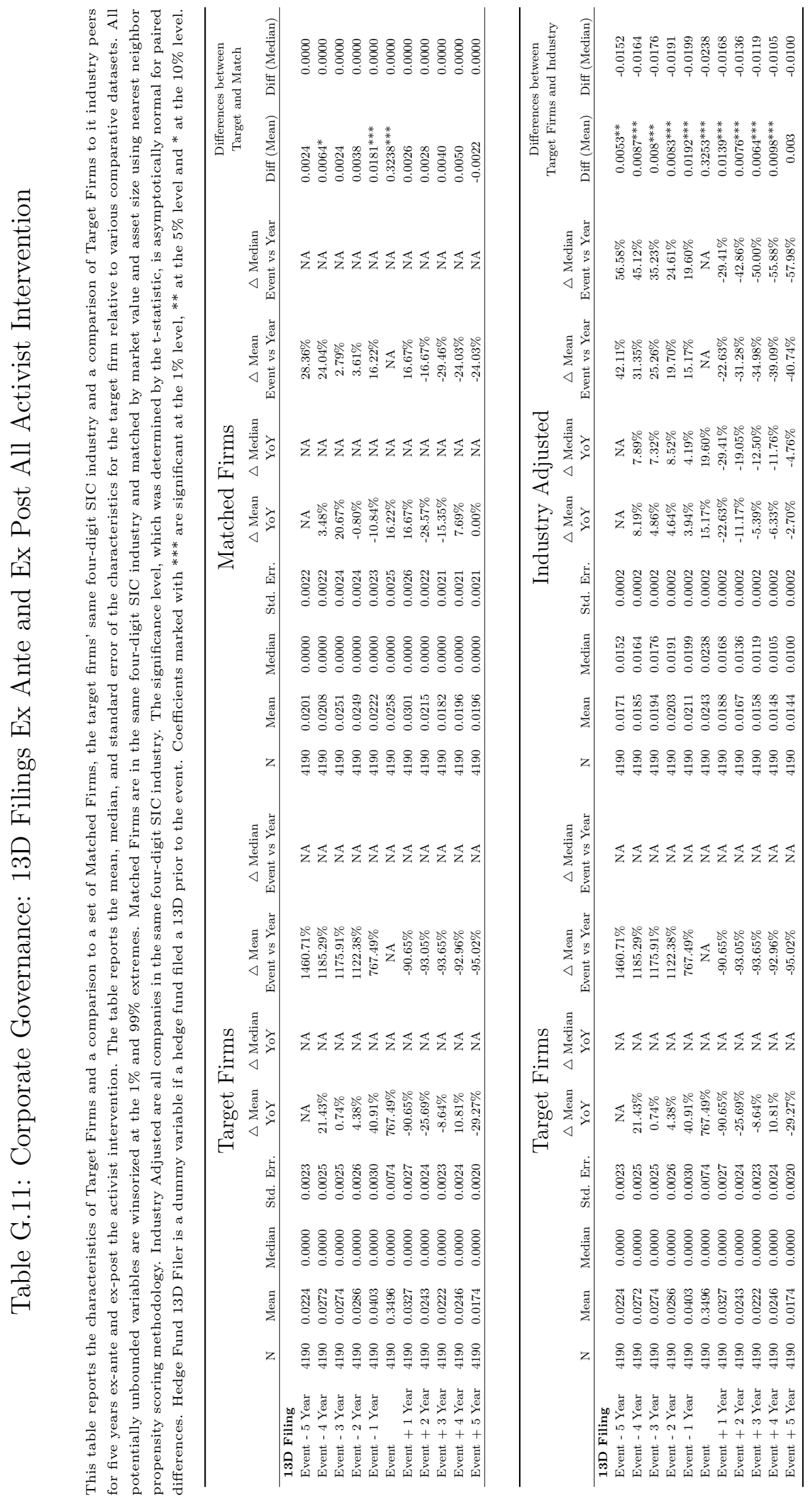


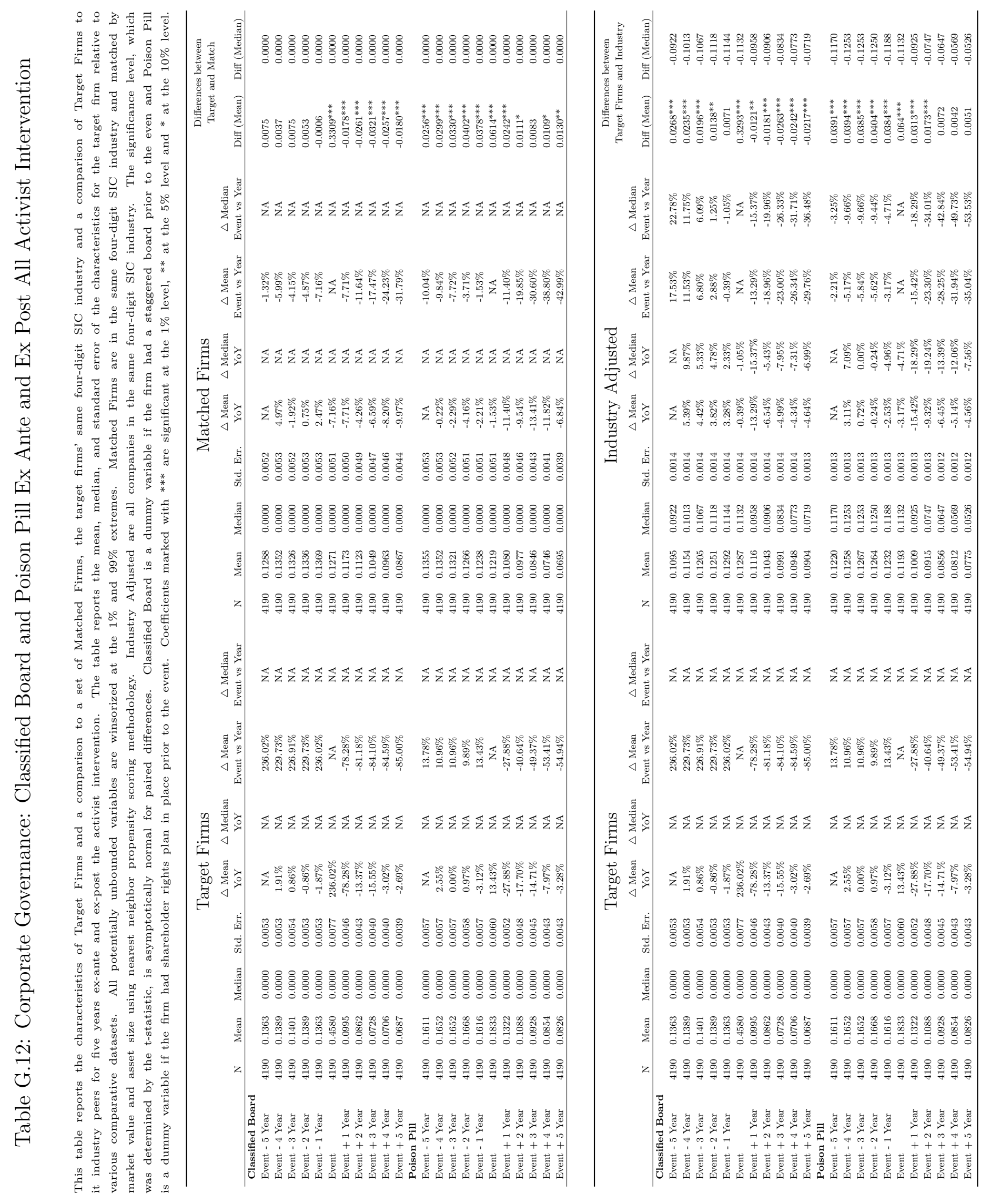




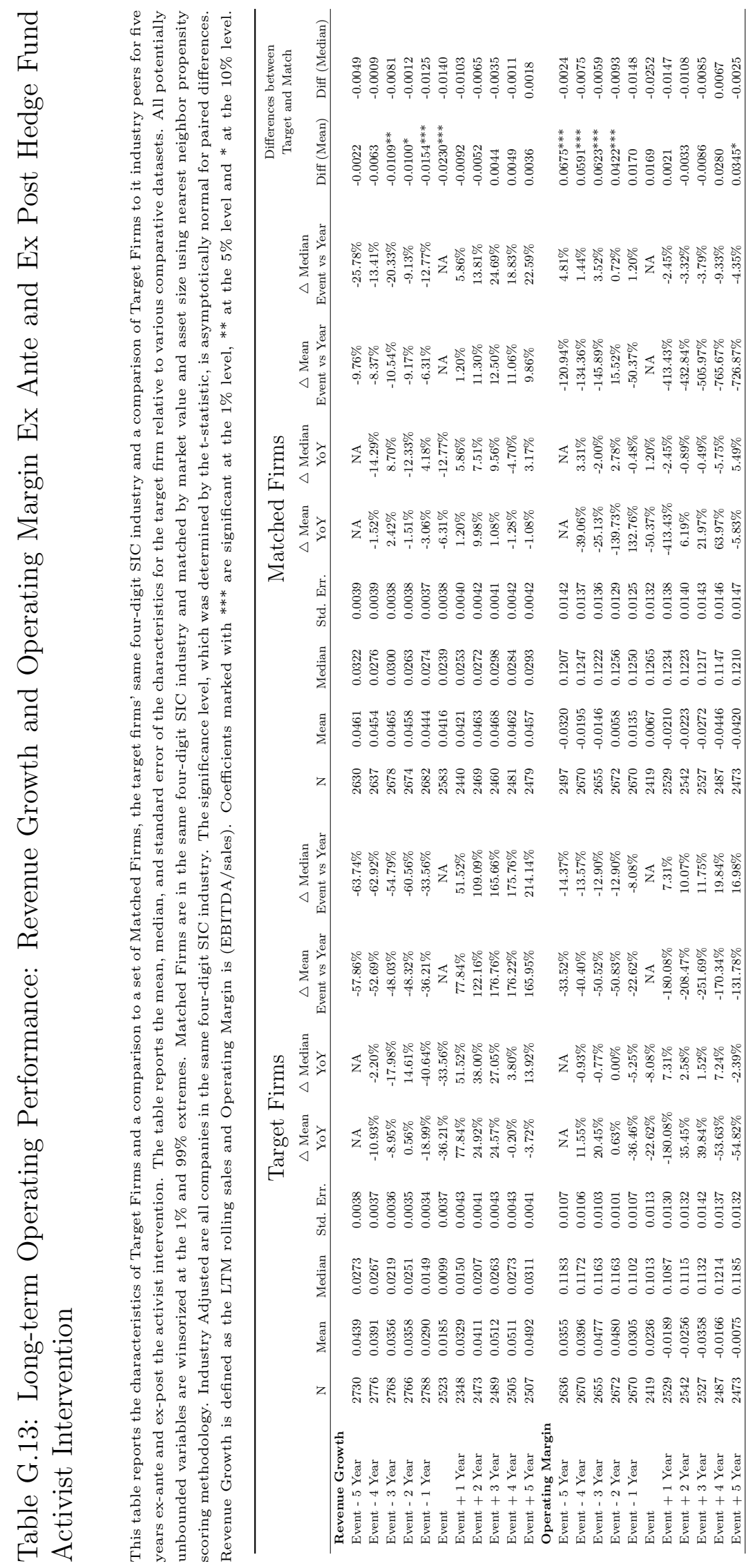

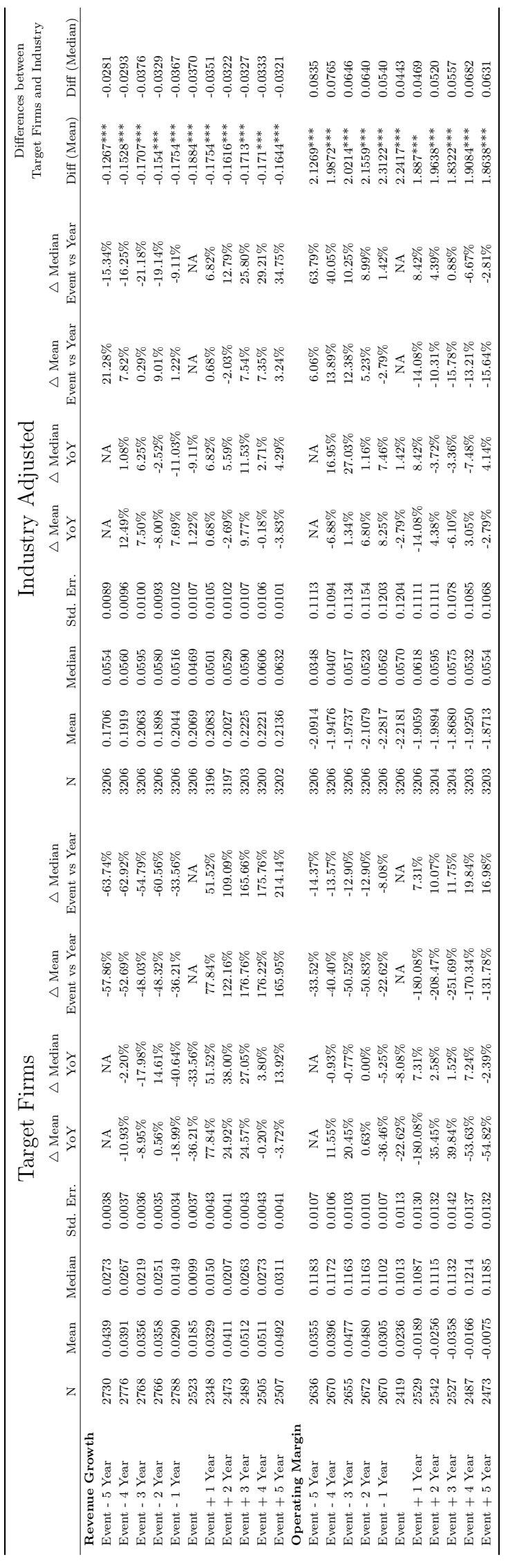



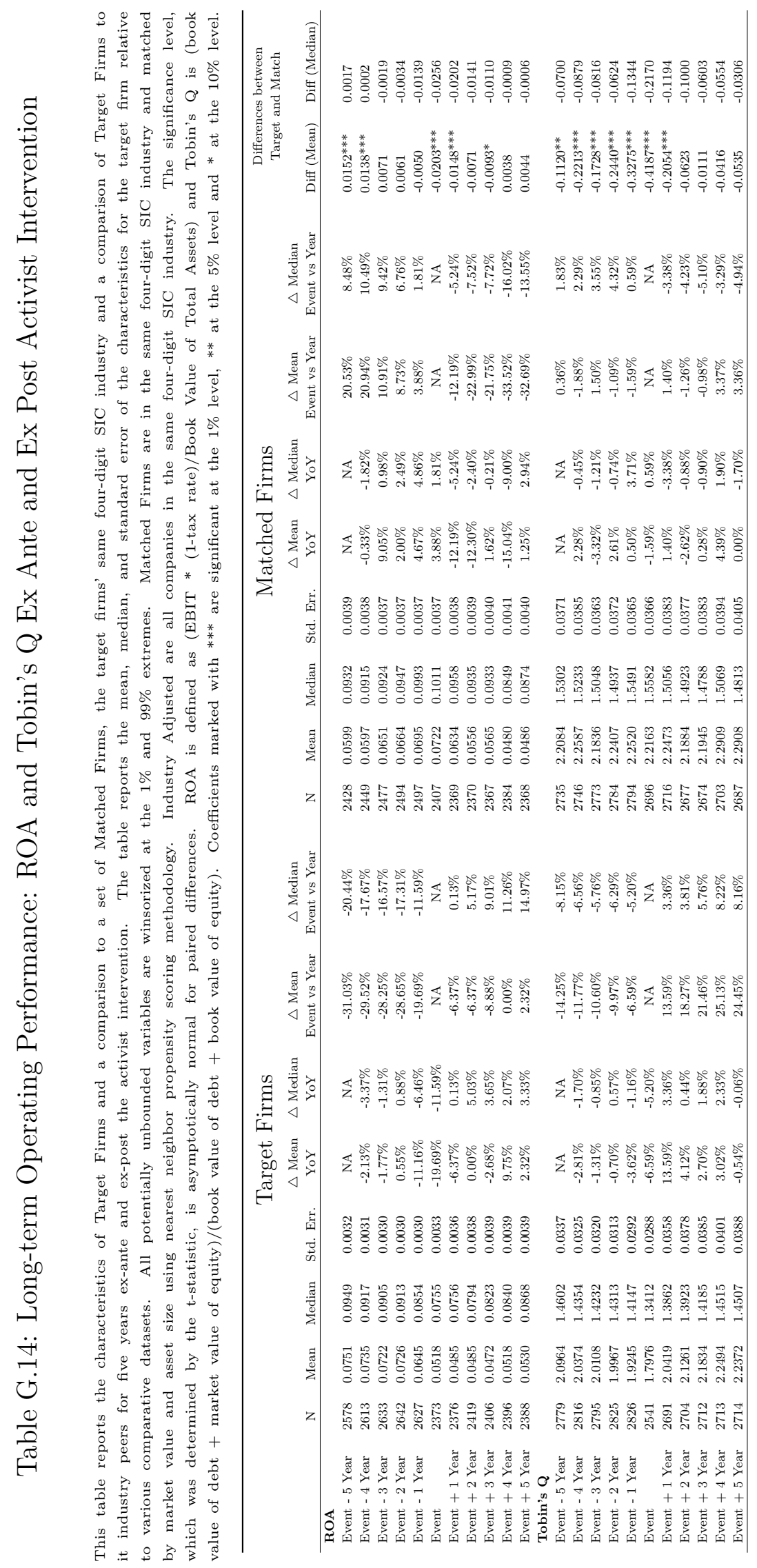

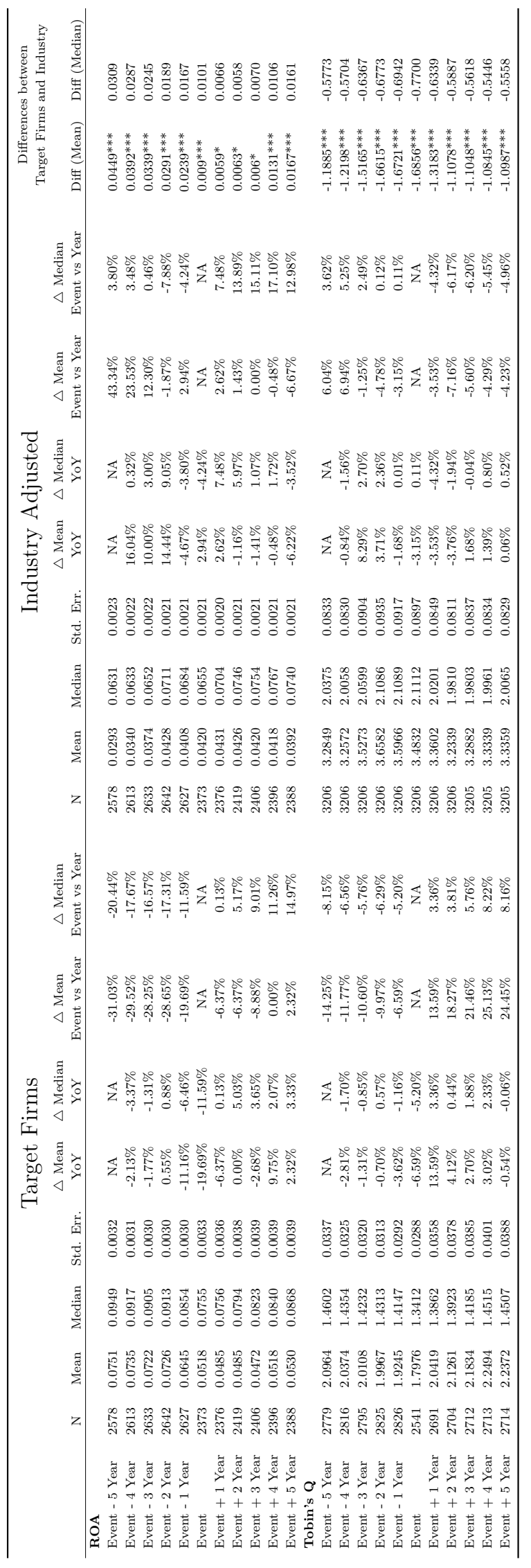




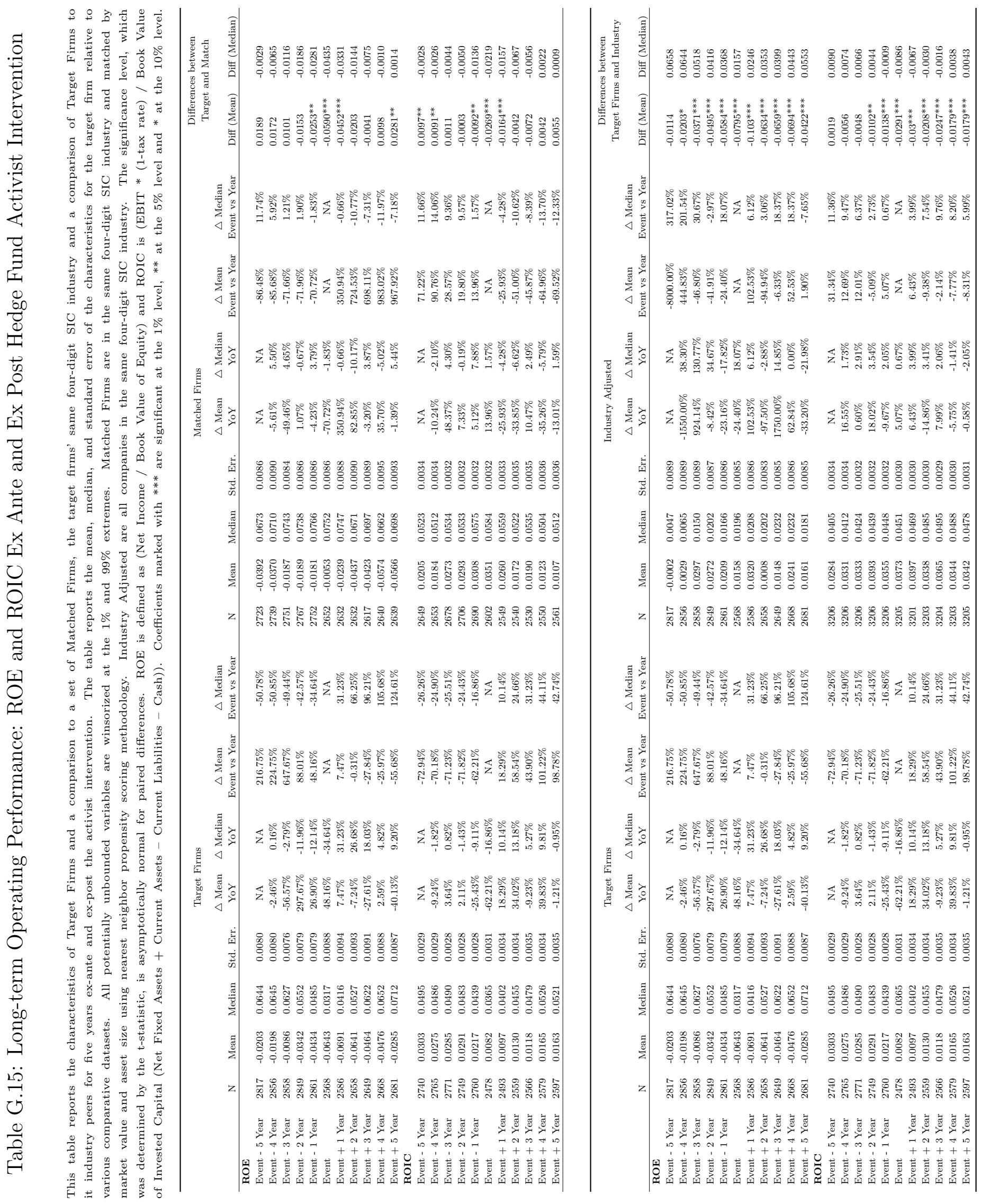




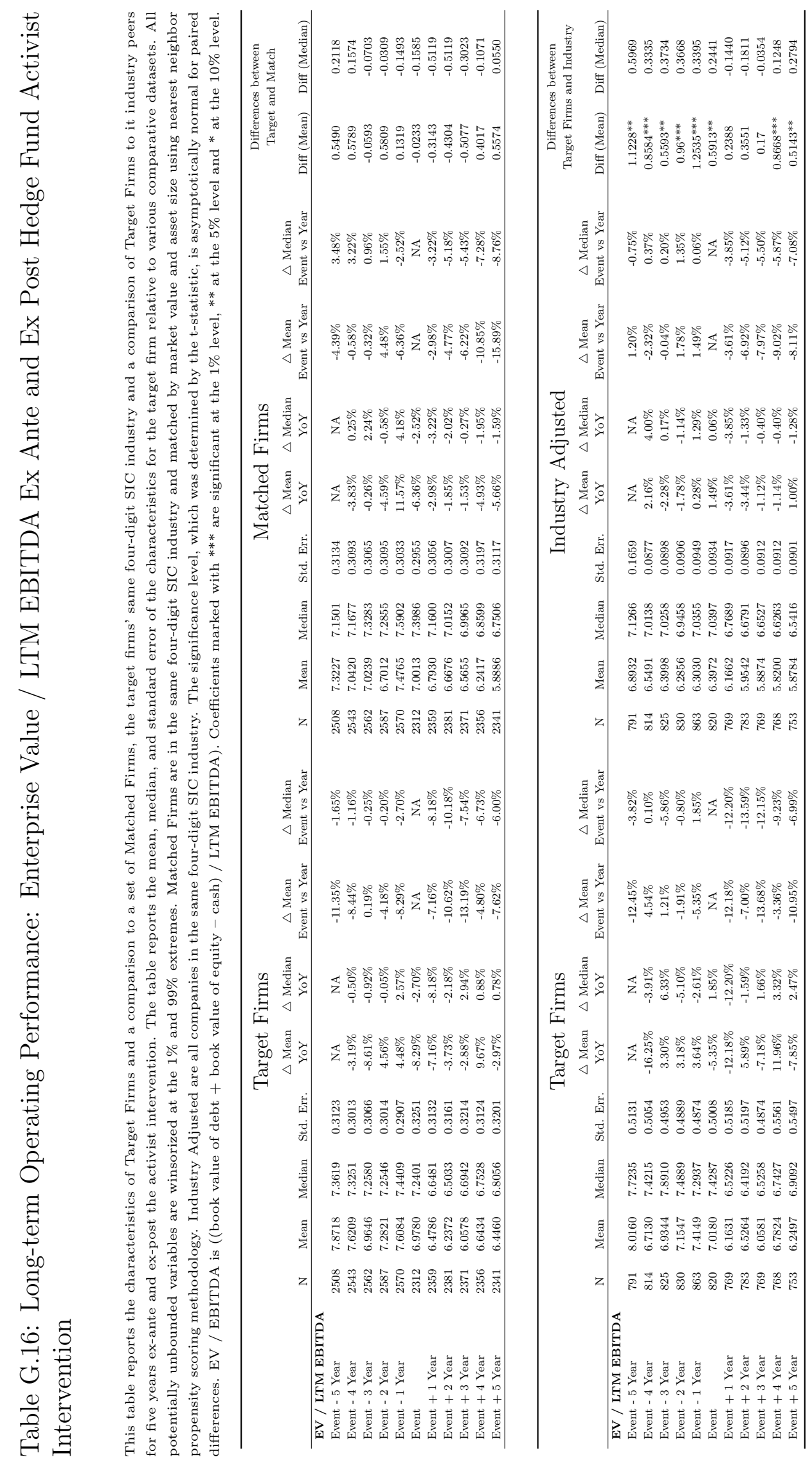




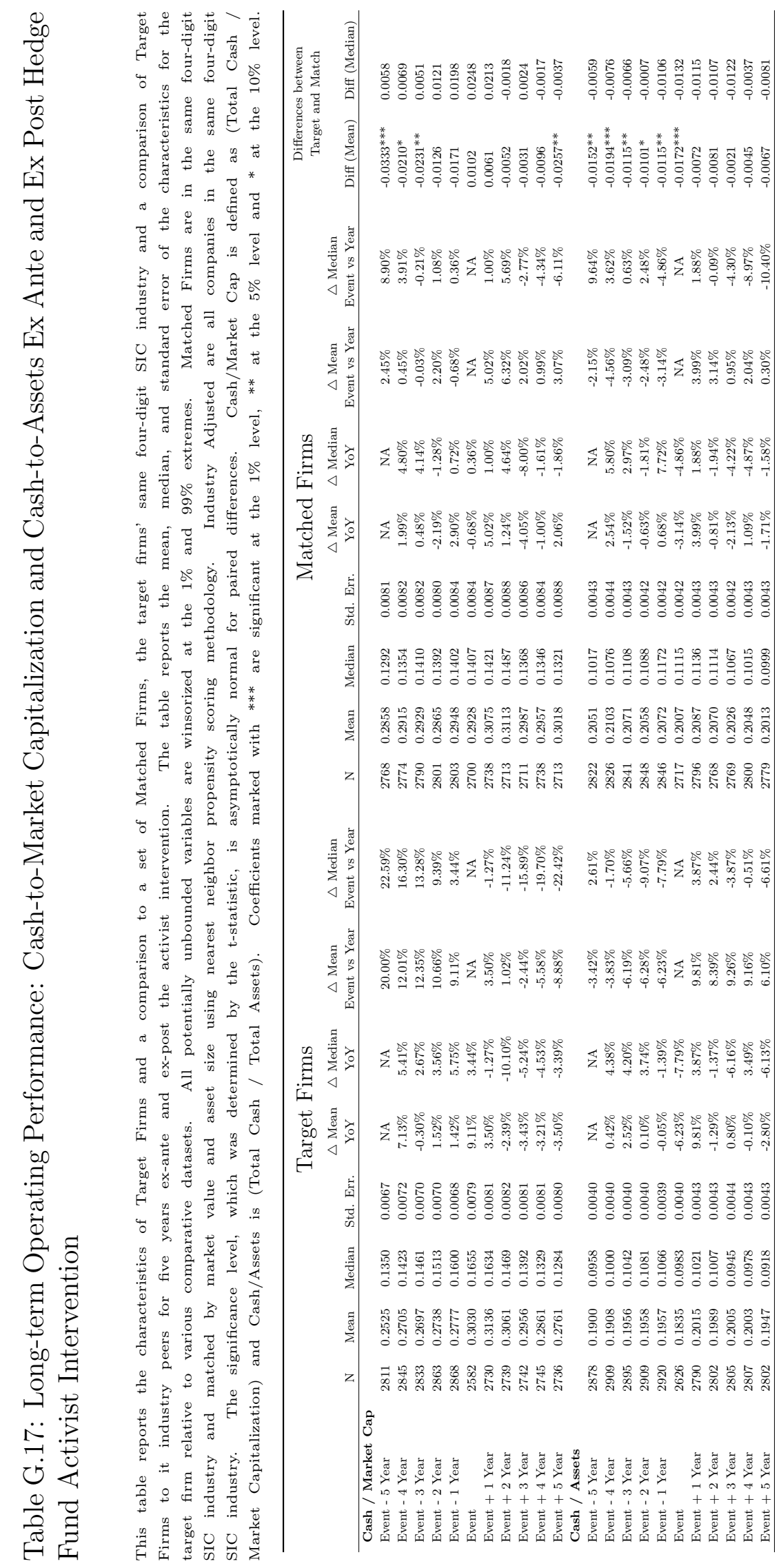

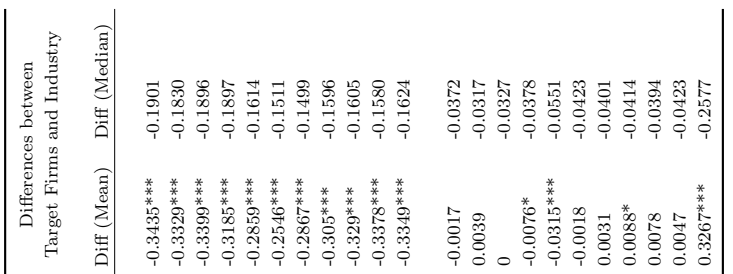

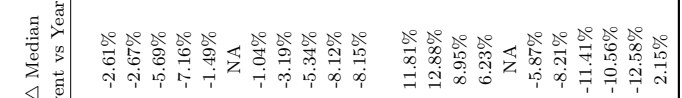

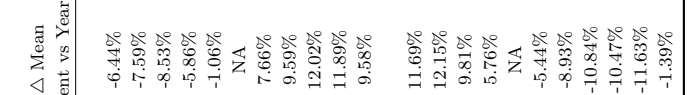

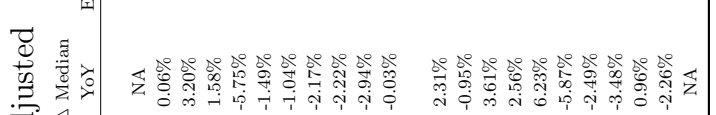
安 $\triangleleft$

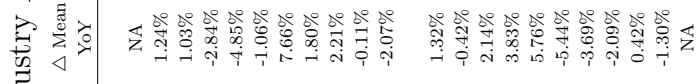

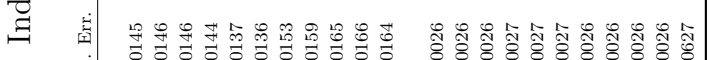

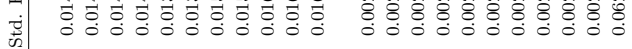

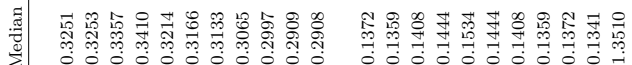

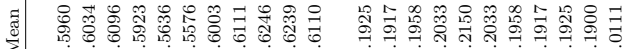
य में

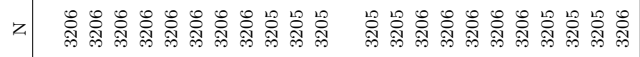

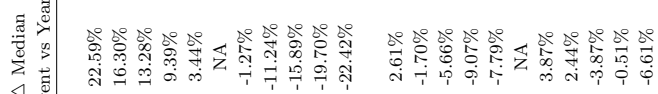
$\triangleleft$ बे

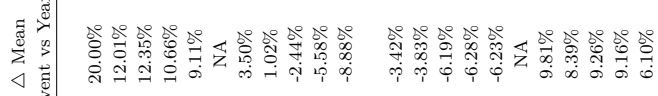

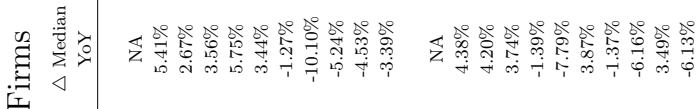

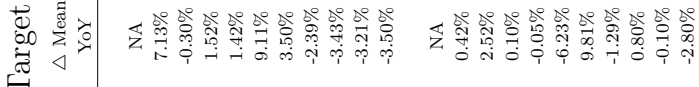

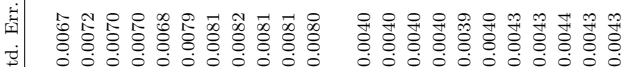

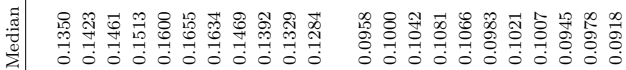

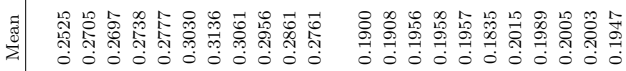

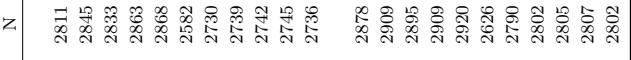
ฮิ

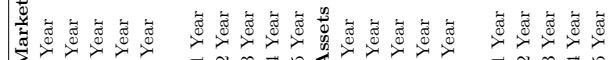

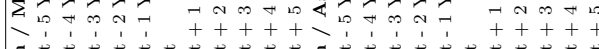

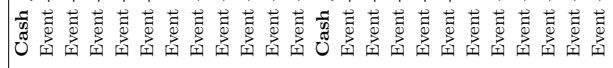




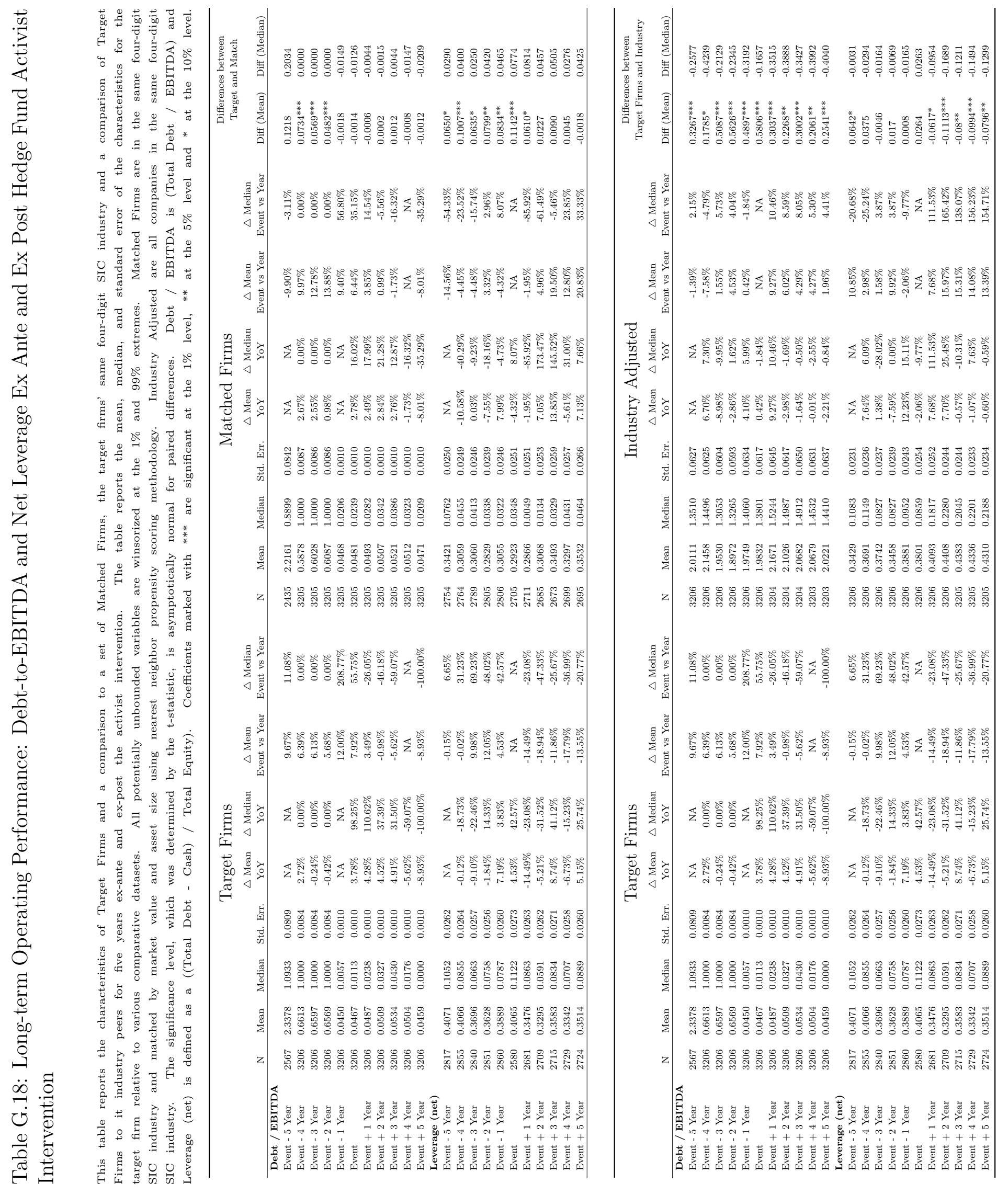



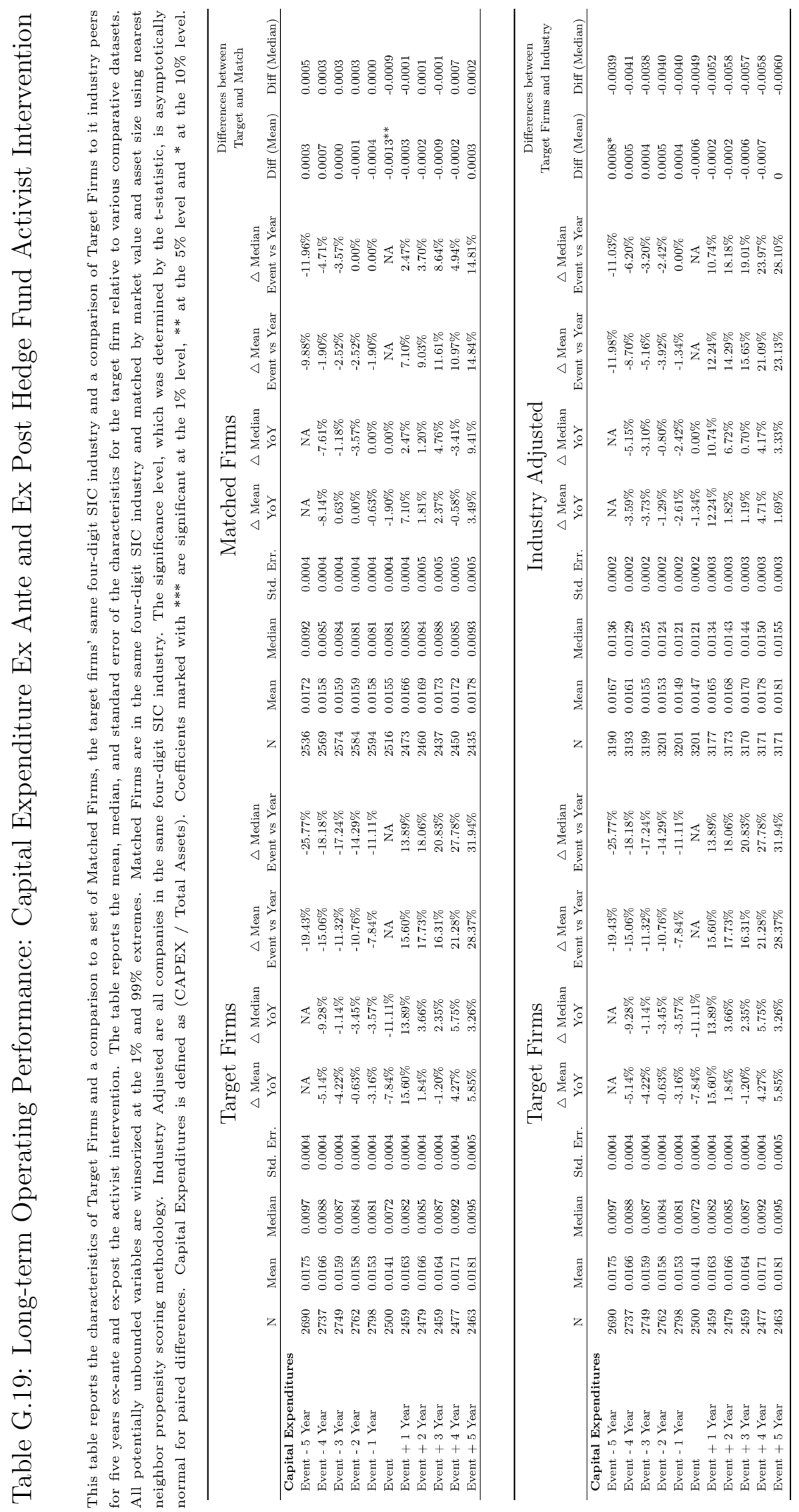

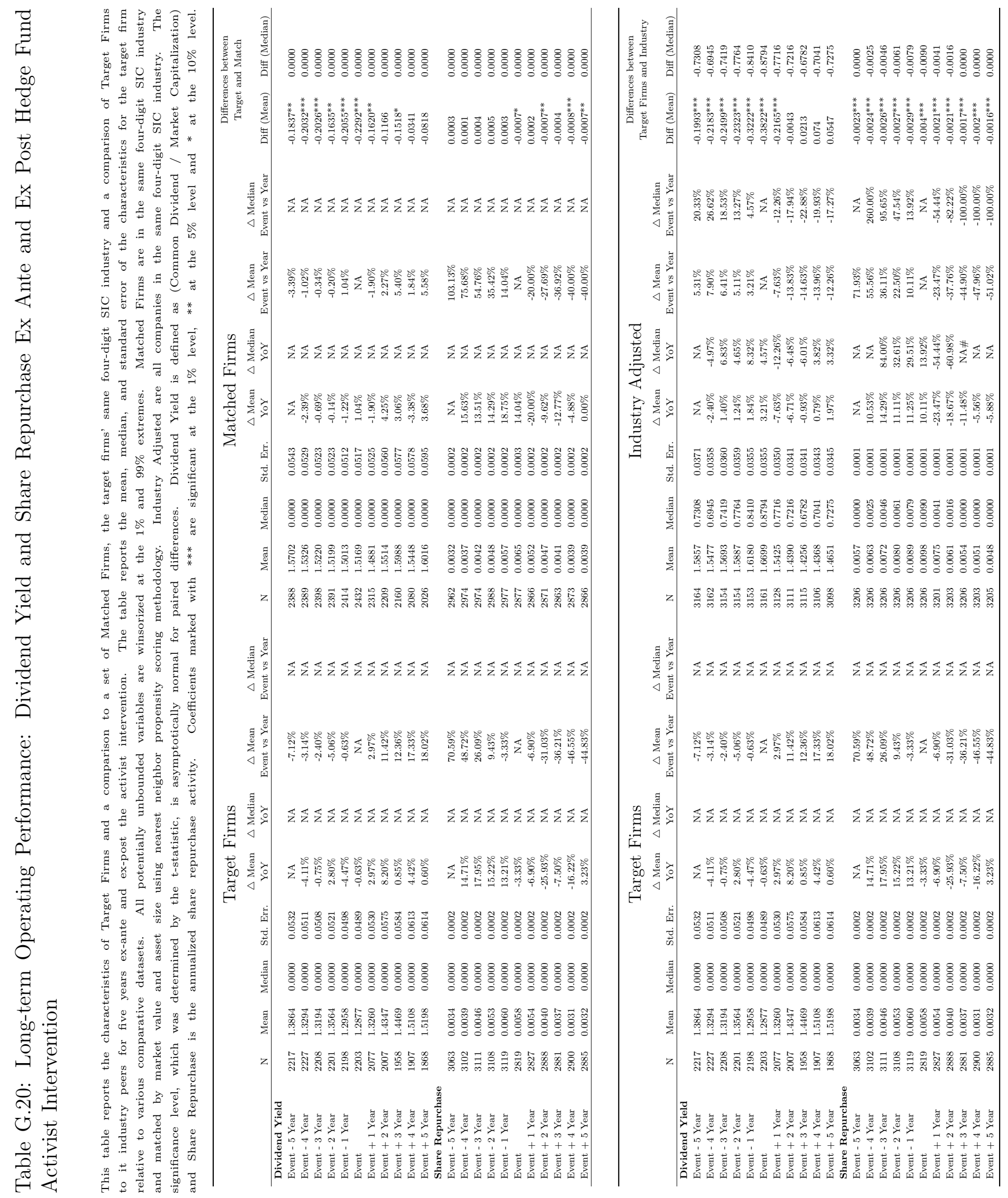


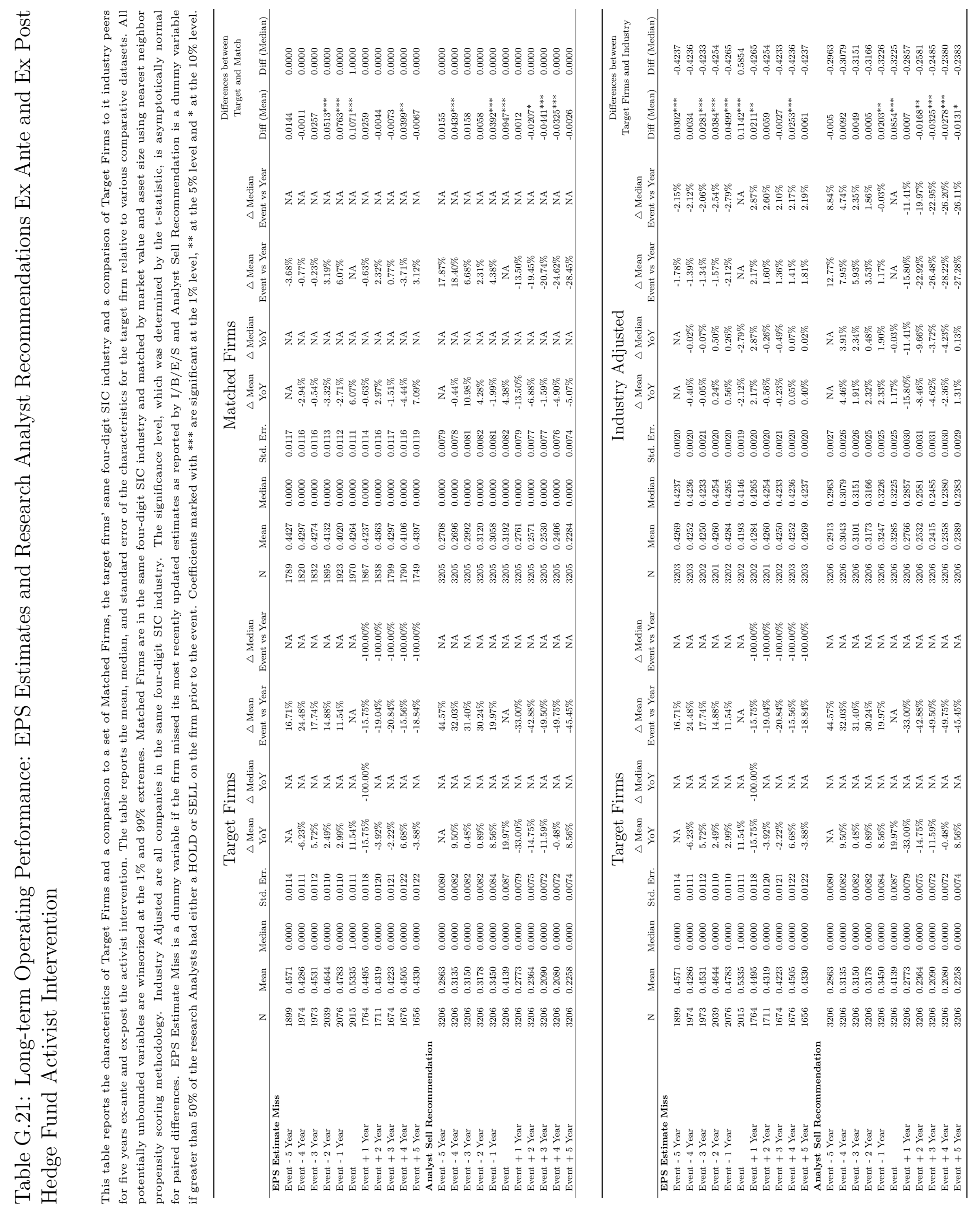




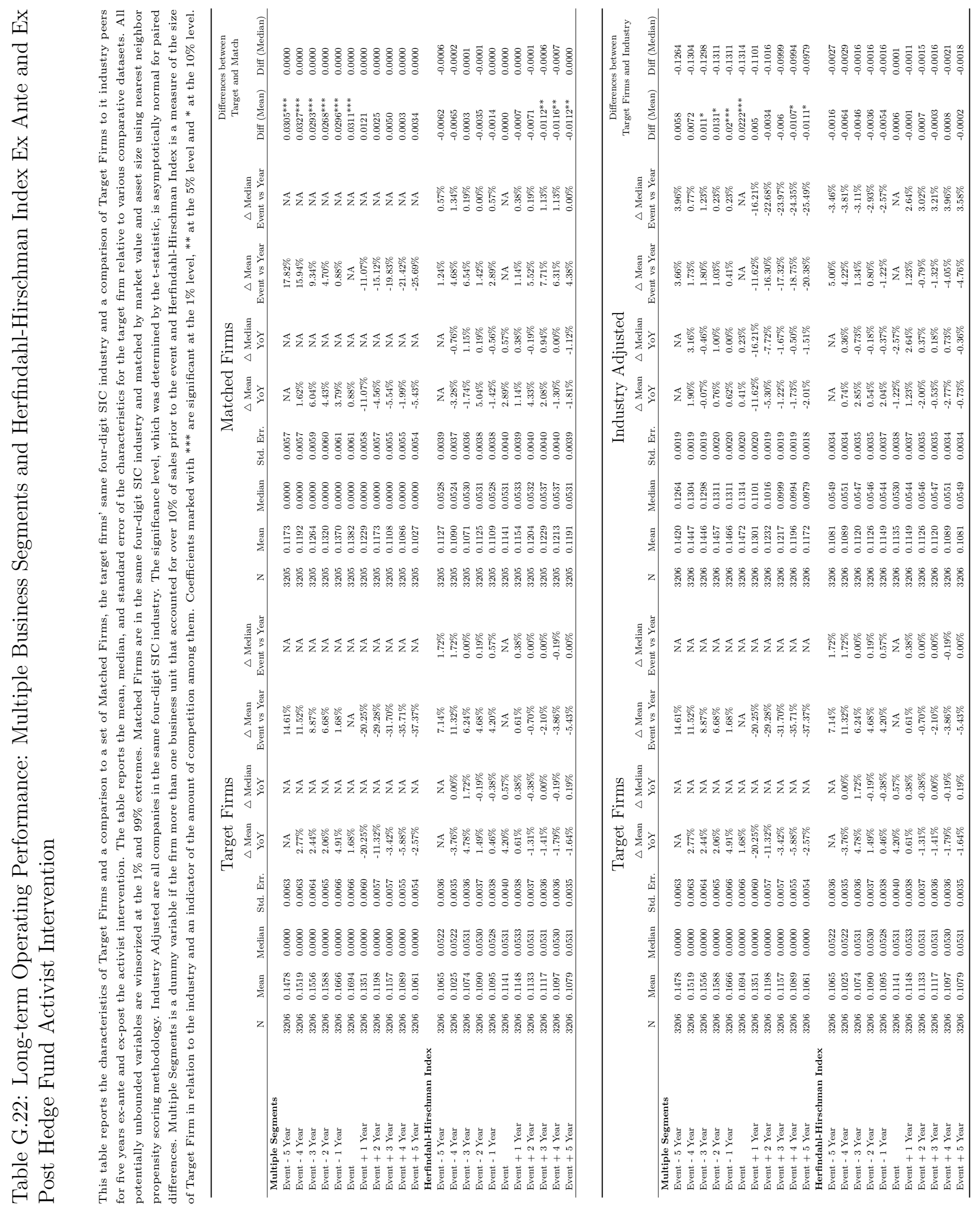



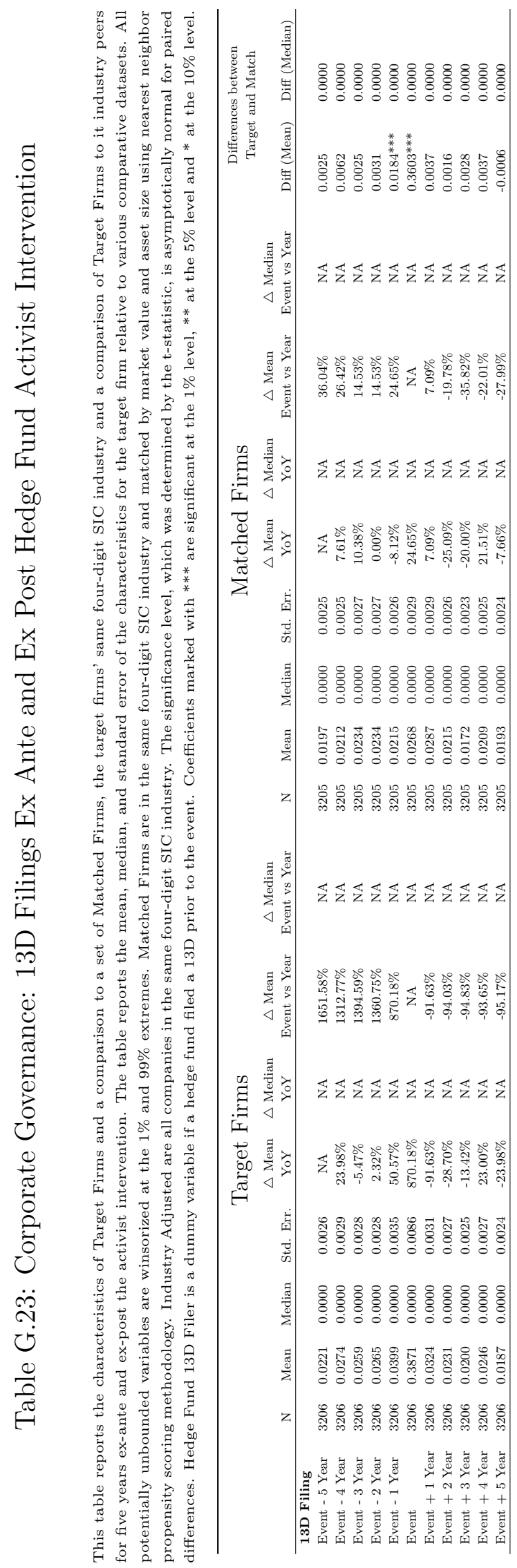

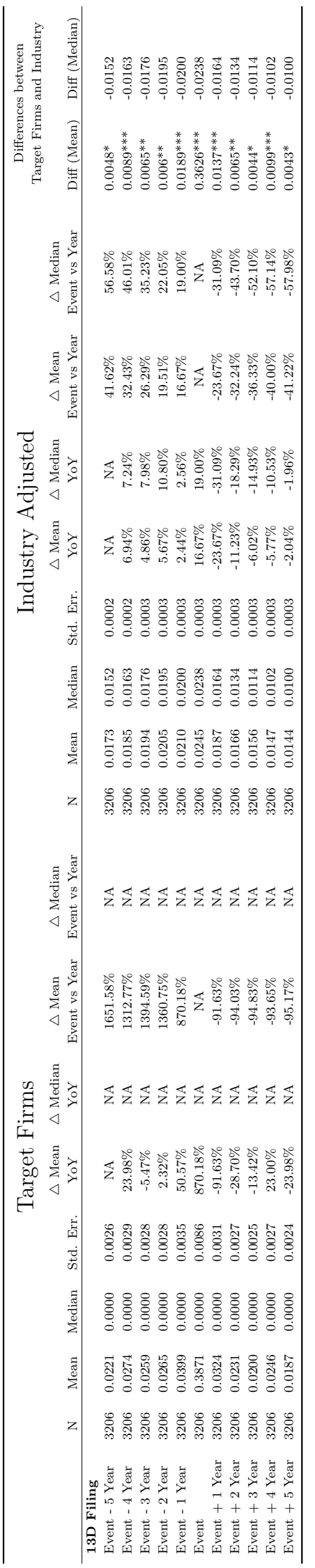




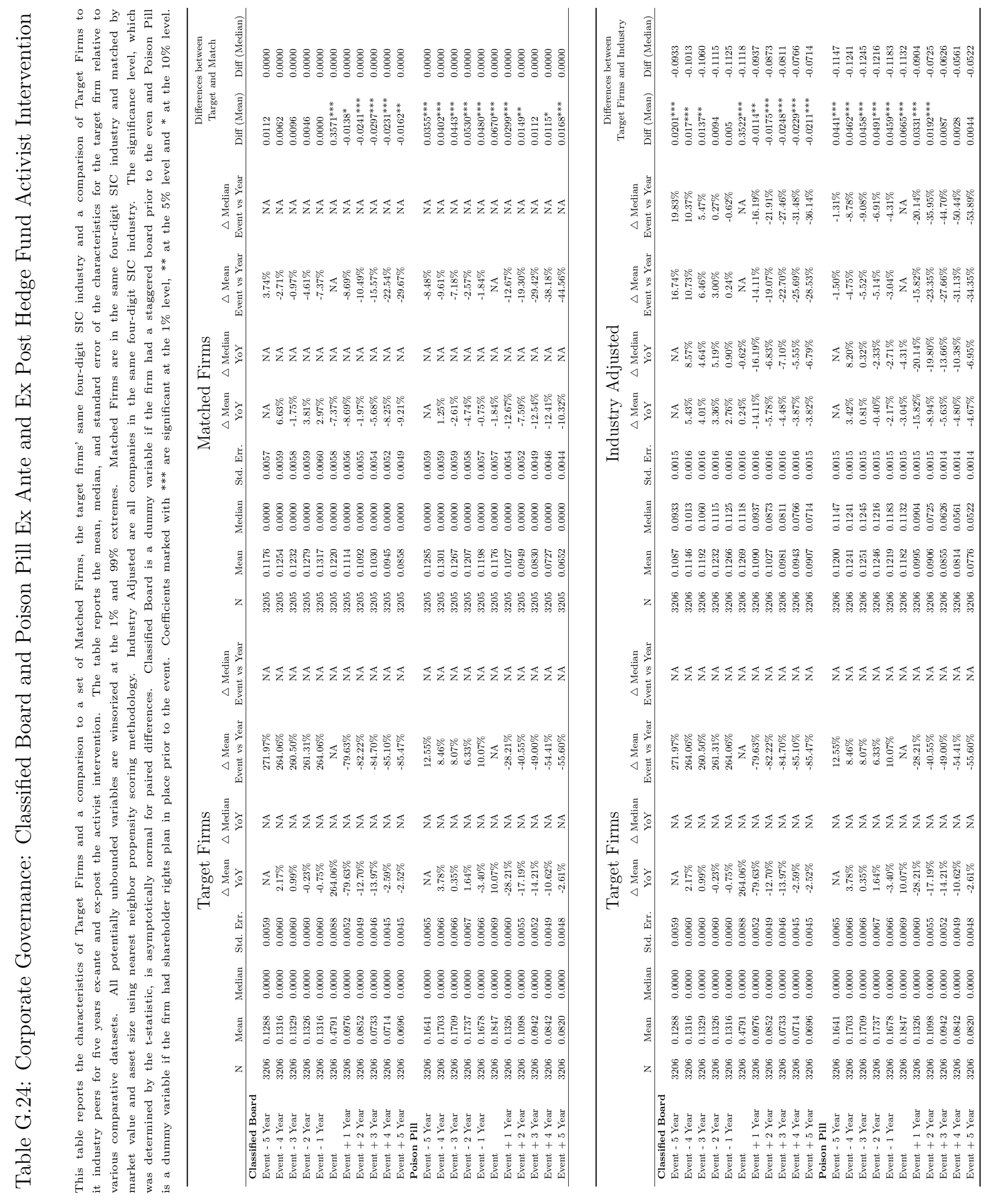



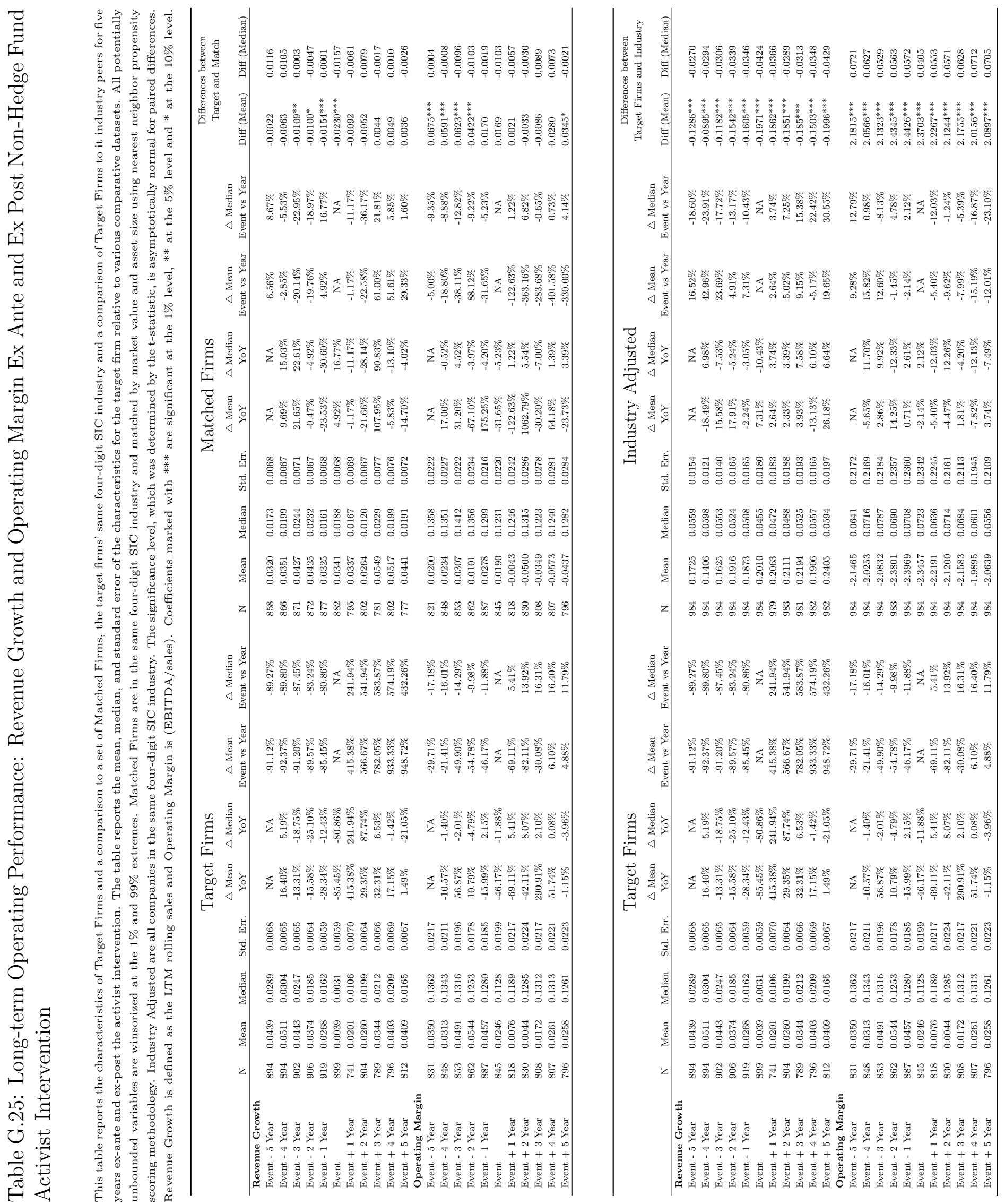


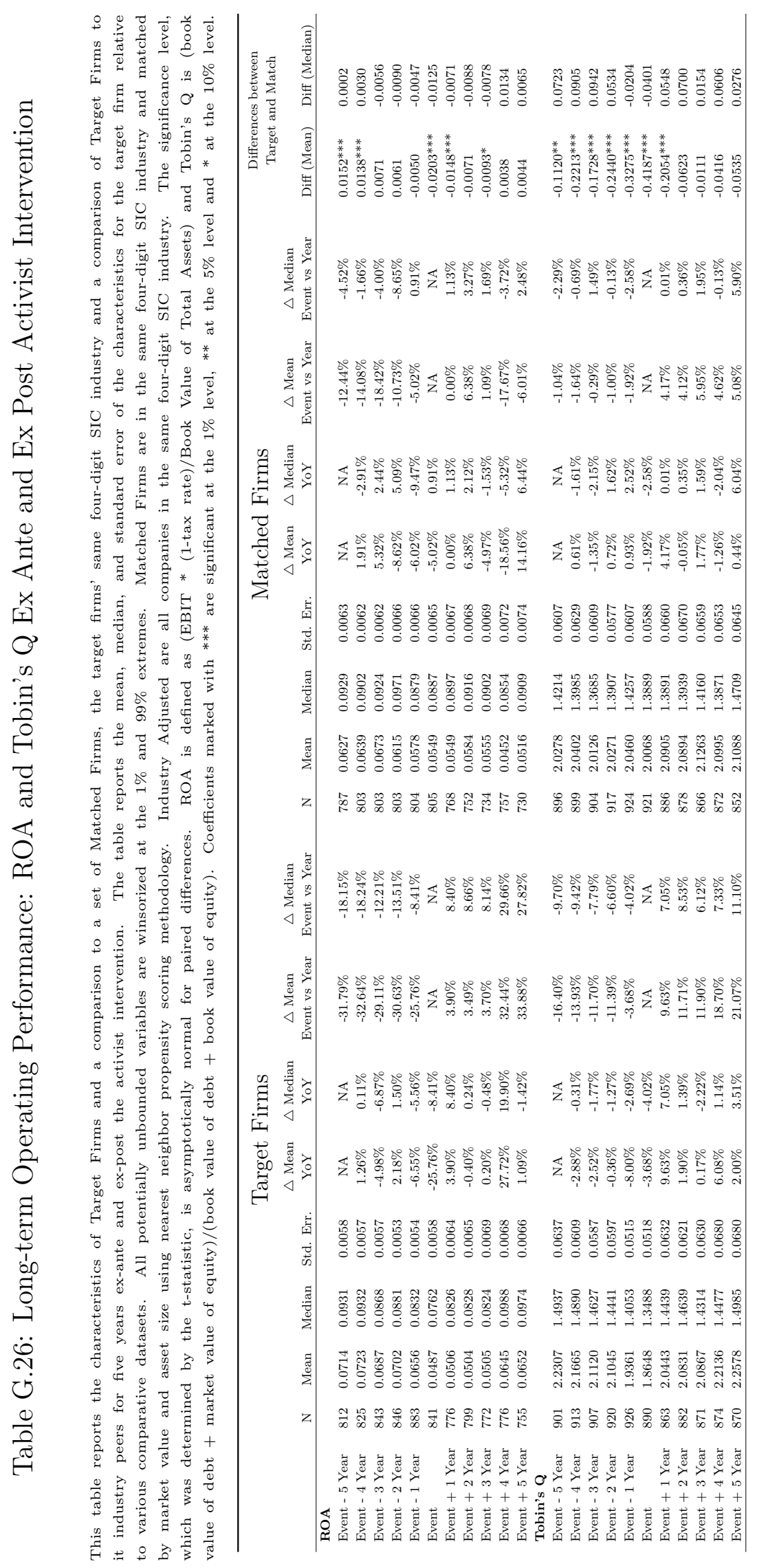

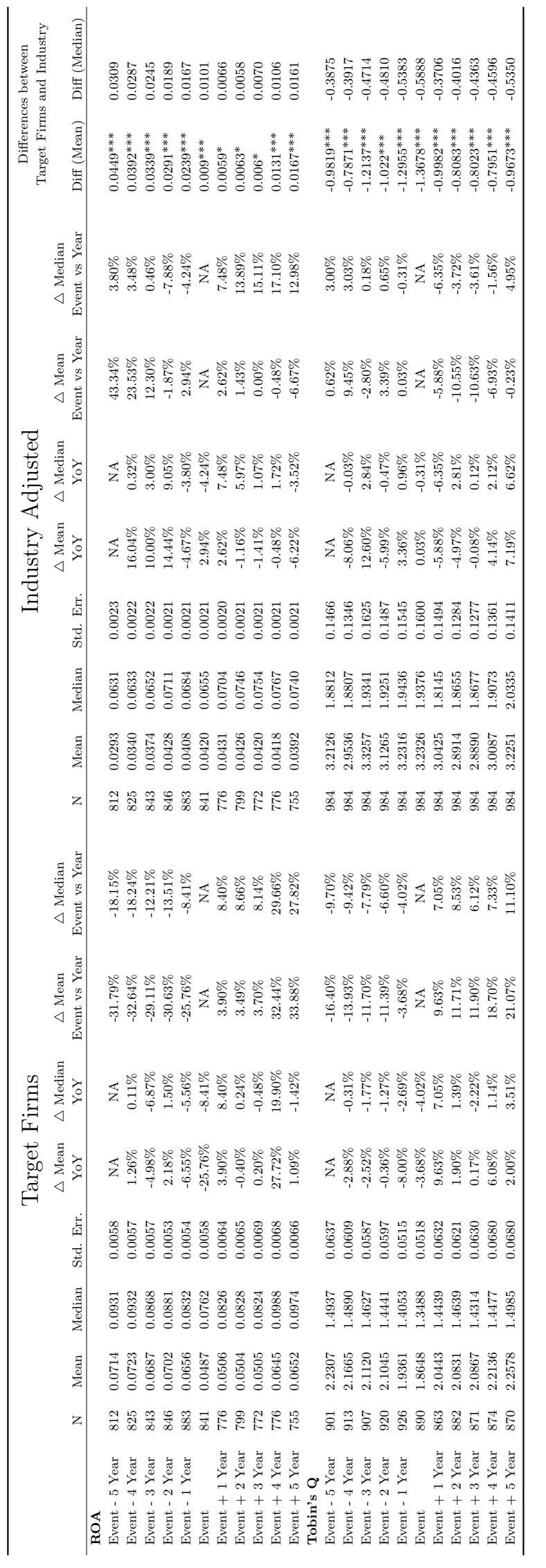




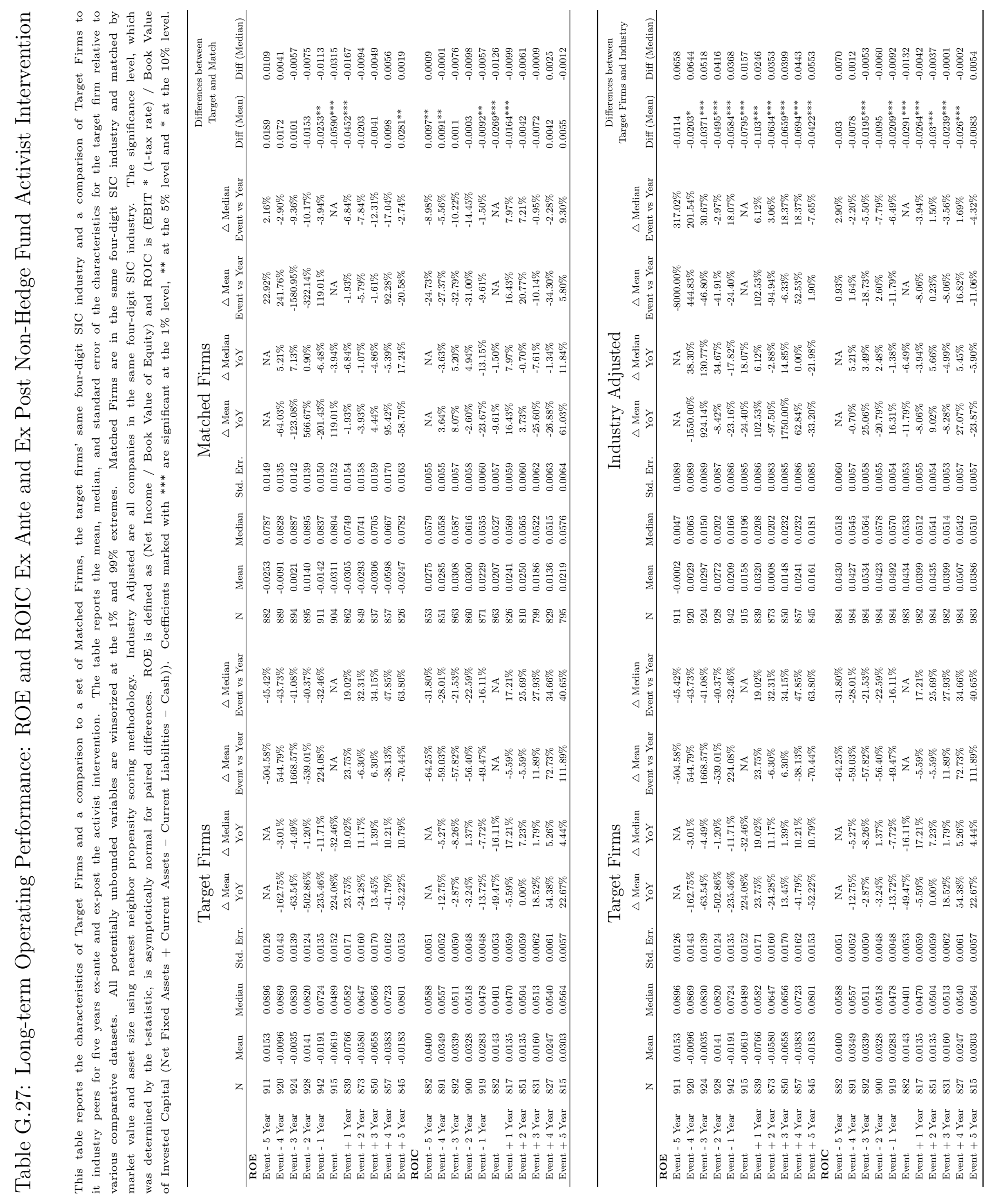




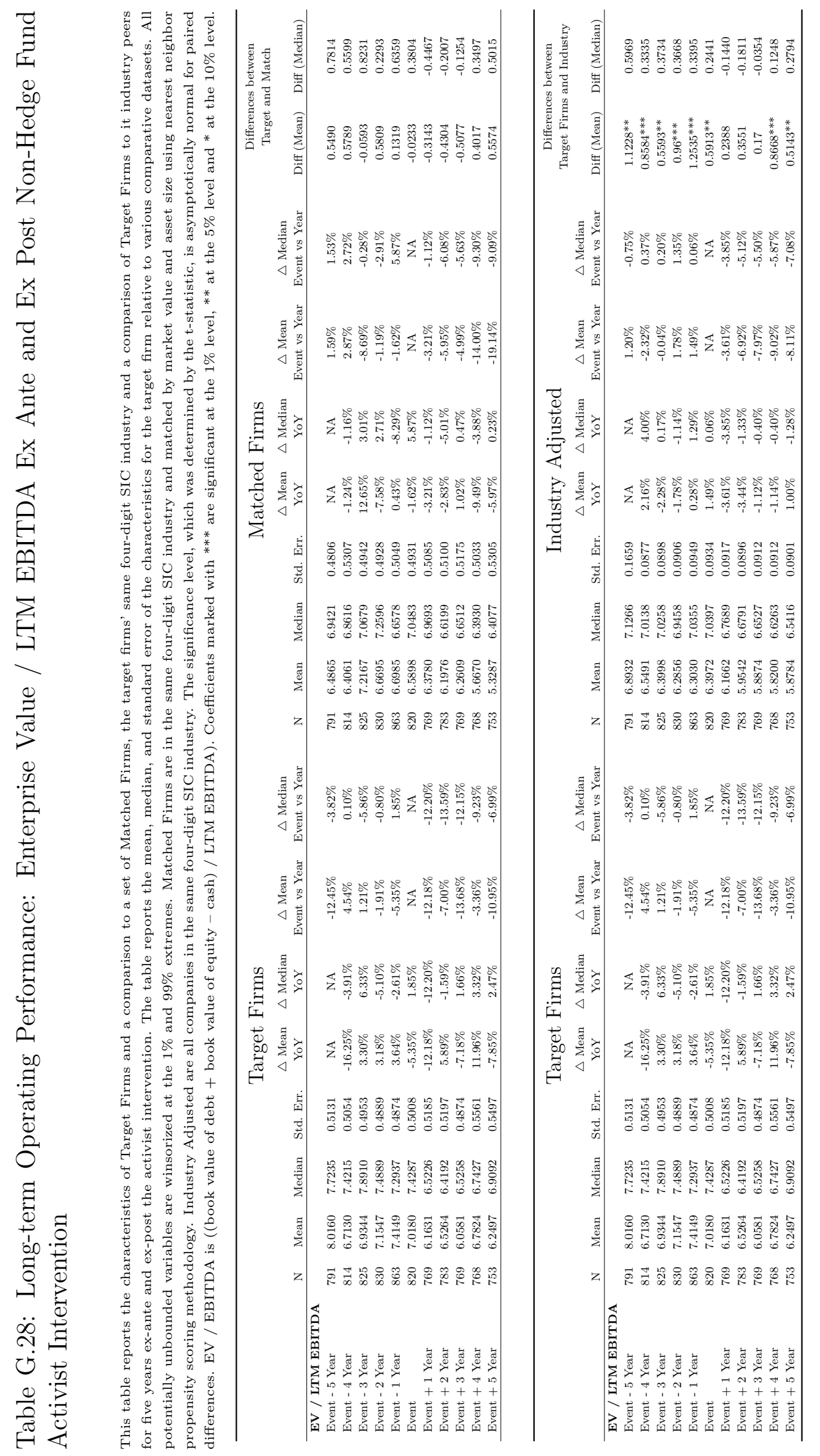




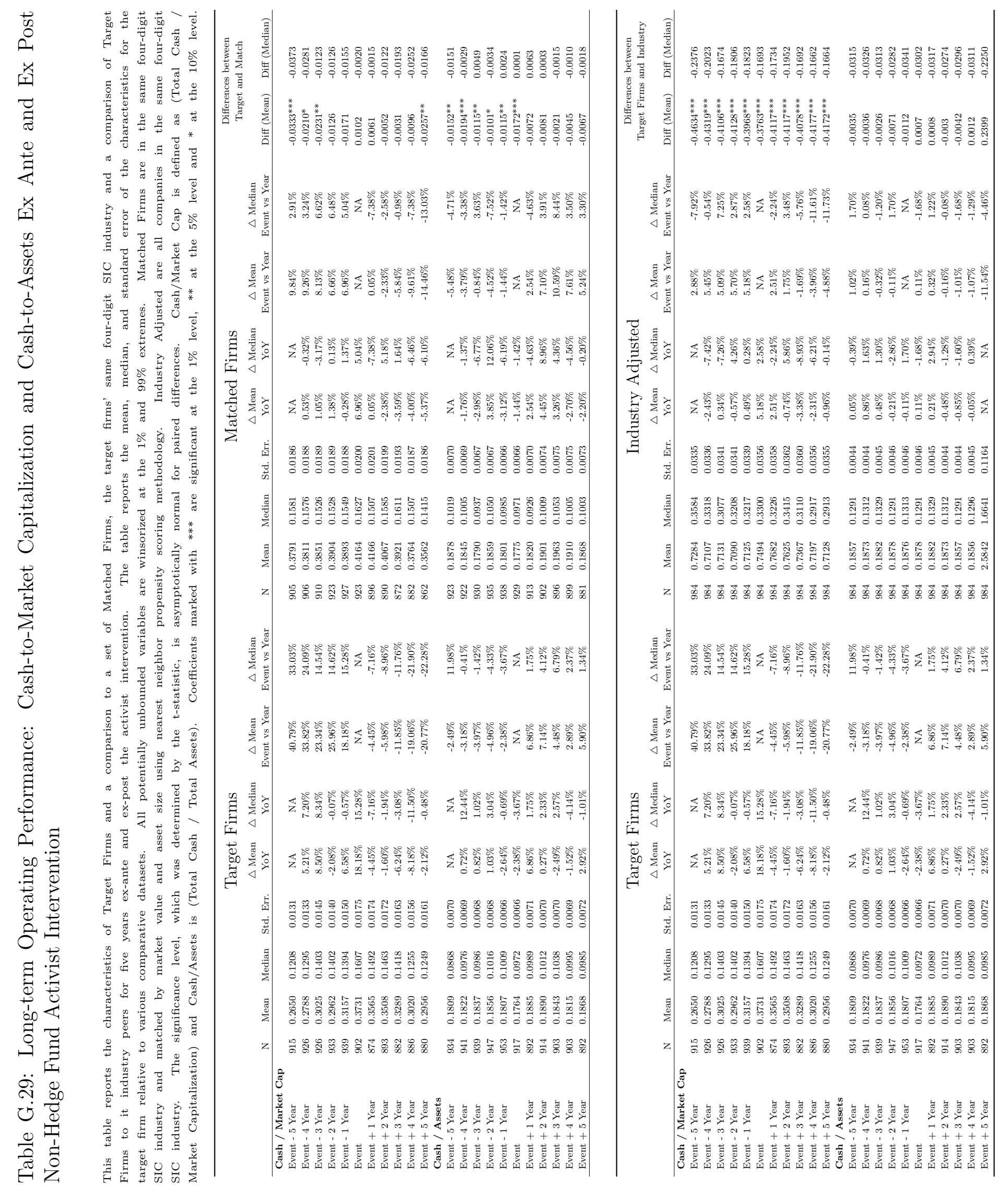




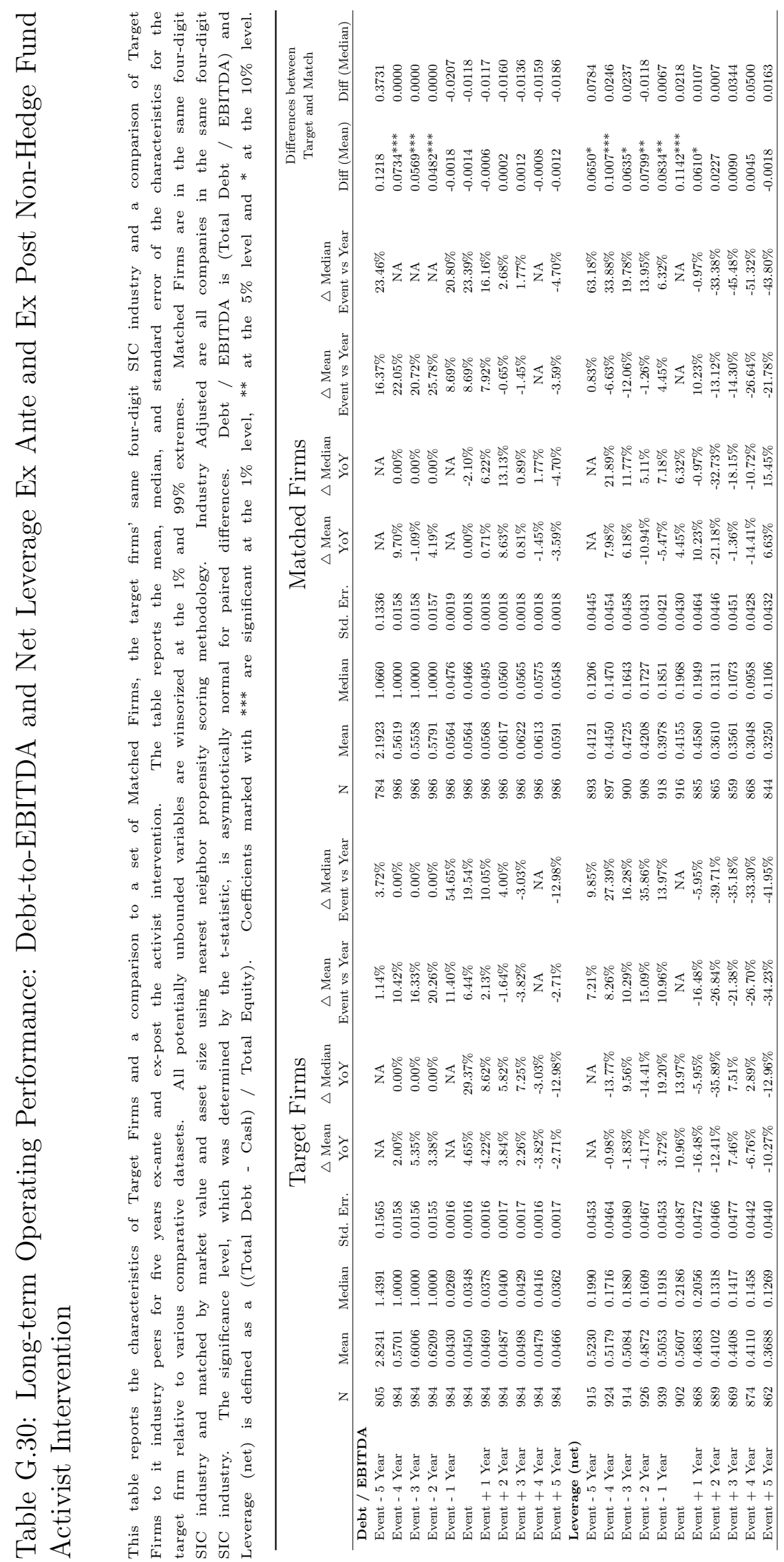

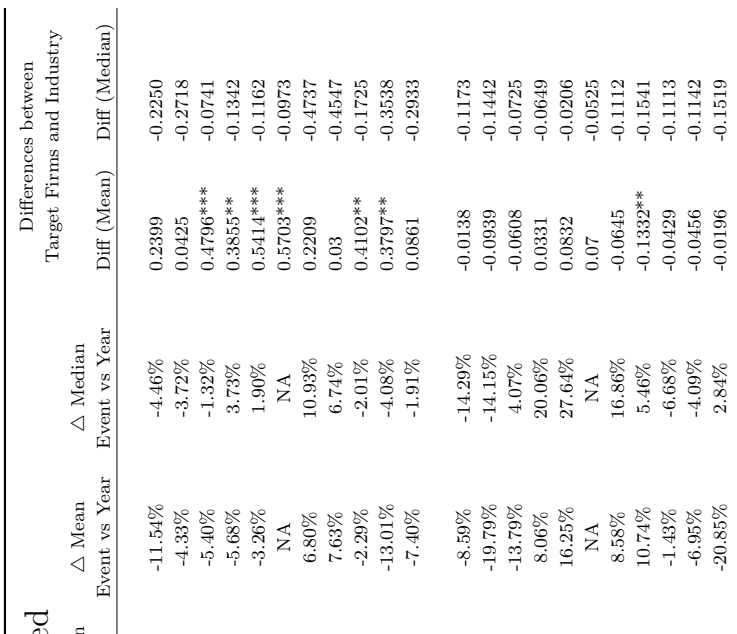

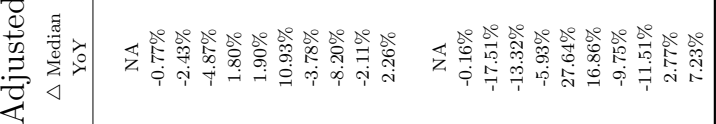

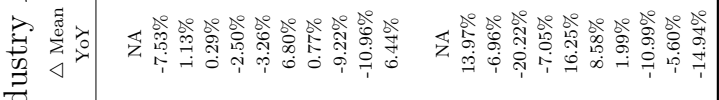

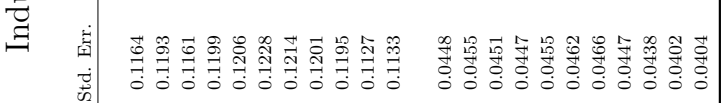

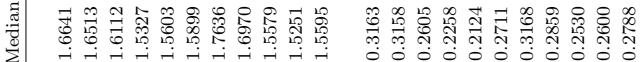

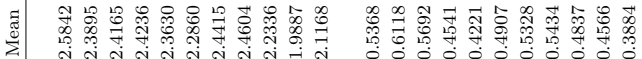

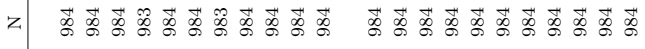

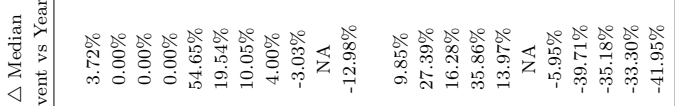

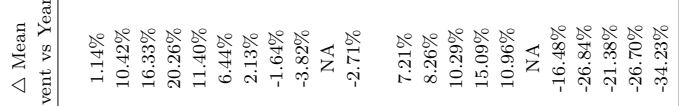

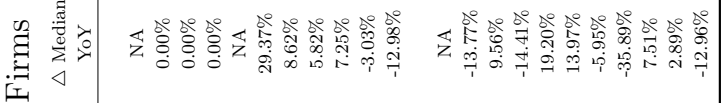

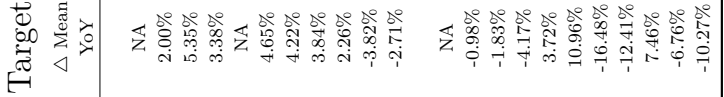

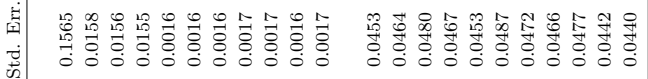

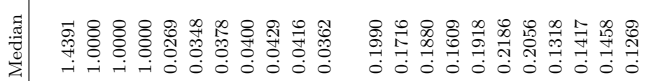

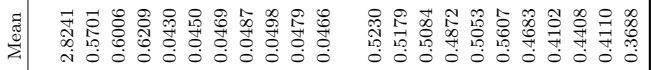

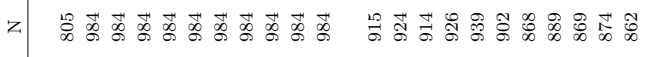

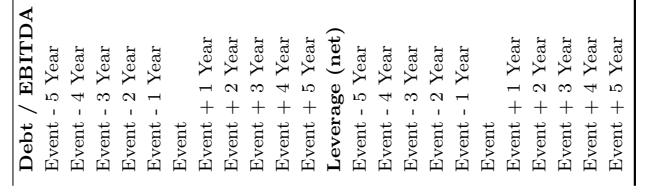




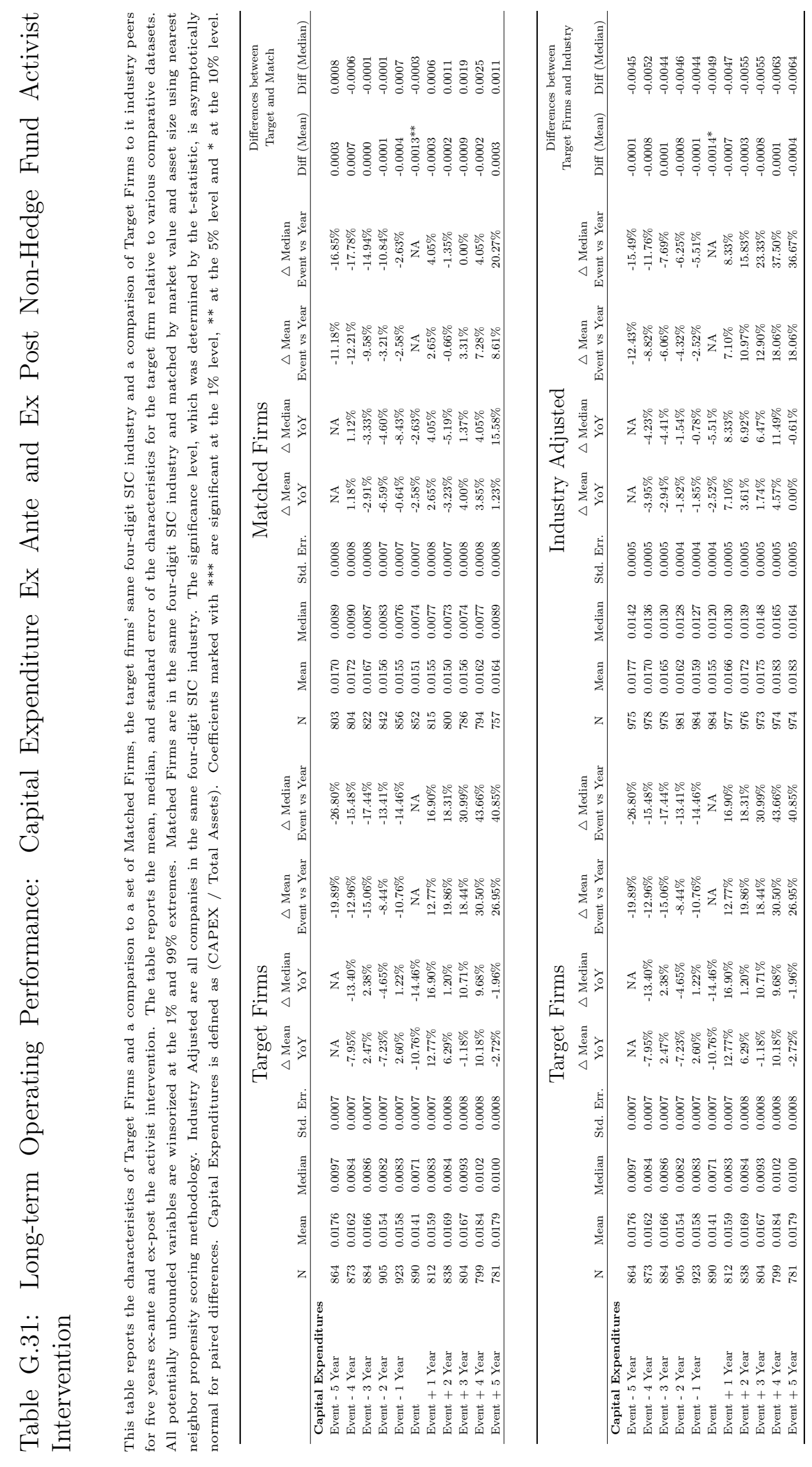




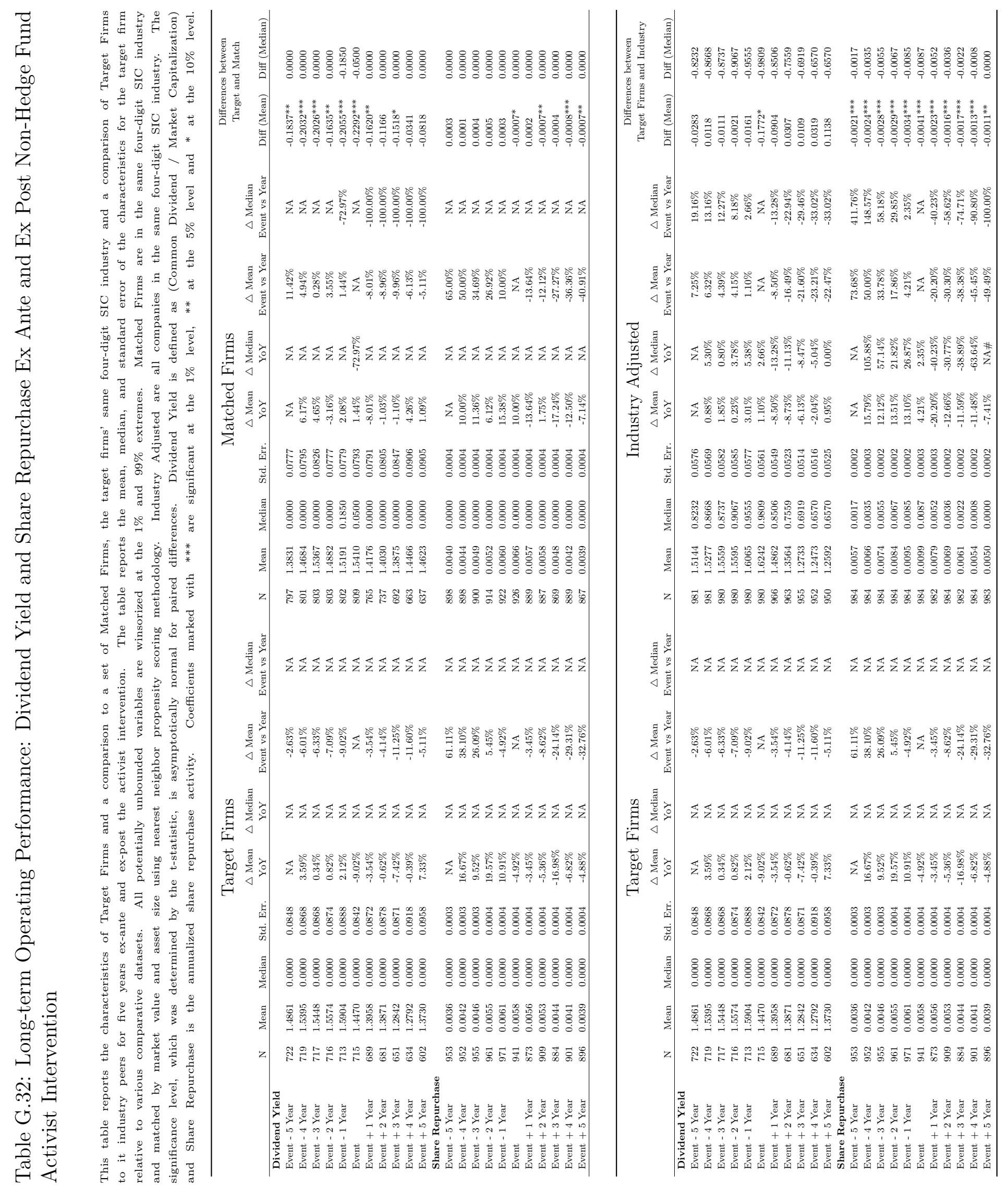




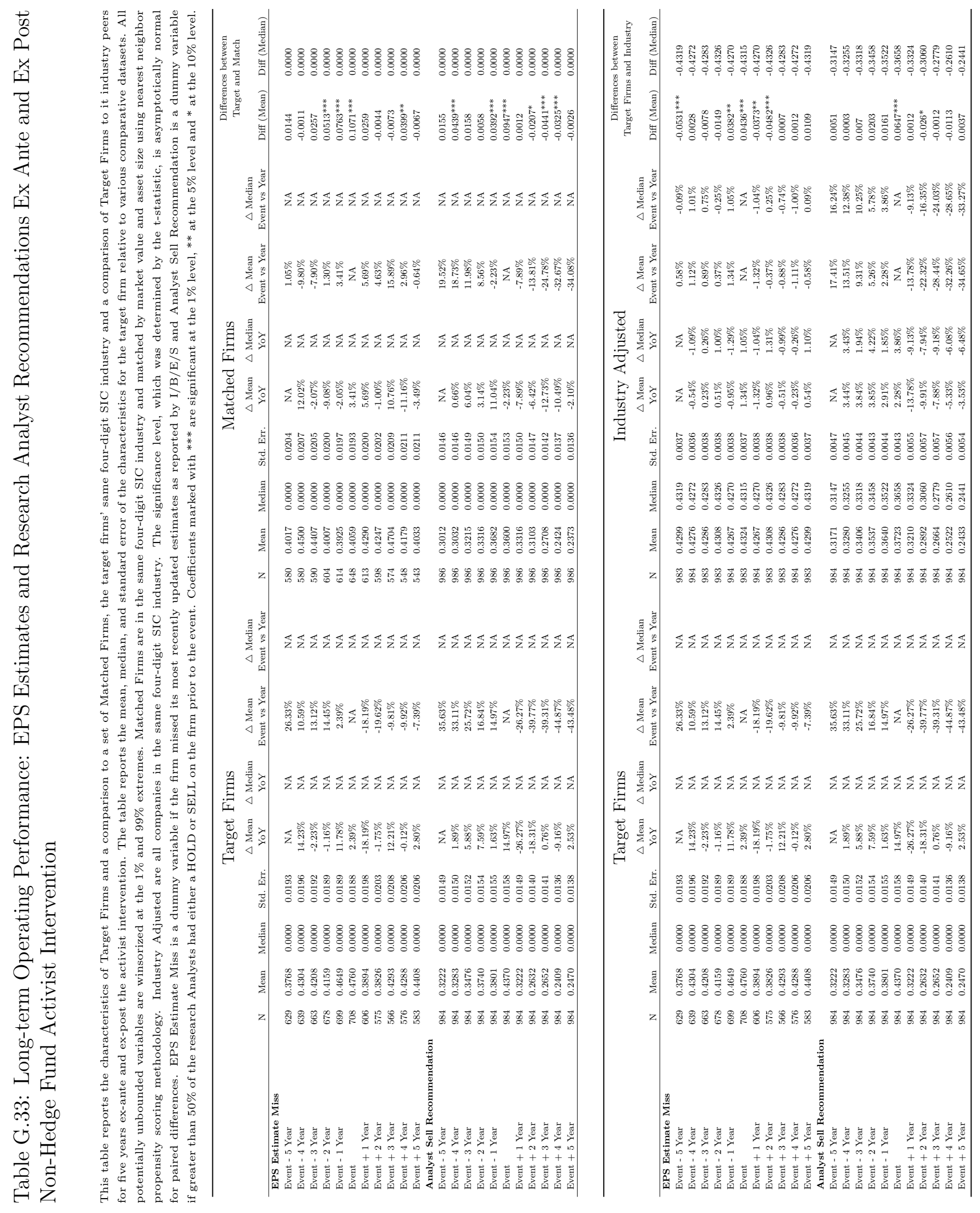



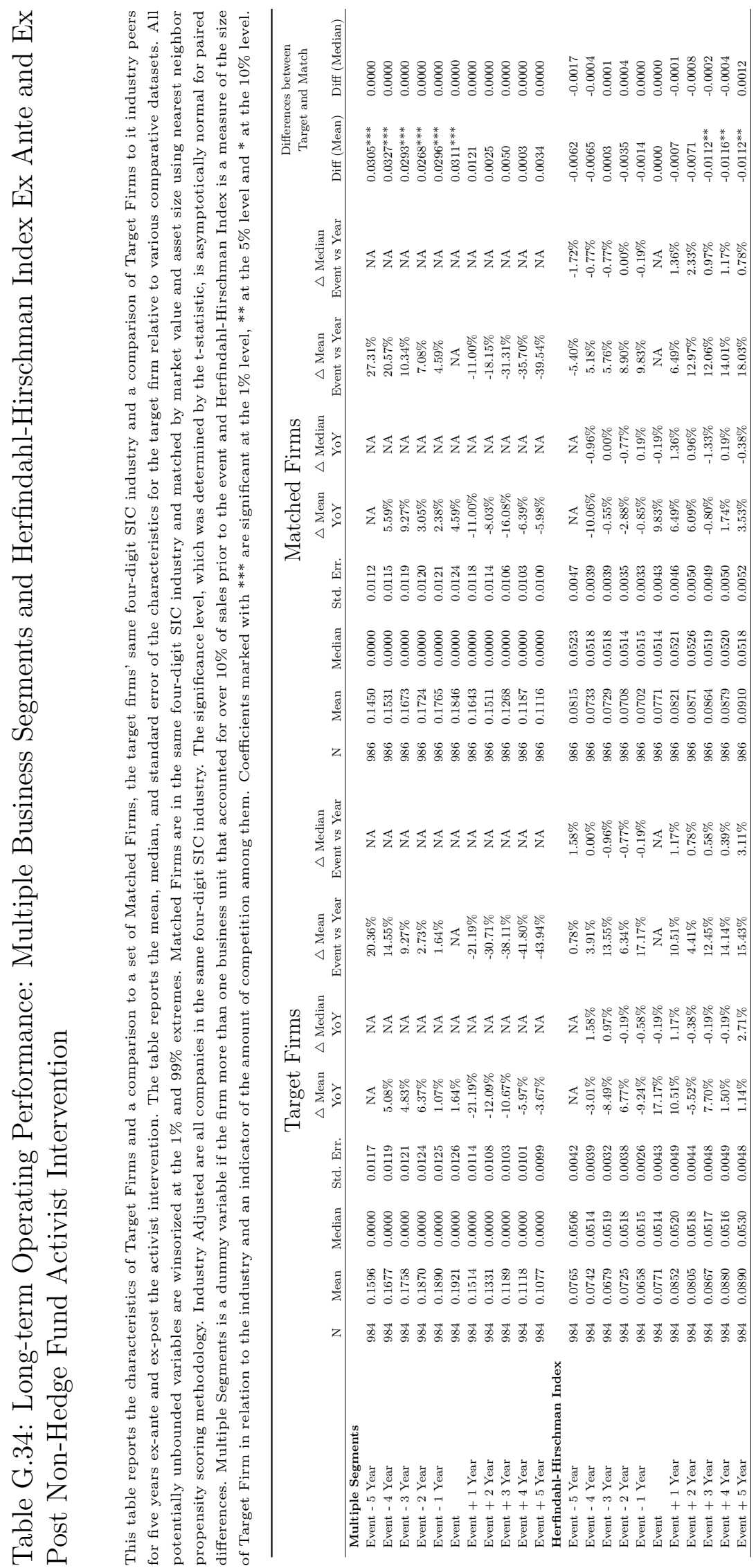

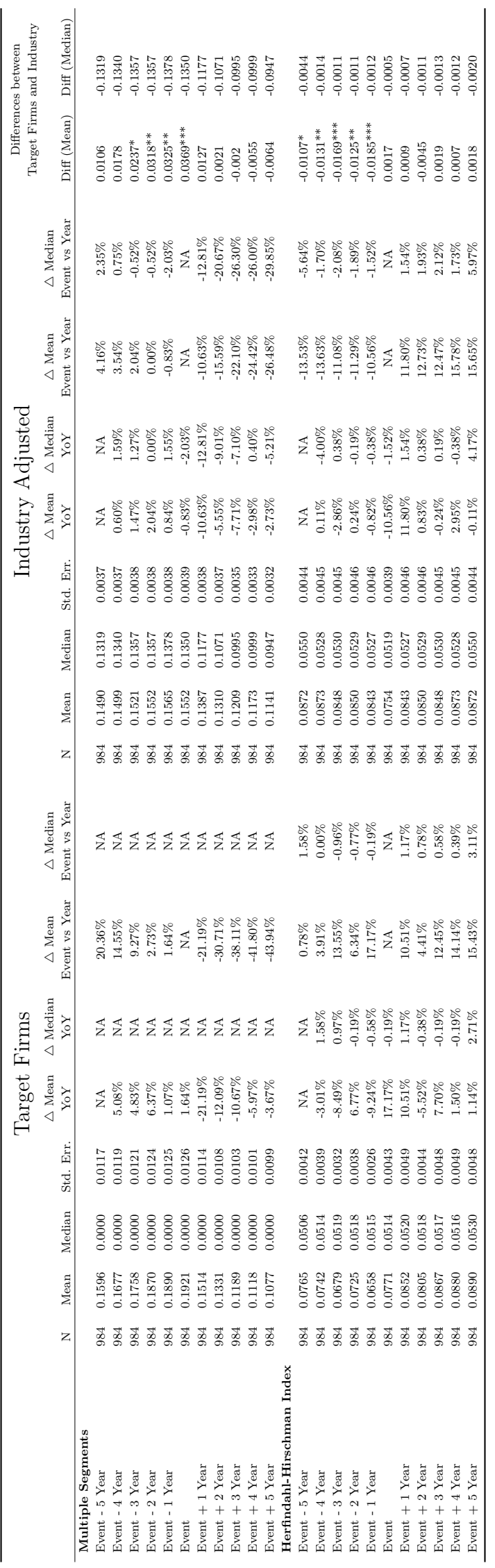



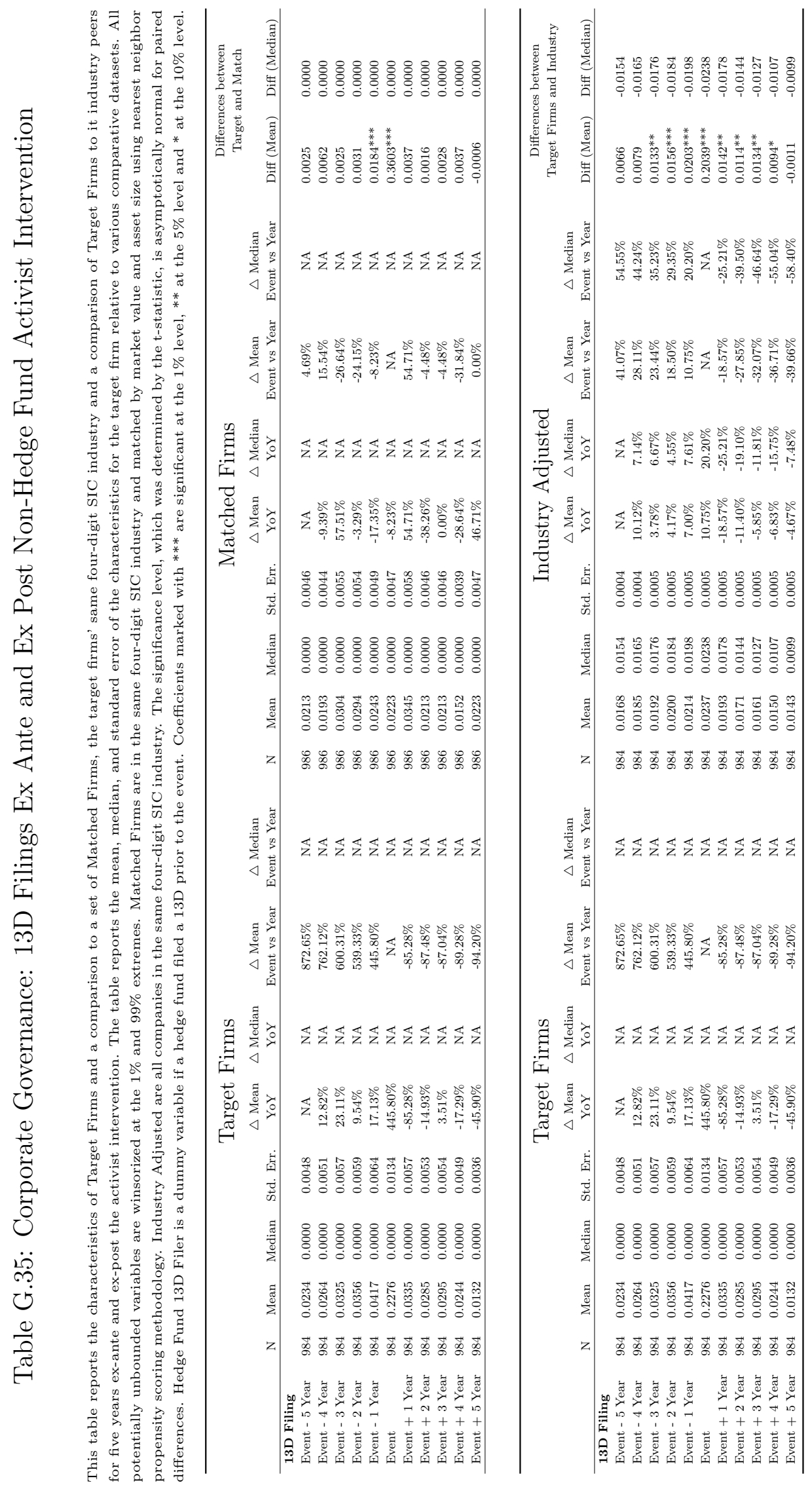

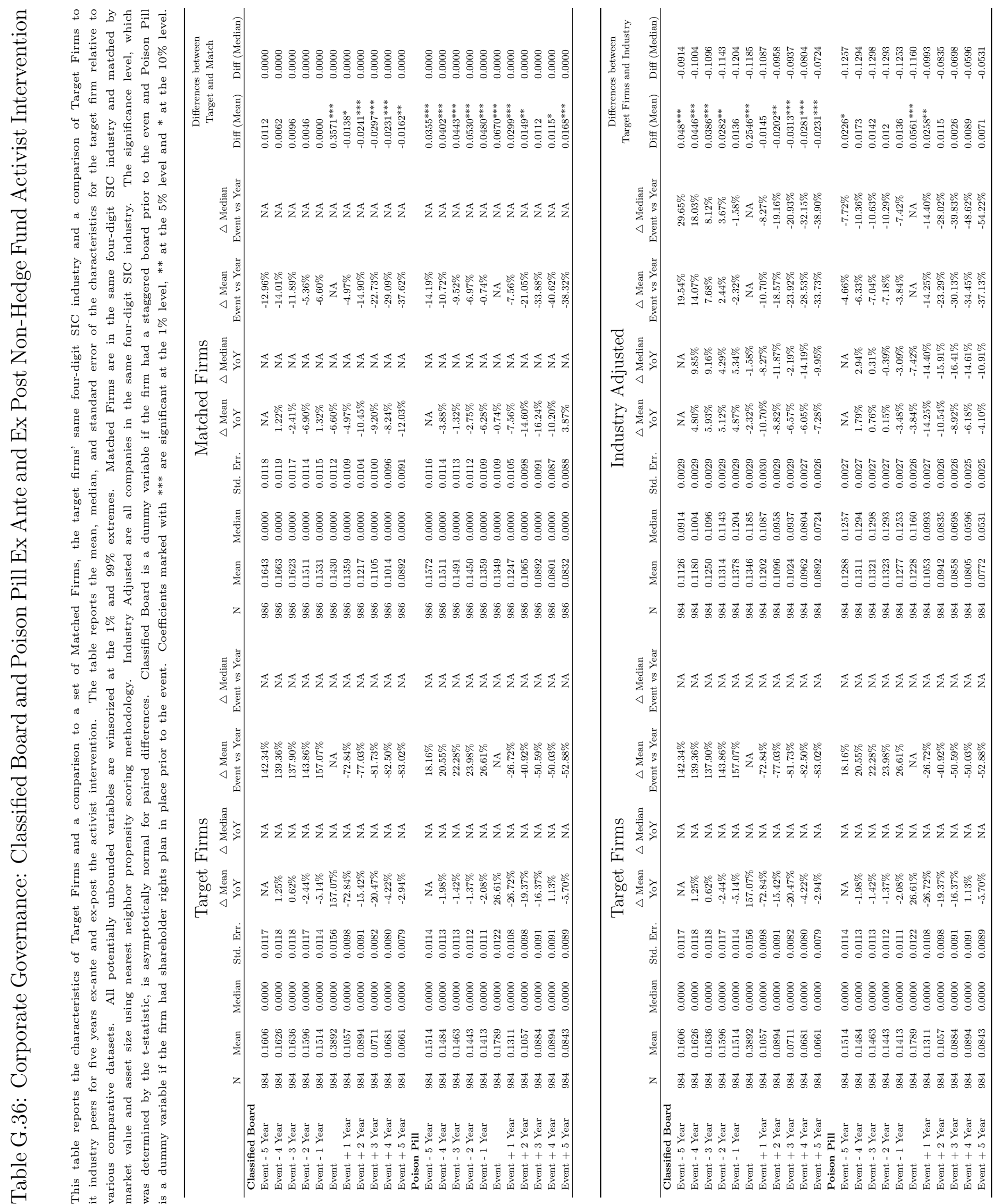

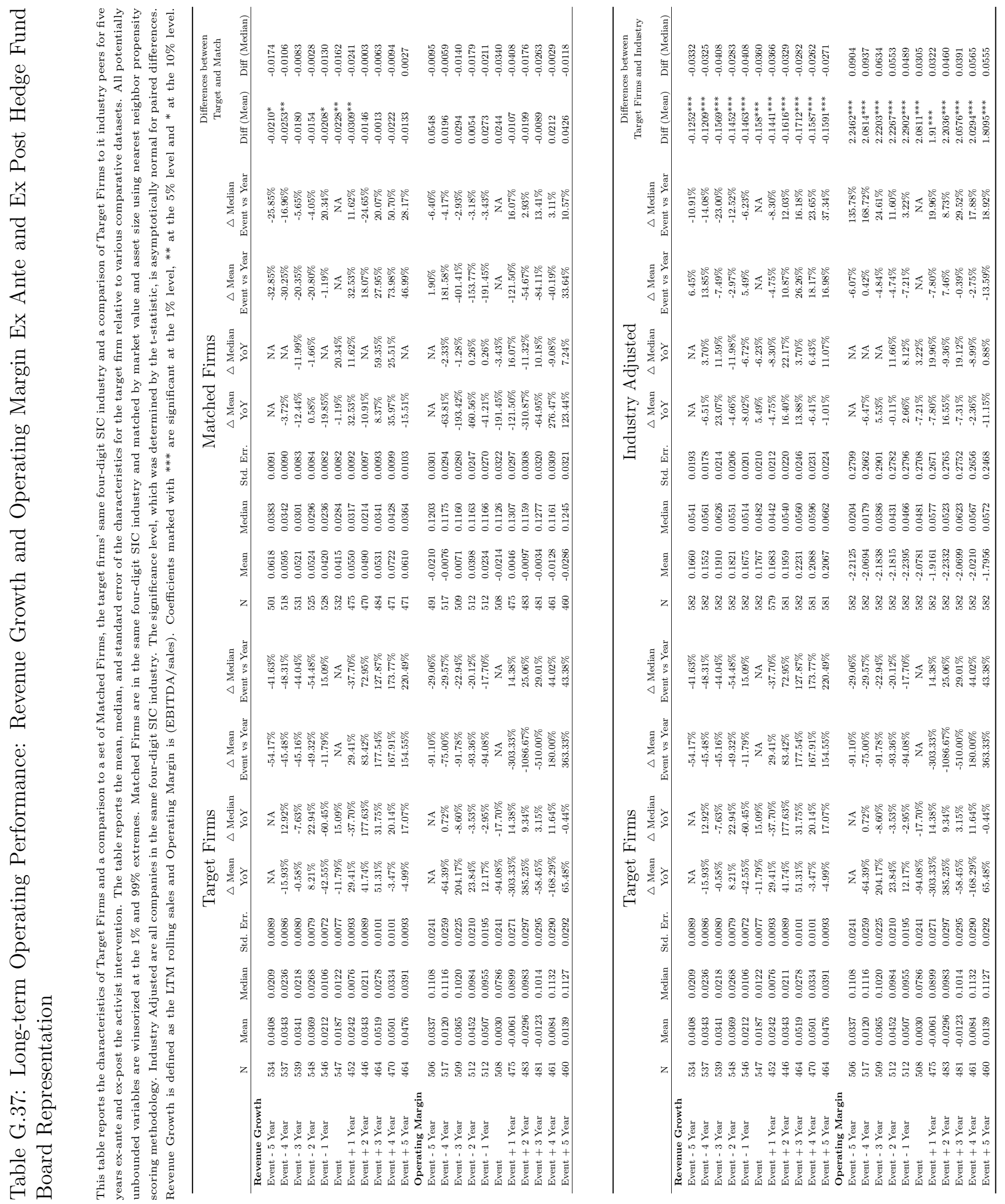


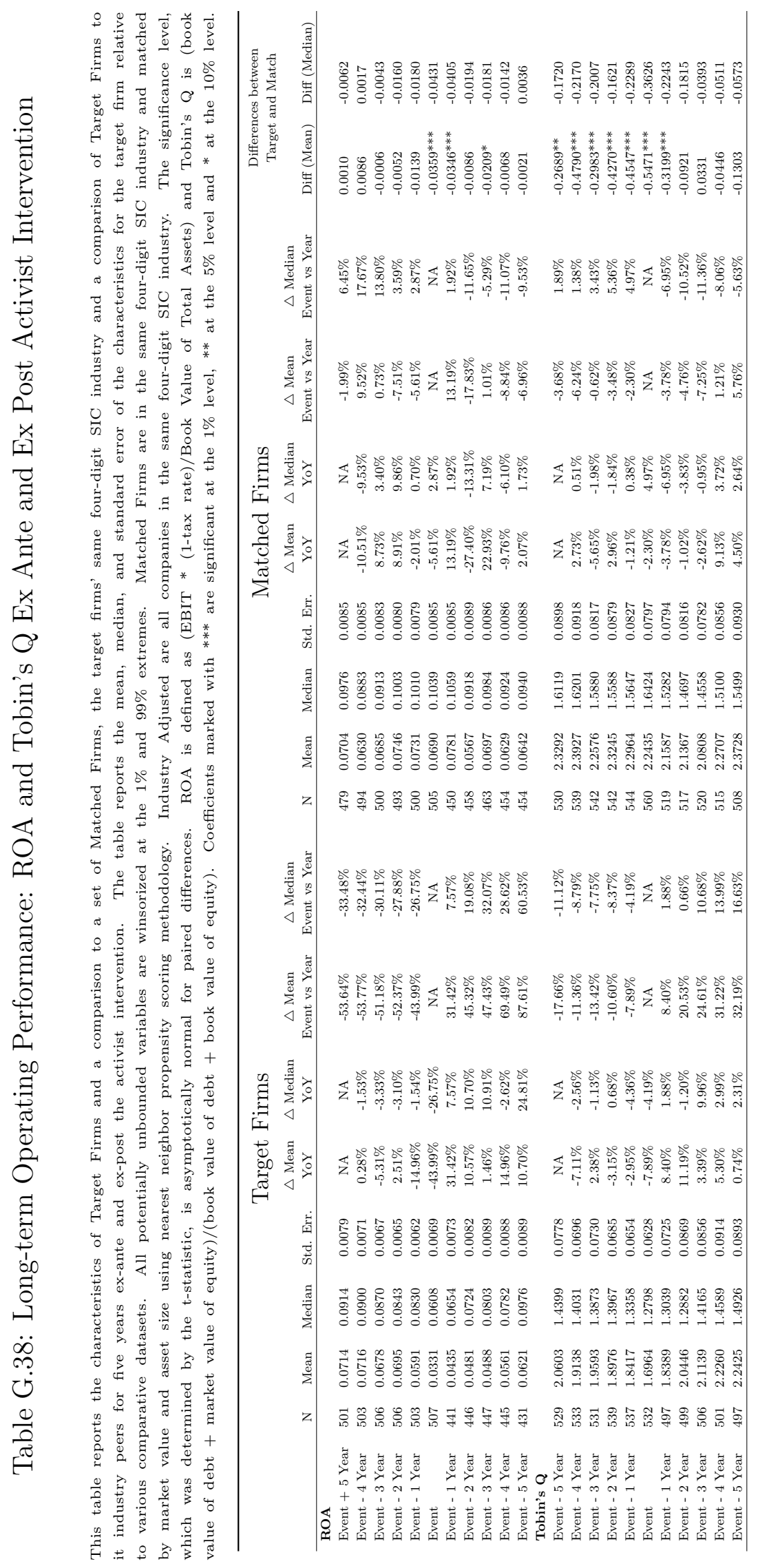

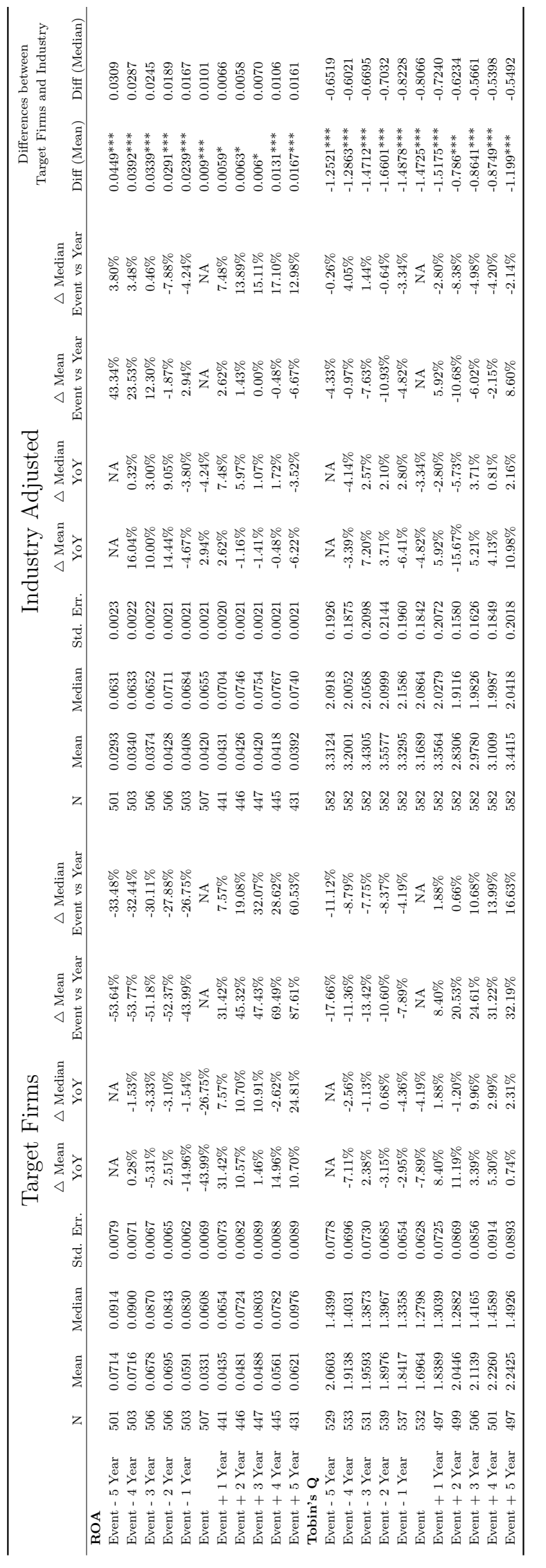




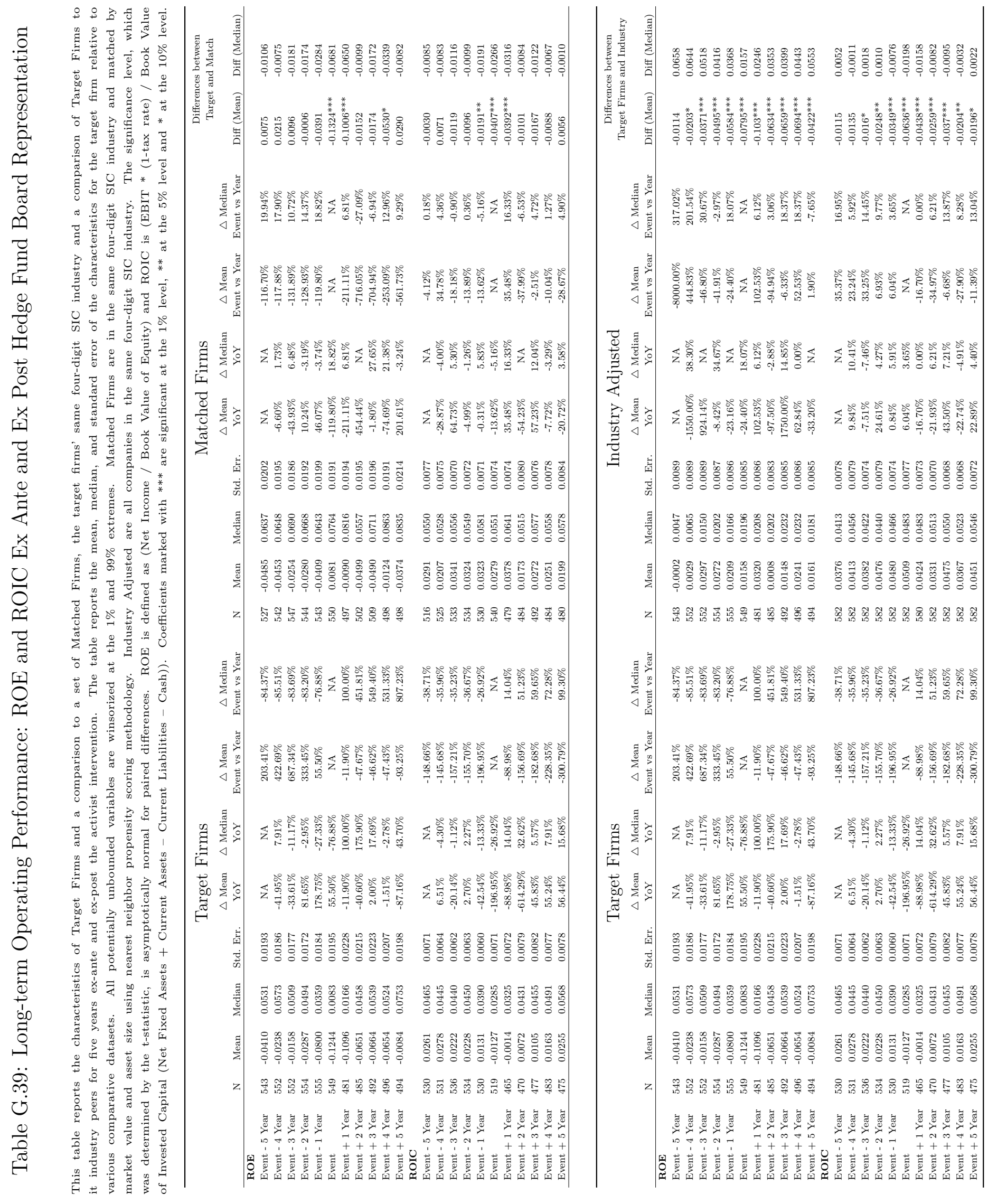




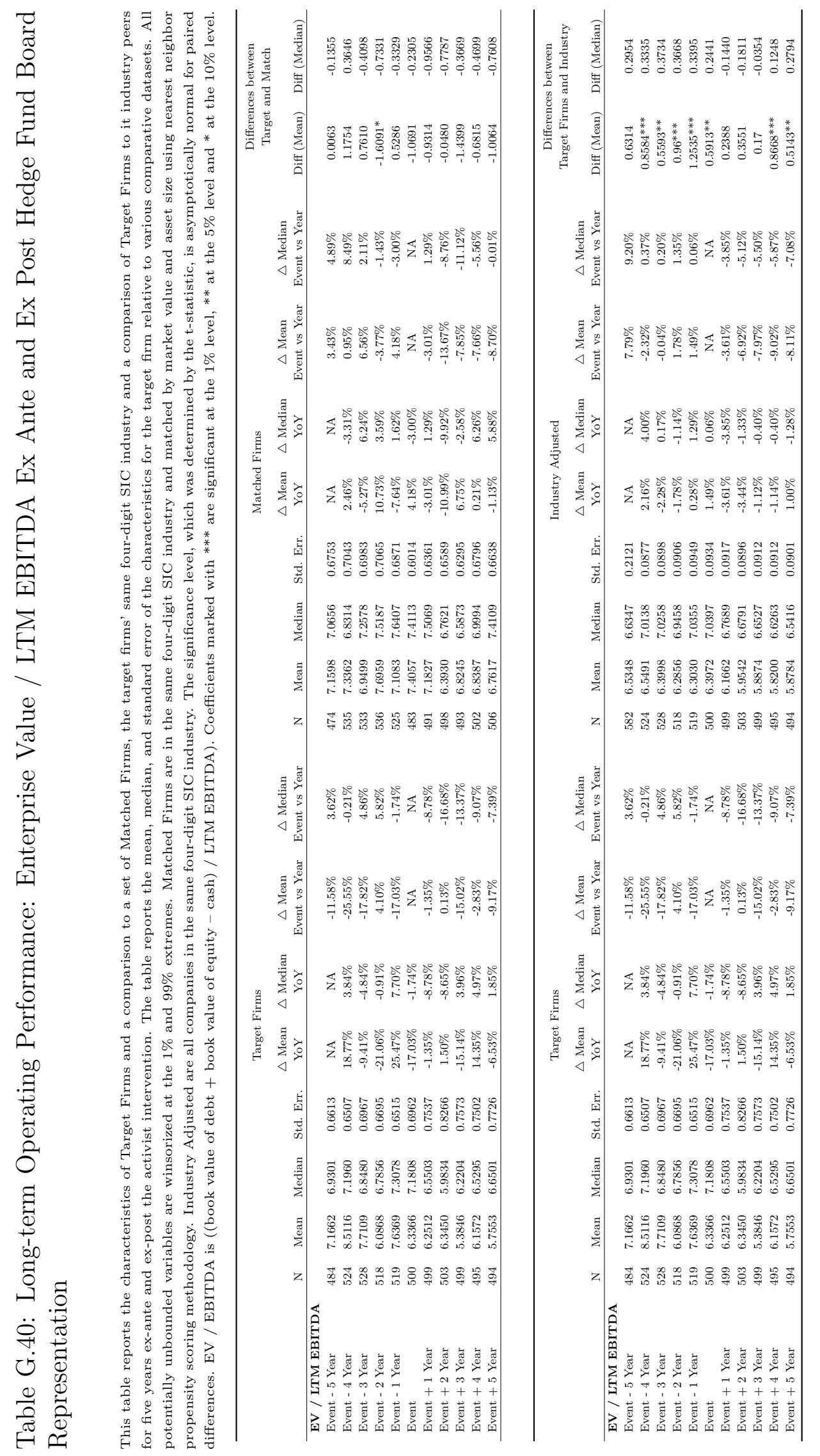




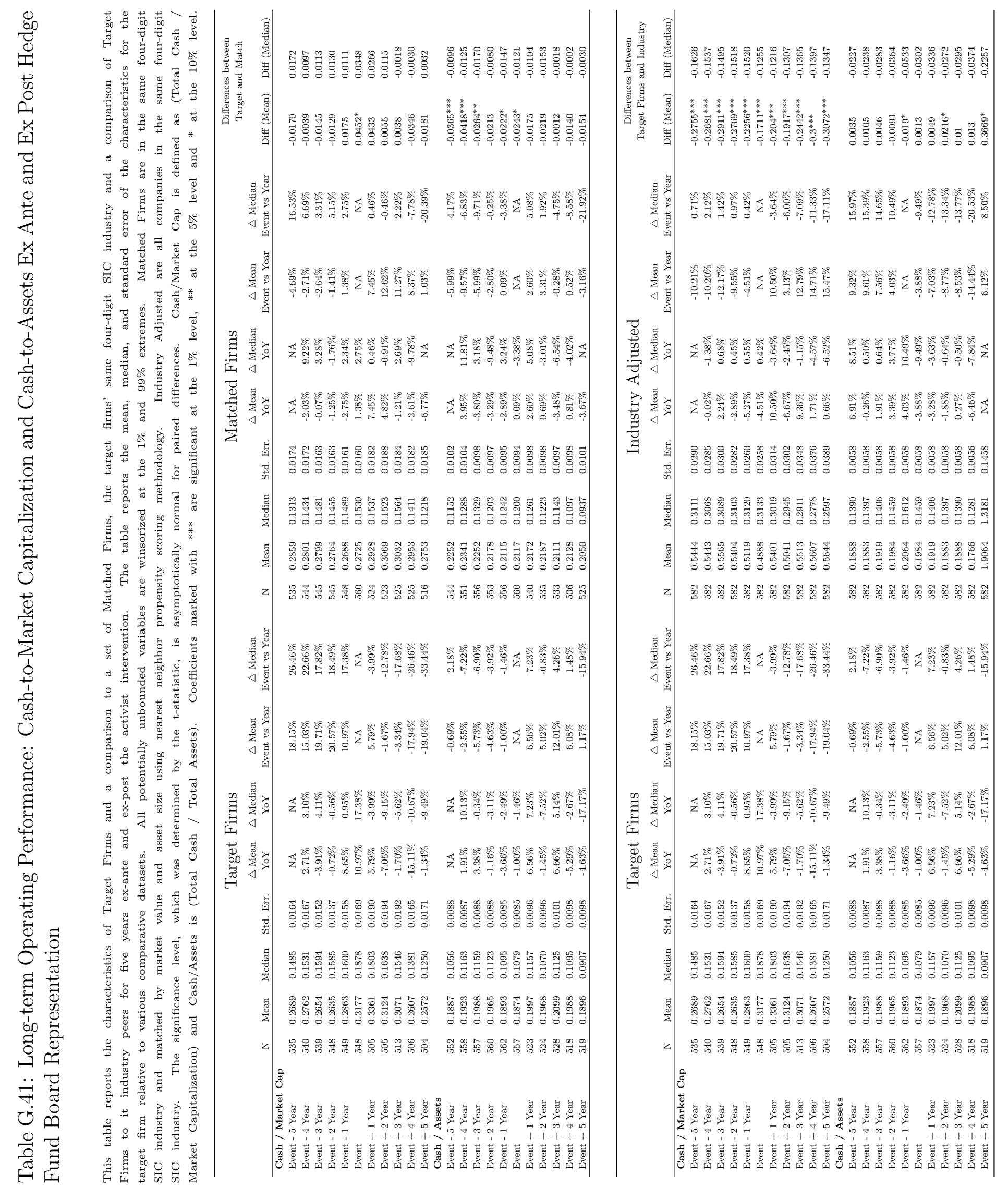



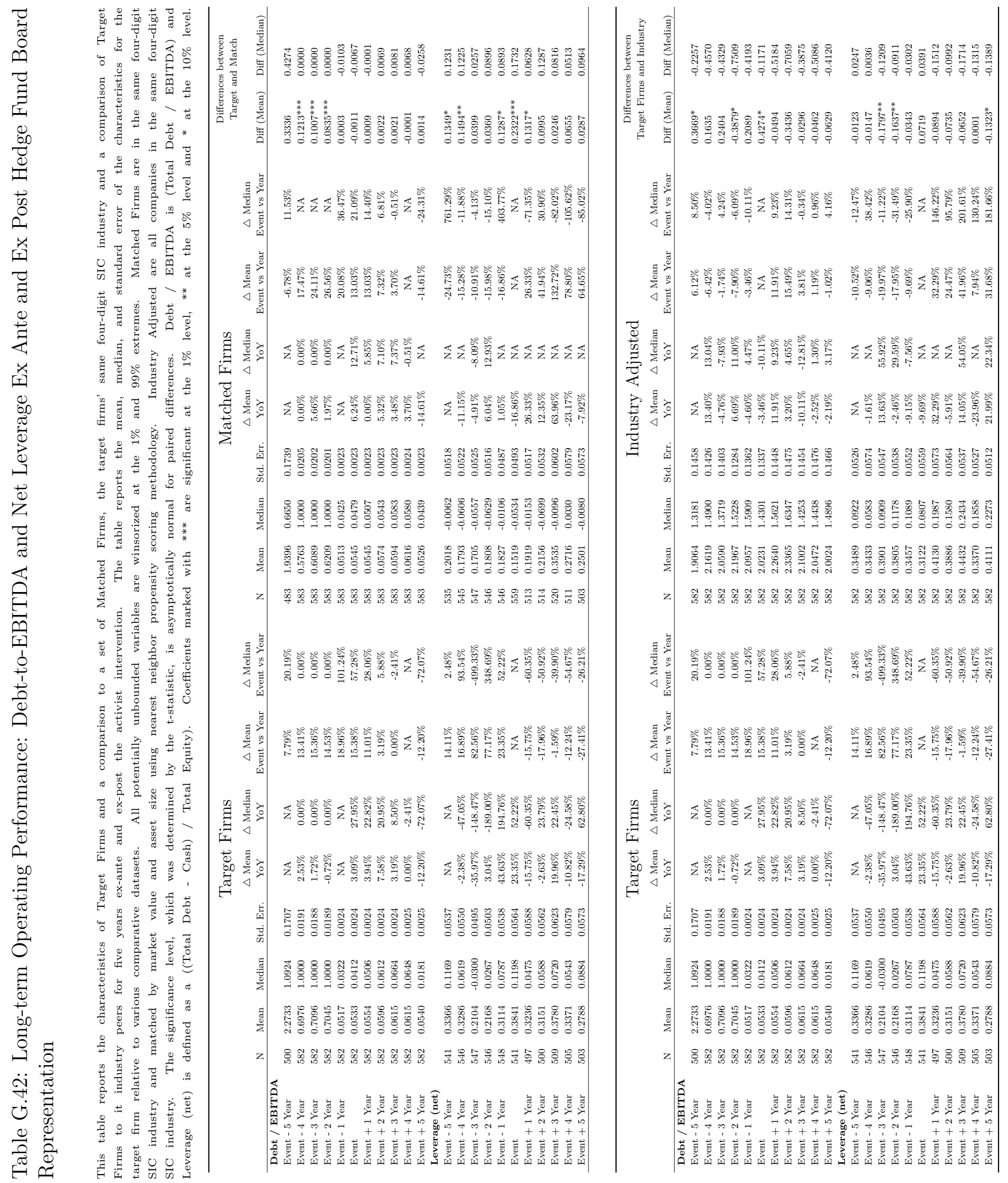

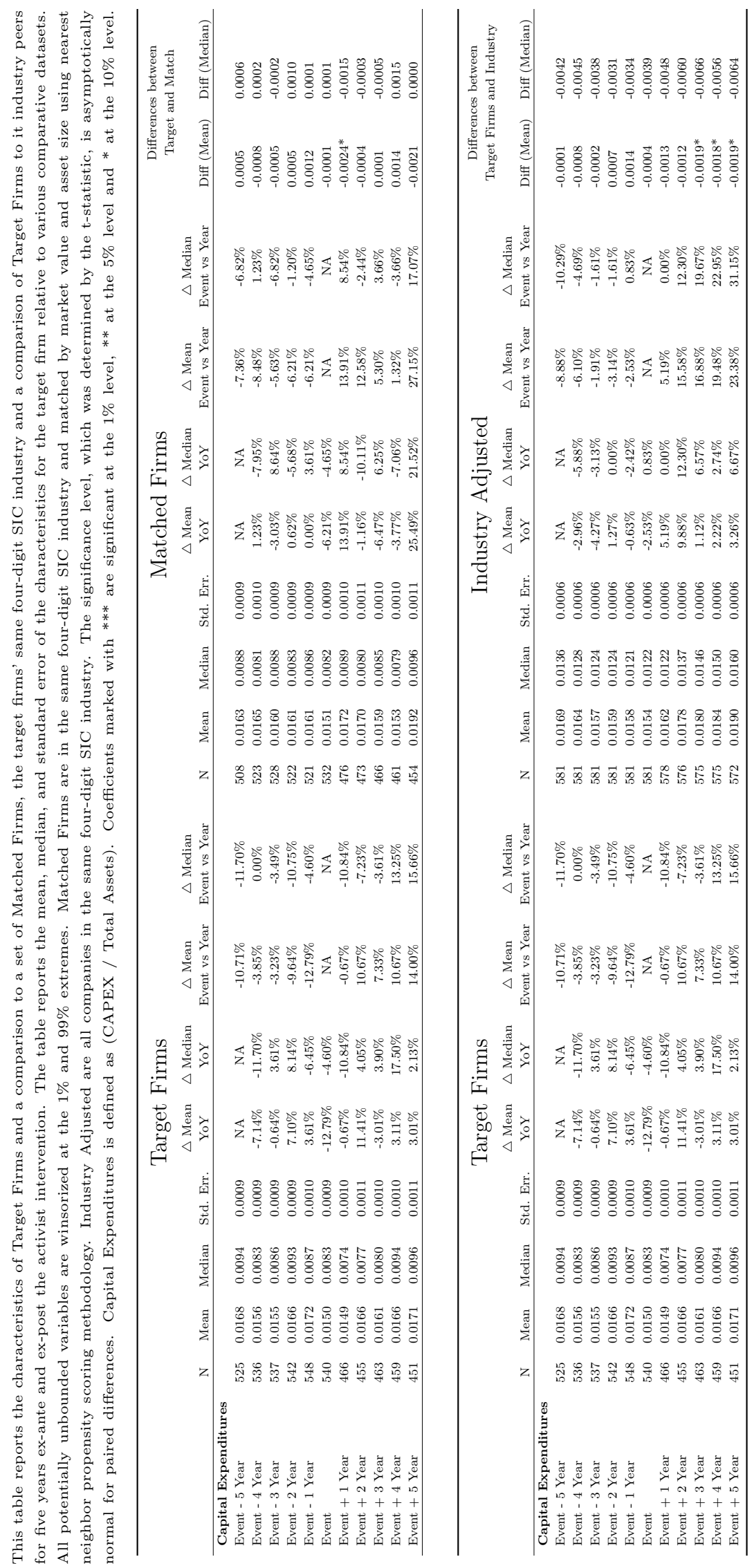


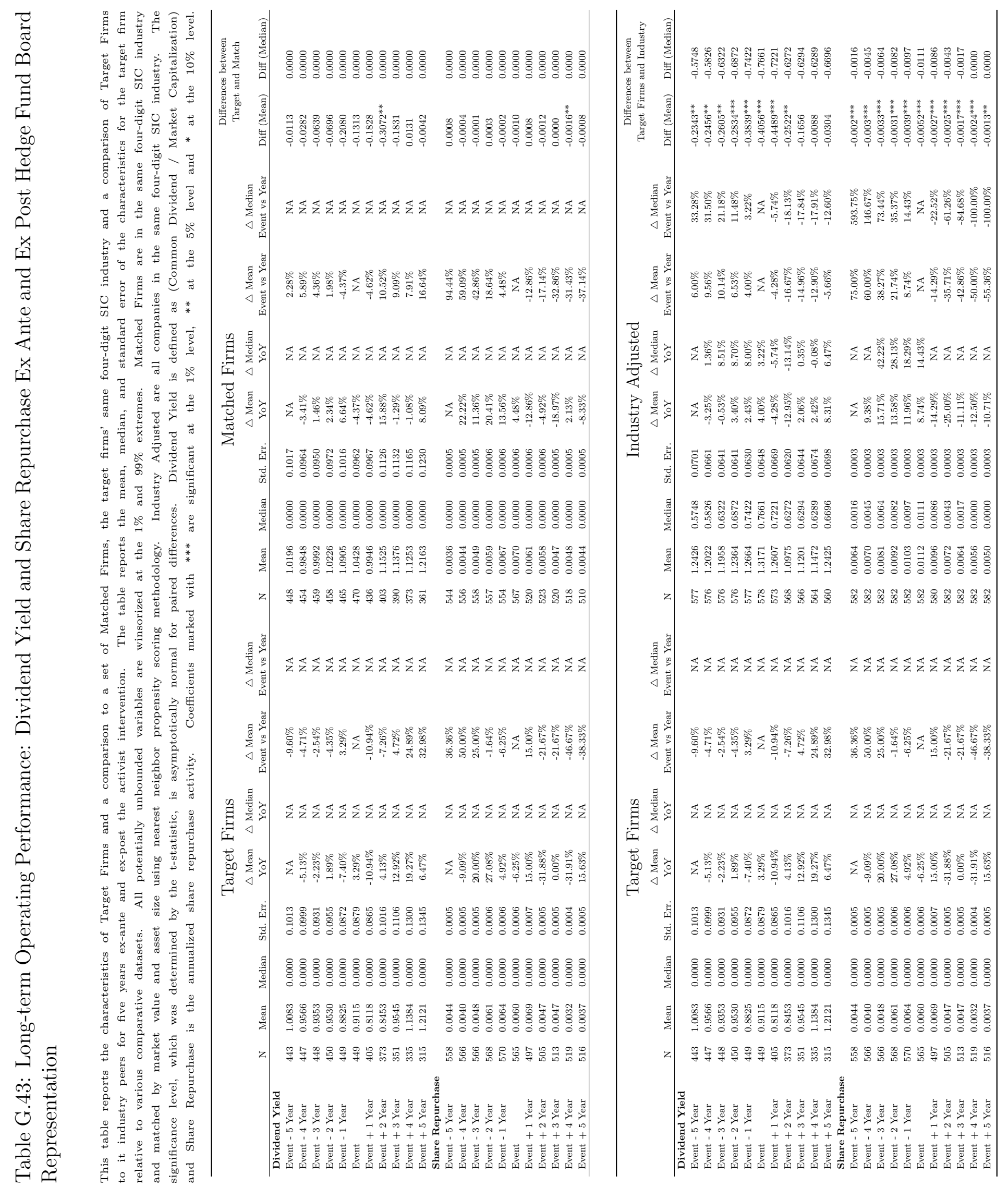




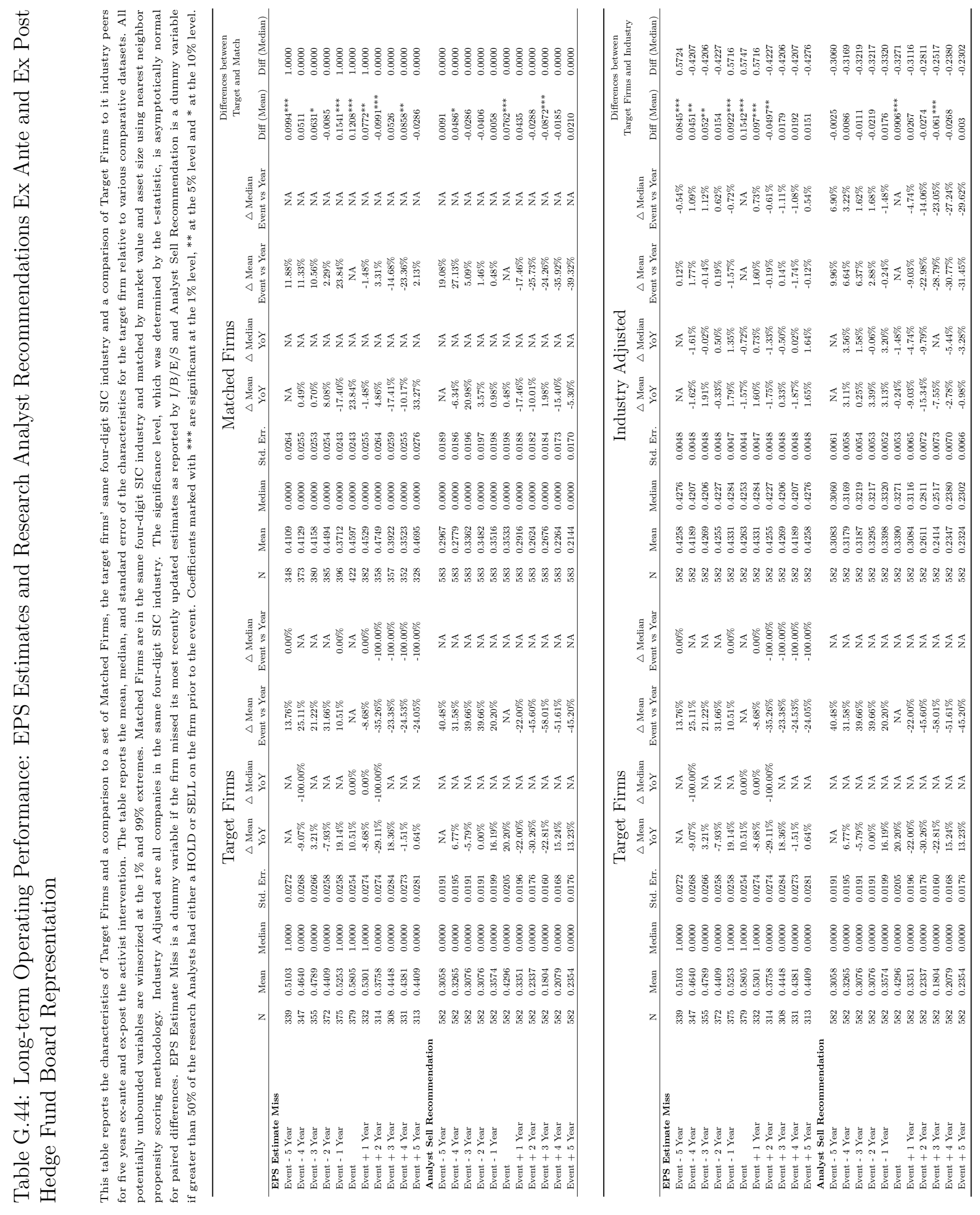



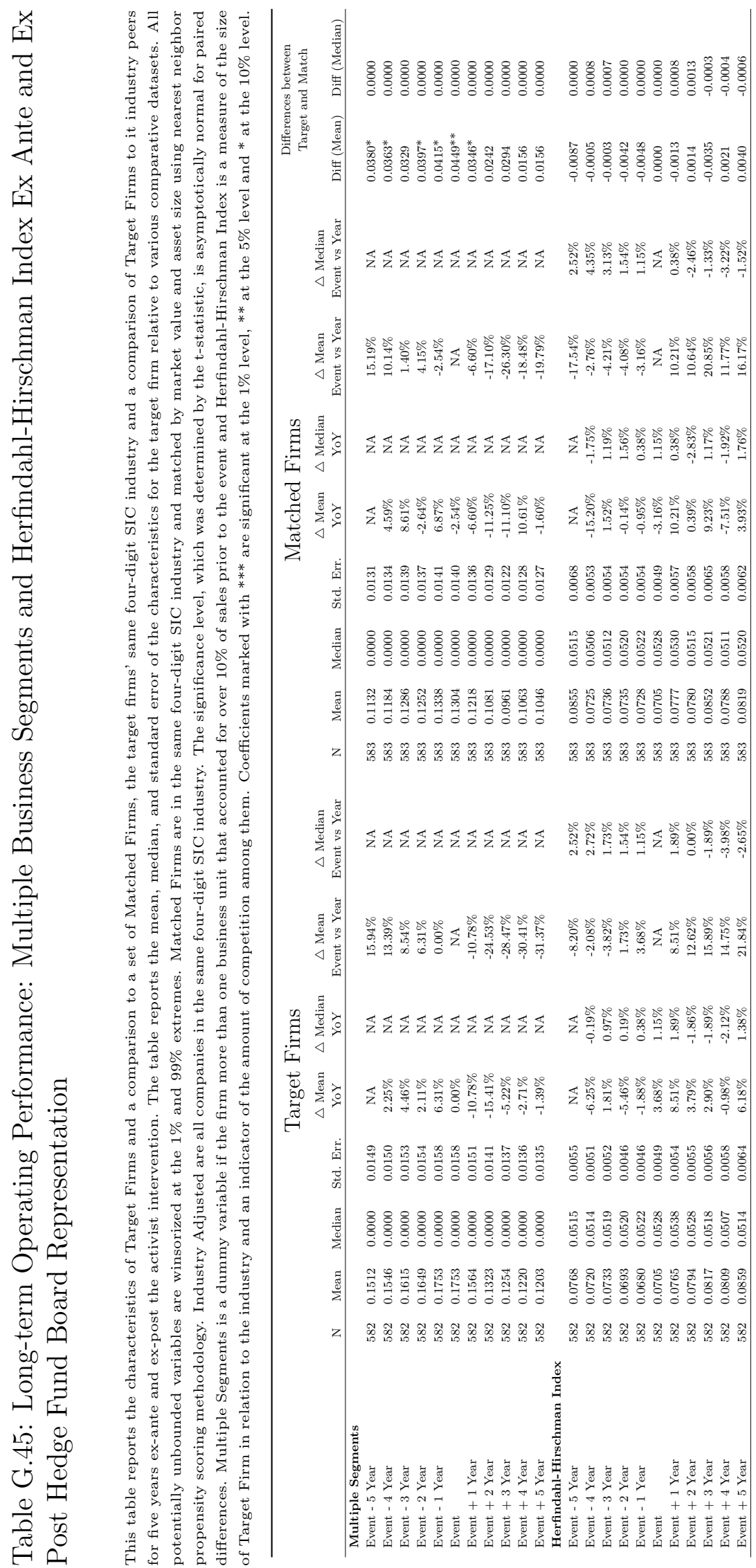

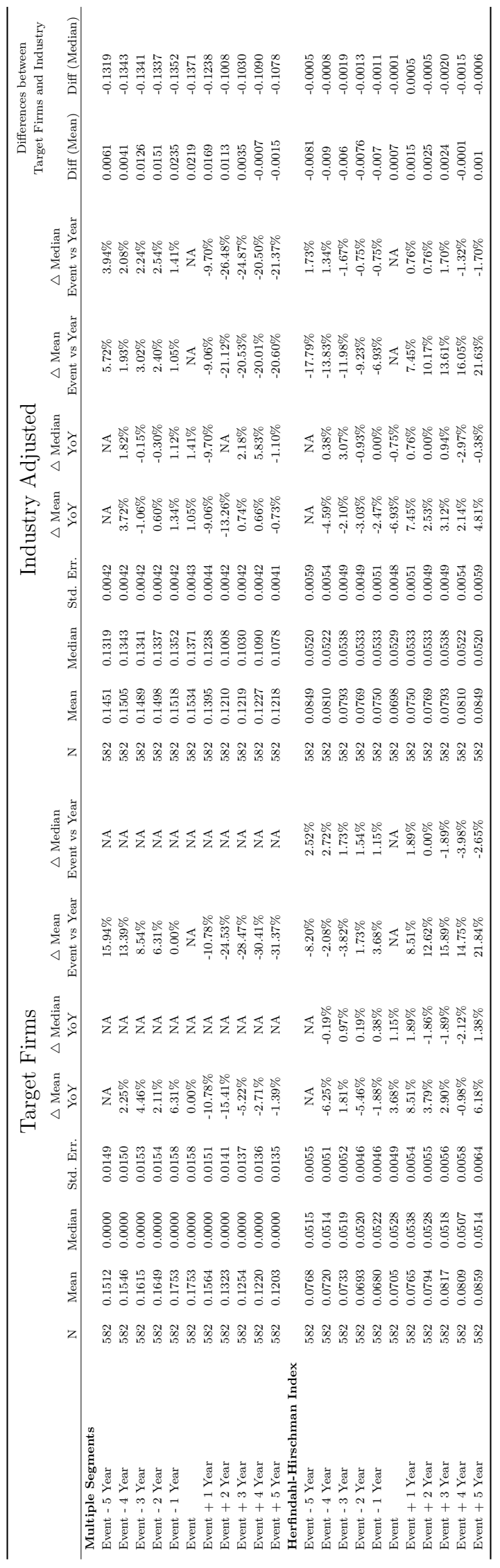




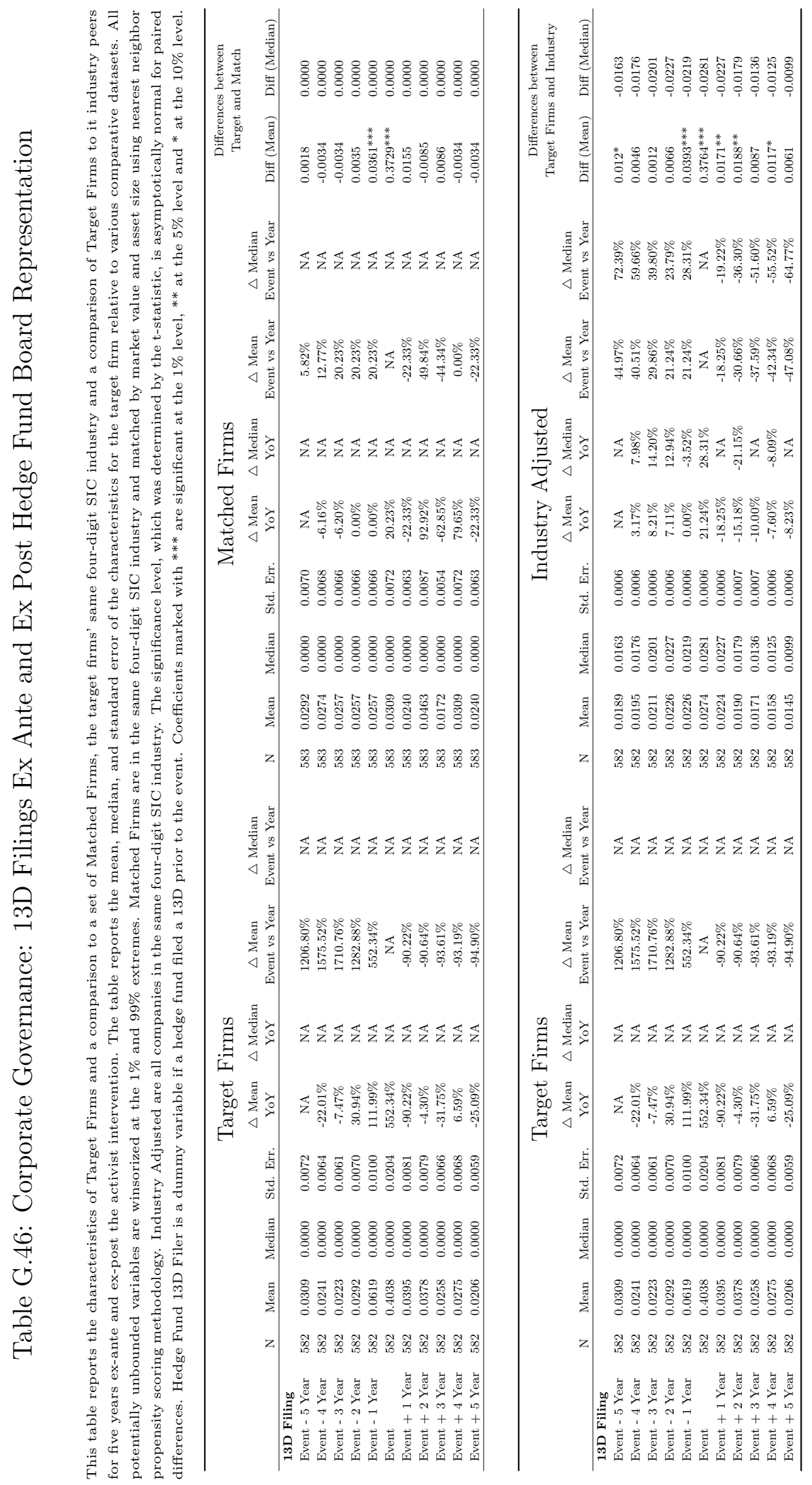



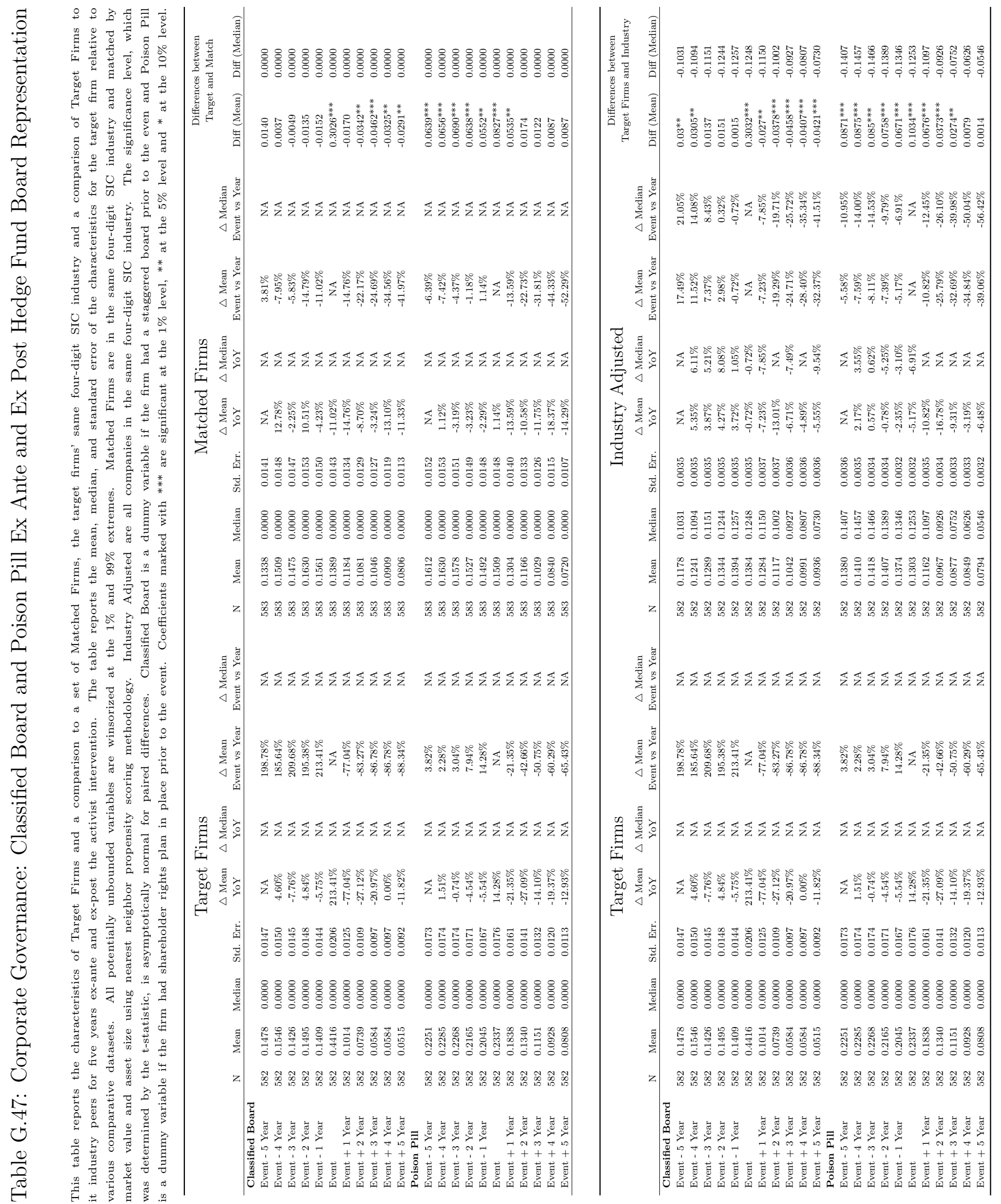

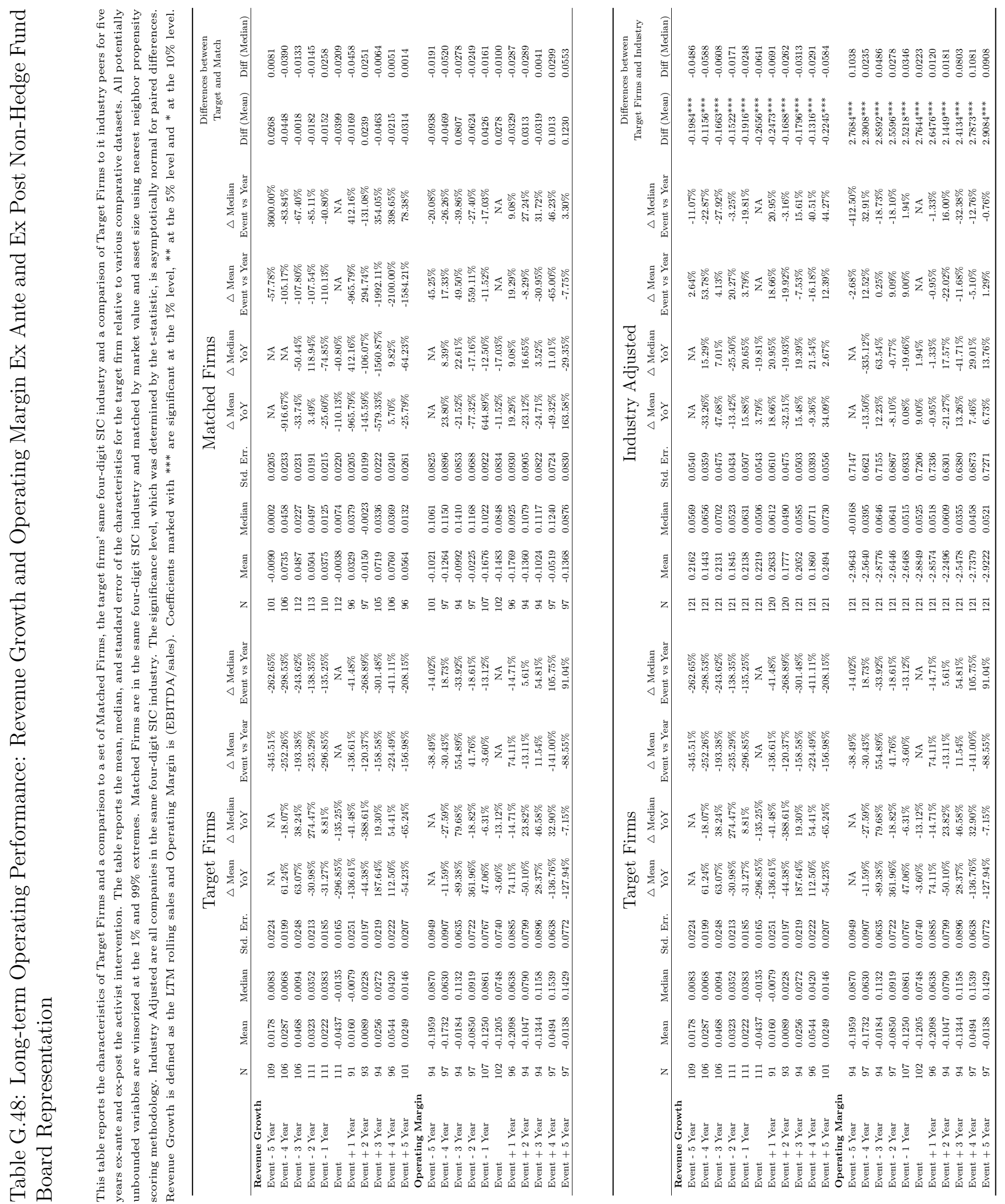


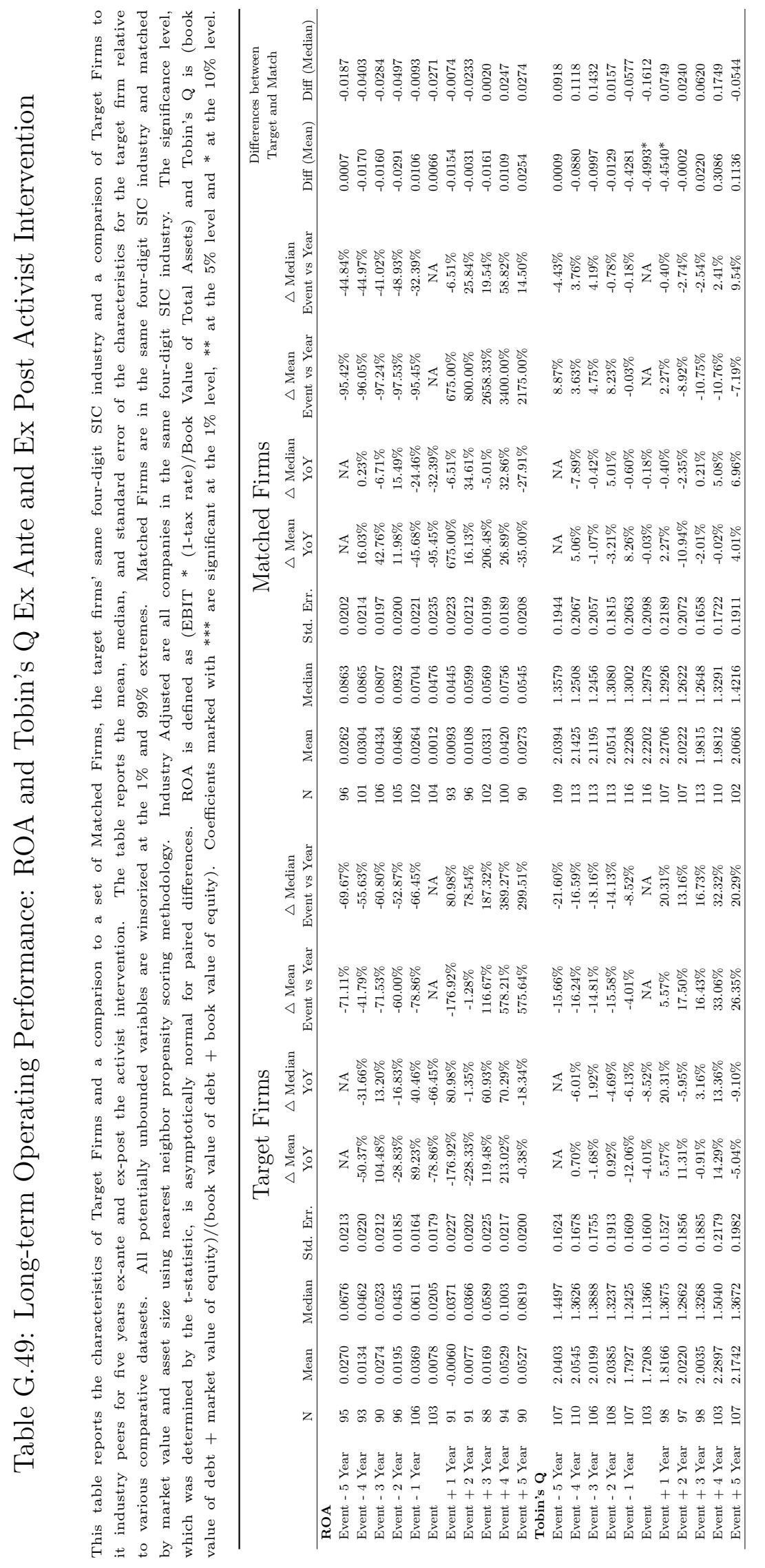

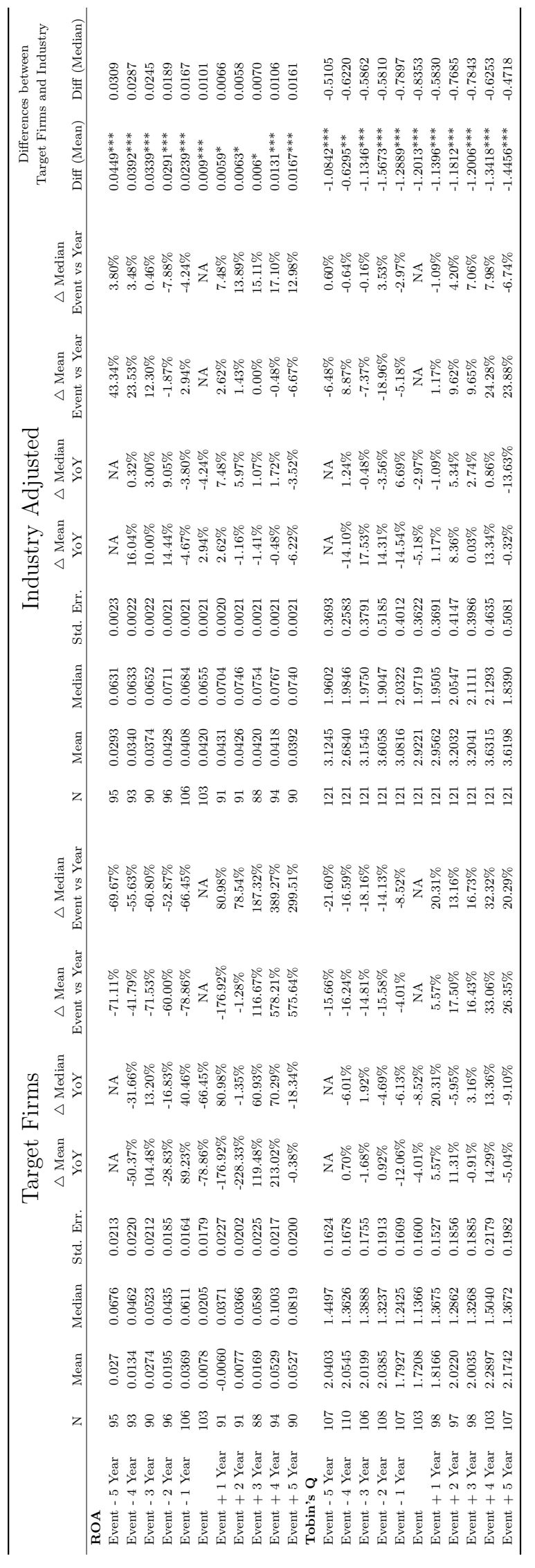




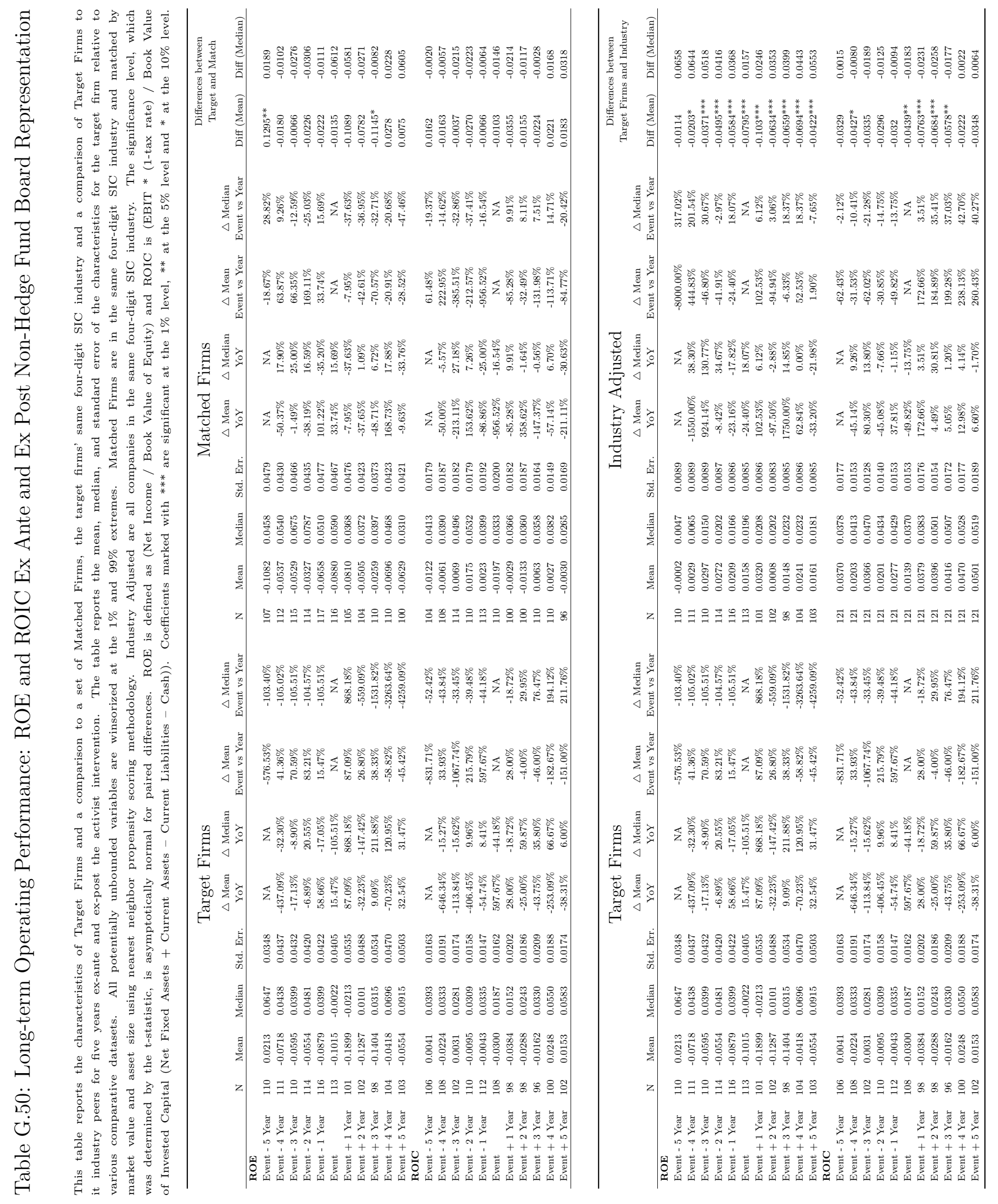




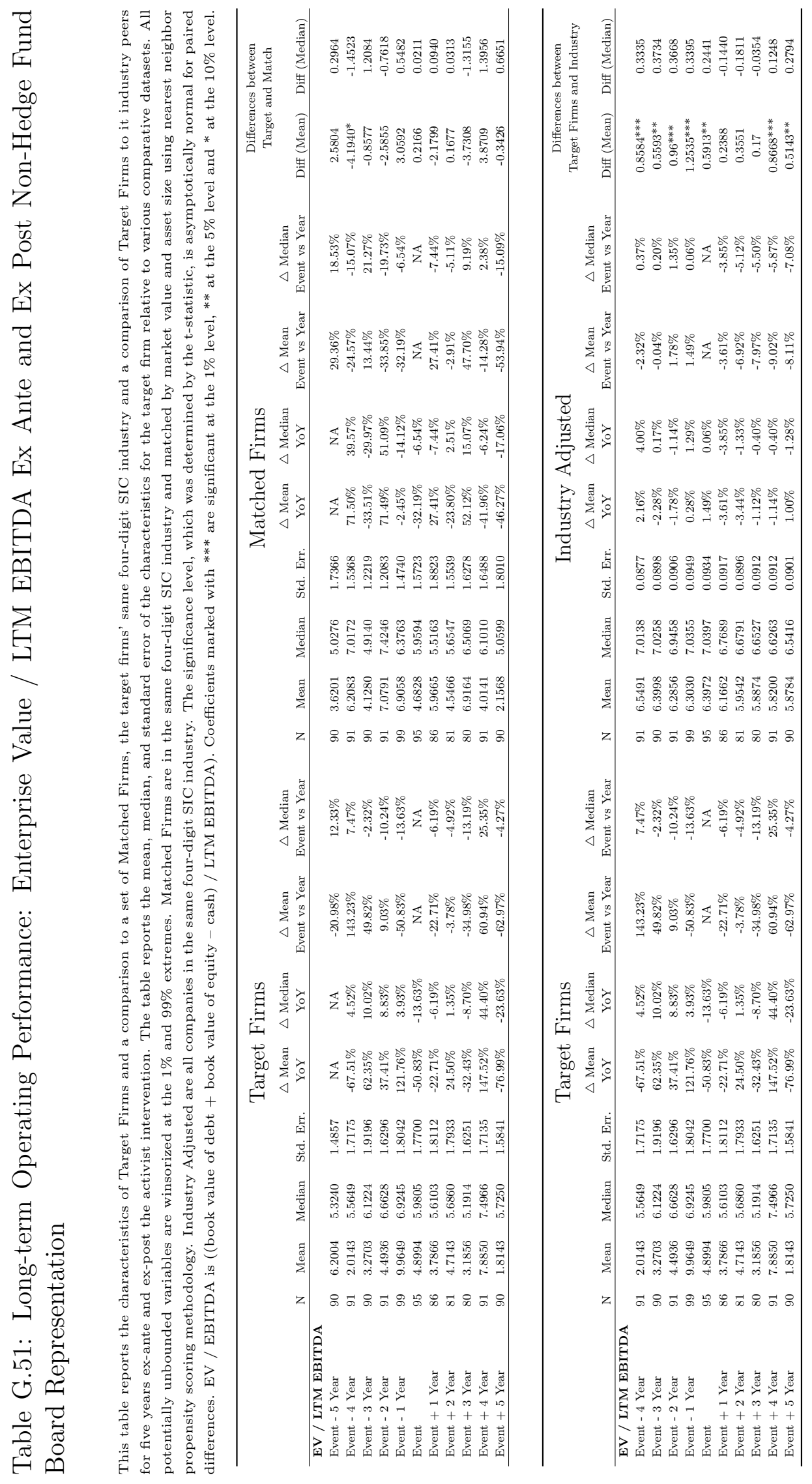



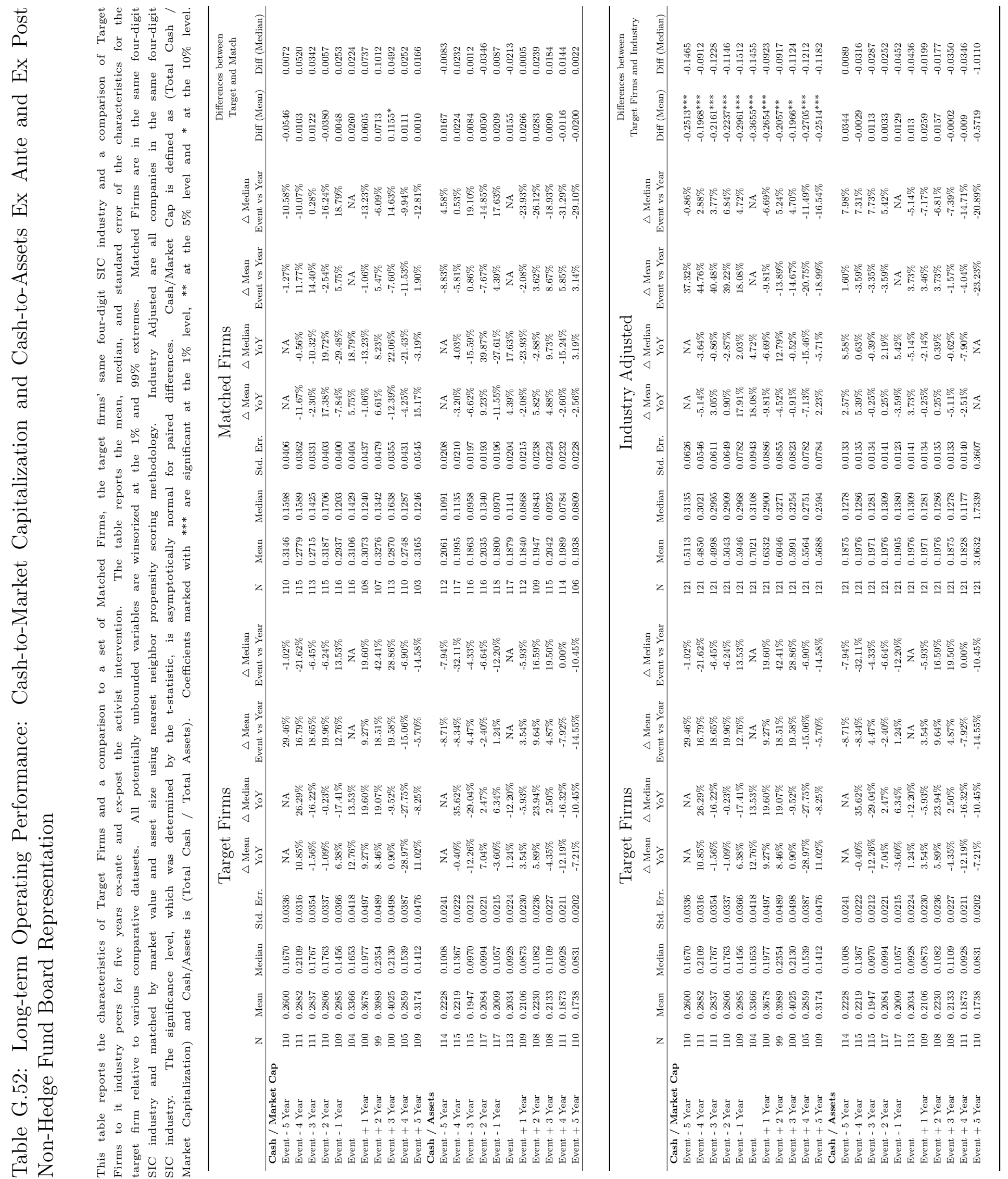


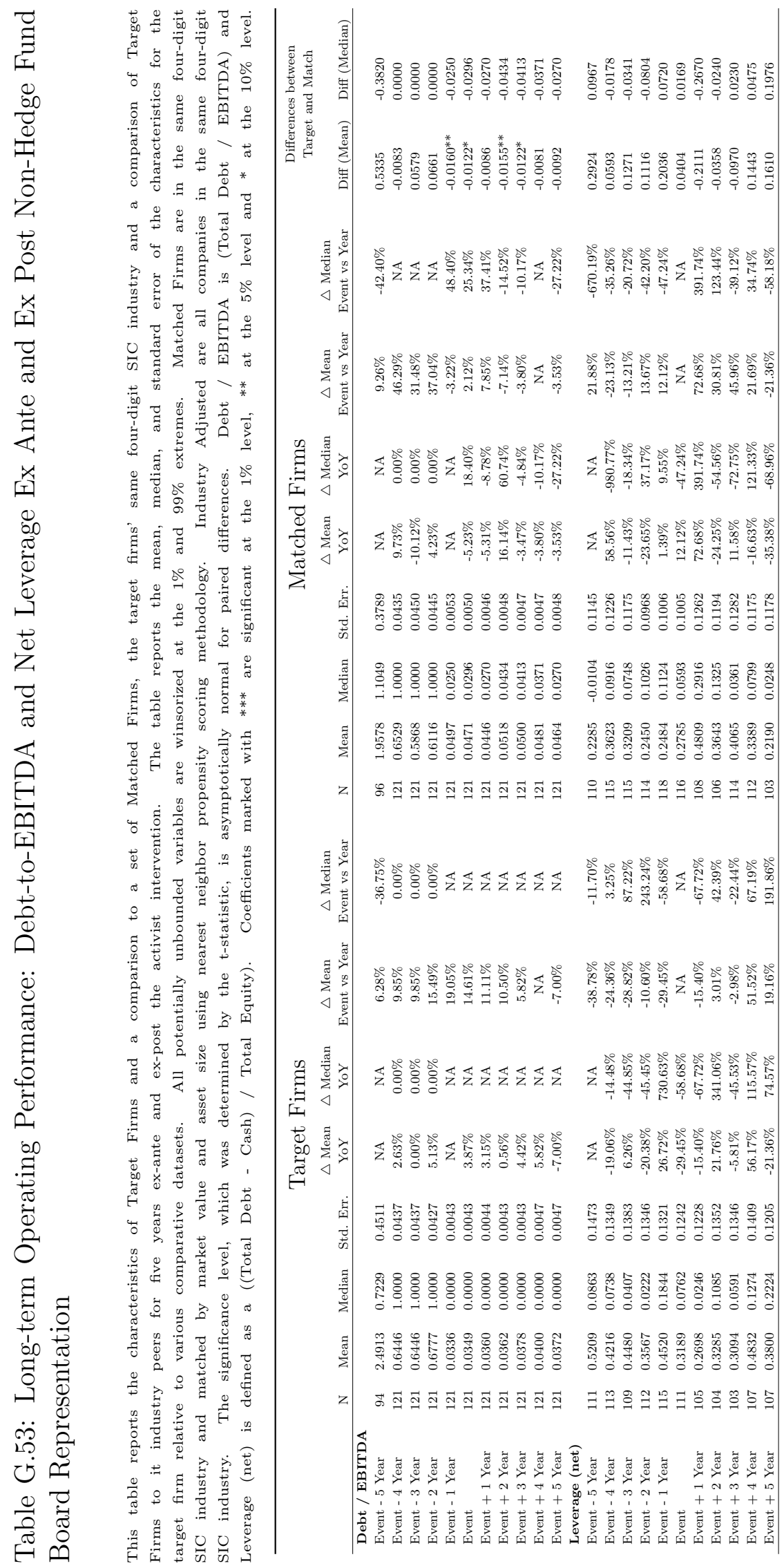

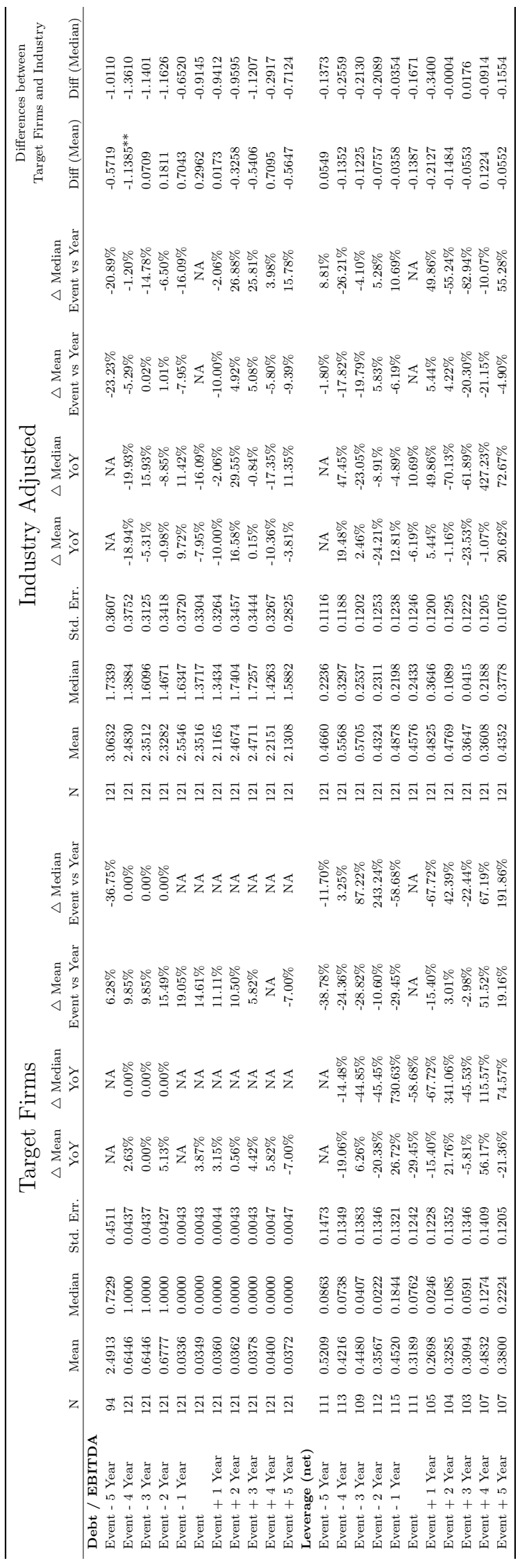




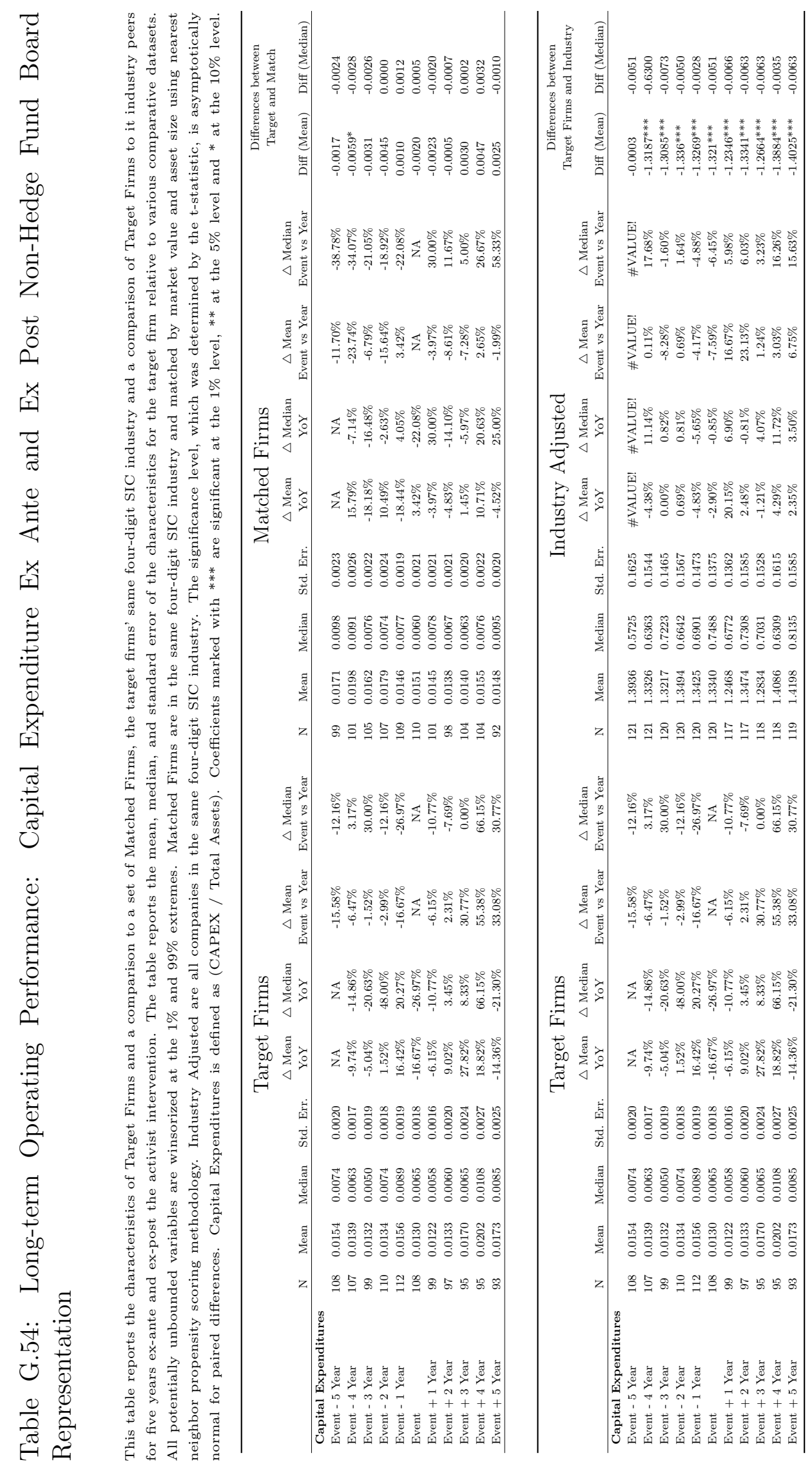




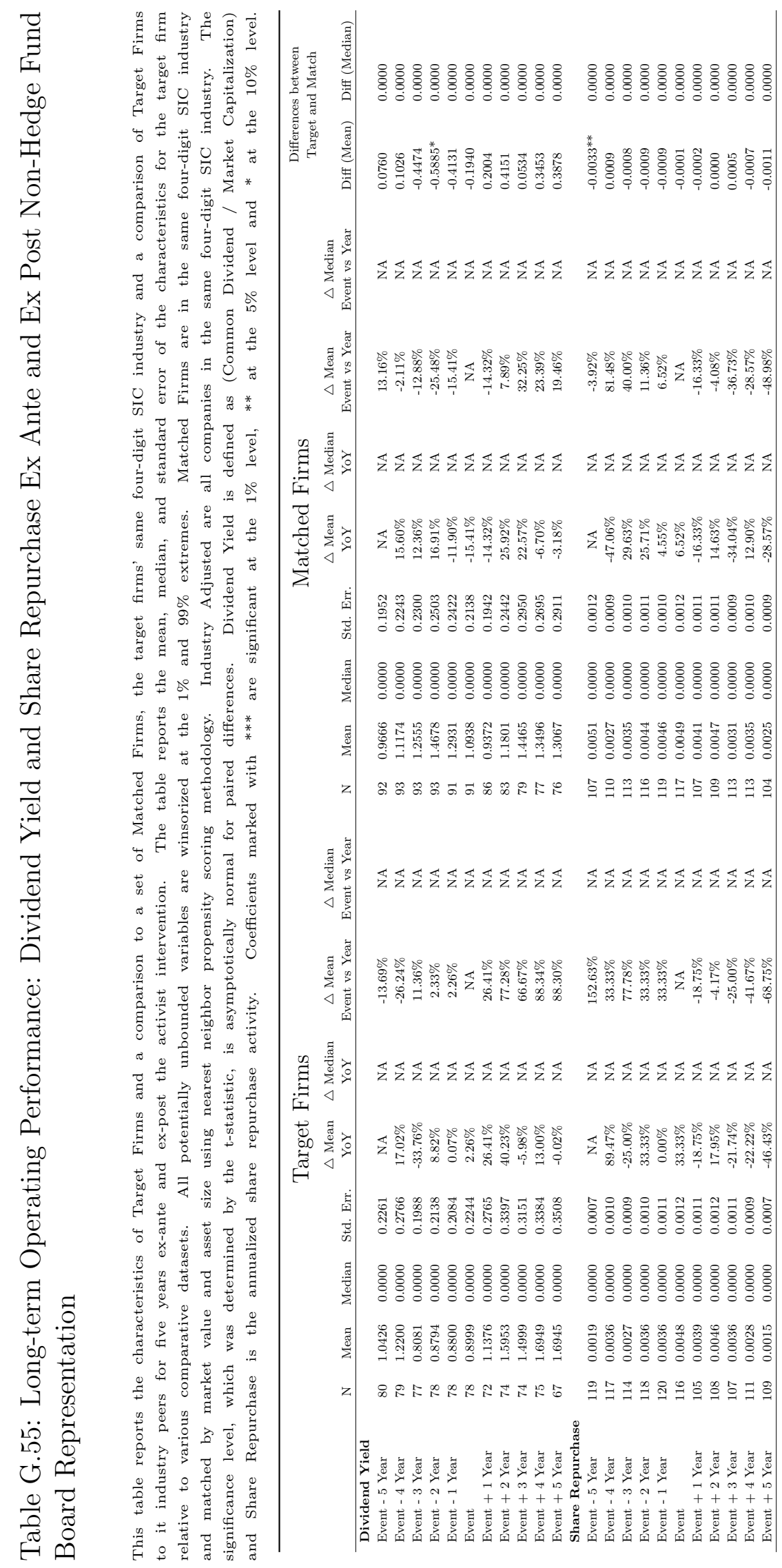

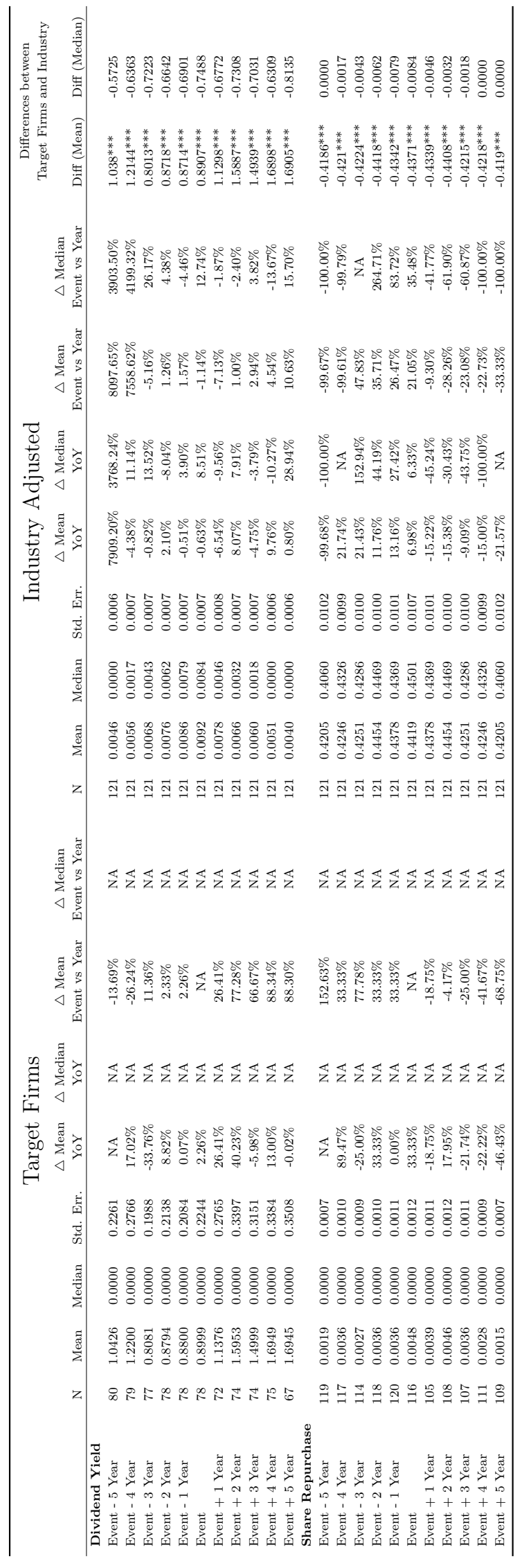




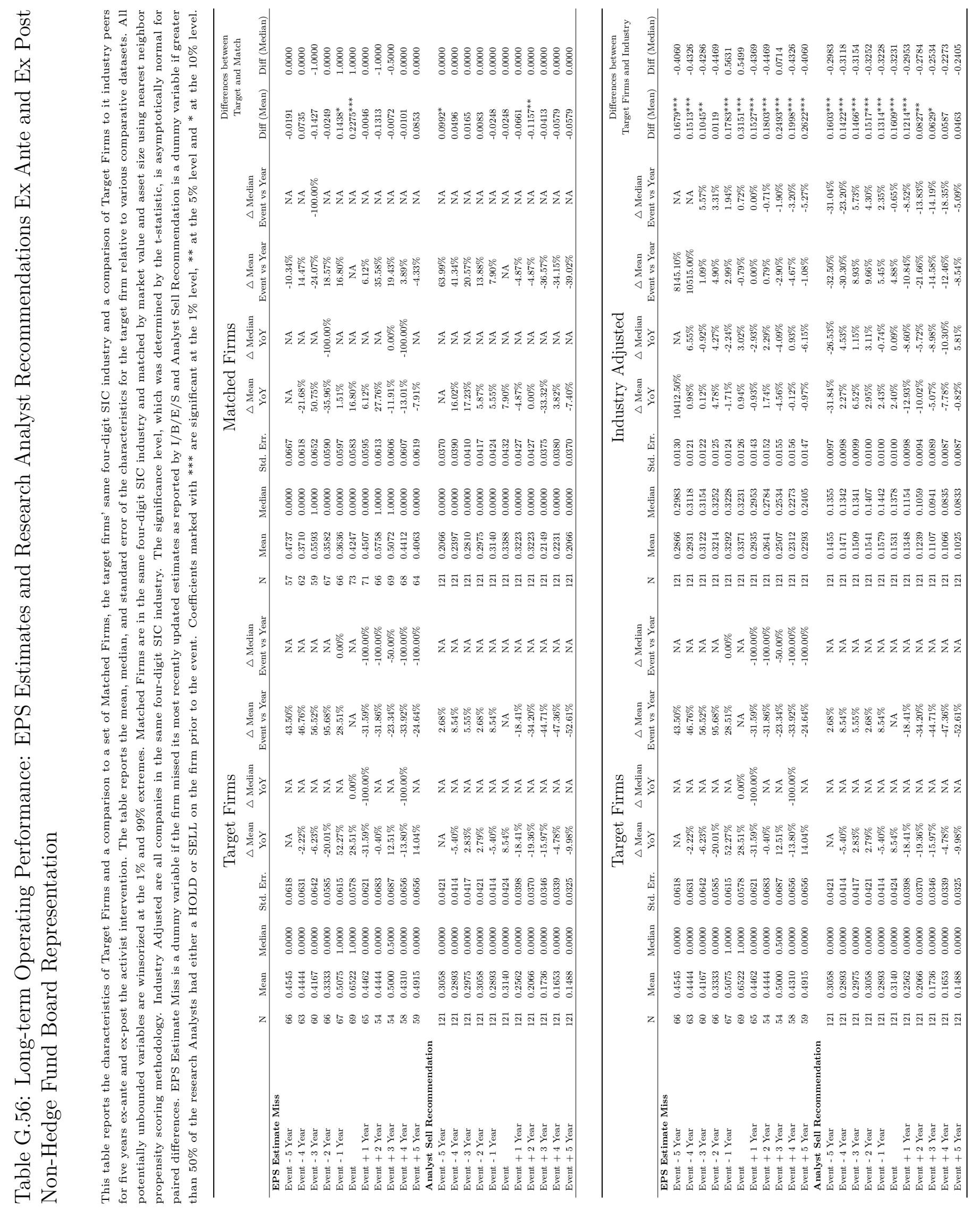




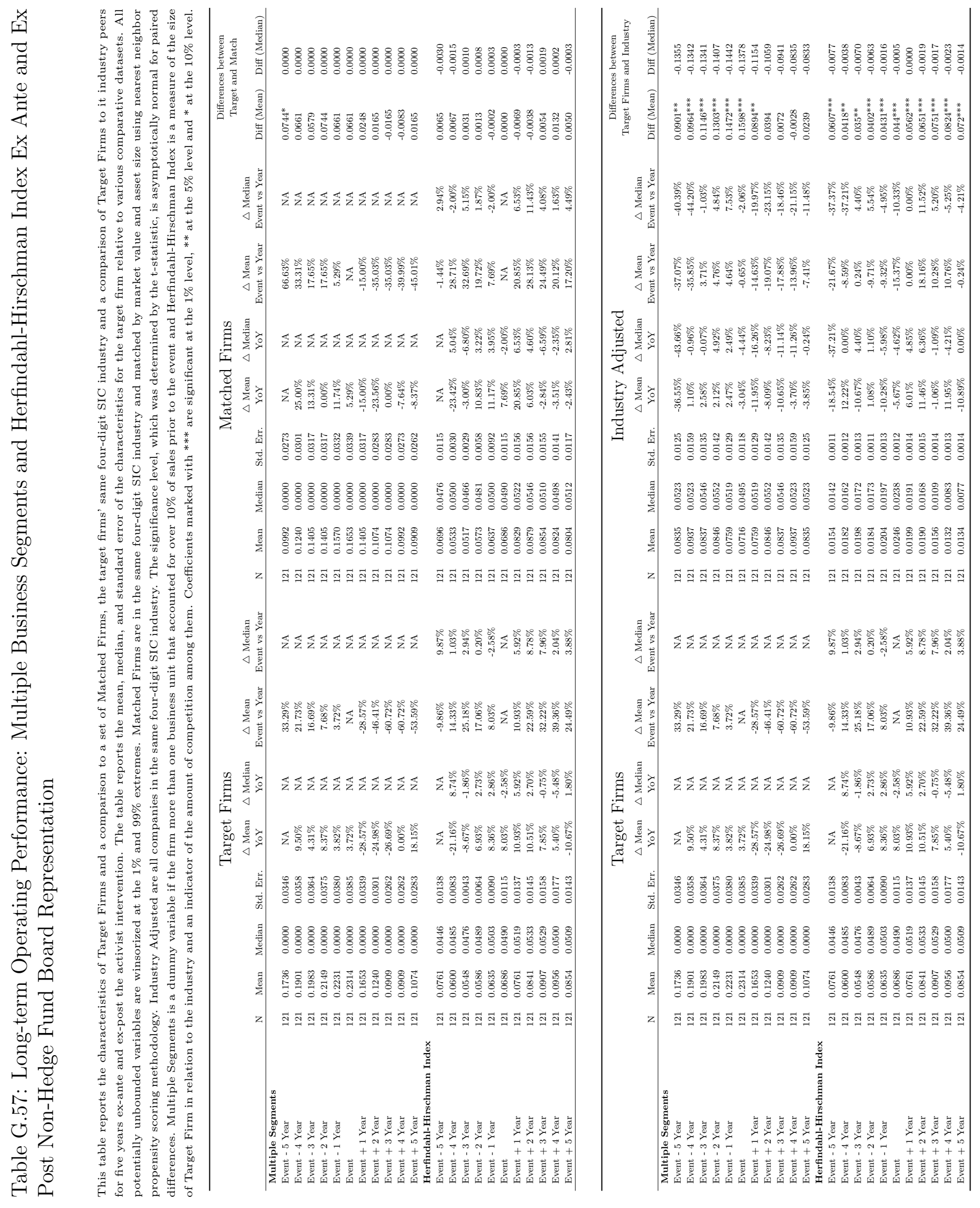



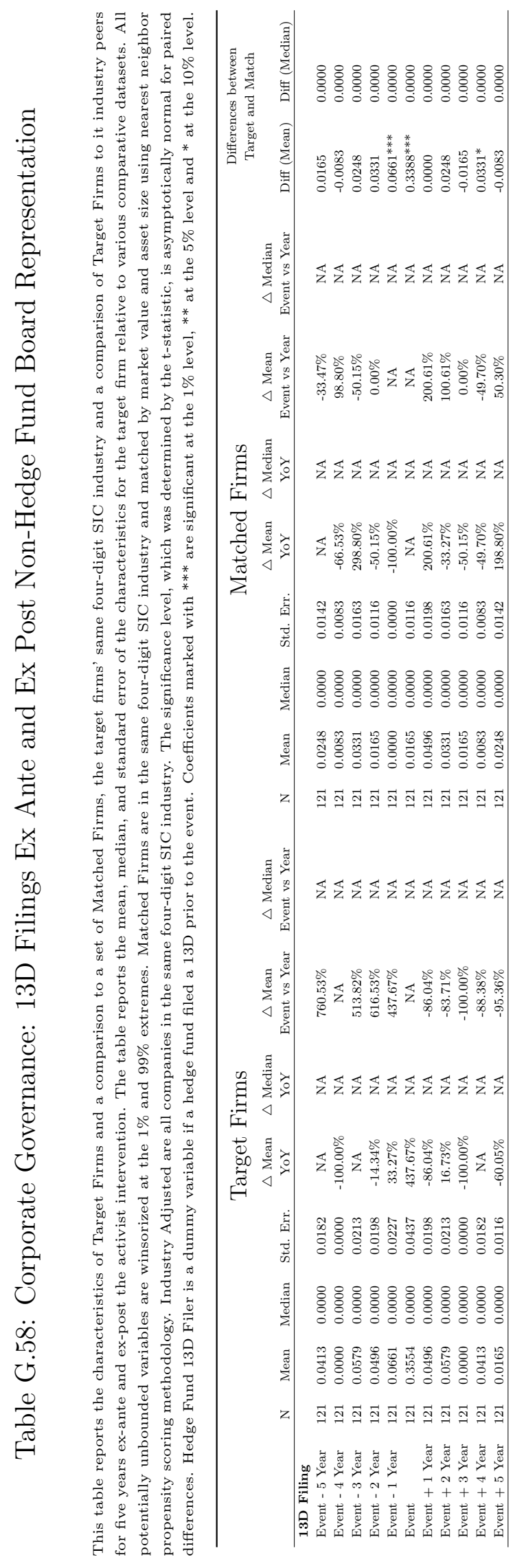

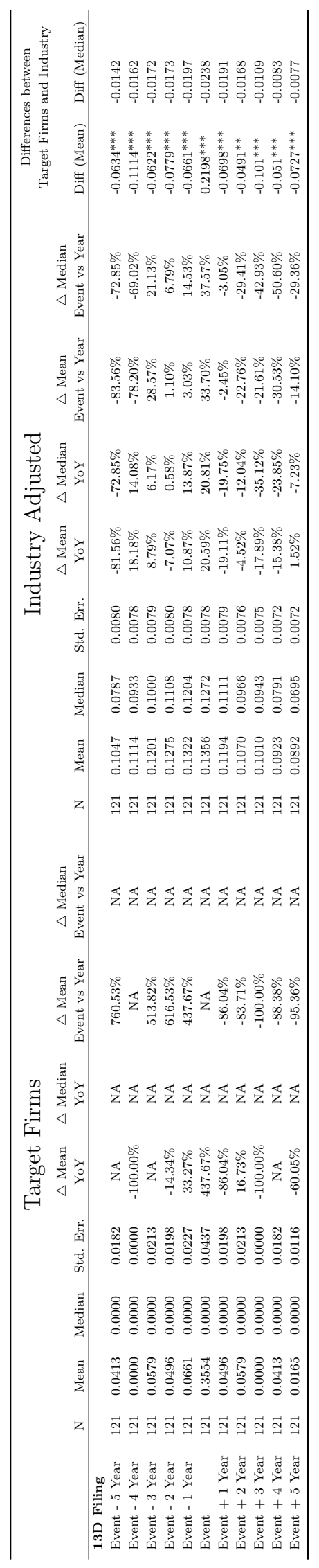




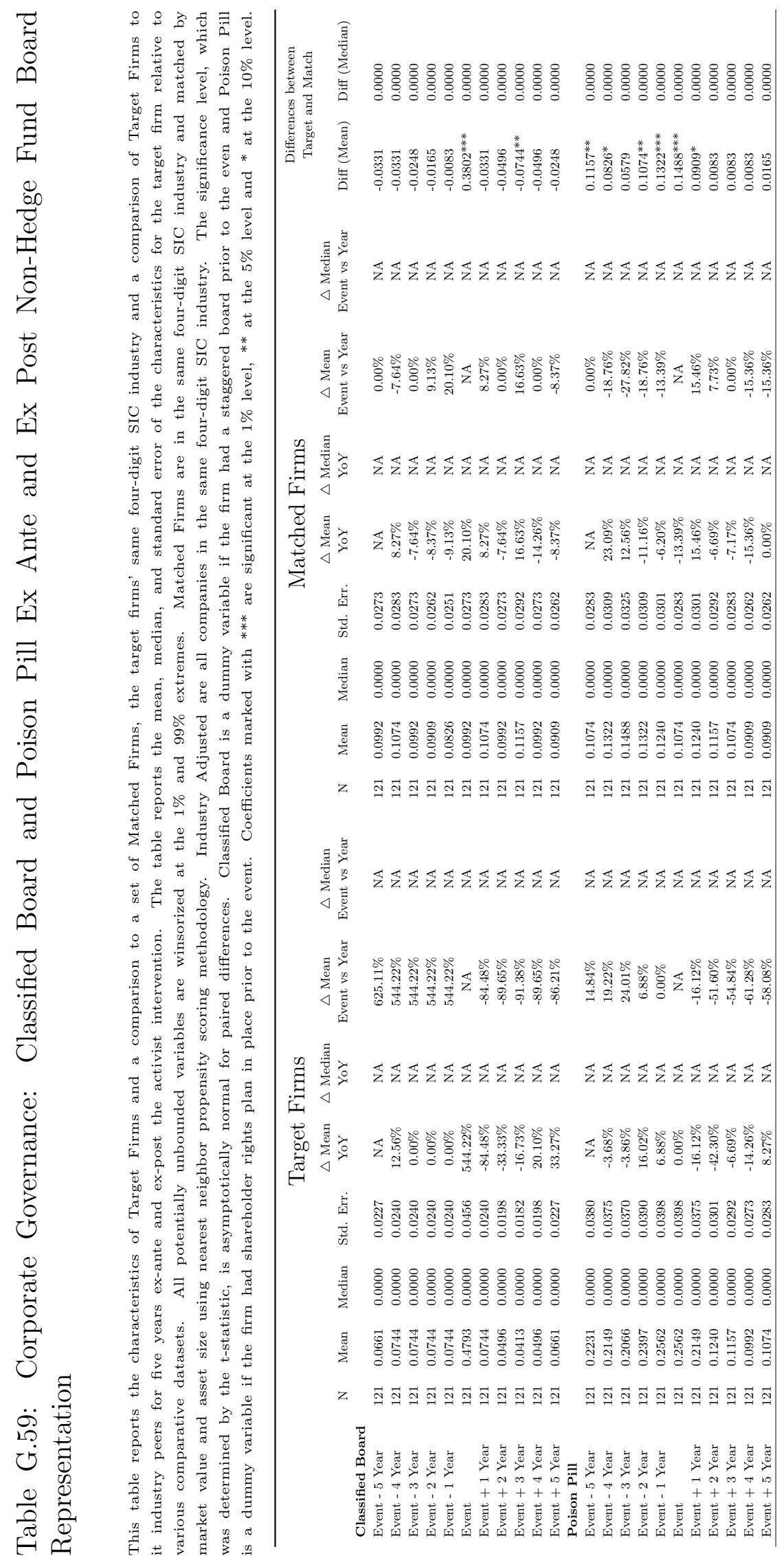

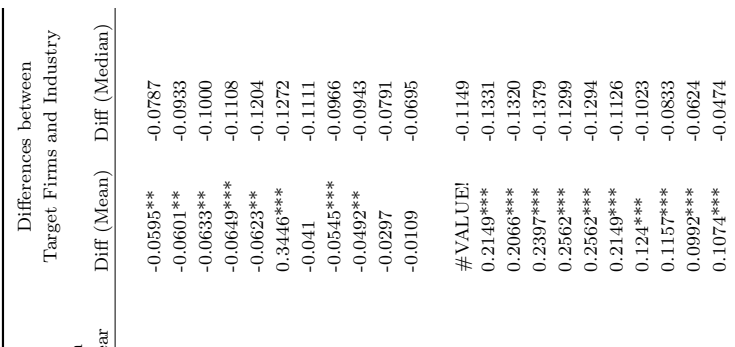

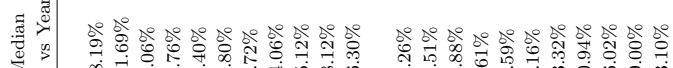

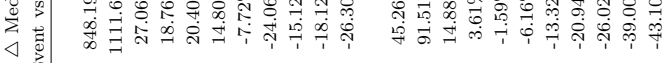

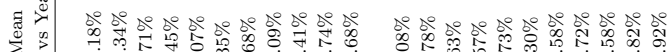

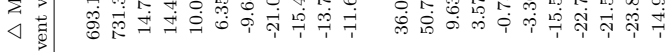

焉焉

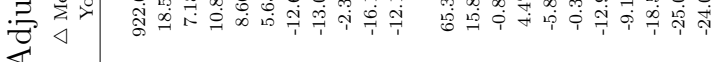

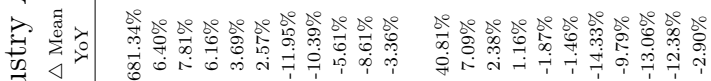
者

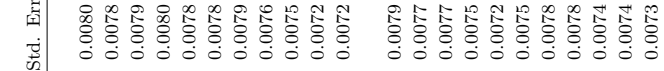

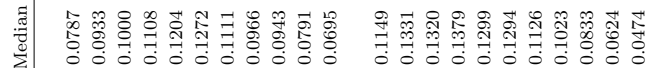

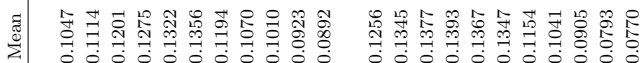

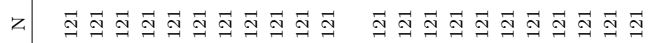

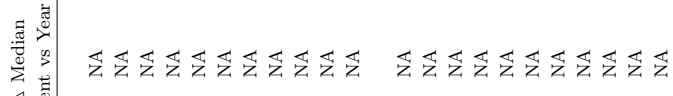
要

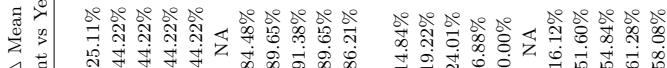

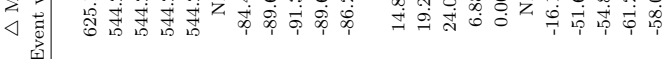

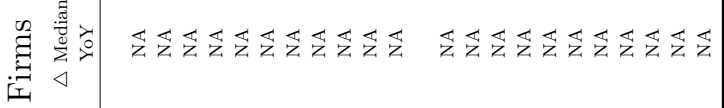

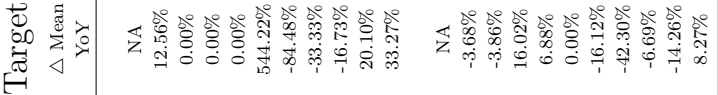

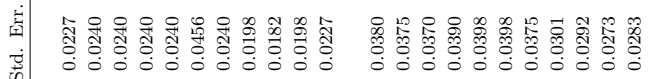

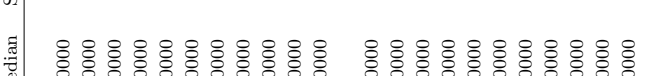
崖

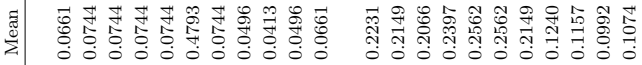

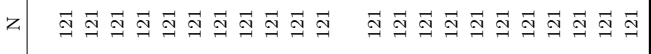

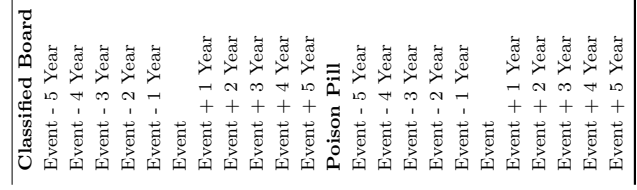



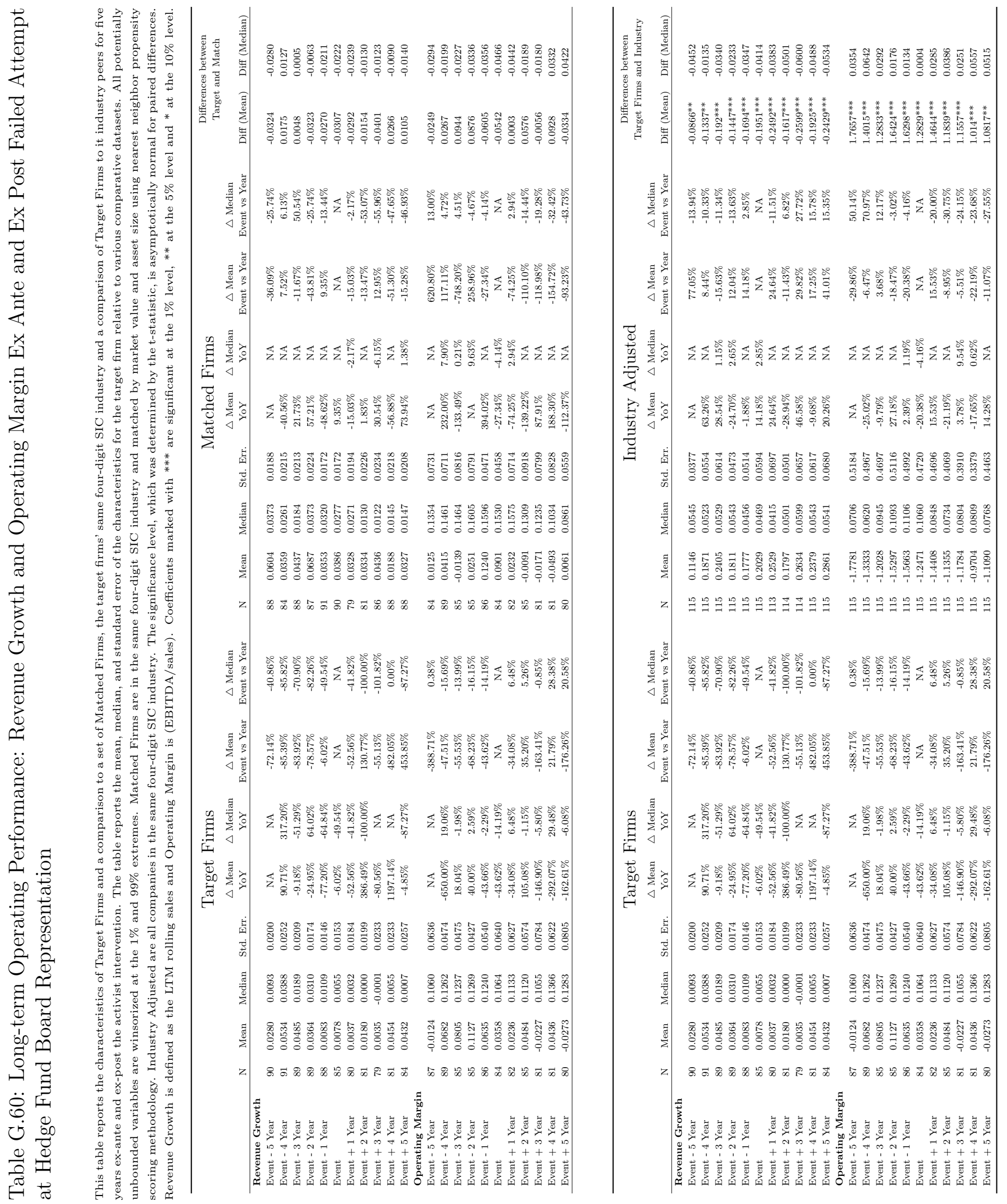


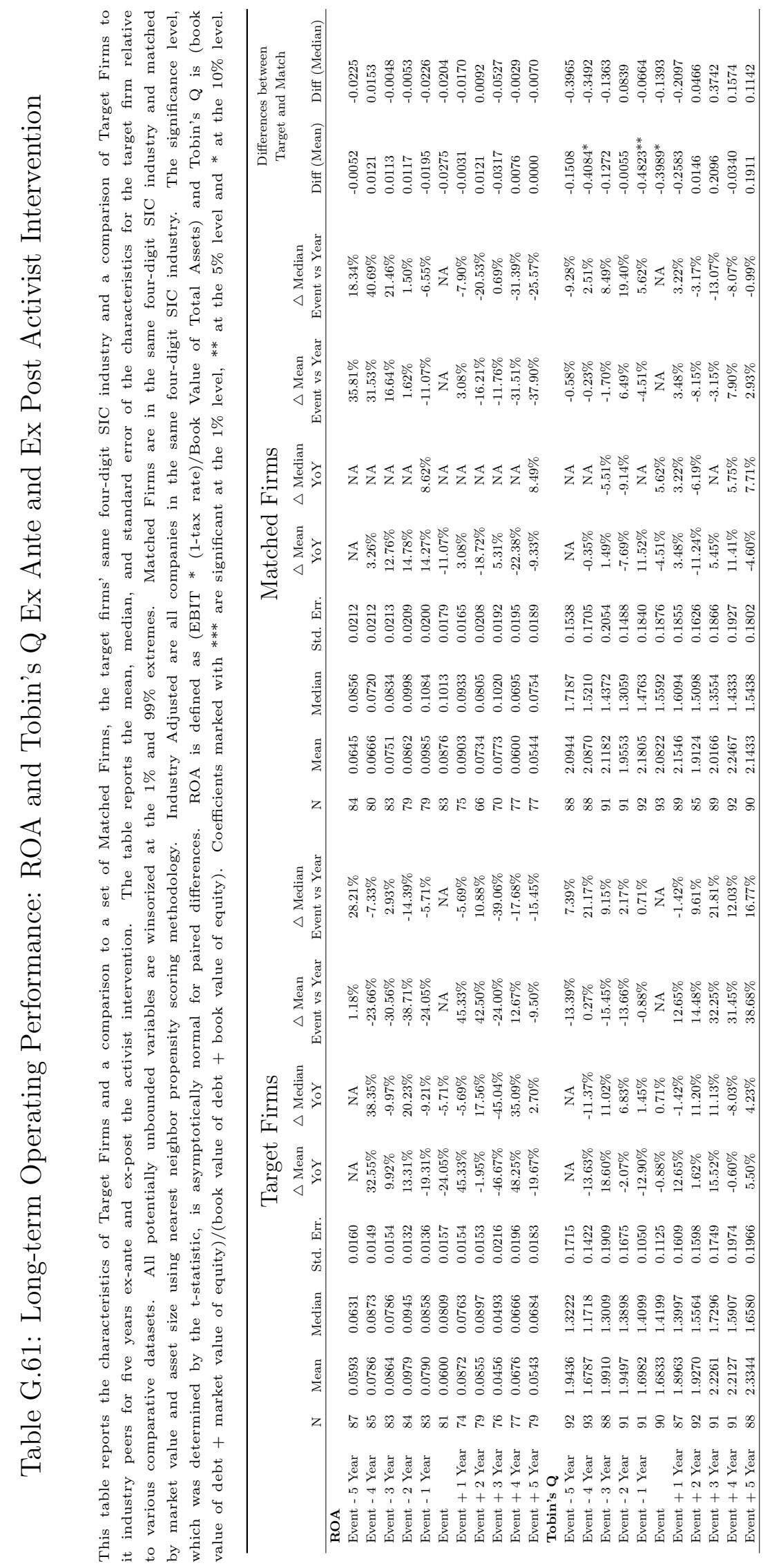

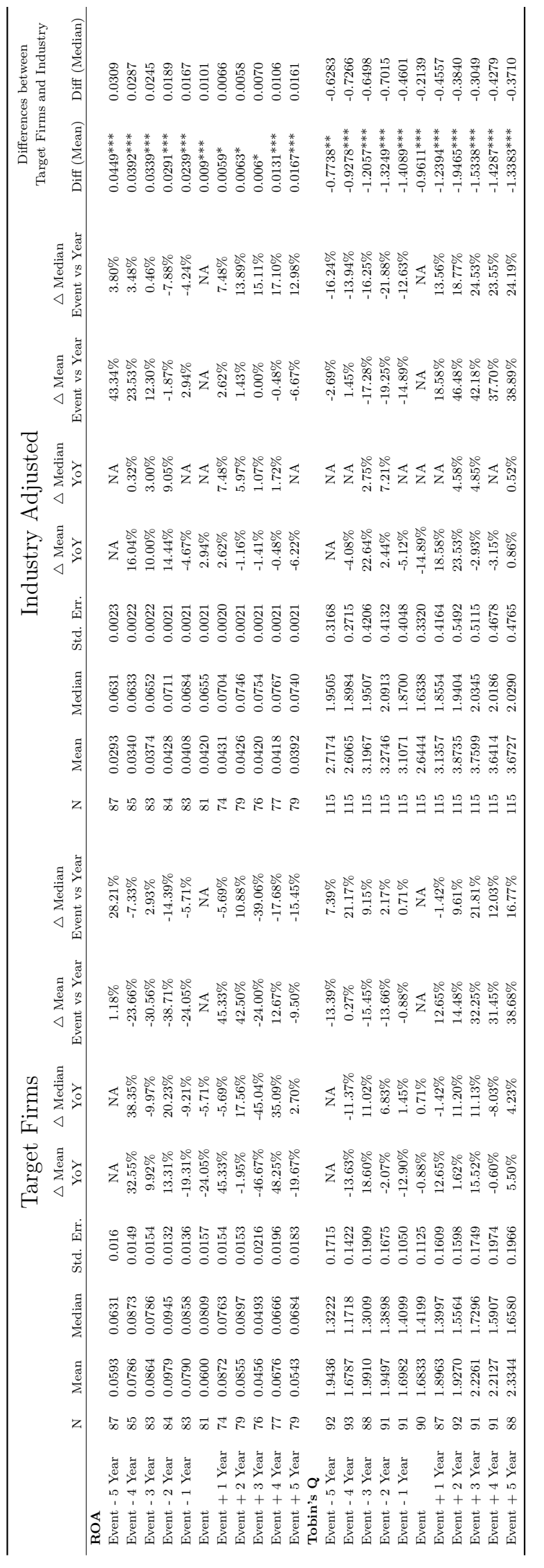



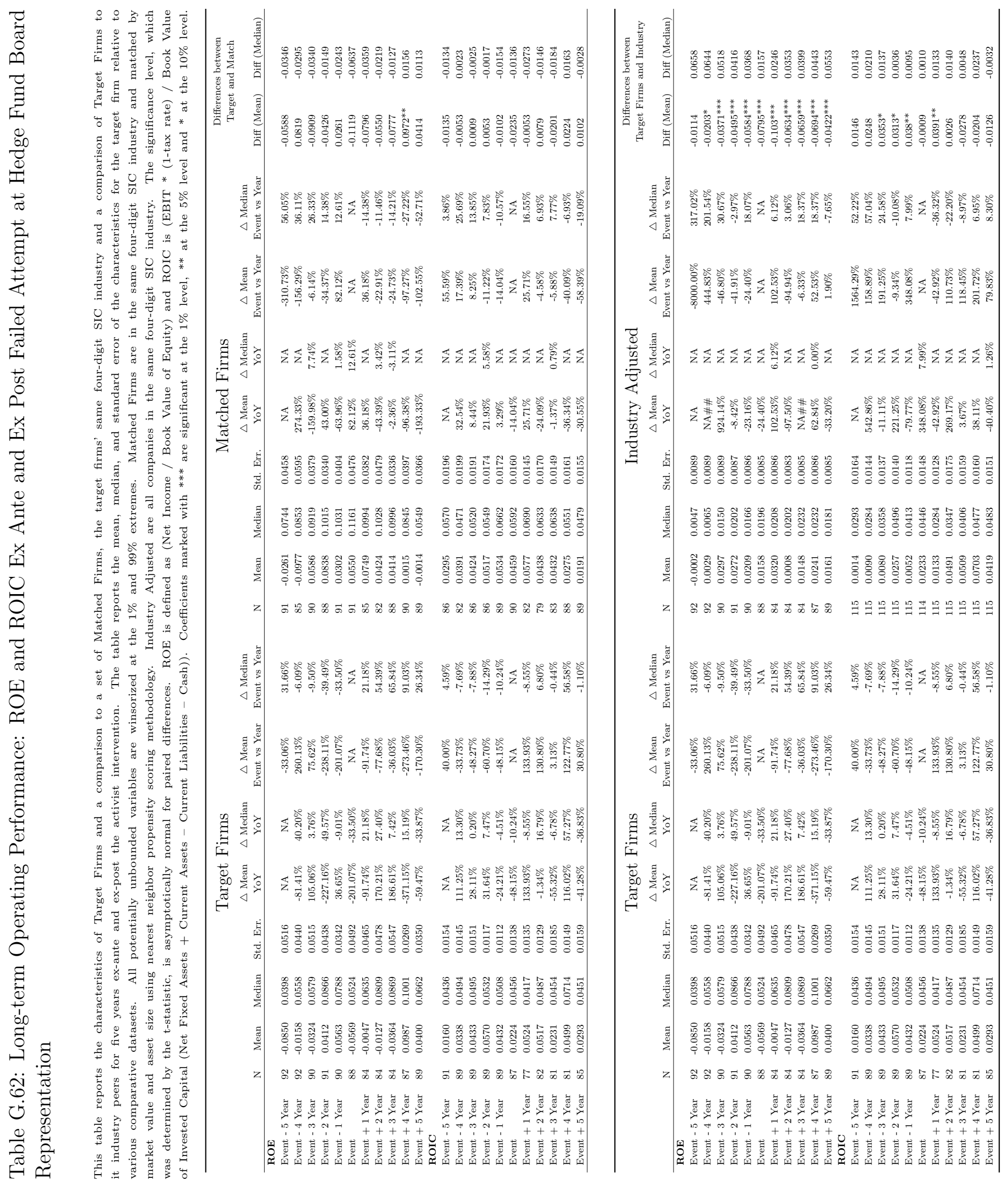


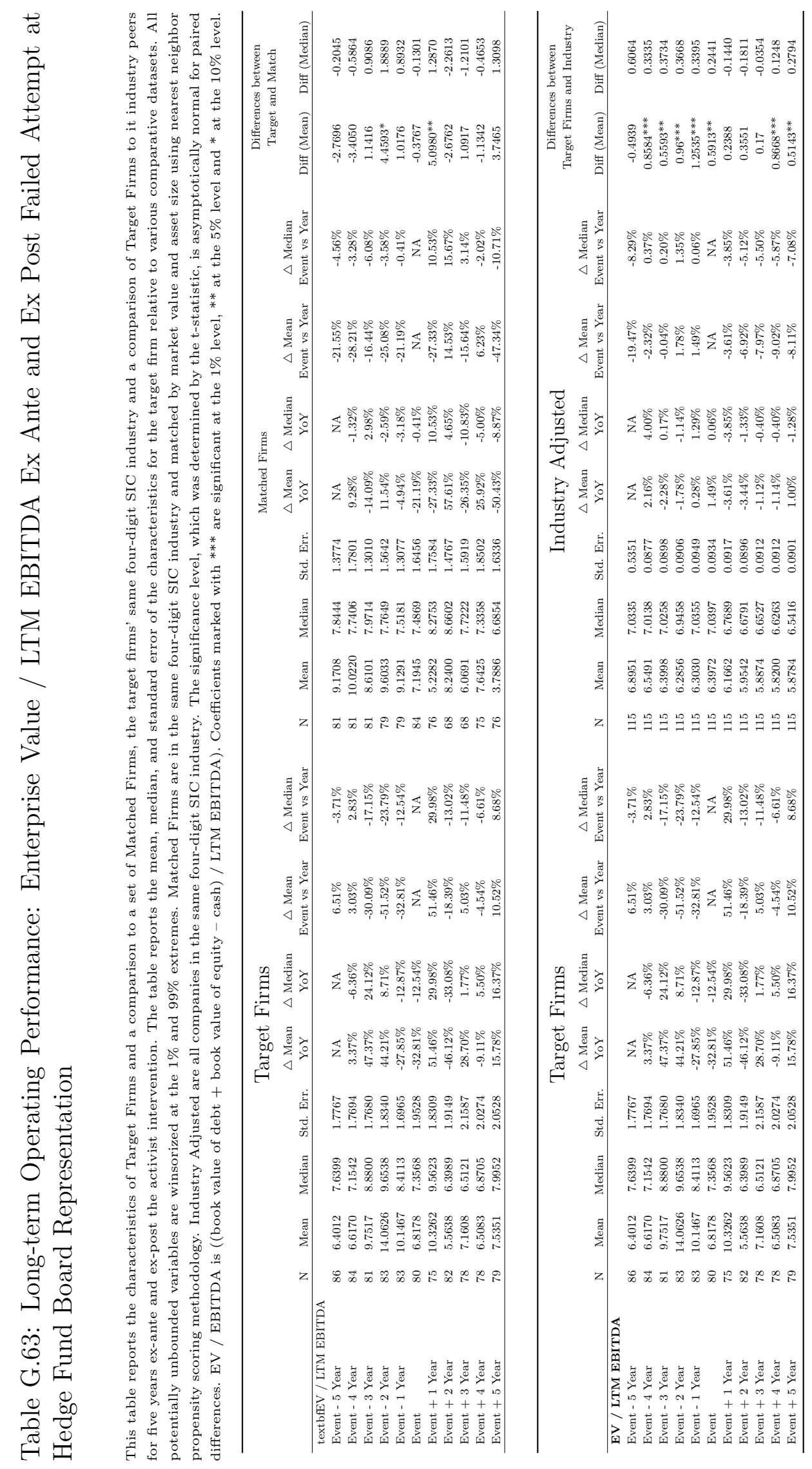




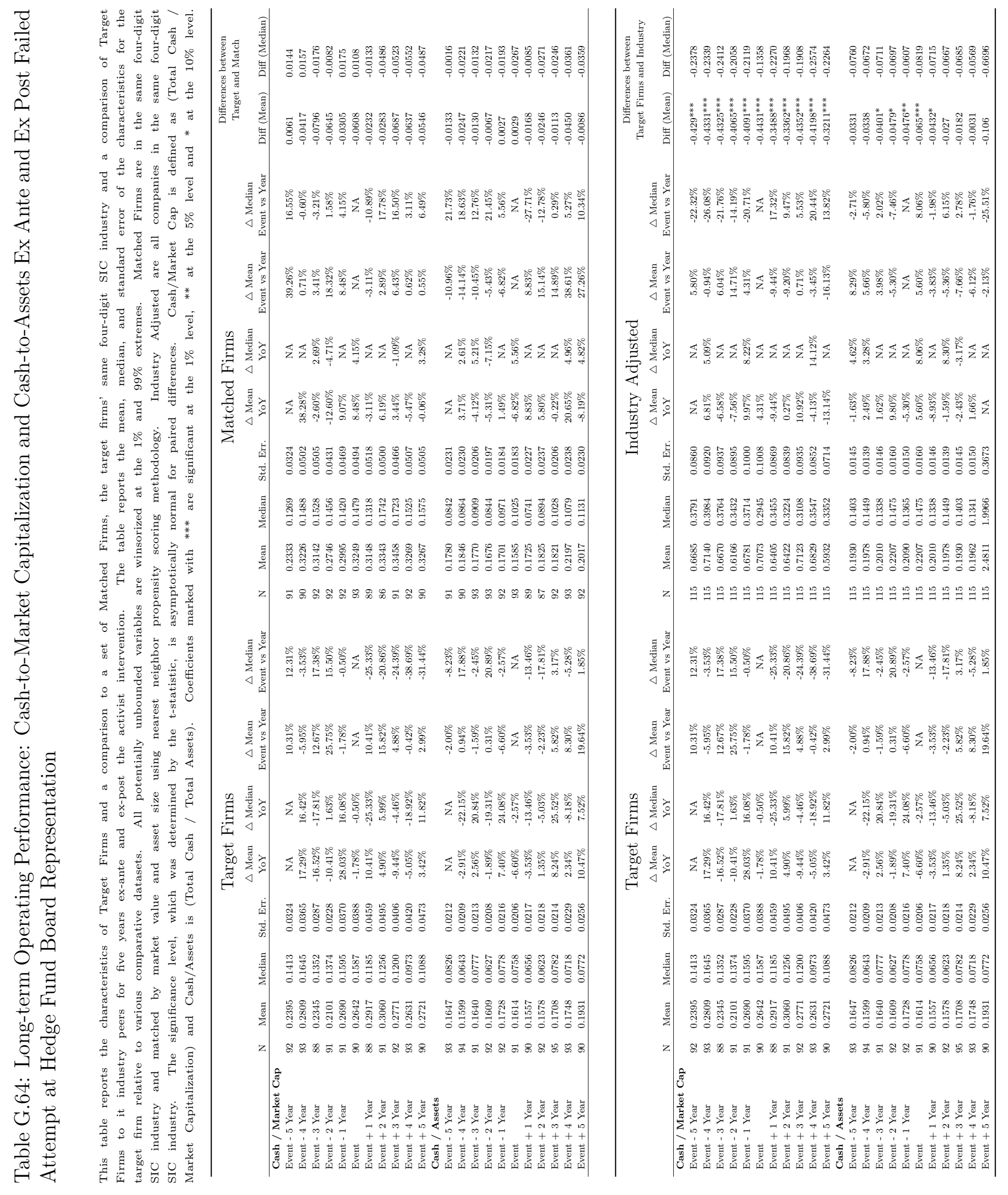



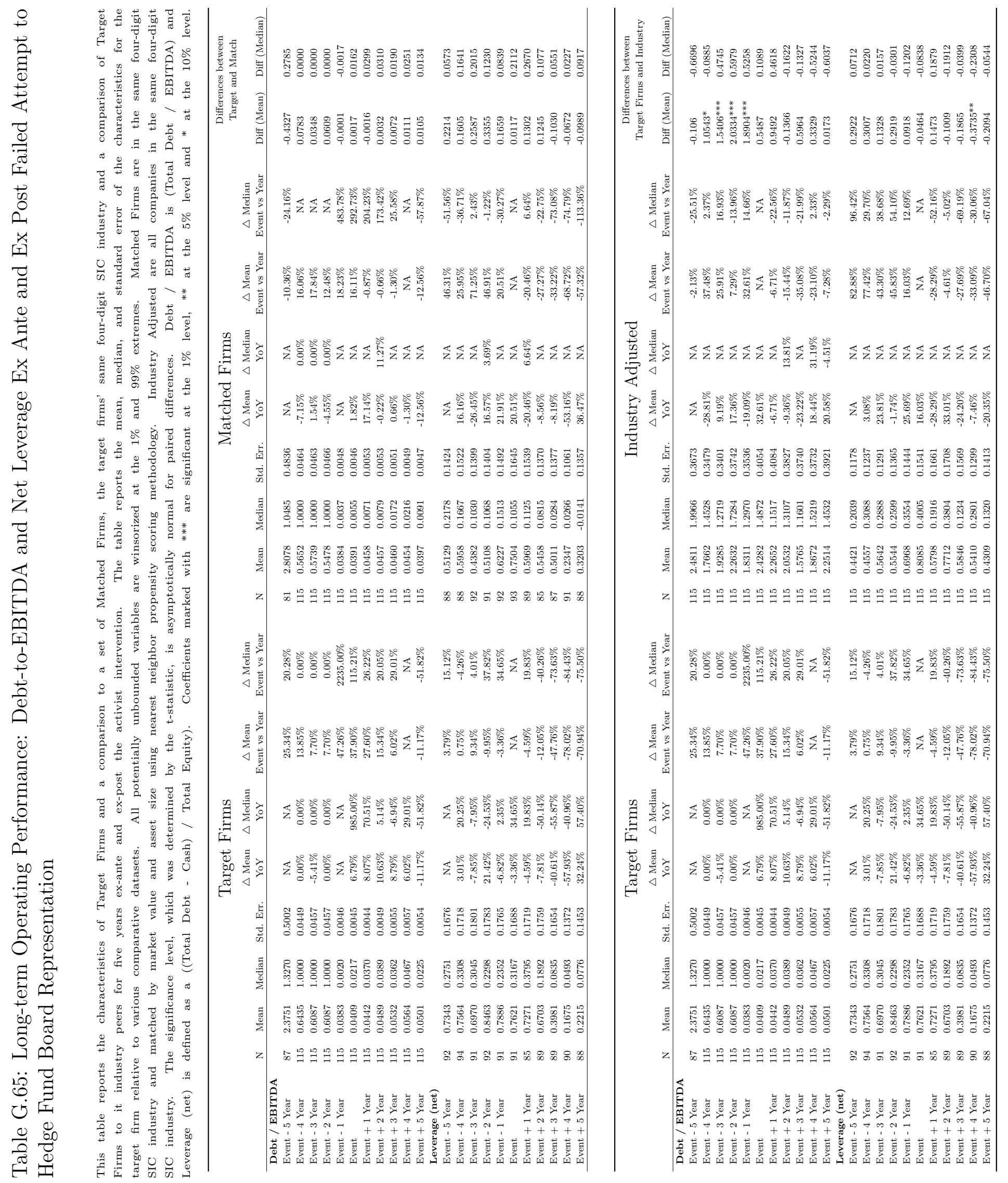


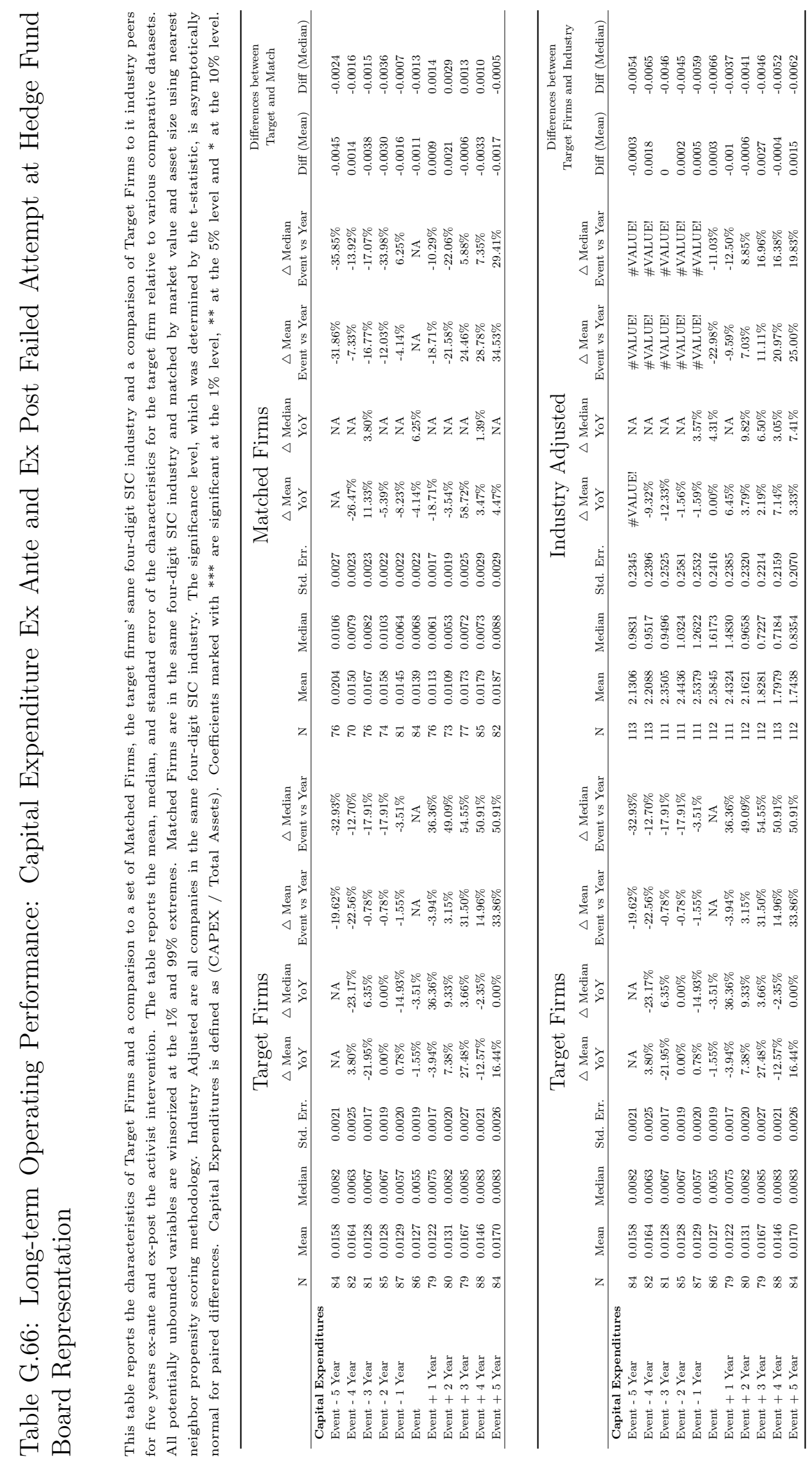




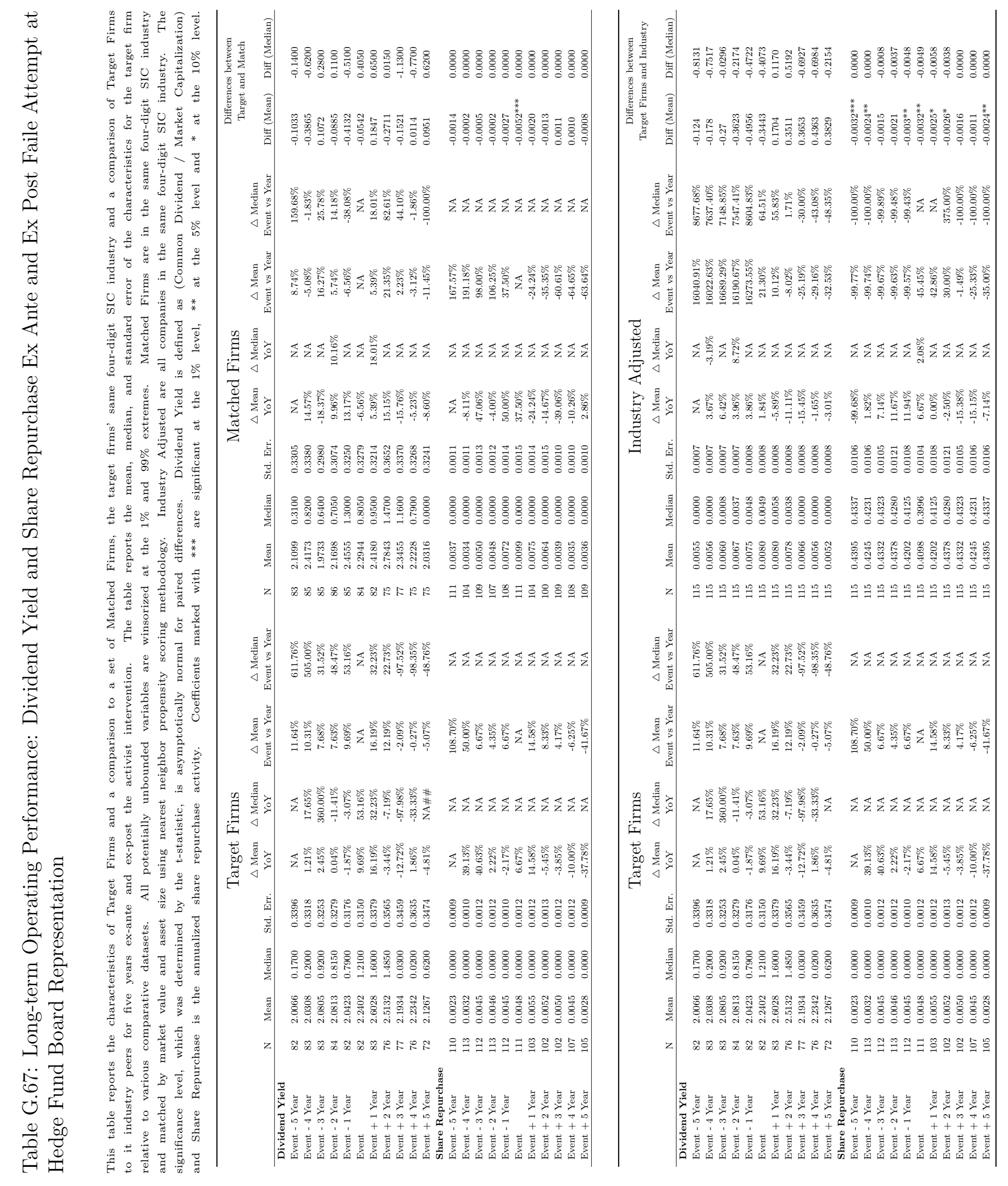




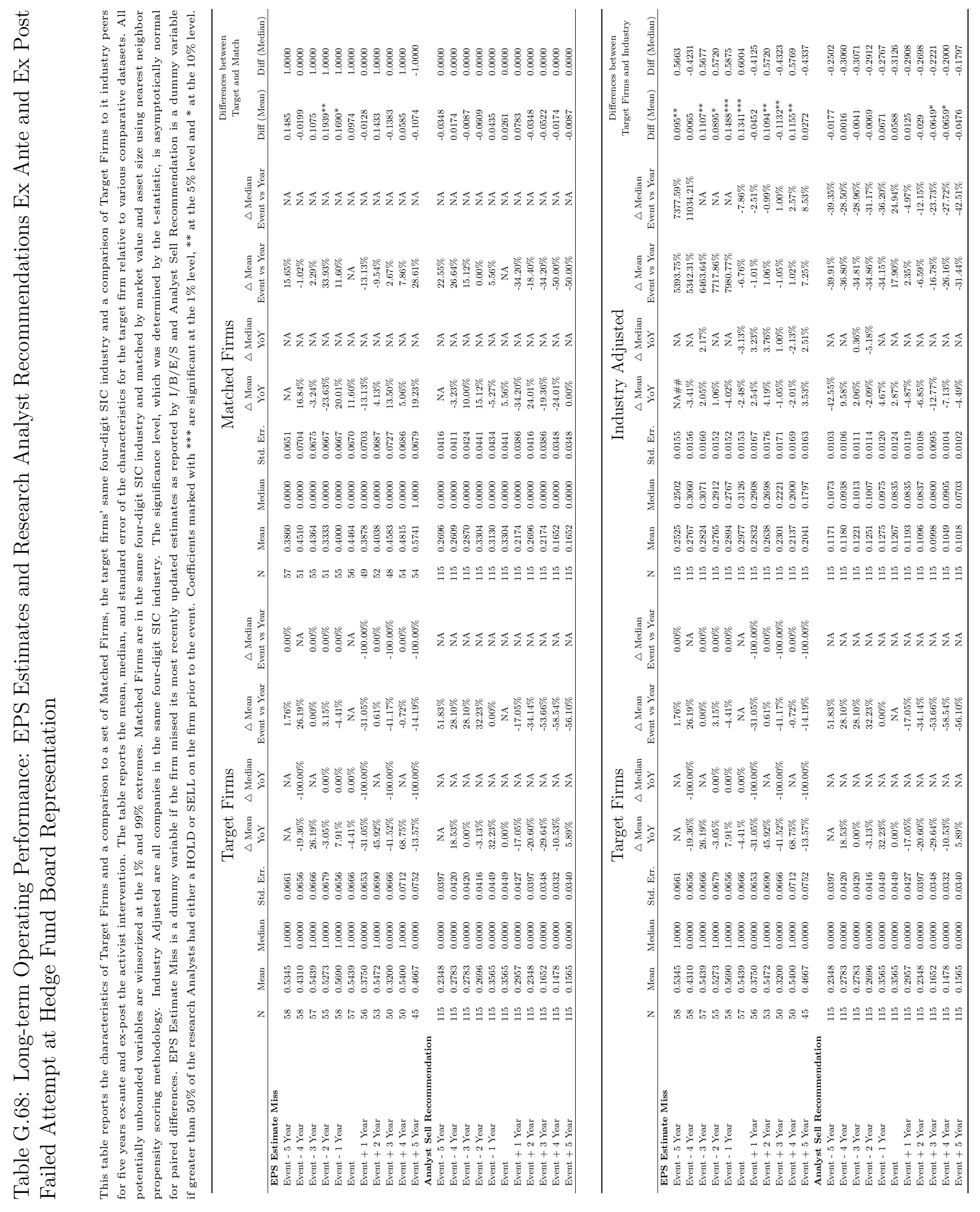



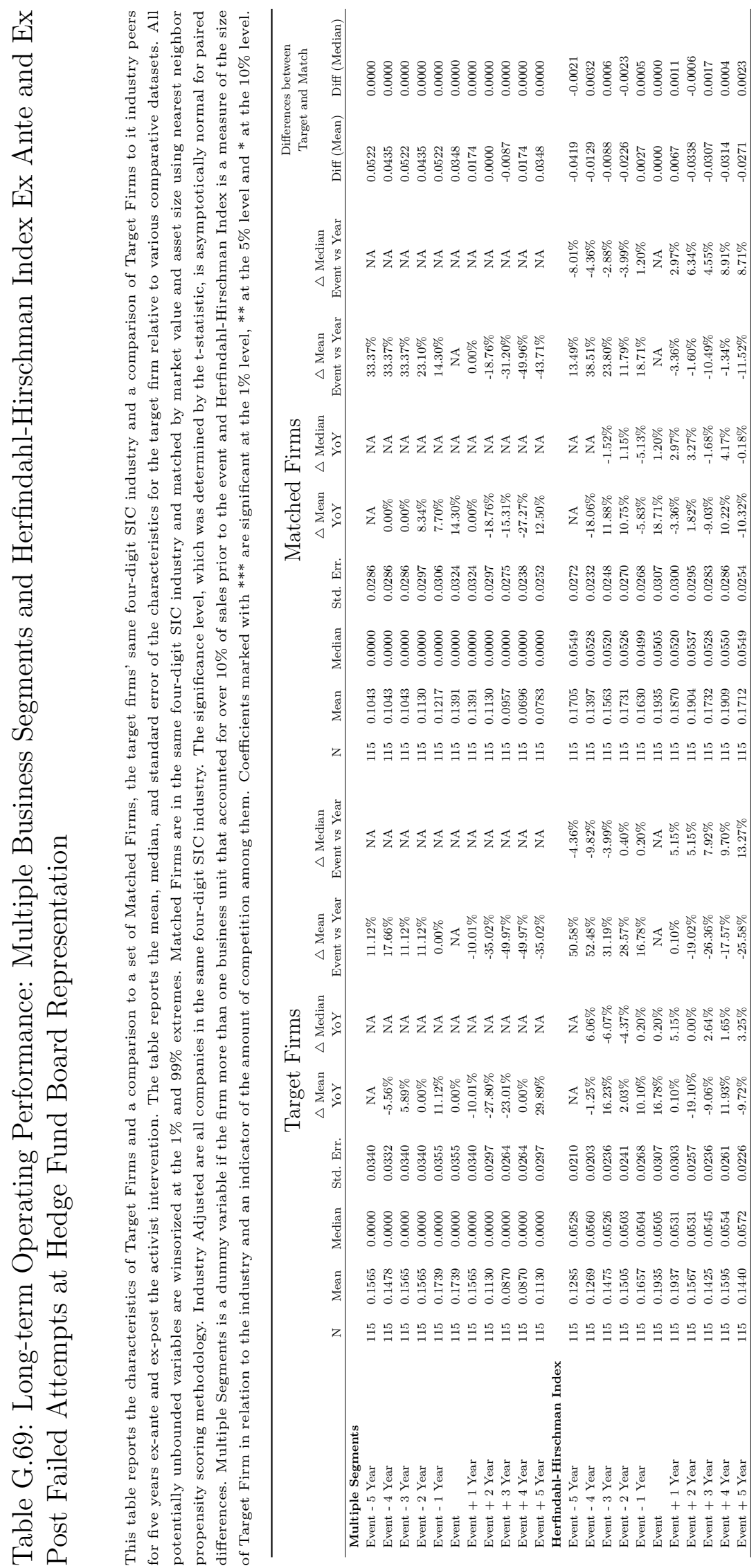

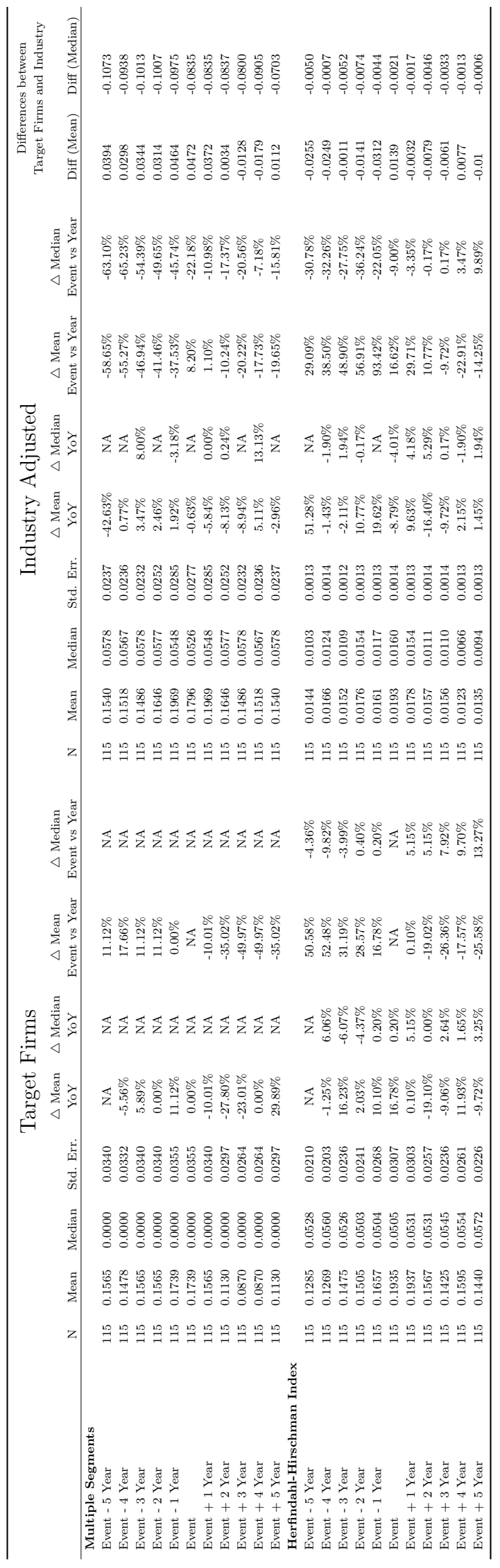



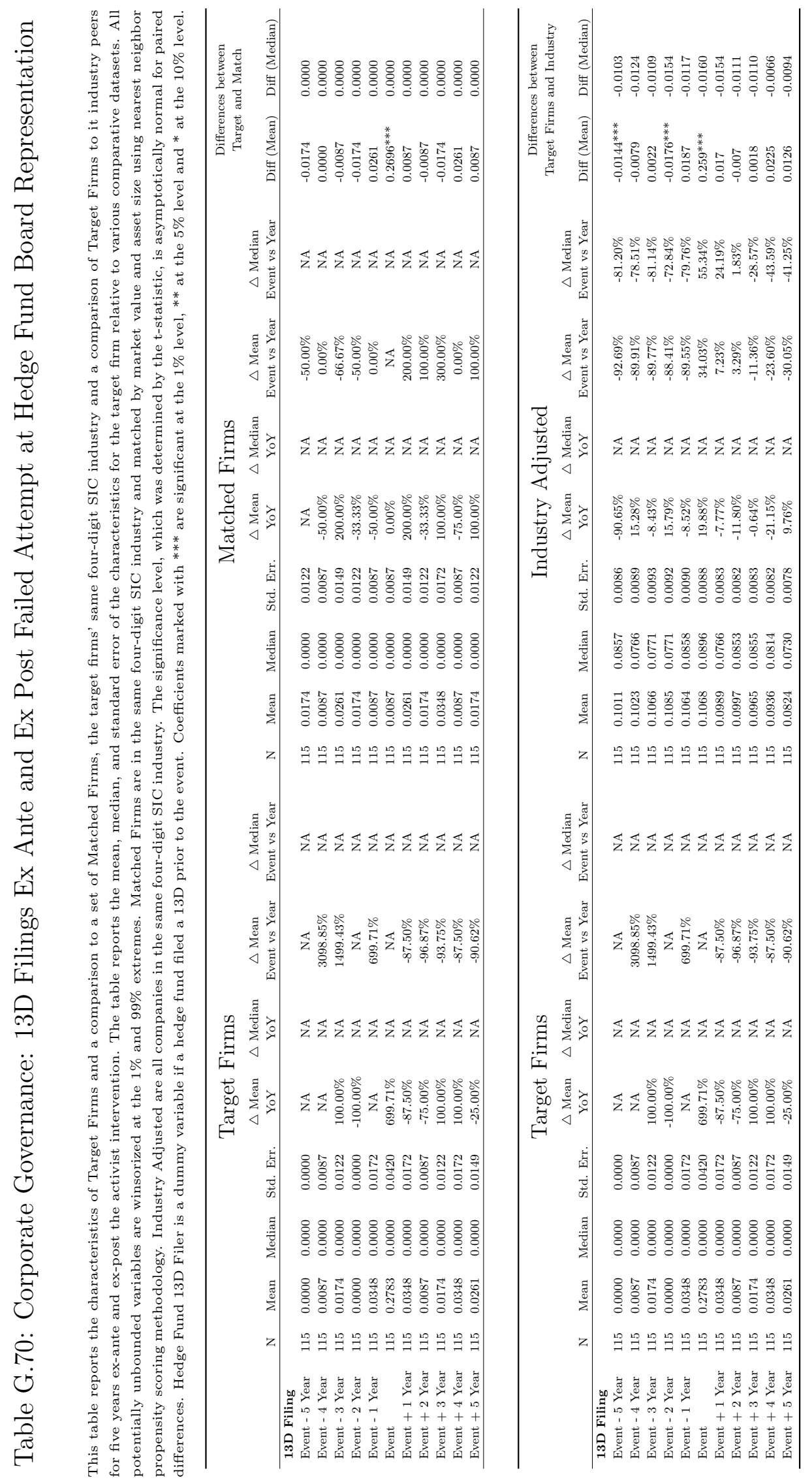

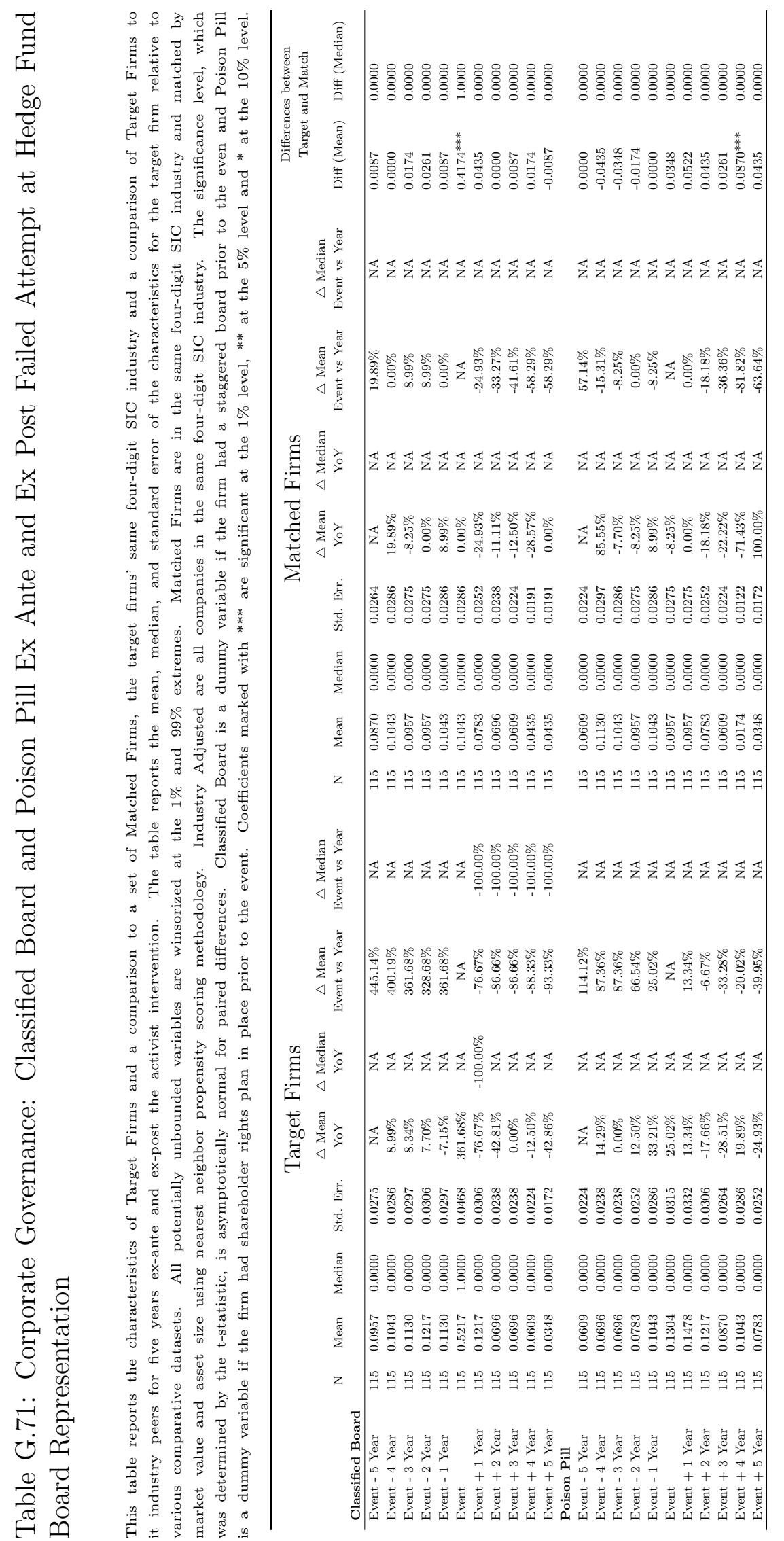

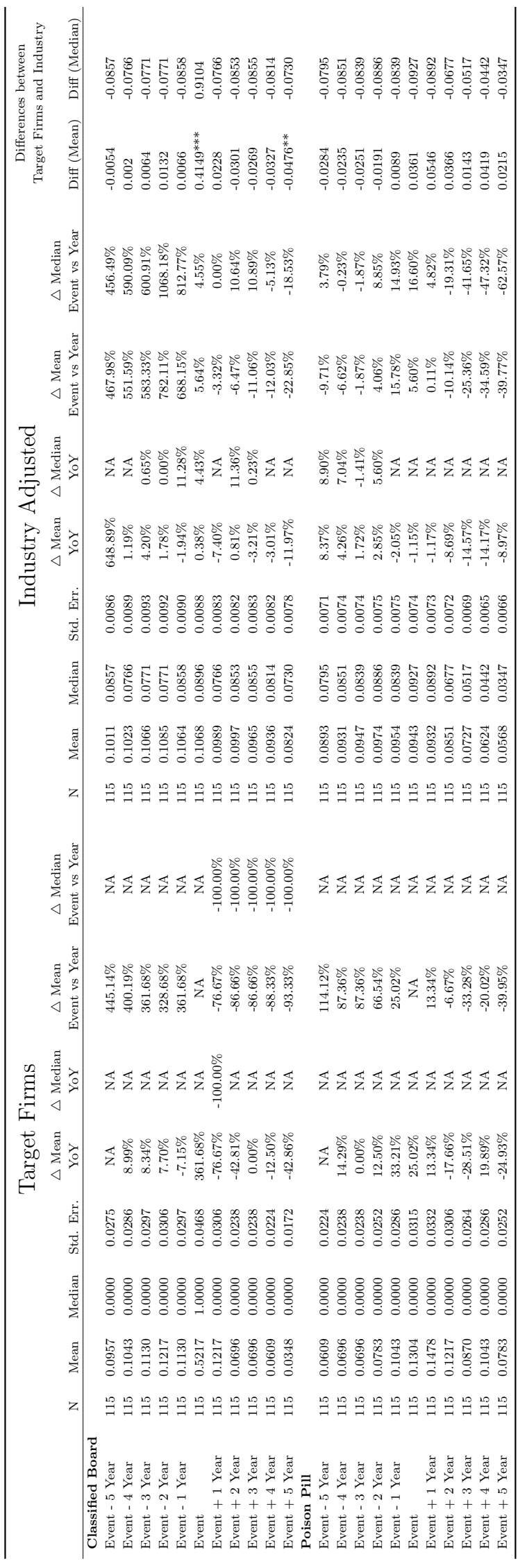


VITA

Shane Goodwin

Candidate for the Degree of

Doctor of Philosophy

\section{Thesis: CORPORATE GOVERNANCE AND HEDGE FUND ACTIVISM}

Major Field: Business Administration

Biographical:

Education:

Completed the requirements for the Doctor of Philosophy in Business Administration (Finance) at Oklahoma State University, Stillwater, Oklahoma in December 2015.

Completed the requirements for the Masters in Business Administration in Finance at Northwestern University in Evanston, Illinois in 1999.

Completed the requirements for the Bachelor of Science in Business Administration at The University of Tulsa in Tulsa, Oklahoma in 1993.

Experience:

Goldman Sachs \& Co.

Wells Fargo Securities

Argus Capital Partners

Citigroup Corporate \& Investment Banking

Professional Memberships:

National Association of Corporate Directors

CFA Institute 